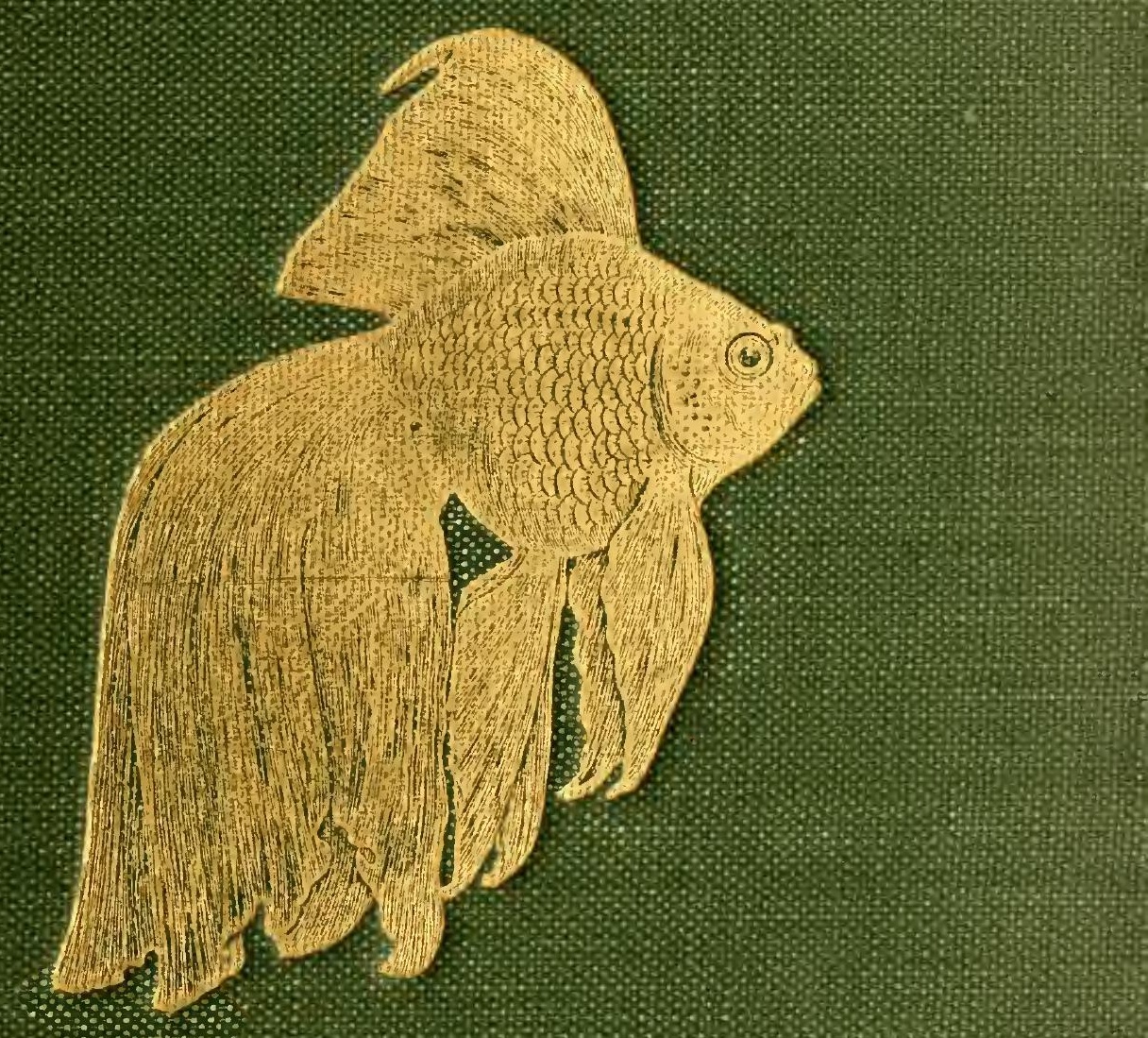




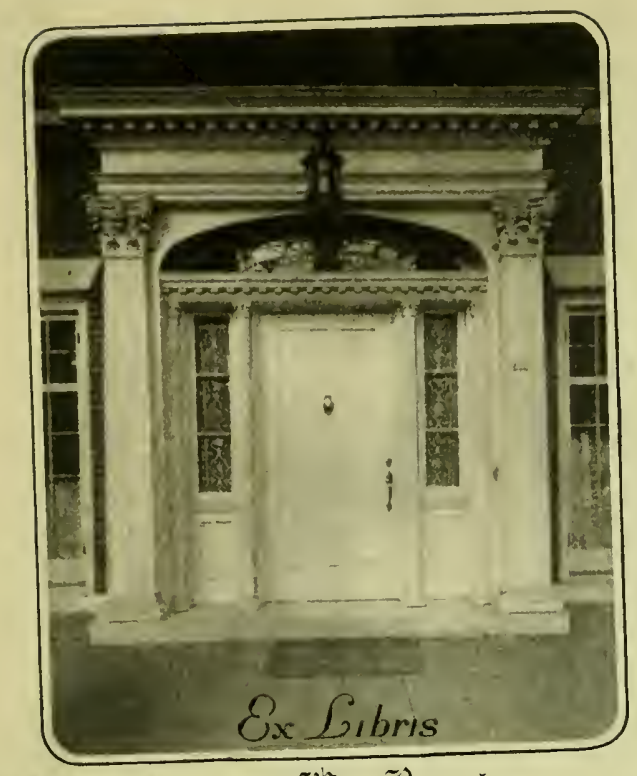

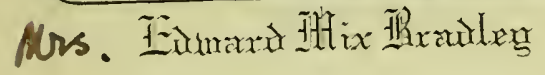

\section{t.}

Dauiremerriman

$$
\text { VI1/4/50. }
$$




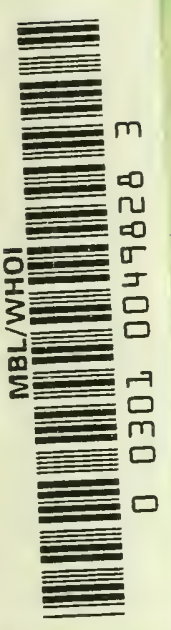






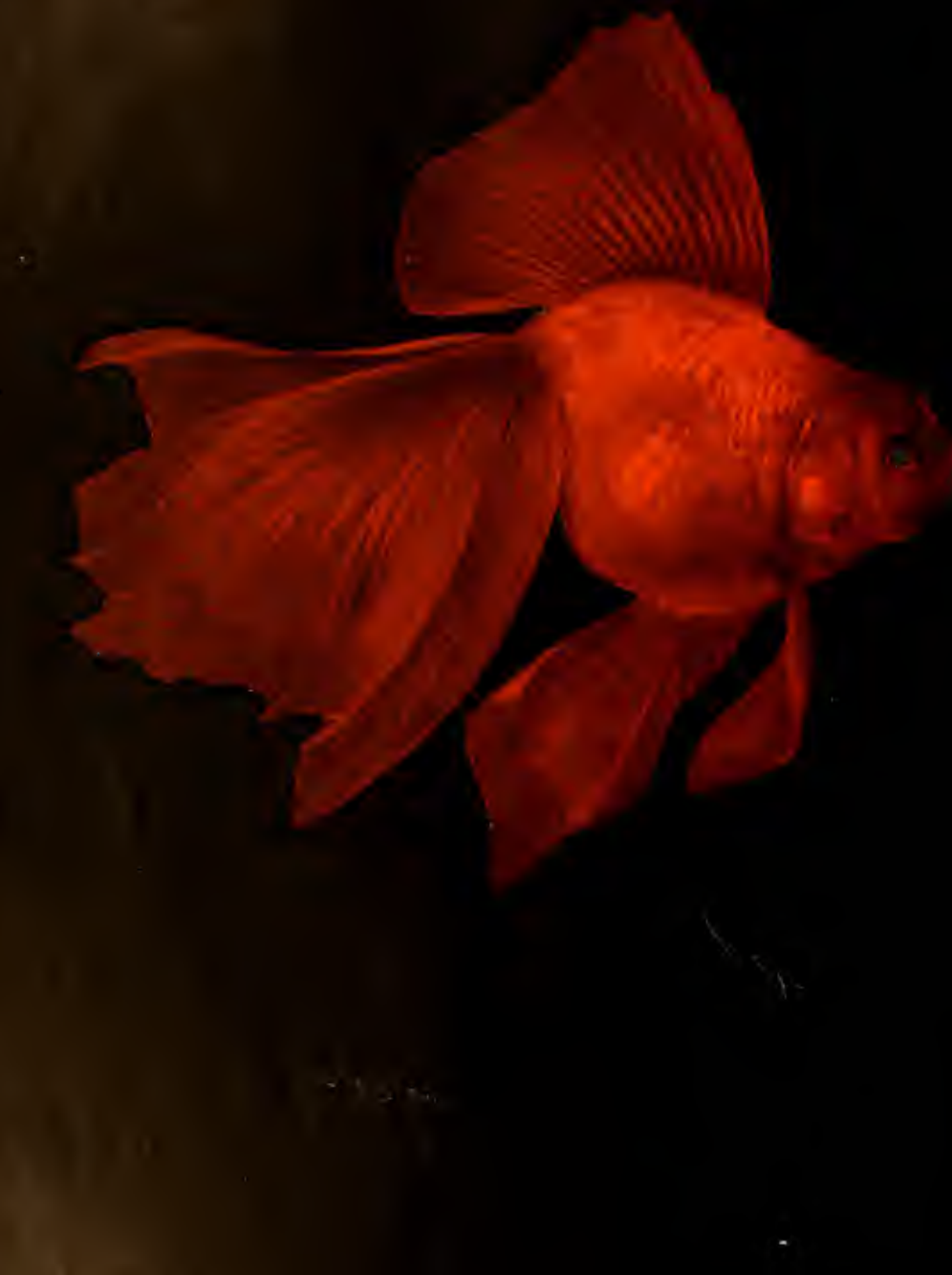




\section{The Complete}

$\mathbb{A} \mathbb{Q} \cup \mathbb{A} \mathbb{R} \mathbb{U} \mathbb{N}$

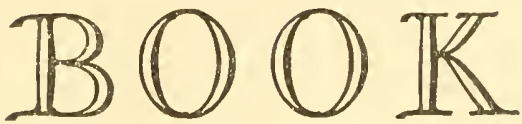

The Care and Breeding of Goldfish and Tropical Fishes

B Y

\section{WILLIAM T. INNES}

Former Presidcnt Aquariun Socicty, Pbiladclpbia

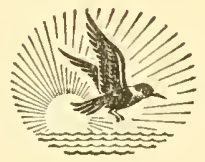

HALCYON HOUSE : NEW YORK 


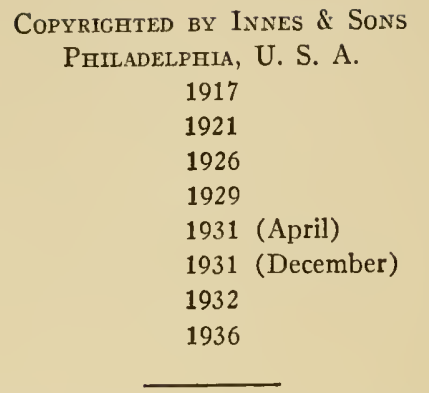

Rights of Reproduction and Translation

Reserved

Halcyon House editions are published and distributed by Blue Ribbon Books, Inc., 386 Fourth Avenue, New York City.

PRINTED IN THE UNITED STATES OF AMERICA BY THE CORNWALL PRESS, INC., CORNWALL, N. Y. 


\section{PREFACE TO HALCYON HOUSE EDITION}

Interest in the aquarium hobby has expanded so tremendously in the past few years that it might now be termed one of our national pleasures.

Since originally published, under the title "Goldfish Varieties and Tropical Aquarium Fishes," this book has gone through 15 editions, each one revised, improved, and larger than its predecessor. It is everywhere recognized as the world's standard book on the subject. While the price has always been $\$ 4.00$, we hoped to find a method of manufacture and marketing that would place the work within the reach of everyone. Through our arrangements with Halcyon House, this is now happily accomplished.

The present edition not only contains everything that was in former printings, but there are several added color plates taken from our new $\$ 5.00$ book ("Exotic Aquarium Fishes"), devoted exclusively to tropicals.

Likewise there are some plates taken from our monthly magazine, "The Aquarium" ( $\$ 2.00$ per year).

We are always glad to write aquarists having special problems (if stamped, self-addressed envelope is enclosed), but as this book answers all the questions received over a period of many years, we request that readers make sure the answer is not here before writing us.

We do not deal in aquarium fishes or supplies.

Innes Publishing Company Philadelphia 


\section{TABLE OF CONTENTS}

PAGE

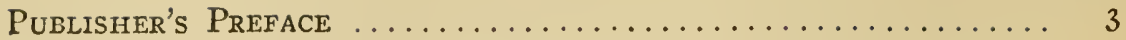

Chapter One: Aquarium Management $\ldots \ldots \ldots \ldots \ldots . . . \ldots$

" Two: Aquatic Plants .................. 25

"Three: Fishfoods ...................... 67

Prepared Fishfoods

Living Fishfoods

" Four: Diseases and Their Treatment.......... 83

" Five: Fish Enemies .................... 96

" Six: Construction of Aquaria, Tanks, Etc....... 103

" Seven: Aquarium Appliances ................ 119

" Eight: The Microscope in Aquarium Work........ 128

" Nine: Photographing Fishes ............. 133

" Ten: Marine Aquaria.................. 135

" Eleven: Terraria .......................... 142

" Twelve: Native Aquarium Fishes............. 151

" Thirteen: The Goldfish .................. 172

" Fourteen : Judging Goldfish Competitions........... 193

" Fifteen: Breeding Goldfishes................ 198

" Sixteen: Wholesale Breeding ............... 217

" Seventeen:Tropical Fishes and Aquaria............ 230

" Eighteen: Tropical Fish Exhibitions ........... 235

" Nineteen : Descriptive Key to Breeding .......... 237

" Twenty: Alphabetical List of Aquarium Fishes, Their Breeding Habits, Care, Etc......... 285

"Twenty-One: Public Aquaria .................. 298

"Twenty-Two:In Short ....................... 302

Illustrations and Their Sources .................... 304

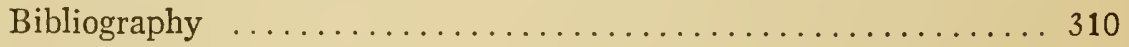

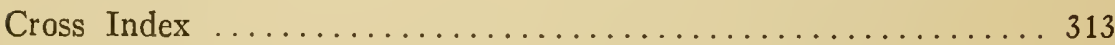




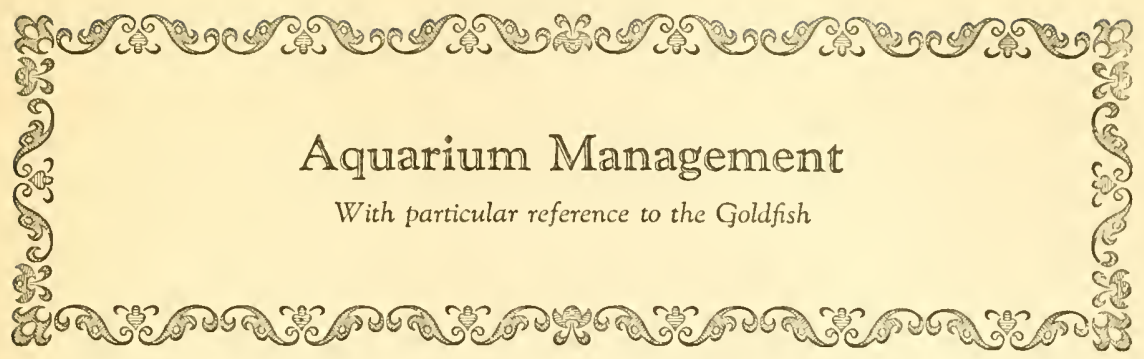

A lady wrote the author, I have just bought eight pretty goldfish in a cute little globe. I feed them three good meals a day and change the water often, but they are always at the top of the water with their mouths partly in the air. This makes a little sound. Do you think they are trying to speak to me?

This letter sounds funny, of course, but it really was not intended as a humorous effort. That makes it sad. Those four short sentences are unique in that they have compressed or crystallized into a few simple words the substance of a vast popular ignorance on the subjects treated in this chapter. The lady should be awarded a medal for crowding the greatest amount of aquarium ignorance into the fewest possible words.

Yet her letter is not without value. On the contrary, it is appreciated for its sincerity, and it points out, in a very clear way, important topics which should be here treated. Those lines from the lady are the text and inspiration of this chapter. After the "ways and wherefores" have been made plain, a part of the reply to the writer will be given at its close, which would seem to be the appropriate place.

One is forced to the conclusion that while the state of affairs described by this particular correspondent is very bad indeed, it is not far from fairly representing a considerable number of kind persons who are barbarous through no fault of the heart, but from lack of information. Take a stroll through a residential district anywhere. See the dwarf "aquariums" and "fish globes" in windows, with their little prisoners in milky water, struggling for air at the surface, and marked for an early death. Would it not be a satisfaction to personally enlighten the owners? The author has often felt the urge, but such an undertaking with a stranger calls for genius in tact. Would it not be like the naturalist who spent his slender income in purchasing caged birds to give them their liberty? No matter how many he bought, the dealers' cages were promptly re-filled. Aquarium keepers are legion. Hence it is that help for the beginner forms one of the important features of this work. 
Most aquarists, however slight their interest in this hobby, or how humble their ambitions, are true lovers of their pets. Also many of them have a keen appreciation of Nature, and would like nothing better than to have in their homes a reproduction in miniature of a section of the water world.

Can an aquarium be made such a little world in itself, populated by well and happy fish folk? Decidedly, yes. All we have to do is take a few hints from Mother Nature Herself, and we will be able to change what our insurance friends call the "life expectancy" of aquarium fishes to years instead of months.

In aquatic life we find four conditions of the first importance to fishes. To emphasize that importance we will set them out in this fashion:

\author{
Plentiful water surface \\ No sudden temperature changes \\ Growing plants \\ Not too much food
}

Now let us see just how these four conditions can be applied to the management of a household aquarium so that its inmates will have no just complaint against their masters or mistresses. We will consider these major topics in the order named, and, as we go along, cover certain subjects which are allied to each.

\title{
WATER SURFACE
}

To begin with, do you know that a fish breathes air, just as much as we do? Perhaps you know, friend reader, but most do not, so here is the explanation: It is a natural physical property of water to contain a certain amount of air. We might correctly say dissolved air. The cooler the water, the more air it can hold. Please remember that. We will return to it more than once.

A good proof that air is in water is to let a tumbler of cold water stand in a warm room. Everyone has seen how the bubbles of air leave the water and adhere to the sides of the glass. Very many more, which you do not see, escape at the surface. While this simple experiment shows that there is air in the water, it also shows the fact already mentioned, which is that cool water has more capacity to hold air, and as the tumbler warms, the air is forced out in the form of bubbles. A tumbler of tepid water in a colder room will not develop bubbles. On the contrary, it will absorb and hold more air, but of course, this cannot be seen. You may safely take science's word for it-it is there.

This air is the breath of the fish. As the water passes through the gills, air is mechanically extracted. The gills are equivalent to the lungs, 
only they have both to extract the air and then absorb into the fishes' blood the oxygen which it contains.

Bearing in mind the fact that water holds a certain amount of air, the question arises, how is the air to be renewed as it is exhausted by the fish? Also what becomes of the impurities (mostly carbon dioxide) exhaled by the breathers of air-in-water?

The surface of the water is our great friend in solving these two important questions. That is where most of the magic takes place. New air is absorbed here and carbon dioxide is liberated. These processes take place with certainty, but not rapidity. The state of affairs in the aquarium, then, is fish exhausting the oxygen by breathing, and the water replenishing it by absorption at the surface. This rather lengthy but necessary explanation, it is hoped, will bring the reader to the conclusion that the most important factor in aquarium management is plenty of water surface in proportion to the number and size of fishes. Certainly it is true of aquaria containing temperate-water fishes, the subjects we have in mind at this time. Tropical varieties will be treated of elsewhere.

A graphic illustration will perhaps better fix the principle in mind. If water permanently filled the figures 1 and 2, each having just the same water surface area, which would successfully maintain more fishes? The reader who has followed carefully will answer "Neither!" If both were stocked with too many fishes, figure 1 would last longer without a change of water because it would be starting off with a larger total supply of oxygen, but after the initial supply had been exhausted, the capacity of both aquaria for maintaining fish life would be precisely the same, be-
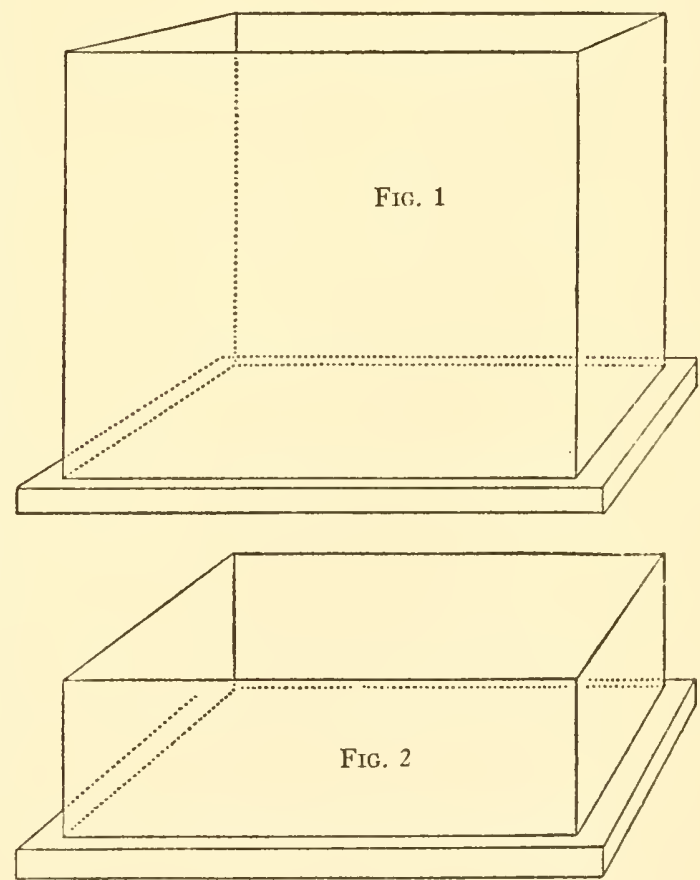
cause the air surfaces are the same. A straight-sided aquarium from which more than half the water has evaporated will continue to satisfactorily support fish life, provided it was not overstocked in the beginning. 
If one were working on the plan of keeping too many fish and changing the water to keep them alive, then of course the deeper aquarium would last longer without a change, but a real aquarium, reproducing natural conditions, should never need a change. Never? Well, in the famous words from "Pinafore," hardly ever. Once in a great whilesomewhere between six months and six years-would be all right. The best of homes, on land or in water, need an occasional housecleaning, but an aquarium under the proper conditions should be able to continue in a healthy condition indefinitely, only adding water to make up for evaporation. To prove the correctness of this theory they have in the Aquarium Building at Battery Park in New York City a small aquarium which has not been disturbed for over thirty years! A thorough cleansing and re-planting once a year should be sufficient for a properly arranged household aquarium.

Fish Capacity Rule. By this time the patient reader will no doubt like to know how much of this wonderful water-surface a fish needs. Good. Let us put theory into practice. We will first consider the less favorable conditions, which are, highly developed fancy goldfish in a temperature from 78 to 90 degrees Fahrenheit. That is, delicate fish in water containing comparatively little oxygen. Since most of us must keep our fishes in the same container throughout the year, we had best base our calculations on meeting the greatest disadvantages we are likely to encounter, on the principle that a chain is no stronger than its weakest link. A good working rule is Twenty-Four SQuare Inches of Water Surface to Every Inch of Body Length of Fish. That is to say, an aquarium containing a water surface of $8 \times 12$ inches, which makes a square inch area of 96 inches, should, the year round, in the average temperate zone, be able to keep in health either one four-inch, or two two-inch or four one-inch fancy goldfishes. (Mark you, please, the words either and or.)

The common long-bodied goldfish with single tail is hardier and can do with a little less space. Take people in a closed room. Some of the delicate ones will feel distress before the stronger notice any discomfort. Even common fish, however, should not be given less than eighteen square inches of water surface to the inch of fish body. (These computations all exclude the tails.) It is to be assumed we all know that the square measure is obtained by multiplying the length and breadth together.

Surface Measure of Circle. The surface measure of cylindrical and globe-shaped aquaria is found by another easy rule. The radius (which is half the diameter) is multiplied by itself. This result is multiplied by $31 / 7$. For example, a circular surface is 6 inches across. The radius is 3 inches. Multiplying this by itself we have 9, and multiplying 9 by 


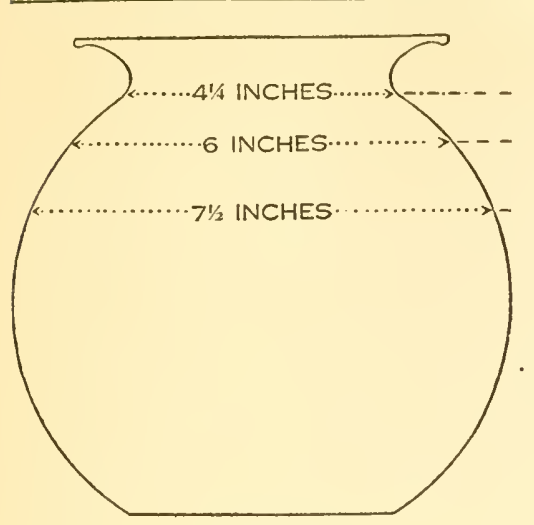

makes 14 square inches of surface

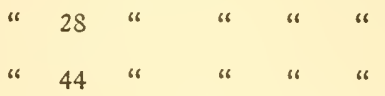

Surprising how rapidly the surface increases as the water lowers from the top of a globe. The bottom level shown will support three times as many fishes as the top, and the middle one twice as many. The matter of how far a globe is filled may make the difference between failure and success.

FIG. 3

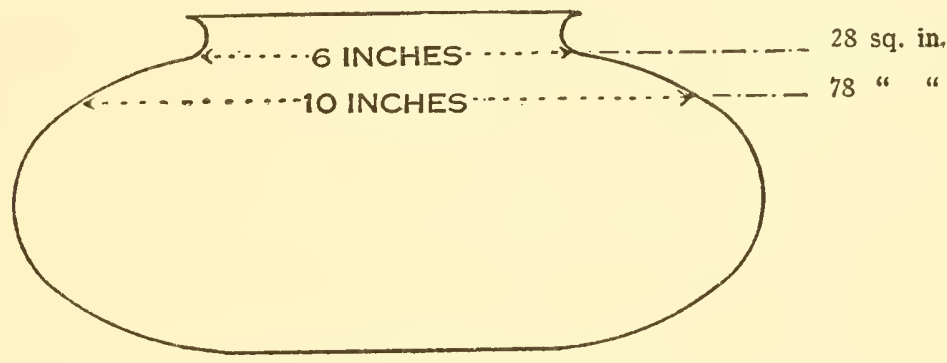

FIc. 4

The modern flattened globe has a lot more style and very much more air-contact surface, especially when carried a little below the top level.

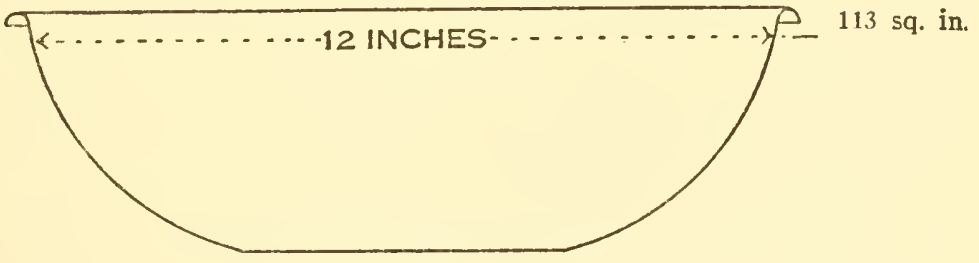

FIG. 5

The main intent of these diagrams is to show the practical application of the allimportant air-surface principle.

These three containers are reduced in the same proportion and each has approximately the same water capacity. As an aquarium the lower design is much the best. Theoretically, when filled, it could support eight times as many fishes as the top globe filled. In practice the old style globes are almost always overcrowded, and the thing to do is to take goldfish from these and place them in better-formed aquaria. However, owners of flat-shaped aquaria are not to be encouraged in the possible idea that they would be justified in increasing their aquarium population just because the old-style globe is less efficient. 
$31 / 7$ we have a little over 28 square inches. This could very well represent one of the popular-sized globes. According to the measurement it should not contain more than one fish, a little over an inch in length. Of the millions of such globes, few are populated for the welfare of their inhabitants, hence repeated failure and final discouragement.

Another practical rule which has been advocated by some writers, for estimating the fish capacity of an aquarium, is one inch of fish to the gallon of water. To find the gallon capacity, multiply the length, breadth and height together in inches. Divide the result by 231 . The result will be in gallons. This rule is all right for aquaria of average proportions, but the air-surface measurement of the water is more trustworthy, because that is the factor which counts most. Also, it is more apt to keep the correct principle in the mind of the aquarist.

Any rule is bound to be only approximately correct, because temperature makes a great deal of difference. Fishes breathe slowly in cold water and fast in warm. Furthermore a four-inch fish consumes much more oxygen than four one-inch fishes. It would, therefore, be well to bear in mind that in constant high temperatures ( 80 to 90 degrees), or for large fishes, more room should be allowed than the rule calls for.

The reader may sometime see an aquarium containing contented fish in much greater quantity than recommended by the formula outlined by the author. It will always be found that these aquaria are quite cool. Our calculations are made not for the most favorable conditions, but for the average that will be met through the year.

Experienced aquarists on being asked to diagnose the troubles of the beginner, and advising less fish or more room, are often met with the rejoinder "Why the man in the store said I could keep that many fish." Clerks in pet shops are like clerks elsewhere. They are well intentioned but often lack real experience. Besides, they are naturally a little prejudiced in favor of making more sales.

Start with few fish and success will be much more likely. If there are too many they will all decline and then it may be too late to save any of them.

Fish Globes. Much argument has raged about fish globes, some extremists declaring them a cruelty on account of their supposedly focusing the light into the eyes of the fishes. The true objection is that they are nearly always overcrowded, and, owing to their shape, the air surface of the water is small. This can be overcome to some extent by only partial filling. When only two-thirds filled the surface area is about twice as large as when filled to near the top. Except for keeping some of the miniature tropical fishes the small globe is indeed an abomination. None for goldfish should be of less than eight inches at the widest point, not 
even for the small-sized goldfish. A twelve-inch globe, two-thirds filled, can be made into a fairly respectable aquarium, although all globes have the disadvantage of distorting the appearance of the contents. To avoid cracking, the larger sizes should be set on a piece of thick felt or in a saucer of fine sand, so that the weight will be carried evenly.

The more modern shapes of flattened and dish-shaped bowls are great

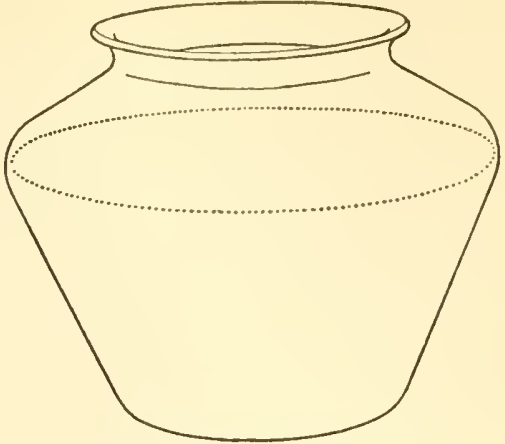

Fig. 6 Keystone Globe improvements. The "keystone" shape shown in illustration is now made in the cheap globes, and when filled just to the widest point is a vast improvement over the old style.

To Tell When Fishes Have Insufficient Air. It is when they rise to the top, "sucking bubbles" as some call it, or gasping. It is their way of panting for breath. It is wonderful indeed how the fish know that lifesaving oxygen is at the surface of the water. Look at an overcrowded pail of minnows just freshly caught. Probably not in their whole lives have they ever needed to come to the surface for air, but the moment the necessity arises, each and every one that is able will hang to the surface for dear life. That is what the lady's goldfishes were doing when she felt they were trying to speak to her!

When fishes are found trying to "speak" in this way, their owner should pay heed and act promptly. The condition sometimes arises from uneaten food which has started to decompose. Perhaps it is a dead fish or snail hidden in the grasses. If it is from food, the water is apt to be cloudy. If the water has turned bad it has to be changed. If the trouble is overcrowding, temporary relief can be had by a partial change of water and placing the aquarium in a cooler position.

"How Often Must I Change the Water?" is truly the commonest question of the beginner. He seems to expect a reply such as "every day", "once a week" or "once a month". There should be no such answer. When the fishes gasp at the surface for air they need attention-probably a partial change of water. Though the water was changed only two hours before and they again come to the top and remain there, they must be looked after. As soon as they seek air in this way their conditions are wrong, even though they do it only every few days. If an aquarium is apparently going along all right for several weeks and the fish come to 
the top on a dull, heavy day when the barometric pressure is low, that should give no concern. It will pass with the weather.

A hungry fish begging at the surface for food is quite different from one that is there for air. The hungry beggars only rise at the approach of a person and do not remain constantly at the top. Fish struggling for air stay there, or only go down for a few moments when frightened.

While temporary relief may be had by changing water, that does not really solve the problem. Either the number of fish must be reduced or a larger container provided.

\section{TEMPERATURE CHANGES}

Changing the Water. Repeated changes of water are injurious to fishes. In many localities even one change is dangerous, because the new water may contain an extra heavy charge of disinfectant or other chemical. Water must, however, be changed sometimes, and there is a right way to do it. Here we apply the second on our list of Nature's ways, "No sudden temperature changes". No matter how rapidly the air temperature may alter, the water in streams and ponds never jumps several degrees instantly. To change fish suddenly from one temperature to another is unnatural and injurious. It is the cause of much disease among them.

Draw the water and allow it to stand at the same temperature as the aquarium at least two hours before use. If the fishes are suffocating they should not wait so long for a complete change of water. Take out say a quarter of the contents and put in fresh, first tempering it by the addition of warmer or cooler water to equalize it with that which they are in. Just a trifle cooler is allowable for partial changes made for this reason.

In drawing new water from the spigot, if the presence of chlorine is suspected, hold a finger over the nozzle and squirt the water as hard as possible into the bucket or other container. This liberates much of the gas. The finest spray from a hose nozzle is even better. Chlorine may be entirely removed by boiling the water. Contrary to general belief, boiled water is not objectionable, only it should be aerated by pouring after it has cooled.

A good way to place the water in the aquarium is to pour it from a sprinkling pot. Filling the pot with aquarium water and sprinkling it back is one way to freshen it.

Many experienced aquarists are so suspicious of new water (or raw, as they call it) that when drawing off dirt and sediment they allow the old water to settle in a pail and return the clear portion. Some even filter it, so as to lose as little as possible. A method of doing this will be found on page 125. Raw water is more dangerous in the winter and spring. 


\section{PLANTS}

We have now pretty well covered the important conditions regarding aquarium water and taken several necessary side-excursions without losing, it is hoped, the thread of the main ideas on oxygen and temperature changes. Now let us consider the plants, for they help in much the same way as the water air-surface, but in a lesser degree.

Plants Absorb the Waste Products of Animal Life and Give Back Oxygen. The principle of exchange benefits between plant and animal life in the aquarium was discovered in about the middle of the last century, and as the idea took hold it gained a somewhat exaggerated importance. The term "balanced aquarium" grew into use, meaning that the plant and animal life balanced each other on a nearly equal exchange of chemical elements. This mutually beneficial exchange undoubtedly does take place. Plants in an aquarium without fish will virtually stand still in their growth. On the introduction of fish a marked quickening of their development can be noticed. The author is an intense admirer of beautiful growing plants in the aquarium, and knows they have real value of a practical nature. The fact is, though, we should not depend upon them to compensate for overcrowding the aquarium with fishes. This is for two reasons. First and most important, the plants only give off oxygen under the influence of fairly strong direct or diffused sunlight. This means that for more than half the twenty-four hours they are practically useless as oxygenators, to say nothing of their idleness on dull days when barometric pressure is low and their services are most needed. The second reason is that their oxygen-supplying activity is small compared with that of the air-surface of the water.

It must even be admitted that plants which are in a badly lighted situation are likely to do more harm than good.

Use plants, and plenty of them, provided there is good daylight. They are beneficial and beautiful. No imitation of aquatic Nature is complete without them. They are, however, frail friends, doing good work when conditions favor them, but sleeping at critical times.

The fish need plenty of oxygen all the time; day, night and dull days. Water-surface will not fail them, provided there is enough of it.

There are many beautiful aquatics which may, under proper conditions, be used in the aquarium. Those which can be readily obtained and are of a useful character, as well as attractive in appearance, are few in number. Of these, Sagittaria, in its different varieties, stands out in importance above all the rest. The description of this and other plants will be found in the following chapter on Aquarium Plants.

Light. As above stated, aquatic plants in order to thrive and help purify the water must have good light. When in the sun many of them 
can be seen releasing a steady stream of fine bubbles. These are almost pure oxygen.

Strong diffused light with an hour or two of direct sun is approximately ideal. Ordinary artificial light is worthless so far as any effect on the plants is concerned.

Direct sun in the summer months is dangerous to small aquaria, as it is liable to raise the temperature too high for the fishes.

\section{FEEDING}

This is the fourth of our major topics, but by no means the least important. Again we shall see what we can glean from Nature's way of doing things.

Fishes in natural conditions are nearly always hungry (except sometimes when their lunch is served on a barbed hook). Also they never get enough to satisfy their appetites. This is our cue. Feed sparingly. Goldfish over one year old should never have all they can eat. When they swim coaxingly to the near side of the aquarium, using what eloquence they have to beg for food, it is a great temptation to yield, but true kindness bids us steel ourselves against doing so if the feeding time has not arrived.

There is no feeding rule which can be successfully applied to all conditions and times. Remember that all of a fish's functions are directly affected by temperature. They are cold-blooded animals, and when cold they are slowed down in all ways, needing less fuel to keep going.

Unlike warm-blooded animals, food does not fortify them with heat against the cold. In excess it merely clogs their systems with substance which poisons because it is eliminated too slowly.

When the water is 60 degrees or higher it is allowable to feed once daily. When 55 to 60 degrees, every other day is sufficient, while from three to six days is often enough at temperatures from 40 to 55 degrees. This has to be done with a certain amount of personal judgment.

A meal should be small enough that it is entirely consumed in five minutes. Any surplus food remaining after that time should be removed, but experience in feeding soon makes this extra work unnecessary. Results will be better if only one person is responsible for the feeding.

\section{It is better to err by feeding too little than too much.}

The ingredients of the food should approximate in content that which the fish would secure under natural conditions. A goldfish would not on its own account be likely to find oatmeal, crab meat or hen's eggs, but these and other substances contain the elements which, when properly combined, approximate natural fish food. Definite food formulæ will be found in the chapter on Fishfoods (Page 67). 


\section{IN GENERAL}

Temperature. Try to keep a goldfish aquarium within the limits of 50 to 80 degrees. From 60 to 70 degrees is the preferred range, but in winter, which is the natural rest period of all fishes of the temperate zone, a little cooler water will do no harm. Floating thermometers with red or blue spirits are easily read and are of value in all aquarium management.

Water. We sometimes hear that certain water is too pure for fishes to live in. This is "pure" nonsense. Extremely small, newly-hatched fishes eat some of the microscopic life commonly in water, but as they grow larger they are unable to strain out such fine matter.

Distilled water, on account of its lack of desirable mineral content, is not beneficial to fishes, and, on the other hand, some natural waters are so heavily charged with minerals (sulphur and lime mainly) that they cannot be successfully used for aquarium purposes. Ordinarily the city water is satisfactory unless an extra heavy charge of germicide has been placed in it. If one has aquarium troubles and the water is suspected, it is a good plan to refill the aquarium from a stream known to contain fishes. While muddy water is unsightly, it is not harmful.

Water, as might well be surmised, can be adversely affected by the character of the vessel it is in. Copper, brass, zinc, galvanized iron, new wood and new concrete all have their dangers to fishes. Even a brass drain pipe in the aquarium should be nickeled. Wood and concrete are not safe, even for a few hours use, until they have held water for several weeks, unless seasoning has been somewhat hurried by running water. A moderate amount of iron rust is not injurious but is unsightly. A few aquaria have iron bottoms inside. It is a good plan to lay a sheet of glass over the iron, and sand on top the glass. This will confine the rust.

Green Water. A popular question by beginners is, "Why does my aquarium water turn green?" This is easier to answer than to remedy. Floating everywhere in the air are spores or cells of many forms of life. Only those develop which chance to come into contact with conditions favorable to their particular needs. Some of them like a cool, moist rock in the depths of shaded woods. This turns out to be moss. Others like to get at Mother's jars of preserves when they are not perfectly sealed. Here we find mold; likewise mildew on bread stored in a warm, damp place. A number of spores like the conditions found in an aquarium. Some of these are lower forms of animal life which when developed are mostly too small for the unaided eye to detect, but which are eaten by young fishes. Many others are aquatic-vegetal, which develop in such numbers in certain kinds of water as to render it green. Although these belong to the vegetable kingdom, some of them at one stage of develop- 
ment swim with such agility that it is difficult to see them under a microscope. After they have satisfied themselves with a good swim they attach somewhere and develop into a staid and sober mossy thread of algæ. Others become fully developed bits of delightfully green plant life, of somewhat geometric shapes, idly suspended in the water, but annoying the aquarist by turning it green.

The conditions which favor the green water algæ are too much light and too many fishes. Fewer or smaller fishes and a reduction of light, perhaps by the intervention of tissue paper, will usually clear the water within a few weeks. Slightly acid water is more likely to stay clear.

Suspended algæ seems to occur in cycles and is only stimulated to new growth by a partial change of water in the aquarium. On the other hand if it is allowed to disappear naturally, the aquarium is likely to remain clear for a long time.

If one does not wish to wait for Nature to do the work, the clearing can be hurried by adding one grain (by weight) of permanganate of potash to each gallon of water. Remove snails or any tropical fishes, but the goldfishes may safely be left in this solution. The water becomes at once lavender, later brown and finally clears in a few days. It will not stay clear, however, unless the conditions are changed.

As a matter of fact, green water is apt to be healthy water. Many a sick fish has been cured by being placed in it.

If water has been very green and practically opaque for a long time, one should be on the lookout for a turn to a yellowish brown color. This change may occur over night, especially in warm weather. It means that the suspended algæ is dying. As its decomposition will soon kill the fishes, an immediate change of water is advisable.

Also very green water in strong light may develop gas which gets inside the fins of fancy goldfishes, presenting an appearance of bubbles. These are injurious but will disappear if the fish is placed in old, clear water.

Live Daphnia in plentiful numbers (Page 73) will clear green water in a few days.

To see the bottom of a tank or pool where the water is opaque, take a bottle which is longer than the water is deep, press the base of the bottle close to the point to be examined and look through the open end. A milk bottle serves well in shallow water.

Chemical Changes in Water. Many chemical changes are always taking place in the aquarium. These are mainly due to the breathing and the excrement of the fishes, as well as the action of plants. In time an unbalanced condition is liable to develop, especially if there are not plenty of healthy, growing plants. It is desirable to check up occasionally on the water. Owing to the recent development of very cheap and simple testing sets, this is an easy matter to do with sufficient accuracy for our purposes. In the average aquarium the water should be maintained near the neutral point-neither strongly acid nor alkaline. If it leans toward the acid side there will be less likelihood of disease and cloudy water. The acid reading of the scale accompanying the test set 
should be brought to about 6.8 by use of acid sodium phosphate. Alkaline conditions are produced by using washing soda. The highest reading (alkaline) should not exceed 7.4. The chemicals mentioned should be used only in conjunction with a testing set-never by guesswork-especially the soda. See also page 95. An equal mixture of plaster of Paris and precipitated chalk made into a thick paste in water, hardened and broken into small lumps is a slow neutralizer of acid conditions. About a shellbark-size piece to ten gallons.

Testing sets are advertised in the various aquarium magazines. They are sometimes of value in testing the water which is proposed for aquarium use, especially where highly alkaline "hard" artesian or well water needs to be neutralized.

Sick Fishes. It is always safer to remove an affected fish from the others. If the trouble is a contagious one, the aquarium or tank should be thoroughly disinfected, not overlooking the plants in this matter. For all practical purposes they can be sterilized by placing for one hour in a permanganate of potassium solution, 3 grains by weight to the gallon of water. Satisfactory results will also be given by dipping plants for a few moments in concentrated lime water, or in household ammonia, reduced to one-fiftieth strength. Either of these methods should be applied to all new plants introduced into the aquarium, especially those collected from the wild, or from aquaria of doubtful condition. In case of an aquarium becoming contaminated, it can be disinfected by dissolving in it permanganate of potash to the strength already indicated, allowing it to stand from two to three hours, first removing all mussels, snails and fishes. In changing to clear water again it will do no harm if a little permanganate remains.

Unless newly acquired fishes come from a source beyond suspicion it is a grave risk to introduce them at once into an established aquarium of healthy fish stock. They really should first be quarantined and carefully observed for at least two weeks, this being particularly true of imported goldfishes. They may already be inoculated with diseases only in process of incubation, but which will nevertheless develop.

Care of Fish Nets. It is a safe practice after using a fish net to always rinse under a tap of clear water. The germs of fish diseases and the spores of green-water algæ which might later infect another aquarium are thus eliminated. It might be added, for the reassurance of any who need it, that no fish disease can be communicated to a human being by contact.

Scavengers. These are natural agencies for getting rid of most of the harmful offal and decomposition in the aquarium. They consist largely of those species of snails that do not attack the plants. Among the best 
known, most satisfactory and easily obtained are the large Japanese Snails (Viviparus malleatus), the so-called African Paper-shelled Snail (Lymnaea auricularia), the Ramshorn Snail (Planorbis), and the Pond

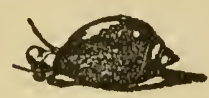

Pond

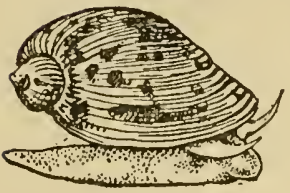

Fig. 7. African

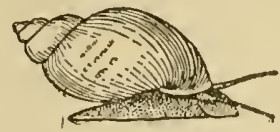

Australian Red

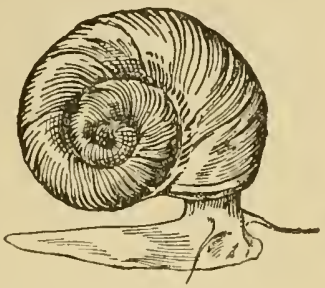

Fig. 8. Red Ramshorn

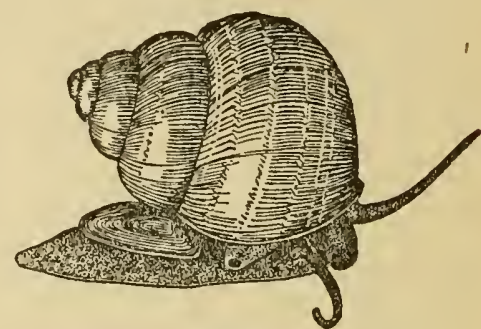

Fic. 9. Japanese

The Best Freshwater Aquartum Snatls (Life Size)

Snail (Physa). These are all active in eating mossy growth from the glass, or particles of food which the fishes have not taken, and in no case will they injure any of the aquarium plants. Most snails consume decomposing animal matter, such as dead tadpoles, fishes, etc. Living snails will not injure young nor adult fishes, nor pollute the water.

Snails are sometimes useful trouble-indicators. If they persist in staying at the edge of the water, it may have turned foul. They will also do the same thing if new water has not been seasoned. They seem to have a distinct objection to an excess of oxygen in the water.

JAPANESE SNAILs are very interesting in that they bring forth fully developed young about the size of a small pea, able to take care of themselves among goldfishes. These snails are either male or female, but a female once impregnated seems, like a queen bee, to remain fertile for the remainder of her life. The right horn of the male is somewhat the shorter, this serving a sexual purpose. These snails are quite long-lived and grow to the size of a large walnut. They can be identified by the slightly raised keels showing on the last spiral. Another snail resembling the Japanese species is the Potomac Snail. Running in the direction of the spiral are three brown stripes on a horn-colored background. It is quite attractive and is frequently sold as the Japanese Snail, but it is too slug. gish to be of much real value. 
The African or Paper-shelled Snail is very prettily marked with brown spots on a horn-colored background, and is an extremely rapid breeder, but is of short life.

RAMSHORN SNAILS in both the European and native varieties are excellent aquarium scavengers.

The European Red Ramshorn or Coral Snail (Planorbis corneus, var. ruber) is a comparatively recent introduction and is unique on account of the bright red coral color of the body. It is an active worker, but is often a victim of larger goldfishes, who find it to be a choice morsel of food.

The Australian Red Snail (Bulinus australiamus), is a still later introduction, and a good one. It is an attractive shade of orange red. Fairly hardy, a rapid breeder and a good worker.

The Pond SNaIL is extremely common in the Eastern and Middle States. It may be identified by the left-hand turn of the dark-colored shell. It is both the most active and the hardiest of all snails in the aquarium, and is an intrepid scavenger. It breeds at an early age and the young have sufficiently hard shells that goldfishes do not molest them.

The foregoing snails will usually survive winter in outdoor pools.

No kind of snails can be kept in the company of carnivorous fishes, such for instance as Sunfish (except Chætodons) and many of the tropicals-Paradise Fish, Chanchitos and the like.

Do not forget that snails can starve in a constantly spick-and-span aquarium. If kept in such an aquatic parlor they should be occasionally removed and given a meal such as is indicated in a later paragraph on "Snail Breeding."

LIMPETs are very flat, translucent snails about one-eighth inch in diameter, the shell extending completely over the body. These are both harmless and useless. They are occasionally found in the aquarium.

The Frog TAdPole has been used by many as an aquarium scavenger, but its value is of considerable doubt. They dash about the aquarium in an aimless manner, keeping the water stirred up and the natural sediment agitated. Furthermore, they soon learn to eat fish food, and, after that step in education, they are no longer scavengers.

Another scavenger is the freshwater mussel. The chief value of the mussel is to keep down the vegetable growth which causes aquarium water to turn green. Mussels are equipped with a sort of siphon arrangement, by which they suck in water in one opening and eject it from another. In the few moments which they hold the water they extract from it the floating vegetable organisms. Two or three mussels can keep a ten-gallon aquarium free of green water. Care should be taken to occa- 
sionally see whether the mussels are living, as they decompose very rapidly and spoil the aquarium water. This can be done by tapping lightly on the shell and seeing whether they respond by closing. It is doubtful whether the benefits arising from their use are equal to the risks incurred in their dying, especially in tropical aquaria. They may be gathered by raking the mud and sand of freshwater bodies. Their presence is usually indicated by some half-shells lying around in the water.

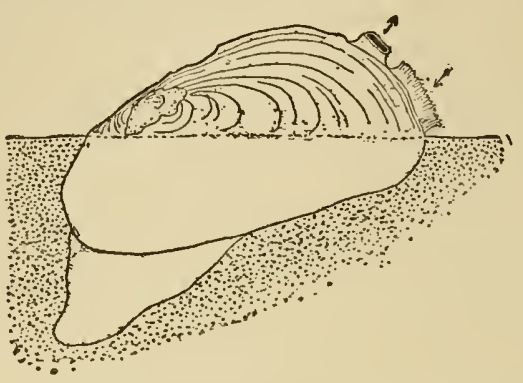

Fic. 10. Freshwater Mussel, Showing Water Intake and Outlet; Also "Foot" With Which It Burrows and Travels

Weatherfish. A curious and useful scavenger is an eel-like fish called the Weatherfish. Varieties are native to Europe and Asia. They are freely imported and inexpensive. When not scouring the aquarium bottom for bits of decomposing matter, they sometimes burrow into the

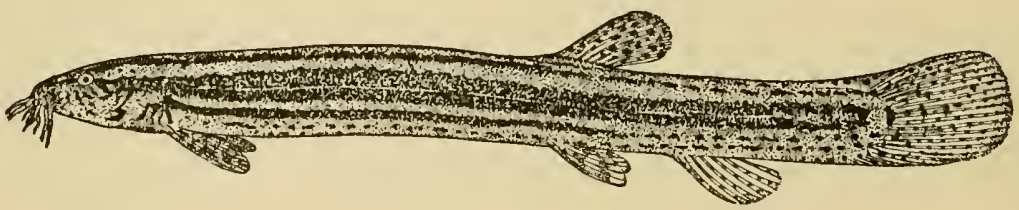

Fig, 11. The WeATHerfisin (Misgurnus fossilis)

sand, leaving only the head exposed, producing a quaint appearance. In their special occupation as scavengers they employ a method which is both effectual and interesting. The dirt and top sand are taken in the mouth and rapidly shot out through the gills. Any particle of food considered edible is automatically separated from the bulk of the dirt and swallowed.

Goldfish keep the sand loose and in good condition by picking it up in their mouths, but most other aquarium fishes do not touch it, which allows it to cake. The Weatherfish can be introduced with such fishes, even a single small one keeping the sand in a large aquarium loose on the top. Sizes of four inches or less are best. They are all apt to agitate the sediment, especially the larger ones. 
Snail Breeding. The breeding of snails is extremely simple, yet there are certain conditions that are necessary to success. Among the ordinary and really useful aquarium snails there are only two kinds whose breeding requires any attention. These are the African and the Ramshorn, especially the coral variety. Both these snails deposit eggs on plants or glass in small, gelatinous masses, which in warm weather hatch in about three weeks. The young of the Japanese and Pond Snails are able to live among the gentler fishes.

The most important point is to see that the young hatch and spend the first several weeks of their lives where there are no large fishes. Naturally this will be done either by removing the plant leaves with attached eggs to a special tank, or by removing the fishes from where the eggs are laid. Snail spawn is often placed with newly-hatched fishes, and they grow together. It is well to remember though, as elsewhere stated, that snails eat fish spawn, but never living fishes, of even the smallest size.

The second point has to do with feeding. If the tank is an old one with green-covered sides and some decaying vegetation, no special feeding is called for. Otherwise they will need some attention in order to thrive. Dried powdered lettuce leaves, flour, or finely powdered fish food sprinkled on the surface of the water, are satisfactory foods for the young snails. The thick paste from boiled oatmeal is good, both for young and adults.

It is just as well to remove parent snails from the young, so that the latter will get all the food, especially if artificial feeding is not resorted to.

After snails have passed the early stage of development they relish lettuce leaves. Snails, especially the breeders, thrive finely on raw meat or fish, which they eat as soon as it begins to decompose. Cantaloup rinds, tomato parings, sliced bananas, raw or cooked spinach are among their favorite foods.

Cypris, a small crustacean figured on page 73 , is injurious to snails and should be excluded if possible.

There are commercial possibilities in the breeding of Japanese and Coral Snails. If one does not care to rear these snails to keep up a stock, the young African and Ramshorn may be used as a valuable diet for fishes. Their extensive culture has been proposed as a diet for the young of our food fishes.

Aquarium Covers. It is a popular idea that a free access of air to the aquarium is essential to the welfare of the fishes, but this is not so, particularly if there is a liberal plant growth. A glass cover, raised about a quarter inch, promotes a more luxuriant growth of plants, keeps the 
surface of the water free of dust or bubbles, prevents objects from accidentally falling into the aquarium, keeps the fishes from leaping out and our friend the cat from fishing in. Wire gauze, properly secured, will serve the latter purposes.

With most tropical fishes the glass cover should rest directly on the aquarium or jar, with no intervening space. This keeps the water a few degrees warmer. Furthermere, there are a number of tropical fishes which can leap through a very small opening. This they are most apt to do when newly placed in an aquarium or otherwise disturbed. Our wild native fishes have an increased tendency to leap as the breeding season approaches, this characteristic being shared by the single-tail goldfishes.

Artificial Aeration. With the idea of adding to the oxygen-content of water, particularly at night when the chemical action of plants is negligible, some of our more ambitious aquarists install an air pump which is piped to each aquarium and there air is liberated in fine bubbles. This scheme to some extent counteracts the evil effects of overcrowding. It tends, however, to agitate and circulate aquarium sediment. Electrical pumps are the most satisfactory. Complete outfits are usually advertised in the magazines listed after our Bibliography.

Testing Aquaria. Before putting plants or sand in the aquarium it is well to test its tightness. More often than not the larger sizes leak after moving or standing dry. These leaks can usually be corrected in a few days by filling with very muddy water, stirring it occasionally.

Removing Dust and Scum. When the aquarium has no cover glass or when there is a considerable decomposition of old plants there is sometimes a scum formed on top of the water. To remove this, tear a piece of newspaper to the width of the aquarium. Float the paper at one end of tank, lifting by one edge, and draw quickly over the length of the water. Repeat once or twice with fresh paper.

Foul Sand. Sometimes sand or pebbles will turn black and become quite ill-smelling. The cause for this is not always easy to determine. It is more apt to occur where the light is feeble and the plant growth poor, also where sand is too deep. If taken out and dried in a thin layer it will clear up. If the conditions seem right and there are sufficient plants, do not be hasty about taking out dark sand. The condition often corrects itself if given a chance, and besides, it may be just a little natural dirt which does no harm.

Algæ and Confervæ. Should the plants become completely covered with algæ or "moss," try introducing a considerable number of small snails. The large Japanese variety is not always suitable for this, as it is unable to crawl on the smaller leaves. If this fails, remove and destroy the plants, thoroughly disinfect the aquarium in every particular and replant. Do not allow quite so much light in the future. 
There is a very long, hard conferva about the thickness of horsehair which grows into matted masses. This is quite a pest when once established, as it soon fills the aquarium and enmeshes young fish, which usually die before being rescued. The only way to get rid of this is to take up all plants, go over each carefully and see that no single thread of the conferva is left. If the smallest bit remains the growth will soon be as bad as ever.

A blue-green, rather smelly alga often over-runs aquaria containing tropical fishes. Goldfishes are very fond of this and they will soon clear it out if given the opportunity. Snails will not eat it. We are often asked how the glass of tropical aquaria can be kept clean. The only answer we know is, clean it by hand and then subdue the light a little.

Cleaning the Glass. When the aquarium glass has become green or dirty, it may be quickly cleaned by scraping with a safety razor blade. Handy holders for these can be had cheaply in hardware and chain stores. A thorough cleaning of the empty aquarium is accomplished by rubbing with either whiting or table salt on a moist cloth. Sand should not be used. It causes minute scratches, which are unsightly and may lead to the breaking of the glass.

A chore ball of woven copper, such as used in kitchens, is most excellent for cleaning either straight or curved sides of aquaria.

Coal Gas. Water absorbs most gases and fumes readily. This includes coal gas, which is so injurious to all life, plant and animal. Many homes are cursed with the presence of this gas at night, to the detriment of every inhabitant in the house, especially the fish. A way should be found to correct the condition, but if this is not at once practicable, cover the aquarium tightly with glass during the hours of exposure to the poisonous influence. The same precaution should be taken when the air is laden with tobacco smoke, fresh paint, varnish or shellac.

Hints to Beginners. The author would draw special attention to what follows under this heading. It is founded on wide observation, and if followed will prevent much loss and disappointment for those going in for fancy goldfishes.

In starting with fancy breeds go to a reliable dealer or breeder, preferably in September or October, purchasing fish of the spring hatching. The style of fish to select is a matter of personal taste, but do not pick undersized fishes by any inducement of price or word, especially on explanation of their being "a late hatch." The bodies, exclusive of tails, should at this time be at least $1 \frac{\mathrm{T} / 2}{2}$ inches long. Two inches or more is better. Be willing to pay the charge for robust goldfishes. The runts are dear at any price. 
If it is not convenient to purchase in autumn, make it a rule not to get fishes over one year old. Buying spawn in the spring is an interesting way to start.

Unless desirous of making a flashy show in an aquarium at once, it is very bad policy to purchase fully developed fishes with long fins. These have usually reached their zenith and are ready to "go back." The change of aquarium is enough to start them on the down grade. Good young stock will develop the fins later and will be more likely to "stay with you." None except advanced fanciers who know what they are about should purchase the older stock and they seldom $d o$.

Try to avoid purchasing goldfish which have been forced in growth in running water. Most of them decline or die in their second year.

A Word for the Pet Store Man. The author was one of those boys with a passion for going into pet shops. One of the questions which often occurred to him was, "Why are pet store keepers so disagreeable?" Having since appreciated what they must contend with, the answer is no longer a mystery. Besides their difficulty in securing healthy stock, feeding it a long time, experiencing many losses, they have to contend with two very irritating classes of persons. One of these is the timeconsuming curiosity-seeker who pretends to be a prospective customer but who has no intention of purchasing. The other is the "bum sport" who blames all his troubles and losses on the dealer, and who wants to exchange dead pets for live ones. Stock in a pet store is necessarily crowded, therefore difficult to keep in good condition. The dealer does the best he can in delivering apparently healthy pets. The customer's eyes should be his market. After the deal is completed there should be no more ground for complaint than if a lady bought a piece of goods in a store, took it home, cut it wrong and then came back for an exchange. Wrong treatment of pets at home can be quite as fatal as the pair of wild scissors. Let us regard the pet store man "more in sorrow than in anger."

\section{THE ANSWER}

And now we close the chapter, as promised, with the reply to the good lady whose letter was quoted at the outset:

Dear Madam:

Undoubtedly your fishes are trying to speak to you. Anyone with a slight knowledge of fish language would be able to tell what they are saying. It is "Mistress, have mercy on us; we are suffocating." 
CHAPTER TWO

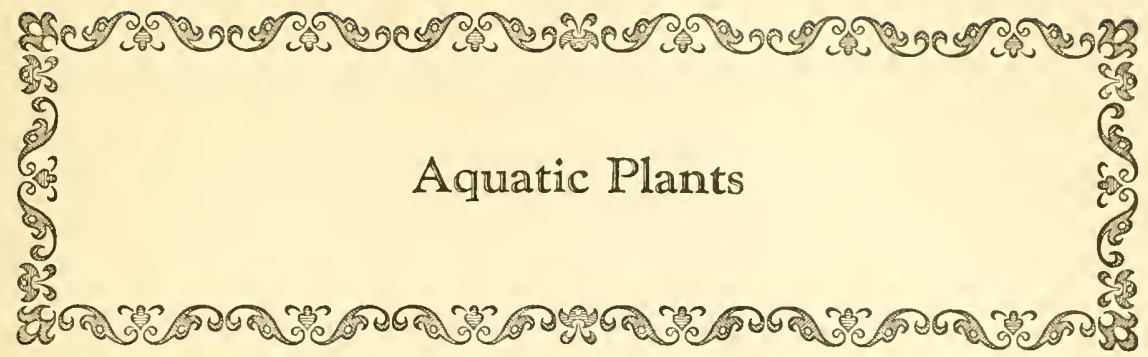

Whether aquaria are kept for scientific study or for the enjoyment of the beautiful, aquatic plants will always be found a useful, if not indispensable, adjunct. The fact that plants give off oxygen under the influence of light has been mentioned at several other places in this volume.

That the roots of healthy aquatic plants absorb the products of decomposition in the bottom of the aquarium is an established fact. When an aquarium has been established for some time, the sand has become a little dirty and the plants have spread so that the roots of some are against the glass, a close observation will show a condition similar to that pictured in Figure 12. The sand near the roots is distinctly whiter than that beyond their reach.

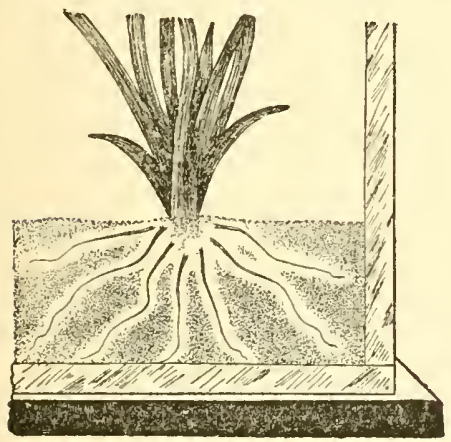

Fig. 12.

Absorption by Plant Roots

No arguments need be put forward to establish the æsthetic value of plant life in the household aquarium or the pool in summer. So well understood is the value of aquatic plants that aquarists are constantly on the lookout for anything new which might enhance the beautiful results already achieved. Occasionally something of real merit is found. We are pleased to be able to list several of these newer species here, together with the better-known favorites. Only those plants having been proven satisfactory are described, but naturally in such a large range it will be found that the same conditions are not suited to all.

Readers of former editions of this work have made many inquiries as to where some of the more unusual plants can be obtained commercially. Dealers have complained that they are unable to secure several of the plants listed, which makes their firms appear at a disadvantage 
when such orders are received. This complaint is not without reason, so we hasten to say that such plants as Hair Grass, Nitella, Spatterdock, Fontinalis, Quillwort, Mare's Tail, Lace Plant, Cryptocoryne, Frogbit and Water Chestnut can only be had here and there, sometimes from some amateur enthusiast, and again only by personally collecting.

The truth is that those plants which are easily obtainable commercially and which have year-round merit in the aquarium are very few indeed. Only one plant fulfills all requirements, and that is Sagittaria in its several forms. It is far the best aquarium plant. It is an excellent oxygenator, will thrive and multiply in any reasonable good position, is not easily injured either by fish or net; it is a beautiful, strictly aquatic plant appropriate to the aquarium, and it is easily obtained.

Let us rightly name the aquarium plants. Correspondents have called them "weeds," "moss," "water-weeds" and even "sea-weeds!"

As to sources of supply, see advertisements in magazines listed on slip near back of book.

It is a good general rule to select young plants. They transplant better and sooner adapt themselves to new conditions. If old plants are used, the half-dead leaves should be removed.

Sand or Pebbles? Much discussion has been brought out as to the best methods of planting, principally as to whether to use soil, sand or pebbles, or whether, in some cases, planting is necessary at all. Success has been attained in many ways. The author believes in the use of coarse sand, either with or without a mixture of pebbles, this latter being a matter of preference only. The disadvantage of pebbles is that they are likely to get into a siphon and clog it. Pebbles without sand collect dirt and food particles which cannot be removed nor reached by fishes or snails. While it rarely happens, fishes have been known to strangle on a pebble. Sand varies considerably in different localities, but usually building sand is satisfactory for our use. Any kind which is as coarse as granulated sugar will do. Pin-head size is ideal. There are no experienced advocates of sea or other fine sand. It packs too hard for the roots to penetrate.

Quantity of Plants. Beginners reading of the merits of vegetation in the aquarium sometimes expect magical results from two or three plants. The fact is that each makes a very small contribution towards the desired end. It takes a battery of them to obtain an appreciable result. Three sides of the aquarium should be planted somewhat closely, but allowing for multiplication from such runners as are put out by Sagittaria and Vallisneria. In short, there is no danger of overplanting so long as the fishes can move about freely, and the view is not obscured. 


\section{PLANTING}

Planting is usually done directly in the sand or grit. Some aquarists prefer planting in miniature pots or special earthenware or cement trays, so that when it is desired to clean the aquarium it will not be necessary to uproot the plants. In potting plants in this manner a few pebbles should be placed in the bottom of the pot and then a layer of clean soil, preferably from a pond or stream. Spread the roots well into the soil and then cover with about one-half inch of sand, so that the earth cannot become free and thus cloud the aquarium water. An inverted piece of turf may be used instead of aquatic soil. As a rule, it is not advisable to use any soil in planting the aquarium itself.

The first operation in planting an aquarium is to see that the sand or grit is thoroughly clean. This can only be brought about by a long and thorough washing. After the water runs clear from the sand, spread the bottom of the aquarium to a depth of, say, half an inch. If rockwork is to be introduced, place this now. Next fill with about two inches of water. Now take the roots of Sagittaria, Vallisneria, or other rooted plants, and spread them out well on the aquarium floor. After the proper arrangement of plants is made, add from an inch to two inches of coarse sand, being careful not to completely cover any of the leaves. Do not make the sand deeper than sufficient to hold the plants in position. Now fill the aquarium, and then with a slender stick lift any leaves which have been held down by the sand. After the leaves have been brought into an upright position, take hold of them and pull upwards until the crown of the plant comes just to the surface of the sand. Aquatic plants with crowns seem to do better if the crown is not quite covered. The crown is the point from which the leaves put out. Such plants should be inserted singly and room left for young plants to spread from runners.

Plants that have become uprooted in a filled aquarium can best be replaced by the use of planting sticks described on page 121 .

Care is needed in planting so as not to allow the leaves to become even partially dry. This can be prevented by frequent sprinkling, and the work should be completed as rapidly as possible.

Bunches of Anacharis, Cabomba, Myriophyllum and other plants can be added last. These need to be weighted down with bits of lead or tin wire. In filling the aquarium it is a good plan to place a piece of paper in the center of the aquarium and let the water strike on this. After there is sufficient water to allow the paper to float, place it on the surface. A moderate stream poured on it, instead of sinking it, as one might expect, causes it to ride on the top of the water. By this method the plants will not be seriously disturbed. The use of a watering pot 
for filling will also prevent any considerable disturbance of the plants. The aquarium should be allowed to stand at least a day before the fish are introduced, but a week would be better, so that the plants may become established and active in time to be of real use to the fishes.

Some aquarists use a thin sprinkling of powdered sheep manure in the sand just below the plants. Like the little girl with the curl, when the results are good they are very good indeed, but when they are bad they are horrid. The bad results-mainly the fouling of the sand-are probably produced by an excess of the fertilizer. Hence the writer hesitates to recommend this plan to the general public, although it can be very stimulating to plant growth. Where the vegetation has not prospered in favorable conditions of light, etc., it might be well to try the fertilizer method. If the water is clouded for a week or two after planting, it will do no harm.

There is simply no end to the possibilities of arrangement and planting effect in the aquarium. Miniature boulders, natural bridges and grottos of stone form charming settings for plants. All stones should be free from sharp edges which would be liable to injure the fishes.

Worn stones, arranged to imitate the whims of Nature, will be found much more satisfactory and appropriate than any silly mermaids, submerged castles or other misplaced bric-a-brac.

\section{SAGITTARIA}

This plant in the three described species comprises the most important group of aquarium plants. It has not the commercial importance of Cabomba, because the latter is convenient to use in small bunches in the "fish globes" seen everywhere, but to those who plant in real aquaria, Sagittaria receives first consideration.

It is a plant with bright green slender leaves of grass-like form, so that it is popularly referred to by aquarists as "grass." It takes its name from the arrow-shaped summer-leaves which stand above the water, Sagittarius being the sign of the archer in the Zodiac. The white flowers are the shape of miniature cups, with yellow centres, standing above the water. Although seeds are formed, the principal means of reproduction is by runners. Small tubers or corms are also formed among the roots, particularly in crowded situations. These produce plants.

Aquarium-grown Sagittaria plants are the more desirable, but unfortunately there are not enough of these to go round. Consequently we have to largely depend on wild plants, which to some extent have to be naturalized. The wild plants usually have very few and very short roots. Obtain aquarium-grown plants if possible, and from healthy aquaria. 


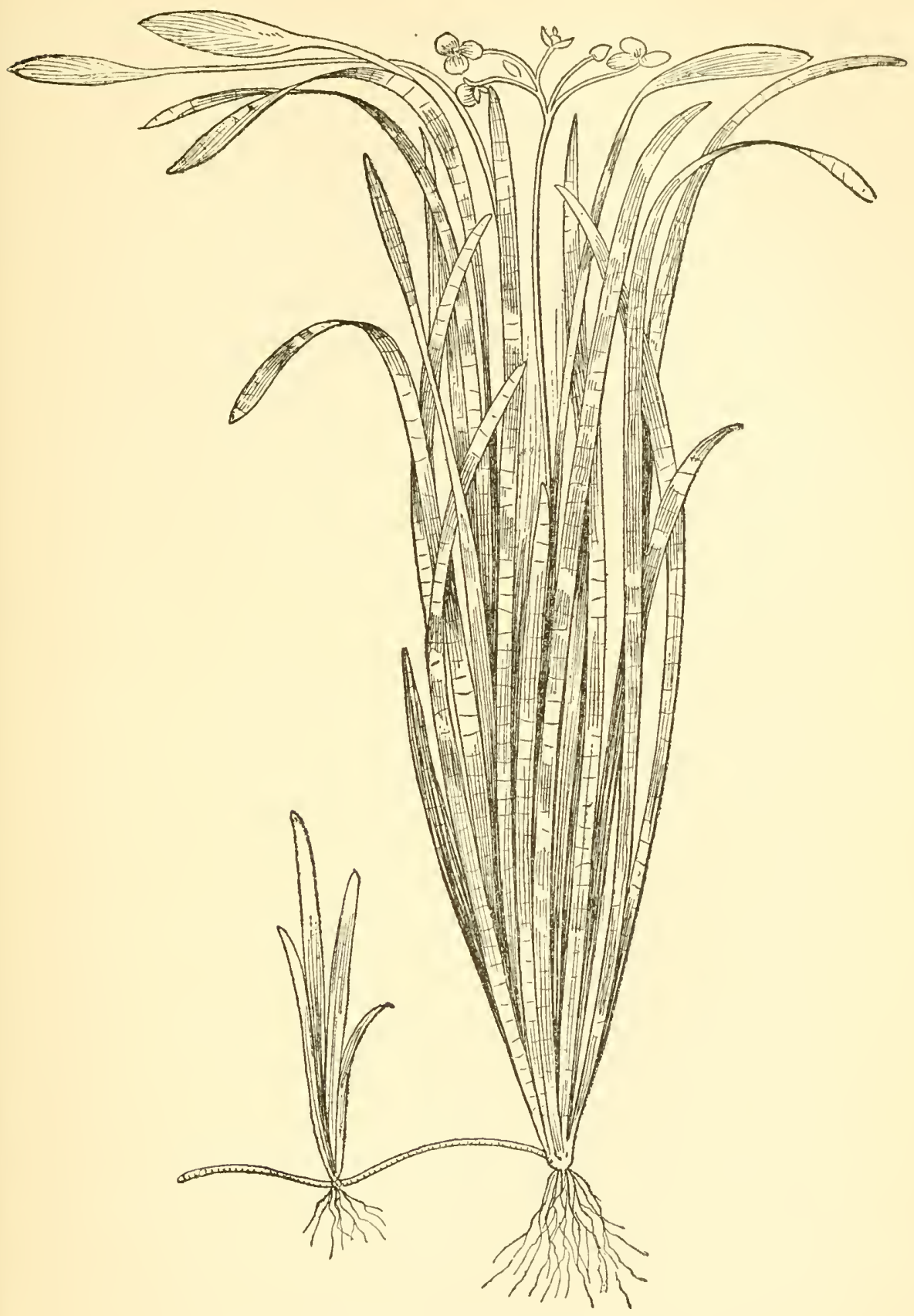

FIG. 13. Sagittaria natans (Reduced one-third) 


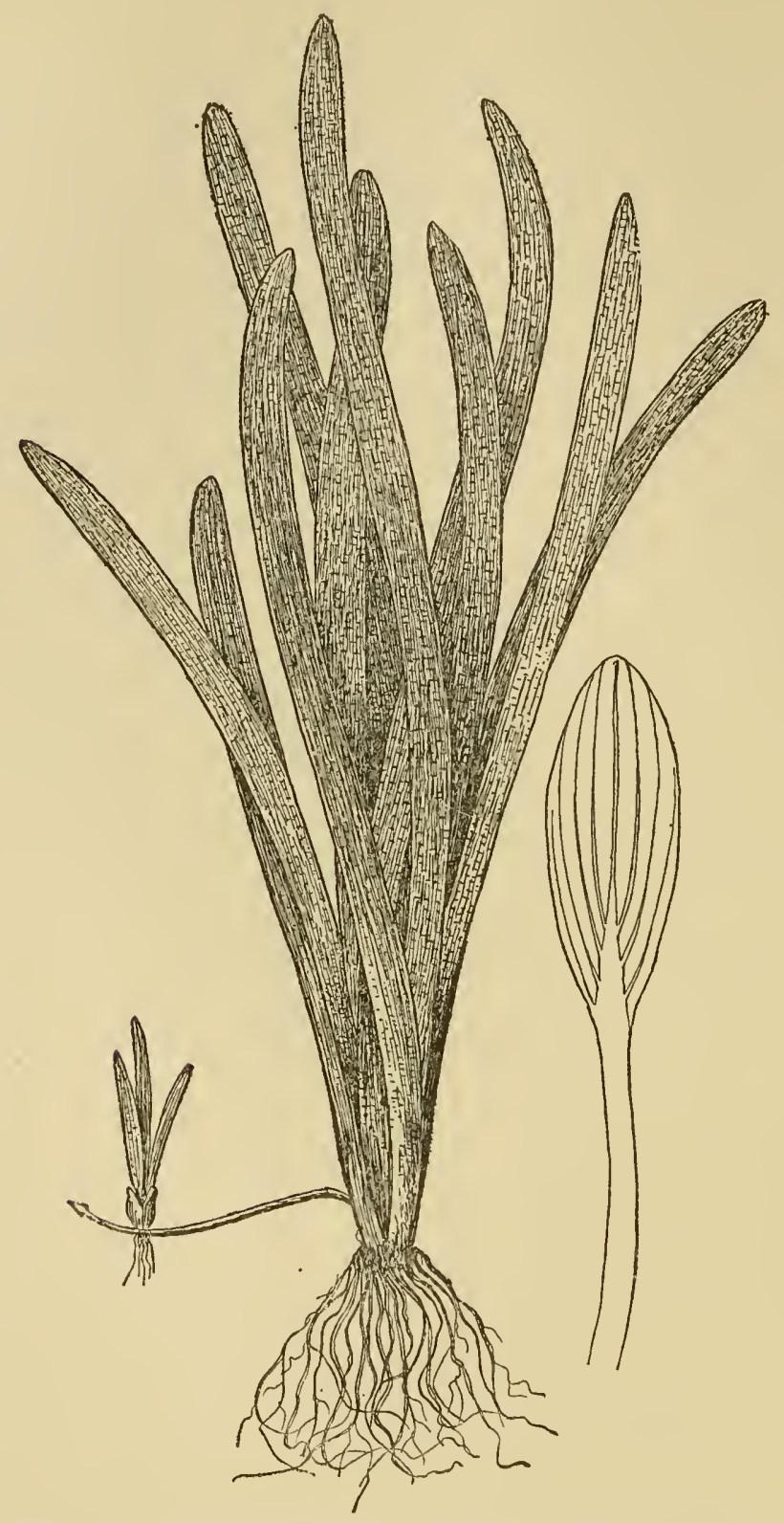

FIG. 14. Giant Sagittaria (S. sinensis) [Reduced one-half] 


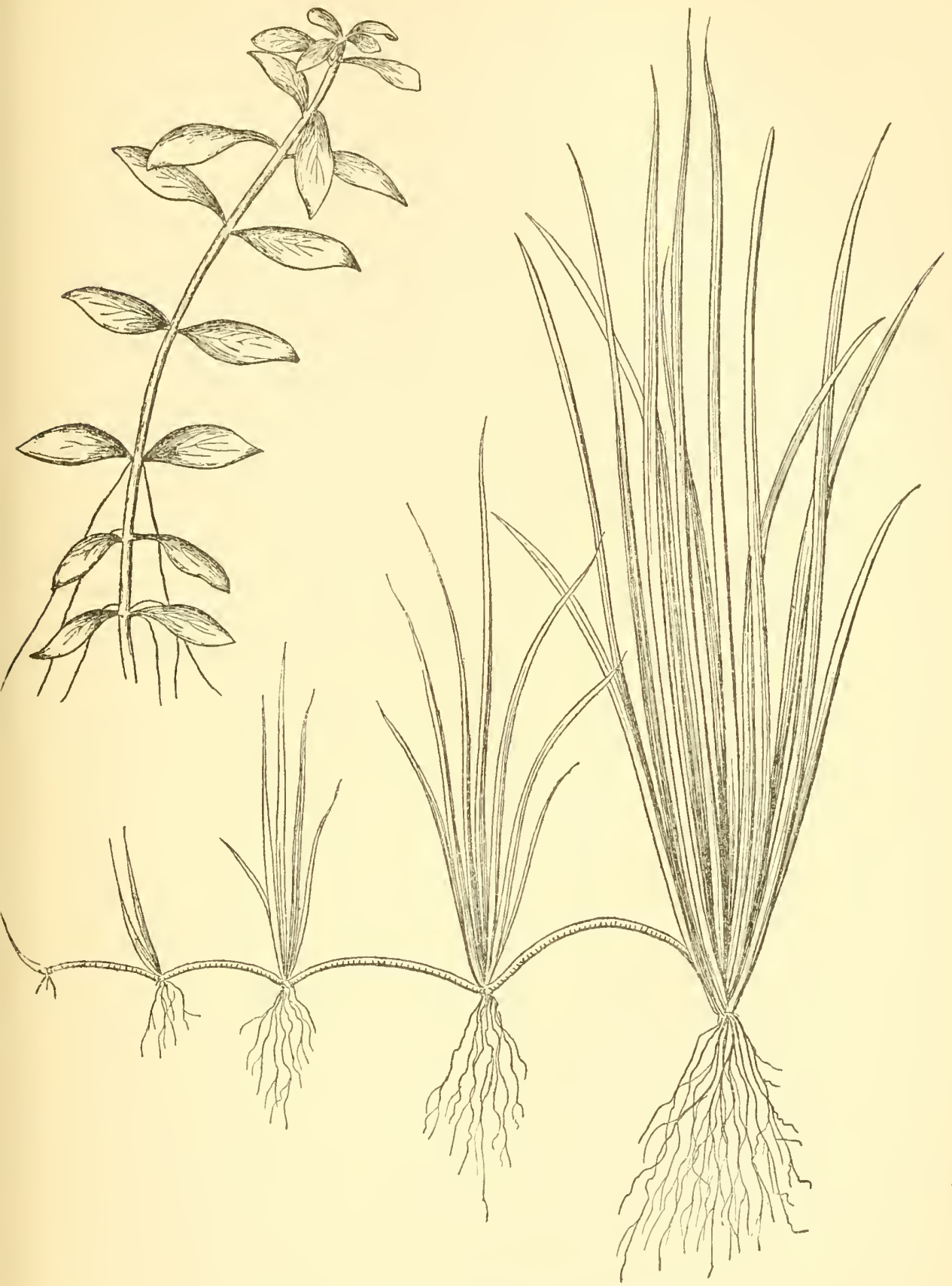

FIG. 15. Ludwigia glandulosa (Natural size)

Fic. 16. Sagittaria subulata (Natural size) 
A number of species are distributed throughout the United States, many of them quite large, frequently with leaves extending well above the water are only useful as bog plants. The majority of wild Sagittarias are not suited to the aquarium.

Sagittaria natans, known also as Ribbon Arrowhead, is, to the aquarist, perhaps the most important of the group. It is of moderate size and is suited to the average aquarium on that account. Multiplying slowly, growing the entire year, supplying a large amount of oxygen and thriving under varying conditions, it is very valuable. When an aquarium is uprooted on account of Sagittaria or Vallisneria becoming too thick, it will be found that the sand is not foul-smelling, showing that the matted roots purify the soil.

Sagittaria gigantea is believed to be a cultivated variety of $S$. sinensis. Its leaves are broad and stocky, having a decidedly substantial quality, and is one of the easiest plants to succeed with. A healthy specimen is quite light in weight, and on this account must be well planted with roots extending in different directions. Once established, it holds well and will stand more rough usage from contact with fish-nets, etc., than any other aquatic. Height, 10 to 15 inches. It is better suited to a large aquarium than a small one, but a single Giant Sagittaria in the centre of a smalle1 tank, surrounded by some of its lesser cousins, makes a good effect. So popular has this plant deservedly become that dealers have difficulty in supplying it, and they are always ready to buy up any surplus stock.

Sagittaria subulata has recently come into popularity on account of its small size. Fanciers of tropical fishes, now becoming so numerous, generally use small aquaria, and in order to produce a symmetrical picture it is necessary to introduce plants of suitable proportion. The leaves are of a rather dark shade of green, narrow and thick through, presenting a strong, wiry appearance. Sagittaria subulata grows from 3 to 7 inches, the stronger the light the shorter the leaves. It multiplies from runners and eventually carpets the aquarium, making either a good spawning bed or a miniature thicket in which young fishes may hide from cannibalistic parents. Can be had from some dealers and is collected in the coast-wise States from New York to Alabama. It is incorrectly known as S. pusilla.

\section{VALLISNERIA}

Vallisneria (Vallisneria spiralis) is another of the grass-like plants, and has strap-shaped leaves of the same breadth almost their entire length. It is known as Channel Grass, Eel Grass and Tape Grass. Appearing somewhat like Sagittaria, it has a distinct individuality of its own. The leaves are of a lighter green and have a more translucent quality 


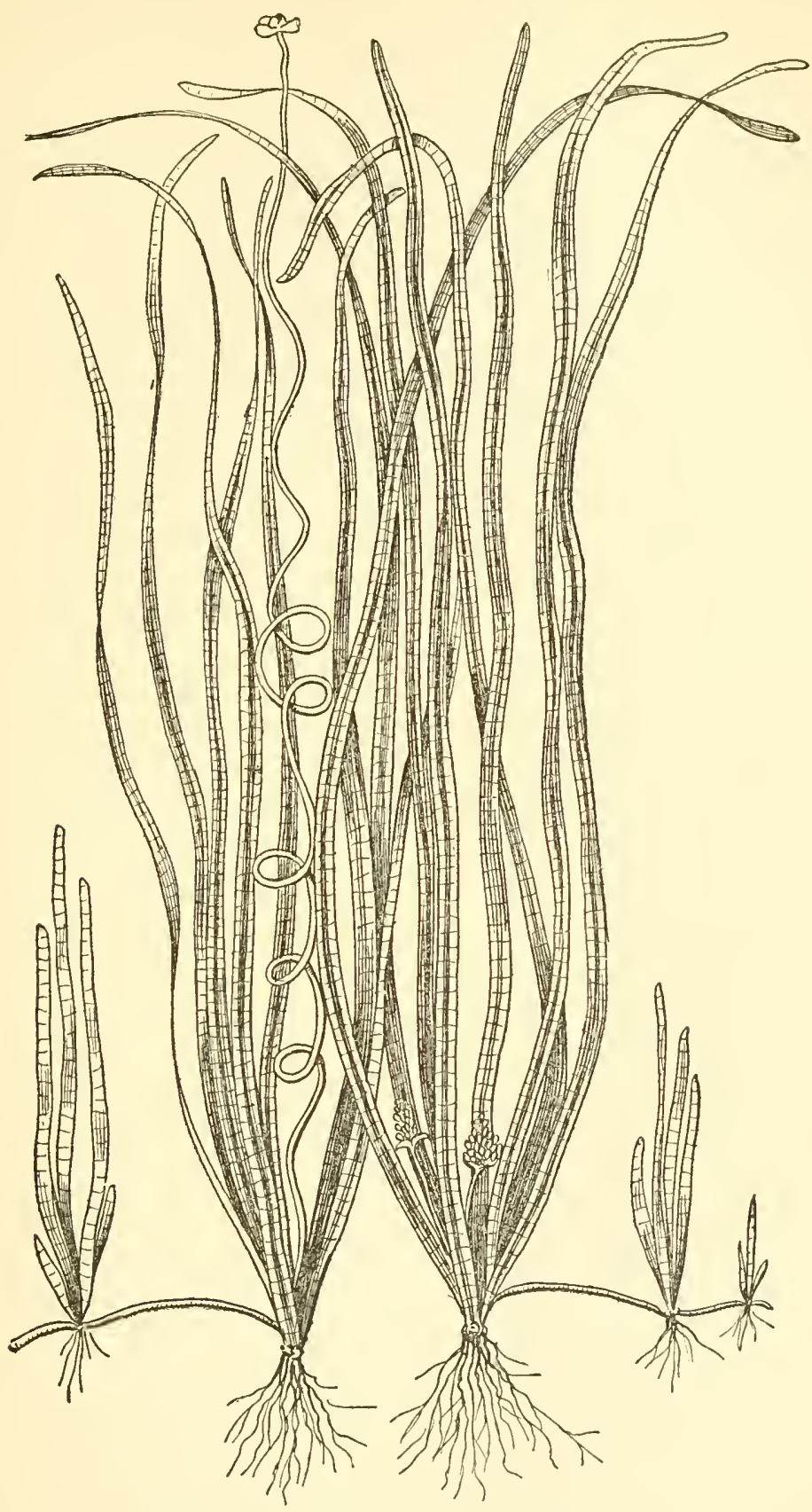

FIG. 17. Vallisneria spiralis (One-third size)

(Italian stock) 
than Sagittaria. Also the plant tends more to rise vertically in undulating lines, which produces a very pleasant decorative effect, being of a less spreading contour than Sagittaria. The leaves may also be identified by the margins being of a slightly different shade of green. By reflected light the margins appear the darker, but if held up to transmitted light, the centre is the darker. Vallisneria is probably without a superior as an oxygenator. For use in large aquaria, particularly where artistic effects are striven for, it is without an equal. The aquarium shown in colors on page 111 is featured principally by this plant, although printing ink falls short of giving an adequate idea of the radiant, silky green leaves.

For some years American aquarists depended upon plants gathered locally from rivers, creeks, mill races, etc. Owing to the long-established habit of dying down to the tuft in winter, the plant had a strong tendency to keep to the schedule, even when kept in a warm aquarium over winter. In order to overcome this difficulty a search was made for a stock growing in a climate without severe winters. This plan was successful. We were fortunate enough to secure a small stock from Italy which, by careful propagation and distribution among leading aquarists, has now multiplied itself into millions. There is every reason why it should establish itself in further favor among those having large or fairly deep aquaria. It grows and multiplies constantly and the runners lie close to the bottom, not requiring to be pushed down like young Sagittaria plants. Contrary to the views of some writers, we advise against deep planting. It is important that the crown be not covered, but just at the surface. The plant is not well suited to small aquaria, as it grows from 18 to 36 inches, according to conditions. If closely confined it is likely to get into a tangled mass whenever a fish has to be caught. Allowed to rise to the surface and then extend horizontally on it for some distance it produces a luxuriant picture. Rising from either end of the aquarium and trained over the surface towards the centre, Vallisneria makes the best of frames to show off the brilliant colors of the fishes. The sexes are separate in Vallisneria, fertilization taking place in a peculiar manner. The female flower, small, cup-shaped and white, floats at the end of a long spiral scape on the surface of the water. The male flower on another plant comes only a short distance from the crown. It is a case containing pollen balls. When the case splits the pollen floats to the top, where, by the action of wind, insects or other chance, fertilization is accomplished. Few of these plants in the aquarium start from seed. In propagation by runner only one sex appears along a line, males and females producing only their own kind. The first plants imported were all females. No males were seen for several years. These were likely propagated from the seeds. 


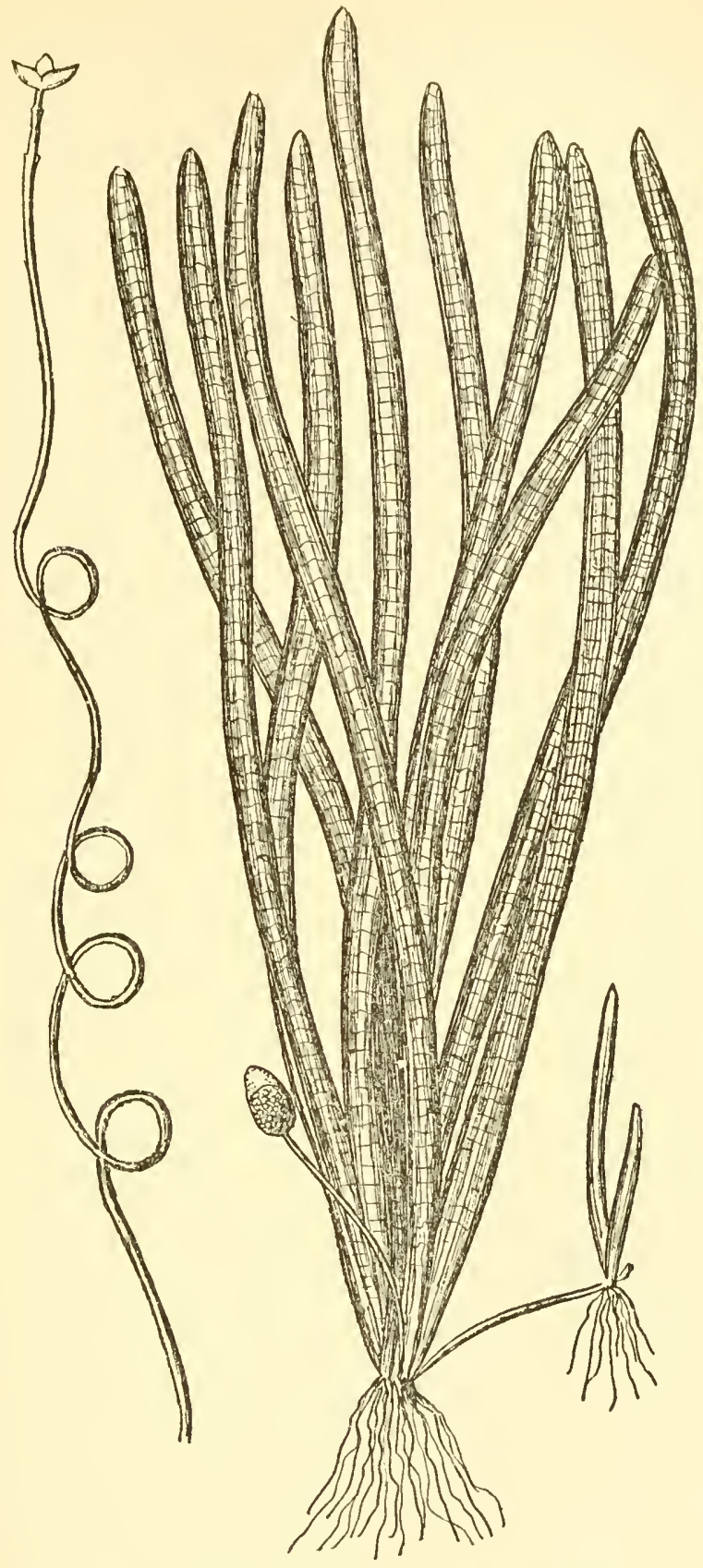

Fic. 18. Giant Vallisneria (One-quarter size) 
For one or two impressive plants to dominate the centre of a large aquarium, nothing is better than Giant Vallisneria, now brought from the Southern States by some of our leading dealers. Its leaves are as wide as those of Giant Sagittaria, but much longer, varying from two to four feet, depending on conditions. This variety is also a constant grower. Stocks of Vallisneria suited to the aquarium do not do well outdoors in direct sun, the old leaves dying and the new ones only developing a few inches in length.

\section{CABOMBA}

Commercially there is no doubt Cabomba is the leading aquatic plant. Its finely-cut, fan-like, bright green leaves make a very good first impression, although it does not live so well in the aquarium. It is brittle and the fishes if active soon pick it to shreds. Even though this does not occur, it becomes long, spindly, and degenerate. Enormous quantities are gathered from ponds, some of them purposely planted, from Pennsylvania to North Carolina.

The plant under natural conditions is a good producer of oxygen, but in the aquarium its activity in this respect is doubtful.

Cabomba caroliniana is the species usually sold in bunches in pet shops. It is well known as Washington Grass, Fanwort, and Watershield. In habit it is purely aquatic and propagates mainly by branching. The stems in nature attain a length of several feet.

Cabomba roseafolia is a species whose principal distinguishing characteristic consists of a distinct reddish hue on the stems and lower sides of the leaves. It, too, is a handsome plant when first introduced.

\section{ANACHARIS}

Known to American aquarists as Anacharis and in Europe as Elodea, it is also popularly called Ditchmoss, Water Pest, Water Thyme, and Babbington's Curse. Some of the rather uncomplimentary titles are due to a characteristic which, at least in the aquarium, should be considered a favorable point, that is, rapid growth. It may generally be taken for granted that if an aquatic plant is thriving it is doing good work for the aquarium. Several species are distributed throughout the United States and Southern Canada. A cultivated variety, probably derived from $A$. canadensis, is considerably larger than the common local specimens to be found. The plant grows several feet in length, sending off occasional shoots and a few roots at random that reach down into the soil. In the aquarium it is best to only retain from 6 to 15 inches of the newer growth, cutting away the old ends and replanting. As the plant 


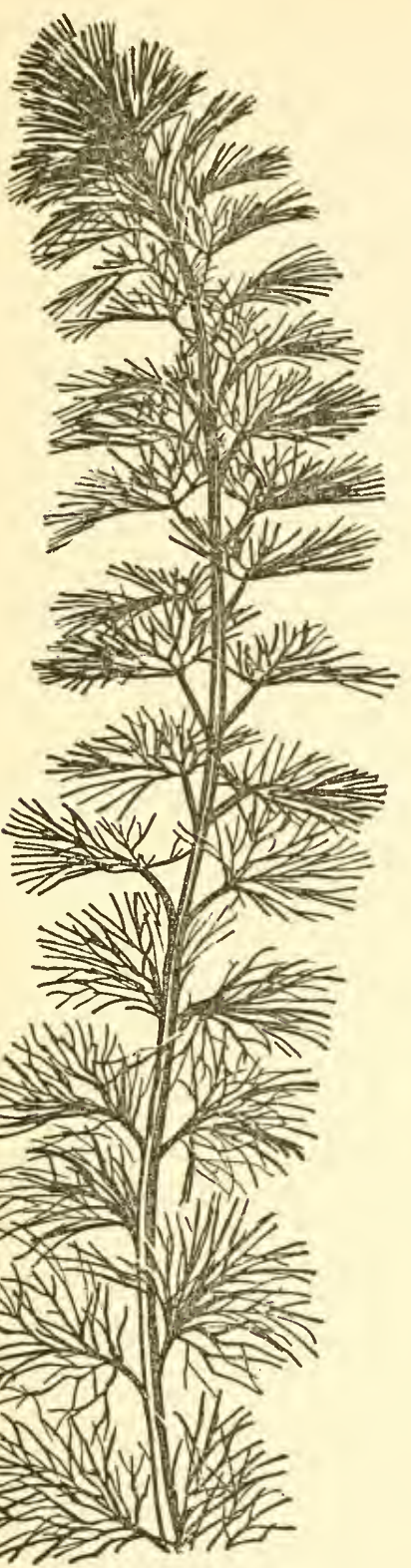

Fig. 19. Caвomba (Life Size)

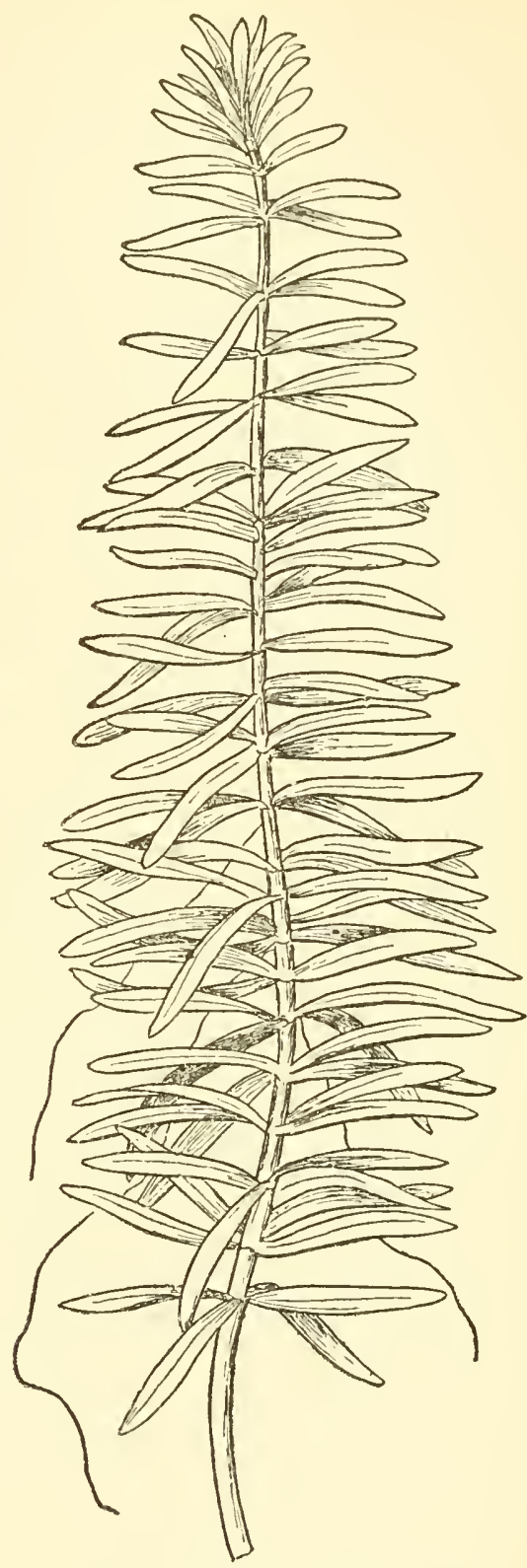

Fig. 20. Cultivated Anacharis (Life size) 


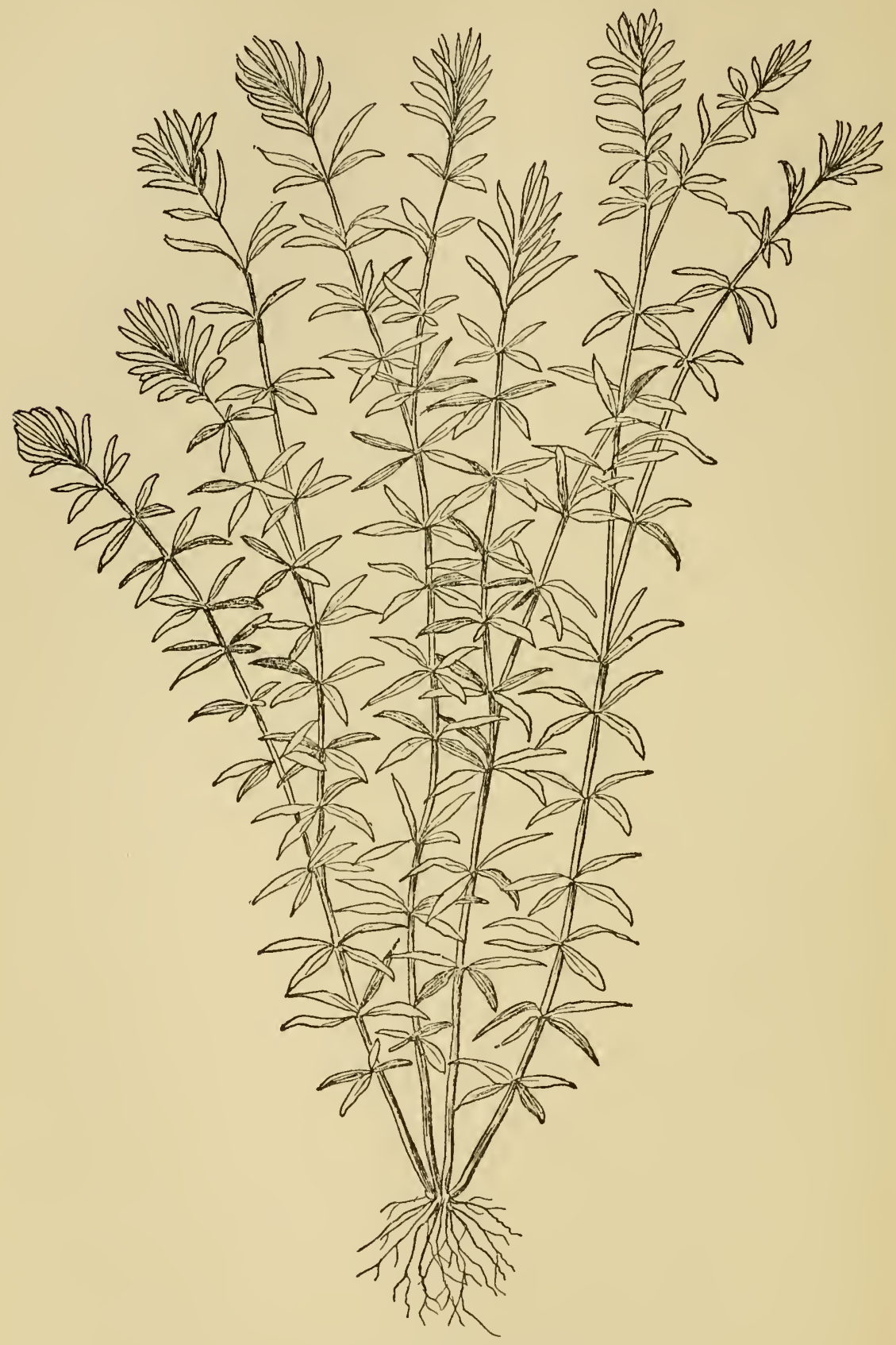

Fig. 21. Wind Anacharis 
grows yellow at the old end it should be lifted out, pinching off the yellow and replanting the fresh green portion.

Anacharis under suitable conditions no doubt lives up to its reputation as a wonderful oxygenator. It is happiest in an open pond in Summer with a moderate amount of direct sun. Indoors it needs an abundance of light. Placed in the aquarium in Autumn it quickly finds itself at home and continues growth, but gradually becomes spindly and degenerates in size. By Spring it is in need of another vacation out doors, preferably where its roots may take hold in dirt. On the whole we would say that the merits of Anacharis as an aquarium plant are overrated. As a pond plant, and when under control so as not to overrun the place, it is a brilliant success. To be had of dealers generally.

\section{MYRIOPHYLLUM}

Here we have another plant which at first looks well in the aquarium, but which deteriorates. It has, however, a strong redeeming feature, the very finely divided hair-like leaves being ideal for receiving the spawn of goldfishes. For this purpose it has grown more and more into favor. It is used either in the bunches as they are sold, or made into a spawningring as shown on page 210. As a spawn-receiving plant it has one advantage over Water Hyacinth in that the individual pieces may be spread out so as to give all the eggs a similar amount of sun, whereas with Hyacinth one side is usually much more protected than the other, making the eggs hatch at different times. Before using Myriophyllum to spawn on it should be well washed by moving it about in clear water, being careful to remove all insects, snails and snail eggs. When hatching is finished the plant might as well be thrown away, although if rooted in an outdoor tank or pool it will grow beautifully.

There are a number of generally distributed species throughout America, all having the same general characteristics, but some are bettet than others as "spawning grass" on account of closer and longer leaves. Myriophyllum is popularly known as Water Milfoil.

Myriophyllum verticillatum. This is the best American species and is found in both shallow and deep ponds throughout the United States and Lower Canada. Its leaves are dense and crowded, making an excellent spawning plant.

Myriophyllum proserpinacoides or Parrot's Feather is a partially submerged form which should be allowed to creep on the surface of the water, where its blue-green, feathery leaves display a charm exclusively their own. Does well in the greenhouse or established on the edges of partially shaded lakes, where it becomes very robust. 


\section{CERATOPHYLLUM}

Hornwort, as it is generally known, is mentioned here on account of its resemblance to Myriophyllum, for which it is sometimes gathered. It is an extremely poor aquarium plant, being very brittle and liable to rapid decomposition. Besides its characteristic of being fragile, it may also be recognized by having practically no roots, absorption taking place in the leaves.

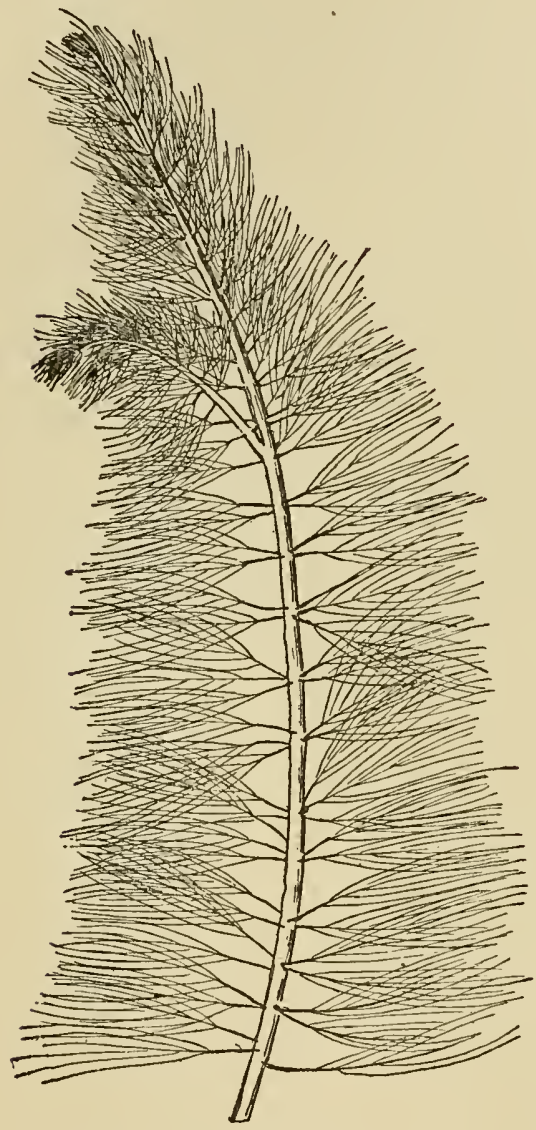

Fig. 22. Myriophyllum

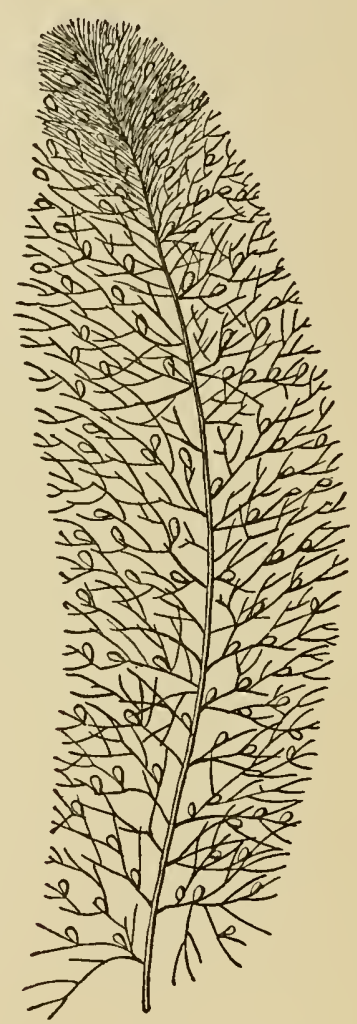

Fig. 23. Greater Bladderwort

\section{UTRICULARIA}

Many kinds of Utricularia, or Bladderwort, are distributed in the Temperate Zone. One form has the appearance of the finely-divided leaves of Myriophyllum, but may be identified by the small bladders dotted throughout. Our figure 23 of $U$. vulgaris gives a good idea of the 
general type. Some are thread-like. They thrive for a time in the aquarium if given plenty of strong light. The Bladderworts are carnivorous plants, trapping the microscopic lower forms of animal life in their bladders, where they are digested. It has been claimed that they can trap extremely small fishes, such as the young of Dwarf Gourami, but this is very improbable. There can be no question, however, that the plant does take living food which would be useful to young fishes, and to that extent is objectionable. On the other hand the matted masses of the thread-like varieties afford good hiding places for young fry.

\section{HAIR GRASS}

Eleocharis acicularis, a dainty hair-like aquatic of recent introduction, fills small tropical aquaria in a very agreeable manner. It is another

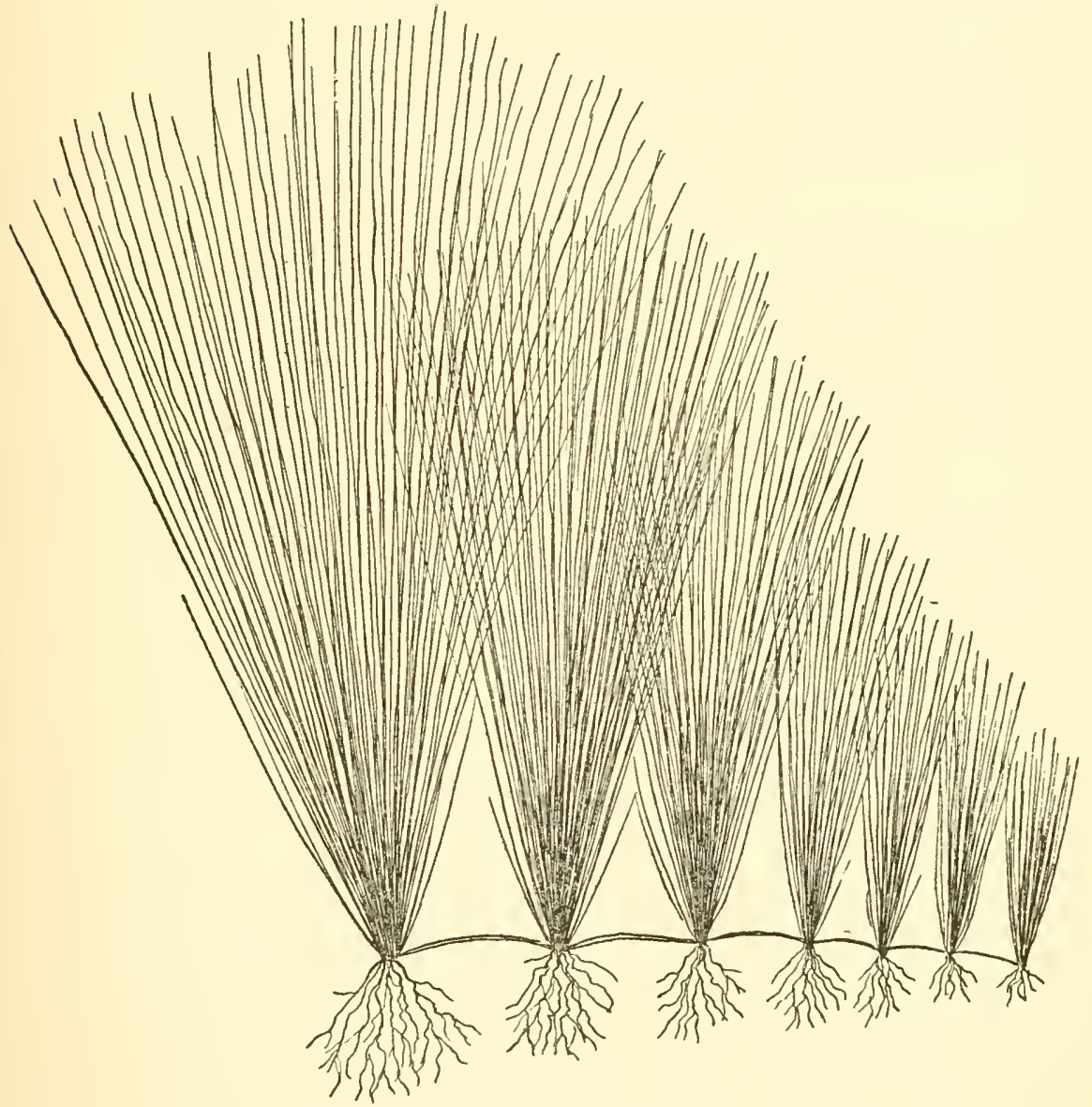

FIG. 24. HaIr Grass (Life Size) 
of those plants forming a useful adjunct to the breeding of tropical fishes. It multiplies from short runners. Of a pleasing shade of light green, it makes a contrasting group among other plants in a large aquarium, but it shows to best advantage in a small aquarium by itself. It grows from 3 to 8 inches and is native to ponds in the Middle Atlantic and Southern States. Not often obtainable commercially.

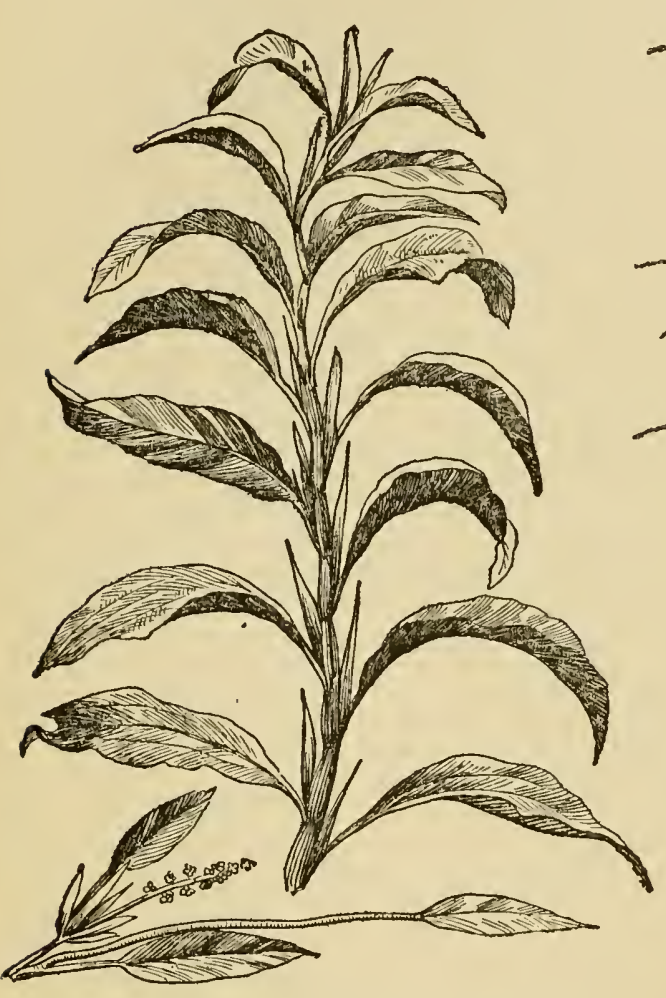

Fic. 25. Potamogeton densus (Half size)

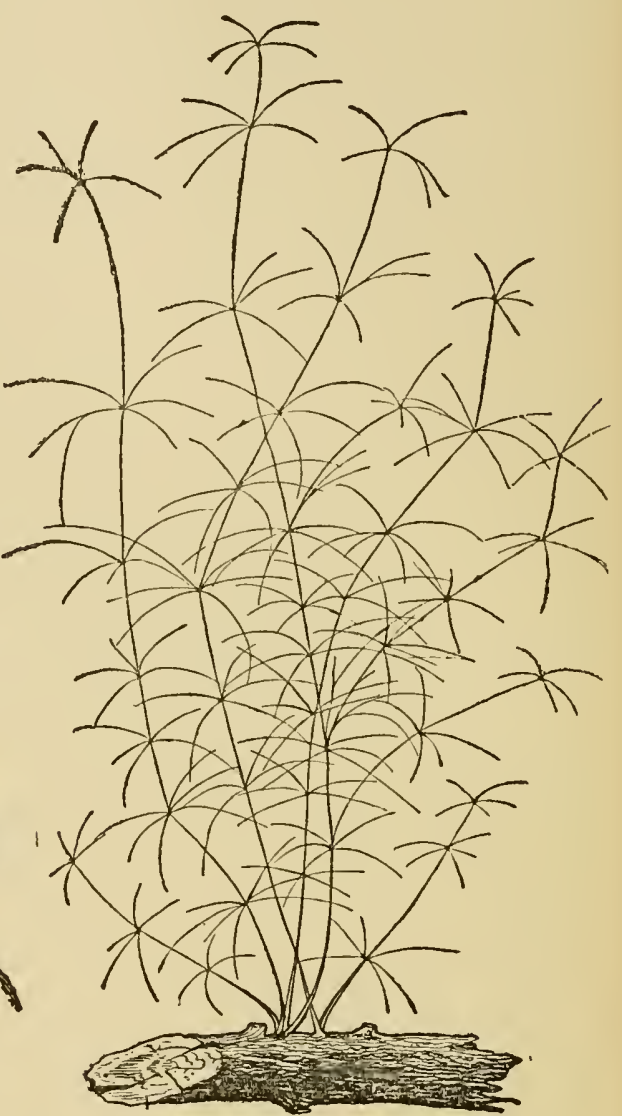

Frc. 26. Nitella gracilis (Two-thirds size)

\section{POTAMOGETON}

In strong contrast to the foregoing dainty plants is Potamogeton densus, or pondweed. As will be seen from illustration, these leaves are broad and robust. In color they are a bright green. This variety is said to be of European origin, but is now common in ponds in the United 
States. If established in soil in flat pots it flourishes in a well-lighted aquarium. Pieces collected from the wild may be introduced by fastening into the sand. They present a very attractive appearance and will last for quite a time, but should only be regarded as temporary and when the leaves begin to turn yellow should be removed. There are many widely distributed species of Potamogeton, all looking quite attractive in a state of nature, especially $P$. crispus with curly leaves. They appear very tempting, but none seem to survive long in the aquarium except $P$. densus, and that only when established just to its liking.

\section{NITELLA}

Of the slender-leaved aquatics, Nitella gracilis is one of the best. Figure 26 gives a good idea of its dainty form. It is not freely distributed, but is found occasionally in ponds and streams in the Eastern States, usually attached to bits of stick or stone. From this it receives its popular name, Stonewort. In removing the plant to the aquarium, it is best to take also the base upon which it holds. If placed in a position to its liking, Nitella prospers wonderfully in the aquarium and is a fine oxygenator. Under the microscope the leaves show the circulation of protoplasm better than any other plant. Requires plenty of light. Not commercial. This plant is really an Alga and has no true roots, but "holdfasts."

\section{LUDWIGIA}

Popularly known as Swamp Loosestrife, this plant in about twentyfive species is widely and thickly distributed in North America, mostly growing at the edges of streams, like Watercress. Although in reality more of a bog-plant than a pure aquatic, it does well in the aquarium, particularly if kept in the earth of the pot in which it was propagated from a cutting. Propagation is very easy in the greenhouse. About five short cuttings are placed in a two-inch pot, having a top layer of sand. This is not done under water, but the pots need to be kept saturated and the air very moist. They soon root, and when they have developed about an inch of new growth should be submerged in the aquarium.

Ludwigia is one of the more important aquarium plants on account of its decorative value and pronounced individuality. When kept in a strong light the under sides of the leaves become a beautiful red color. Wild stock is not altogether satisfactory. It throws out too many roots to make a pleasing appearance, and in the aquarium becomes attenuated in character. A cultivated variety said to have come from South America is better in every respect and is easily obtained, for it is the kind propagated by dealers in aquatics. As it is sold in the original pots before 


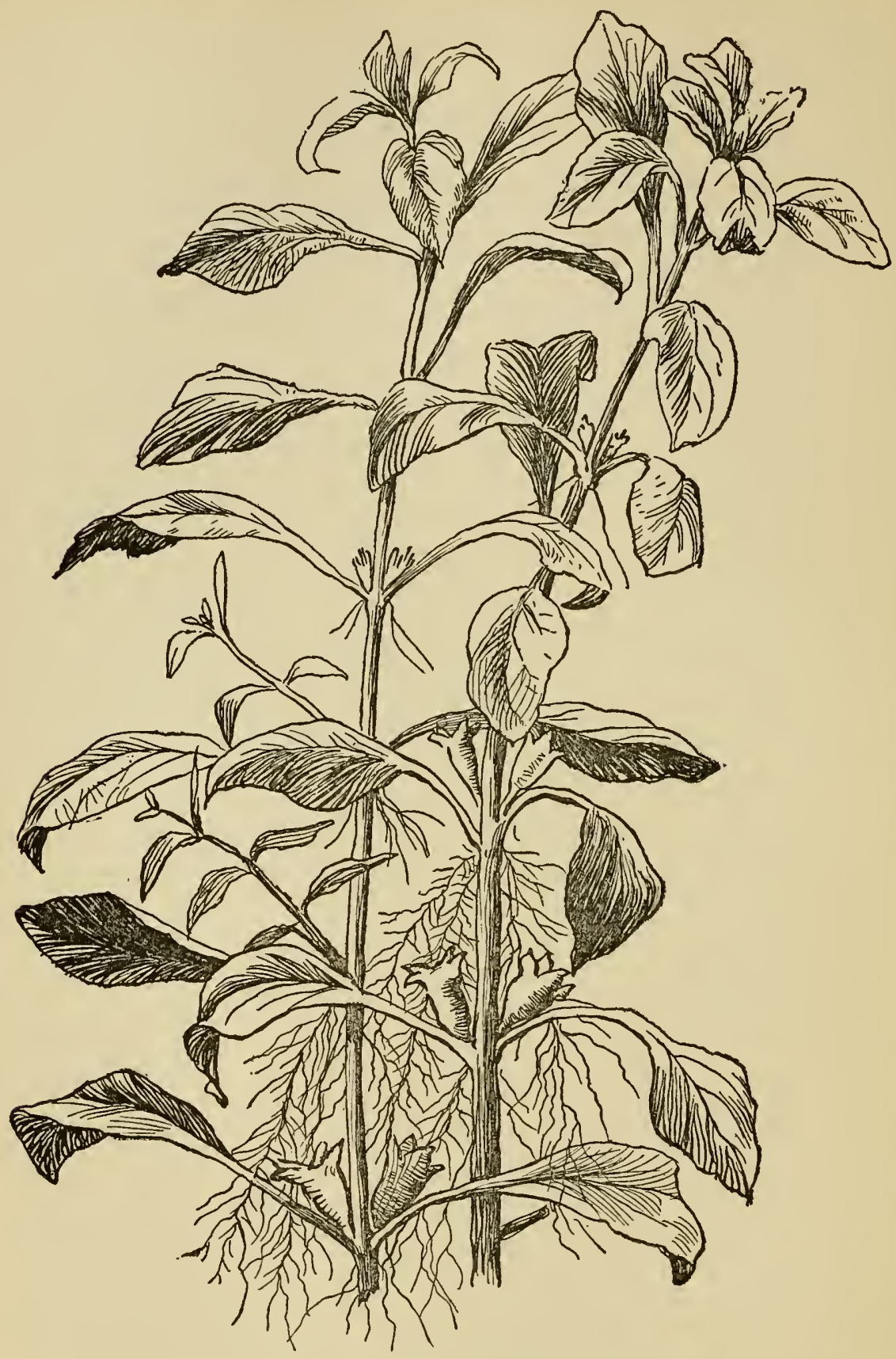

Fig. 27. Cultivated Ludwigia (Life size)

(Now listed by botanists as Isnardia palustris) 
being plunged into water, it can safely be sent long distances. Growing to a length of several feet if untrimmed, it is suited to large aquaria, but may also be kept small by pinching back. Unlike Anacharis, it should not be trimmed at the root end unless the stock has become quite old and no longer prospers. Does best in strong light and may also be propagated in the aquarium from cuttings. It likes to be able to get its upper leaves out of water. A little Ludwigia can be seen in our illus. tration of a concrete aquarium. (Page 111.)

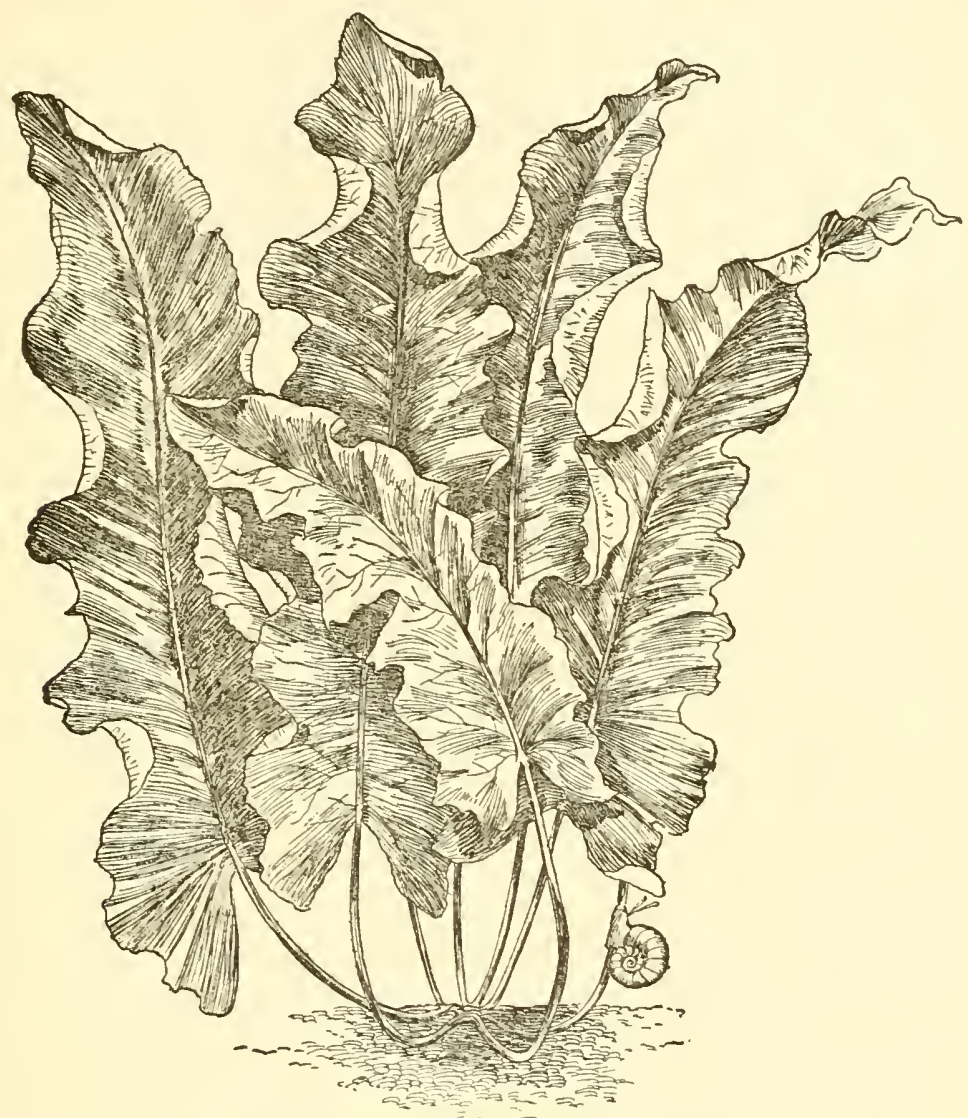

Fig. 28. Carolina Spatterdock (Half Size)

\section{SPATTERDOCK}

Among the newer introductions into the aquarium are the submerged Spatterdocks. The large arrow- or spade-shaped leaves make a very characteristic appearance. Seedling plants gathered from lakes and ponds in the fall will do well in the aquarium over winter. If summer leaves 
appear and become too large for the aquarium the plant had best be removed. The Southern Spatterdock, Nuphar sagittcefolia, does not develop aerial leaves, but they gradually lengthen as the warm season progresses. The illustration shows the plant in March. Later the stems and leaves will be longer. In October a new growth starts close to the thick, running root or rhizome. The leaves of this Spatterdock are of the brightest green hue and do not darken in strong light. Where the rhizomes, or thick runners, have been broken off they have a tendency to rot, eventually killing the plant. This seems to be overcome by planting in good soil.

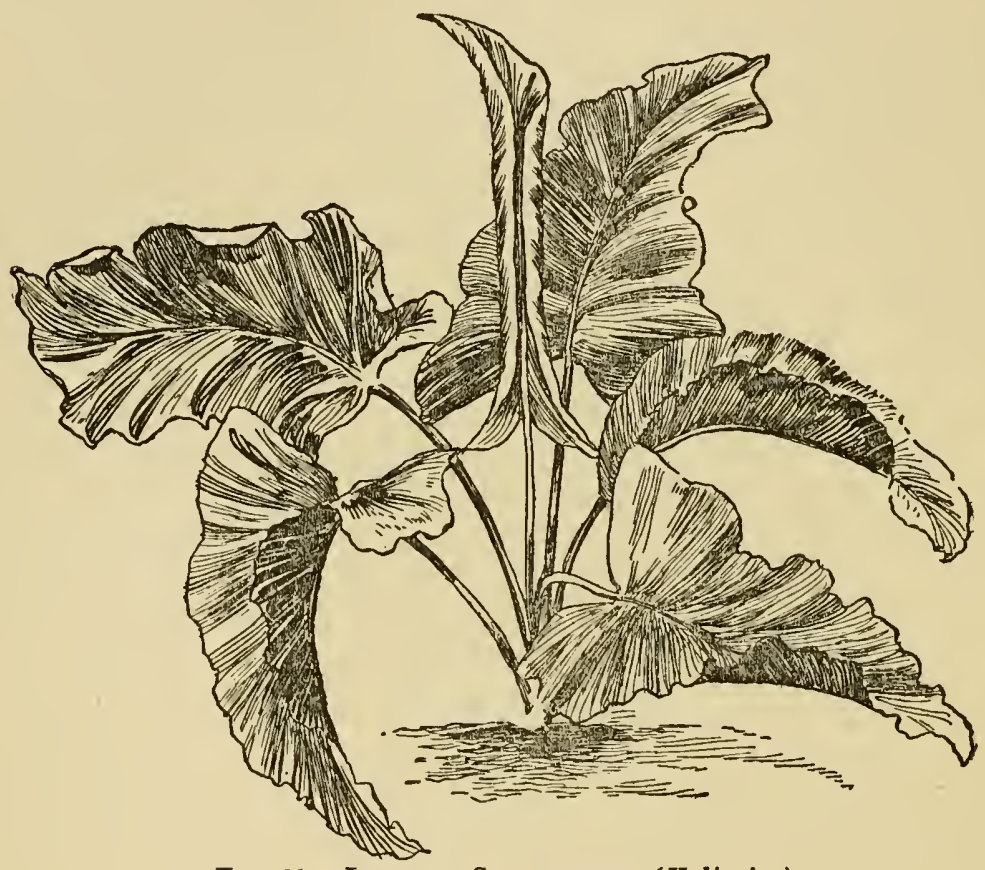

Fig, 29. Japanese Spatterdock (Half size)

The Japanese Spatterdock, Alisma spec., has leaves of a considerably darker sage green, broader at the base. It is a continuous grower, has no aerial leaves and multiplies readily at the rhizome. Altogether a satisfactory plant for the large aquarium.

\section{QUILLWORT}

Isoetes is a widely distributed genus of a number of species. It is found in the mud and sand at the edges of streams and ponds. In size it varies from a few inches to several feet. The small submerged species are worth trying in the aquarium, as they are tenacious of life. The leaves 


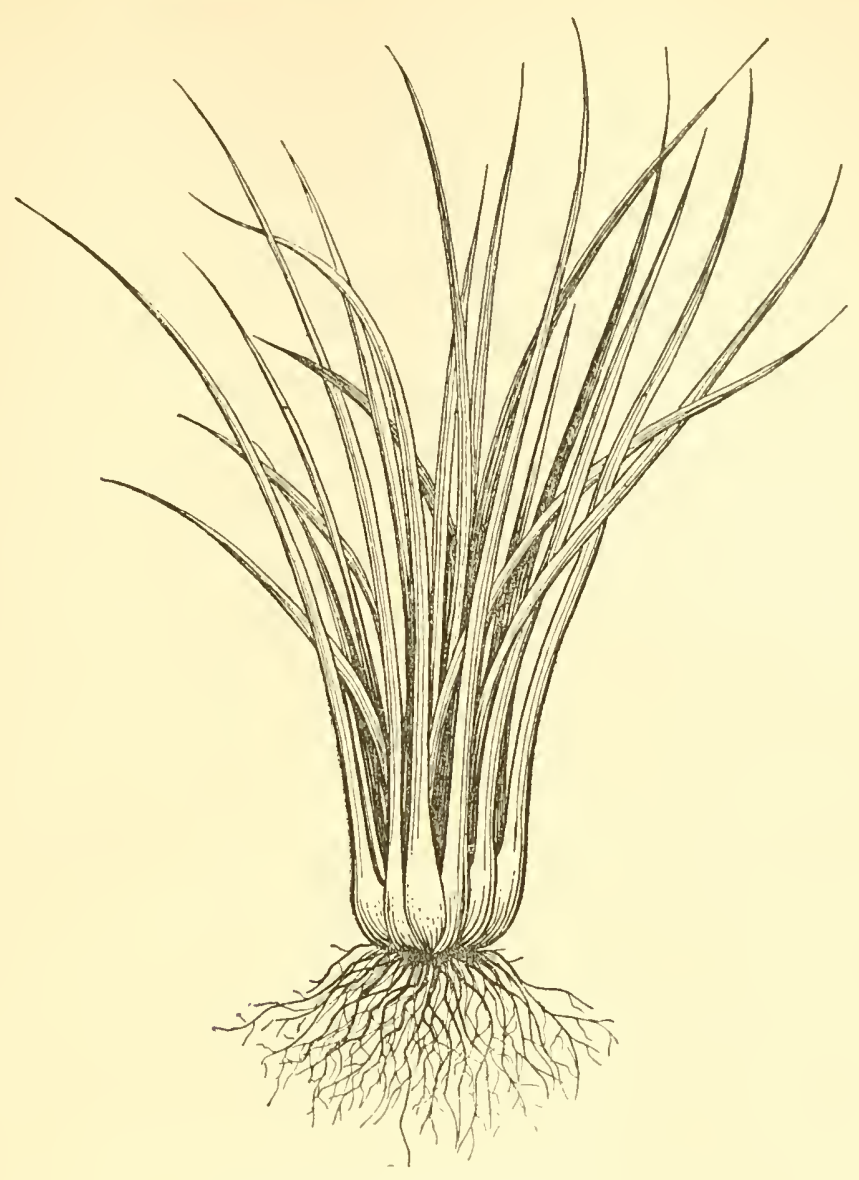

FIG. 30. Quillwort (Half size)

rise from the centre of a circle or rosette, producing a very pretty effect. Quillwort should be placed in a good light. It is eaten by some snails and fishes. Not easily obtained.

\section{FONTINALIS}

Known as Willowmoss, these plants are found attached to stones or other substantial objects. They are of a pleasing dark-green color and have the advantage of doing well in a subdued light, although a moderate amount of direct sun does them no harm.

Fontinalis antipyretica grows in long-branching form, with leaves closely adhering to the stem. It occurs in cold-water streams. Very plentiful in some localities, but not freely distributed. 


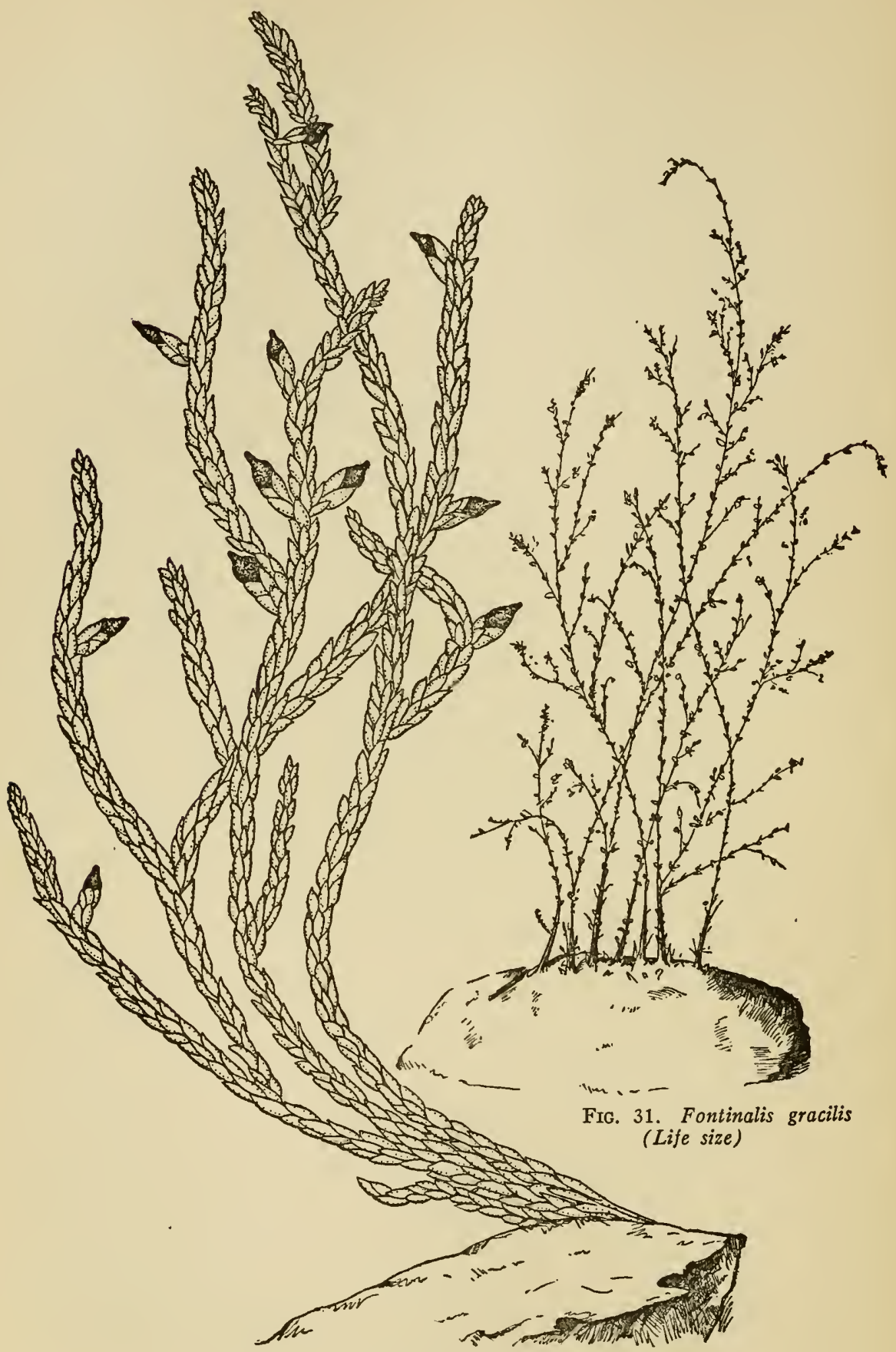

Fic. 32. Fontinalis antipyretica (Life size) 
Fontinalis gracilis is very much smaller and thread-like, the leaves being so small as to appear like a roughness on the stem. In the aquarium this plant seems to have a faculty of soon becoming covered with sediment. Indeed, some aquarists find it useful to clear the water. As soon as the plant becomes well covered it is taken out, rinsed off and returned. As the stems are strong, they stand this treatment. A stone containing a thick bunch of Fontinalis gracilis is an attractive feature in the aquarium. It is a slow grower. The new leaves are bright green, but soon turn to a dark sage color. Not often obtainable commercially.

\section{HERPESTIS}

Herpestis amplexicaulis bears a general resemblance to Moneywort, but in essential characteristics is quite different. It is a pure aquatic with thick leaves and a stout stem. Native to the ponds of Southeastern United States as far as Florida. It is one of the best of the recent additions to aquarium plants. On account of being a slow grower, its introduction is not likely to be rapid, but once established it does very well, holding its bright green leaves a long time. When out of the water it has a faint, pleasant odor. Being of Southern origin, it will prosper in the temperature of tropical aquaria where some plants will not do so well, although it thrives in cool water also. Incorrectly known as Bacopa. Stocked in season by larger dealers.

\section{CALLITRICHE}

Floating in small, cool streams throughout the United States and Lower Canada, one will find patches of brilliant, light-green, small leaves. Examination will show them to be the floating leaves of a long-stemmed plant growing in the mud. These are various forms of Callitriche, or Spring Starwort, sometimes also called Water Funnel. When the plant is loosened we find it disappointing, for the lower leaves are thinner and quite different in appearance. The stems are tangled and difficult to disengage.

Callitriche verna is the commonest form, as well as the most easily established in the aquarium, but it shows to best advantage in shallow tanks, where a top view can be had of the surface leaves. It should, however, only be kept with tropical fishes unless it is intentionally given to goldfishes to eat, as they are fond of it. The stems and roots when taken are usually swarming with various aquatic insects and crustacea. Although many of these are fishfoods, it is best to rinse this and all other plants before placing in the aquarium. 


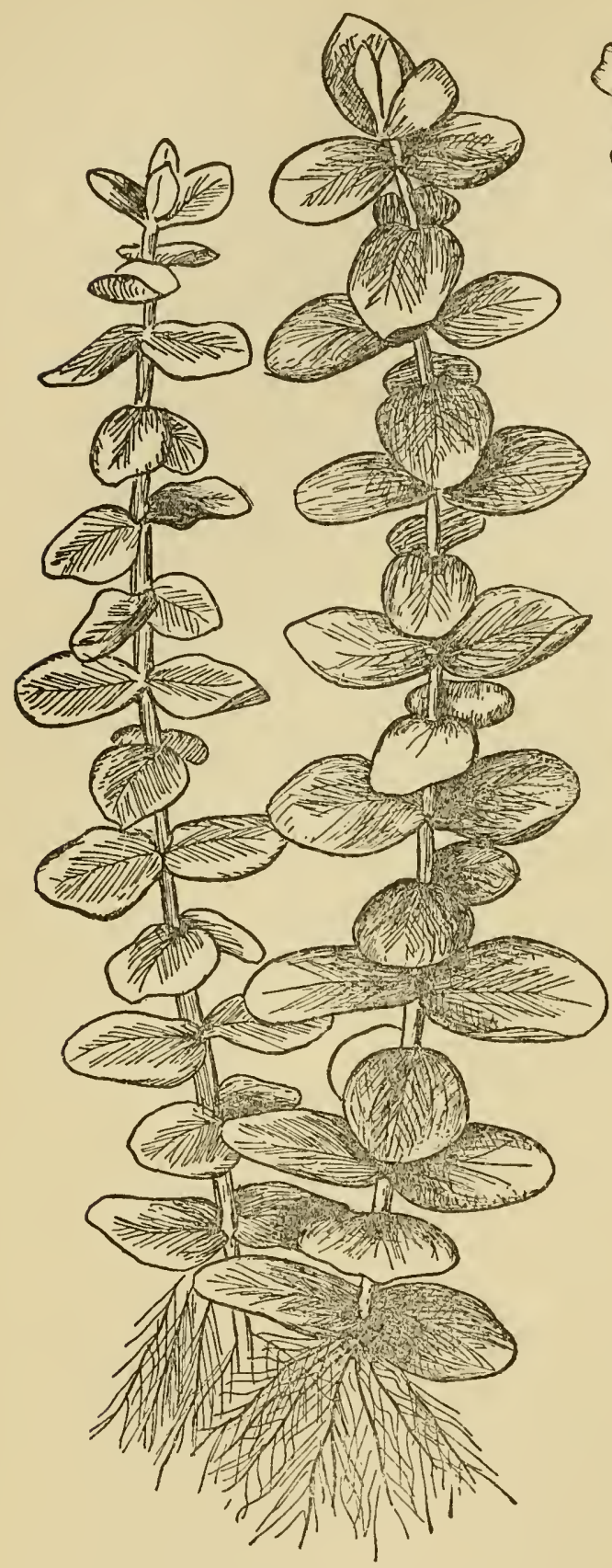

FIG. 33. Herpestis (Life size)

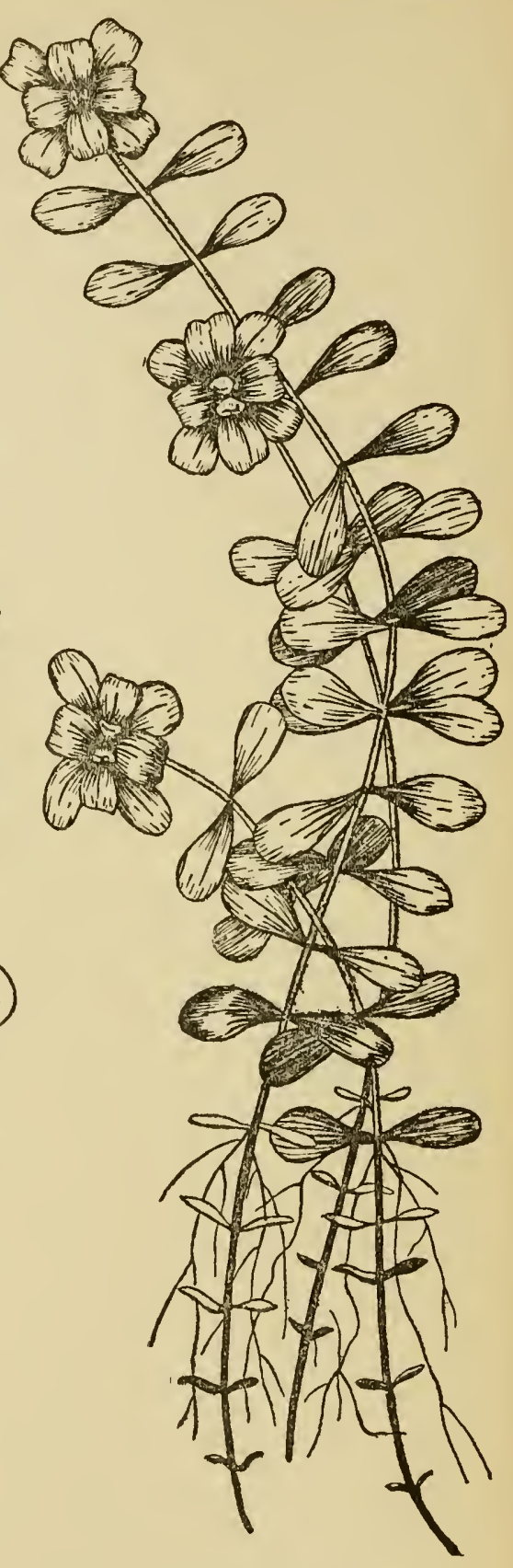

FIg. 34. SPrING Starwort (Life size) 


\section{HIPPURIS}

Formerly used as an aquarium plant, Mare's Tail has been over. looked of recent years, possibly on account of its tendency to stand above the water. Used in a suitable way, this feature could be utilized to advantage. Not commercial.

\section{MONEYWORT}

Lysmachia nummularia, or Moneywort, is also known as Wandering Jew, Creeping Jenny, Herb-twopence and Mouse-ear, the latter names and Moneywort no doubt being derived from the rounded shape of the leaves. It is very common in all the Eastern States, growing in damp places, usually in lowlands near or bordering streams. Considering that it is scarcely even a bog plant, it does remarkably well in the aquarium, where it grows straight up to the surface of the water, regardless of where the light comes from. If kept submerged the leaves gradually dwindle in size, so that it is best to gather a new stock once a year.

\section{LACE PLANT}

This extraordinary plant, Ouvirandra fenestralis, is a native of Madagascar. Its dark-green skeleton leaves appear very fragile, but

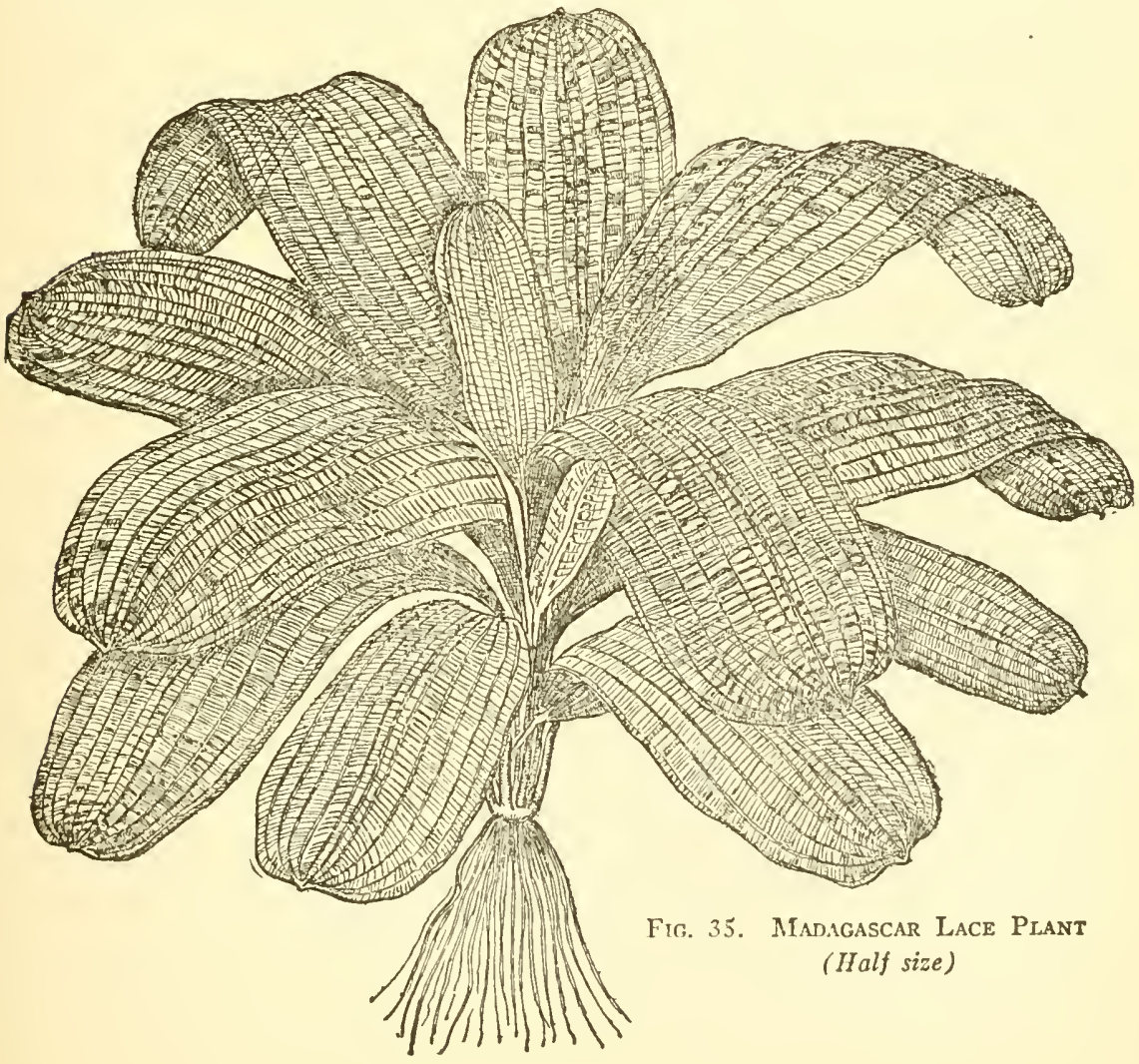




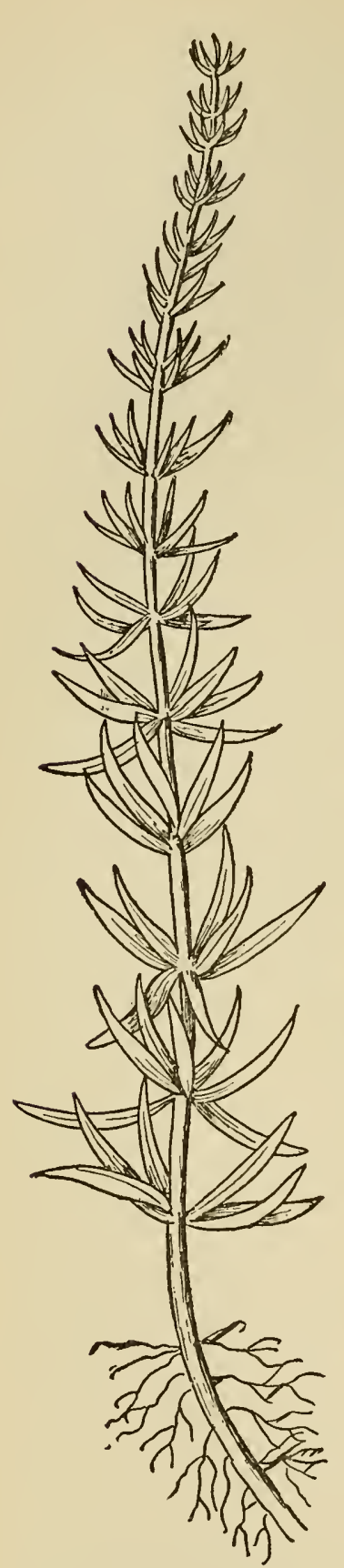

FIc. 36. Mare's TaIL (Life Size)

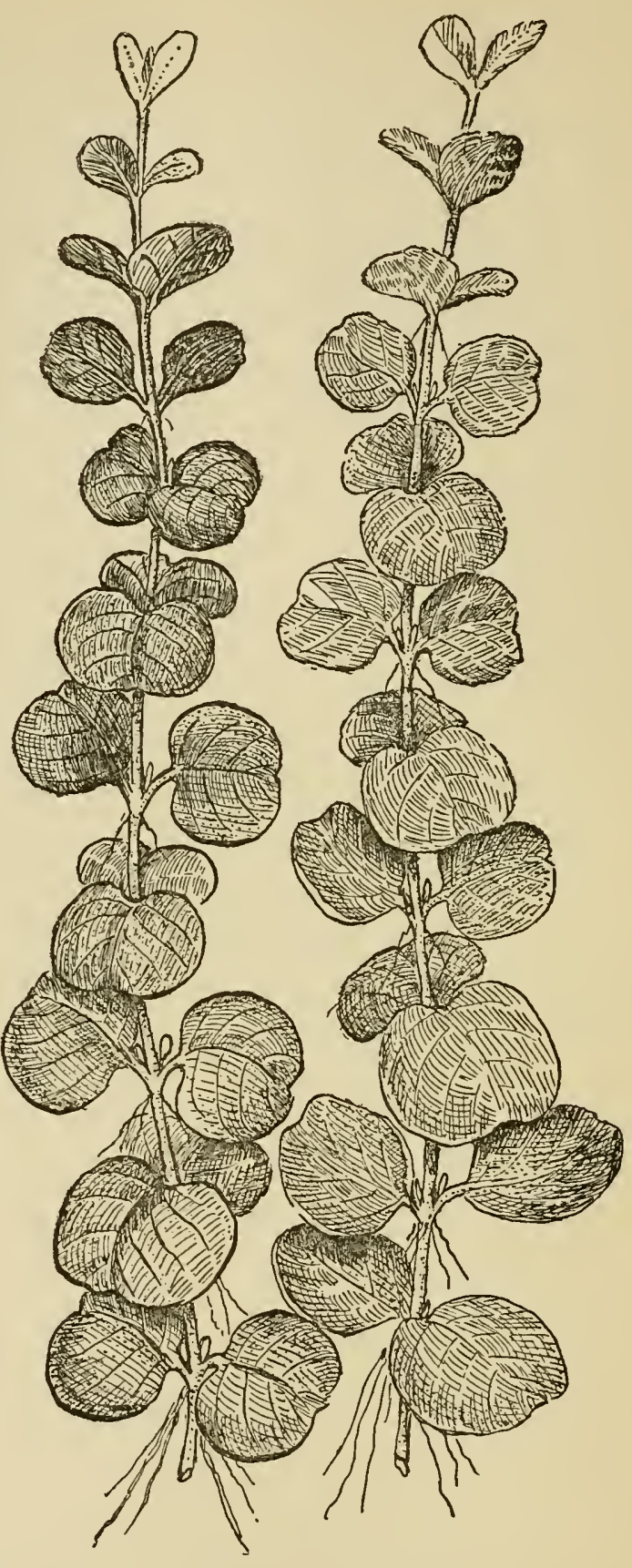

Fig. 37. MONEXWORT

(Life size) 
in reality they are the toughest-leaved aquarium plant we know of. They are slow of growth and prefer a subdued light. Propagation is by division at the root. This sometimes takes place in the aquarium, but they do best in wooden tanks. At best they are slow growers, which in a way is an advantage, for they eventually become rather large. The Lace or Lattice-leaf plant is used for ornamental purposes, its qualities as an oxygenator being negligible. Of recent years the commercial supply has unfortunately almost disappeared.

\section{CRYPTOCORYNE}

This attractive aquarium plant is an importation from Europe. Although introduced several years ago, it has never received the attention it seems to deserve. It is of an agreeable size and flourishes well in a good light if not disturbed. Propagation principally by runners and corms. The crown is at the surface of the sand.

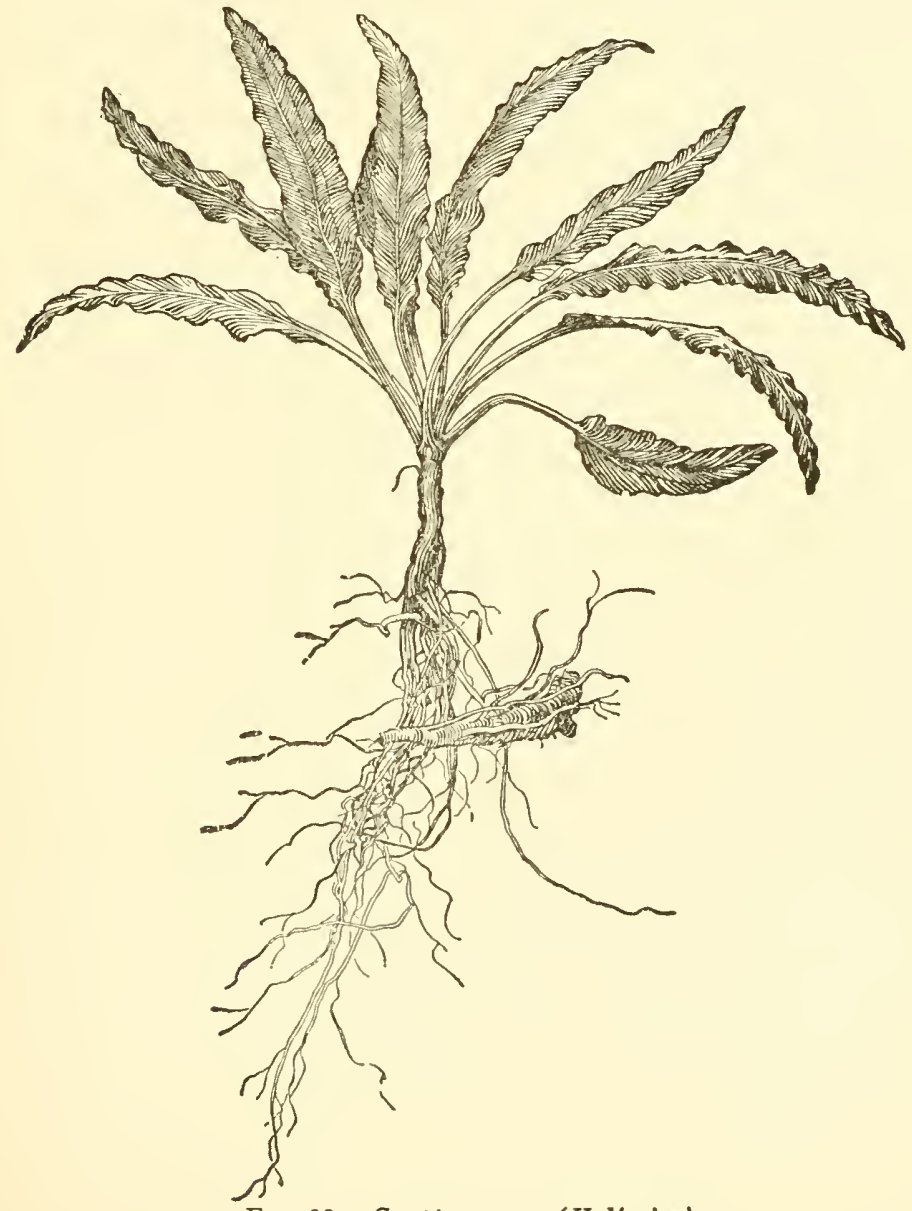

FIG. 38. Cryptocoryne (Half size) 


\section{HETERANTHERA}

Heteranthera zostercefolia is a very light green plant, slightly resembling Anacharis, but with longer, more widely separated leaves. It is a rapid grower, soon reaching the top, where it lies limp on the surface of the water. Can occasionally be had of dealers.

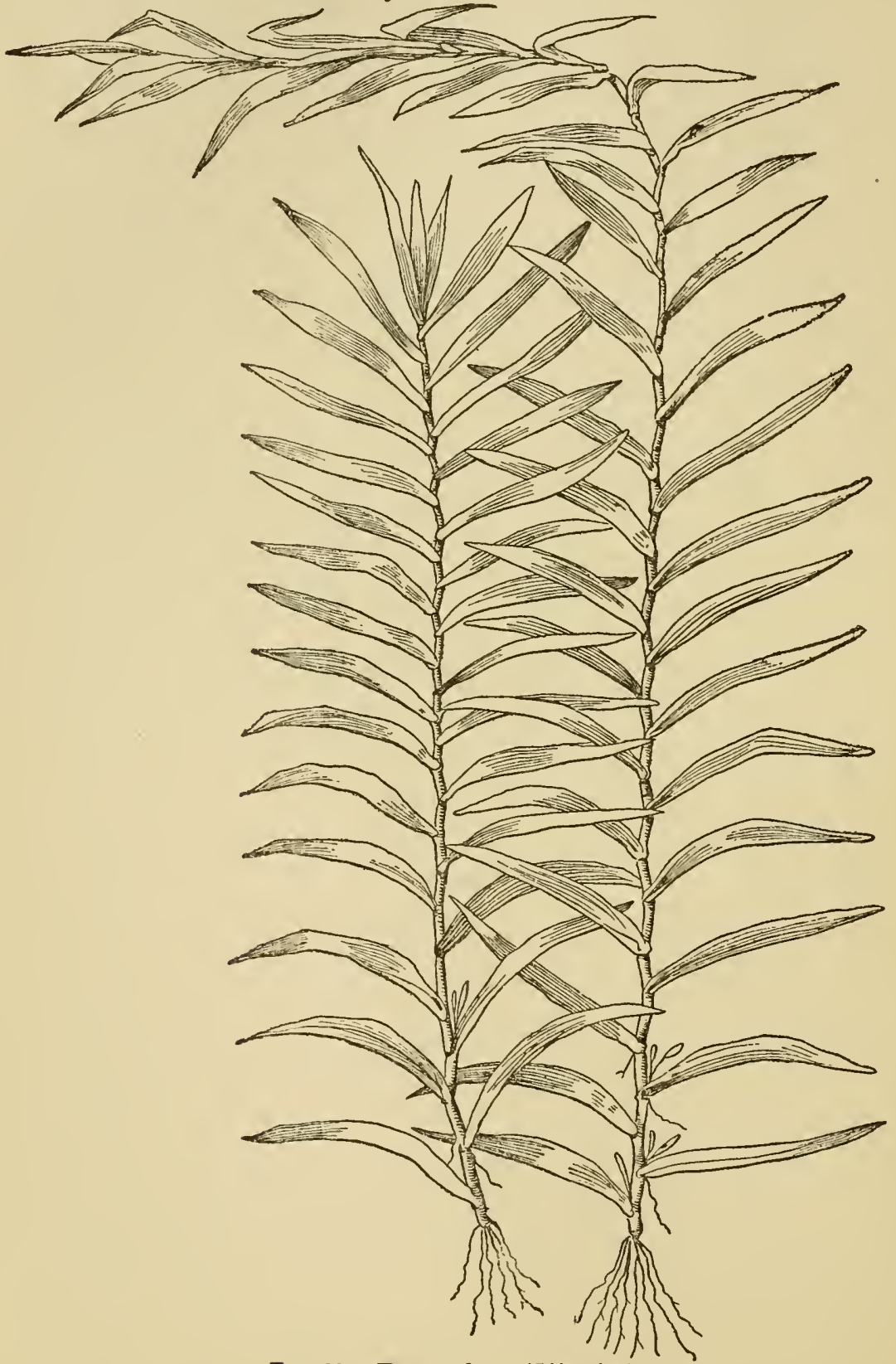

Fic. 39. Heteranthera (Life size) 


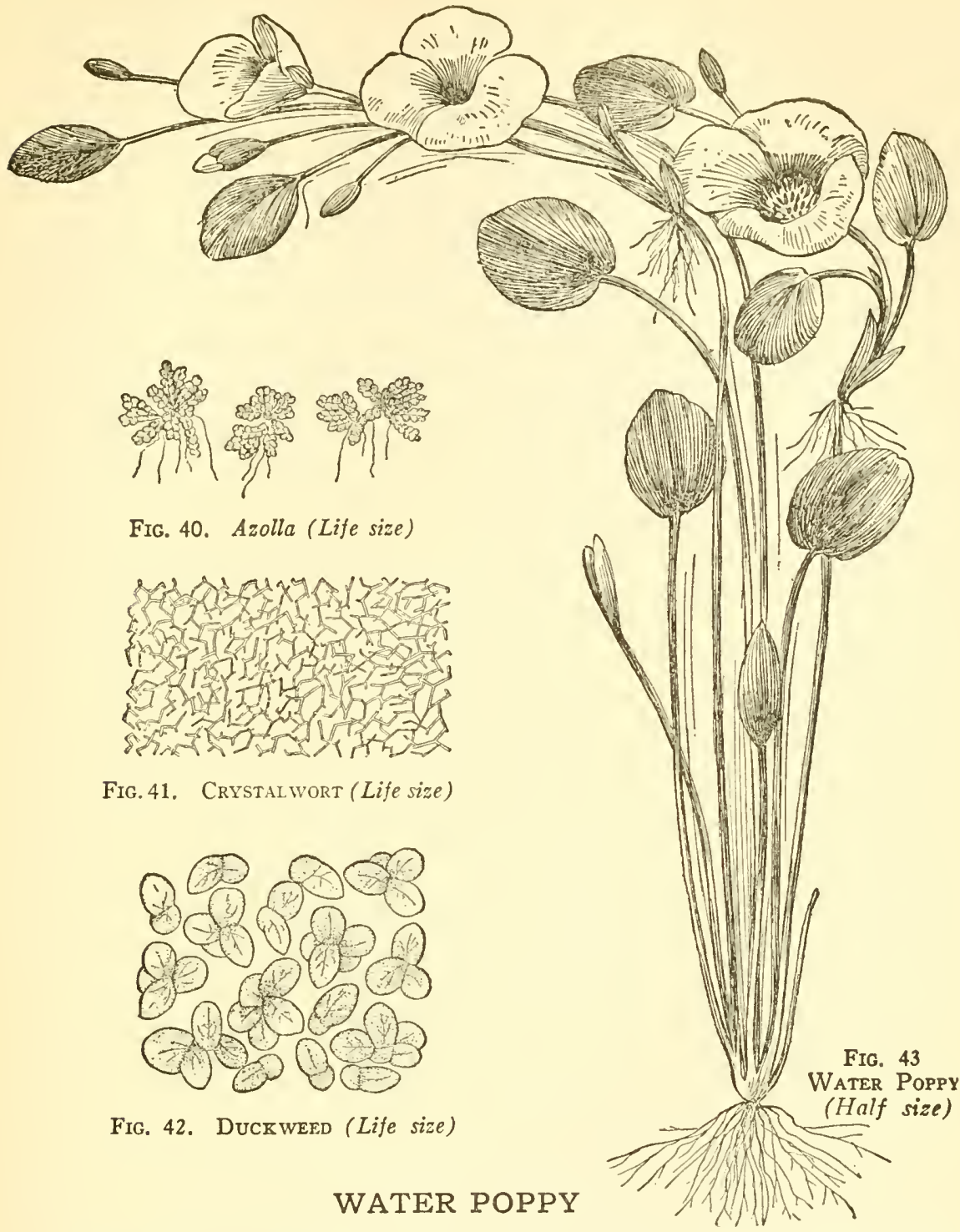

Limnocharis humboldti has become one of the most popular plants in the indoor and outdoor tank, as well as the large aquarium. In hot weather and strong light it grows very rapidly and continuously sends out new plants. Usually a new bud blooms every day. The three-petaled yellow flower with a brown eye or centre only lasts a few hours, but is a most pleasing and æsthetic flower. The parent plant should be potted, preferably not very deeply in the water. The new plants run at the surface, occasionally sending down strong runners to obtain a fresh rooting. Can be had of the larger dealers in aquatic plants. 


\section{AZOLLA}

Azolla caroliniana is une of the less-used of small floating aquatics. It is not in any way a brilliant plant, but has a rather quaint charm. The leaves are of velvety appearance and range from a dull sage-green to dark red, according to age and the conditions of light. To be had of some dealers. Native to the Southern States.

\section{CRYSTALWORT}

Riccia fluitans grows in masses. It floats just beneath the surface and is valuable in the propagation of small tropical fishes, some depositing eggs in it, and the new-born young of the live-bearing varieties using it for hiding places.

Riccia is an extremely active oxygenator and when in masses holds large bubbles of oxygen well into the night, until absorbed by the water. A valuable characteristic. The plant likes a few hours of sun. Native to the Eastern States and may be had of dealers in aquatics.

\section{DUCKWEED}

This commonest of all floating plants is found in several species in still pools everywhere. From the middle of summer until cold weather many ponds are completely covered with its green mantle, greatly interfering with the work of collecting daphnia for fishfood. Duckweed itself is a good food for goldfishes large enough to eat it, and has a laxative effect beneficial to the finer breeds. The form most commonly found is Lemna minor. Propagation is by offshoot extensions.

\section{SALVINIA}

Of the small floating aquatics Salvinia is one of the best. The heartshaped leaves with bristle-like growth on the upper surface seem like

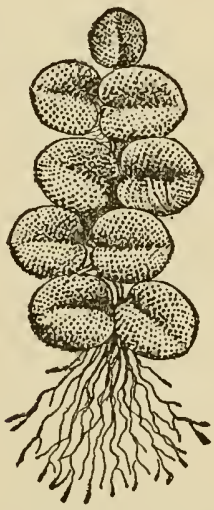

FIG. 44. Salvinia (Life size)

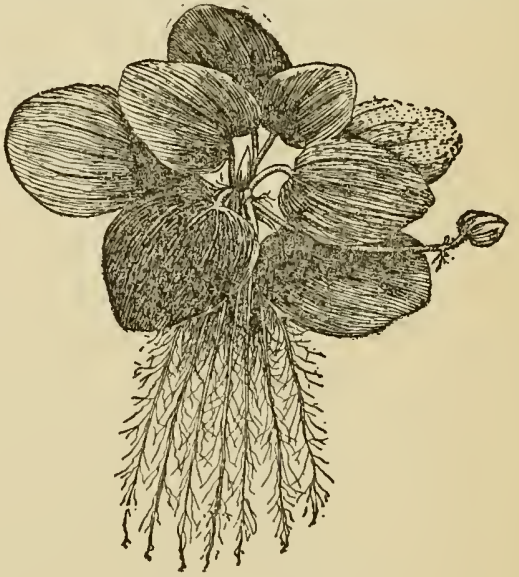

Fig. 45. Trianea (Slightly reduced) 
bits of velvet connected by a thread. The roots are naturally long for the size of the plant, but fishes usually eat them down to about half length, which interferes with a full development of plant. In the greenhouse, where they have a moist atmosphere and no interference, they develop with great rapidity. The variety illustrated, Salvinia natans, is native to Europe and is the variety commonly used.

Although it is claimed that neither Salvinia nor the common wild Duckweed performs any oxygenating function, the author and others have many times seen aquaria completely covered with either of these plants and, with no other plants in the aquarium, the fishes were getting along perfectly well-a state of affairs which would be impossible if the water were blanketed over by an inert substance.

\section{TRIANEA}

Trianea bogotensis is an attractive, small floating plant with thick, heart-shaped leaves. It needs a moist warm atmosphere and not too much direct sun. Under these conditions it thrives and is a valued feature in the summer pool or greenhouse tank. It is not found locally in temperate climate, but may occasionally be had of dealers.

\section{FROGBIT}

Hydrocharis morsus-rance, requiring the same conditions as Trianea bogotensis, deserves more attention than it is receiving. Of very pretty

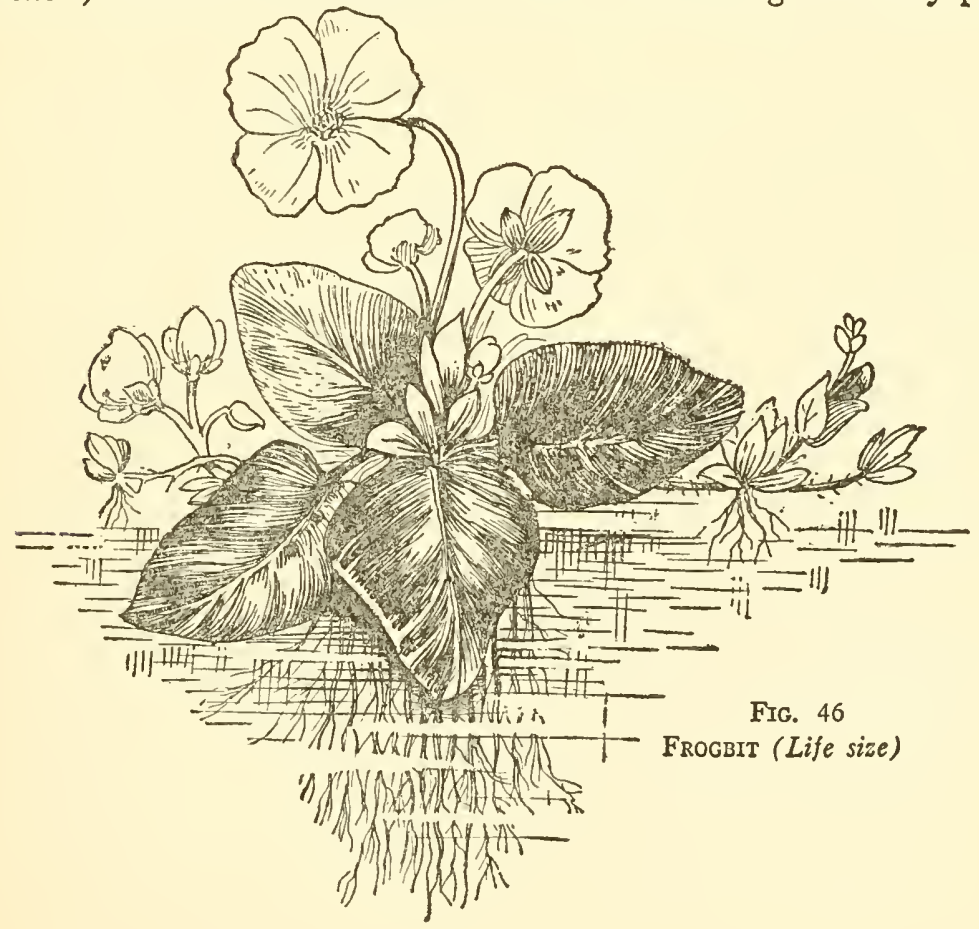


appearance when in flower, there is no reason why it should not be better known. As will be noted in illustration, it propagates from runners, but the seeds also germinate under favorable conditions. The plant is of European introduction.

\section{WATER LETTUCE}

Pistia stratiotes is a floating plant with fluted, light-green, velvety leaves, forming a rosette. It likes plenty of heat, a moist atmosphere and protection from the sun. Under favorable conditions it grows to a diameter of about four inches or more and is very attractive indeed.

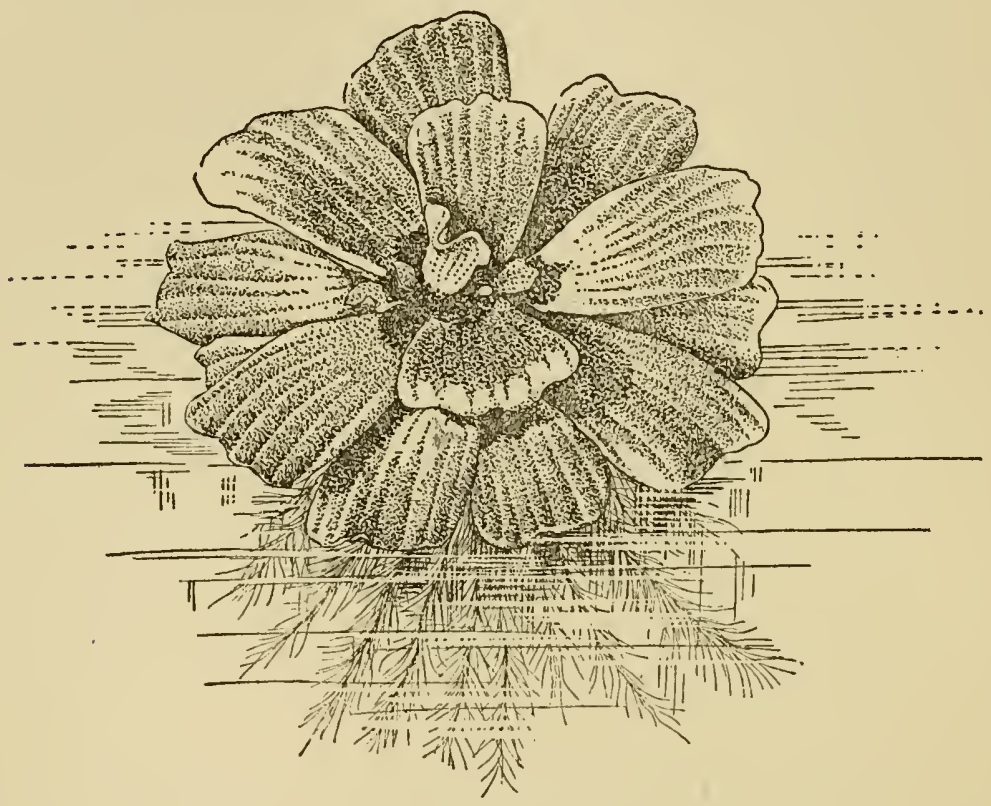

Fig. 47. Water LetTuce (Two-thirds size)

The roots sometimes attain a length of eighteen inches, but they are not sufficiently dense to use for spawning purposes. Multiplies rapidly in a congenial environment, but degenerates and dies out in a dry atmosphere. Obtainable from the larger dealers in aquatic plants.

\section{WATER FERN}

Not looking particularly fern-like, the Water Fern, Ceratopteris thalictroides, is the only truly aquatic species of the fern family. It is of comparatively recent introduction into the aquarium and indoor pool, and is more suited to the latter. In a partially shaded position in the greenhouse it grows into floating masses a foot or more in diameter, 
piling up to some height on account of its peculiar means of reproduction, the new plants springing directly out of the parent leaves, as pictured in illustration. Ordinarily the plants are about six inches in diameter and are of very pleasing appearance. Native to the tropics around the world.

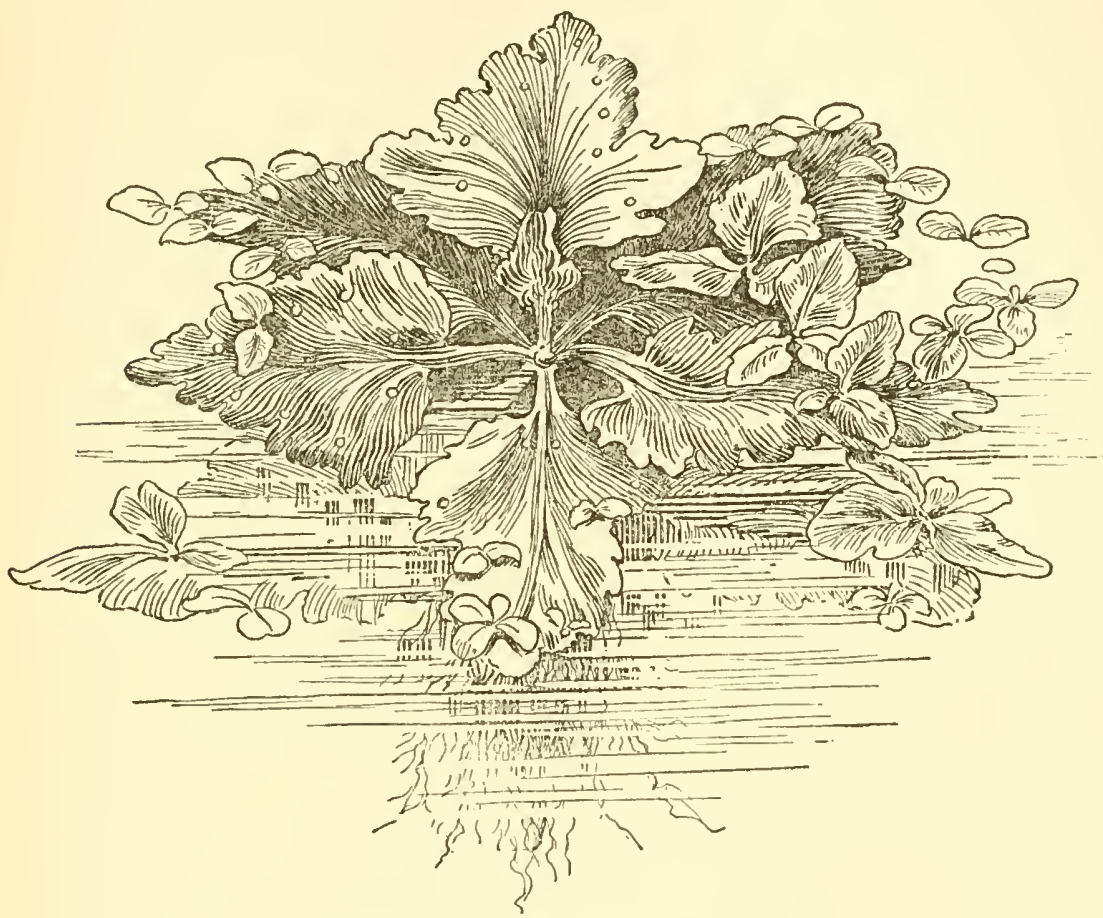

Fig. 48. WATER FERN (Reduced one-half)

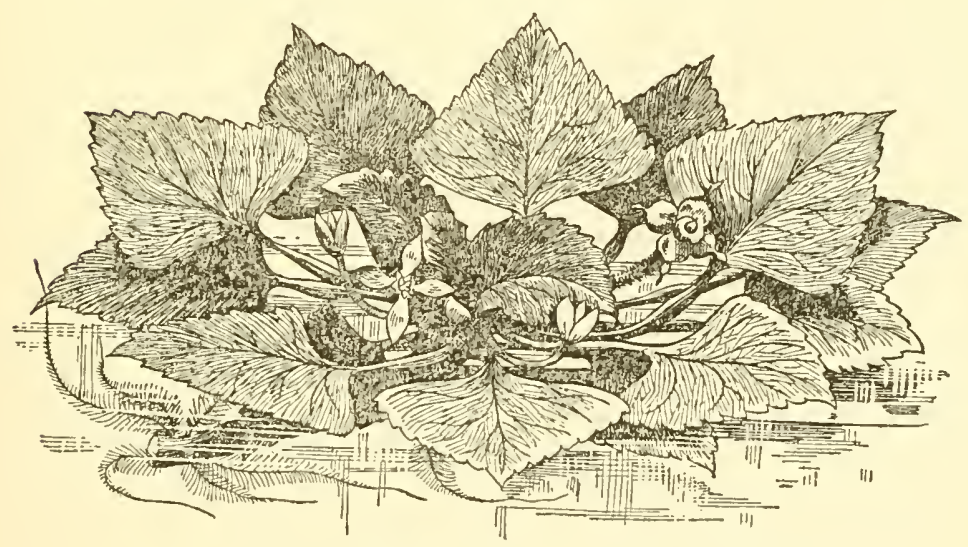

Fig. 49. Water Chestnut (Two-thirds size) 


\section{WATER CHESTNUT}

Probably obtaining its popular name from the serrated edges of the leaves somewhat resembling those of the Chestnut tree, Trapa natans forms one of the pleasing varieties among floating aquatics. It is an annual doing well in exposed outdoor positions. New plants are produced each year from large, hard seeds. The big, black, two-horned seeds sometimes sold in Chinese stores are of a closely related species of Trapa. Can be had of the larger dealers after May 15.

\section{WATER HYACINTH}

Although Water Hyacinth, Eichhornia, is considered a pest in its native habitat on account of clogging up rivers and lakes, it is none the less a favorite with the aquarist, especially the breeder of goldfishes. Its long, finely divided, dense roots are admirable for receiving the eggs of any fishes that spawn on plants. The pale purple flower-spike only blooms for a single day, but is quite beautiful, having the general form of its namesake, the Hyacinth. Propagation is by runners at the surface of the water. Water Hyacinths do best if their roots can enter or drag in soil. Outdoors they do not like to be blown about nor to strike against the sides of a tank, although apparently not minding how closely they are crowded together. This plant does well in a warm greenhouse the year round. Unless supplied with plenty of light and heat during the winter it degenerates very much.

\section{WATER SNOWFLAKE}

Limnanthemum indicum is one of the most charming of the small floating aquatics. White, star-like flowers of 1-inch diameter are freely borne above the water. Parent plant should be rooted in soil near surface.

\section{WATER LILIES}

Fish pools or large tanks standing in the sun should have water lilies growing in them. They are of easy culture and not only give protection to the fish from excessive sun and from bird enemies, but add greatly to appearances. Small or large varieties may be had, according to the needs of the space. Water lilies are divided into tender and hardy varieties, and the tenders are sub-divided into day-blooming and night-blooming kinds. The tenders are very decidedly the more free-blooming and the day-blooming tenders are the more fragrant, as well as presenting the greater range of color. They usually open in the fore part of the morning and close in mid-afternoon. The night-bloomers open in the evening and close about nine in the morning. They are not fragrant nor 


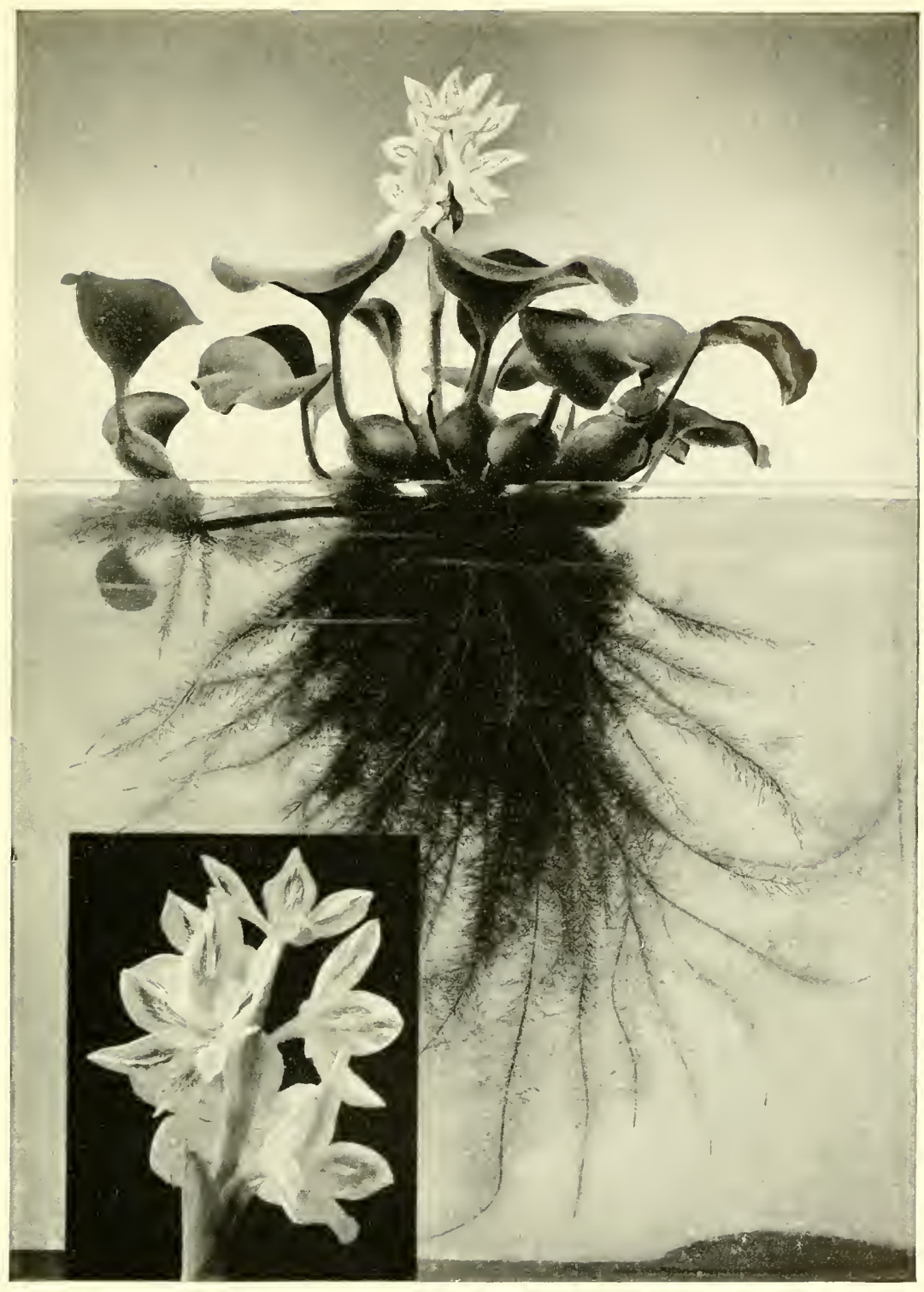

Fig. 50. Water Hyacinth (Eichhornia crassipes major) Showing Offshoot of New Plant Hower in Detail Shown in Inset 


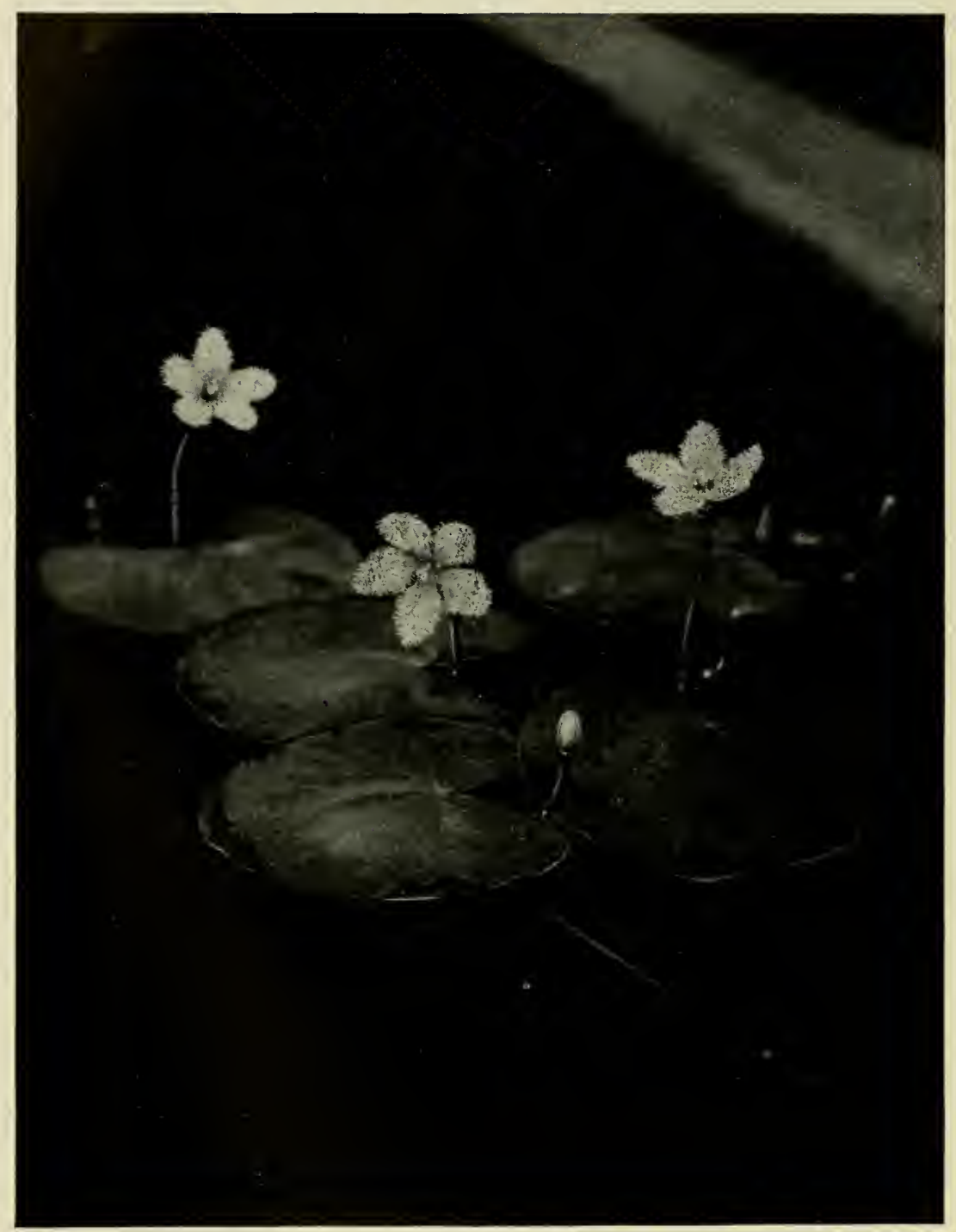

Fig. 51. WATER SNowflake (Limnanthemum indicum) 


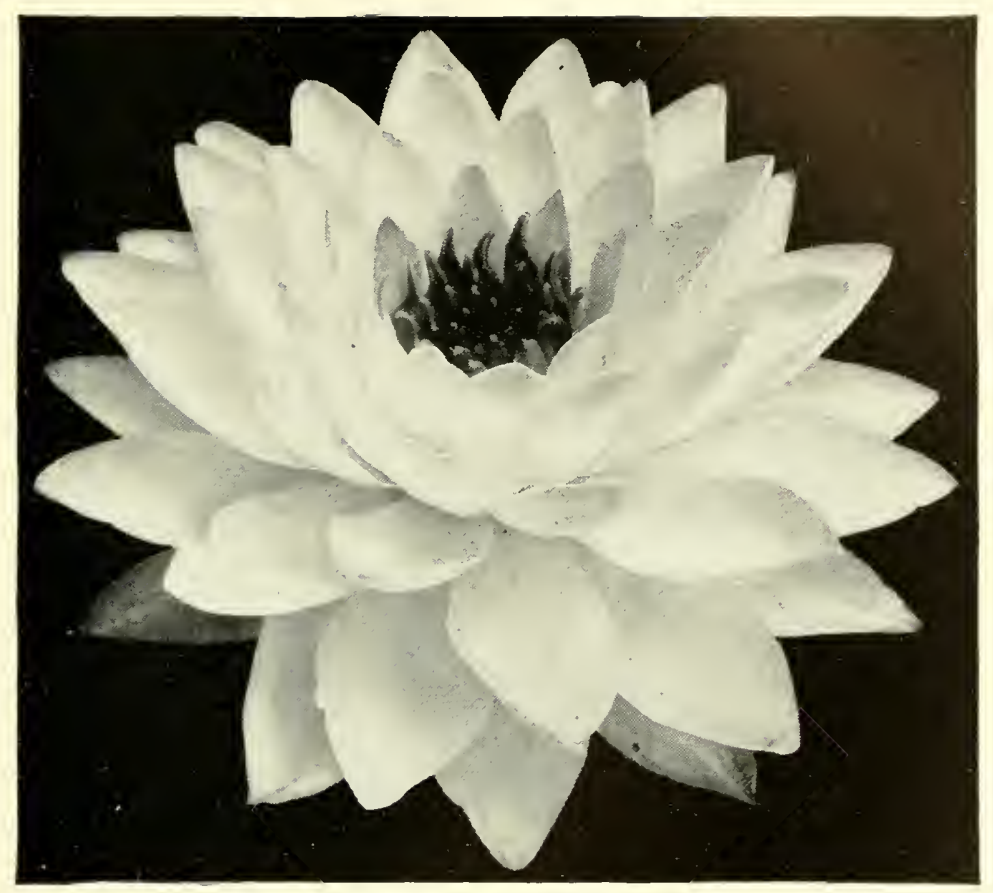

Fig. 52. Hardy White Water LiLy (Tuberosa richardsoni) 


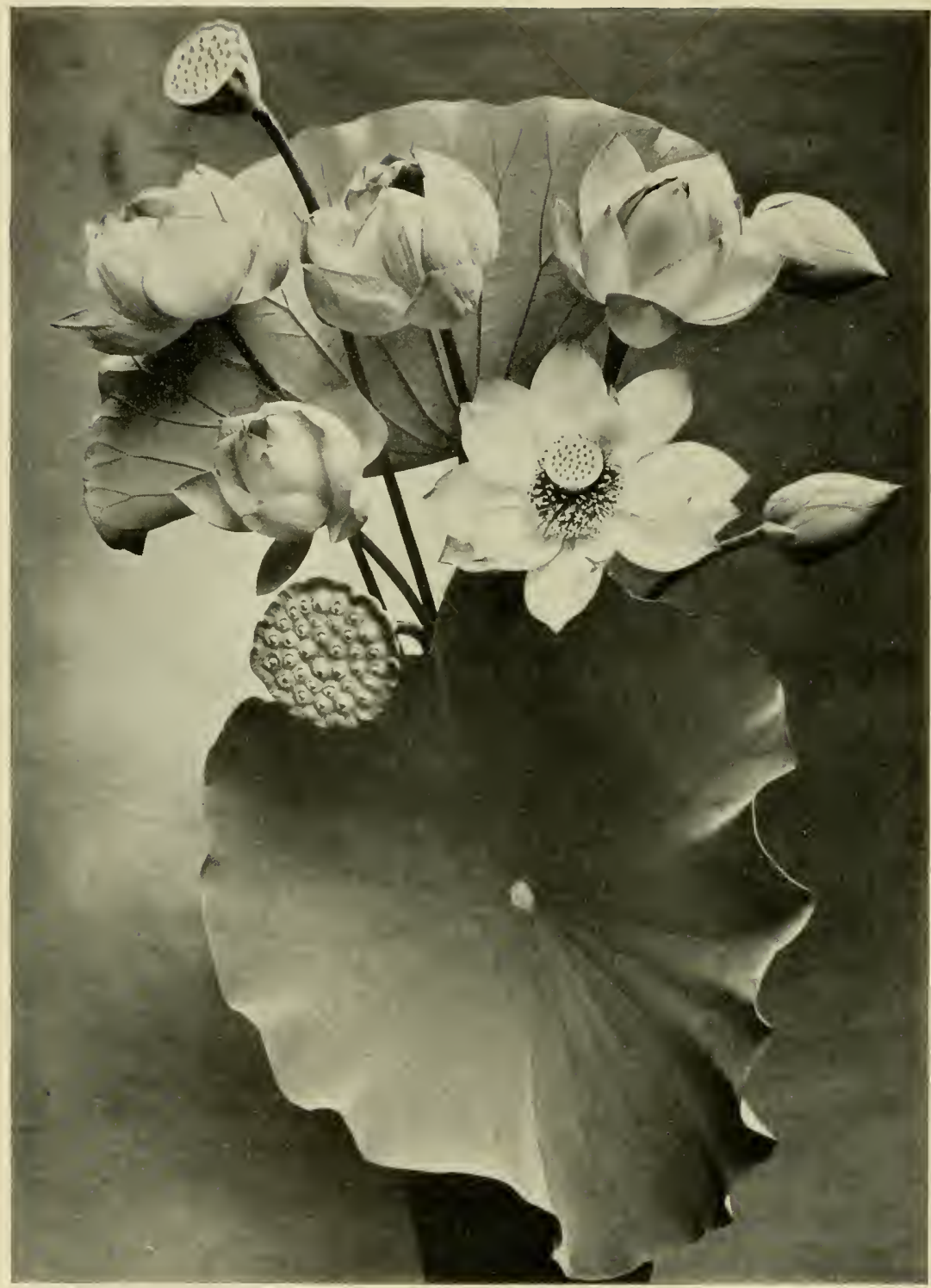

FIG. 53. Nelumbium speciosum

The Sacred Lotus of the Orient, from 4 to 7 feet in height, is easily the most mag nificent of aquatics with leaves and flowers above the water. 
as elegant as the day-bloomers, but they are called the business man's water lily, because he can see them in bloom in the evening and in the morning.

Water lilies like extremely rich soil. A mixture of half clay and half cow manure suits them very well. An inch top layer of sand will prevent any of this soil from getting into the water. The crown of the plant should not be covered and ought to be about 8 inches below the surface of the water for tenders, and 8 to 20 inches for hardys. They need an abundance of sunlight.

Before freezing weather sets in, the tender plants should be taken up. Close to the main root will usually be found a few tubers about the size of shellbarks. These are the starts for next season's plants. They are to be broken off and slowly dried. In April they may be laid in shallow, warm water in the sun until sprouted, then placed in submerged pots, and later permanently planted out in June.

Hardy water lily roots only need to be kept moist and from actual freezing. In a pond they may be left out. In early spring they form a number of new crowns. Every two or three years the parent root should be cut up into pieces, allowing a crown to each piece. Plant only one crown to a pot. Let all water lily pots be as large as space will permit. Most tenders will grow and bloom in a seven-inch bulb pan in an ordinary tub, but they are dwarfed from lack of space. They will do better in an open pool planted in a box about a foot deep by thirty inches square. Tropical water lilies show a surprising degree of intelligence in adapting themselves to the size of the pool they are in, reducing leaf and flower to accommodate themselves to the available space. The ordinary hardy water lily if given as much space as it can use will have a surface diameter of about five feet. The usual tropicals spread from ten to fifteen feet, but will do well in pools of six-foot diameter.

There are but few firms specializing in aquatic plants. Their names can usually be found in the advertising pages of the aquarium magazines listed in the end of this book. The catalogues of these firms contain much valuable information as to suitable plants for different conditions and purposes.

\section{OTHER POND PLANTS}

Lotuses (Nelumbiums). Album grandiflorum (white), Luteum (yellow), Speciosum (rose), Pekinensis (red).

The culture of Nelumbiums requires more root-space than for water lilies. Planted in a shallow pond where they have plenty of space for the strong roots to branch out and travel, they prosper amazingly. They 
are hardy over winter, and if it is desired to confine them to a certain space or locality they should be boarded in or otherwise divided from the rest of the pond. The roots go several feet deep. The Lotus is one of the most beautiful of all decorative plants. Its magnificent leaves and flowers swaying majestically in the summer breezes convince us that this plant well deserves the prominent place it has been accorded in the literary classics throughout history.

Bog Plants. Among the best of the bog and pond plants are Variegated Sweet Flag, Cape Pond Weed, Marsh Marigold, Umbrella Plant, Cyperus papyrus, Water Arum, Pickerel Weed, Sagittaria japonica, Sagittaria montevidiensis, and Lizard's Tail.

It is safer to use no fertilizer in planting bog plants.

\section{ENEMIES OF AQUATIC PLANTS}

The most serious enemies are muskrats. These eat the roots of several hardy aquatics, particularly over the winter season. They are partial to the roots of the small yellow water lily, Pygmaea helvola.

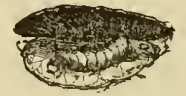

Fig. 54. Aquatic Cutworm in ITS Case

A leaf-cutting worm (Hydrocampa), sometimes becomes quite a nuisance. It cuts a piece from the edge and, laying it on the leaf, attaches the two together and uses the two pieces as a cocoon. Loose bits of water lily leaves, Sagittaria, etc., observed floating around will, if pried apart, often be found to contain this white worm. The illustration is life size. They should be hunted out and destroyed. They are the larvae of a moth which can be caught at night by use of a fly paper lamp shade. The light bulb itself should also be banded with the paper. Sticky side out in both cases.

Plant Lice. Several varieties of aphis, or plant lice, attack aquatic plants. A few on water lily leaves seem to do no harm, but sometimes large colonies rapidly develop on the standing leaves of plants like Sagittaria in such numbers as to kill the leaves. If fishes are present in the water, the use of chemical spray is too dangerous. A stiff spray from a hose nozzle will dislodge most of them. If one wishes to take the trouble they can be wiped off the plants and killed.

In an aquarium they can be eliminated by wiping the glass above the water edge and then floating a piece of newspaper on the surface, cut to completely cover it. This will drown the remaining aphis in an hour. 
CHAPTER THREE

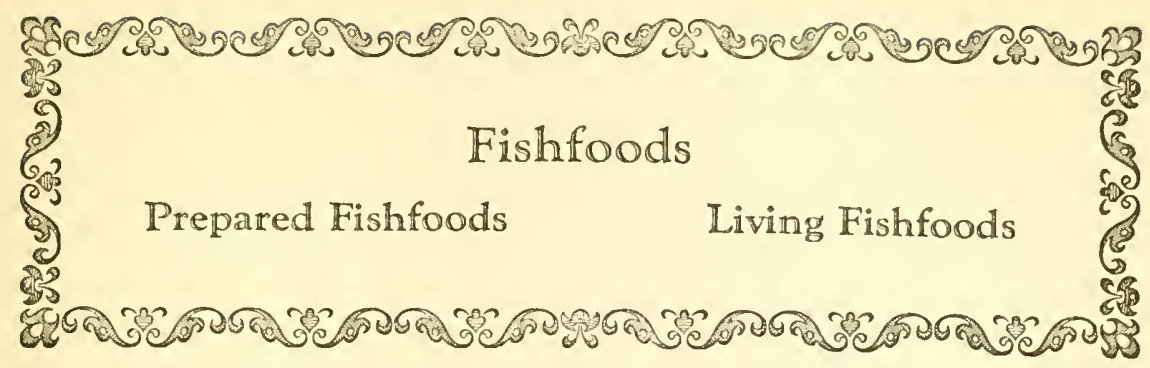

\section{PREPARED FISHFOODS}

Of recent years a number of careful experiments have been made as to the best and cheapest foods to be used at food-fish farms. The results of these tests confirm in a general way the principles borne in mind by most of our manufacturers of food for aquarium fishes. At the same time it must be admitted that we are a long way from any exact knowledge on the subject, so far as the aquarium is concerned, especially as to the actual comparative merits of different compounds in dried foods. The condition of a fish is dependent on so many factors other than the ingredients of its food that it is difficult to arrive at scientific conclusions in this matter. The question of food quantity is one of them. A fish fed the proper quantity of a poor food will be better off than one fed an improper quantity of a good one. This fact could easily bring us to a false conclusion regarding the merits of the two foods in question.

The author, after thirty years of observation among fanciers and breeders, together with his own experiments, believes that any reasonably balanced food is satisfactory; that no food however excellent can counteract incorrect aquarium conditions or practices; that when there is sickness among fishes, the kind of food is the last place to look for the trouble. A strange statement with which to open a chapter on an important subject, but undoubtedly sound.

When one observes that among a large number of successful fanciers scarcely two use the same fishfood, but all practice virtually the same principles in aquarium management, it is not difficult to place the emphasis where it belongs.

We do know a few facts about foods for aquarium fishes. The rest is guesswork, based on principles which in the main are probably correct.

Nearly all aquarium fishes naturally desire a variety of foods, and the nearer we can approximate Nature in this matter, the better will be our results. Whatever foods we employ we should always keep in mind the necessary balance of vegetable, animal and mineral content required. 
The most popularly known food is the white wafer, made of rice flour and white-of-egg. This is used by novice goldfish fanciers everywhere. Experts consider it too limited in its content. Also any uneaten surplus quickly clouds the water. There is no denying, however, that many persons have kept fish well for years by feeding wafer in small enough quantities so that there is no surplus.

Better foods have been placed on the market, most pet stores keeping at least one of them. They are granular in form, usually of a dark color and are composed of a mixture of dried insects, meat, fish roe, flour, codfish and other ingredients. Unless one needs a large quantity it is better to purchase a prepared article of the sort described, rather than to undertake its manufacture.

A very good fishfood is puppy biscuit broken up and ground to small sizes in a coffee mill. This is cheaper than regular fishfood and is very satisfactory. It is used as a base by many dealers in which to add a few ingredients and then place it on the market under special labels. If one uses this biscuit in quantity it may be had cheaply in bushel lots from manufacturers who save broken pieces for this purpose and grind it to size.

A food used with considerable success is oatmeal prepared exactly as it comes to the breakfast table, containing the same amount of salt. This is especially recommended for feeding young goldfishes when daphnia have become scarce. The shape of a goldfish is permanently infuenced in its body development in the first few months, and different methods of feeding produce, to a certain extent, different shapes. The effect of oatmeal, fed plentifully, is to build the short, round body so generally desired. For fishes under ten weeks old the oatmeal should be squeezed through cheesecloth to take out the kernels. Let the young fishes have as much as they can eat all day, but let no food remain over night. This does not apply to fishes in their second year or over, although oatmeal in much smaller quantity is good for them also.

An improvement on boiled oatmeal is secured by adding a moderate portion of powdered shrimp, dried fish roe, dried mussel flesh or powdered shredded codfish. For preparation of ingredients, see page 70 .

Dried bread crumbs make good food for goldfishes, or for vegetarian wild fishes, especially when Graham or whole-wheat bread is used. If one is out of other fishfood this will be found, for a time, a convenient and satisfactory substitute.

Practically all fishes enjoy scrambled eggs. Beyond doubt it is a fine change from dried foods, possessing both nutritive and laxative qualities. A little Cream-of-Wheat or Cream-of-Barley mixed in before 
scrambling increases the bulk and improves the balance of the food. For those who, like the author, had to learn to scramble an egg, we give the method: Beat the egg, add a bit of salt and a tablespoonful of milk or water to make it more tender. Stir in teaspoonful of the cereal if desired. Pour into saucepan which had been thinly greased with butter and place over a moderate fire, stirring rapidly to prevent sticking. It will be finished very quickly. In feeding it should be somewhat broken up. The slight grease on the water does no harm and soon disappears. The beaten egg may be rendered into greaseless flakes by slowly pouring into boiling water while stirring. Add a little salt to the water, as well as the egg. Gather flakes by pouring through tea-strainer.

Finely chopped crisp lettuce leaves are eagerly taken by many fishes, no doubt to their benefit.

Boiled spinach as prepared for the table, chopped finely, is enjoyed, especially by goldfishes. It seems to have a distinct laxative effect.

In feeding any kind of dried granular food it is best to use small sizes. Water causes large grains to swell considerably. This sometimes produces indigestion when the food swells after being swallowed. Some fanciers scald dry food just before feeding, which is possibly a good practice, although it may wash out some of the "flavor."

It might be well to repeat here that the use in the aquarium of pebbles without sand is inadvisable because granular food lodges in the stones, where it cannot be reached by the fishes, eventually decomposing and fouling the water.

For those wishing to make a general fishfood suitable for all except strictly carnivorous fishes, the following recipe will be found to be very good:

Quarter tumbler powdered cod

Three-quarters tumbler powdered shrimp

Three tumblers flour

One teaspoonful Epsom salts

Three teaspoonfuls baking powder

Three teaspoonfuls powdered chalk

Add two raw eggs and sufficient water to make the mixture into the usual consistency of bread dough. Place in pan and bake like bread in oven. When properly baked allow to cool and cut into thin slices. After thoroughly drying slices, grind in coffee mill and sift into desired sizes. Place all dry fish-foods immediately after manufacture in well-secured jars or other actually tight receptacles. Moths, flies and other insects 
gain a foothold and soon turn the food into a mass of worms and worthless dirt. If one has a large stock of such food it is a good plan to store it in the coldest possible place over winter, which will either kill the insects or reduce their activity.

In foregoing recipe, cod is prepared by purchasing a package of shredded cod, drying in a slow oven and grinding fine in a coffee mill. This is very easily done. Dried shrimp may be had at Chinese grocery stores. It needs to be broken in pieces, put through a coarse setting of the mill, then well dried for a few days and lastly ground fine. A fine grade of dried shrimp ready for grinding is obtainable from German dealers at low cost. There are several wholesalers of dried shrimp in New Orleans, Louisiana.

Whole wheat flour is preferable to white flour.

Those desiring to experiment on a food according to their own ideas of ingredients and proportions may safely use any of the following items in addition to those already mentioned; Pea flour, rice flour, rye flour, vermicelli, boiled fish, boiled yellow of egg, fine corn meal, ant eggs, chopped earthworms, water crackers, dried bread, dried blood, chopped meal worms, dried and powdered lettuce leaves, dried fish roe and dried daphnia. In preparing the latter two ingredients they should be parboiled with a moderate amount of salt, then placed in cheesecloth, water squeezed out, spread out thin on tin plates and dried quickly in the sun or slow oven. The drying must be thorough and quick. In drying it will be found that the shrinkage in volume will be very great. It should, therefore, be remembered that they are highly concentrated and to be used accordingly. The same is true of dried blood, which may be purchased of seedsmen.

A very simply prepared fishfood on which the author's fish thrive is made by mixing two tumblers finely powdered puppy biscuit, quarter tumbler each of powdered cod and powdered dried shrimp. Add, say, a teaspoonful of powdered agar-agar. Prepare boiling water, but first stir the dry mixture over a fire in a saucepan a short time to warm it. The object of this is to prevent the boiling water from being chilled by the mixture before it has made sure of killing any larvæ which may be present. Now stir in the boiling water until the mass is moist all through, but not quite wet. After it has partially cooled, mix in a beaten raw egg. If this does not thin the mixture sufficiently for smooth spreading, add sufficient water or milk. The ladies of the household may object to using the inside of the pie plates for drying fish-food, so use the bottoms. 
Spread to about a quarter inch thick. Stand them in the sun or on radiators to partially dry. Better select radiators at the top of the house and pick a time when the rest of the family is out, especially if they have keen nostrils. In about two hours, when the surface has become a little dry and caked, separate the food from pie plates with a thin knife, placing the dry side down on either newspaper or fine screen. Either replace over radiator, or in sun or in slow oven until bone dry. Grind to suitable sizes and save the finest sifted powder for baby fishes.

The author prefers slow oven or radiator drying to sun drying because there is less chance of fly eggs being deposited in the food. On the other hand too much oven heat drives some of the virtue out of the ingredients.

An important point about such foods is this: If a quantity is made to last a considerable time, only that part of it should be ground that will be used in a few months. In coarse pieces it is much less liable to attack by insects and their larvæ. If bone-dry and placed in tight preserve jars it will last for years.

Dried fishfoods should be sifted through suitable screens to sizes desired for use. There is always a considerable amount of fine powder which is declined by many of the larger fishes, and which is liable to do harm unless found by the snails or other scavengers. The powder and very small grains can be fed to the young stock, or to breeding snails.

When fishes have been without fresh or living food for some time it is well to occasionally give them a small quantity of dark, soft part of oysters, chopped and slightly rinsed. Fresh shrimp, obtainable in most fish markets in winter, if passed through a fine meat chopper, makes an excellent change of diet. Canned shrimp has come to be a fishfood of decided value. Several of the fishes which otherwise demand live food take this readily and thrive on it, notably Pterophyllum scalare and the Banded Sunfish, the only other prepared food these two seem to relish being scrambled egg. This is something of a coincidence, as a similarity is often noted between the general appearance and movements of these really very different fishes. After opening a can of shrimp keep contents dry in a covered saucer in refrigerator. . It keeps about three days. Canned salmon, with a little of the surplus oil washed away, is a very good fishfood, in fact one of the best.

One of the most relished tidbits for your aquarium fishes is flakes of boiled fish, just as it comes from the table, especially a tender steak. fish like cod or halibut. Cutting with scissors across the grain minces it well. Same for crab meat.

A crushed oyster crab or a canned shrimp suspended from a thread makes a choice morsel for tropical fishes to pick at. 


\section{LIVING FISHFOODS}

It may safely be said in general that fishes do better on living foods than on an artificially prepared diet. The difference seems to be about the same as that between canned and fresh food in our own experience. The living foods which are really of practical merit and which are so universally distributed as to make their mention here of value are few in number. They are infusoria, daphnia, mosquito larvæ, flies and earthworms.

Earthworms. Also known as angleworms, gardenworms, rainworms, and groundworms. It would be difficult to overstate the value of these worms to aquarium fishes, especially to highly developed goldfishes. They are a one hundred per cent. natural food and are somewhat laxative in effect. Correspondents have many times asked the author to diagnose their fish troubles when all conditions are apparently correct. The usual advice is to try feeding earthworms if possible, and in a majority of cases the trouble disappears. Worms from one to three inches long are best. The large sizes become tough. Personal judgment will have to be used as to whether to cut the worms, and to what sizes. The pieces should be easily swallowed. It is unnecessary to wash or scald them, notwithstanding some contrary theories on the subject. Fishes can apparently eat more worms without injury to themselves than they can of prepared foods, but this is also true of the other live foods. All they can consume at a meal does not appear to be too much. The difficulty is more likely to be in keeping up the supply, especially over winter. One should collect as large a stock as possible in the early fall, storing in damp, loose earth in a large box kept cool but not cold. Occasional bits of mashed potato placed in the soil will be eaten by the worms. It should be without salt, preferably.

There are two principal kinds of angleworms, the earthworm or gardenworm here referred to, which is of a solid pinkish red color, and the dungworm, the body of which is marked with red rings, and which exudes an unpleasant yellow secretion when handled or cut. These are not so tempting as bait for wild fishes, and the aquarium fishes show the same preference for the gardenworm. The dungworm is found in manure piles and in heavily manured soil. It has the advantage of being more readily obtained in winter. By placing in moist sphagnum or other moss for a few days it is claimed they lose some of the unpleasant odor. The writer cannot vouch for this. Earthworms form a satisfactory substitute for daphnia in raising goldfishes if one has the opportunity of securing a large and continuous supply, this of course meaning after the fish is large enough to take finely chopped pieces, which should be in about six weeks. 
Daphnia. Among the breeders of aquarium fishes, Daphnia holds the supreme place of importance as a fish food. The fish will consume great quantities of these crustaceans without suffering the usual effects of being overfed. A certain degree of care must be exercised not to place so many daphnia into the aquarium as to suffocate the fishes. Daphnia breathe the free oxygen in water the same as do fish and therefore too many will soon exhaust oxygen from water. The fish will die of suffocation sooner than the daphnia. Many beginners have lost fish in this way. A good practice is to give the fish all they can eat in about a quarter of an hour and still leave some few daphnia swimming about.

A popular name for daphnia is "ditch fleas." This will give a hint
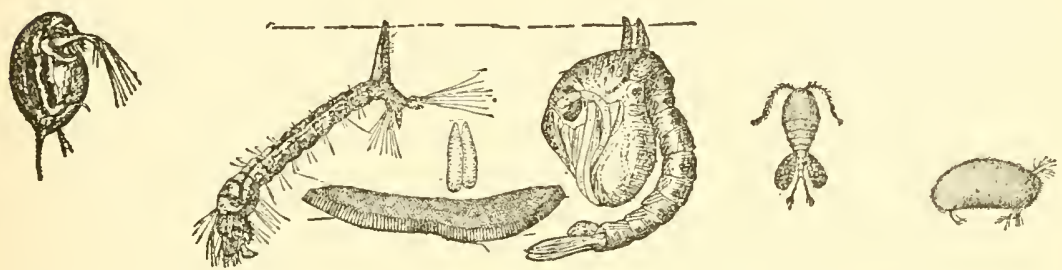

Fig. 55

Fic. 56

Fig. 57

FIG. 58

FIG. 55. DAPHNIA (Greatly enlarged)

Fig. 56

Mosquito LaRva (Greatly enlarged)

EgG Raft and Individual Eggs (Greally enlarged)

Pupa Before Transforming to Mosquito (Greatly enlarged)

Fig. 57. CycLops (Greatly enlarged)

FIG. 58. CrPRTS (Greatly enlarged)

as to their appearance, as they are approximately the size and shape of a flea, except that they have two rather long, branched swimming arms which are always in motion and which give the animal a sort of hopping motion through the water. Without this perpetual swimming the daphnia would sink to the bottom, as they are heavier than water and have no air bladder. A greatly magnified illustration is shown in Fig. 67.

Daphnia (pronounced "daffney" in the vernacular) are known among fish breeders as "insects," but they are really not such, being perfect freshwater crustaceans as much as a crayfish. The shell, though soft, cannot be digested. This helps the digestible portions to pass through the intestines. This little creature is found in freshwater nearly all over the world, principally in still pools where there are no fishes. For the 
practical purpose of catching daphnia in sufficient quantities to feed fish the collector should hunt pools in which there is considerable animal or vegetable decomposition in process. Such conditions are found to perfection in the pools on the ground where city refuse is dumped. When the conditions are favorable the daphnia rise to the surface in such quantities as to color the water, the usual color being a rusty red. The color varies from this to olive and gray. Fish breeders like to see the daphnia as bright a red as possible, although it is an open question as to whether the red ones are better food. The same individuals will alternate in color, probably due to a difference in food. Usually these crustaceans are not so plentiful as to color the water, and we have to use our eyes more closely to locate them. The collector should provide himself with a cheesecloth net about 12 inches in diameter and 15 inches deep, fastened on a pole or jointed handle not less than 6 feet long. If an examination of the water does not at first reveal any daphnia, the net should be tried anyhow, using a gentle stirring motion back and forth, to stir up the bottom water. Daphnia have very peculiar habits, and one can never tell from day to day just how they are to be found, so that the collector will always have to depend somewhat on his own resources. If an examination of the net after dipping for a few minutes shows nothing, try elsewhere. If a swarm has been located do not take too many into the net at one time, as the weight of the top ones crushes those beneath. A mass that would bulk about equivalent to a small orange should not be exceeded. Reverse net into pail of water and repeat until the water is thick with daphnia. In cool weather the pail may be carried in this crowded condition for about an hour. If the day is hot, a piece of ice should be added to the water-enough to keep temperature down until home is reached. Newspaper wrapped about the can helps the ice to last longer. As soon as home is reached, add fresh water to the pail and transfer the daphnia to tubs or tanks kept for the purpose. Like fish, the water they are in should have as much air surface as possible. Do not try to keep too many in stock, as overcrowding suffocates a number and these, in turn, decomposing, kill the living ones. The coolen they are kept, the longer they will last. In hot weather they can be kept about three days and in October about two weeks.

In transferring from carrying pails to stock tanks it is well to first pour in small portions to a white enamel basin, which enables one to carefully go over the catch and remove any insect enemies. (See page 96.) If the daphnia are too thick to be readily examined, some water should be added. A little care in keeping out the enemies at the start is energy well invested. Most of the enemies and the dirt may be sifted out (under water) by using a screen just large enough for the daphnia. 
A beginner will do well to make the acquaintance of an experienced daphnia collector and go along with him on a trip. There are now aquarium societies in many of the large cities, part of their activities being the dissemination of such knowledge. All those interested should have active or corresponding membership in such an organization.

All beginners seem to develop the idea that sufficient daphnia to feed with can be raised in a tub or trough. This has been tried many times, but seldom with any degree of success. If the daphnia pools are too distant to make collecting practicable it is best to try to inoculate some suitable pond nearby, but there should be no fish in the pond. Daphnia, if not crowded, may be shipped quite a distance.

The practical way to raise daphnia for food purposes is described in the chapter on Wholesale Breeding (page 217).

A Method of Carrying Live Food growing in favor is to crate them (without water) in layers in a tin box. Frames about $10 \times 12$ inches, made of $7 / 8$-in. square wood, are covered on one side with thin muslin. These are floated, the daphnia dropped in, spread out evenly while the raft is floating, then carefully lifted and placed in carrying box, which,

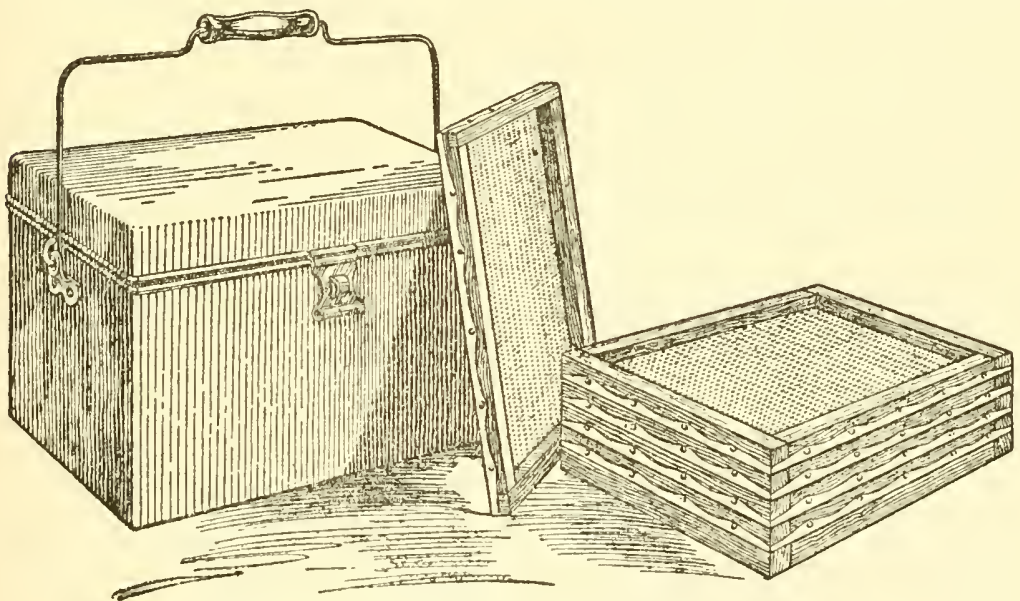

Fig. 59. Carrying Case and live-Food Trays

of course, needs to be airtight. The number of layers is only limited by the depth of the box. Daphnia may be spread to a depth of about 1/8-inch, but mosquito larvæ may be piled to 1/4-inch without injury. This method avoids carrying the great weight of water needed in collecting pails, and, in the experience of the writer, gets a higher percentage of the food home alive. If spread out thinly and in a cool temperature in October they have been kept alive in a moist condition on the rafts in storage for two days. The only disadvantage is the chance that the rafts, 
if not watched, may blow across the collecting pond. If the rafts are dried immediately after using and all daphnia cleaned out from between the fabric and the wood, they will last several seasons. The bottom frame is usually blank, so that the slightly sagging cloth on the one above will have drainage and not stand in the shallow water bound to collect in the bottom of can. Drainage could, of course, be obtained by placing small blocks on the bottom frame.

Cyclops. We list these crustaceans because they are so widely distributed and because they are actually a food for those fishes which can catch them. A little smaller than daphnia, they move through the water in straight lines with a jumping motion. The shape is also different, as will be noted in the illustration. The two tabs at the tail are not always present, these being egg pouches which drop off. Cyclops are carnivorous. They devour infusoria. It is also a belief that they kill newly hatched fishes, possibly by getting into the gills, so that there is some doubt as to whether this animal should be listed as a fishfood or an enemy. They are introduced into the aquarium with daphnia and are seldom entirely eradicated except by small, active fishes.

Flies. While it is usually a difficult matter catching enough flies with which to feed fishes, they are really a splendid food and should be used if opportunity offers. Fishes soon get to looking for these delicate morsels after sampling them a few times. Cutting the wings off with scissors is undoubtedly painless and makes the fly "stay put" on the water. Those freshly killed with "fly swatters" are as good as live flies, except for feeding lizards, etc.

Small crickets and small soft grasshoppers are also very acceptable to fishes able to eat them.

Mosquito Larvæ. These are often known as "wrigglers" and are familiar to those who have looked in rain barrels. Their bodies are straight and about a quarter of an inch long. Most of them rest at an angle to the surface of the water with head down as shown in Fig. 56, and are always ready to "wriggle" to the bottom at the first sign of danger. From midsummer on they may be found in still water where there are no fishes. They are taken in the same manner as daphnia, except that one has to get them with a quick sweep before they can get down into the water. They can usually be seen floating together in black masses. The city entomologist, whose duty it is to rid a community of mosquitoes, will give information as to where they may be obtained and will be glad to have his burdens lightened by the fish breeder.

Mosquito larvæ may be termed a special food. It can only be had in large quantities towards the middle and end of summer, and is only 
suited to the fish large enough to easily swallow it. As a food for putting growth on fish an inch long or over it probably has no equal. The main drawback to these larvæ is that those not eaten quickly by the fish are liable to turn to mosquitoes. This difficulty can be minimized by proper management. Keep the stock of larvæ in a tank covered by a sheet of glass, leaving about two inches at one end not covered. Over this open space place a piece of mosquito netting, drawing it up several inches over the opening into a sort of inverted bag. Then draw a string around top edge of tank to secure netting. As the mosquitoes hatch they will fly upward into the netting bag, where they may be killed before lifting the lid to get larvæ for the fish. The author usually keeps these larvæ in a 5-gallon drinking water bottle, half filled, and with a bit of netting over the top, secured by a rubber band. To get larvæ, remove netting, place hand over opening and quickly invert bottle. The larvæ in their excitement swim downwards into neck of bottle. Release hand and empty the required quantity. Return bottle to upright position, replace netting and add water to make up to former level. When most of the larvæ have been used and a number of mosquitoes remain in the bottle, fill with water (through the netting) and they will be drowned. A netting bag trap secured on neck of bottle will also catch the majority of the mosquitoes.

The larvæ should be kept out of the sun and in as cool a situation as possible so as to retard the hatching. They will stand great crowding, their only requirement being that there is room for them all to get to the surface at one time, for they breathe air. This is one advantage in placing larvæ with fish, for, unlike daphnia, they extract no oxygen from the water. By feeding them to the fish we not only do well for the fish, but serve the interests of humanity by cutting down the mosquito pest. In open pools goldfishes are one of the best agents in keeping the neighborhood free of mosquitoes. Unfortunately the mosquito larvæ can live and hatch in temporary pools and in water too foul for any fish to survive in.

Cypris. Incorrectly known as "hardshell daphnia," cypris forms an important article of fish diet. These crustacea inhabit stagnant pools, particularly those well stocked with decomposing vegetal matter. Although capable of swimming freely they are more apt to remain close to the bottom, but more especially to decaying wood. They are of a dull, purplish black or reddish color about the size of an ordinary pinhead. Inexperienced observers frequently mistake them for daphnia. Fishes do not appear to be quite so fond of them as of daphnia, but they are a good second choice. They are extremely hardy and will withstand dense overcrowding in the foulest of water. Under favorable 
conditions cypris multiplies with astounding rapidity. It has been claimed that they devour spawn and young fishes. This is undoubtedly an error, but they do greatly annoy snails and eventually cause their death by getting into some inner recesses of the animal.

Blood Worms. In freshwater pools nearly everywhere can be found deep-red, jointed worms about half an inch long. They usually stay at

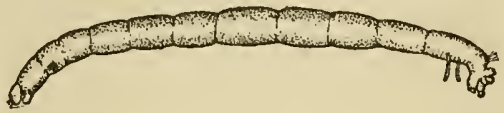

Fic. 60. BLOodWorm (Enlarged four times)

the bottom, living chiefly on decomposing vegetal matter. Often they will writhe their way awkwardly through the water in a series of figure eights. They are the larvæ of midges and form an important article of diet for our native fishes. They are often found in large numbers in daphne pools and should always be taken when possible. If too large for the young fishes, they make choice morsels for the older ones.

Tubifex Worms. These are small thread-like worms living in mud and sand. They form a tube or case below the surface, extending the upper ends of their bodies from this in search of small organic food, causing a circulation of water about themselves by a constant weaving

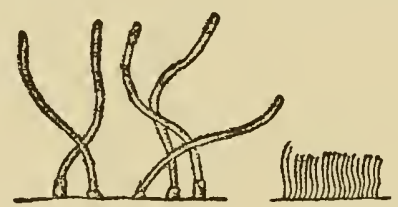

Fig. 61. TubIfex Worms (Magnified, and as they appear to the naked eye)

motion. When alarmed they draw back into the case. They are extensively cultivated in Europe as a food for tropical fishes. A similar variety is often introduced into goldfish aquaria when feeding daphnia, where they become an unsightly nuisance, for goldfishes cannot catch them. To get rid of them it is necessary to boil or renew the sand or else keep other fishes in the aquarium for a long time. The worms have to be eaten off many times before the stock dies. Germicides strong enough to kill them will also destroy the plants, as they can withdraw into the sand. Along the edges of ditches they are often so numerous as to make a solid rustyred color. If they are scraped up together with the mud and then washed free they are greatly enjoyed by gold and tropical fishes, but it is inadvisable to introduce them where there is sand or soil.

Infusoria and Rotifera. Of prime importance as food for very small fishes are the Infusoria and other microscopic creatures in water. Some idea of their minuteness may be had when it is pointed out that they 
are the natural food of cyclops and other small crustaceans. All except the very largest of the infusorians will pass through ordinary cheesecloth nets, but silk bolting-cloth of fine texture will hold those which

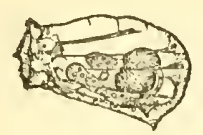

FIG. 62 Asplanchnopus myrmelco

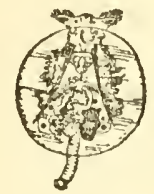

FIG. 63 Pterodina patina

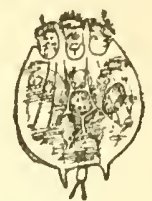

Fic. 64

Typical RotIfERs (Greatly magnified)

are large enough to be of real use. Further information on this point is contained on page 129. Infusoria are shown in Fig. 109.

Freshwater Shrimp (Gammarus). While this shrimp is not plentiful enough anywhere to feed in large quantities, it is a delicate morsel for grown fishes and should be taken as opportunity offers. They are found principally in small streams, under stones and around decaying wood under water.

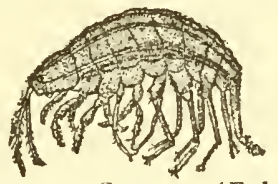

Fig. 65. FreshWATER SHRIMP (Enlarged three times)

Placed in a large aquarium or tank with plenty of vegetation they will multiply rapidly.

Enchytræ. Thread-like small white worms usually bred in winter as a substitute for daphnia for feeding to tropical fishes. Goldfishes are also very fond of them, but it is a difficult matter to cultivate a sufficiently large quantity to satisfy the appetite of several goldfishes. For some of the smaller fishes requiring living food they are almost indispensable in winter.

The culture of these worms is quite easy and requires very little attention after the start is made. Many dealers and fanciers have a supply of enchytræ, from whom a stock can be procured at a slight expense. These are placed in ordinary garden soil from which all worms and larvæ have been carefully removed. Wooden or earthenware boxes about 15 inches long, 7 inches wide and 6 inches deep may be filled with earth to a depth of 4 inches. A cover glass must be provided, this sitting directly on the soil. Proper feeding is the principal keynote to success. They like thick sour milk, white bread, mashed boiled potato, cheese rinds, etc. In a box of this size, four or five small holes are dug out with a spoon; the food is dropped in and the earth replaced. This is 
done as often as the food is consumed and in three or four weeks the harvest of worms will be ready. Care should be taken not to overfeed, as this will sour the soil. The soil should be removed from the box about every two weeks, broken up, loosened and returned. This is considerably facilitated if about half the soil is composed of leaf mold. The breeding box does best in an average temperature of about 60 degrees Fahrenheit. Ants, beetles and mice kill these worms, so they should be excluded.

The worms are separated from the earth in a number of ways. If but a few are desired the simplest way is to remove two or three spoonfuls of soil and place in water just deep enough to cover. In a very short time the worms will come out of the soil and entangle themselves in a bunch near the surface of the water, when they may easily be collected.

Another method of separating the worms from soil is to place a portion of the earth in an enameled dish, pouring on sufficient water to cover soil, and placing a sheet of glass tightly over dish. Because this will prevent sufficient oxygen from penetrating the dirt or water, the enchytræ will promptly leave the soil, crawl up the sides of the dish and the underside of the glass cover, and cling there. The cover can then be removed and the worms washed or scraped off and fed to the fish. This, of course, is a slow process, but by preparing an hour or so before it is desired to obtain the worms, an ample supply may be procured.

It is not advisable to feed all of the worms thus obtained. When a considerable number are placed in a tank at a time, some are bound to escape and, burying themselves in the gravel or sand, die and pollute the water. A clever method of avoiding this risk is by use of a floating

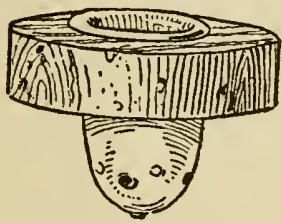

FIo. 66 feeding tube as illustrated. Inserted in a cork float is a glass thimble in which are several little holes. A small bunch of worms is placed in the glass. They gradually make their way through the openings and into the waiting mouths of the fishes. This little device is made commercially, and sells for a trifle. WHITE WORM FEEDER

Mealworms. These are rather hard, glossy, light brown worms about an inch long. They are good food for the hard-mouthed fishes, of fair size, such as the Sunfish and the Cichlids. Lizards thrive on them and they are about the only obtainable food to carry insectivorous reptiles and toads over the winter unless they are maintained in a hibernating condition. Pet stores sell them as bird food. They feed on bran or other meal in which they are kept. If undisturbed and kept in a liberal supply of bran they presently turn into small beetles which in turn lay eggs and hatch into a new and much larger stock of mealworms. 


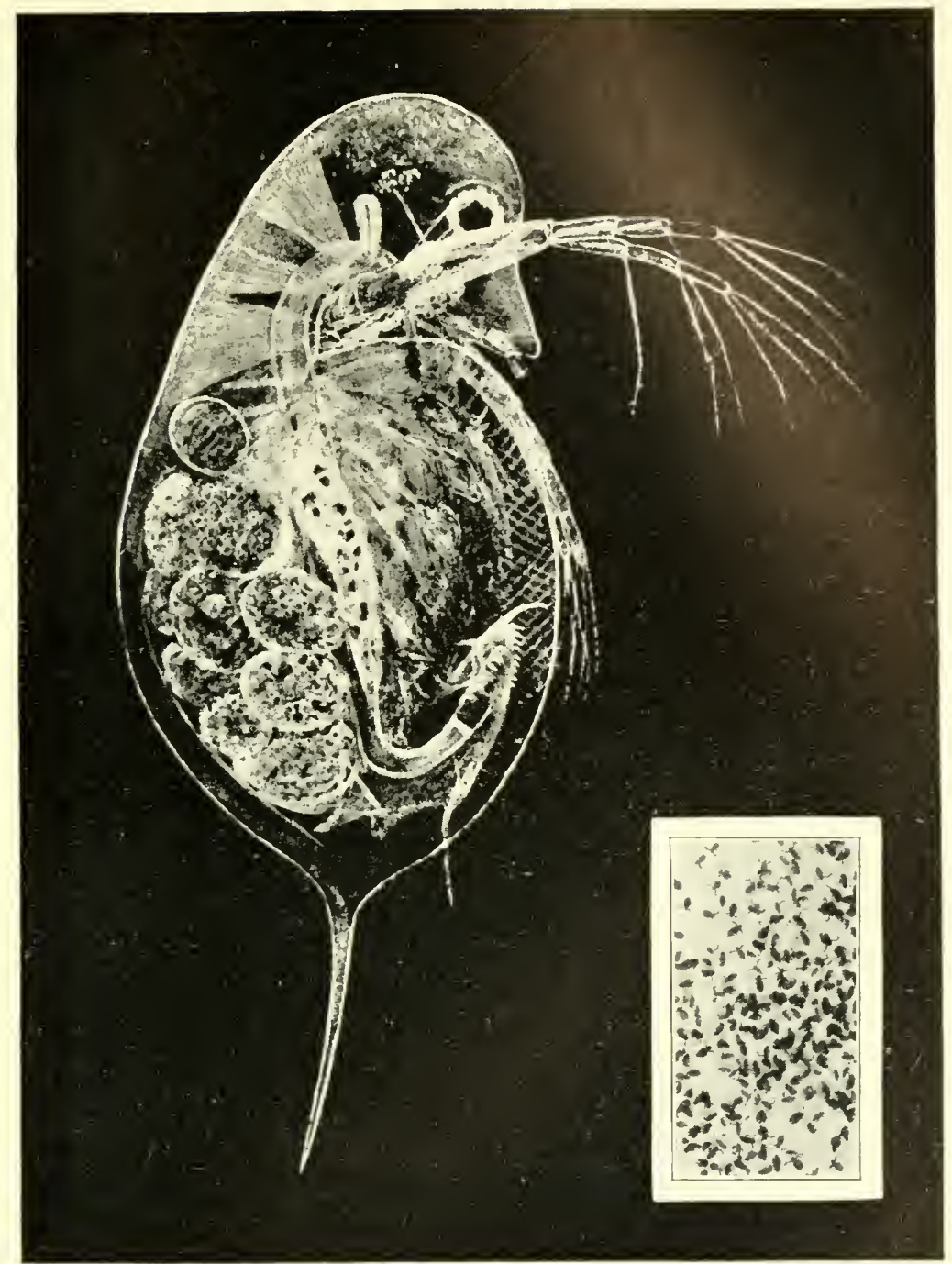

FIG. 07. DAPHNIA

A photo-micrograph of the little crustacean of supreme importance as food for youne fishes, especially the goldfish. They are taken greedily by practically all the smaller iresh-water fishes. Being only the size of a pin-head, it takes a few millions of them to satisfy the appetite of several large goldfishes.

The ovals shown in the body are eggs, which are carried until hatched. Fishes too small to eat an adult daphne follow it around waiting for it to drop the young. The branched arms are for swimming. They are strictly vegetarian, despite former views on the subject.

The inset shows a characteristic life-size group of daphnia, presented mainly in the interest of numerous readers who would like to collect the "bugs", but are unable to identify them from Fig. 55 and our limited word description. 


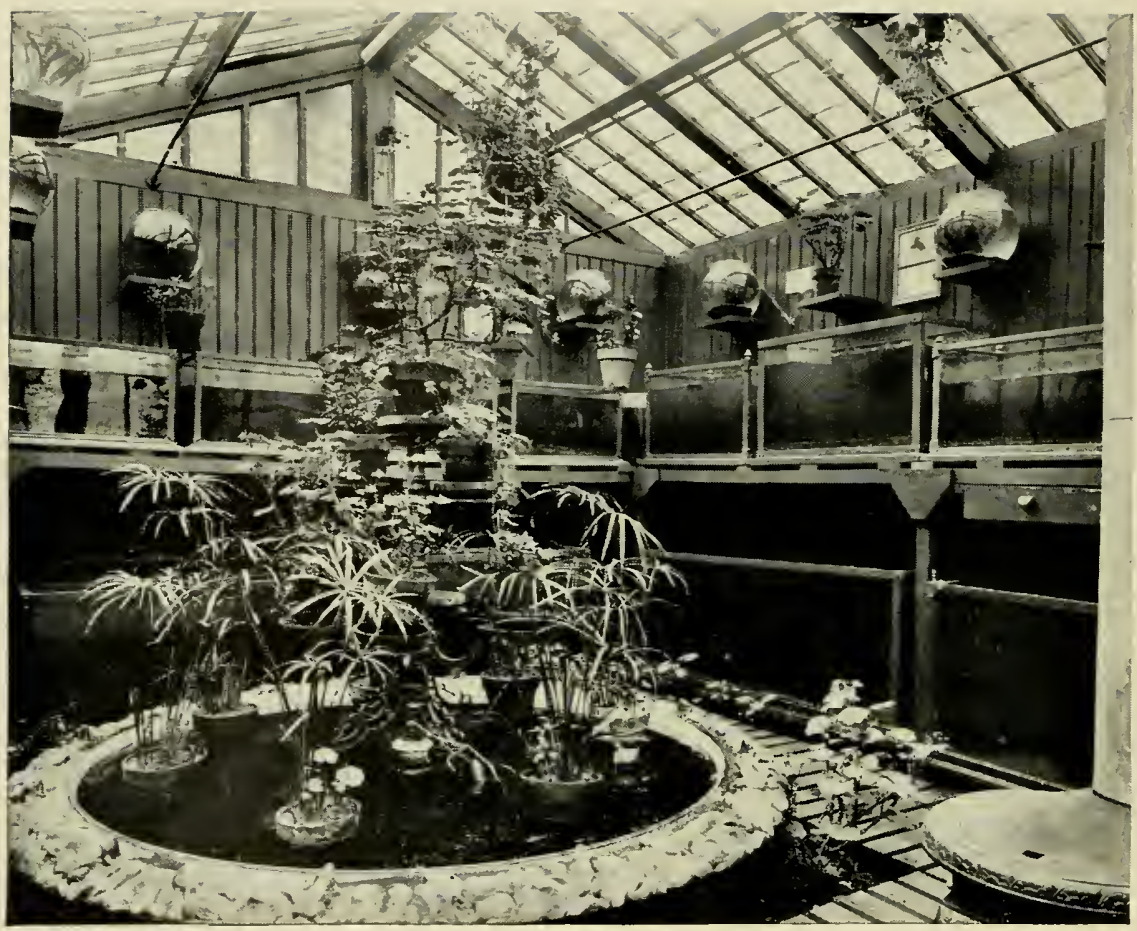

Fig. 68. Semi-Professiunal Breeding Establishment

Many fanciers with sufficient space in their back yards for small vreeding houses earn quite a little money during the year by breeding aquarium fishes.

The large size aquaria and pool indicates this to be a goldfish breeder's establishment 


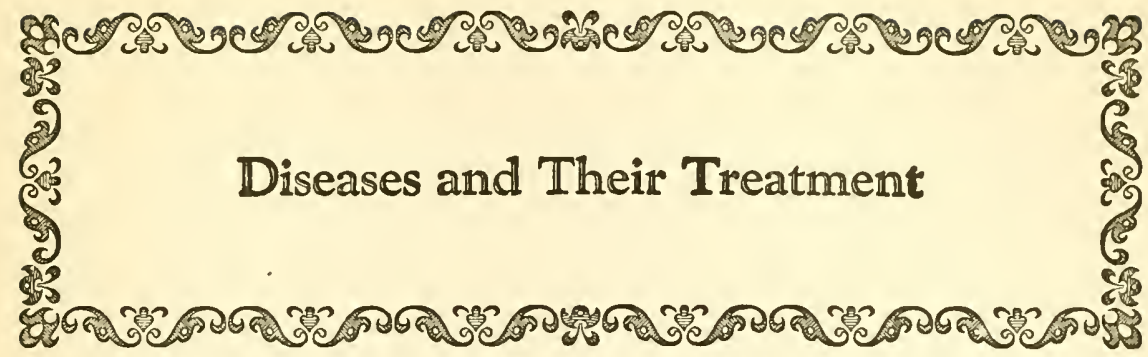

Even in a state of Nature fishes are sometimes attacked by disease and parasitic enemies. It is little wonder, then, that aquarium fishes, weakened by inbreeding and kept under artificial conditions, should be subject to a number of maladies. The wonder is that the majority of the diseases can, under the circumstances, be successfully treated.

Half the battle is won by taking the trouble in time. The aquarist should always be on the alert to detect when his pets are a little out of condition. This is shown by listless movements, loss of appetite, drooping dorsal fin (when the fish is in the habit of holding it erect), congested or frayed fins, white slime on body and bubbles in the excrement. When a fish is even suspected of being in doubtful condition it should be observed carefully for a day or two, and, if improvement is not noted, given the required treatment-promptly.

Affected fishes should be immediately removed from their fellows. There is always the possibility that they are suffering from a contagious disease which may quickly spread. Great care should be exercised not to use the same nets in handling sick and well fishes unless they are sterilized after exposure to disease germs.

Salt Treatment. Most of the disease-producing bacteria of fresh water are unable to live in moderate salt solutions. The point, then, is to find the right strength of solution that will kill the bacteria without injuring the fish. As the salt treatment is the standard one for curable diseases, we shall go into this at some length.

KIND of Salt. Ordinary table salt is likely to contain chemicals to prevent caking in damp weather. These are injurious to fishes. However, if no other salt is obtainable, this can be made to do. The very best medicine is real sea water, properly diluted. The next best is rock salt or evaporated sea water. Where the fish shows a tendency to constipation, one-quarter of the salt content may be Epsom salts. Some writers recommend this addition in all cases. 
Strength of Salt Solution. Common practice among the uninformed is to throw a sick fish into a strong brine solution, leaving it there a few minutes until it shows signs of expiring. This treatment is perhaps better than none at all, but is unnecessarily severe and is not so successful as the milder solutions. In fact, the strong salt takes the protective slime off the fish and leaves it in a condition where it is liable to be quickly re-infected, and in a weakened condition where treatment is not likely to again be effectual. The usual practice of the author is to make a solution in which salt is just discernible to the taste. As the sense of taste varies in individuals, this is not a very accurate rule to give others. A suitable proportion is one ounce of salt (approximately two heaping teaspoonfuls) to each gallon of water. If sea water is used, mix one part to five parts of fresh water. This solution is excellent.

Methods of Treatment. Nearly all sick fishes do best in shallow water and out of bright light. A shallow enamel tray is very good, or a well-seasoned tub is suitable. In placing the patient in the medicated water, see that there is no considerable change in temperature. In warm weather a change to very slightly cooler water is stimulating and probably does no harm. In winter, when goldfishes may be run down, the temperature during treatment should be gradually brought up to about 68 degrees. Except for the air-breathing species (Paradise fish, etc.), a sudden change to several degrees warmer water is liable to produce suffocation, warm water holding less free oxygen than cool. Aquarium fishes can live indefinitely in the solution described, but in two days a salt solution begins to smell stale and needs to be changed. A daily change is better. Should the patient not show signs of improvement in four days, gradually increase the strength of salt solution for two or three days until it is up to two ounces (four heaping teaspoonfuls) to each gallon of water. After remaining in this for two days the salt proportion is slowly weakened down again to the first formula.

Ammonia Treatment. A popular treatment among European fish culturists for fungoid diseases is the ammonia method. This has not been generally accepted in the United States, but has been tried with remarkable success in some instances where other treatments have failed. We feel, however, that it should only be tried as a last resort. To one gallon of clean water add ten drops of ordinary household ammonia. (Unfortunately, this varies somewhat in strength.) Place the fish in this for five minutes, but take out sooner, should it turn over. Remove to plain water and then back to its tank.

Special Attention. All fish should, if possible, be placed, after any chemical treatment, in a healthy tank containing green water. Sometimes this is, indeed, the only treatment required. 
Another very good after-treatment which may be used in summer is to place the hospital tank under a small stream or drip. In making the final change from salt back to fresh water, the drip is a very good way to accomplish it. Dripping water may do all that is necessary, especially if a fish is only on the doubtful line, which is more often the case than not.

Summer offers one more treatment when all others fail-place the affected fish in a shallow mud-bottom tank or pool. This is especially beneficial to goldfishes.

When a skilled aquarist finds a fish a little out of condition, but with apparently nothing radically wrong, his first treatment is to remove the fish to another tank if he has one available. This often has the stimulating effect of a change of climate and usually wards off more serious trouble that might be developing. As with ourselves and all animals, it is much better to prevent an ailment, if possible, by improved conditions, rather than by recourse to drugs or chemicals.

The foregoing is general in character but will be found useful in most of the diseases that can be cured. We will now deal specifically with the diseases and ailments, first with those of the goldfish.

Fin Congestion. This is the commonest of goldfish troubles, and is especially liable to attack the highly developed fins of fancy goldfishes. Their long fins are no doubt deficient in circulation, causing low powers of resistance. As soon as the fish is slightly indisposed through overfeeding, sudden chill, protracted low temperature or other causes, fin congestion is usually the first symptom of trouble. The fins of fancy goldfishes may be considered very good barometers of the condition of the fish. The appearance produced by the disease is well indicated by the name-fin congestion. The fins are more or less red and streaked with veins. In advanced cases they commence to split and fray, particularly the tails.

Treatment. Fin congestion, as well as being the commonest of goldfish diseases, is also the most easily cured. The salt-water treatment described previously is without a superior. Another method is to dip the affected parts for half a minute or more in coal oil, keeping the head and gills wrapped in a moist cloth. Usually lighter feeding and plenty of room in fresh water will be all that is necessary if taken in time. Two grains of permanganate of potash to the gallon of water is a suc. cessful treatment for goldfishes, but is dangerous to tropicals. It is best to use this in an enamel or a glass receptacle. Organic substances, such as wood or floating particles of dirt, quickly decompose the chemical. The fish may be given the permanganate treatment an hour at a time, but a fresh solution should be made daily. 
An entirely different kind of fin congestion is sometimes prevalent in the fall, especially when the fishes are first taken in, the young being more liable to attack. The base of the tail and other fins becomes suddenly blood-red, the color sometimes extending to the body immediately adjoining. If allowed to continue, this form of the disease is rapidly disastrous. Fortunately, it yields with surprising quickness to either salt water or permanganate of potash treatment. When alternatives to salt-water treatment are suggested, the fancier will certainly be on the safe side by giving the salt the first trial, particularly if carefully followed out as we have directed.

White Fungus. This is next to the most common disease among goldfishes and is responsible for the majority of deaths, except among

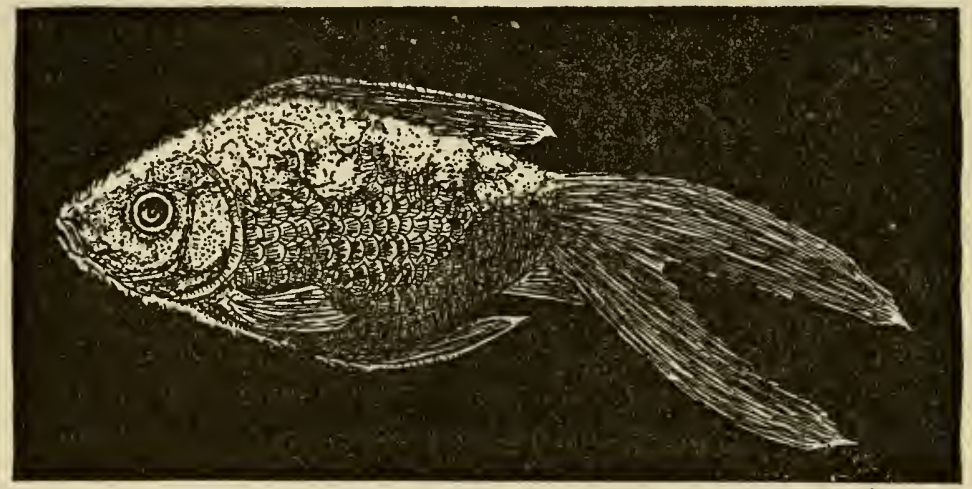

Fig. 69. Fish Affected With White Fungus

This illustration is characteristic of sick fishes in general. The fins are collapsed and the general appearance is one of listlessness.

very young fry. It begins on the tail and other fins, extending over the body and into the gills. When it reaches this stage it is usually fatal. The progress of the disease is marked by the development of a white scum which destroys the fins, prevents the natural functions of the skin, and when the parasite enters the gills causes death by suffocation. The latter stage is not always reached, the fish often becoming so emaciated as to die in the second stage of the malady. The fungus causing this disease is present in virtually all water, but can usually make no inroads on a fish in good condition. A weakened fish once infected will breed so many bacteria that they can successfully attack the remaining well fish. White fungus, therefore, is contagious, and the sufferer should be removed from the others at once. This disease is caused by overcrowding, overfeeding, lack of proper plant life, sudden temperature changes and by bruises in shipment. 
Treatment. Fishes suffering from white fungus should be treated exactly the same as those having fin congestion. If the fins have become very much frayed and it is necessary to trim them, this can best be done by a sharp knife, using a board to cut on. Scissors make a very poor result. It is well to treat the new cut edges with a permanganate solution of one grain to a glass of water. By grain we of course always mean a certain quantity of weight, and not simply a small particle.

Sometimes raw spots are left after the fungus has been removed. These or similar spots from other causes can be greatly helped by the following method: Wrap the head and gills of the fish in a moist rag, dry the affected spot and, with a small piece of cotton, apply some Turlington's Balsam. Allow to dry for three or four minutes. This will not endanger the life of the fish so long as the gills are kept moist.

Itch. One of the common complaints in temperate and tropical aquaria. The fishes are observed to quickly rub their sides against the firmer objects in the aquarium, often against sand or pebbles on the bottom. This is different from Ichthyophthirius.

Treatment. Although this trouble is caused by different organisms, they nearly all yield to the progressive salt treatment. The aquarium should be cleaned out before fish are returned, and care exercised to keep it in a cleaner condition, paying particular attention to seeing that no uneaten particles of food are left lying about. The introduction of more snails in goldfish aquaria will help to avoid a recurrence.

Constipation. Among the highly-bred, short bodied fishes, constipation, as well as other mechanical internal disorders, are naturally common. The much shortened bodies throw the internal organs out of position, give rise to swimming bladder troubles and tie up the muscles which must discharge eggs and also the excrement of the fishes. Lack of proper exercise in the cramped confines of the aquarium and too highly concentrated foods are other causes leading to constipation. The excrement should be of a brown color and free from bubbles or any slimy appearance. In health it usually is seen in long sections.

Treatment. A bath half each of sea salt and Epsom salts, made to a strength of one ounce of salts to the gallon, will usually prove beneficial. It is better not to feed the fish during the period of treatment -about two days. The trouble may be due to overfeeding, and in any case a short fast will probably do good.

Goldfishes readily eat Epsom salts. A pinch dropped in the aquarium once weekly is beneficial, and at the same time replaces some of the mineral content of the water depleted by the plants and fishes drawing 
constantly upon it for the chemicals necessary to sustain life. This practice has a tendency to prevent constipation.

Chopped earthworms will be found a mild laxative. In severe cases some fanciers place a drop of castor oil well down the throat of the fish by means of a dropper. The author has never been convinced that the fish swallows any medicine administered in this way, but results are claimed for the method. A physician friend hypodermically injects castor oil into small earthworms before feeding them to the fish, thus insuring the swallowing of the dose-a sort of living capsule! Scrambled egg, salted with Epsom salts, undoubtedly is a splendid laxative. Chopped, crisp, lettuce leaves are also beneficial.

Tail-rot. This disease first affects the end of the tail and other fins; the appearance is one of being frayed and split. If allowed to continue until the base of the tail is affected, the fish will die. Taken in time the trouble is easily corrected. It must not be supposed that every case of split and ragged tails is one of tail-rot. This is often a manifestation of a generally run-down condition, and in addition to the regular treatment for tail-rot, also requires a general building-up under improved environment.

Treatment. The same treatment as that for white fungus is indicated. Dipping the tail in a $10 \%$ solution of peroxide of hydrogen is beneficial. Should the ends be hopelessly frayed, they may be eaten off by a $50 \%$ peroxide solution. On returning to the water the treated parts will be full of bubbles and will slough off in a few days, leaving a less sharp line than when cut with a knife.

Consumption. This is a real form of tuberculosis, but caused by a bacillus different from that in warm-blooded animals. The body becomes wasted and thin, and so shrunken that the head appears to stand out from the body. Listlessness and loss of appetite are accompanying symptoms.

Treatment. This trouble seems to be deeply seated and is difficult to treat successfully. Unless the fish is a particularly valued one, it had best be destroyed. Place fish in an ample supply of green water or water containing $1 / 2$ ounce of sea salt to the gallon. Feed well on daphnia, chopped earthworms and soft bits of oyster. Placing fish in a shallow muddy pond or tank may be beneficial.

For fishes that are slightly run down, a reliable correspondent, who seems to be no joker, informs the author that diluted whisky dropped in the throat of goldfishes effects a wonderful cure. He dilutes the whisky with five times the volume of water and drops four drops in the throat of the fish twice daily.

Dropsy. The cause for this distressing complaint is not known, but 
it is considered to be due to a disordered liver. It is more apt to attack fancy goldfishes and tropicals, the Dwarf Gouramis being particularly susceptible. The manifestations are a swelling of the body and the scales standing out at an angle. This can best be seen from a top view. Strangely enough, the victims do not seem to feel depressed until within a few days of death. See text accompanying Figure 227.

Treatment. No cure is known for dropsy in fishes. They have been known to improve under absolute starvation lasting several weeks, but a recurrence is likely to take place. There is a current belief that a few drops of digitalis in the water sometimes effects a cure. The author has never been able to verify a single such case.

Swimming Bladder Trouble. Highly bred, short-bodied fishes are the more susceptible to this not uncommon disorder. Sometimes the victims are unable to rise from the bottom except by a violent effort, or again they may lie at the top of water at an angle, or even upside down. Scaleless varieties are the more susceptible, particularly the light colors. Reduced temperatures, even when brought about slowly, are responsible for most cases. In normal condition this bladder balances the fish.

Treatment. No sure cure for swimming bladder trouble is known, but it is sometimes relieved by placing the fish in very shallow, slightly salt warm water. If the patient is benefited it will always have to be kept in temperate water, preferably shallow.

It should be borne in mind that not all cases of loss of equilibrium are due to bladder trouble, but may be caused by accumulated gases resulting from indigestion. Treatment for constipation will relieve these cases, but such fishes will have to always be watched carefully thereafter. The author has had some remarkably good results in these cases by feeding earthworms.

Gill Congestion. There are two forms of gill congestion. The most important, generally known as "gill fever," is that attacking fry from two to five weeks old, and is easily responsible for more losses among goldfishes than all other causes combined. The gills become inflamed and swollen, presenting a distended appearance. Owing to the minuteness of the fish at this period a further observation is difficult except with a magnifying glass, which shows white threads like bristles sticking from the gill plates and openings. The disease is highly contagious, so that if one affected fish is found in a thousand, it is very difficult to save any of them, even though the sick fish be removed at once.

The other form affects mainly young fishes about 2 inches long. The gills swell rapidly, the infection spreading to the throat and producing a gray or whitish appearance. Without treatment, death is sure to come 
quickly. This was formerly a common disease among fancy fishes, but for some unknown reason has largely subsided; we hope permanently.

TrEatMent of Fry. Innumerable experiments have been tried to cure this devastating disease, but without consistent results. So fatal is it considered by many expert fanciers that when they find a few affected fishes they destroy them, together with perhaps thousands of their fellows in the same tank without attempting a cure, throwing out bad and apparently good alike. The tank is then disinfected with strong salt water or more powerful germicides. The great trouble is that any chemical which will kill the parasites is also very apt to kill the delicate fry. However, it is almost certain a cure can be found, and it is a great pity, to neglect an opportunity for experimenting. Cases have been cured, but exact data are lacking. The most encouraging thing that can be said in this connection is that the disease can almost always be avoided by not overcrowding the fry. Allow at least three square inches of water surface per fish up to six weeks old, and more thereafter.

Treatment of Larger Fishes. This form of gill congestion has also been considered necessarily fatal, but such is not the case. The fish should be placed in strong salt water ( $3 \mathrm{~T} / 2$ ounces to the gallon) until it rolls over from exhaustion. It is then transferred to a tank of gently running water which overflows. It appears as though the salt loosens the disease-germs and the running water carries them off while they are weakened. Treatment is repeated daily until improvement is noticed.

Eye Inflammation. The protruding eyes of Telescope fishes are quite subject to injury, especially against the sides of cans in travel. Painstaking treatment can go far to relieve this condition and ward off permanent blindness.

TREATMENT. Make a saturated solution of boracic acid in tepid water. This is gently applied daily to the affected parts by a bit of absorbent cotton. The fish should be placed, if possible, in a large tank free from obstructions, that the injured eyes may not be further irritated.

Instead of boracic acid, the eye may be swabbed with a mixture composed of one part of tincture of iodine with nine parts of glycerine. One treatment is usually enough. It takes about two weeks to clear up. This mixture is a most efficient home remedy for applying to cuts or other open wounds, giving all the benefits of iodine without its burning qualities.

\section{ANIMAL PARASITES}

There are only five of these of sufficient importance to keepers of aquarium fishes to require mention. Food fishes and all wild species are more or less subject to numerous parasites, many of them serious or fatal. No doubt aquarium conditions are not favorable to their propaga- 
tion; otherwise we would have more trouble in this direction on account of the large numbers of wild fishes from so many parts of the world being imported for aquarium purposes.

Leeches. There is a small white leech about $1 / 4$ inch long occa sionally introduced with living food (daphnia), more particularly in the spring. This attacks the bodies and gills, and if the fish is only a few weeks old the results are fatal. In an aquarium it is easily possible to see them on the glass and the breeder should be on the lookout for them. If any are discovered the fishes should be carefully removed to an aquarium where they can be kept under observation. The aquarium should be disinfected by ammonia (page 102). These and larger. leeches can be removed from the gills of larger fishes by the injection of strong salt water, or by the progressive salt water treatment previously described.

Fish Lice. While not very common, and seldom if ever fatal, this crustacean parasite is very annoying. It is about $1 / 8$ inch in diameter, very flat, of a nearly rounded outline and is quite translucent, but distinctly showing handsome iridescent colors under a good magnifying glass.

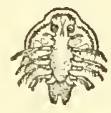

FIg. 70. FISH LOUSE. Argulus (Enlarged four diameters)

They are free swimmers and are able to hold most tenaciously to their hosts. So tight is their hold that even after death by poisoning they still adhere where fastened. Owing to their translucent quality they are difficult to see. The fishes will scratch themselves much the same as in cases of the "Itch," but one can notice small irritated spots, particularly on the fins. The body, however, is not free from attack. The lice adhere tightly, but can be scraped off with the point of a knife.

Treatment consists in the use of permanganate of potash, the strength varying according to conditions. If there is much organic matter present, such as leaves, settlings and green water, the strength may be made as high as $1 / 2$ grain by weight to the gallon of water, especially in a wooden tank. If the container is very clean and there is nothing in it except the fishes, $1 / 8$ grain per gallon is enough. In general, $1 / 4$ grain per gallon is safe. Unless the fishes show signs of dying, the water does not need to be changed, as most of the chemical expends its strength within an hour and clears in a few days.

As the treatment does not affect the eggs of the parasites, a second application should be given in a week, especially in ponds or pools.

Flukes. The detection of flukes is not easy without the aid of a microscope, the cause being a small parasite worm (Gyrodactylus elegans), chiefly infesting the gills. The fish breathes unnaturally fast, frequently 
coming to the surface of the water for air. The fins twitch and occasionally the fish will dash wildly and aimlessly about the tank, coming to a rest after exhaustion. Before death the body becomes thin and emaciated.

If the fish is not too far gone it will stand the formaldehyde treatment, which will usually effect a cure. Place the fish in a solution of 5 drops of formaldehyde to the quart of water. Add one drop per minute (per quart) until there are ten drops to each quart. Allow the fish to remain in this for ten minutes unless it sooner shows signs of exhaustion. Return to a thoroughly disinfected tank and repeat the operation next day. Two or three treatments will usually be sufficient. As a rule, all the fishes in a tank are affected, so if this parasite is positively identified, it will be well to treat every fish that has been exposed.

Most animal parasites can be destroyed by adding 1 part of glacial acetic acid to 490 parts of water. Treatment lasts twenty seconds.

Ichthyophthirius. If a dangerous disease may be called interesting, ichthyophthirius would be entitled to that distinction. Of recent years it has been the centre of attention among aquarists and writers in aquarium periodicals. It has no doubt killed more prized tropical aquarium fishes than all other diseases combined. Numerous goldfishes have also succumbed.

The disease is caused by an animal parasite, spending one stage of its development in or on the fins and bodies of fishes. Its presence is made known by the appearance of tiny white spots, which eventually become so thick as to produce a whitish appearance. One illiterate fancier rather aptly called it "pepper and salt fungus" because the fish appeared as though seasoned with salt. The spots are considerably smaller than pin heads, yet not difficult to see.

Formerly this parasite was always found to be fatal, but since we understand its life history or cycle, it can usually be destroyed. The tiny organisms which have embedded themselves in the flesh and fins of their victims soon drop eggs to the bottom of the aquarium. The parent parasite soon dies, the eggs hatch, become free-swimming, burrow into a fish and start the cycle over again in hugely increased numbers.

Mercurochrome, of the usual strength as purchased in drug stores, used at a ratio of 4 drops to the gallon of water, is one of the surest remedies. Plants and fishes need not be removed from the treated tank. The temperature during treatment should be kept at about 85 degrees, regardless of what medication is used. The treatment usually produces improvement within 2 days, and a cure within a week. After the cure, most of the water should be siphoned off, care being taken to remove all sediment. If the fishes are large enough to handle in a net, the mercuro- 
chrome may be applied, full strength, to the body and fins, using a little absorbent cotton, held in tweezers. Some aquarists successfully use salt instead of Mercurochrome, 2 teaspoonsful to the gallon, in conjunction with the heat of 85 degrees.

The disease principally affects tropicals.

Tropical fishes are the principal victims, and attacks are usually caused by the water becoming chilled, or by the use of unseasoned water, or by sudden temperature changes, either up or down, but mainly down.

Goldfishes yield to the same treatment, or may be given the permanganate of potash treatment as described under "Fin Congestion" a few pages back. Then again they have simply been wiped off goldfishes with a piece of cheesecloth dipped in kerosene, placing the fish in new water and a new receptacle after treatment. A repetition on the second day is usually necessary.

Thread Parasite. Although the Lernean parasites of many species have long been known to science, and are indeed quite common both to fresh and salt water fishes, it was not until 1931 that this pest made itself apparent to fish farmers. The first manifestation is a pimple, commonly near the tail. From this develops a tough thread-like growth about half an inch long, usually with a slight branching at the end. It is anchored deeply in the flesh of the fish with a small spreading foot, and when removed by a steady pull, leaves a sore which heals itself, but which had best be touched with a bit of mercurochrome. If not removed the parasite will presently die and drop off, but the numbers very greatly increase if nothing is done about it, so that they attach themselves to all parts of the body, even into the mouth, when the results may be fatal. The outer end of the thread contains an egg sac. The young become free-swimming and burrow into the flesh of the fish, which starts the described pimple. Treatment consists in picking off all the threads, removing the fish to another receptacle and treating their tank with a tablespoonful of chlorinated lime to each gallon of water. This will kill practically all life in an hour. Flush tank and refill. If convenient, the fish should not be returned to their tank for two days, to see whether embryo parasites already in the fish develop. Where the foregoing treatment is impracticable, it is advisable to try the permangenate method as recommended for Fish Lice.

Diseases of Tropical Fishes. Tropicals usually cannot so well stand the different chemicals and treatments recommended for goldfish. The principal cause for their lack of condition is too low a temperature. If placed in a uniform warmer temperature, with one ounce of sea salt to each gallon of water, and fed up on daphnia, small chopped earthworms, or white worms, they will usually improve rapidly. 
The most common disease among them is ichthyophthirius, already described. This epidemic kills more tropical fishes than any other cause.

As stated in the Chapter on Heating a good plan is to suspend the glass portion of an electric bulb in water. It is again mentioned here because it is a splendid emergency method of raising the temperature in any particular aquarium. The greatest heat is obtained from the old style carbon filament, particularly from an old bulb. While this gives less light, it generates more heat.

Wounds, Ulcers, Etc. All fishes are liable to injuries, but in this paragraph we have particularly in mind that not infrequently some savage tropical fish "beats up" another. If the victim is not too far gone, there is a slim chance of saving it. Swab the injured parts with coal oil and return the fish to slightly salted water which has been boiled and cooled. Daily treatment may be necessary. Usually within three days the fish will either die or pass the danger point. When the injury is confined to a small location the spot may be touched with $2 \%$ mercurochrome (usual commercial strength). Turlington's Balsam has been used with success on injuries, especially on marine fishes in public aquaria, where wounds are apt to be of a serious nature.

Scales knocked off will in time be replaced if the fish passes the first week without developing fungus.

Sometimes fishes, particularly Pterophyllum scalare, are occasionally attacked by some affection which eats a hole into the flesh. Perhaps it is an ulcer. At any rate, without treatment it terminates fatally. This may be healed by swabbing into the opening with an equal mixture of tincture of iodine and tincture of aconite, applied by a little absorbent cotton rolled on the end of a toothpick. A few treatments suffice.

In General. There are times when a fish gradually sinks into an emaciated condition without apparent cause and without serious loss of appetite. The belly becomes hollow and the back arched. This is more apt to be the case with tropical fishes, particularly with females of the livebearing group that have bred freely. It seems to be the natural end of life and there is nothing much to do about it. Many of the tropicals mature quickly, breed rapidly and continuously. It can only be expected that their natural span of life will be short. "Guppys," for instance, are old in three years.

Many correspondents inquire whether their fishes have died of strangulation, on account of the fact that they were found with their mouths wide open and gills distended. Dissection rarely shows anything in the throat. In common with most animals their very last instinct is to relax their jaws, which probably causes them to die in the condition described. 
Last Resorts. Occasionally someone tells us that they have conscientiously followed every direction in our book and yet their fishes seem droopy and listless, or perhaps they are dying. Unusual microscopic and chemical conditions arise in water at different locations which are difficult to analyze, especially from a distance. Usually they are only temporary.

A good plan in such cases is to give the fishes a complete change into other water which has been boiled, cooled and aerated. This eliminates bacteria or chlorine. As elsewhere stated, it is also a good idea to take water directly from a stream or pond known to contain fishes. A change of diet to chopped earthworms is a further help, or, if they are not available, to one of the animal foods mentioned in the chapter on "Fishfoods." Finally one should take another sharp look for ichthyophthirius or other disease, and also check up on the air-surface-per-fish rule, if goldfish are being considered.

No air-surface rule has been worked out for tropicals because of their infinite variety, and while most of them can stand close quarters, they surely would enjoy getting into an aquarium where they can stretch their legs!

Acid-Alkali Tests. Modern research has definitely established the fact that many forms of life are vitally affected by acid or alkaline environment, the two being of opposite qualities, like positive and negative electricity. Vegetation and lower aquatic animal life are often keenly susceptible to these conditions, particularly in the matter of reproducing themselves. It is, therefore, our interesting problem to find the condition which will be unfavorable to fish enemies without harming the fishes. Simple and inexpensive testing sets are now available to aquarists, and in use by many of them, not only for the control of disease, but also in establishing favorable breeding conditions for the different species. Much has yet to be learned in this field, but it appears to be well worth delving into.

On the scale accompanying these sets (called $\mathrm{pH}$ or hydrogen ion sets) the neutral point is at 7. All above is alkaline, and below is acid. The accepted safe range for aquarium fishes is between 6.4 and 7.4. Water kept at about 6.8 is suited to most aquarium fishes and is unfavorable to many bacterial and parasitic enemies and to micro vegetal organisms which cloud the water or turn it green.

Under control of a test set there are several acids which are safe to use. Among them are hydrochloric, acetic and acid sodium phosphate, the latter being preferable, as well as more permanent in its effect. The simplest agents for turning water to the alkaline side are bicarbonate of soda (washing soda) or lime water. 
CHAPTER FIVE

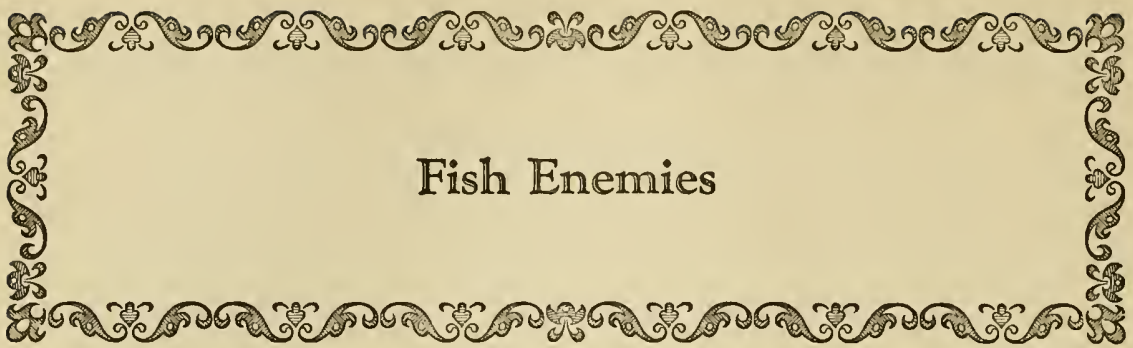

Among the troubles that beset the fish culturist, not the least are caused by insects and their larvæ. This applies both to the propagator of food-fishes and those interested in fancy aquarium pets. We use the term "insect" here in its popular sense and not according to exact scientific definition.

Some of these enemies are much more readily detected than others, but most of them may enter the rearing tanks when so small that detection is practically impossible. Wire screen or netting will keep out those that fly, or a large enemy in the water can be separated from daphnia or other living food by passing the "catch" through a fine wire gauze under water, but despite these precautions it is essential in the summer season to be ever on the lookout for any of the pests which may have gotten by our keenest observation. Fortunately for the aquarist, there are not many kinds of insect enemies with which he is actively concerned. There are only three, all of them being larvæ. While the others are none the less savage or fatal, they are not so often met with, or else are so easily detected that they are not such serious factors with which to reckon.

Water Tiger. This is the larva of the Predaceous Diving Beetle (Dytiscus), itself also a very powerful but easily detected enemy. The Water Tiger is easily the most rapacious, savage and insatiable enemy

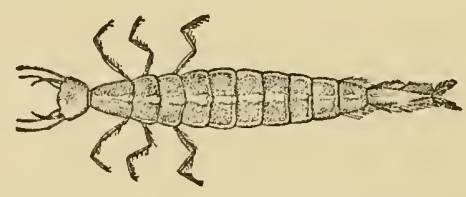

Fig. 71. Water Tiger (Life size)

of young fishes. It does not idly wait for its prey to pass nearby, but adopts business-like methods of going after its unwary victims. The flat head is furnished with a strong pair of hollow mandibles, through 
which it sucks enough blood to kill its victim and then wantonly goes after another. In this way a single individual may kill an entire hatching of fish over night. This larva can usually be recognized by its spindle-shaped body; flat, strong head; pale translucent brown color and a steady progress through the water, coming to the surface frequently to breathe a moment through the rear end. Although growing to a length of $2 \frac{1}{2}$ inches, at which time it attacks larger fishes and any small aquatic animals, it is the smaller sizes with which we are principally concerned. From a length of $1 / 4$ to 1 inch they are not so easily seen, but are capable of doing great mischief.

Spearmouth. While not quite so common as the Water Tiger, its habits are similar and it grows to an even larger size, reaching 3 inches.

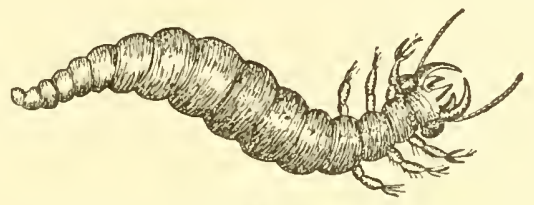

Fig. 72. Spearalouth (Life Size)

The body is thicker and the mandibles are shorter. From the aquarist's standpoint both these larvæ could be classed as one. The Spearmouth is the larva of the large Water Scavenger Beetle (Hydrophilus).

Dragon-Fly Larvæ. Almost everyone who raises fish outdoors is familiar with these unpleasant individuals. There are two reasons why they are difficult to altogether avoid. When newly hatched they are very small and will go through the same strainer as daphnia; furthermore, the mother Dragon Fly (Odonata) is an excellent flier and may deposit her eggs in any body of water that provides proper facilities for her needs. These larvæ live more by their cunning than by any agility as

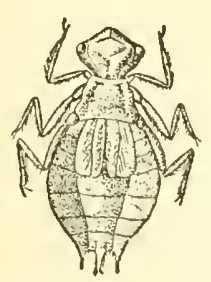

Frg. 73.

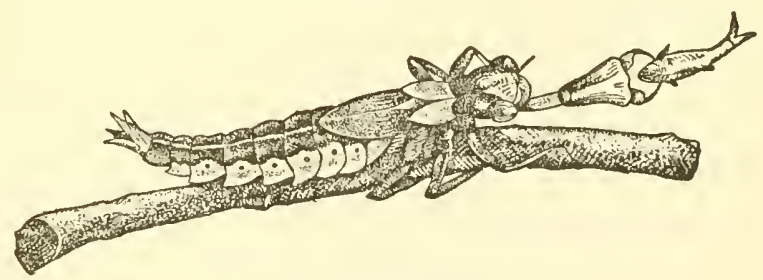

FIg. 74.

Nymph of Dragon Fly

swimmers. Waiting on a dirty pond-bottom or attached to sticks, aquatic grass or other object, they mark time until a victim comes within close reach. Then they quickly pounce forward, extending a vicious, pincher-like organ called the "mask," rarely missing the object of attack. The method 
of propulsion through the water is peculiar, being brought about by a series of expulsions of water from the rear end. This enables them to make a very sudden leap towards a victim. The "mask," shown in Figure 74, when not in use is folded before and under the head. Dragon Fly larvæ are strictly carnivorous at all periods and will attack any pond creature reasonably near their own size. If given enough time a single individual will destroy an entire hatching of fishes, growing by what it feeds upon so as to be able to devour the remaining fishes which are also becoming larger.

Predaceous Diving Beetle (Dytiscus). Fortunately this beetle is of such size that it can scarcely escape notice, especially as it is obliged

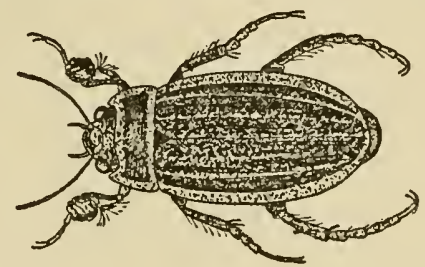

Fig. 75. Predaceous Diving Beetle (Life size)

to come to the surface for air, which it takes at the end of the abdomen. It is rapacious in extreme degree and is a good swimmer. A large specimen was once placed in an aquarium for observation. It so quickly attacked a goldfish that the scales fell in a small shower and the fish died before it could be rescued. They are usually of such a dark brown as to appear black, but are sometimes bordered with yellow.

Water Scavenger Beetle (Hydrophilida). We mention this beetle here because of its resemblance to the large predaceous diving beetle.

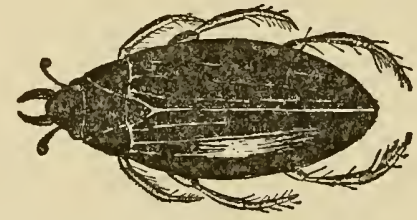

Fig. 76. Water Scavenger Beetle (Life size)

It swims differently, using its legs alternately, while the diving beetle moves opposite pairs together. The Scavenger Beetle is also different in that it breathes at the surface from the mouth. Instead of long antennæ, they have palpi looking like club-shaped antennæ. This beetle lives chiefly on decomposing vegetal and animal matter, although taking soft living plants such as Nitella. It has been claimed to be predaceous, 
but there is doubt about their attacking fishes. They have been kept in aquaria with them without doing damage. On general principles, however, it is best to exclude all beetles, large or small.

Water Strider (Hydrobatida). Another of the predaceous aquatic insects is the Water Strider. Quite as well known as the Whirligig

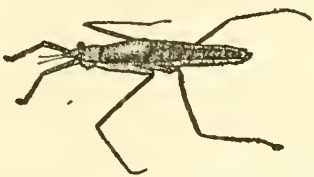

Fig. 77. Water Strider (Life size)

Beetle, it adopts somewhat the same methods of securing its prey, darting over the surface of the water, waiting for the stream to bring down some helpless insect victim that has fallen overboard. They are capable of catching young fishes which come to the surface.

Giant Water Bug (Belostomatida), also known as the Electric Light Bug, is one of our common bugs, both on land and in water. Flying clumsily but strongly before electric lights, or patiently awaiting a victim at the bottom of a pond, the bug is one and the same. They are fiercely predaceous and very powerful. While this is a vicious enemy, it is not one that frequently gets into the fish tank except by flight, and as only the adults fly they are easily detected by their size. In large outdoor rearing pools or lakes they are a very practical menace.
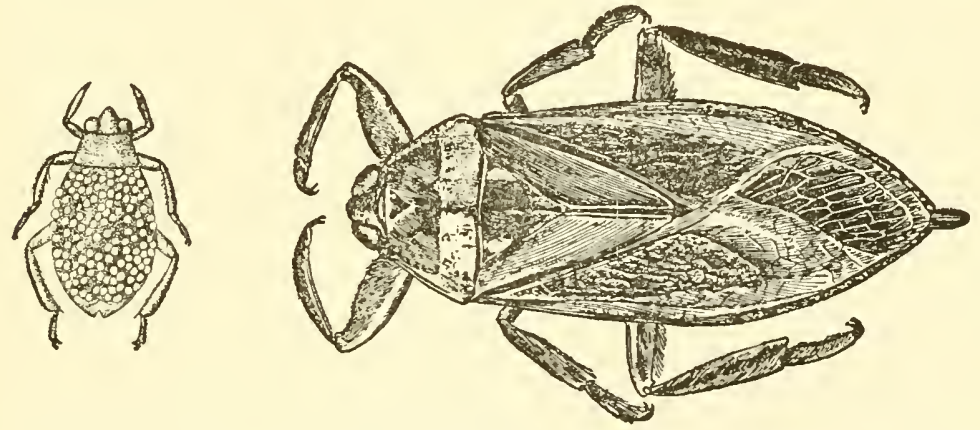

Figs. 78 and 79. Giant Water Bugs (B. serphus and B. americana). The smaller a Male With Eggs on Back (Life size)

The colors range from clear, dark reddish brown to dull olive. With some of the smaller genera, Serphus and Zaitha it was supposed that females lay the eggs on their own backs. Some writers have accepted this popular misconception without investigation. It has been fully established that the female fastens her eggs on the back of an unwilling male, who only submits to the indignity after a struggle. 
Water Scorpion (Neptida). We have here another of the insects spending most of its time in aquatic dirt and rubbish awaiting innocent

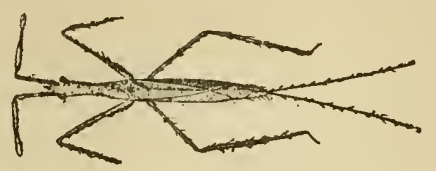

Fig. 80. Water Scorpion (Life size)

passersby who, for their unwariness, will pay with their lives. While this insect is common enough to the naturalist, it is not one with which the fish-culturist need be seriously concerned.

Whirligig Beetle (Gyrinidce). This well-known beetle is common to many slow-flowing streams and pools, keeping up a perpetual movement on the surface of the water, on which it glides apparently without effort. On account of its size and shape it is often called the coffee bug. The breeder of fishes is not harassed by this insect, but occasionally an aquarist will be tempted to introduce one in a fish-tank. This is a mistake. They are predaceous and can inflict a severe bite. The larva,
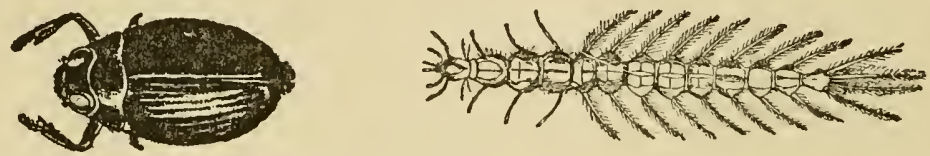

Figs. 81 and 82. Whirligig BeEtle and Larva (Enlarged three times)

which is not so well known, is also predaceous. This little beetle when held in the hand emits a faint but pleasant odor.

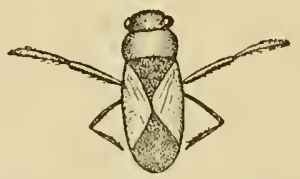

Fig. 83. Water Boatman (Slightly enlarged)

Water Boatmen and Back Swimmers (Corixidae and Notonectide) are found everywhere in still or slow-moving water. There is a wide variation of opinion as to the predaceous characteristics of these insects. This is because fish breeders ordinarily class them all as "boatmen," a very natural mistake owing to their general resemblance. The facts are that Back Swimmers (fortunately much the fewer in numbers) are carnivorous, predaceous and capable of inflicting a severe bite when being handled. They are fish enemies. Water Boatmen are harmless scavengers. In swimming they use their longest pair of legs like oars, which accounts for their name. 
Back Swimmers may be recognized by the fact that the back is down and the legs up while swimming, and also that they breathe at the surface through the end of the body. As a matter of practice it is easier to remove all such insects rather than try to determine the species. Scalares and other large hard-mouthed fishes like to eat water boatmen.

Mites (Hydrachna). These odd-looking little balls of intense vermilion are sometimes placed in small tropical aquaria with fishes. This

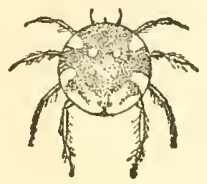

Fig. 84. Water Mite (Enlarged about four times)

is inadvisable, as they are parasitic. It is doubtful whether they actually kill their host. They are common in the still water of lily ponds.

Hydra. Although Hydra is not an insect, we include it here as an important enemy of young fishes. Hydra is a polyp which attaches itself to plants, stones or the sides of the aquarium. Being thread-like in appearance, it is apt to be overlooked, especially by the inexperienced. It is usually introduced with living food caught from pools. The spores are so small as to be unrecognizable, and therefore they cannot be avoided. The animal itself has a cylindrical body with from 5 to 12 tentacles surrounding a mouth. The shape varies so amazingly that an accurate description is difficult. The two figures shown are of the same individual. When alarmed the tentacles are entirely withdrawn, making recognition still more difficult. The figure at the left is the usual form when not alarmed. In this condition it reaches from $1 / 8$ to $1 / 4$ inch in length, but the body may be considerably thinner if food is scarce.

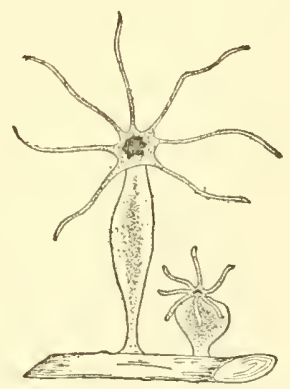

FIG. 85. HYDRA (Greatly enlarged)

Propagation is by budding, by spores and by division. If one of the tentacles be cut off it will develop into a perfect hydra. 
They rapidly deplete an aquarium of daphnia and newly hatched fishes. When a school of fry under 5-16 inch long is disappearing without apparent cause, it will be well to take a sharp look for hydra.

Hydra possess a poison which quickly stupefies their prey, and to fish large enough to eat the hydra this poison doubtless has an unpleasant taste. There is no fish known which will eat them. To get rid of this pest, remove all fish, snails, etc., from the tank and place in it one teaspoonful of household ammonia to five gallons of aquarium water. Allow this to stand for two hours, change water and replace fish. This treatment will not kill plants. Raising the aquarium temperature to 110 degrees $\mathrm{F}$. for a few minutes will also destroy hydra.

\section{LARGER ENEMIES OF FISHES}

It should not be understood that the foregoing are the only serious enemies of pet fishes. In the greenhouse, outdoor pool, or even the library, misfortune is liable to descend in various guises. Chief among these are the cat, rat, muskrat, snake, heron, kingfisher and small boy. Fishes are also taken by the sandpiper, horned owl, blackbird and crayfish. The blackbird specializes on picking out the eyes of telescopes, if the water is near enough to the edge of tank for him to reach them. Frogs will eat fishes of nearly their own size. Slow-moving fancy goldfishes are easy prey for them and inexperienced fanciers have lost many of their best specimens through ignorance of this menace. Rats are extremely daring and resourceful in finding ways to get at goldfish tanks, especially in greenhouses, where they cause great losses to fish stock. They will even burrow from the outside and gnaw their way through a weak portion of cement flooring.

Kingfishers can be destroyed by setting a steel trap on the high lookout point where they watch for their victims. The trap is not baited. It is set off by the bird alighting on the trigger. Aside from this suggestion the owner of the fish will have to use his personal ingenuity to combat these enemies as occasion arises. The author must here content himself with pointing out the possible sources of trouble.

It very rarely happens that a large goldfish is an offender in a peculiar and surprising way. This is in the gentle and shocking art of sucking the telescopic eyes out of other goldfishes. If the owner of telescopes finds one of his pets with an empty eye socket he should do a little detective work to find the culprit among the other fishes and place it where no further damage can be done. The loss of an eye in this way never seems to seriously inconvenience the victim. 


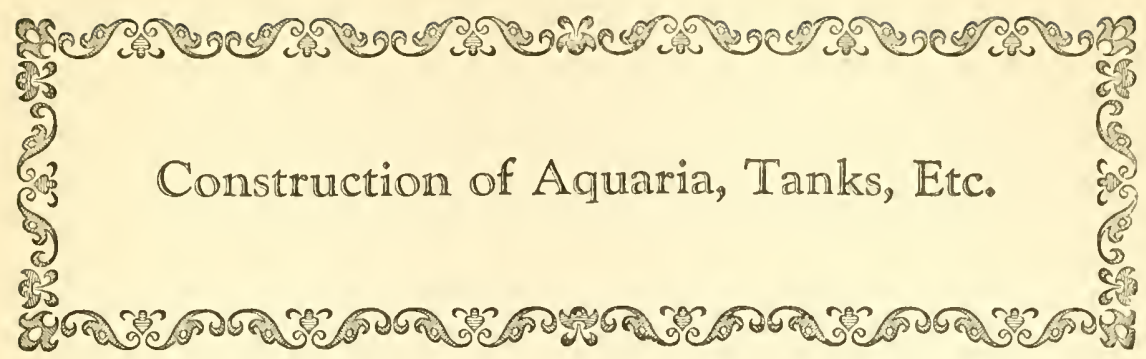

\section{AQUARIUM CONSTRUCTION}

The amateur aquarist with a little talent for things mechanical can find profit as well as pleasure in making an aquarium according to his own ideas and requirements. The few necessary tools either are, or ought to be, a part of every household equipment.

Naturally the first consideration is that of the space to be occupied by the aquarium. In determining this it is well to be influenced, as far as conditions will permit, by the needs of the aquarium inmates, not forgetting that most aquarium fishes do best in shallow aquaria with plenty of water surface. However, for artistic arrangement and symmetrical plant growth we must have a certain amount of depth. Twenty inches deep is sufficient even for large aquaria. For all-round purposes, bearing in mind both the artistic and the practical, a good general rule is to make the aquarium in the form of a double cube. That is, the width and height identical, and the length twice that of either. Unless an aquarium is to be viewed only from the top, it is not advisable to make the width over twenty-five inches, as even a slight cloudiness of the water considerabiy obscures the fishes when there is so much of it to look through. Within reason, make the aquarium as large as possible, but nothing over a seventy-gallon size is to be recommended for the household. An accidental breaking of the glass, even at this size, is too great a catastrophe to contemplate with composure. Since it is very little more trouble to keep a large-sized aquarium than a small one, and the results are so much better, at least with goldfishes, we would unhesitatingly say to those weighing the merits of two sizes, take the larger.

For most varieties of tropical fishes, a number of small aquaria will be found preferable. These will be treated hereafter in the present chapter.

We will now take up in order the points of construction, remembering always, the factor of safety. 
Bases. The best material for general use in aquarium bases is slate. It is inexpensive, durable, easily worked, free from cleavage cracks, and in every way reliable. The requirements for thickness are from $3 / 4$-inch for sizes up to 30 gallons, to $11 / 4$ inches for 130 gallons. Polished Tennessee marble makes a handsome and durable base. White marble is too glaring and besides is easily chipped in moving an aquarium about. Also when brought into contact with aquarium cement it absorbs and spreads the oil, making a bad appearance.

Aquarium bases usually extend from one to one and one-half inches beyond the frames on all sides. Slate or marble bases ought to be beveled sufficiently on the upper edges and corners to take away the sharpness. The necessary holes through which the frame is to be bolted can be drilled with an ordinary metal drill, but it costs very little extra to have the slate-worker do this when he is finishing the base. The under side of the hole should be countersunk with a larger drill to allow for bolt nuts. Aquaria up to 10 gallons require 4 bolts, 20 gallons 6, and for the larger sizes they should be placed about 10 inches apart.

Frame Metals. Angle brass, iron or aluminum form the best metal aquarium frames. For the amateur worker, brass offers the most advantages. It is easily sawed, drilled and soldered, besides making a handsome appearance when polished and chromium or nickel-plated. If nickeled it should be heavily plated. Angle iron is not so attractive in appearance, but is undoubtedly more rigid. It cannot so well be soldered. Consequently the four corners of the upper and lower frames have to be riveted through connecting elbow pieces on the inside or special castings on the outside, and then the whole riveted to the uprights. Aluminum has seldom been used, but makes an attractive frame. As the soldering of this metal is of doubtful durability, it is safer to rivet the same as with iron.

For aquaria up to 25 gallons $5 / 8$-inch angle metal is suitable; up to 50 gallons, $3 / 4$-inch; up to 75 gallons, 1 -inch; up to 125 . gallons, $1 \frac{1}{4}$-inch. The author prefers seeing as little of the frame as possible and for many years has successfully used a 60 -gallon aquarium constructed with only $5 / 8$-inch angle brass, but he would not care to make this as a general recommendation. It is mentioned so that if others have the same idea they will know that it is a mechanical possibility.

Unless constructed of heavy angle iron, it is best to carry a light rod across short dimension of the centre of top frame of aquaria over 30 inches in length, to prevent bulging by water pressure.

Frame Construction. A hack-saw with fine teeth for metal working will be needed to cut the proper lengths of angle metal. After carefuily determining proportions desired, cut the four uprights and then the 
material for top and bottom frames. If working in brass, the upper and lower frames should each be left in one piece. By accurately beveling the two ends and preparing right-angle cuts at three points, as shown in

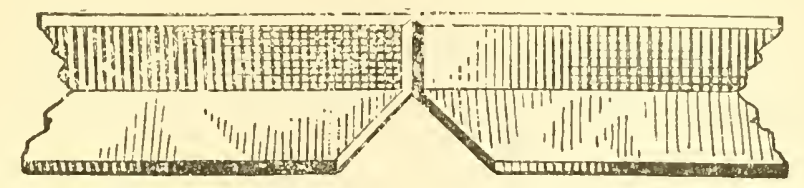

Fig. 86, Cut, Preparatory to Bending Angle Brass

above figure, the whole can be bent into a frame that will produce very neat corners and make soldering easy. The right-angle cuts should be finished with a square file and carried within about 1-32-inch of going through. This leaves the bar very weak at these points and considerable care is necessary in handling in order that some accident does not break them apart before it is time to bend. If one breaks it is not a very scrious matter, only the corner will not have quite such a neat appearance. In practice we find it best to bend each cut as soon as finished and roughly fasten with solder. When all three bends have been completed, place within it a wooden form, as shown below. Except for the corners being

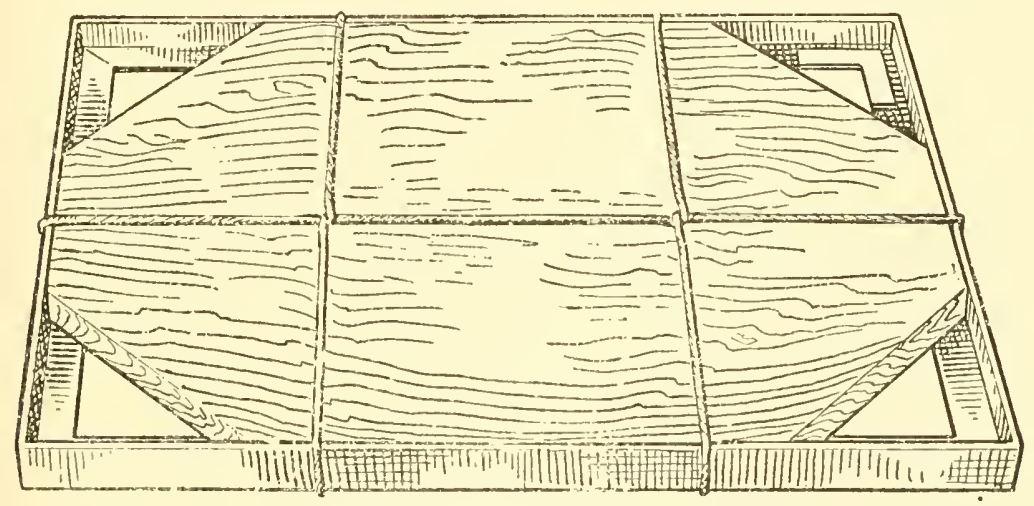

Fig. 87. Frame Secured on Wooden Form Note Reinforcement in Upper Right Corner

cut off (to allow for soldering), the edges of form should be perfectly rectangular and fit closely. Now secure quite firmly with stout twine. After all corners are trued up with the board, apply the permanent solder. Melt solder from any corner that does not stand true without forcing, and re-solder. In the upper-right corner of illustration will be noted a rightangle flange reinforcement, cut from a flat piece of 1-16 inch brass. It is advisable to use these. They add greatly to the strength and actually 
make the work of soldering easier. After preparing the surfaces with solder-flux it is only necessary to place solder on the frame, lay the flange on top of it and apply torch beneath. When solder melts, press flange down and into exact position with a small stick of wood. It is better to have flange sufficiently narrow to allow the uprights to fit in back of them.

The same form can be used for upper and lower frames. Should there be any irregularity in shape, they will both be alike, and so far as strength is concerned, it will only be necessary to keep corresponding defective corners parallel with each other, so as not to make any twisting strain on the.glass - a force which, sooner or later, will cause it to break. If the frame is too large for a board form to be laid within it, it may be trued by lines drawn on floor or table to lay it over. The use of forms, however, is so desirable to the amateur that we recommend having boards cleated together in order to secure sufficient width.

To test the squareness of upper and lower frames, lay them on the floor, make marks at the corners and turn completely over, trying both length and width in this way. Tests by carpenters' squares at corners are only approximate, as the angle metal is seldom perfectly straight, especially in lighter brass. Before leaving the subject of bending the frames to right-angles, we strongly suggest that an experimental bend first be made with a waste piece of angle brass. A little practice will be necessary to learn just how thin a particular lot of brass must be filed in order to make a good bend.

The next step is to bore holes in the lower frame where it is to be bolted through the base, countersinking for depression of bolt head, and allowing enough room not to interfere with the glass. Now solder in uprights to connect top and bottom frames, not melting former soldering.

It will be observed that the glass will be supported by the upright posts, but not by the top nor bottom frames. This is corrected by soldering, about every eight inches, a small piece of brass (cut from the same material) to the horizontal frames next to where the glass is to come, thus giving it even support or bearing on all four edges. The pieces are soldered down perfectly flat, and if high should be filed down. Before the glass is finally inserted it must be laid in the frame to see that the points of contact are even. Deficiencies can be made up by a drop of solder on the brass, and filed down as required.

The frame being trued up, it is now bolted through the base, aquarium cement being liberally supplied in the bolt holes and between the frame and the base, all surplus being immediately wiped away.

Soldering. In these times when nearly everybody is either building or altering radio sets, it would seem needless to offer any suggestions on soldering. However, the chapter would not be complete without it. 
The modern electric soldering iron is a very convenient tool, but the author has managed very well with only an automatic alcohol blow torch. Before soldering, the surface is properly prepared by scraping and the application of a flux composed of hydrochloric acid which has dissolved as much zinc as possible. Very good flux pastes are obtainable in hardware stores. When the heat is applied and the liquid of the flux has boiled away, touch the heated surface occasionally with soft solder wire. Apply a little more heat after first sign of melting, withdraw flame and proceed to quickly solder. Where work is in a position so that it is diffcult to hold the pieces steadily in place while solder cools, an assistant can instantly "set" it by pouring on a little water. Small "C" clamps are most useful while soldering to hold uprights and side frames together. They may be obtained for twenty-five cents or less. If acid flux darkens the hands, the stain can be removed by diluted ammonia water.

Small Aquaria. Compact, neat and substantial aquaria can be made, but without projecting base-in fact, without slate at all. The bottom is self-contained concrete. The top frame and upright corner posts are of $1 / 2$-inch angle brass, and the bottom frame of 1 -inch size. In the inside edges of bottom are soldered a few brass screws. Now prepare a mixture of one part of Portland Cement to two of clean sand, brought to a thick, mushy consistency by addition of water. Lay the frame on glass and pour in the cement to a depth of $3 / 4$ inch, seeing that it lies smooth, particularly at edges where the aquarium glass is to rest.

After the cement is poured and smoothed, it should be covered and allowed to dry slowly. In about two days the frame and base can be slid off the glass. The screws soldered on inside will always bind the concrete base securely in place. To prevent free chemicals washing out of cement into the aquarium water, it is well to waterproof the inside of base before setting glass in. This may be done by melting, under a blow-torch, chips of paraffine on the concrete.

Frames should be plated before pouring the cement base.

After making one of these aquaria the knack becomes very easy. A row of them of uniform size presents a neat appearance and can be used in a small space, since there is no projecting base. This style of construction is suitable for aquaria with bases up to 11 by 18 inches.

Wired ribbed glass or slate bases may be used instead of Portland Cement, and are recommended for larger sizes.

Glass for Aquaria. Although double-thick window glass may be used for aquaria up to the 25-gallon size, plate-glass is so much handsomer and costs so little more, it seems like a wise investment. If window glass is used, the imported kinds will be found best. Plate-glass is now made in 3-16 inch thickness. This is suitable for aquaria under 50 gallons. 
For those for 50 to 75 gallons, the best thickness is $1 / 4$ inch, and for the still larger sizes up to 120 gallons, is $3 / 8$ inch.

Cutting the Glass. A firm, flat surface, a good straight-edge, a sharp wheel cutter and a steady hand are the essentials in this work. Bear on the cutter firmly but not heavily. First experiment on a worthless piece of glass. If the wheel does not make a continuous scratch, go over the missed portion, but do not again pass wheel over former scratch, as this ruins the wheel. When scratch is complete, break glass with thumbs and fingers by bending upwards at one end of scratch. If glass does not divide easily, tap the under side of scratch with solid part of cutter until small splits occur along the line. It will then be safe to break. Large plate glass is best broken by placing the scratch line over the straight edge of a table and bearing down on glass.

Setting the Glass. The edges of the glass should be carefully cleaned with whiting, ammonia or alcohol to remove any grease. It is well to first coat with gold size the edges which are to come into contact with the cement, allowing this to set for a day or two. This is more particularly needed with large plate-glass aquaria. Apply a liberal coating of aquarium cement to the inside of frame, and a thin but well-covered coat to the contact edges of the glass. Press into place slowly but firmly, cleaning away at once all surplus cement. Light sticks cut of a length to brace across inside of aquarium should be used to maintain an outward pressure on the glass for several days until it is fairly set. After the glass is well set, it is advisable, especially with the larger sizes, to run a line of aquarium cement up the inside corners and along the bottom edges, covering with a narrow strip of glass, or, better, embedding a round glass rod of from $1 / 4-$ to $3 / 8$-inch diameter in it, pressing in as far as possible and wiping away the surplus cement. After about two weeks, fill slowly and allow water to stand a week. Re-fill at least once again before introducing fishes.

Stopping Leaks. Large aquaria nearly always leak a little at first, or after moving them, or even after emptying without moving. This usually corrects itself within a few days, but, as elsewhere directed, it can nearly always be stopped by making the water very muddy. The particles of dirt get into the leak and choke it up. This may require several days. The water should be stirred occasionally.

If an aquarium is quite old and fails to respond to the muddy water treatment it should be thoroughly dried for not less than two weeks. Tip the aquarium at a suitable angle and pour enough spar varnish into each (inside) edge to saturate the cement and fill any cracks. Let each edge stand until "set." Dry for a few days before re-filling. Repairs on the outside are useless. 
Aquarium Cements. The prime requisites of an aquarium cement are resistance to water, adhesiveness, moderately quick setting without ever becoming stone-hard, and being non-poisonous. A cement combining these qualities is composed of one quart polishing or other fine sand, one quart Plaster of Paris, one pound litharge, two ounces powdered resin, mixed with double boiled linseed oil to a consistency of putty for glazing. This cement has been found to be good for both fresh and marine water aquaria. A durable cement for those who cannot obtain fine sand is made of equal parts by weight of zinc white, whiting and litharge, mixed with double boiled linseed oil to a firm but tacky consistency.

\section{CONCRETE AQUARIA}

As individual ideas will vary so widely in the design of concrete aquaria, only a few (yet important) directions can be given. Cement should be of the highest grade, fresh and free from lumps. A mixture of one part cement to two of clean, sharp sand is about right. Wooden forms ought to be soaked with water just before using, or else thoroughly paraffined. Cement mixture should be wet enough to just pour, and needs to be well tamped to avoid bubbles. Steel reinforcement rods (1/4-inch diameter) are essential, especially around the top edge, where a continuous band should be formed. Through the bottom the bars should be wired together, forming 4-inch squares. Do not be in a hurry to get the forms off. The whole job should be moistened for a day and allowed to stand for two more days if removal of forms is going to cause any strain. Glass must not be embedded directly in the concrete, but provision made for later setting it in with ordinary aquarium cement. If sides do not support the glass evenly they should be cut away or built up until they do. Otherwise glass is sure to crack when the soft aquarium cement yields to the water pressure. After base is finished it is well to paraffine it as described on page 107. All cement pouring should be done at one operation.

\section{CONSTRUCTION OF WOODEN TANKS}

Many fanciers are of the opinion that for the welfare of fishes there is no receptacle equal to a well-seasoned wooden tank. For breeding purposes they are especially valuable, but in no case should new tanks be used at once. Occasional changes of water for eight weeks make a new wooden tank safe for fish.

The best wood for tanks is well-seasoned cypress, the natural habitat of the tree being in wet places. Any size tank may be made, but there are two sizes found quite convenient and which cut out of the lumber to good advantage. The larger measures 16 inches high, 30 inches wide 
and 48 inches long. The smaller one measures 9 inches high, 24 inches wide and 32 inches in length. For the larger size $1 \frac{1}{4} /$-inch lumber is used, which is about $11 / 8$ inches when dressed. Here a board 16 inches wide is used, avoiding seams in any of the sides, there being but one in the bottom. The side and bottom boards are rabbeted to $1 / 4$-inch depth and

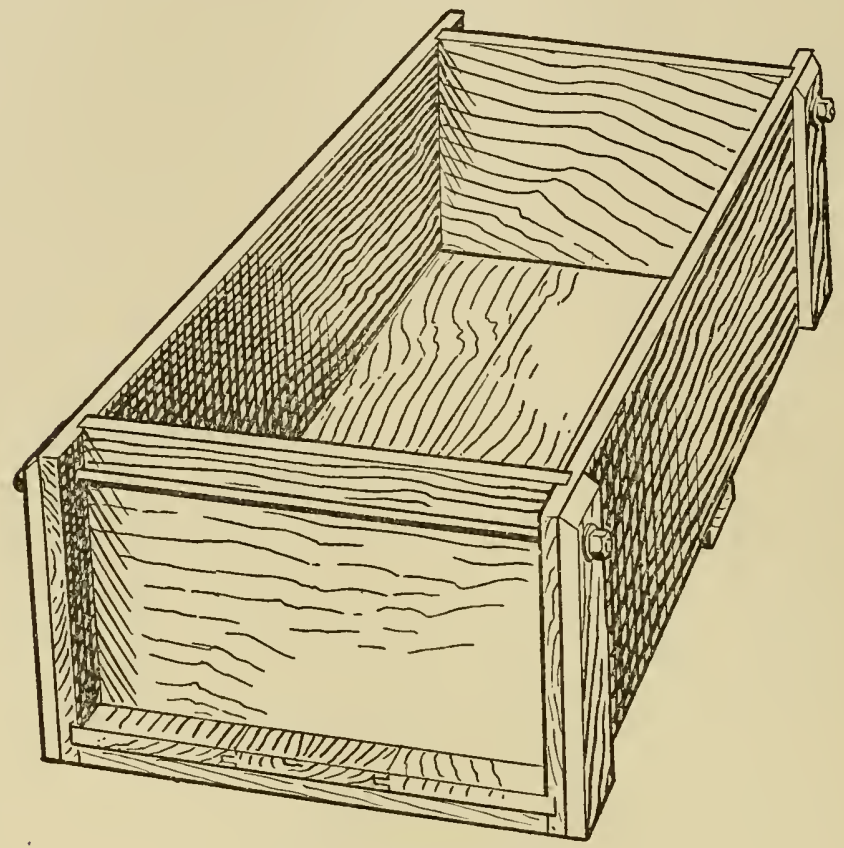

Fig. 88. WoOden TANK

$11 / 2$ inches from edge to receive the ends. Bottom boards are tongued and grooved. All joints should receive a preliminary coating of white lead paint. After this is dried, a thicker coat should be applied just before putting joints together. The tank is then clamped and 13/4-inch screws inserted through the sides into the bottom and ends, and through the bottom into the ends. Cleats 3 inches wide are placed across centre of bottom and all the way around the ends. Through the top of latter is passed an iron rod $1 / 4$ inch thick, then secured and tightened with washer and nut at ends. The smaller tank is constructed in the same manner, except that cleat across centre bottom, and the iron rods are omitted.

While painting the outside improves the appearance, it has more of a tendency to rot a tank than preserve it, as the paint prevents the evaporation of the moisture naturally gathered from the inside. Leaks will usually correct themselves in a few days, but should they not do so, 


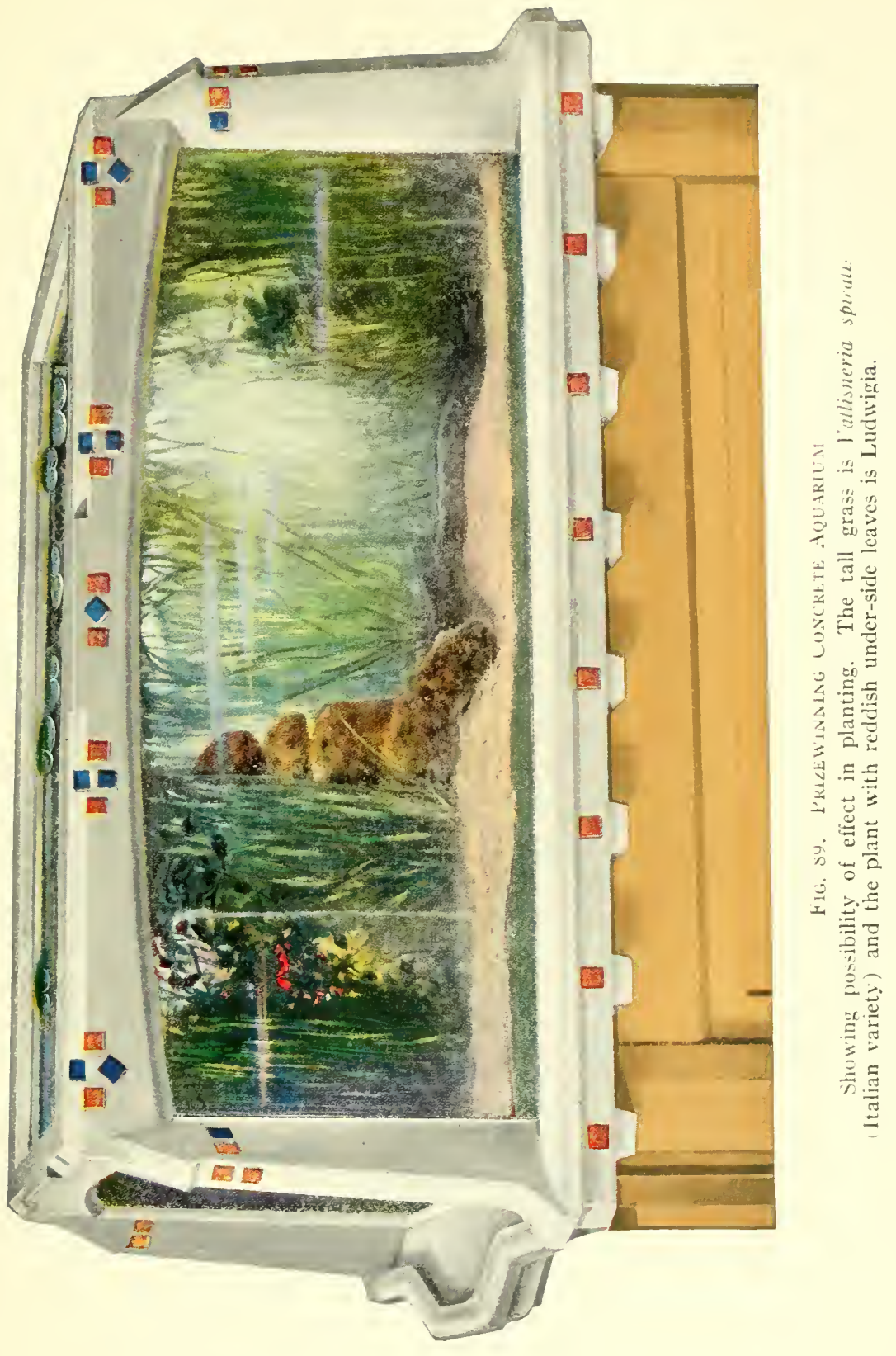




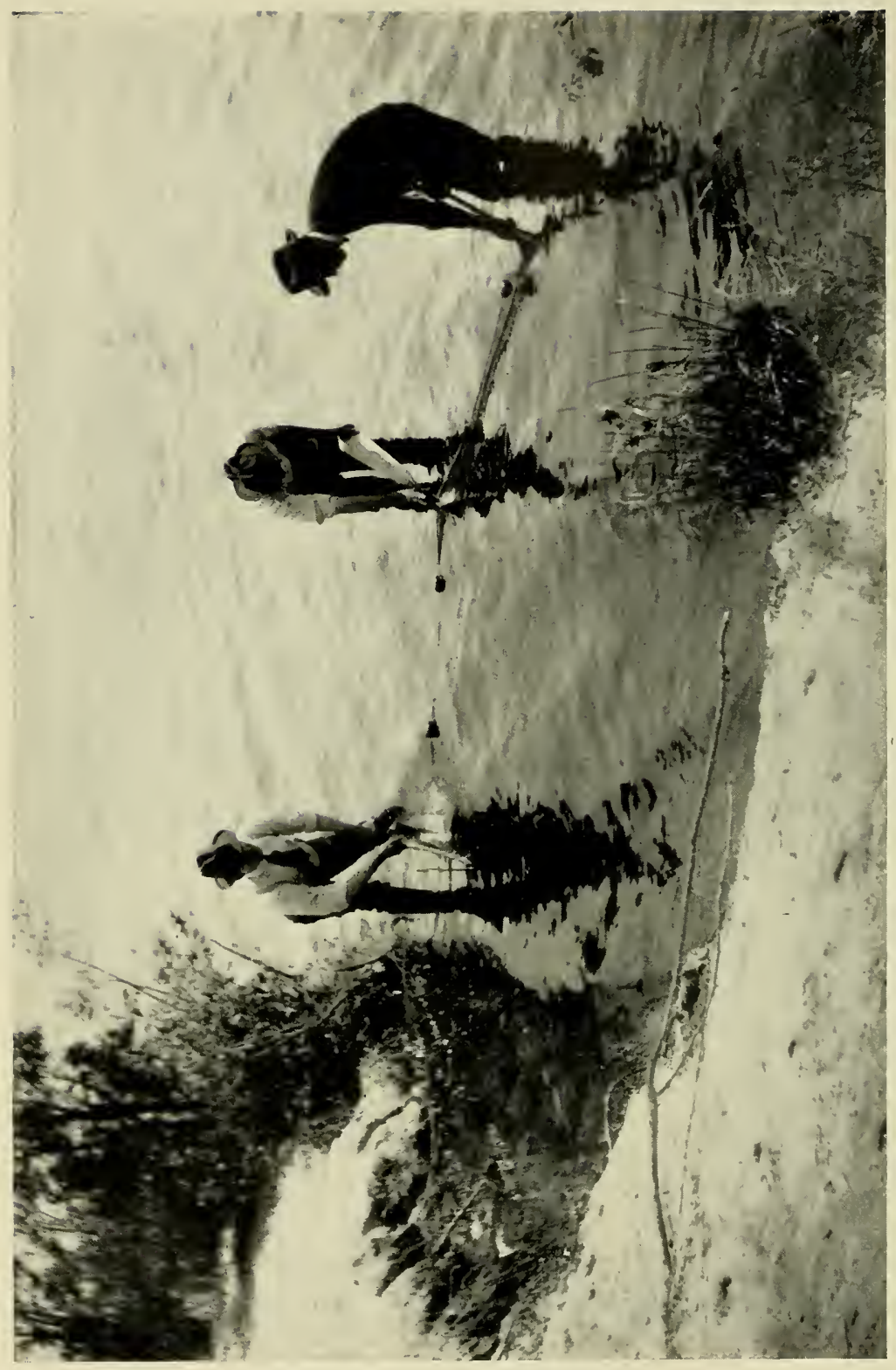

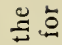

응

घี

․․

胥

है

ชัํํำ

艎

도

요응

魷骂

公

क

骨点语焉

के

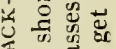

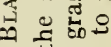

응.

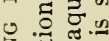

可

ज्ञ

क 응

S.

욜

(1) त्ञ

은.

幺ั้

.

to

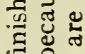

㐘告

施

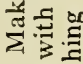

苋苋 
a few handfuls of earth stirred in the water and allowed to stand several hours or days will make the job tight. Occasional stirring of the dirty water helps. Before filling with water the white lead should be allowed two days to harden.

If in a place where freezing will not occur, wooden tanks should be filled all winter. Bad open seams in dry old tanks usually close by wetting for a week.

Weight of Water. With large tanks the weight of the water is sometimes a serious matter to reckon with. A gallon weighs $81 / 3$ pounds. As before stated, the gallon capacity is calculated by multiplying the inch height, breadth and length together and dividing the result by 231 . For instance, a tank 20 inches deep, two feet wide and six feet long would be computed in this way: $20 \times 24=480 \times 72=34,560$, divided by 231 $=$ about 150 gallons, which, multiplied by $81 / 3=1250$ pounds.

\section{CONSTRUCTION OF TANKS AND POOLS}

Three types of pools will be considered, each suited to different conditions and requirements. The first is the simplest, which is merely a hole dug in the ground. It is the kind used by a number of commercial goldfish farms. It is inexpensive and makes possible the rapid expansion of pond capacity as requirements demand. Furthermore goldfishes do extremely well in a soil bottom-probably better than in cement.

If the soil is porous, it will be necessary to have an available supply of water, or else the surfaces must be puddled with clay. The depth should be about three feet, the water being filled to not over two feet to avoid overflow during heavy rainfall. If water rises, it should be drawn off to standard level. Make one corner of the pond lower than the others. Fishes are caught in nets after water has been drawn off so that it is standing only in the low corner. Large establishments use pumps for reducing water level. For winter storage of hardy goldfishes, have the pond water two feet deeper than the prevailing frost line for your part of the country. Soil bottom ponds can, of course, be made any size, but fish farms usually have them about $30 \times 40$ feet and arranged in rows. A large farm will have perhaps a hundred or more such ponds.

Of course water in a goldfish pond with a mud bottom is cloudy, the fish are hard to see and it is a messy job cleaning it out. Where ponds are smaller and economy of construction not so important, one might well adopt the second type shown in figure 91 . This is a slopingside, fairly deep ( 2 or 3 feet) concrete pool with walls about five inches thick. Reinforcing is not always necessary, but nevertheless a layer of heavy chicken or fencing wire within the concrete gives a margin of 
security. No wooden forms are needed unless it is decided to make the ledge for holding earth for bog plants, which, by the way, is an effort that will well repay in added beauty to the pond.

Concrete mixture should be one part cement, two of sand and four of coarse gravel or small broken stone. Finishing coat a half inch thick, one part cement, two of sand. The concrete pouring and later the finishing coat should, if possible, each be carried on as continuous jobs. There is apt to be a weakness at points where the work is halted from one day to the next, especially where reinforcement is not used. Tamp concrete well. A pool of this style if well constructed will resist frost.

In winter fill concrete pools to ground level to counteract freezing pressure from the outside.

The inclusion of a concrete water lily container, as well as the ring of soil around it for other aquatic plants, is optional. If square, it will need board forms. If round, galvanized iron circles not joined at ends, the outside pieces tied around and the inside ones braced across. The lily pot should be 15 to 20 inches wide and about 8 to 10 inches deep. Topping off edges at ground level with a coping of flat, natural stones set in cement is quite a pleasing addition.

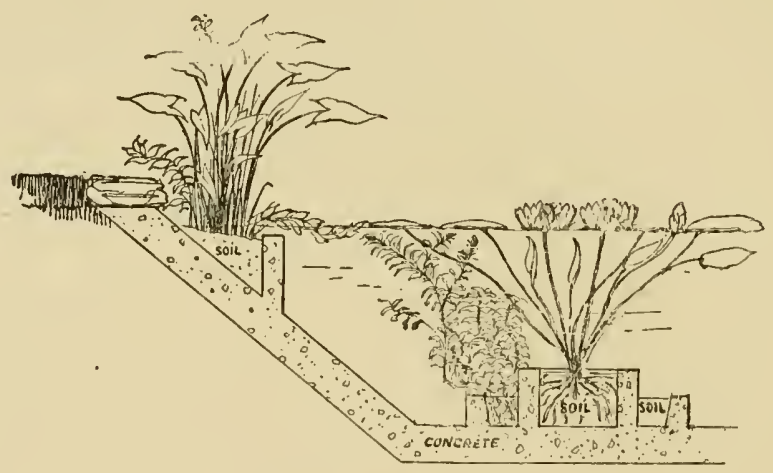

Fig. 91. Simple Foral of Concrete Pool

This requires no wooden forms unless ledge is made. Hardy water lily flowers float at the surface as indicated.

This type of pool is well suited to hardy water lilies. If they are used, the top of soil should be about six inches below the freezing line. Arrowheads and most bog plants in the ledge of soil survive freezing.

Ground-level pools have charming possibilities for artistic planting outside the edges. Their principal disadvantage is that the fishes are open to the attacks of snakes, frogs and rats if these pests are present. 
The third type of pool has concrete vertical sides, and may be used either at ground level or above. Diagram is self-explanatory with the exception of one point. Tropical water lilies should have the crown and

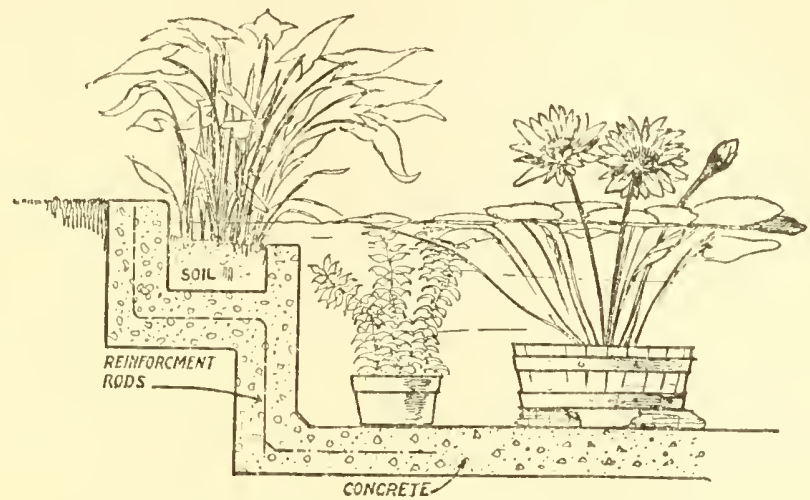

Fig. 92. Strongly Constructed Concrete Pool

Straight sides have some advantages, especially when fishes must be caught in a net. Tender water lilies raise their flowers above the water, which should not be deep.

soil about 8 to 10 inches below the surface of the water. The tub only needs to be raised on stones as shown if necessary to make this adjustment.

Reinforcement is required if anything more than a light frost is possible. Extra reinforcement at all corners is advisable. While giving advice we could well add the suggestion of having the assistance of an experienced concrete worker, or at least a helper with strong arms and back!

The base of this pool should be about 6 inches thick and the walls about 5 inches. A slight outward slope to the walls is desirable.

It is important that concrete work dry slowly. Protect from the sun with litter. Sprinkle if necessary. Forms may be removed in two days. Finishing coat follows immediately.

All concrete pools should have at least six changes of water over a period of two weeks before introducing fishes or plants. This is important.

We have seen many amateur-built concrete pools which were off level. This is indeed a sad defect to discover when the first filling with water nears the top. To avoid this embarrassment, attach a good spiritlevel to the narrow edge of an ordinary straight board long enough to reach diagonally across corners of pool. Test it between two fixed points that will bring the bubble in the center. Turn board around so that reverse ends will rest on the same points again. If bubble again settles 
in the middle, level is true; otherwise it must be adjusted by placing pieces of paper between board and low end of level. Now start from one corner, and level the other three from that. Check carefully before pouring the concrete. Another way is to dig a shallow temporary trench around the space, fill it with water and drive in four stakes to any required height above the water. To level the form with strings drawn over tops of stakes will then be positive and easy.

We recommend against fountains and removable pipe drains. Running water chills the plants and drains are an ever-present source of danger, as well as often being leaky. Have a low point in the bottom and to empty, siphon from there. A screened overflow is necessary, preferably through the side.

Of course it is not necessary to have the bog ledge. If used it ought to be about 8 inches wide and 5 inches deep. If a pool is already constructed a bog can easily be made by placing within it a hollow square of cypress boards on edge coming to within the desired distance of the walls. The top edges of boards may be either below or above water surface, as water seeping through from pond will keep the ground moist, even though raised several inches. This scheme really offers an advantage, in that one may also use moist-situation terrestrial plants, such as certain ferns and fancy-leaved Caladiums. The luxuriant effect in figure 95 is worked out on this principle.

If tiles are used to beautify the concrete, they should be set on mounds of cement immediately after concrete is poured and before finishing coat is applied.

As the author owes his entrance into the delightful fish hobby to his previous entrance into the equal delights of a water garden, may he here make a plea for his first love? Surely there is no other kind of garden so sure of success, or that is so independent of rain, or that requires so little attention, or has so few insect enemies, or that produces its best for so long $a$ period.

It gives a final touch of poetic beauty to any garden, formal or informal. As for water lilies themselves, they seen to exist in a calm, mystical world of their own. Most of them have a perfume suggesting a delicious sense of purity; all have a beauty of which one never tires. If any reader is considering having a lily pool (with fish, of coursel) the author hopes the vote will be in the affirmative, and that it will be as large as possible! 


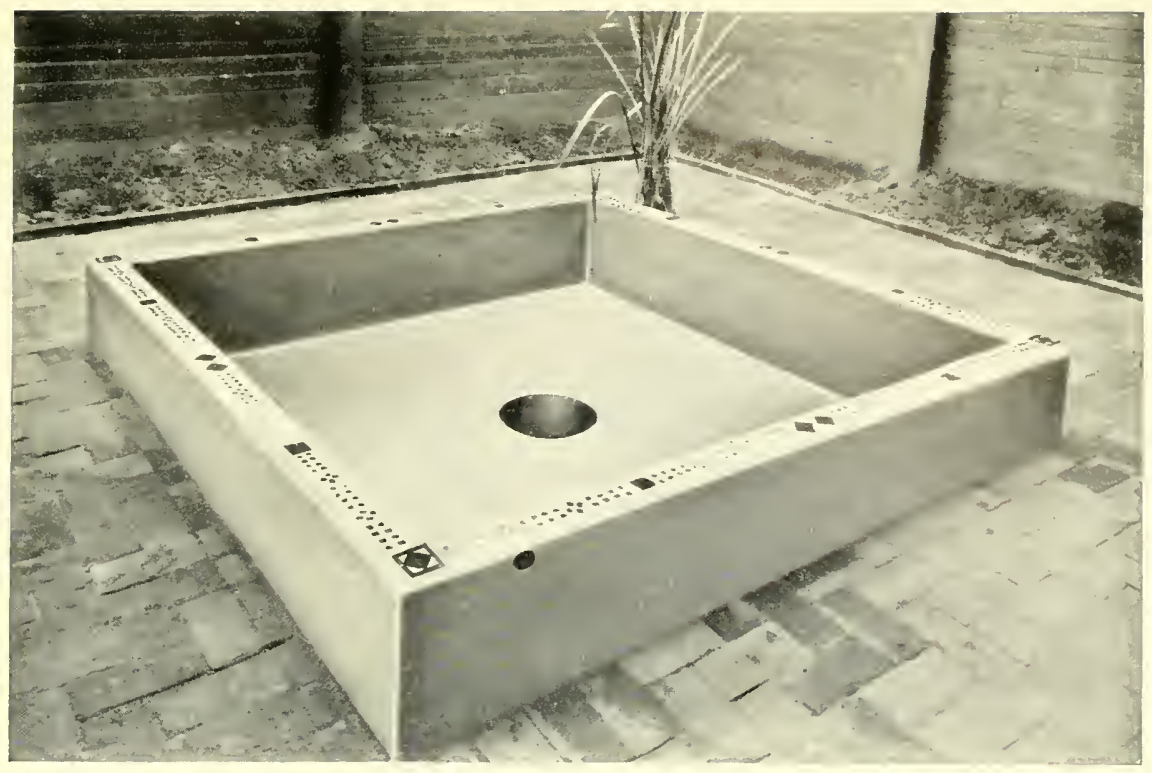

Fig. 93. Straight-Side Raised Pool With Sunkex Pot for Water Lily

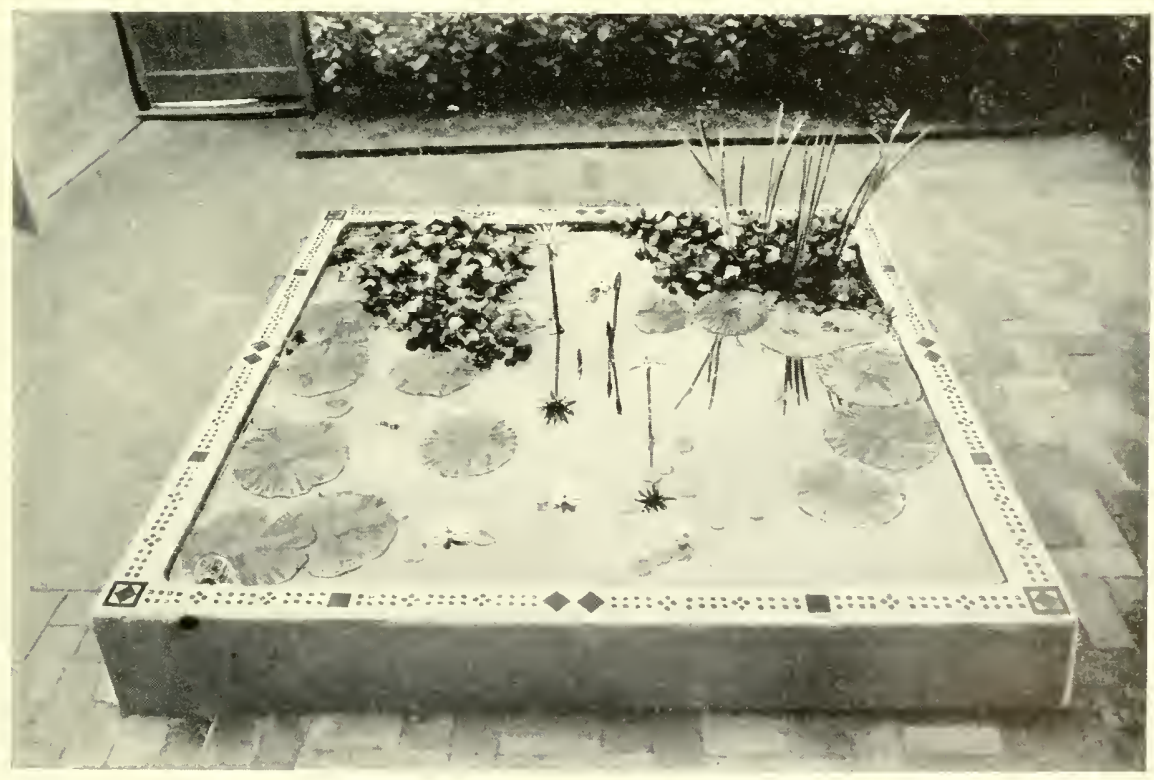

FIG. 94. SAME IN USE 


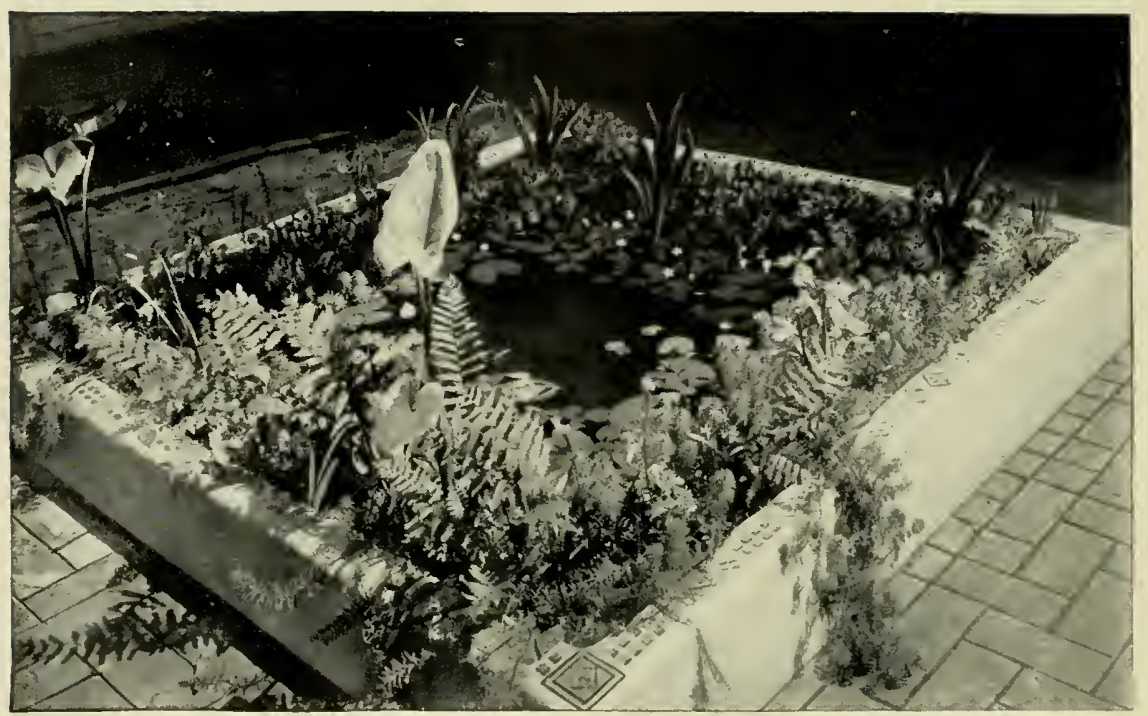

Fig. 95. Concrete Pool and Bog

It will readily be seen that this illustration is the same pool shown on preceding page. It has been greatly improved, however, by the addition of Bog Plants. A hollow square of four cypress boards is laid in the pool, the inside square being 8 inches smaller than concrete edge. It is also 3 inches lower, allowing a forward slope to the soil. Soil is composed of peat, light soil and sand. The plants consist of such Bog Plants as can be selected from the catalogues of seedsmen, or obtained by personal collection, consisting largely of swamp ferns, Calla Lily, Myosotis (Forget-Me-Not): Ludwigia, Moneywort, Wild Iris (Common Blue Flag), Pitcher Plant, Sundew and Parrot's Feather (plant hanging over outside wall of pool). The small white flowers on the water are Water Snowflakes. Altogether this is a most delightful improvement and can be recommenderl as an interesting experiment to make.

This produces the same visual effect as the more substantial constructions shown in Figs. 91 and 92 . 


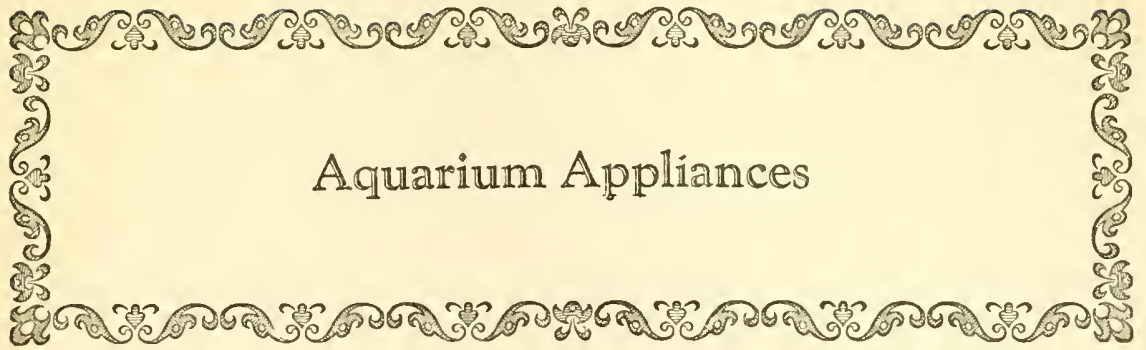

Nets. The most important tool in aquarium work is a net with which to catch the fish, yet in most instances it is of faulty construction. The scales of a fish are easily knocked off by the hard knots in the coarse threads composing nets usually sold. This is very bad for the fish. A far better material is Brussels netting, such as is used on window curtains.

When fishes have to be caught from a globe, a round net is convenient, but for a straight-side aquarium, a square or oblong net is very much better. Usually these cannot be purchased, but to make one is a

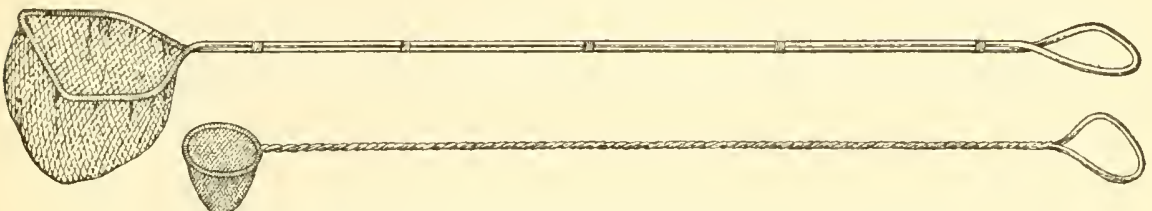

Fig. 96. Proper Nets for Goldfishes and Young Tropicals

simple matter and well repays for the effort. Perhaps the easiest way is to purchase a round net, remove netting, bend wires to an oblong form and re-cover with Brussels netting. The larger kind shown is bent from a single piece of $1 / 8$-inch galvanized wire, the ends beveled and soldered together at the handle. The two strands of wire are tied together at intervals by fine copper wire, secured by a little solder. A net about 5 inches wide with a handle about 16 inches long is generally satisfactory.

Nets 9 or more inches square are almost indispensable for catching small, active tropicals in large aquaria. Stout aluminum frames with short handles are on the market. They are excellent. Net should be somewhat shallow.

Dip Tube. Sometimes particles of food remain too long after feeding. Also dirt collects in spots. Such places can easily be cleaned by use of a dip tube. Any tube of from one-quarter to three-eighths inch inside diameter and about six inches longer than the depth of the aquarium will do. Glass is preferable. Hold the thumb firmly over one end, place other end near particles to be lifted. Remove thumb, allowing water 
and particles to rush into tube. Replace thumb, lift out and empty. The capacity of the tube can be considerably increased by heating the centre over a Bunsen flame and blowing a sort of bulb. A blown dip tube, with a specially designed section enlarged to about the size of a duck's egg, may be purchased from stock.

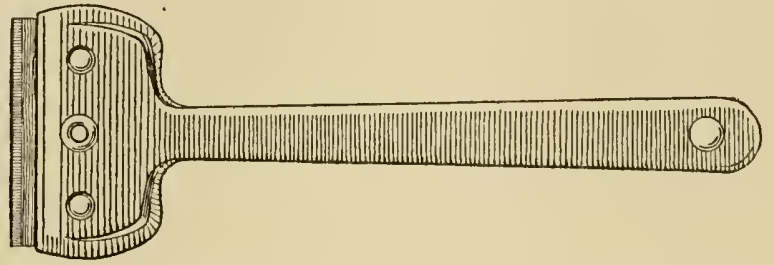

Fig. 97. Safety Razor Blade Aquarium Glass Cleaner

Glass Cleaners. One of the best devices for cleaning the inside glass of straight aquaria is a safety razor blade secured in a holder which can be obtained in hardware stores for a few cents. A blade may be used directly in the hand, but in that case it is better to dull one edge first in order to avoid cutting the fingers.

A chore ball of woven copper, such as used in kitchens is most excellent for cleaning either straight or curved sides of an aquarium.

A dime rubbed flat against the glass will clean it.

Siphon. When much dirt needs to be removed or the aquarium emptied, a siphon should be used. This consists simply of a hose sufficiently long to reach from the bottom of the aquarium, up over the edge and down again to a point near the floor. The longer the drop, the more rapid the flow. Fill tube with water, close both ends by finger pressure, insert one end in the aquarium and hold the other as low as possible. Simultaneously release the ends of tube and the water will flow as long as there is water in the aquarium at a higher point than the discharging end of tube. Care should be taken not to draw in fish or snails.

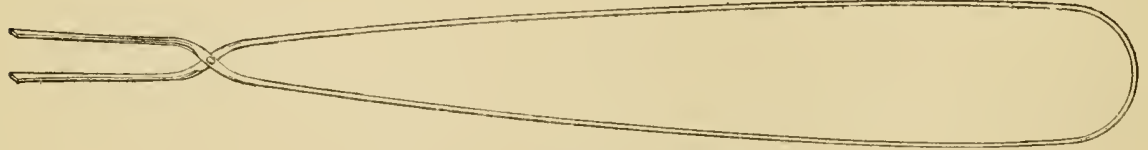

FIG. 98. AQUARTum Forceps

Forceps. A pair of wire forceps for aquarium work is very handy. Their construction is simple. Take a piece of $1 / 8$-inch brass wire thirty inches long and bend to shape shown in the figure. Where the wire crosses, hammer out a small flat space through which a rivet can be fastened. A small section of brass wire or a copper tack can be used as a rivet. 
When the forceps are otherwise completed, flatten out the ends by hammering on an iron vise or other firm surface. The jaws of the forceps automatically remain open. Pressure on the loop closes them. They will be found useful in adjusting plants, lifting out snails, stones or other small objects.

f

Fig. 99. Planting Stick

Planting Sticks. To secure the roots of plants in sand would seem a very simple matter, but when the aquarium is filled it is most difficult to set them without the help of one or two planting sticks. These are as simple as they are useful, being merely thin sticks with a dull notch in the end. About three-eighths of an inch is a suitable size diameter for the sticks. The notch should be slightly rounded on the edges to avoid cutting the roots as they are forced into the sand. Two sticks are better than one. Plants like Giant Sagittaria should be pressed down from two sides. After the plant is placed to the proper depth, it should be held with one stick while the other is used to push sand over the roots and to press down straggling roots which have not been covered. Aquaria should not be planted while filled, but sometimes a few plants ride loose on the first filling, or some are added later. For such occasions planting sticks are needed. A pair of rulers will do in an emergency. Make sticls about 6 inches longer than the depth of aquarium water.

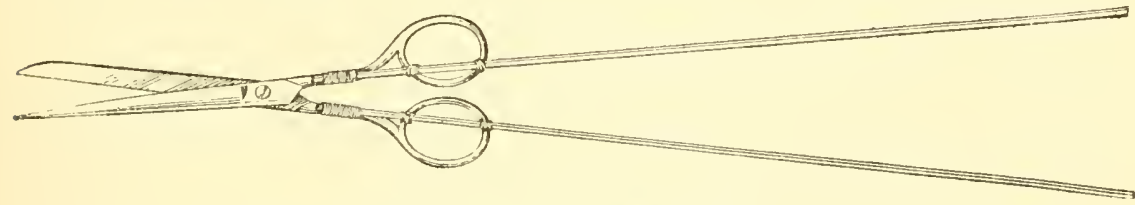

Fig. 100. Aquarium Scissors

Scissors. A pair of scissors with a 15-inch rod securely wrapped to each handle is used for trimming dead leaves from plants. With this tool plants can be reached without disturbing anything, and one can get a better view of what is to be done than when working elbow-deep in the water.

Live-bearing Traps. With most varieties of viviparous (live-bearing) fishes it is desirable to promptly separate the mother and other fish from the young in order that they will not be eaten. One simple method is to take a glass funnel about six inches across the top, file a nick where funnel joins stem, break off tube and place a small piece of U-shaped wire in the opening, so that the wire divides the hole in half. The funnel is then placed in a cylindrical jar or other aquarium of a size that will suspend it by the edge; bring the water as high as possible in funnel, 


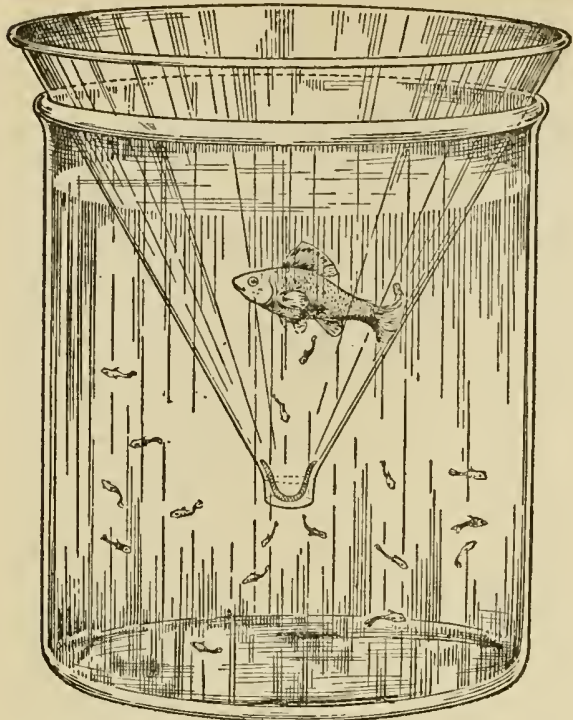

FIG. 101

FunNel Trap for Live-bearing Fishes Obstruction in neck of funnel is a piece of bent wire, and is open on either side.

place female fish in funnel and cover over with screen, so she cannot leap out. The small wire previously mentioned will prevent the mother fish from becoming jammed in the outlet, but will allow the young to pass through and collect in the lower portion of jar.

Another very simple and effective arrangement is shown in Figure 102 being merely two pieces of glass laid in an aquarium at a sloping angle and set into two blocks so cut as to leave a slight space between the glasses at the bottom of the $V$. This opening should be just large enough for the young fish to pass through. The plan has the advantage of giving the female plenty of space. In fact several females could be kept in such a "maternity ward" at one time. Unless feeding on daphnia, a small butter dish or similar object should be placed across the bottom of glasses to catch the falling food until the fish can eat it. Also a number of snails in the lower part of the aquarium or jar will be needed to consume

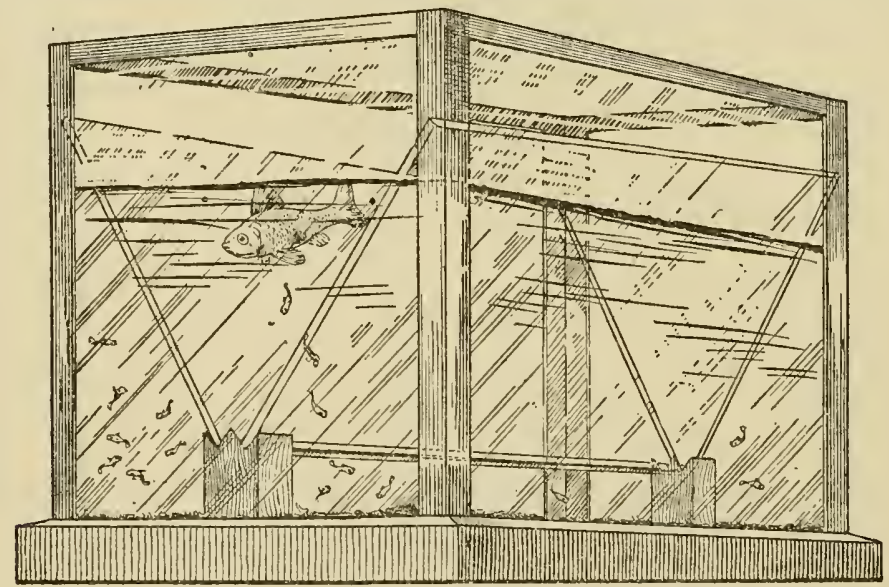

Fig. 102. Aquartum Trap for Baby Fishes

the food that falls through the opening. Snails must breathe air, so keep water level a little below top edges of the sloping panes. An important 
point is to rub off the sharp edges of the glass, as the fish, if alarmed, may injure herself trying to get through the small separation.

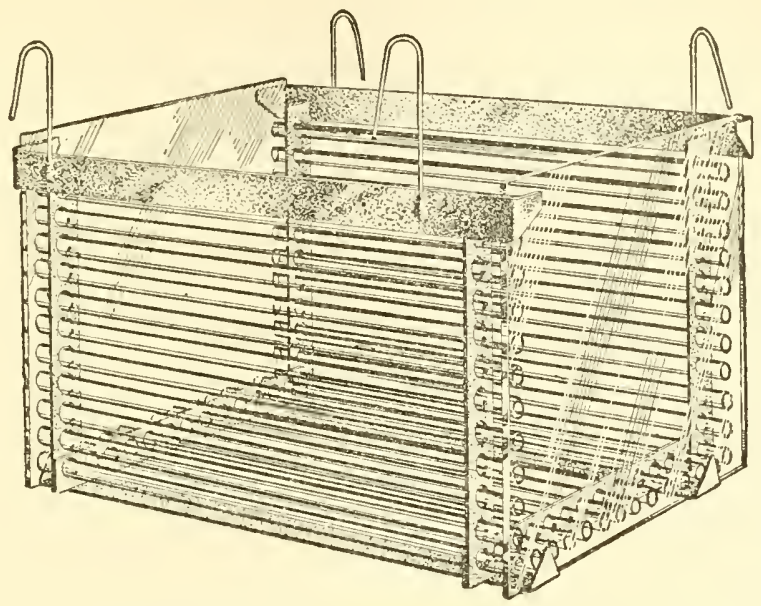

Fig. 103. Glass-Bar Breeding Cage

The cage trap shown in above figure has several important advantages, one of them being that it is a commercial product, and may be obtained, at a very moderate price, from a number of dealers, delivery by mail being quite safe. The sides and bottom are composed of glass tubes spaced slightly apart and inserted in holes through a metal frame, the ends being of plain glass secured against ends of tubes by bending terminals of frame. The cage is $51 / 2$ inches long, 4 inches wide and $31 / 2$ inches deep. It may either be suspended by the wire hooks from sticks across the aquarium or hooked on the edge. Free water circulation takes place and the young may escape through bottom or sides.

At the present price it would not pay to make this device, but should it later be unobtainable commercially (such things do happen) our readers will have little trouble making it. Brass is the easiest metal to work, and should be nickel plated when finished. The glass bars or tubes ought to be of about $3 / 16$ inch diameter and set apart the thickness of a half dollar. The two connecting strips at the bottom (turned up at the ends), continue the entire length, and are secured by soldering, the same as the upper strips.

A number of years prior to the invention of this cage our friend L.M.D. developed the very good idea of a mat of glass bars, secured by number 18 gauge fuse or aluminum wire, as shown in figure 104, the wire thus spacing the bars perfectly apart. This is made to just fit the inside 


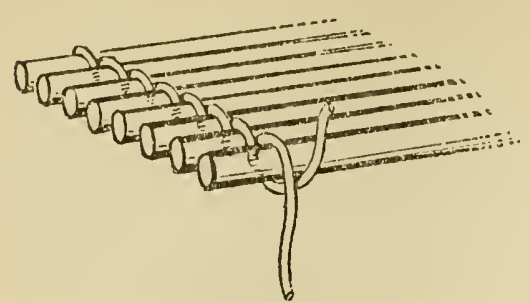

Fig. 104. Method of Constructing Mat of Glass Bars

of aquarium and is raised any desired distance from the bottom by two strips of glass standing on edge. Glass bars or tubes are easily broken to exact length by first rubbing a nick with the edge of a fine file.

The original purpose was for the spawning of fishes having non-adhesive eggs (Danios principally), but the idea is applicable to the live-bearing species also.

Spawning Net. In the spawning season aquarium space is often limited, particularly among amateur breeders who have perhaps a single aquarium. The breeding fish should be separated from the others, as the idle fish would eat the spawn. An easy way over this difficulty is the

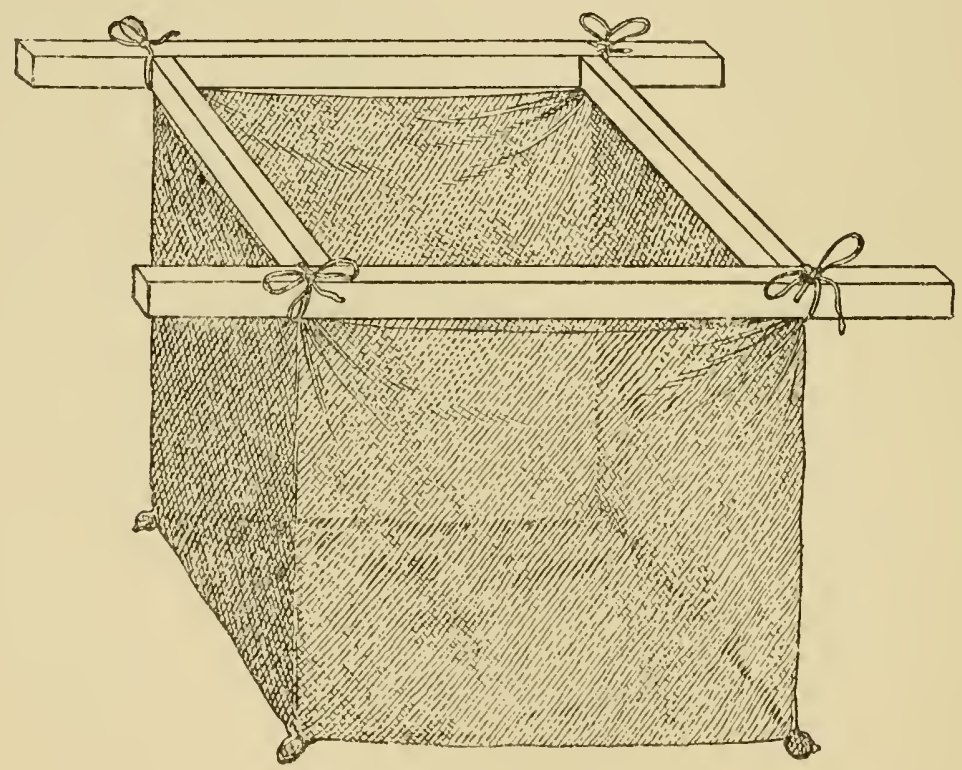

Fig. 105. Spawning Net

use of the spawning net. This is simply an oblong bag of cheesecloth suspended in the aquarium. The illustration will show how this may be done. The four corners should be weighted down with bits of lead or stone sewed in. The plants and spawning fish are simply transferred into the net. Confined in this comparatively small space, the chances of the eggs becoming fertilized are increased, while the netting is sufficiently 
open to allow the aquarium water to flow slowly through it and prevent suffocation. In this way the large amount of dirt usually stirred up in an aquarium at spawning time, and which can do the adhesive eggs no good, is entirely avoided. The size of the net will depend somewhat on the proportions of the aquarium, but the capacity of net (portion in water) should be about twelve to eighteen inches long, ten inches wide, and ten inches deep. In constructing, allow extra material for space between top frame and surface of water.

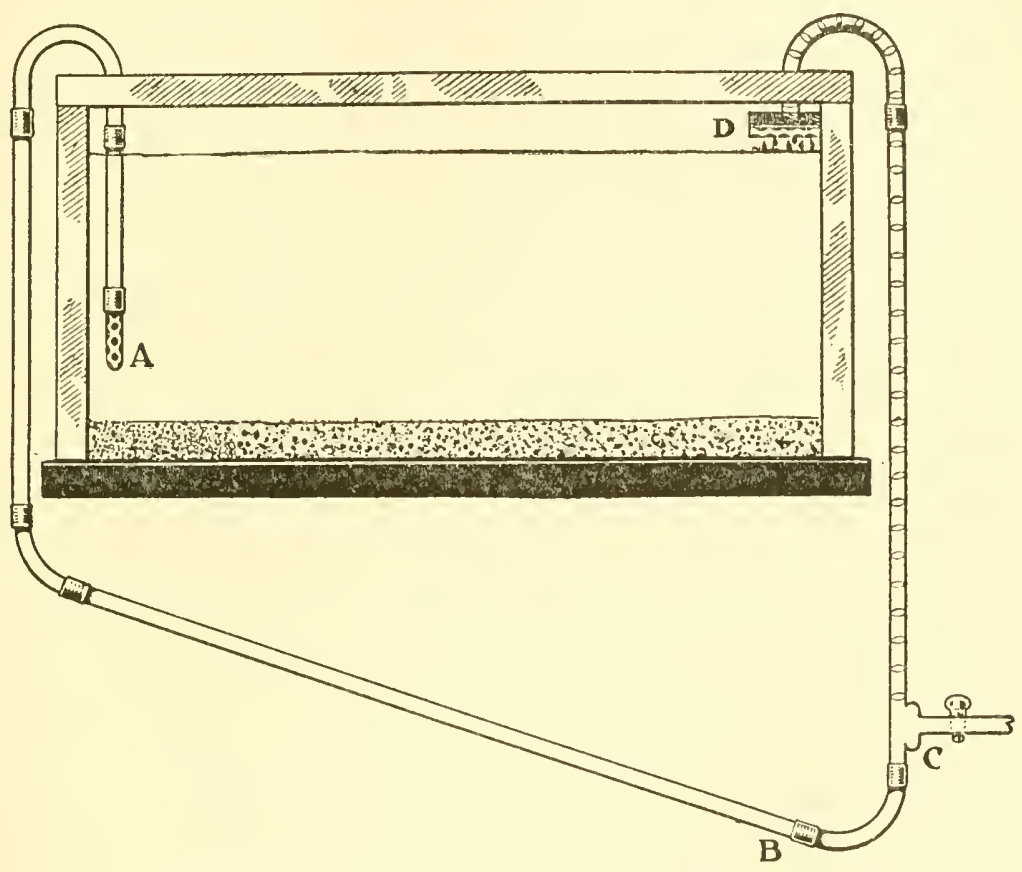

Fig. 106. Water Circulation by Air Pressure

Constant Aquarium Filter. This device is for use in connection with electric or water-power air pump. It is capable of a number of variations, once the principle is understood. There are two columns of water in the tubes, one solid and one punctuated by air bubbles, thereby making it the lighter. This causes it to rise and therefore establish circulation as long as air is supplied. A $3 / 8$-inch diameter glass surgical drain is shown at A. This should contain about eight small openings and be suspended two inches above the sand. This is connected by a short piece of rubber tubing to the rest of the system, which is of glass tubing from 5-16- to $3 / 8$-inch inside diameter. The dark sections represent rubber joints, making the system more flexible, less liable to breakage. 
less expensive in case of repair and makes cleaning of each section easy. (The tubes require an annual cleaning.) Air is injected under pressure at $\mathrm{C}$, which should be five inches above lowest point of pipes. This starts the flow, which is discharged into D, a small filter suspended in the corner of the aquarium, and just above water level. It may be made of glass, aluminum, porcelain or earthenware, and should approximate in size five inches in diameter by two deep, the bottom having a few perforations. The best filtering medium in this work is absorbent cotton, which should be laid on a few pebbles, glass bars or bits of charcoal for good drainage. The force of air and the distance between $\mathrm{C}$ and the surface of water determines the speed at which the water travels. The lower the point at which air is injected, the greater the speed. To start the system, disconnect at $B$, suck with the lips to start siphon, re-connect while water is running. After water in rise-tube has reached aquarium level, turn on air-cock at $\mathrm{C}$. This cock should always be closed when air is not wanted and pump not working, in order to prevent water backing up into air supply pipe. All rubber joints should be tightly secured by wrapping with thread or narrow strips of adhesive tape. Rubber cement spread on connecting surfaces helps make a good job.

This arrangement both filters and aerates the water. If filtering is not needed, the filter can be removed and aeration will go on.

Water can be raised by this method from fifteen to twenty-five inches above level. To secure the greater height, use $1 / 4$-inch inside diameter tube, take plenty of drop and allow eight inches from lowest point to C. By this means and a little ingenuity a return fountain can be made. To secure a uniform flow it would require a small tank to receive the discharge from the pipe, and from this an overflow to aquarium in case the water supply comes too rapidly for discharge rate of fountain.

It is not necessary to carry pipes over edge of aquarium as shown in diagram; they may be carried through the bottom, carrying dirty water directly down. The rise tube should be brought up through inside, over edge of filter. Short pieces of tubing long enough to reach above the sand and to extend an inch below the aquarium base should be used for passing through the slate. A very effective means of securing these in permanent positions in the base is to melt by alcohol blow-torch some chips of gum shellac which have been piled up around the tube. This melting is done in the aquarium directly around the tube and is continued until a small mound is formed. A piece of wet cardboard will protect nearby glass from the heat. Gum shellac has perfect resistance to water. It will adhere to almost anything and is of special value in connecting glass to metal. When cool it is quite hard. 
Fish-Carrying Case. A box similar to illustration, built to hold the standard straight-side candy jar is a great convenience in carrying fishes for short distances. It may safely be used for tropicals in moderately cold weather if the jar is completely wrapped in several thicknesses of news-

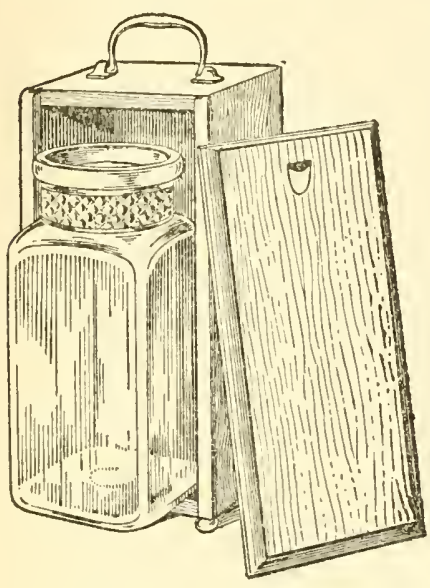

Fig. 107. Carrying Case paper before placing in box, provided the exposure is not unreasonably long. Many of these cases are in use. The height is 14 inches.

Feeding Rings. Many aquarists prefer training their fishes to look for food at a certain place in the aquarium. One way of doing this is by use of a feeding ring, in which floating food is placed. It has the advantage of confining the food to one spot, and that when it sinks it can be over a cleared space where it will easily be found Telescopic-eyed goldfishes are nearsighted, and a feeding ring helps them locate the food. It must in truth be said that such fishes find their food largely by the sense of smell, and that they will, in nearly all cases, eventually locate it, but they come to it with more certainty, having learned the use of the ring.

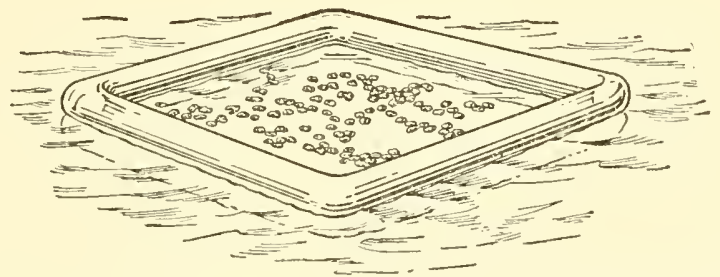

Fig. 108. Glass Feeding Ring, with Food Floating In It

The illustrated subject is three inches in diameter, and is made of bent glass tubing. Sold by the dealers in aquarium specialties. They may be made from a piece of cork, with a large hole cut in the centre. After the cork becomes partially water-logged one can sow grass seeds on it. When the grass has become about an inch high the cork is turned upside down so the fish can enjoy themselves nibbling it off. 


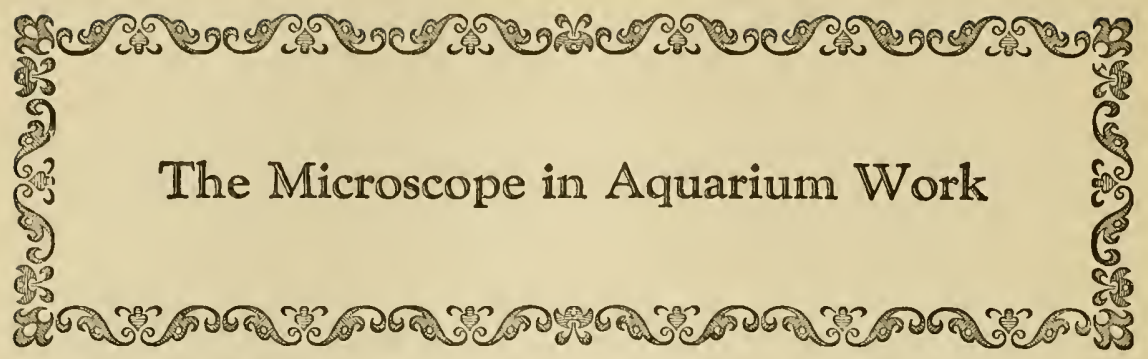

Aquarium work in general and fish breeding in particular can be made both more interesting and more successful by the use of a microscope. For most purposes a very cheap instrument is satisfactory. In fact, a low power lens is preferable to a high in examining water for microscopic fish food.

All aquaria contain various beautiful and highly interesting forms of microscopic life, some harmful, some negative, but mostly beneficial to fishes. The constant changing of varieties and quantities presents a vast field for new study, but we are here mostly concerned with the practical points of raising young fishes. On page 78 we refer to the use of infusoria as food. To determine the presence of this food, touch the tip of the finger lightly to the surface of the water, preferably to the side nearest the source of light. This is because they are mostly at the surface and they seek, the light. Place this drop on a glass slide and observe under a good magnifying glass or a low-power microscope. The latter is rather preferable, as the focus can be changed as required, and it is fitted with a mirror to facilitate observation. In the absence of a microscope the small pocket folding lens known as a "thread counter" will do. In using this the frame of the counter should be laid directly on the glass contain. ing the drop of water, and the whole placed over a mirror held at the proper angle to reflect light upwards, but too strong a light should not be used. A little experimenting will soon show the best light to work by.

The creatures which are of value as food to newly hatched fishes are generally of a size just too small to be detected by the naked eye, or at most they look like specks of dust. At the same time they are plainly observable under a good magnifying glass or low-power microscope. There is a great deal of life in the water of a smaller size than will be shown in this way and which probably has no food value to fishes. The highpower microscope would show many of these organisms and thus be apt to deceive the inexperienced observer as to the actual food value contained 
in the water. Also with high magnification the field of vision and the area of sharp focus are smaller, while movements are apparently much more rapid, making observation difficult.

The majority of the valuable organisms are rotifers. These move in a steady, revolving or rotating manner. On page 206 will be found instructions for propagating these organisms for purposes of feeding young fish. Most rotifers can be readily identified as such because they swim through the water by means of circlets of hairs or cilia arising from the front of their heads, by the vibratile action of which they swim and
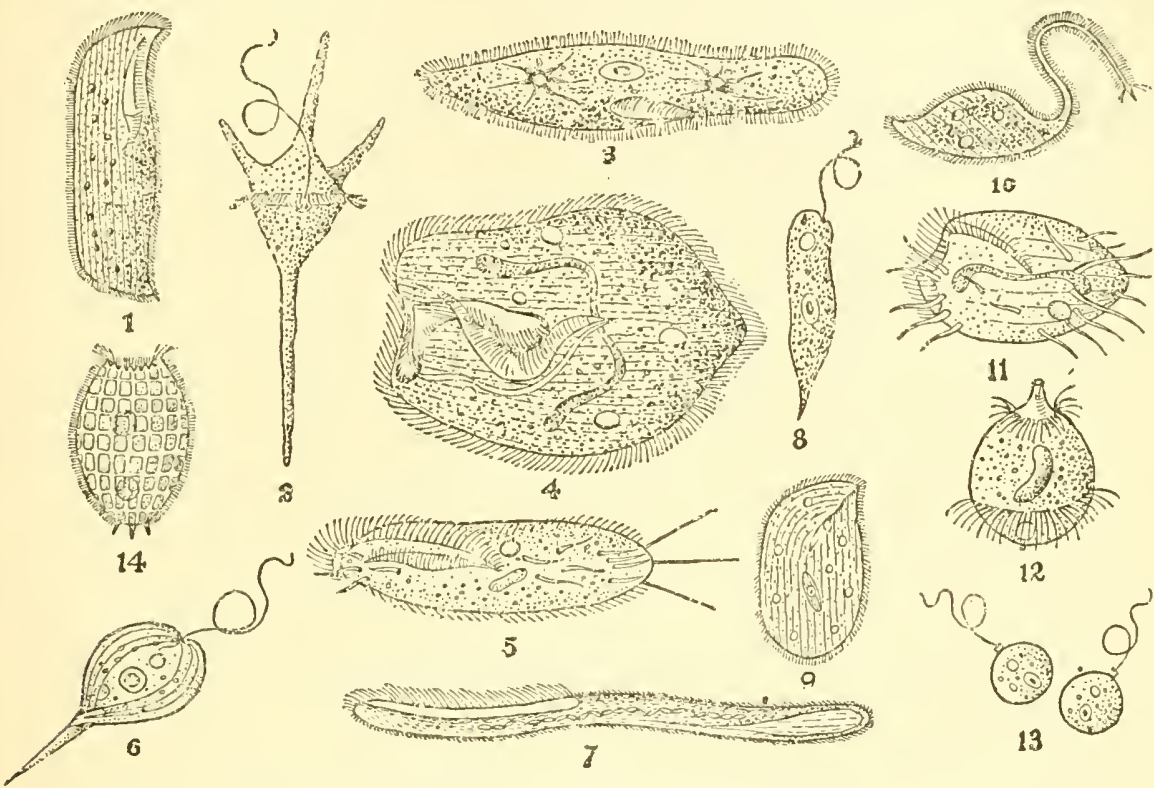

Fig. 109. Common Forms of Microscopic Antmal Life in Fresh Water (Greatly magnified)

1. Loxodes, a very common form

2. Ceratium, a very common form, especially in ponds and lakes

3. Paramaecium, a very common form, the slipper animalcule

4. Bursaria, a very common form, one of the largest

5. Stylonycha, a very common form, found everywhere

6. Phacus, not so common as the above numbers

7. Spirostomum, common everywhere

8. Euglena, common everywhere

9. Chilodon, common everywhere

10. Trachelocerca, common everywhere, the swan animalcule

11. Eupolotes, not an aquarium in America without examples

12. Dadinium, predaceous, feeds on paramaecium and others

13. Trachelocerca, small but plentiful

14. Coleps, the barrel animalcule, common 
disport themselves through the water. In fact, rotifers derive their name from the wheel-like appearance produced by the motion of the circlets of cilia while feeding and swimming. For culture water to have practical food value a single drop should contain at least half a dozen living animals that can be seen in the manner suggested. Water rich in life will show rotifers so thickly that they almost touch one another-probably two hundred in a small drop. In taking water from the culture tank to feed the fish it should be skimmed from the surface or the animals extracted from the water by a plankton net, which is nothing more than a small net of the finest bolting cloth.

Besides the examination of water for living food there are many other interesting possibilities for the microscope in aquarium work. Diseases, the development of eggs, plant structure, algæ, the structure of daphnia, cyclops and other crustacean foods are a few of the subjects which may be taken up with profitable interest.

A study of the microscopic world within the aquarium will prove a most fascinating pursuit. An instrument equipped with a 16 m.m. (2-3 inch) objective and a high- and a low-power eyepiece will show everything needed, giving satisfactory magnification.

Those wishing to explore this field further will find the following works to be helpful: "Aquatic Microscopy for Beginners," by Stokes; "Marvels of Pond Life," by Slack; "Evenings at the Microscope," by Gosse. 


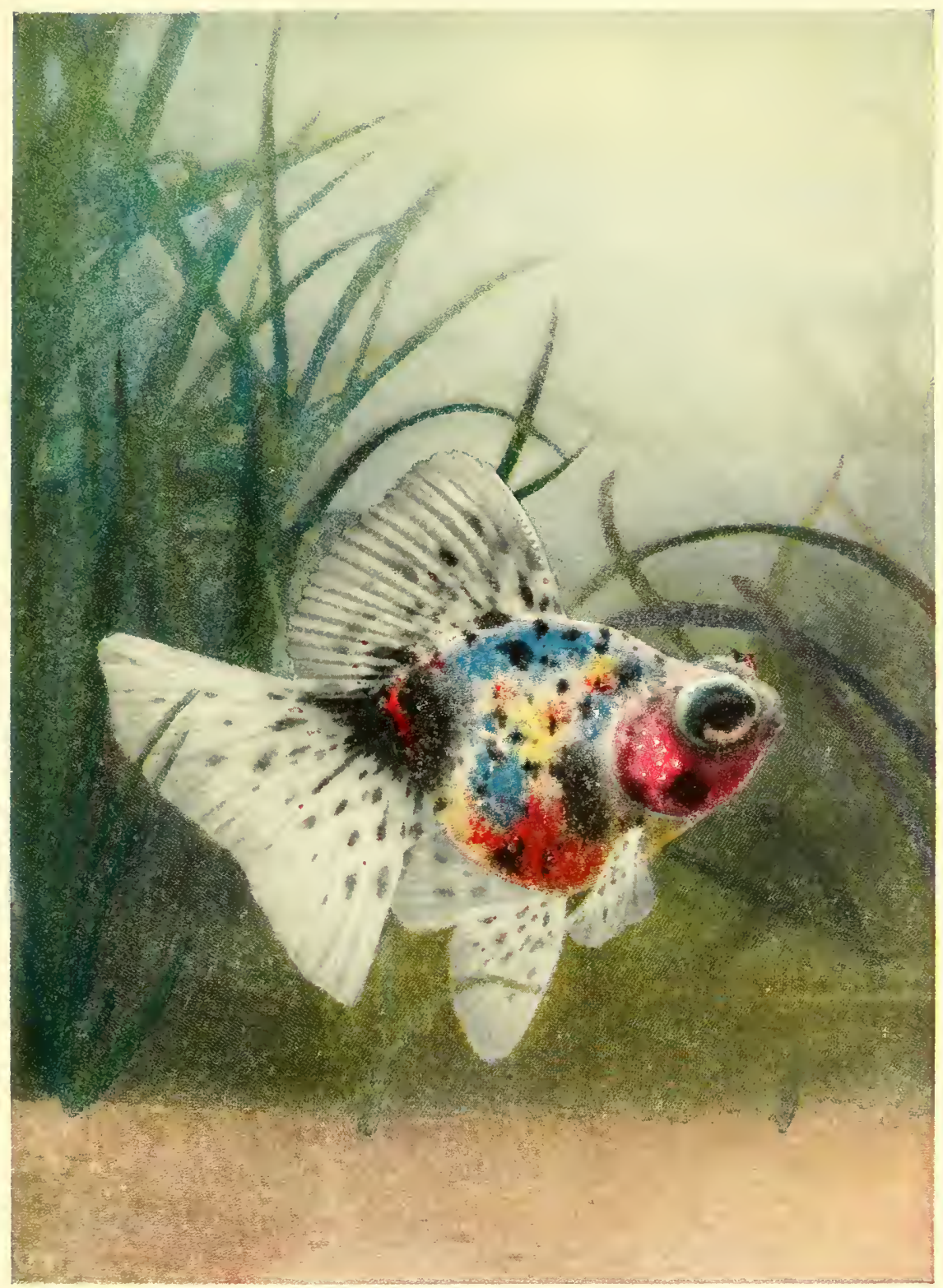

Fig. 110. A Champion Young Calico Telescope Goldfish (From life) 


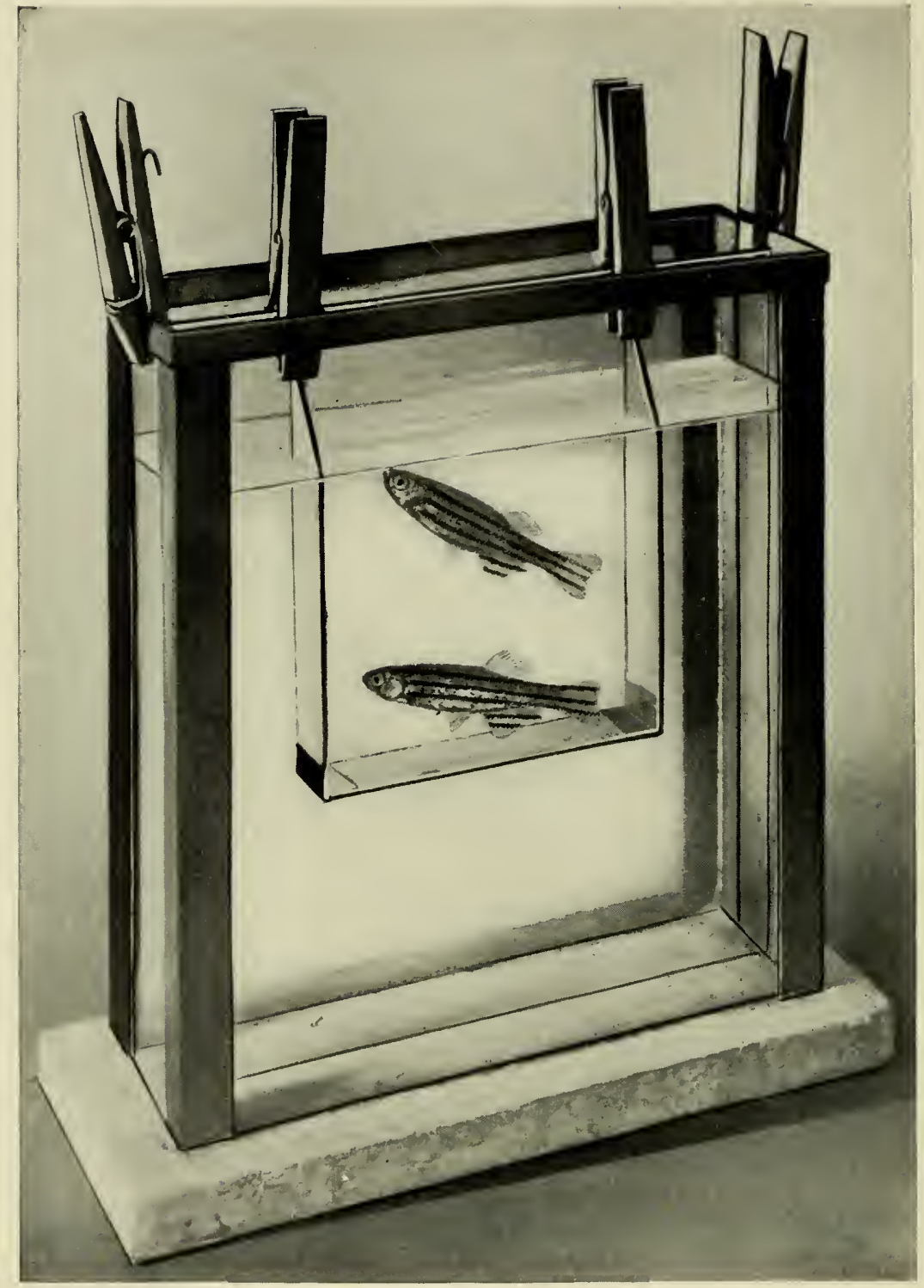

Fig. 111. Photographing AQuarium

The outside clips hold the dividing partition forward. On this partition the inside clips hold the smaller glass form, selected according to size of fish to be photographed. To remove fish, allow partition to fall back. When fish swim out, remove entire partition and lift fish with a small net. 
CHAPTER NINE

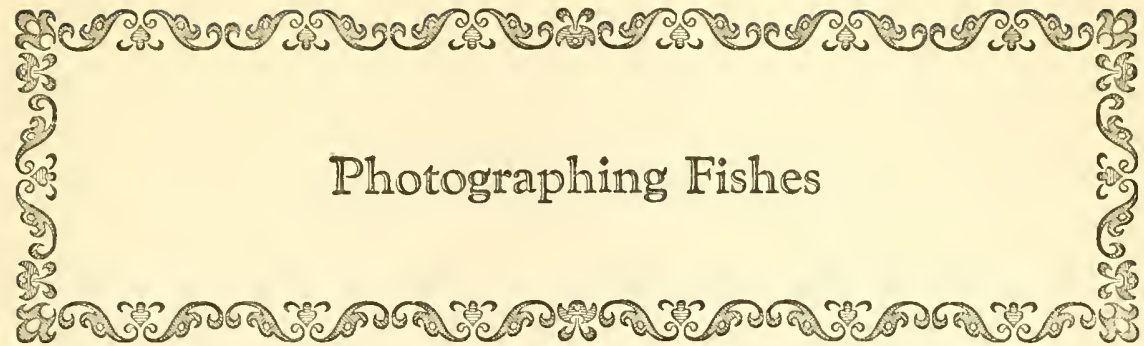

It is obvious how important, as well as interesting, photographic records of fishes can be. In writing on the subject in the hope of having others enter this field of work, the author presupposes a fair photographic technique to start with. The main requirements are a small aquarium with a front of thin plate glass and an adjustment for keeping the subject in focus, a few card backgrounds of different shades, a sliding board on which to focus the camera by moving the whole instrument (preferably, but not necessarily, of back-focus design), and a lens working at about F5 to F6. The author does his own work on a board, the ends of which are laid on the seats of two chairs, fastening a piece of cardboard to the back of one of the chairs to act as a background. The aquarium, with a front seven inches square and a thickness of two and one-half inches, is usually stood about a foot from the background, to keep it out of focus and to avoid shadows from the edges of the aquarium. The fishes are kept in the focal plane by use of an adjustable glass partition. For holding small fishes in place the following simple arrangement is used: three pieces of glass are cut about twice the width of the thickness of the fish, and of a length from three to five inches, according to requirements of length of fish. The ends are fastened together with adhesive tape like three sides of a square. The free ends are given a cut to end them off at about forty-five degrees or less. These free ends are fastened to top edge of partition by clips, first filing a nick in the beveled surface for the clip to catch in. The glass partition with this three-sided cage attached (open at top) is then pushed up against the front glass and the apparatus is ready to receive the fish. This not only confines the fish strictly in the focal space, but keeps it out of the corners of the aquarium, where it would delight in exhausting the patience of the photographer. It is a good plan to have a number of these little cages made up to different sizes to suit the measurement of the fish to be photographed.

Photographing to about two-thirds size is usually satisfactory. Larger than this cuts down speed and focal depth too much. Water 
absorbs much of the light, so that only bright days should be used. The angle of the sun at noon is a little too much overhead to strike fully on the side of the fish, although this can be remedied and the speed much increased by the use of a reflecting mirror in addition to the direct sun. This sometimes makes a beautiful effect on a silvery fish. Our photographs of Pterophyllum scalare, Trichogaster trichopterus and the Banded Sunfish were done in this way.

When a black background is wanted, procure the darkest medium obtainable and construct a shade above it, so as to cast a shadow on the background itself. Nothing seems to be sufficiently black if the sun strikes directly on it. The water should be as free from particles as possible, particularly when using a dark background.

It is desirable to cover the camera with black velvet to prevent reflections in the aquarium.

Some operators use flashlights, but to the writer nothing seems as good as direct sun, preferably from April to September, although it was outdoors in February, with the sun glaring on recently fallen snow, that the author made his best photograph of a goldfish-the frontispiece of the present edition.

In photographing down through the top of an aquarium it is necessary to suspend a glass at the surface, so that the bottom of it is wet and the top dry. This obviates blurring caused by refraction due to ripples. Where clear waters prevail in nature there is no doubt that fine photographs of the natural bottoms of the shallower bodies of water can be made through a glass-bottom aquarium, slightly submerged in the water.

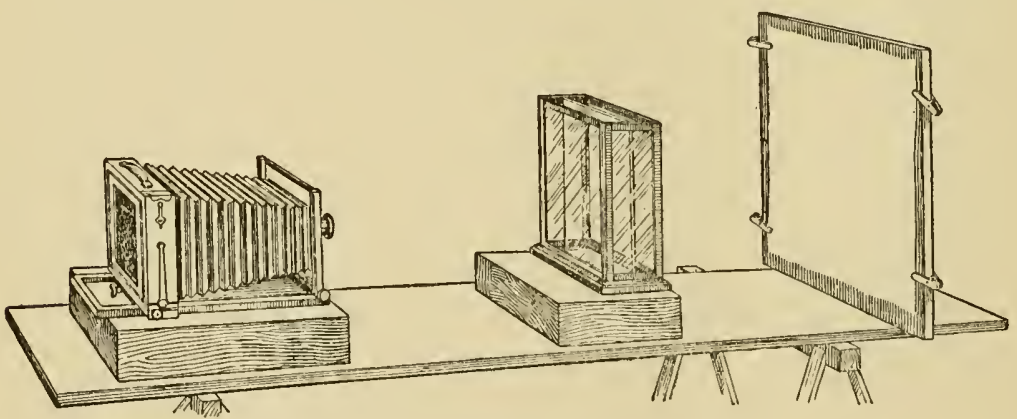

Fig. 112. Photographing Arrangement

The distance between aquarium and background should be sufficient to prevent a shadow falling on background. The aquarium is raised so that the board below will be out of the picture. 


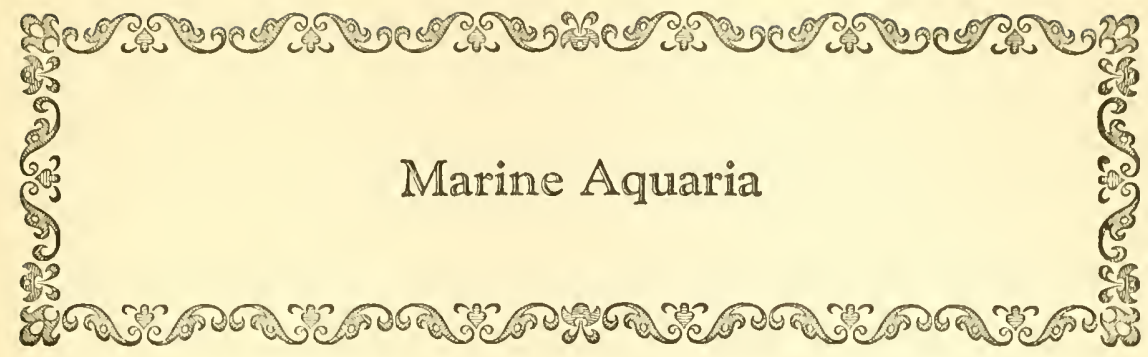

The maintenance of a marine aquarium is really much simpler than is generally supposed. If aquariun lovers realized the great charm and the unlinited possibilities of a marine tank, there can be no doubt many more would interest themselves in this particular form of the hobby. It is safe to say that not a score of persons in America at this time have saltwater aquaria, although when once established they are as easily kept as the freshwater kinds. Then, too, there is the fascination of collecting from a field of inexhaustible variety, giving the student always something new to work on, with the ever-present possibility of discovering some fact of value to science or to his fellow aquarist. To those living within easy journey to the shore is the added attraction of the trip to the seaside, the pleasures of which are doubled by the pursuit of such a delightful and absorbing study.

Aeration. There are just a few points of radical difference between the fresh and saltwater aquaria. We have elsewhere pointed out the oxygenating value of aquatic plants, and shown how their work is desirable in a "balanced" or reciprocating aquarium. This factor must be left out of consideration in the saltwater aquarium, for marine plants perform this function to so small a degree as to become unimportant. The Ulva, or sea lettuce, is the most satisfactory of the easily obtained plants. It has been known to do well for quite long periods. A few bits of cork placed beneath will cause it to float to the top, where it looks and does best, at the same time shading the water. The beautiful Actinix, or Sea Anemones, which are flower-formed animals, present a bewildering array of form and color far surpassing any freshwater plants. These were once supposed to form a connecting link between the animal and vegetable worlds, but this is an error, the beautiful creatures belonging purely to the animal kingdom. As far as appearance is concerned, other beautiful attached animals also make up for the lack of vegetable life.

For the absence of oxygen from plants we have either to depend upon mechanical processes, or to substantially reduce our number of aquarium 
inmates. The surface of the water takes up enough oxygen to maintain a few animals, but if our ideas are more ambitious it will be best to install an air pump, operated by electrical power. This will more than compensate for any plant deficiency, especially if the air is liberated in very small bubbles. In the case of large marine aquaria where the water is constantly pumped out, filtered and returned, the oxygenating is accomplished by a very simple and, at the same time, clever device. The water is discharged with some force from a small pipe into the open end of another pipe just enough larger that the water discharge pipe will fit loosely in it. The second pipe is the mixer, and is carried to the bottom of the aquarium, where it is bent to a right-angle so as to shoot the air and water somewhat horizontally across the aquarium. If the aquarium is very deep ( 3 to 5 feet), the intake of mixer pipe should extend about 8 inches above the surface of the aquarium. Otherwise the air in the column of water in the pipe would make it so light that it would back up instead of discharging in the bottom of the aquarium. In shallower aquaria the end of the mixer pipe will not need to stand so high above water-level. By this method the air bubbles are mostly very minute, producing the effect, from a little distance, of smoke. The high specific gravity of marine water helps to break up the bubbles much finer than in freshwater.

Marine Aquaria. While it may not always be possible to entirely avoid having metal come into contact with the water of the marine aquarium, this risk should be reduced to a minimum. Copper, brass and zinc are particularly dangerous. The metal now coming into use, Monel metal, is not entirely free from copper, but, on the whole, is very satisfactory, and has the advantage of great strength as well as a pleasing light color. Marine bronze is also good and not so expensive as Monel. Iron pipes and valves lined with lead are now made, especially for resisting chemicals. These are very fine for carrying marine water to and from the aquarium. For the aquarist working on a comparatively small scale, lead pipe is best.

With the all-glass aquarium we have no metal problem to contend with. Aquaria of the smaller sizes are satisfactory for marine purposes if not overstocked. In the executive offices of the Battery Park Aquarium in New York City, they have in successful operation a number of jar aquaria, one of them having continued without interruption, except for change of animals, since 1900. This should give reassurance to those who hesitate to establish marine aquaria.

Lighting. Another radical difference from the freshwater aquarium is that the marine aquarium requires considerably less light. When we see such intense light at the shore, it is difficult to realize that only a few 
feet down the light is so absorbed as to produce a very subdued effect, yet such is the case. If a moderately strong light is kept on marine water it will quickly turn green. To clear it will take several weeks of standing in the dark. Requiring only a weak light should, in many instances, prove a strong recommendation for the keeping of a marine aquarium where one has insufficient light for the successful development of freshwater plants.

Strength of Marine Water. For some reason not understood, pure ocean water is not as successful in the aquarium as that which has been somewhat diluted. The reason may be that while the fishes can successfully withstand the change to weaker water, many of their microscopic enemies are unable to do so-exactly the reverse of the theory of treating freshwater fishes with a saltwater solution. Be the theory what it may, experienced marine aquarists have obtained better results with diluted water in still aquaria. Naturally, if new seawater can be continuously pumped in, nothing could be better, particularly as this contains the desirable small food otherwise difficult or impossible to supply.

A hydrometer for testing the strength of salt in the aquarium water should be provided. Natural seawater has a strength of 1.023 to 1.031 . If this is reduced to about 1.020, the animals will do better than at full strength. It should not go below 1.017, nor above 1.022 .

Having established a certain water-level at a proper hydrometer strength, it ought to be maintained at that point by the addition of pure freshwater, never using marine water to make up for evaporation. The salts do not evaporate, but concentrate, and soon the aquarium would be in the lifeless condition of the Dead Sea or Salt Lake. A glass cover will prevent some evaporation, but if an air pump is used, some evaporation will be inevitable. No trouble will be experienced if the water is kept to a level, as suggested, by the addition of freshwater.

Shipping Seawater. If seawater must be shipped, careful consideration should be given to the kind of carriers used. The action of saltwater on zinc, copper and brass is rapid, the resultant chemical action charging the water with poisonous metallic salts. Galvanized iron is to be avoided, as it is zinc-plated. The best metal in which to ship is tin. This, or any other metal, should first receive a coating of asphaltum varnish. Even galvanized iron when asphaltum-coated is safe for journeys of moderate length, but the asphaltum will eventually chip off and the pail or can should be carefully looked over each time before using. It might be well to say here that the life of tin pails for any water will last much longer if coated with asphaltum varnish. A thin coat spread evenly lasts better than a thick one.

The very best water-shipping medium is a protected glass bottle or carboy. Arrangements can usually be made to rent or borrow a few of 
these from drinking-water concerns. If possible the water should be taken from several miles out at sea and not near the mouth of any large river. Clear seawater may be stored indefinitely in carboys in a subdued light, although it would be better to first filter it to remove the larger microscopic life.

Evaporated sea salt, if dried in enamel or glass pans, is the next best substitute for ocean water. In re-dissolving the salt, measure the strength by hydrometer readings.

Synthetically-made seawater has not been very successful. It contains 663 grams sodium chloride, 75 grams magnesium chloride, 50 grams magnesium sulphate, and 15 grams potassium sulphate; all dissolved in 25 litres of water. Newly-made artificial marine water ought not be used for several days, but be given a little time to ripen. An occasional stirring helps the process.

Clearing Marine Water. It is desirable to keep the marine aquarium crystal-clear, both for the benefit of the inmates and the pleasure of the observer. To this end several factors must be borne in mind. Start with clear water. Do not overcrowd nor overfeed. Use only subdued light. Quickly remove decaying plants, dead mussels, anemones, etc. Occasionally siphon off the bottom (see page 120) and, after settling, pour back the clear water or return through filter. Very little loss of water is occasioned if the dregs are thrown away after water has settled, particularly if a tall jar is used. The filter arrangement described on page 125 is very desirable for the marine aquarium.

Temperature. This matter depends very largely upon the climate from which the aquarium inhabitants come. For this reason it is not well to mix animals of tropical and temperate zones. Many of the tropical fishes come north in summer and can successfully withstand a temperature of 62 degrees $F$., but in the confines of an aquarium they will not prosper in the lower temperatures. Tropical fishes are happy in a temperature ranging from 68 to 75 degrees. Some of them can succeed when it is even warmer, but it becomes difficult to satisfactory oxygenate the water.

Fishes and other marine animals of the temperate zone prefer a range from 55 to 68 degrees. It will be noted that the tropicals and temperates meet at 68 degrees, so if the attempt is made to mix them, this is the temperature that should be closely adhered to.

Collecting Specimens. The best places for collecting a miscellaneous assortment of marine animals are the back bays, pools, pockets, marshes and small streams where the ocean overflows at high tide and recedes from at low. Rocky coasts furnish particularly fertile fields for the aquatic hunter, and those of New England offer rich attractions in 
varied and wonderfully beautiful vegetation. Wood's Hole is a particularly famed point for all sorts of marine naturalists and collectors. However, anybody can go to the beach nearest home and gather material that will well repay for the effort. Two persons in bathing suits operating a seine 4 by 14 feet (see page 112) will be surprisingly successful right in the surf anywhere. As before stated, the little sheltered places, pools around breakwaters, piers and rocks should be thoroughly investigated by hand and net. As with freshwater, let the collector be not too ambitious for numbers. It is better to get a ferw good specimens home alive and well than have a bucketful of dead and dying.

Tropical marine fishes are of dazzling beauty, a fact enthusiastically attested by those visiting any of our large American public aquaria, or by those so fortunate as to travel in Bermuda, or to have seen the beautiful marine aquaria at Naples or Hawaii. Most of our tropical specimens are collected at Bermuda and at Key West, Florida. The various kinds of kelp and coral fishes make aquarium specimens of such bewitch. ing beauty that any attempted word-description of them would appear extravagant. Anyone wishing to make a collection should employ a local fisherman at the collecting point who knows the haunts and ways of the fishes, and who understands the danger of sudden tropical storms. Such collections should be shipped in a liberal quantity of water and artificially aerated by pump or pouring whenever the train is still for more than fifteen minutes. On shipboard, new water of the proper temperature should be frequently given.

Stocking the Aquarium. Perhaps we can repeat to advantage that it is better to under- than to over-stock the aquarium. This is particularly true of the marine aquarium, first, because if we spoil the water by dead animals it is some trouble to obtain more, and second, because the animals are used to more oxygen in the wind-tossed ocean than can be had in a crowded aquarium.

Extra vigilance needs to be exercised when the occupants are first introduced, as some of them may not survive the change.

It is best to start with some of the more hardy fishes, such as the marine killifish, to see whether the aquarium conditions are in proper working order. It will be time enough to branch out more elaborately after this is proven.

Anemones and other creatures attached to rocks should, if possible, be placed in the aquarium without detaching. Low forms do better if handled with a dipper or spoon. Whether or not mussels are alive can be determined by tapping lightly on the shell with a small stick. In health the shell will promptly close. Gentle disturbances of the water will show whether anemones and other low forms are living, as they will 
respond by slight movements. Care on this point is of vital importance, as decomposition is very rapid.

Sea Horses. Owing to the vastness of the field we cannot here go into a detailed list of marine aquarium inhabitants, but we cannot pass the subject without special mention of those quaint fishes, sea horses (Hippocampus). Although appearing like some mythological animal in miniature, they are true fishes. They make a very striking appearance in the aquarium, always attracting great attention. Their tails are prehensile and are used much the same as a monkey's, fastening themselves to twigs, bits of grass or any small object, ready to let go in a moment, swim a short distance and fasten somewhere else or perchance socially link tails with another. Their movements through the water might be described as being very sedate. Locomotion is produced mainly by vibration of the dorsal fin, the body being tipped forward at a slight angle.

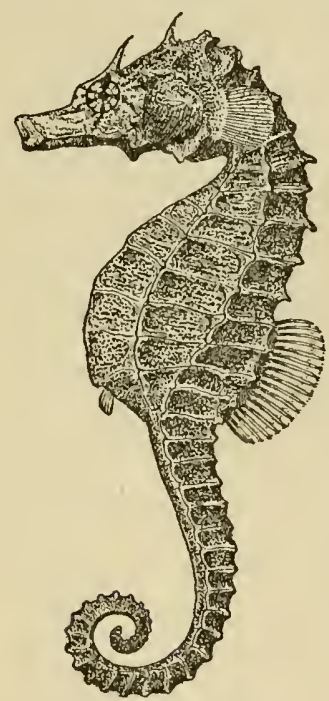

Fig. 113. SEA Horse (Maximum size)

Although the movement through the water is not rapid, it has the appearance of being accomplished entirely without effort. The breeding habits of the sea horse are also most peculiar. The female develops an intromittent organ as the breeding season approaches, while the brood-pouch on the belly of the male becomes thickened and vascular. The fishes face each other, the female advances, places one or more eggs in the pouch of the male, retreats and repeats until the spawning is finished. When the eggs have hatched, the pouch splits slightly and he works the young out of it by gently rubbing against a firm surface. The young are as perfectly formed as the parents.

Sea horses feed upon small marine crustacea about equal in size to daphnia. Some European aquarists claim to have gotten them to eat dried shrimp, but, so far as we are able to learn, nobody in America has been successful in this. Although different attempts were made to induce them to eat daphnia, it has seldom been accomplished. The author was fortunate enough to persuade sea horses to modify their ideas to that extent, the process taking much patience. Daphnia can only live about 5 minutes in seawater, so at first they all die while the sea horses are apparently thinking the matter over. By repeated trials the smaller fishes finally started to eat, and the larger ones took the hint from the smaller. Shrimp will eat the dead daphnia, but if much is left over it 
should be quickly siphoned out or otherwise removed. Sea horses can, no doubt, be brought to living in saltwater of a hydrometer strength of 1.017 , which would probably increase the length of life of daphnia in the marine aquarium to 10 minutes or more. As these strange fishes usually eat by reaching out for food while attached by their tails to a piece of sea-weed, it is necessary to gently circulate the daphnia through the aquarium by the aeration system or other means.

These odd creatures are of world-wide distribution. On the Atlantic Coast they are more plentiful in September than at any other time, when they are often brought up clinging to fishermen's nets. Only one species occurs on our Atlantic Coast. This is the one shown in Fig. 113.

Feeding in Marine Aquaria. Practically all marine animals are carnivorous. Chopped oysters, clams, fish, worms, crab meat, scraped lean beef and shrimp form the principal articles of diet. Canned shrimp is convenient and usually very acceptable. It can be had at all seasons. Little oyster crabs, either whole or cut up, make choice morsels for either fresh or saltwater fishes.

Anemones should have small bits of food offered them with forceps (shown on page 120), lightly touching their tentacles with the offering. Three times a week is often enough to feed these lower forms.

The fishes may be fed every day or two, according to temperature, always remembering that animal food not quickly eaten soon fouls the water.

It is rather surprising to find that many of the small marine fishes relish crisp lettuce leaves, finely chopped. This no doubt makes a beneficial change for them.

Diseased Marine Fishes. Very little is known about treating the ailments of marine fishes. As salt is the general cure-all for freshwater fishes, it has been discovered that less salt is the best general treatment for marine fishes that are out of condition. Short trials at hydrometer test 1.010 are beneficial, this, of course, being brought about gradually. Otherwise, we see no reason why animal parasites, injuries, etc., should not be treated the same as for freshwater fishes.

As there are a number of different hydrometer scale readings, it is suggested that the instrument to be used should first be tried in normal seawater, which would establish a positive basis from which to work with that particular hydrometer. 
CHAPTER ELEVEN

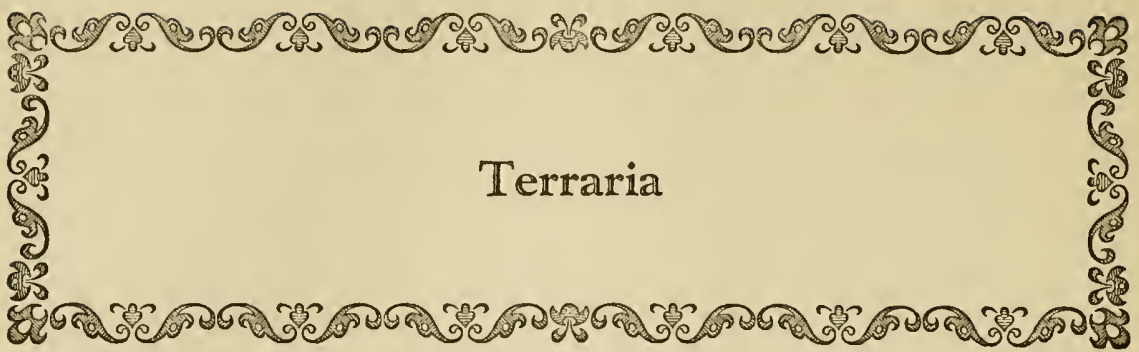

The terrarium has not as yet aroused any marked degree of interest in America, but as we have followed Europe in the cultivation of exotic fishes, it is not unlikely that we shall yet follow their study of amphibians and other inhabitants of the terrarium and aqua-terrarium. Certainly the subject can be made one of keen interest, offering special attractions to those fond of making their own collections. Unfortunately, even in Europe, the terrarium itself has not been developed into a thing of beauty. Most of the numerous designs shown for sale are stiff and clumsy-looking, but this may be largely overcome by artistic planting. Undoubtedly there is still plenty of room for individuality of treatment which would give one more the feeling of witnessing a transplanted bit of Nature, rather than a miniature prison.

The variety of animals which may be kept is extremely large and many of them are of distinctly attractive appearance. Those of us who have learned to admire the telescope goldfish should suspend judgment on some of the apparently less attractive specimens in the terrarium, for it may be that both standards operate on the same general principle, that is, the more hideous, the more attractive!

Aside from the matter of beauty there is a wonderful range for observation, study and original research in the terrarium. In looking over the European catalogs one is struck by the large number of lizards, frogs, newts, turtles, reptiles, etc., which are exported from North America. It will, therefore, be seen that we do not have to leave our own shore to obtain good collections.

Terraria are divided into four natural divisions, according to the needs of their occupants: dry-temperate, dry-tropical, moist-temperate, and moist-tropical. The differences in these will readily suggest themselves to the mind, being matters mainly of ventilation, moisture and artificial heat. The sides are usually of glass, one of them, as well as the top, being removable in order to work inside or to introduce or take out specimens. 
The dry-temperate terrarium is naturally the simplest in construction, the principal requirements being open ventilation and a small drinking pool with cement edge and mirror bottom. This seems to be necessary to some of the creatures, as they are accustomed to seeing the sky reflected in water and without this they do not at first recognize it as water.

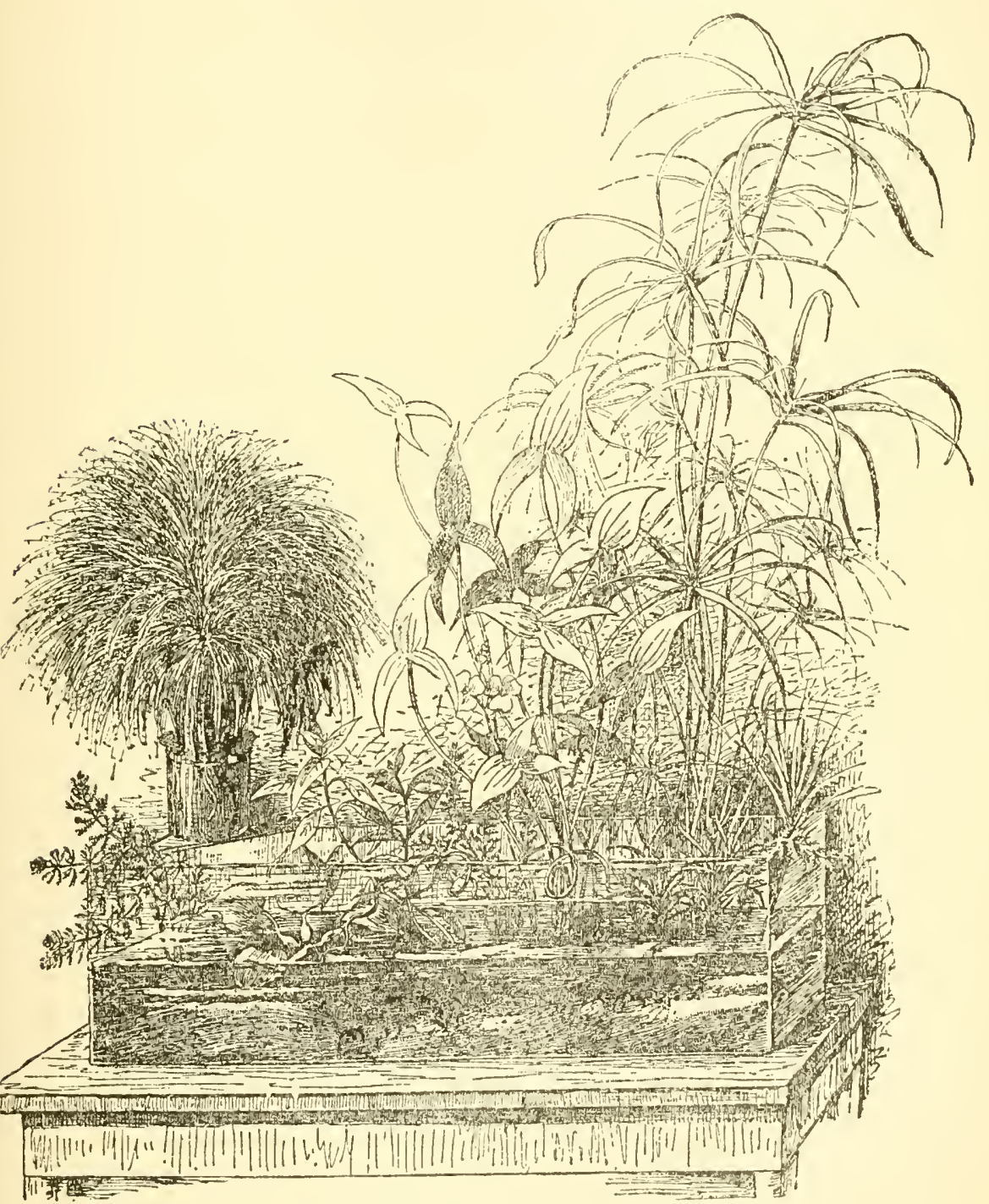

Fig. 114. Swamp Aquartum 
The moist-temperate form is only slightly ventilated and is supplied with a larger water pool, as the animals are usually amphibians. It is well to be able to drain this off without removal of water container.

Tropical terraria, whether moist or dry, are heated artificially from below, the heating device being concealed beneath a false bottom. The heat may be applied either to a pan of sand or water or used in the form of a miniature hot-water heating system as indicated in figure 212 for heating tropical aquaria. The pipes are not carried over the top, but through or around the bottom.

The forms of terraria are quite diverse, according to requirements or fancy. Quite a number are divided into two halves, one side containing a shallow pool with tall bog plants, the other side being for terrestrial plants, the two sometimes being connected by a sloping ladder over the division, so that the animals may cross at will. The same arrangement is further developed into the aqua-terrarium by having the moist side in regular aquarium form and filling about two-thirds deep with water. Where tree frogs or other climbing animals are kept there should be a ladder or other arrangement to enable them to seek varying levels at different times, as this desire. seems to be an important part of their nature. Tree frogs in some parts of the world are better known as "weather frogs." They are kept where they may either remain in water or climb to different levels at will, and are regarded as good barometers to foretell approaching weather conditions. Undoubtedly the state of the atmosphere has something to do with their movements in this respect.

Terraria for moths and insects usually have three sides of screen and one side of glass for clear observation.

Aqua-terraria may be considered a higher development of terraria, since their possibilities are so much enhanced on account of accommodating both terrestrial and aquatic animals and plants. One of the most interesting kinds is devoted to the observation of aquatic insects. These only contain a few inches of water, in which are placed bog plants, so that the leaves stand well out of water. Very few of the aquatic insects spend their entire lives in the water and some such provision is needed for them to climb out. It is important that stones or other creeping-out places be provided for turtles, frogs, newts and other amphibians, for it is cruelty to oblige them to remain constantly in the water.

Quite artistic effects can be obtained in the arrangement and planting of the terrarium and the aqua-terrarium. Natural bridges, lakes, waterfalls, archways, ledges, hollows, cliffs, caves and other details may be used to good purpose, but care should be exercised not to combine the incongruous nor introduce objects out of keeping with the general scheme. Stones cemented together are capable of good pictorial effects. For moist 


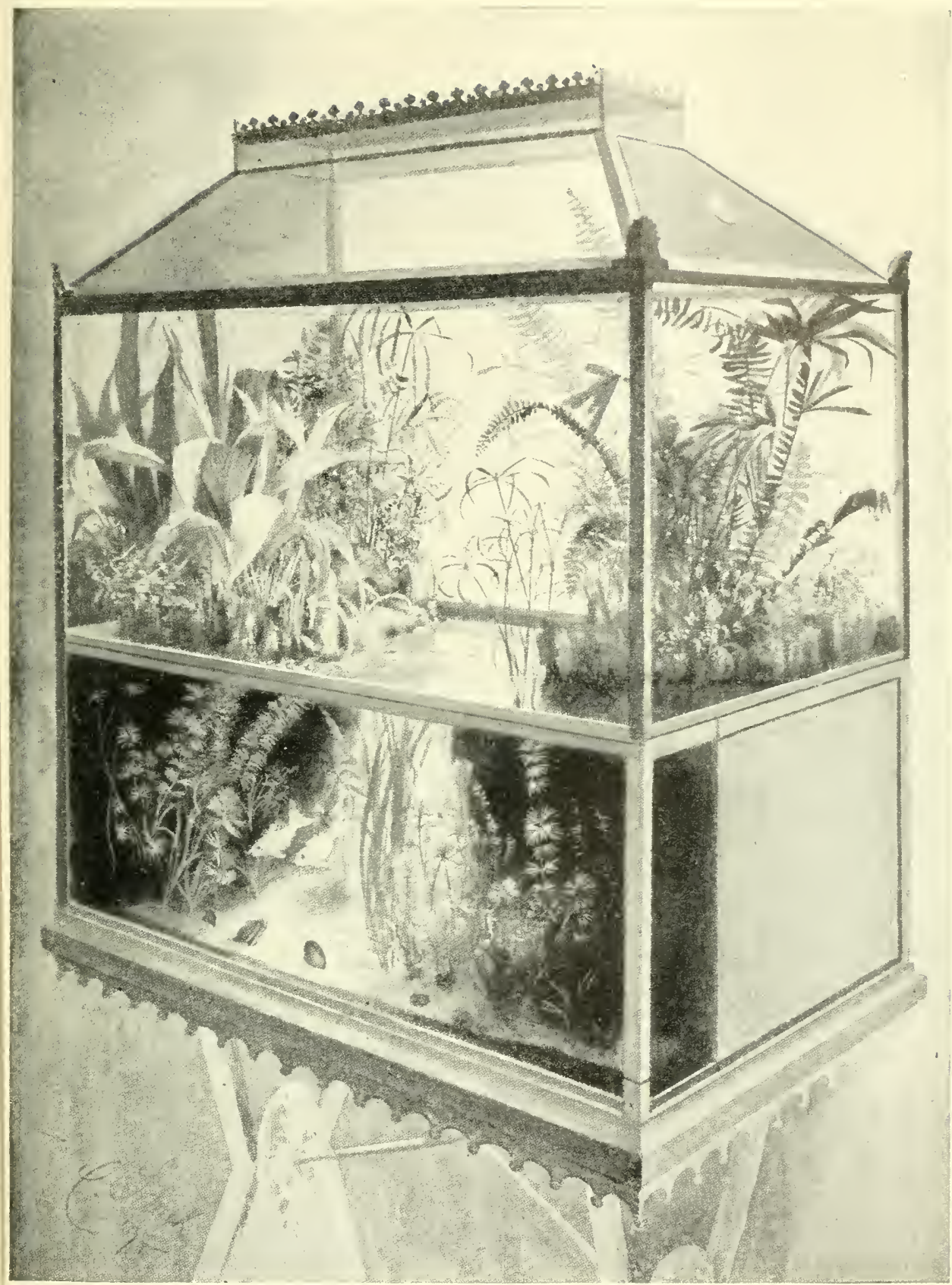

Fig. 115. Enclosed Aqua-Terrarium 


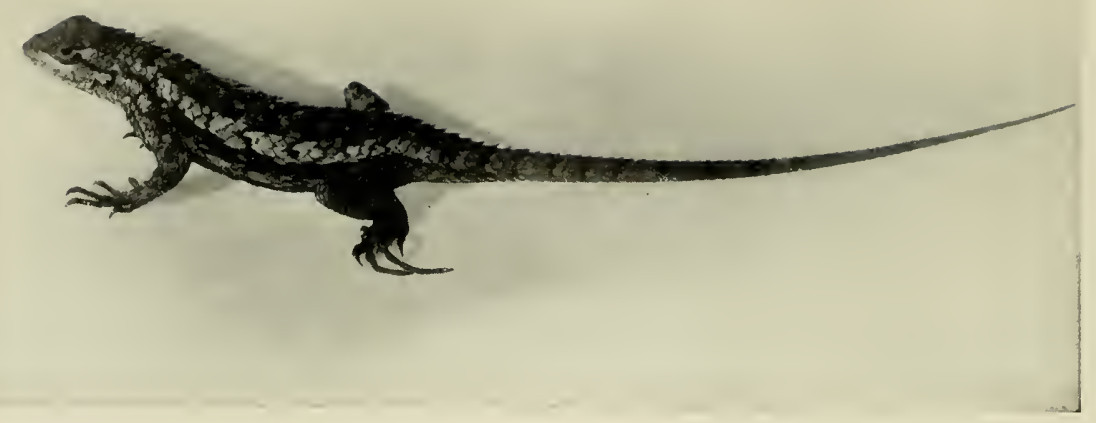

Fig. 115 (a). Pine-tree Lizard (Sceloporus undulatus) [Half size]

The Pine Tree Lizard in its variations is of wide distribution in the United States. It does well in the terrarium and becomes quite a pet. These and other lizards are more numerous than is generally supposed. This is due in a measure to their cleverness in keeping out of view, having much the same habit as squirrels in hiding on the opposite sides of trees and branches from the observer.

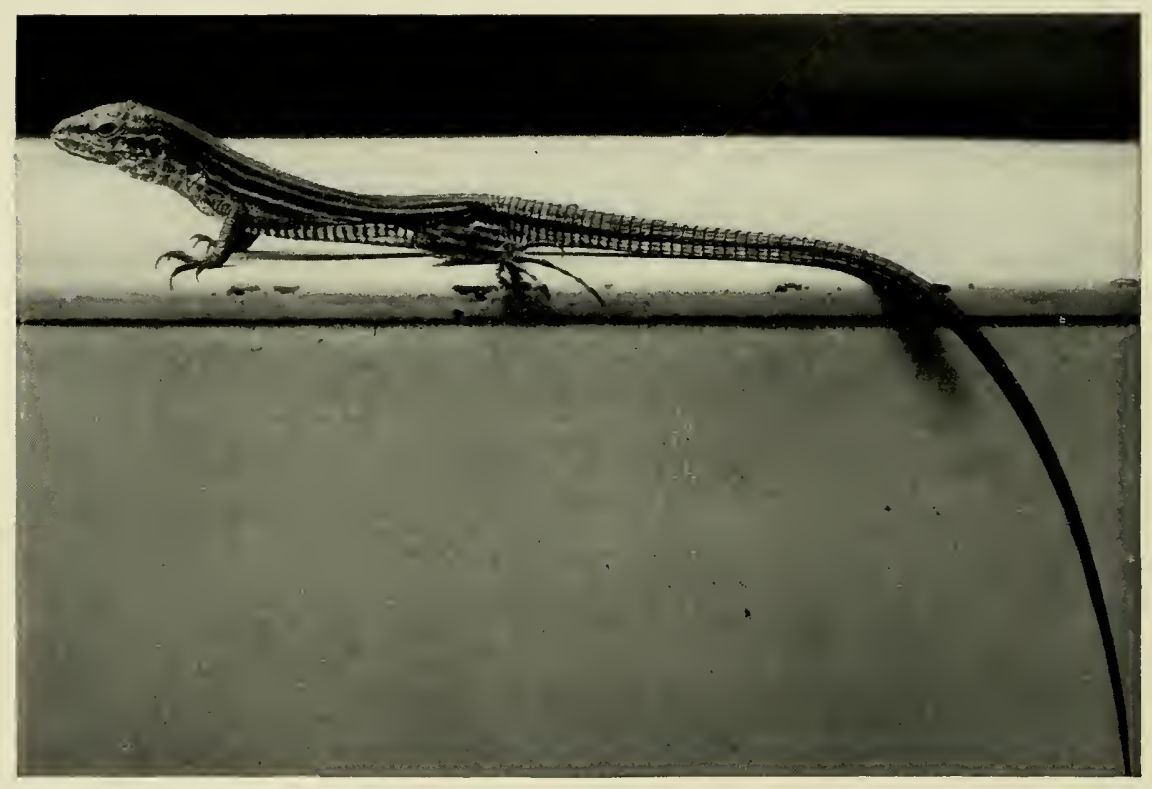

FIG. 116. Six-Lined Skink (Cnemidophorus sexlineatus) [Slightly reduced]

Six-Lined Lizards possess a remarkable grace and attractive coloring, especially the males, whose under-sides are barred with brilliant metallic blue, carried partly up on the side, adding to the sleek, corseted effect of the animal. They are native to the Southeastern States.

No lizards should be caught or picked up by the tail, as they will purposely lose them in order to escape the hold. 


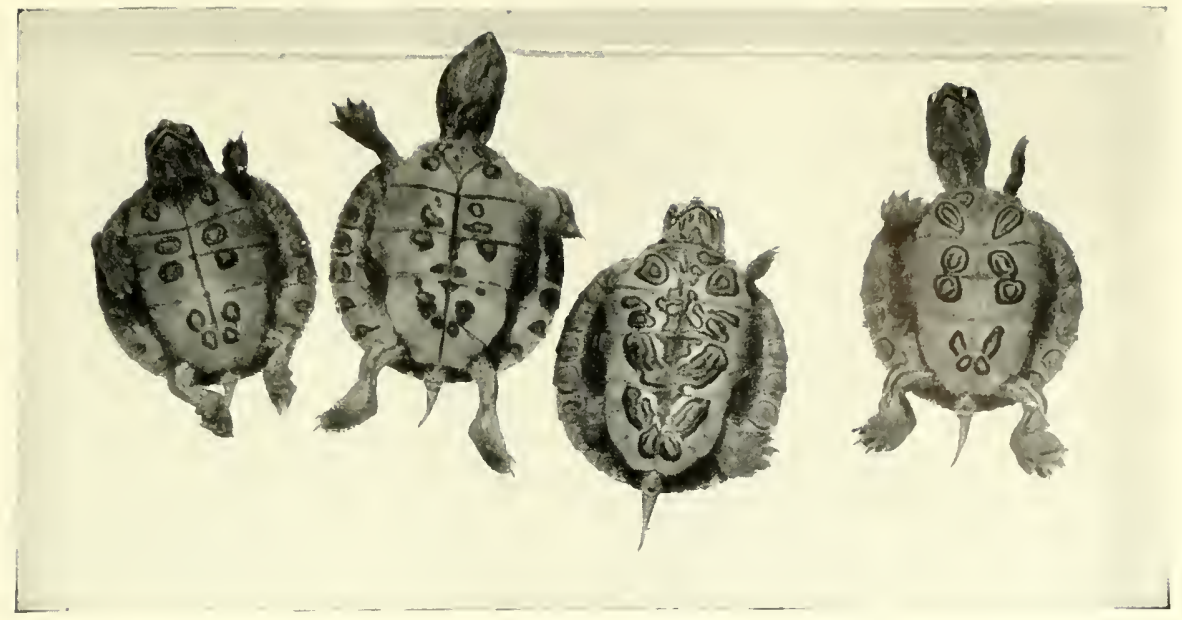

Fig. 117. Cumberland Terrapixs (Young)

The undermarkings are as different as the thumb-prints of human beings, no two appearing to be alike. The backs are usually a pleasing shade of green. Distributed in large quantities in pet shops in the spring. Bright red markings on head. They like small worms, bits of meat or fish and can eat only under water. Give them a place to crawl out and lieep them away from fishes.

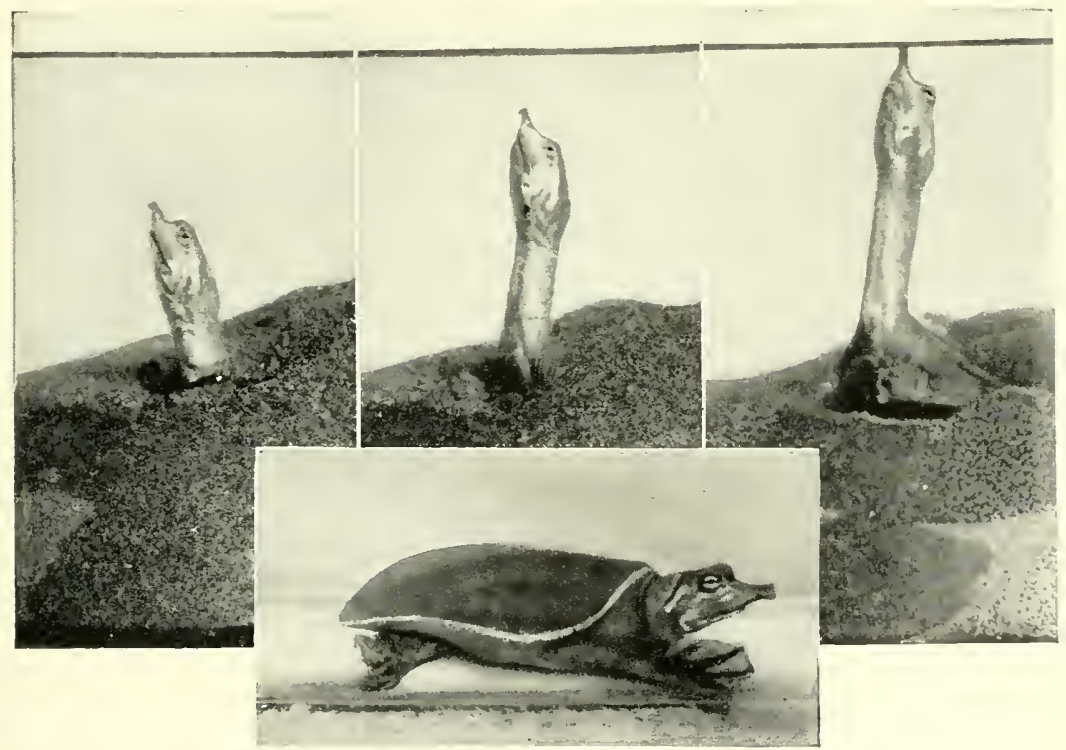

Fig. 118. Soft-Shelled Turtle (Amyda spinifera) [Young]

These curious creatures make interesting pets, and when small can be kept in close quarters. When alarmed they dig into the sand, but must eventually come out for a breath of air. If the surface is within reaching distance they will do the original "rubberneck" act as above, rather than leave the sand. Soft-shelled turtles are purely aquatic and have broadly webbed feet, which enable them to swim rapidly. 


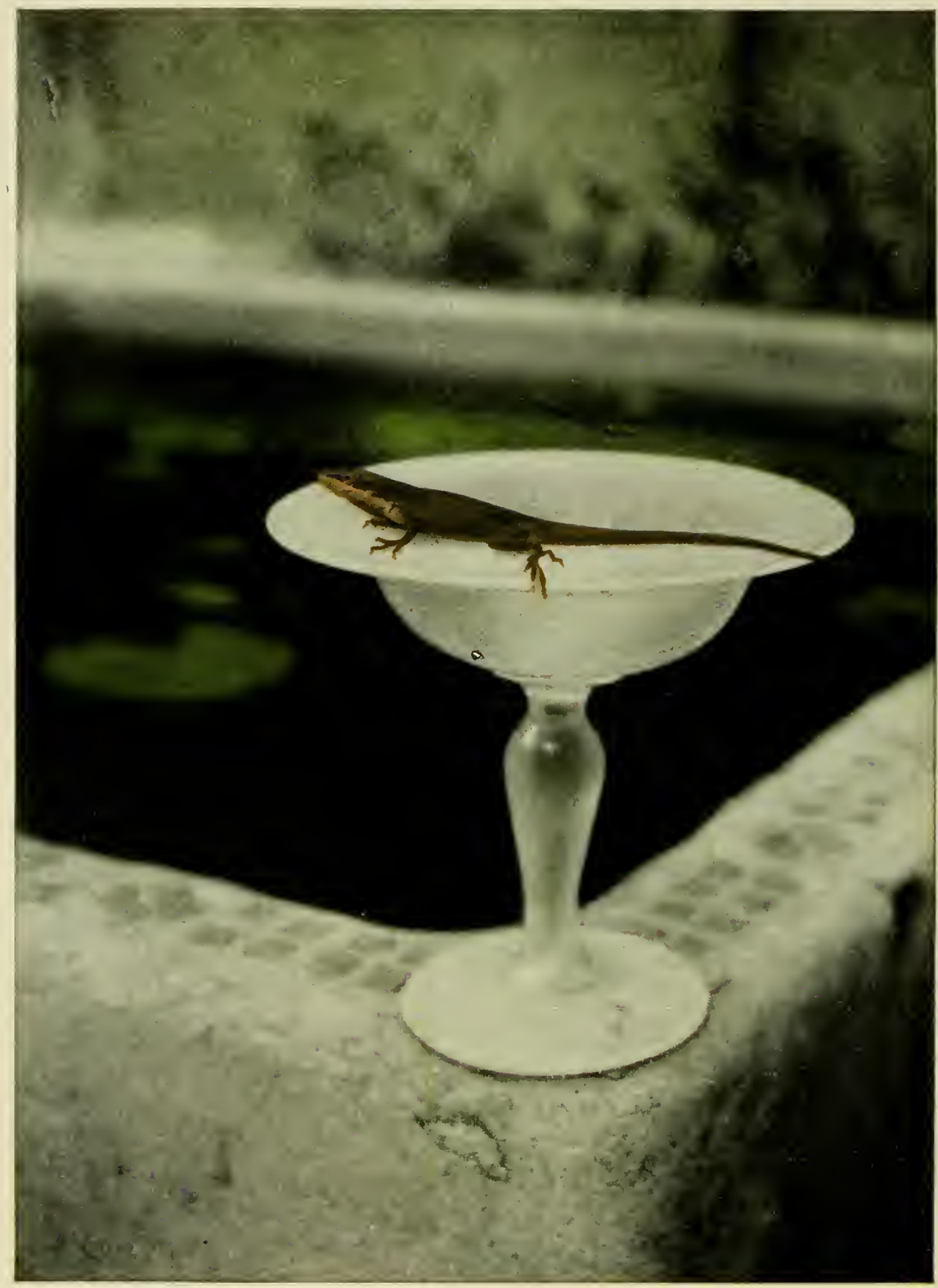

Fig. 119. The American Chameleon (Anolis carolinensis) [Two-thirds size]

The range of protective coloration in our chameleons is not unlimited, as is usually supposed. They mainly alternate hetween the brown here shown (a gond average earthcolor) and a bright leaf-green, which is extremely difficult to distinguish against foliage. 
terraria, pumice or other porous stone will be found useful, as it retains so much moisture and makes a good foothold for ferns and creeping plants.

An aqua-terrarium constructed for pictorial effect is made in the form of an ordinary aquarium with terrestrial plants arranged in the rear corners, thus giving the effect of a complete bit of landscape. The great possibilities of this treatment are shown in the illustration on page 145 . This has the earth in slate containers reaching all the way to the bottom, but in a form devised later the soil is in cement pans 6 inches deep which are hung by hooks on the top edge of the aquarium proper, thus giving more light at the bottom of the aquarium.

Swamp aquaria have received little attention, although they can be made very picturesque, as will be seen in Fig. 114 .

Plants. Most of the plants flourishing in greenhouses will prosper in the moist terrarium, so that the selection is very large. The dry terrarium is much more limited in this respect, the possibilities being confined practically to cacti, agaves, aloes, houseleeks and certain hardy ferns which have come from dry situations.

Planting. The main point in planting the terrarium is to procure proper drainage by the use of pebbles or broken charcoal. Plants can be set either directly in soil above the pebbles or in pots. Fertilizer may be used in the lower part of soil, but very sparingly in moist terraria. In planting it is well to keep in mind the natural surroundings of the animals and to provide, so far as possible, those conditions which are agreeable to their natures. For instance, the reptiles like to sun themselves in open, dry spots, and in planting this can easily be arranged. Amphibious animals like to secrete themselves and at times hide from the light in thick vegetation, a provision easily made in the moist terrarium. These same considerations will present themselves when it comes to selecting a place for the terrarium. The snakes delight to sun themselves for hours, so in planting it is well to use only such plants that will stand plenty of direct sunlight. Terraria have one important advantage over aquaria in that at least the smaller sizes may be shifted from one place to another with very little effort, so that light conditions may be changed at will and hours of sunshine increased as opportunity offers.

Occupants for Terraria. The large majority of cold-blooded animals of suitable sizes may be introduced. In the moist terrarium the principal animals used are young alligators, newts, salamanders, tadpoles, frogs, water snakes, turtles, aquatic insects and their larvæ. For the dry terrarium we have tree toads, hop toads, horned toads, beetles, spiders, lizards, chameleons, tortoises, snakes, butterflies, moths and other insects. The catalogs of European naturalists contain many interesting offerings. 
Feeding in the Terrarium. The different occupants of the terrarium naturally require a varying range of foods. Terraria containing chameleons, frogs, toads, tree toads, do well on flies. It is a good plan to have a fly trap which can be emptied into the terrarium. It is quite an amusing thing to see the animals waiting for the flies to emerge after they have learned that they are fed in this manner. The dexterity with which they are caught and eaten is a never-ending marvel. While these animals can live on little, they ought to be well fed in warm weather, giving them once daily all the flies they can consume, which will be found to be a considerable number. In winter when flies are scarce they may be fed on meal worms and meal bugs, which are easily cultivated in bran flour, once a small stock is started. Particular care should be taken not to allow any of the meal breeding stock to escape into the house, as it is liable to become a pest in the kitchen. Roach traps are useful adjuncts in providing food for the larger lizards and insectivorous snakes.

As with the aquarium, particular care should be exercised not to allow any excess of food which is liable to decay, all surplus being removed immediately after the feeding hour.

Alligators, carnivorous turtles, newts and salamanders are fed on bits of meat, fish, oysters, scrambled egg and worms. Aquatic turtles and alligators can swallow their food only under water.

Aquatic turtles should be provided with facilities for crawling out of the water. They should not be kept with fishes, as fish is part of their natural diet. This is also true of salamanders and newts.

Snakes and lizards require large and small insects, worms, small live fish, toads and animals.

Box tortoises select their food from a large menu. They like almost anything that man eats and a few things besides, including, in the last, slugs and earthworms. Thick, sour milk is taken eagerly, also bread soaked in milk.

To winter box tortoises dig a hole in the ground to a point slightly below the frostline. Place two inches of excelsior below and above tortoise. This supplies air and acts as drainage. The head should be sloped slightly upward. Cover over with earth, heaping it up into a slight mound. Place more excelsior on this to a diameter of about two feet and cover over with newspaper, held down by stones or boards. The tortoise should be buried after the first light frost and dug out after danger of frost is past, say, October 10th to April 10th for the hibernating period in average climate in the Middle States. The author has kept one tortoise in this way for over thirty years. When active they should always have drinking water available, especially in hot weather. 


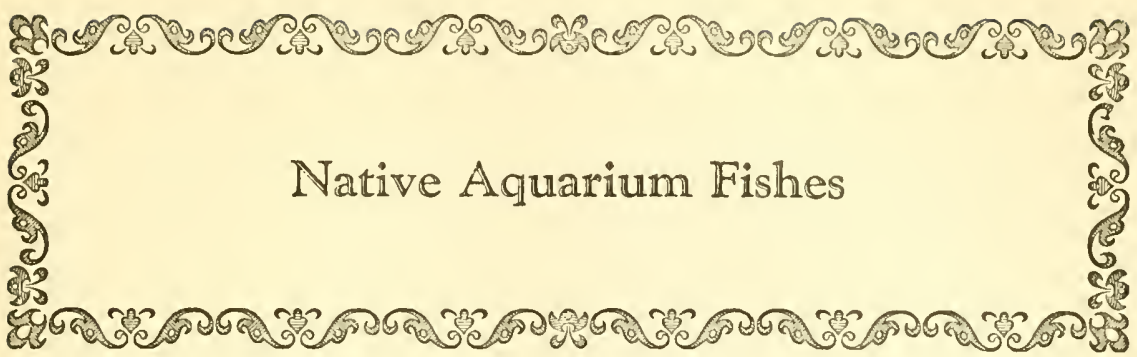

It seems to be human nature, especially in America, to assume that the best things come from distant lands-the more distant, the better. In this search for the rare and interesting we are apt to overlook excellent material close at hand. We have many handsome native fishes admirably adapted to aquarium purposes. They are easily managed, tenacious of life, varied in habits and easily tamed. Those who have made collections of our own fishes have found much pleasure in this form of aquarium hobby.

\section{COLLECTING WILD FISHES}

There are pleasures connected with the stocking of a wild-fish aquarium which are unknown to those interested only in goldfishes. The actual contact with Nature, the study of the fishes in their native habitat, the ever-present possibility of finding something new, the companionship and health afforded on outings are some of the pleasant assets of the collector.

For this work two kinds of nets should be provided. These consist of a minnow seine and a large landing net of fine mesh, fitted with a sectional rod. The seine should be operated by two persons. A pole is used at each end of the net, the sinker and float lines being attached at their respective points. The bottom line should be carried well in front of the top, and while a steady forward motion is necessary, it should not be rapid enough to cause the float line to sink. When working over grassy areas it is a help to have a pole attached to the centre of the lower line, this to be operated by a third man, the idea being to keep the sinker line close to the bottom. Seines of this type are adaptable to streams from 10 to 20 feet wide and to any larger body of water having a gently sloping shore of firm quality and without too many obstacles. If the haul can be ended at a natural recession or "gut" in the bank it will prevent the loss of some fishes. See Fig. 90. 
These small seines as purchased are poorly equipped with floats and sinkers, the former being too heavy and the latter too light. A great improvement can be made by adding large cork floats, binding split pieces together across the top line. The sinkers should be twice as heavy and twice as numerous as supplied. Pieces of half-inch split lead pipe can readily be used to correct this defect.

If fishes are at all plentiful the hauls are large. Care should be exercised to immediately return all specimens not wanted, and it will be the part of wisdom to want few. By crowding in cans on the home trip many fishes die and the rest arrive in such poor condition that their lives in captivity are short. The hands should be wet before touching a live fish. This is well known among fish culturists.

The ordinary 18-inch folding hand-net is used in small streams where one can make a dash into the deeper depressions by the banks. This is done by an overhead, downward swoop, executed with the greatest possible speed. The net is continued in rapid motion, pulling it over the bottom towards the feet of the operator. This is the only way to achieve any degree of success. The up-scoop is the natural way to go about it, but this ends in absolute failure.

With this net, too, we need some alterations. Take off the net from the folding frame. Slip about 100 of $5 / 8$-inch upholsterers' brass rings

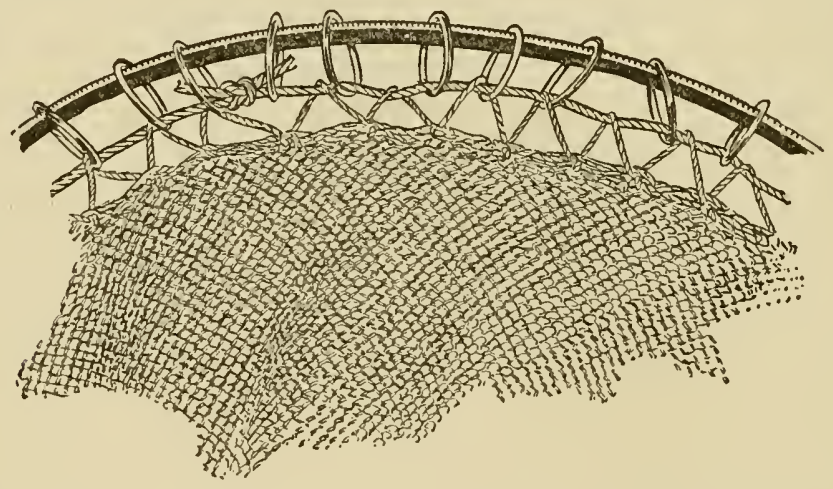

Fig. 120. Proper Way to Connect Hand Net to Metal Frame

on the frame. Now interweave, parallel to the frame, a strong string between the brass rings and the top loops of the net, thus attaching the net permanently. The object of this arrangement is to prevent the cutting of the net when the frame drags over stones and other obstacles. Also the net itself can be improved for our purposes. It should be of a quarterinch mesh and about 24 inches deep. Dyeing it a dark color is a still further improvement. 


\section{THE SILVERFIN \\ Notropis analostanus}

Of all the native fishes tried in the aquarium by the writer the Silverfin stands out as one of the most satisfactory. For aquarium purposes the male fish should be selected. The ends of their fins are of a whitish, satiny color from May till September. Darting around in the aquarium, their sleek bodies overcast with a pale steel-blue, and sides laced with black-edged scales, they make a most attractive appearance. Two of them will often indulge in what appears to be a game of tag, during which they will chase each other around a short circle, producing the effect of a pinwheel.

A 50-gallon aquarium, with plenty of open space, containing about ten adult male Silverfins is most fascinating.

They may be caught in the open reaches of the fresh tidal portion of the Delaware as well as its upland tributaries.

Silverfins have been kept in aquaria for several years, but unusual care should be exercised to cover with a screen to prevent their leaping out.

They are very hardy, tame, and will eat any prepared food. Harmless to other fishes.

\section{THE DARTERS}

With few exceptions the Darters have no swimming bladders and are therefore heavier than water. They move along the bottom in jerky motions somewhat like hopping. When in reach of their prey they make a short leap. Although this seems to be short of the mark they always succeed in getting what they go after. One would imagine them to have a long tongue like a frog, moving with the same invisible rapidity. The action is of course accomplished by suction.

There is something quaint and droll about the Darters. Although to the unscientific eye they look nothing like perches, nevertheless they are classified with that family. They have occasionally been bred in the aquarium. Spawning occurs among stones. The parents have not been observed to protect eggs or young. The majority of them cannot stand warm water.

The Rainbow Darter Esteoma coerulea is probably the most brilliantly colored of our native fishes, being barred with red, blue, orange and green in most striking fashion. On account of its brilliant coloring it is known as the Soldier Fish. It occurs in shallow streams of the Mississippi Valley. Darters are extremely fond of daphnia or very small worms, but may become trained to taking shreds of raw meat, shrimp or fish. They can be kept best in cool water and are well worth the effort. 


\section{THE ROACH, OR SHINER}

Abramis crysoleucas

This fish is one that takes easily to the aquarium and is quite hardy under any reasonable conditions. It is very active. In the sunlight flashing its bright silver sides, it is a very pretty member of the aquarium family. Of a gentle nature and will take any food. The natural distribution is in the Northern States east of the Rockies.

\section{THE KILLIFISH}

Killifish, from either fresh or salt water, are among the most hardy of the smaller fishes. Used largely as bait-fish on account of their tenacity of life, they exhibit the same quality in the aquarium, standing very bad treatment before succumbing. The barred sides and fleeting iridescent colors are most attractive, particularly in the saltwater specimens. They will eat anything and are harmless to other aquarium fishes. Boys usually know this fish in streams as the "bull-head" minnow, while the popular name on the New Jersey coast for the saltwater form is "Mummychog." Average size about 3 inches.

\section{THE MUD TROUT \\ Umbra pygmoea}

Here we have one of the hardiest and most friendly of our small native freshwater fishes. It is not one of the restless kind, yet it is alert and very much alive to what is going on about it, ready to move to its purpose with the least possible effort. The Mud Trout has a fashion of turning its head deliberately towards the subject of interest in a way that suggests a concentration or mental development beyond that of the average fish. Although their manner is menacing they are perfectly harmless. They may be taught to leap several inches out of the water for a favorite morsel of food, such as a small worm, or a shred of raw meat, held on a toothpick. Their color is a pleasing brown, slightly relieved by darker lateral lines and some dots.

Found in lowland and swampy waters from Long Island to North Carolina, east of the Alleghenies. Sometimes to be had in pet stores, where they are sold at nominal charges. One should not estimate the aquarium value of these fishes by their market prices.

There seems to be some division of authority as to the breeding habits of this fish. The author once saw a pair placed in an aquarium with a quantity of algæ, from the same habitat as the fishes. Next to the glass they hollowed out a little grotto, about the size of a fist. In the morning this was found literally lined with eggs, and the female fanning them. Unfortunately they were infertile. 


\section{THE CARP \\ Cyprinus carpio}

The Carp is one of the most widely known of fishes. Its tenacity of life is extraordinary, considering that it is not an air-breather or labyrinth fish. When sold as a food fish it is lept alive for a day or two when barely moistened with water. Common goldfish well wrapped in wet Anacharis or Myriophyllum and packed in a tight tin box can safely be sent on a 12-hour journey or more if temperature is moderate.

A number of varieties of carp are kept as ornamental pond and large aquarium fishes. The principal ones are the Mirror, the Leather and the Golden Carp. There are in this country some extremely handsome fancy carp of Japanese breeding, being marked irregularly with red, white and blue. They have been propagated here and it is to be hoped the breed will become generally known.

Our photograph was made from one of these colored Carp but for general structure it accurately represents the ordinary Carp.

\section{THE REDFIN}

Notropis cornutus

In the breeding season the male Redfin is an individual of striking beauty, the entire pectoral and the ends of the other fins being a blazing red. The color continues in gradually lessening degree until cold weather sets in, when it disappears entirely. These fishes spawn together in large numbers, the action taking place while they are massed in the form of a great, seething ball, flashing dazzling colors. It is as a pond or pool fish that they show best, although at a size of $4 \frac{1}{2}$ inches they have sufficient color to look well in the aquarium, where they may be kept with other fishes. In the 8- to 10-inch sizes they are used as food in most of the Northern States east of the Rockies.

\section{THE PEARL ROACH \\ Scardinius erythropthalmus}

Visitors at different municipal aquaria have for years been much pleased with the exhibition of Pearl Roach. They are of European origin, where they are fairly common, and are really of no relation to our own Roach or Shiner. There is a general resemblance, except that the ends of the fins in the Pearl Roach are blood red at all seasons.

They were originally introduced here into the ponds of Central Park (New York City), multiplying in large numbers, proving their adaptability to pond culture. They should be a beautiful and generally satisfactory pond fish. The larger sizes run to about eight inches. As they 
do not develop the red fins much before they are four inches long, they would be suitable to aquaria of larger sizes rather than small. They have gentle dispositions.

\section{THE SUNFISHES}

The Sunfishes are one of the most widely distributed and best known of our fish families, American boys, in the country districts almost every. where being well acquainted with them. There are a number of varieties. Most of us have seen the tidy, clean spots fanned out by a pair of breeders. This is the "nest" in which the eggs are deposited. Both parents protect the young, attacking all comers in a vicious manner. Excepting the so-called Chætodon, or banded sunfish, all of the several species are pugnacious, especially when large. They should not be kept with other fishes unable to protect themselves, and it is inadvisable to have one much larger than its fellows, as it will "bully" the other inmates of the aquarium. Sunfishes have a decided carnivorous tendency, much preferring live worms or flies to prepared foods. They can be induced to take shreds of raw liver. Of the dry foods, ground dried shrimp is the best for them. The coloring of the Sunfish shows to excellent advantage in the aquarium, and it will be found a very tame and interesting pet. It can withstand severe temperature changes and will survive for years if suitably fed. Particularly destructive to aquarium snails.

Owing to their abundance the beauty of the members of the Sunfish family is usually overlooked. The Blue Spotted and the Long Eared of the Eastern United States, the Orange Spotted of the Mississippi Valley and the Blue Gill from Lake Erie are among the members which rival many of the tropical fishes. The Blue Gill is now widely cultivated in state hatcheries as a food fish, attaining the weight of a pound. It is one of the best fishes with which to stock a private pond.

\section{THE CHATODON}

\section{Mesogonistius chetodon}

Banded Sunfishes (known also as the Chætodon from its specific technical name, which was applied because the vertical bars or bands suggest the marine Chætodons or Angel Fishes of tropical seas) build their nests directly among plants off the bottom. They are less of fighters and depend more upon hiding their young than upon boldly protecting them. The Chætodon is one of the most charming of all aquarium fishes. Many of them are exported to Europe, where they are highly esteemed and bring good prices. This fish has quite an individuality-its peculiar markings, precise movements and genteel manners setting it quite apart 


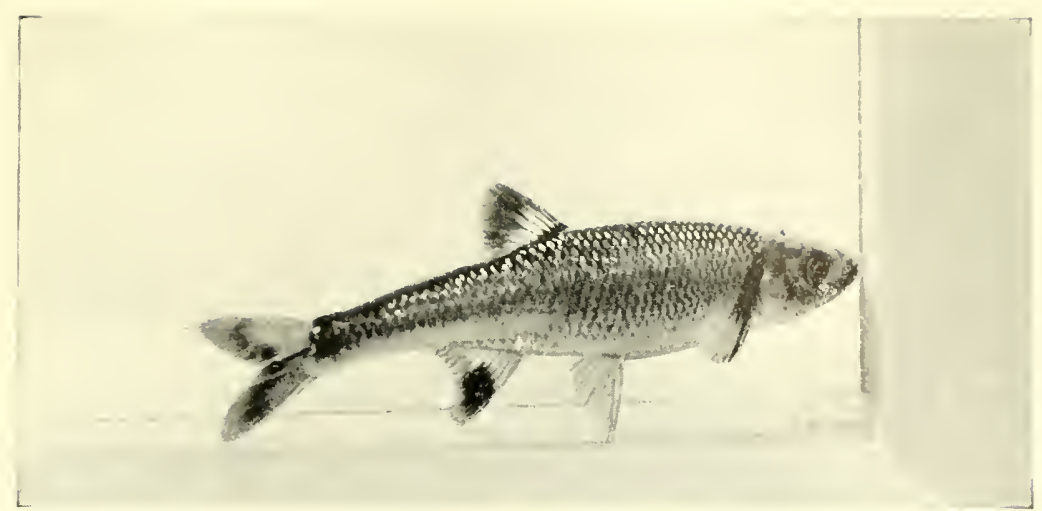

Fig. 121. SOUthern Minnow

A beautiful brilliant Minnow with a gorgeous brick-red color in the fins. Several of these were captured near Roanoke, Va.. but through misfortune they were lost before identification could be made. It is hoped others will again locate this beautiful fish.

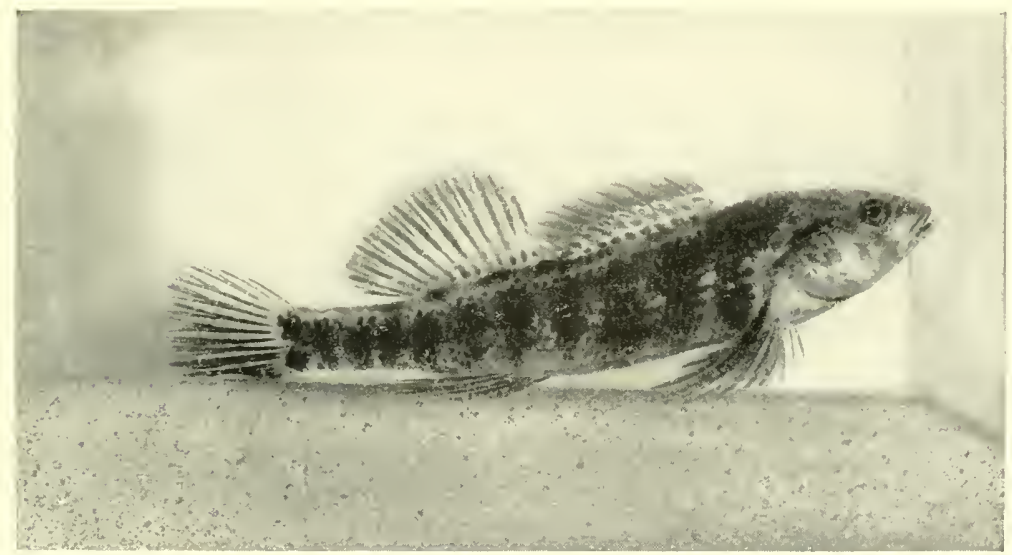

Fig. 122. The Rainbow Darter (Pocilichthys corrueleus) [Life size]

One of the most highly-colored of treshwater fishes, hence its name. Also termed the "Soldier Fish." 


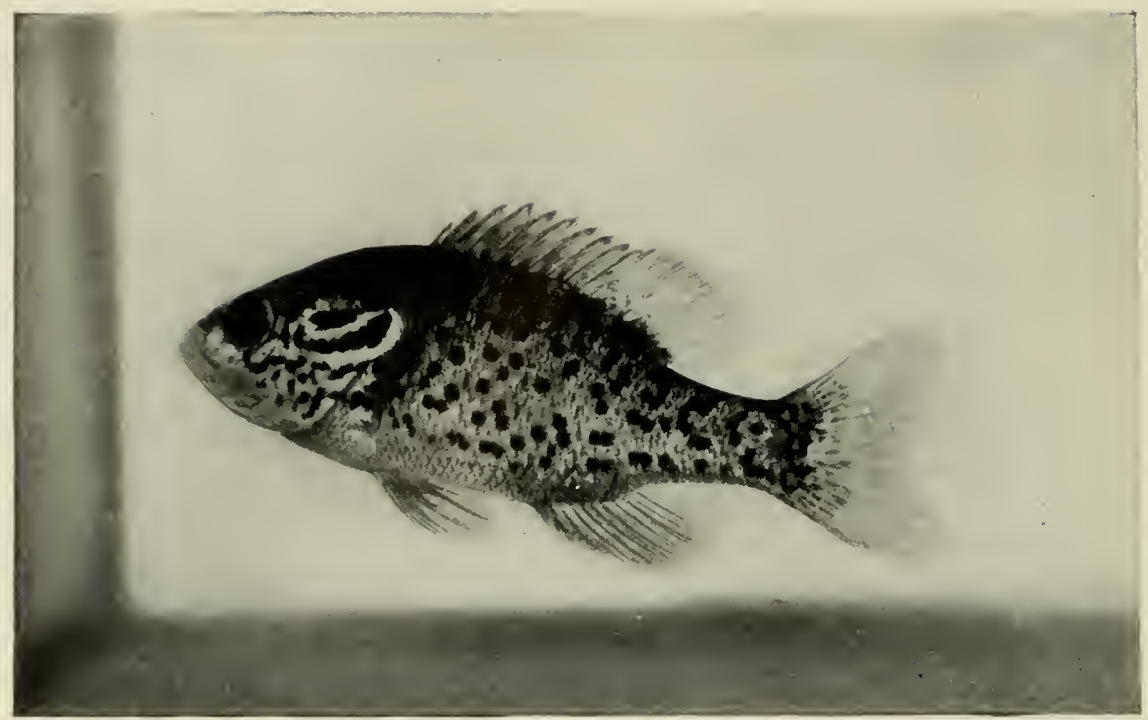

Hig. 123. The Orange-Spotted Sunfish (Lepumis humilus) [Two-thirds size]

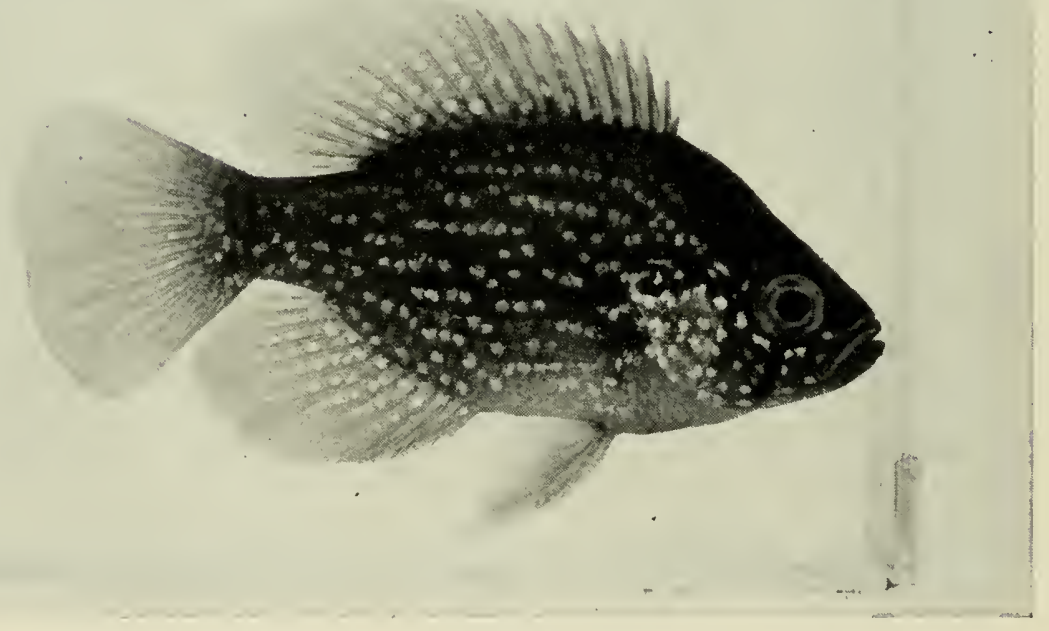

Fig. 124. The Blue Spot Sunfish (Enneacanthus gloriosus) 


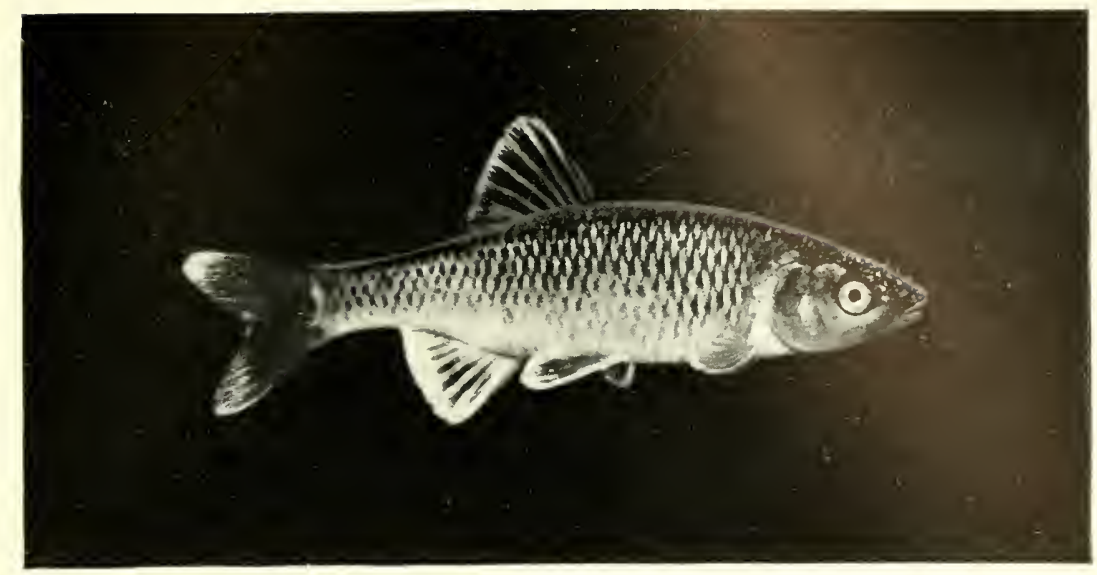

Fic. 125. Male Sulverfix (Notropis whipplii analostanus) [Slightly reduced]

Tubercles such as shown in this illustration appear on the nose and head of a number of fishes during the breeding seasun, especially on the males.

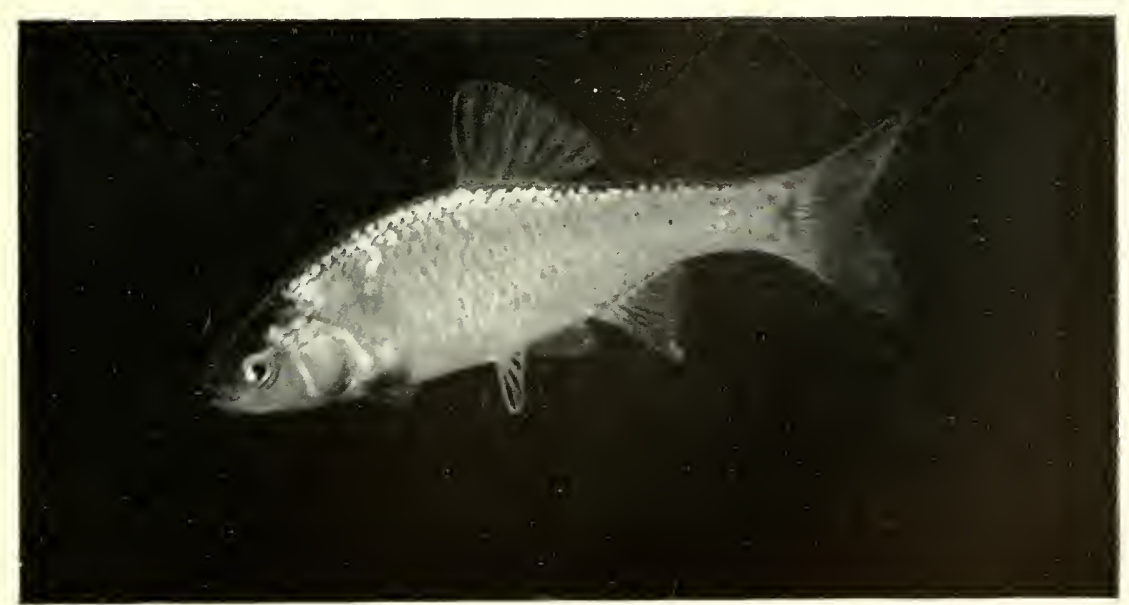

Fig. 126. FEMALE SILVERFin (Slightly reduced) 


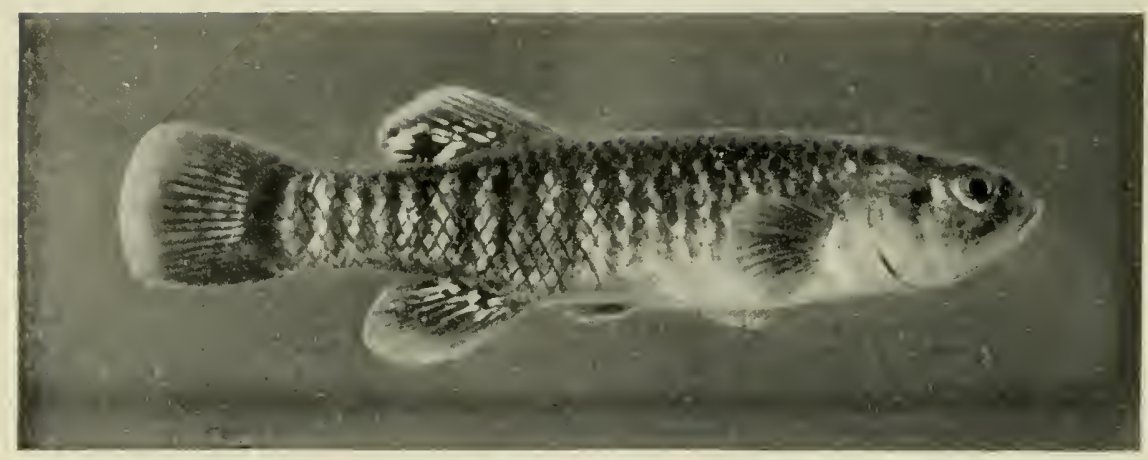

Fig. 127. The Kildifish (Fundulus heteroclitus) [Average size]

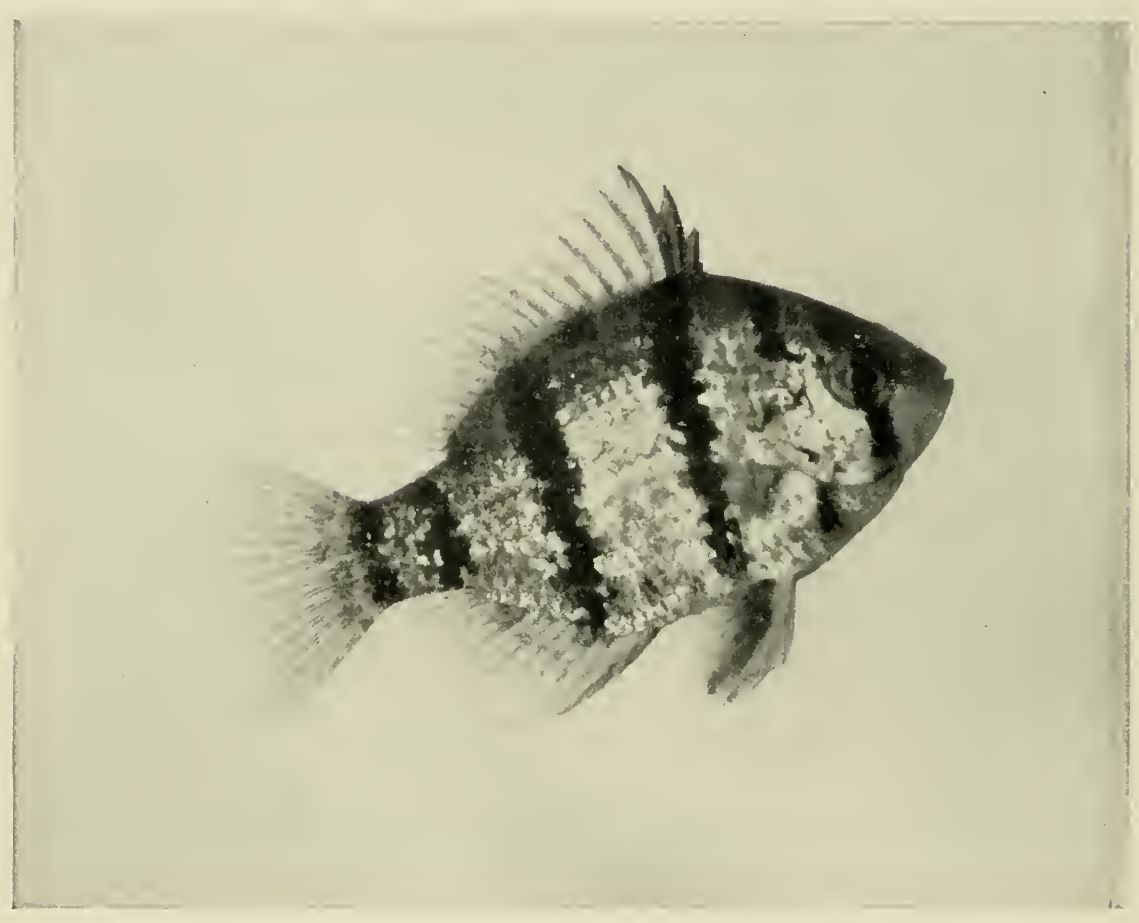

Fig. 128. The Black-Banded Sunfish, or "Ch.ætodox" (Mesogonistius chatodon; [Average Size] 


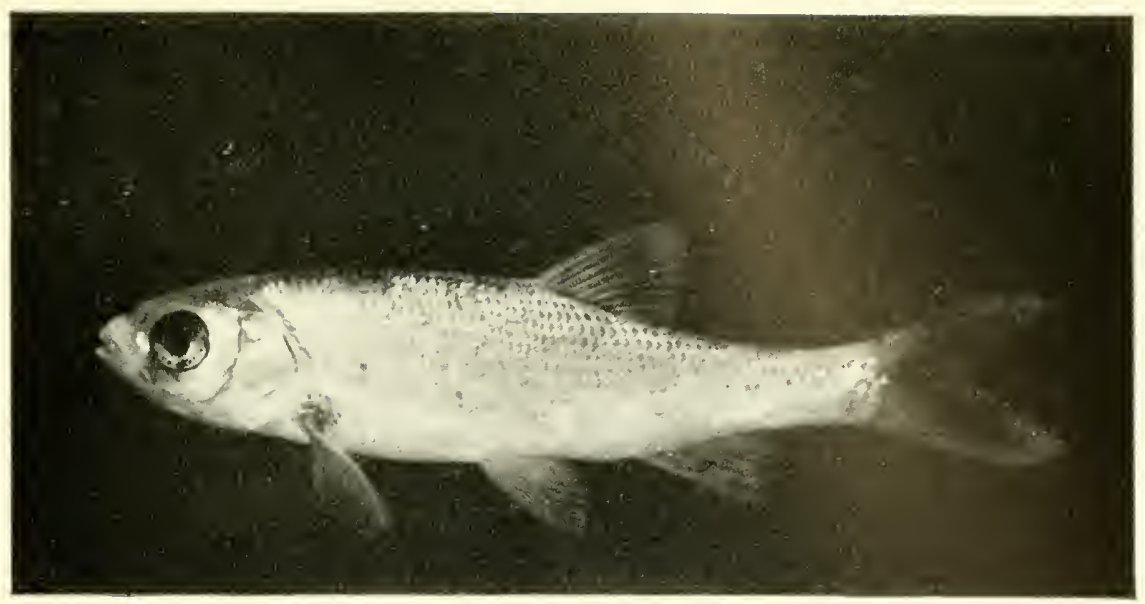

Fig. 129. Young Golden Ide (Idus idus)

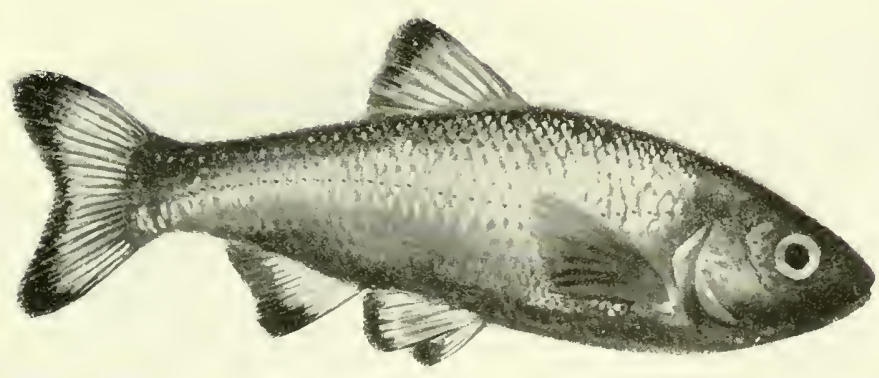

Fig. 130. The Redfin (Notropis cornutus) [Half size] 


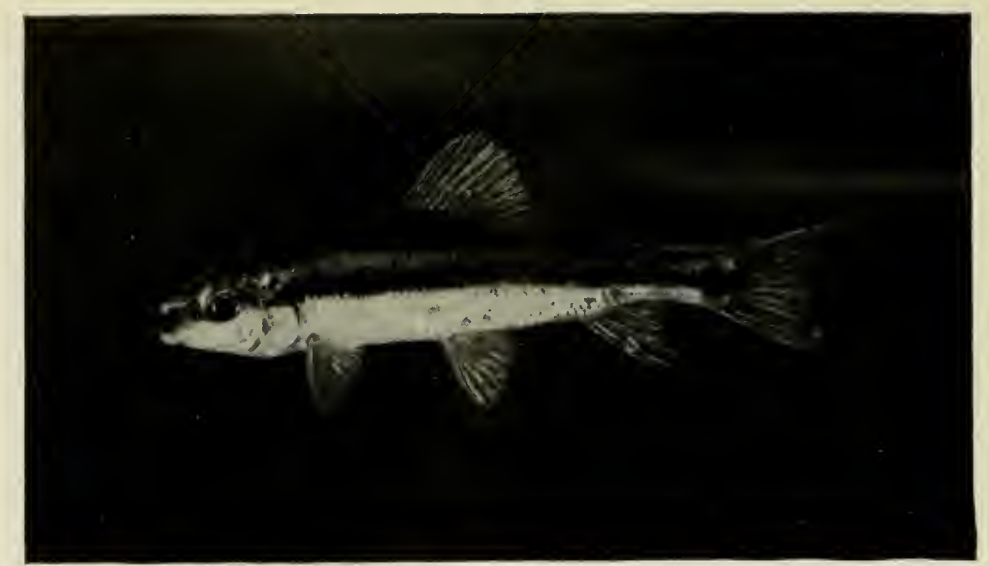

Fig. 131. MUllet or Chub Sucker (Erimyzon sucetta) [Young]

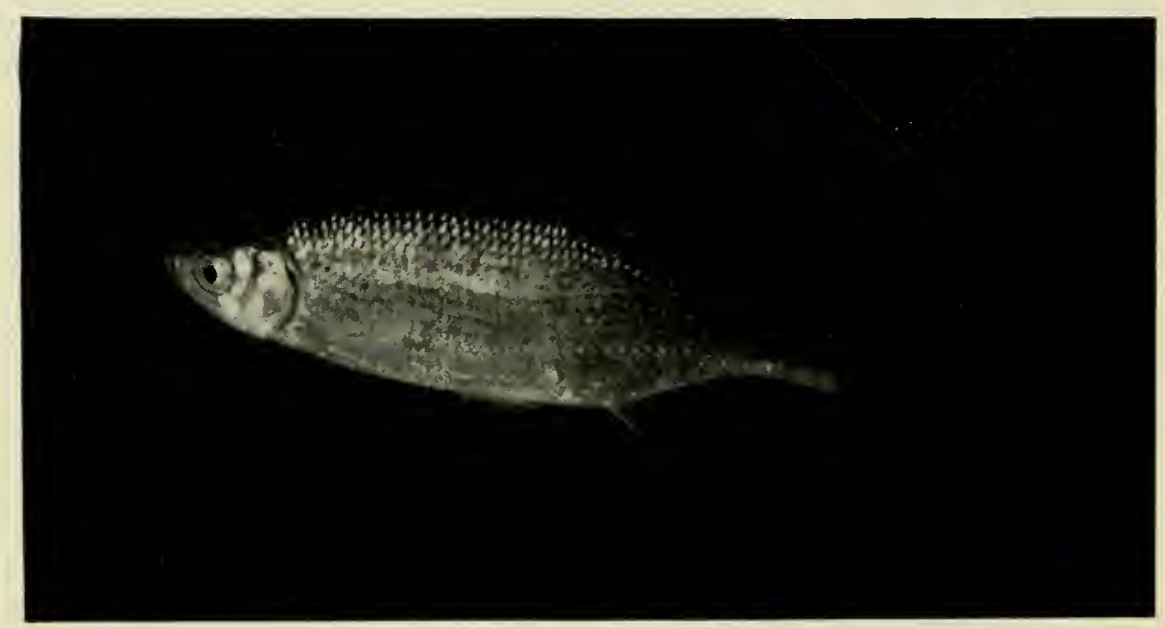

Fig. 132. THE SHiner (Abramis chrysulencas) [Average aquarium size] 


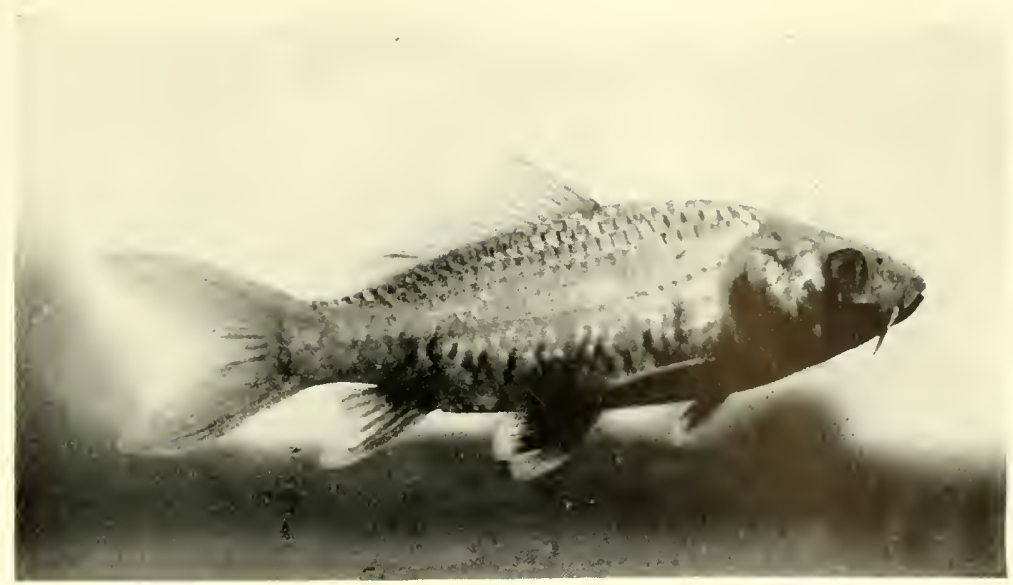

Fig. 133. The Colored CaRP (Cyprinus carpio) [One-third size]

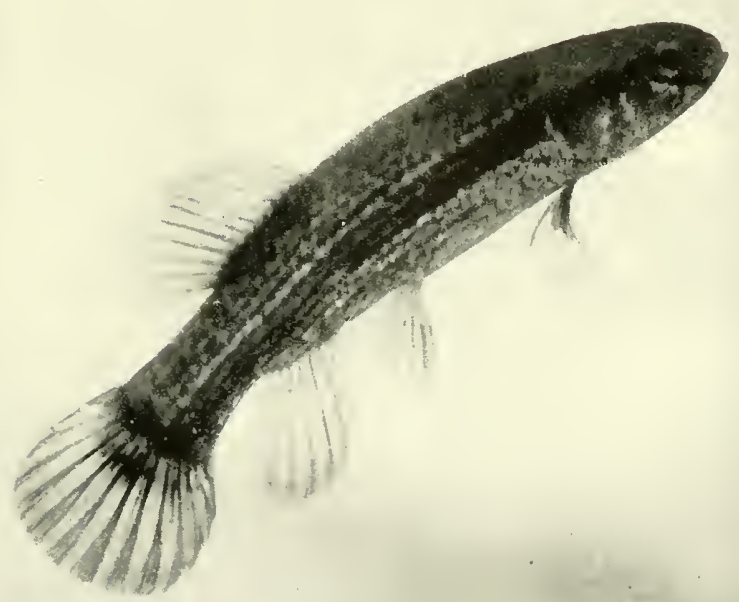

Fig. 134. The Mud Trout (Umbra pygmœa) [Average size] 


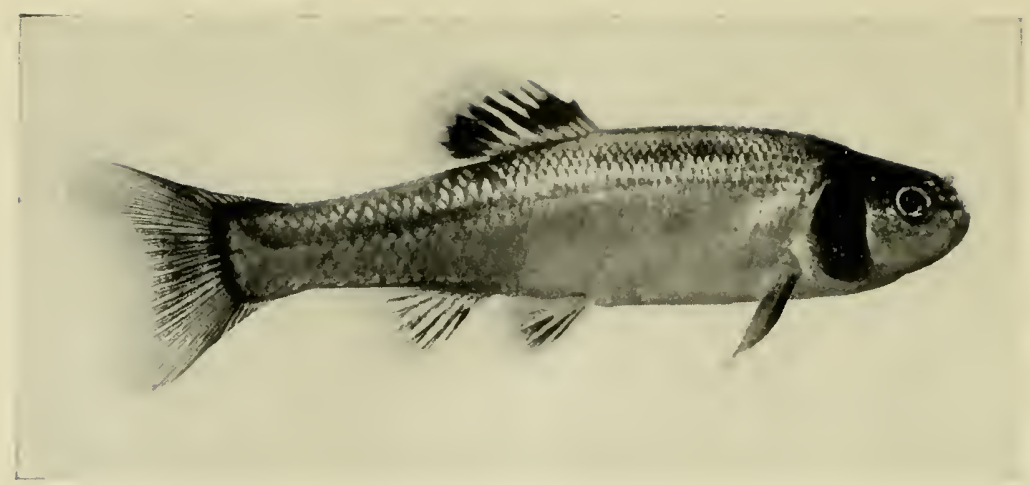

Fig. 135. Black-HeAded MiNow (Pimephales promelas)

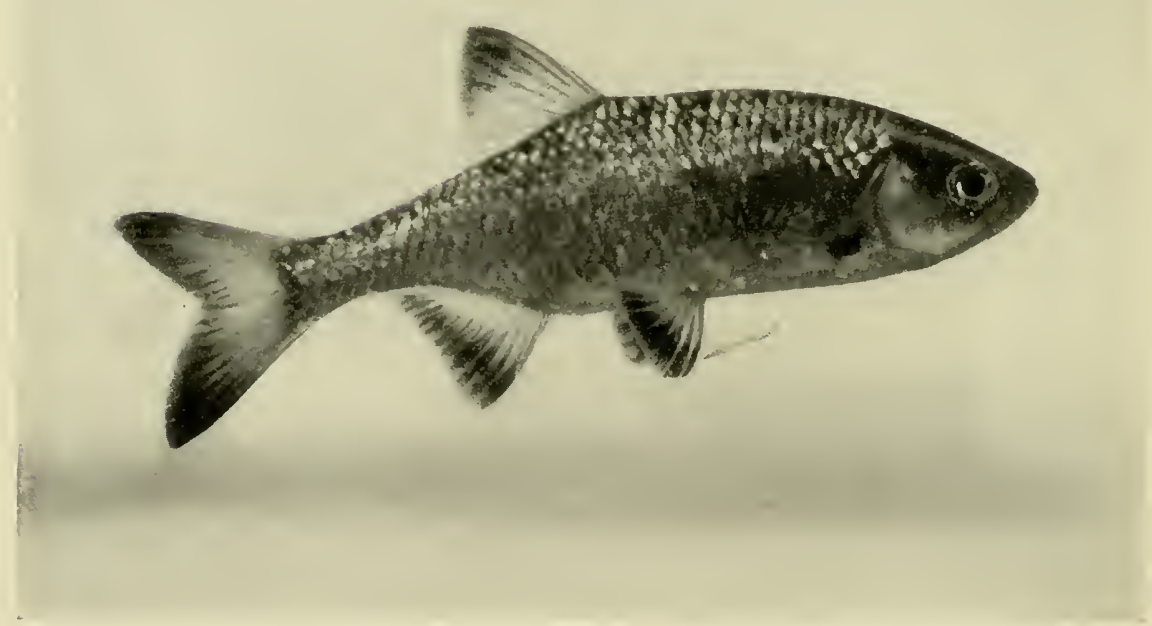

FIG. 136. The PEARl RoAch (Scardinius erythrophthalmus) [Two-thirds size] 
from most others. It swims principally by use of the pectoral fins, which are so transparent as to be scarcely observable, giving the fish the appearance of moving about by will-power, without physical effort. They greatly prefer live daphnia to all other foods, but do well on scrambled egg or particles of boiled shrimp. They are the only sunfishes that will not kill snails. Found in ponds and slow-moving streams from Pennsylvania to South Carolina. They are partial to the cedar swamps of New Jersey. At May's Landing is an excellent collecting point. The Chætodon often contracts a fatal fungus soon after capture, so the collector should be particularly careful not to overcrowd them in the carrying pail, and to give them the best possible conditions on arrival home. Once acclimated they are hardy if fed correctly.

\section{THE MULLET}

\section{Erimyzon sucetta}

Sometimes known as the Chubsucker, the Mullet in the smaller sizes makes a satisfactory aquarium fish, entirely harmless and of rather attractive appearance. The back is green, sides are yellow and abdomen is white. May be fed on ordinary fishfood but has pronounced vegetarian tendencies. The young are sometimes mistaken for Black-nosed Dace, but the difference is easily told by the mouth of the Mullet which is set lower and somewhat resembles that of the Sucker. Habitat, lowland waters of Eastern States.

\section{BLACK-HEADED MINNOW}

Pimephales promelas

The Black-headed Minnow is not well known as an aquarium tish. The contrast of black and silver as shown in illustration correctly indicates that the fish adds a note of novelty to a collection. The author kept them for a season and they appeared to be generally satisfactory. Habitat, Central and lower Mississippi Valley.

\section{THE RED-BELLIED DACE}

Chrosomus erythrogaster

This beautiful fish reaches a length of three inches and is one of the most satisfactory of hardy aquarium inhabitants. During the breeding season the belly, mouth and base of the dorsal fin of both sexes are bright red. There are two black lateral lines on the sides, separated by a band of pale gold, so that even when not in breeding colors, the Red-Bellied 
Dace is an individual of attractive appearance. It is perfectly harmless, will eat any prepared food and is of active habits. Native to the small streams of the Mississippi Valley. It is a community breeder, requiring larger space than the limits of most aquaria. The author placed six of them in a $3 \times 5$ foot tank in May and several months later took out 30 well developed young, but the breeding was not observed.

Owing to their extreme agility it is necessary to catch the wild stock in a minnow seine.

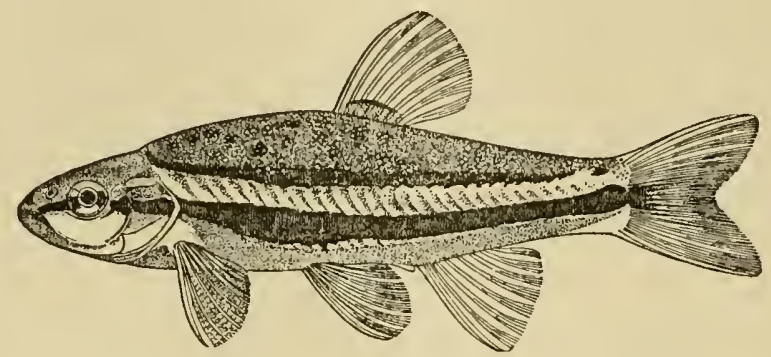

Fig. 137. The Red-Belied Dace (Chrosomus erythrogaster) [Life size]

There is little doubt that the majority who have kept this fish would vote it the most satisfactory of all small freshwater hardy aquarium fishes. It would be difficult to over-praise this little jewel, either as to appearance, hardiness or disposition. Midwestern dealers sell them.

\section{THE ROSY-SIDED DACE}

\section{Clinostomus vandoisulus}

One of the less known, but very attractive aquarium fishes is the Rosy-Sided Dace. The general color is silvery to green. A nearly black

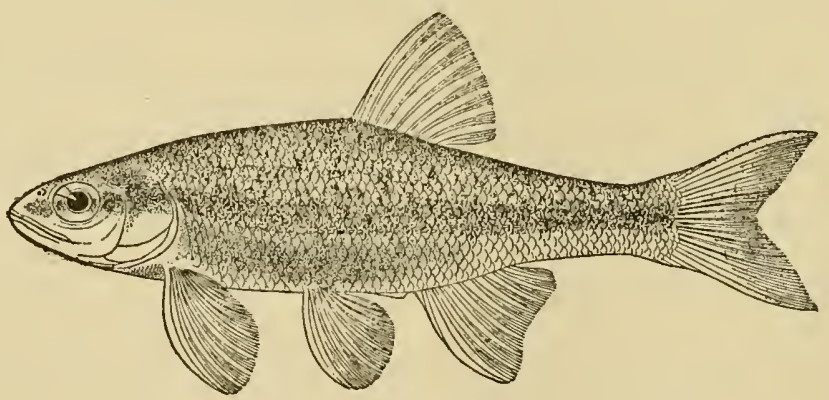

Fig. 138. The Rosy-Sided Dace (Life Size)

lateral line runs the length of the body, and below this on the males is a long patch of red, starting from the edge of the gills, as indicated in 
the illustration. This varies in intensity from day to day, and is brightest from February until September. As these fishes dart about the aquarium the flame-like appearance of the red patches is most striking. Even when not in color there is an interesting bronze-green effect to the scales at the lateral line. This is always visible by reflected light, and seems to show mostly at night. If the light is turned on them at night they show very little red color, but in a few minutes it is quite plain.

The Rosy-Sided Dace is a large minnow, takes kindly to the aquarium and is perfectly harmless, but unless plenty of room is provided it will slowly decline. Found in clear cool brooks, from the foothills of the Alleghenies, from Pennsylvania to the Carolinas.

\section{THE BLACK-NOSED DACE}

\section{Rhinichthys atronasus}

The Black-Nosed Dace is one of the best of our native fishes for aquarium purposes. Found in abundance in small swift-running streams

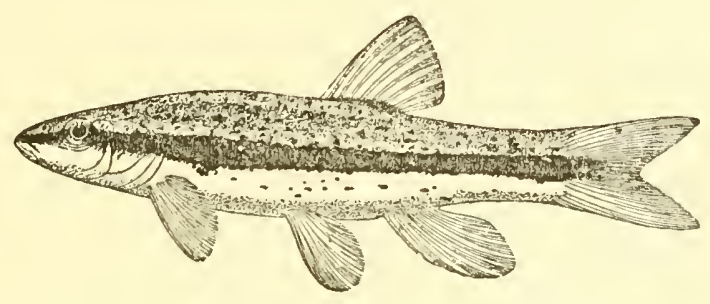

Fig. 139. The Black-Nosed Dace (Life size)

of the Delaware Valley, and is widely distributed over Eastern North America. It is an extremely active swimmer and not easily caught unless cornered in a small pocket. From constant swimming against the current it has developed some specialized kind of balance, so that when introduced into the still water of the aquarium, the forward part of the body continually drops so a level position is only maintained by an effort. This condition disappears in a few weeks and a new equilibrium becomes established.

The Black-Nosed Dace is well rounded and full of body, the belly is clear white and the black band encircling the body is quite intense. It is perfectly harmless and will take almost any food. It is quite subject to a parasite which embeds itself deeply in the sides of the fish, producing an appearance that can best be described as looking like "flyspecks." This is common to many of the small wild fishes, and while it is not known to have any serious results, it is unsightly. Specimens 
free from the parasite should be chosen where possible. The usual length is from two to three inches.

They have been known to survive in the aquarium for several years.

\section{THE STICKLEBACK}

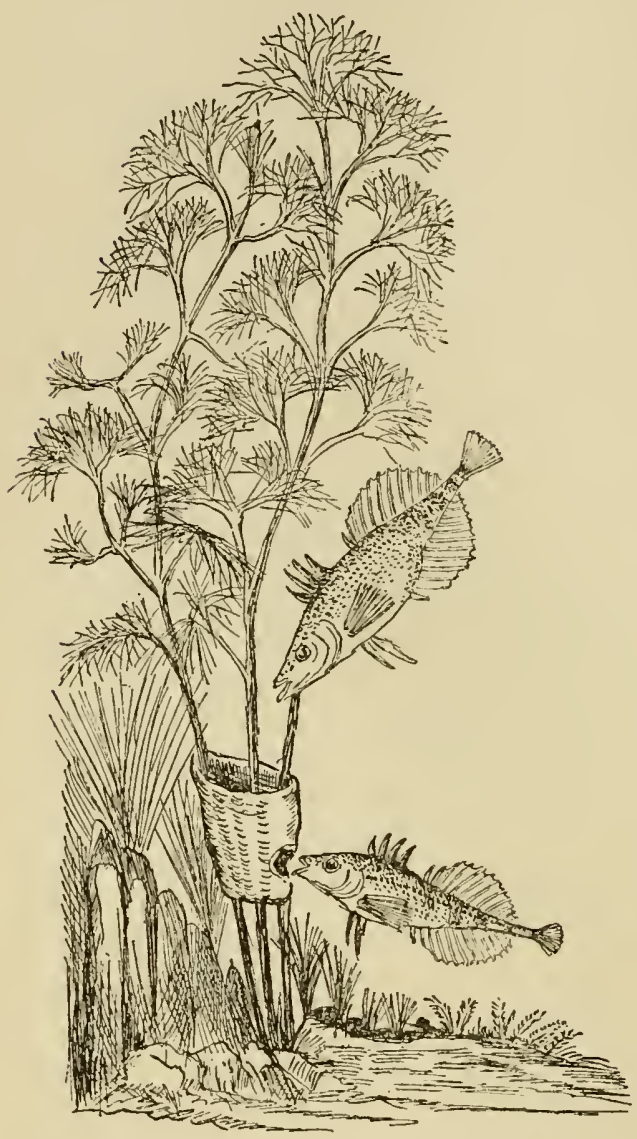

Froebel, the founder of the Kindergarten idea, wrote delightfully of the Stickleback. Perhaps that accounts for its being fairly wellknown, because it is seldom kept as an aquarium fishanyhow not in the United States. This is a pity, because its breeding habits are unique.

The male is the smaller, and during courtship (at least in the four-spine variety) the ventral fins become a fiery red. He selects a group of plants suited to his peculiar needs. From his body is exuded a substance which he attaches to the plants and proceeds to draw it into a silk-like thread which he continues to wrap round and round until he has constructed a wonderful little nest, such as shown in the illustration. An opening for water circulation is left in the side. The female deposits eggs in the nest and there her domestic duties end. Father

Fig. 140. Sticklebacks and TheIr Nest

Stickleback assumes entire charge, his principal duty being to keep up a circulation of water between the eggs. This he does by alternately blowing through the top of the nest and the side opening. Eggs hatch in about a week and for approximately ten days more he guards them jealously against all possible enemies, regardless of size.

Sticklebacks prefer eating live daphnia or chopped clams or oysters. They are not well suited to live with other small aquarium fishes. 
THE EEL

Auguilla rostrata

Small eels may be kept with a collection of wild fishes, but they look out of place with and are dangerous to goldfishes, having the same habit as the sunfish and catfish of nibbling at the long fins. They are good scavengers, quickly eating any dead snails or other decomposing matter. Nothing is too bad (nor too good) for them to greedily eat.

\section{THE CATFISHES}

Any of the forms of the Catfish are well able to take care of themselves in an aquarium. If not large they will not touch other wild fishes,

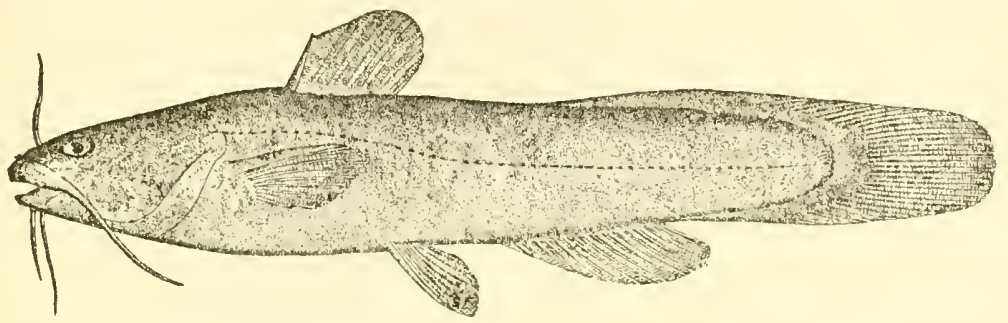

Fig. 141. The Stone Catrish (Schilbeodes insignis) [Slightly reduced]

but should not be kept with goldfishes, as they are likely to nibble at their long fins. Catfishes like animal food best, but will take boiled cereals or the usual prepared fishfoods.

\section{THE GOLDEN ORFE OR IDE \\ Idus idus}

Originally imported from Southern Germany, the Golden Orfe has become one of the best ornamental pond fishes. They do not stir up the

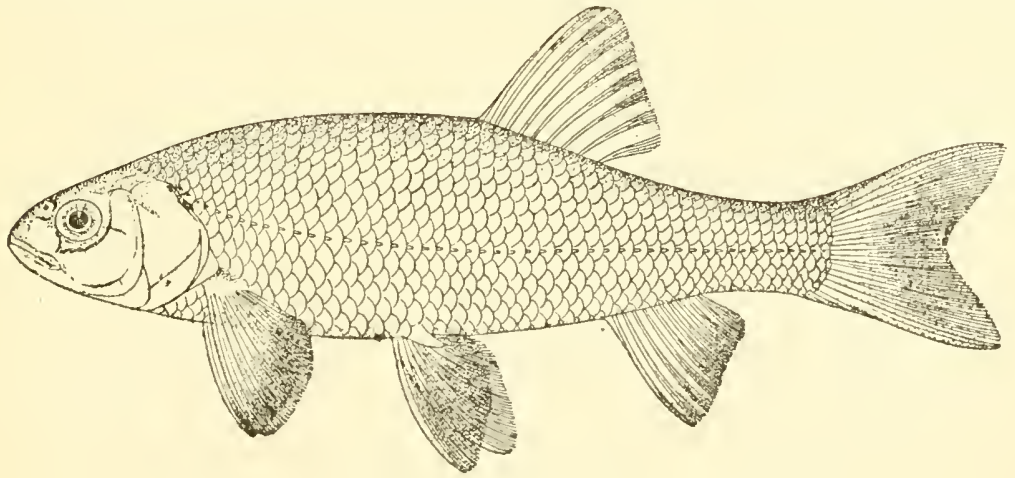

FIG. 142. The Golden ORFe OR Ide (Idus idus) 
mud as do goldfishes and are more active in avoiding their enemies. The color on the back is light orange, shading to lighter on the sides and white on the abdomen. The general appearance is not unlike a common goldfish, of a rather pale, brassy color. The extreme length is two feet, requiring probably ten years of growth under favorable circumstances. The young are suitable for aquarium keeping, but the top must be screened to prevent their leaping out.

\section{THE GOLDEN TENCH}

\section{Tinca tinca, aureus}

As a showy fish of golden orange hue the Golden Tench is considered second only to the goldfish itself. Covered with exceedingly fine scales and dotted with black it presents by reflected light an iridescent effect, comparable to that of an opal. By transmitted light they are sufficiently translucent to show the skeleton and internal organs. Although timid, they become quite tame and will live on any kind of fishfood. Harmless to other fishes and otherwise thoroughly desirable. Tenches should be bred in open ponds with mud bottoms.

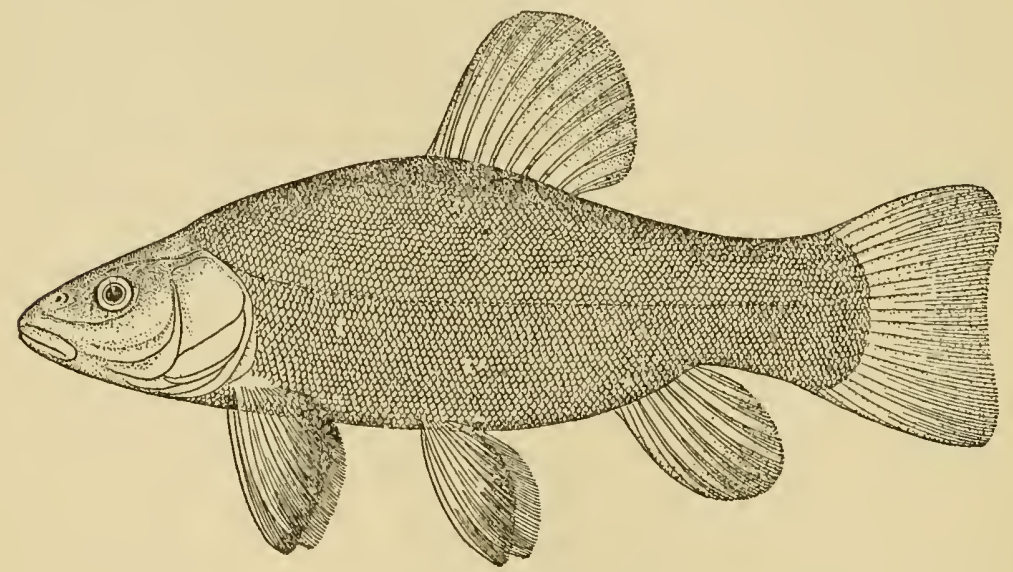

Fig. 143. The Golden Tench (Tinca tinca) [Young]

The Green Tench is the ancestor of the Golden Tench and differs only in coloring, its color being of a bottle-green character. "Tenchgreen" is a popularly recognized shade of color in some parts of Europe. Tenches are liberally supplied with protective slime and it is believed by some that fishes injured by accident search out a tench to rub the injured part against. For this reason it has been known as the "Doctor Fish." 


\section{THE SOLE \\ Trinectes maculatus}

Among the interesting novelties in aquarium fishes is the Sole, often known as the freshwater Flounder. It has been called the "aeroplane fish" on account of its easy, horizontal progress through the water, the swimming being accomplished mainly by an undulating motion of the fins at the edges of the body, as shown in the two upper figures of the accompanying illustration. The third figure indicates the under side of the fish, while the lowest shows the Sole as it lies half concealed

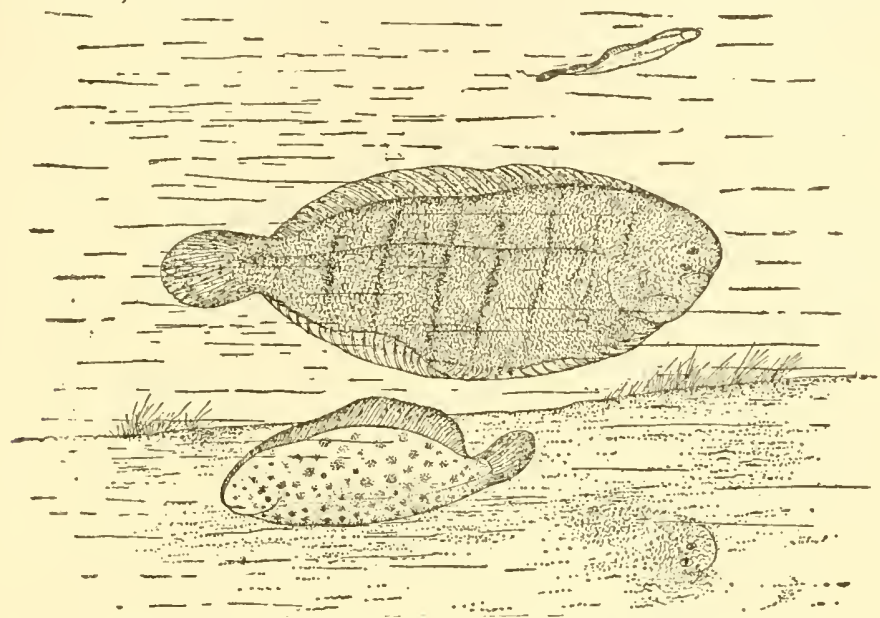

Fig. 144. The Sole (Trinectes maculatus) [Young]

in the mud. In the aquarium these fishes frequently fasten themselves flat to the sides of the glass by suction. They may be gathered from the muddy flats of tidewater streams of the Atlantic Coast. Chopped worms make a suitable diet for them. Sizes such as pictured are good aquarium inhabitants.

\section{FEEDING WILD FISHES}

The majority of native fishes when first subjected to captivity are timid, shy or resentful. Disturb them as little as possible for several days until they have grown into the confidence that they are in the hands of friends. Try feeding with small bits of tempting prepared fishfoods, small earthworms, white worms (see page 79), particles of canned shrimp or such other food as would seem to be particularly attractive to the kind of fish in question. If everything else fails it will be found that nearly all small fishes will eat live daphnia (figure 55).

A very good practice is to place newly caught wild fishes with suitable domesticated ones. They will then learn new ways and to eat new food surprisingly soon. 
CHAPTER THIRTEEN

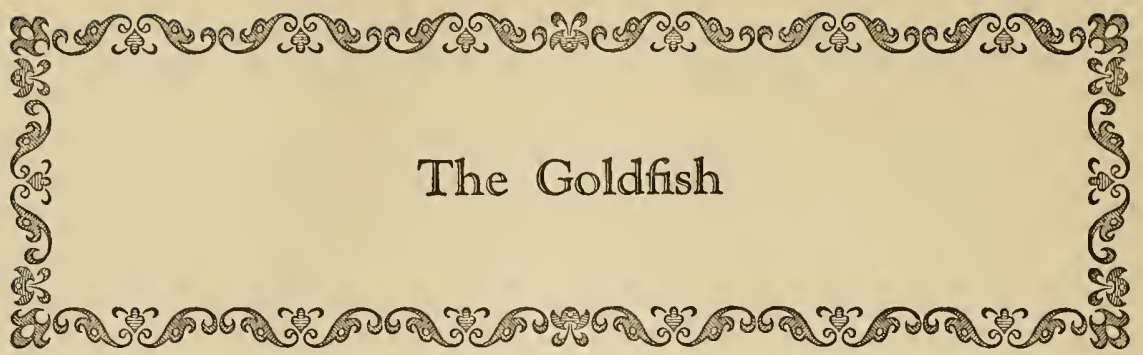

Whether or not the goldfish was first introduced into Europe for the amusement of that famed courtesan, Madame Pompadour, will probably remain an open question. Certainly we owe nothing to that beauty for the development of these wonderful fishes, but to the humble and patient Orientals who must have spent hundreds of years of tireless effort in selective breeding, which culminated in the marvelous specimens brought to America by Admiral Ammon in 1874. These and later importations formed the nucleus for a group of well-to-do enthusiasts, mostly in and around Philadelphia, to use as breeding stock. With particularly favorable local conditions the development of breeding these fancy or toy variations was rapid. Fine stock has for many years been sent to other parts of the country, and in some instances it has flourished.

There are two root-stocks from which the goldfishes of today have originated. Both are members of the carp family. The European goldfish, Carassius carassius, has never been developed into any of the fancy forms except by crossing with cultivated types of the Asiatic stock, Carassius auratus. The Orientals, as stated, and principally those of Korea, China and Japan, must be given credit for first establishing, by selective breeding, the goldfish as an ornamental pet, as well as for the incredible lengths to which they have gone in fixing fancy breeds.

Although a common American goldfish has been described by at least one writer, no such division properly exists. Those sometimes found in American waters are invariably from escaped or liberated stock from one of the two varieties mentioned, or from their hybrids.

The normal color of fish of both root-stocks is of a silver-gray or olivate hue, but with a strong natural tendency towards albinism, which produces occasional specimens of a yellow or golden color. By selective breeding these colors have become fairly well fixed, although in the scaled varieties the color is still at first carp-like, turning to gold, white or black, as a rule, in from three to eight months. Instances are quite common where they live to an old age without ever turning. 
Colors in Goldfishes. There are two great divisions among fancy goldfish-the scaled and the so-called "scaleless" classes. The scaled specimens are those having a metallic lustre, usually of red, white, olive-gray or black. The great majority of commercially bred stock belongs to the scaled division. The more prized colors in common goldfish are deep red (called "gold"), white (called "pearl") and a combination of the two.

Those of smoke-color are known as silverfish, their color and metallic lustre somewhat resembling tarnished silver. It is the ancestral carp color, and every "scaled" goldfish first passes through this color period. Breeders call them "uncolored," because they have not yet turned to one of the more desirable colors. Goldfish of the metallic or "scaled" type are liable to change color at any time, the least liable to turn being the white or pearl fishes. In young fishes the turning takes about a month after it starts, but in older ones it may take half a.year. After the first change from "silver," the rule is to progress towards a lighter color, that is, from black to red or from red to white. Exceptions are very rare. It will also be found that the lighter colors are the more persistent in breeding, and as these are considered the least desirable, it is well to avoid lightcolored fish when it comes time to select breeding stock.

The interesting patterns of red and black we often see and admire are not permanent. They are turning red.

Solid black is a color which for some unknown reason is confined exclusively to the telescope goldfish. In breeding telescopes it not infrequently happens that the abnormal eye development never takes place. These fish may develop any or all of the color peculiarities of their parentstock except that of being black. In the breeding of fancy goldfish any freak combination of characteristics seems liable to occur, but the writer has never seen a good black fish without telescopic eyes, although a number of reported cases have been investigated.

We have referred to "scaled" goldfish. The other division, not known to the general public, but which plays a highly important part in the goldfish fancy, is the "scaleless" variety. These fishes are really not without scales, but the scales are of such transparent character that they are scarcely perceptible to the eye. However, they usually show with moderate distinctness in a clear photograph. "Scaleless" fishes do not have the metallic sheen of the ordinary goldfish. The colors are more refined and present a far greater range of variety. The most important difference is the presence of blue and lavender tints. Among the scaled fish these are not found. A further account of these colors will be found in the description of the Calico Telescope on Page 184 and the chapter on Judging Goldfish Competitions, Page 194. Figure number 110 shows an unusually fine specimen of a young scaleless goldfish of the Calico type. 
Another important peculiarity of this type is that they never go through the period of being silverfish, but at the age of about six weeks commence to develop their permanent colors. The first color is white, sprinkled with small black specks. A good idea of the final color may be had in ten weeks, although as elsewhere remarked, the very finest of the calico colors are not fully apparent under two or three years. "Scaleless" fish have a charm of refinement distinctly their own and make most interesting inmates of the aquarium. So transparently scaled are some specimens that at the breeding season it is often possible to tell females by seeing the eggs through the translucent walls of the abdomen. The main objection to the transparently scaled fish is that the ribs or rays of the fins are rather weak. Soon after the fins have attained a high degree of development the fish is no longer able to hold them in a position where they will show to advantage. In the majority of instances the dorsal and caudal fins (the latter hereafter popularly referred to as "tails") commence to droop and sag in from two to three years, while the scaled fish often maintains an admirable stiffness of fins for years.

Length of Life. Although millions of common goldfish die annually at an early age under outrageously crowded conditions in miniature fish globes, they are endowed by Nature for a long life. Under fair conditions and proper management, they should live from ten to twenty years in an aquarium. In ponds where not subjected to severe winter conditions they will live at least thirty years, if not caught by enemies. The Fish Commission at Washington had a number of specimens over thirty years of age. Questions are frequently asked regarding the length of life of fancy goldfish, but these are always difficult to answer satisfactorily. A large proportion die under the age of 6 weeks. Of the remainder there are quite a few which do not develop rapidly, always remaining "runts." A few of these drop off from time to time during the winter, but in the early spring months they, and all other weak fishes, go rapidly, so that very few of the undersized are left by the first of May. Those passing this period are generally good for a few months more, when the death toll is rather heavy again. To answer the question in a general way, it might be said young fancy goldfish with a body length of not over 1 inch in October (no matter when hatched) are quite unlikely to live a year. Those from 2 to $2 \mathrm{x} / 2$ inches will average about three to four years under good conditions. Anywhere from six to twelve years can be considered a long life for a fancy goldfish, although well authenticated instances exceeding this are known.

Development of Fancy Breeds. In breeding single-tail fish together in which there is no known double-tail stock, one will sometimes find a fish with the lower lobe of the tail double, making it a reasonable suppo- 
sition that this was the first "break" in form away from the common stock. This is called a "tripod tail." The next higher development is the "web-tail," in which both tails are fully formed but joined at the top

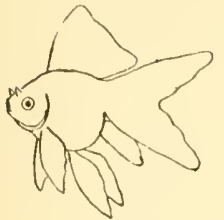

FIG. 145

Single TaIl

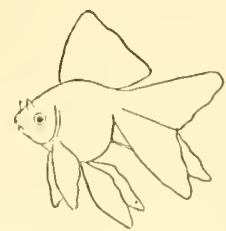

FIG. 146

TRIPOD TAII

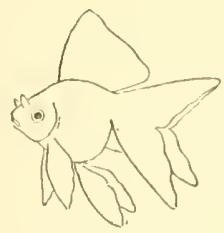

Fig. 147

WEB TAIL

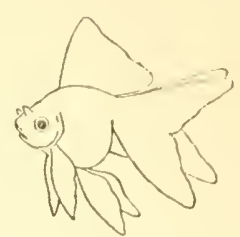

Fig. 148

DOUBLE TAIL

Evolution of Double TaIl or Fantail Goldfish

edge instead of being completely divided. From these early "breaks" have been developed the fully divided tails, double anal fins, et cetera.

The origin of those weird telescopic-eyed goldfish has been the subject of a number of fanciful theories, but there can be little doubt that the strain was produced by selective breeding from the individuals which showed more or less bulging eyes. This would be the correct scientific theory, and a recent discovery helps confirm it. The goldfish belongs in the same family as the minnows (Cyprinidce), and a minnow has been found in Nature with enormous and perfectly developed telescopic eyes, proving that the break is a natural one that might be expected to occur occasionally, and from which a strain of the same kind could be established, especially in a subject so readily bred as the goldfish. The specimen referred to is not a case of the disease called "pop-eyes," common to the sunfish and others. The eyes are purely telescopic and have been so determined by Henry W. Fowler, an ichthyologist of world repute who has specialized on the Cyprinidee. Fig. 167, an actual life photograph of the fish is convincing, but the preserved specimen can be seen at the Academy of Natural Sciences of Philadelphia. In life the fish was shown in a number of local aquarium society exhibitions.

By careful selective breeding, types have become fairly well fixed, but the goldfish has a strong tendency to revert far back to ancestral types, in form as well as color, often to the annoyance of the breeder. One of the most interesting things about a spawning of goldfish is the tremendous variety in the color. In a lot of a thousand young scaleless fishes there may not be two alike, and none may resemble either parent. That this is not always so is a self-evident fact, else selective breeding would be without results.

The accomplishments of Oriental breeders seem only to be limited by the scope of the imagination. Through the most patient efforts, not only of a lifetime, but of several generations of a family, such changes 
have been wrought in form and color that some of the breeds do not seem to even distantly resemble the common goldfish. That this is so is often evidenced by the fact that strangers to the fancy on first seeing a collection of highly developed fishes want to know what they are. An amusing incident illustrating this point occurred in the preparation of the present volume. An engraver who made the die for the front cover billed the publishers with "One Die of Butterfly"! Those outside the fancy sometimes seriously refer to the fins of fancy specimens as "wings." Among fanciers a high dorsal fin is often referred to as the "sail." One of the interesting side-lights on almost any fancy is the spontaneous development of new words to fill special needs, and which will not filter into the dictionaries for a long time. In this particular connection we are reminded of the current use in the goldfish fancy of the word "finnage," meaning the total area and style of the fins. One might say, "This fish has beautiful color and body shape, but the finnage is poor."

When it is borne in mind what a considerable period of time must have been necessary to bring about these strange breeds, it is not surprising that radical ideas and characteristics should, to a certain degree, be expressed in them. The Telescope Goldfish was originated in China and undoubtedly bears a resemblance to Chinese art. It has a sort of beautiful ugliness, a deliberate grotesqueness, intended first to shock and then excite curiosity. The wonderful range of colors, too, suggests the art of the Chinese-that race which continues today to lead the world in the clever use of color. The Japanese Fringetail Goldfish is another expression of national art. It is the very embodiment of that æsthetic elegance and grace so well understood by the Japanese people. America has not been without its logical contribution. Here in this vast melting pot it is our desire to bring forth combinations of the best from the old worlds, to which is added a touch of our own individuality. Although we have made several other combinations in crosses, the two most important are the Veiltail Telescope and the Scaleless Fringetail.

It is believed that the first cultivated goldfish came from Korea, that country from which even ancient China borrowed ideas, education and arts, but so little is known of this that we have to take our facts as we now find them. That there have been and are breeds of goldfish in both China and Japan which have never been exported is well attested by travelers and by a book published in Paris in 1870, by de Sauvigny. This remarkably illustrated work shows many of the varieties in color. The only known copy in the United States is in the reference library of the Academy of Natural Sciences, Philadelphia, where it will be shown those interested. The fact that several of our known breeds are correctly illustrated gives reason to believe in the drawings of the unknown varieties. 


\section{THE COMMON GOLDFISH}

The common Goldfish, being closely related to the original stock, has most of its characteristics. It is very hardy, can withstand extremes of temperatures if brought about gradually, can remain out of water for several hours when kept moist, will eat almost any food, is easily tamed and is a prolific breeder. The body is rather long and flattened on the sides. The head is short, wide, and without scales. Names of the different fins should here be carefully noted, as they are frequently re-

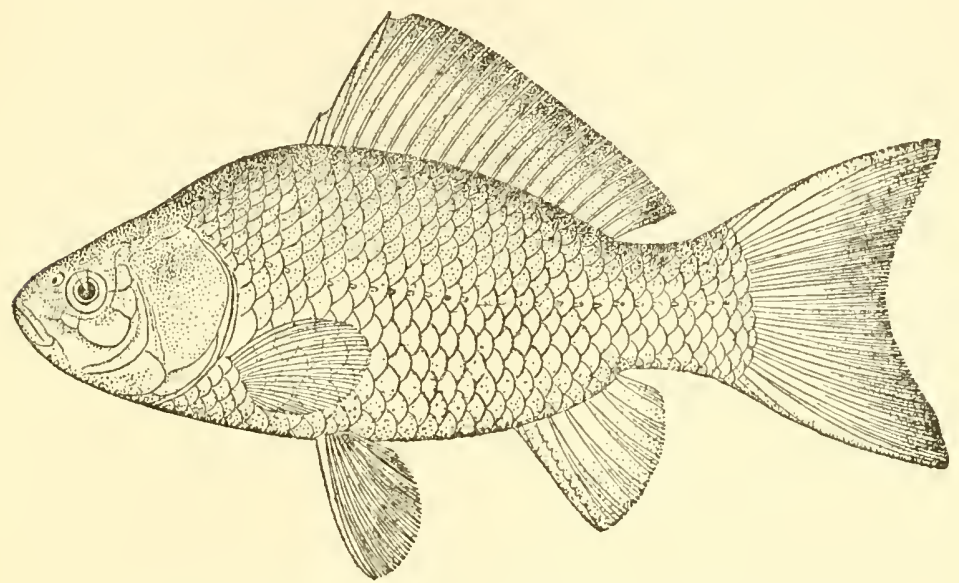

Fig. 149. The Common Goldfish (Carassius auratus)

ferred to in other parts of this work. The Dorsal Fin (on back), the Caudal Fin (the tail) and the Anal Fin (small fin nearest tail) are all single in the Common Goldfish. The Pectoral Fins (nearest head) and Ventral Fins (nearer lower centre of body) are paired.

One of the easiest characteristics to fix in a breed is the lengthening of the body and fins. This brings us to a description of the first of the fancy goldfish varieties or breeds.

\section{THE COMET GOLDFISH}

The first of the long single-tail breed appears to have originated in the ponds of the Fish Commission in Washington in the early eighties. Mr. Hugo Mullertt either secured some of this stock or later originated a strain of his own. At any rate, he was the first to place them on the market in quantity. The Comet is long of body and fins, the tail in particular being very free-flowing. In movement this fish is the most graceful of all the fancy goldfishes and it can swim with great rapidity when necessary. This activity has made it easy for the fish to revert to its ancestral tendency to leap out of the water. Aquaria containing Comets 
should be covered by a screen, particularly in spring. The Comet makes the most beautiful and generally satisfactory pond goldfish where a

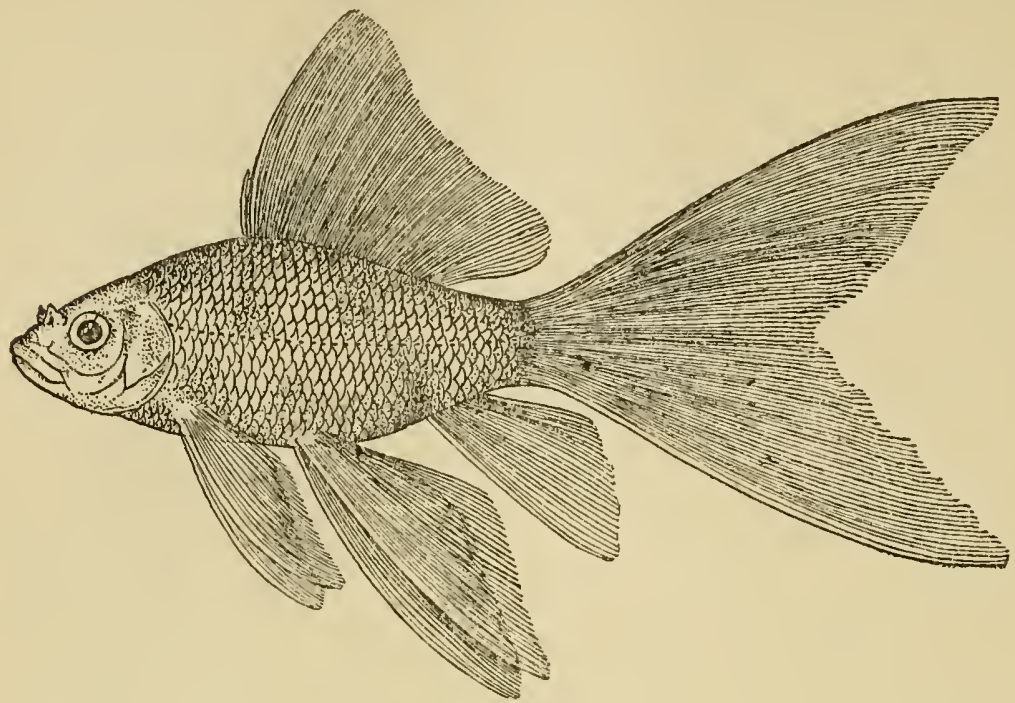

Fig. 150. The Comet

decorative effect is desired. They are perfectly hardy over winter in a deep pool where the water does not freeze to the bottom. The type breeds quite true to form and many thousands of them are raised annually.

\section{THE SHUBUNKIN}

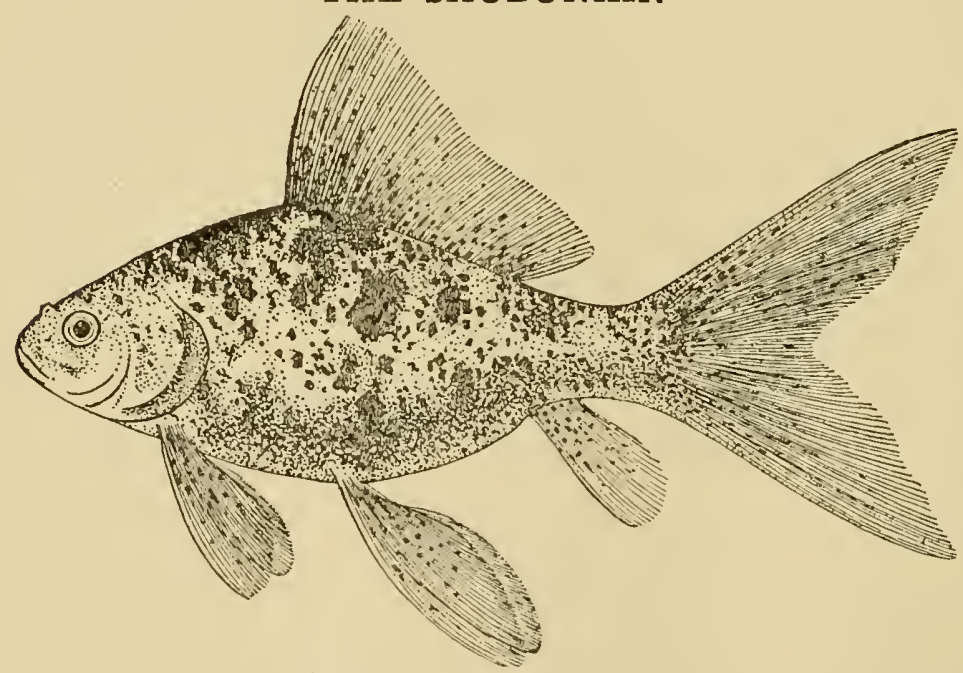

Fig. 151. The Shubunkin

One of the more recent introductions is the Shubunkin. This is simply a transparently scaled, highly mottled, common goldfish. All breeders 
of fancy stock occasionally get fish which are known as "sports" which have reverted back in form, but not in color, to the original type. The Japanese have now fixed them as a breed, and export a fair number of them. They are of the most striking variations in color, and make a hardy, attractive aquarium or pond fish. The colors most sought after are blue backgrounds, sprinkled and mottled with dark red, brown, yellow and black.

\section{THE FANTAIL GOLDFISH}

To the popular mind this type represents "fancy goldfish." It is the "fantail" of commerce and is propagated in enormous quantities in America, Japan and Europe. Being of comparatively long body and not burdened with excessively long fins, it is healthy, agile and well able to take care of itself in culture pools. In a well maintained aquarium it

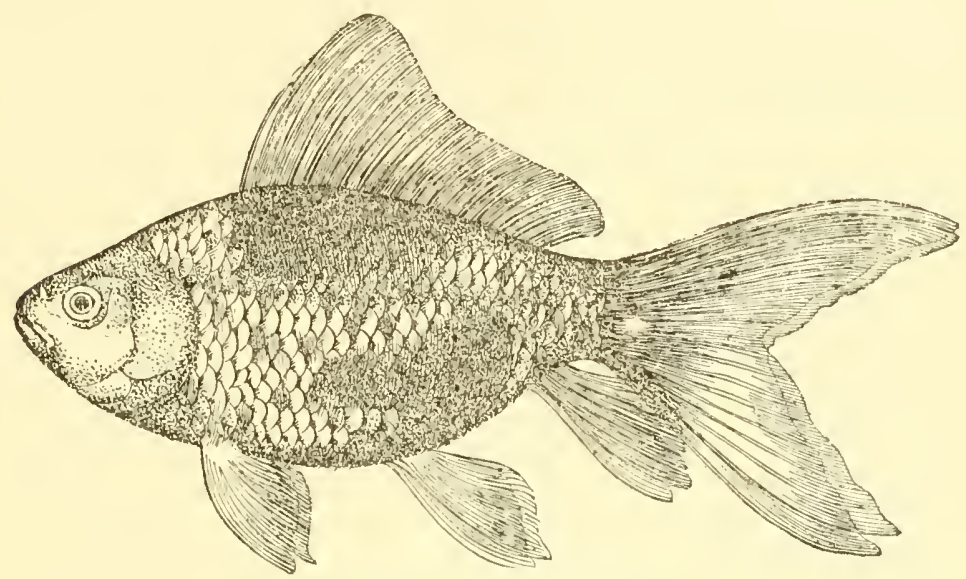

Fig. 152. The Fantail

ought to survive for years. Those who succeed in keeping them in an aquarium for a year or two are sometimes pleasantly rewarded by having their pets develop long, graceful fins.

\section{THE JAPANESE FRINGETAIL GOLDFISH}

In point of pure elegance there is no breed of goldfish equal to the Japanese Fringetail. Our illustration is taken from a sketch of the fish, made by its owner. A few words regarding this, probably the bestknown individual fish that has ever been owned in this country, might be of interest. The Japanese Imperial Government sent a collection of its best goldfish to the World's Fair at Chicago in 1893. Only a few of them survived the journey and still fewer lived through the Exposition 
These had fallen into a diseased condition and were given to Mr. William P. Seal. He cured them and later sold this one, now known as "The World's Fair Fish," to Mr. Barrett, for a comparatively small consideration. At that time the fish had not developed the wonderful qualities which have made it famous. It was one of those cases where "blood will tell."

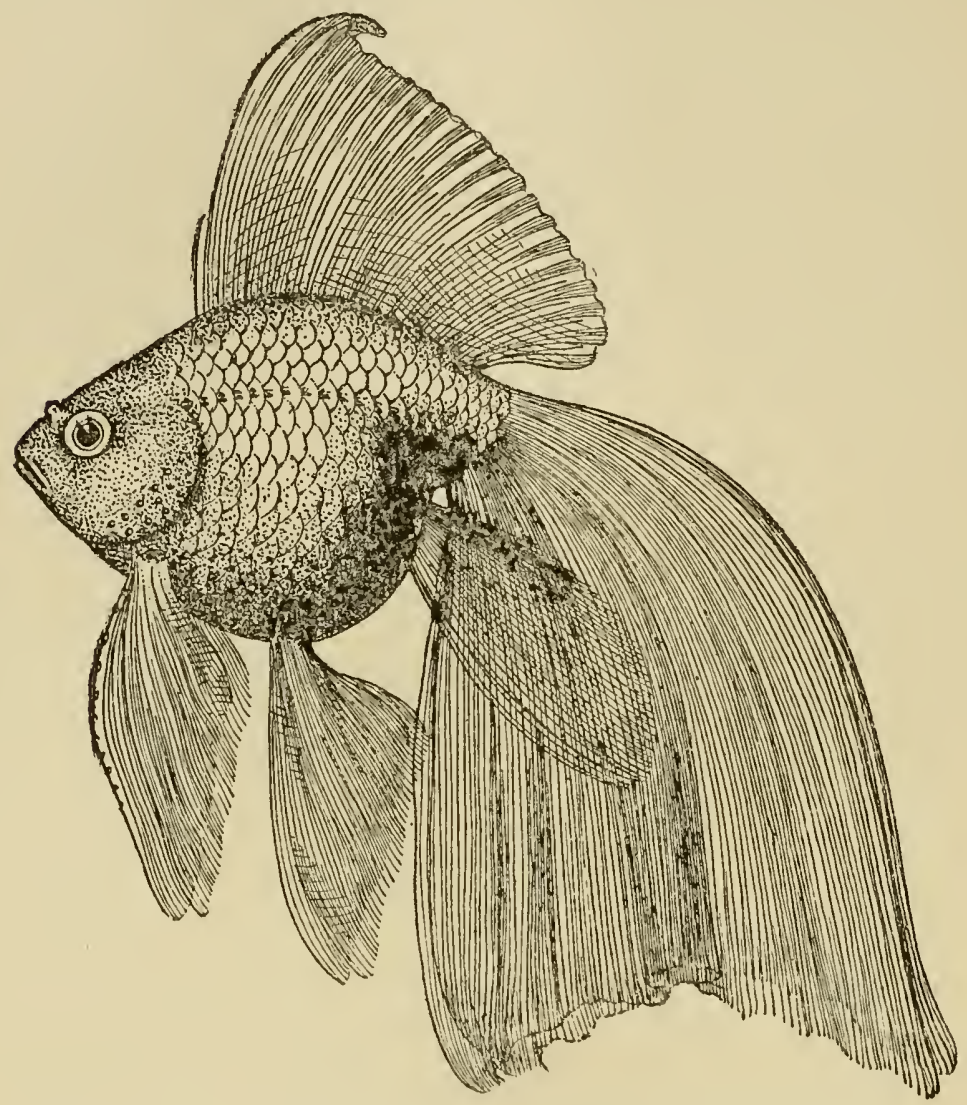

Fig. 153. The Japanese Fringetarl (Veiltail or Broadtail Type)

Regarding this fish as a type of perfection that could not be improved upon, the Aquarium Society of Philadelphia had a drawing of it made from a sketch and used as a society emblem. The society later had the fish struck on its medal. It lived to an age of about fifteen years.

The characteristic points of the Japanese Fringetail are brought out in the illustration. The body is short, rounded and chunky, with short head and flat eyes. The lower fins are long, pendant and delicately lacelike, and are all paired. The dorsal fin is as high as the body is deep. It should be carried erect, producing the effect of a sail as the fish moves 
grandly through the water. As in most other varieties, the deeper colors, both in scaled and scaleless specimens, are the most highly prized. Scaleless Fringetails, the American production obtained by crossing Japanese Fringetails with Chinese Scaleless Telescopes, are exceedingly refined in appearance.

The illustration shows the tubercles or "pearl organs" on the gill plate and pectoral fins, usually indicative of the male sex.

\section{THE JAPANESE NYMPH GOLDFISH}

The Nymph is virtually a single-tail Fringetail. The anal fin and tail are single. The latter, instead of drooping, should be carried out straight, and well spread. This fish is usually a "sport" from Fringetail

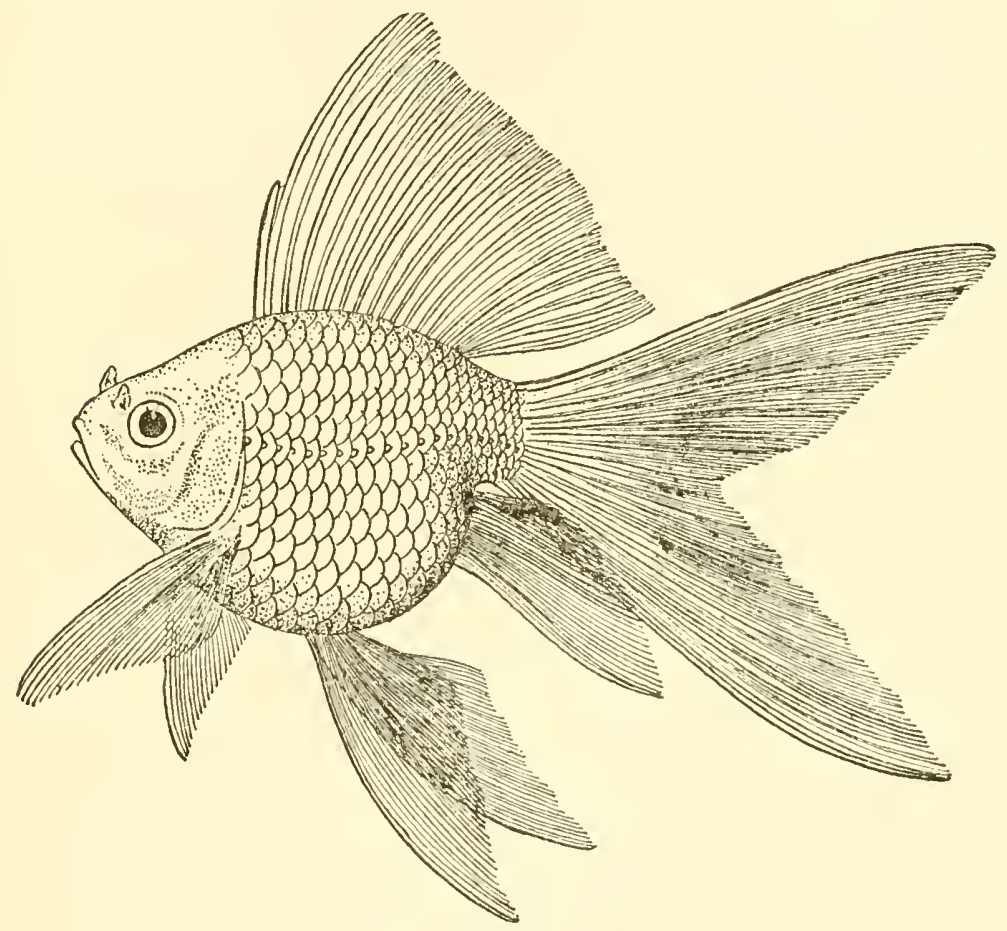

Fic. 154. The NyMpH

stock. Although seldom deliberately bred, fine specimens are very attractive in an aquarium and are often retained by fanciers. In their active movements, as well as in points of conformation, they make a pleasing contrast with the double-tailed varieties. One of the principal features is the dorsal fin, which should be large and carried quite erect, as described for the Fringetail. The body requirements are also the same. 


\section{CHINESE TELESCOPE GOLDFISH}

This most curious fish is either of Chinese or Korean origin, but was undoubtedly brought to its highest stage of development in China. The name correctly implies its chief peculiarity-projecting eyes suggestive of a telescope barrel. These make a very weird appearance, and almost without exception produce a shocking impression on being seen for the first time. Telescope eyes vary quite considerably in shape and in direction. The majority of them are spherical or conical. Tubular eyes

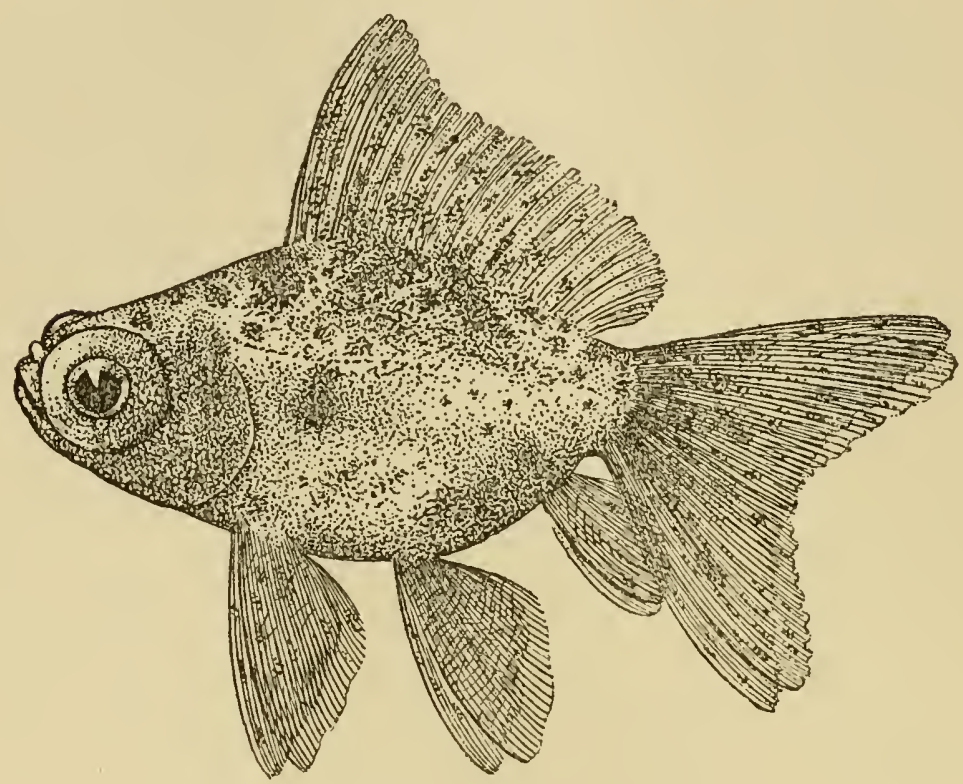

Fig. 155. Early Type Chinese Telescope

are rare and highly prized, but any form is considered good so long as they are large and stand out far from the head. Most telescope eyes point in the same direction as normal eyes, but some point forward. This is unusual. The Celestial Telescope has still more peculiar eye formation. This is described under its own heading.

One point in common between all Telescope goldfish is that in the early weeks of life the eyes appear entirely normal. Until they actually start to "develop eyes" at anywhere from two months to even two years, it is impossible to tell whether or not they will become Telescopes. The usual development period, however, is from three to five months. Should they pass ten months without turning, they may be safely called Japanese Fringetails. Many such fish that have come from Telescope stock are 
used to breed to Telescopes to produce Telescopic young. This is usually successful in the first generation, but it has a tendency to spoil the breed by gradually reducing the size of the eyes. Telescope fishes of the present time are, for the most part, considerably inferior in point of eyes compared with the stock of the first years of the present century, due mainly to breeding too exclusively for short bodies and long fins. Artificial type characteristics in any kind of breeding can, like liberty, only be maintained at the price of eternal vigilance.

\section{THE CHINESE SCALELESS TELESCOPE GOLDFISH}

As before stated, "scaleless" is somewhat of a misnomer, the fish being transparently scaled, making the scales difficult to detect. We use the word "scaleless" in its accepted popular sense.

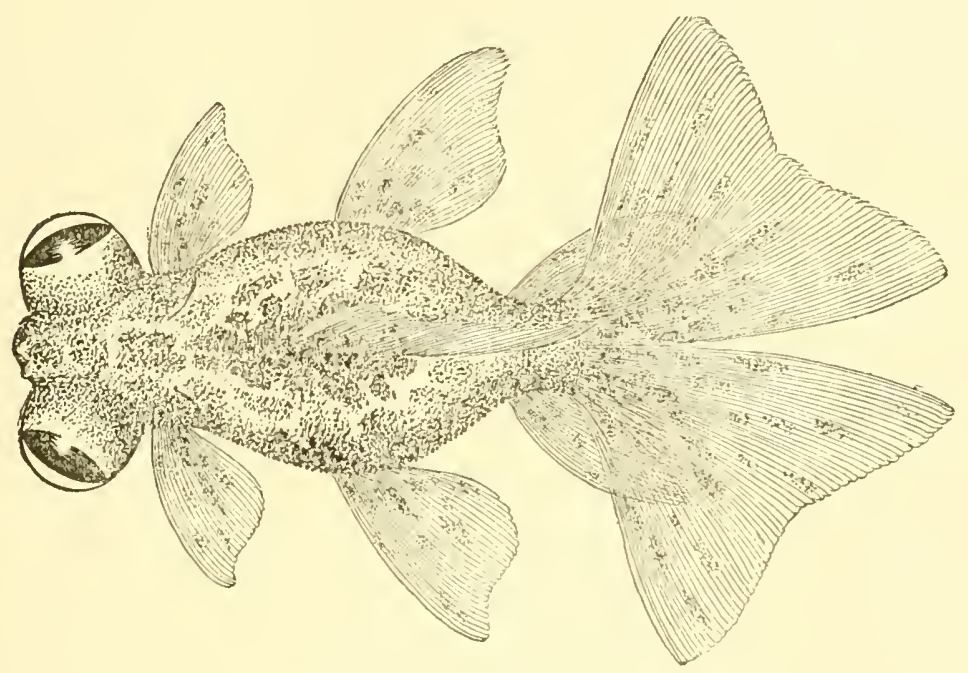

Fig. 156. Chinese Scaleless Telescope (Dorsal view)

Fish of this general division are divided into two color classesPlain Scaleless and Calico. The Plain Scaleless is red, white or a combination of the two. Red in scaleless fish is quite different from that in scaled varieties, being more of an oxblood color, producing a highly refined appearance. In scaleless fish the bodies do not have a metallic lustre. The colors seem as though they had been laid on by the delicate hand of a water-color artist. These fish have white fins, sometimes dotted with black, and rarely mixed with red. During the first few months the roots of the tails are usually dark, but this gradually disappears. 
The Calico Telescope, from the viewpoint of the fancier, is the most important member of the family. To excel in breeding it is the ambition of many. When a prize is offered at a competitive exhibition "for the best fish shown," it will nearly always go to a Calico Telescope goldfish. Its name is suggestive of its coloring, but the colors are by no means in geometrical arrangement, as they are in fabric. Red, yellow, brown, gray, black, blue and lavender are laid in fantastic blotches and spots over the body, usually on a lighter background. Many small dots of black are sprinkled over the body and fins. In extra fine specimens red dots will also appear in the fins. Note figure 110. The color chiefly sought is blue, and the more blue the more valued the fish.

\section{THE SCALELESS VEILTAIL TELESCOPE}

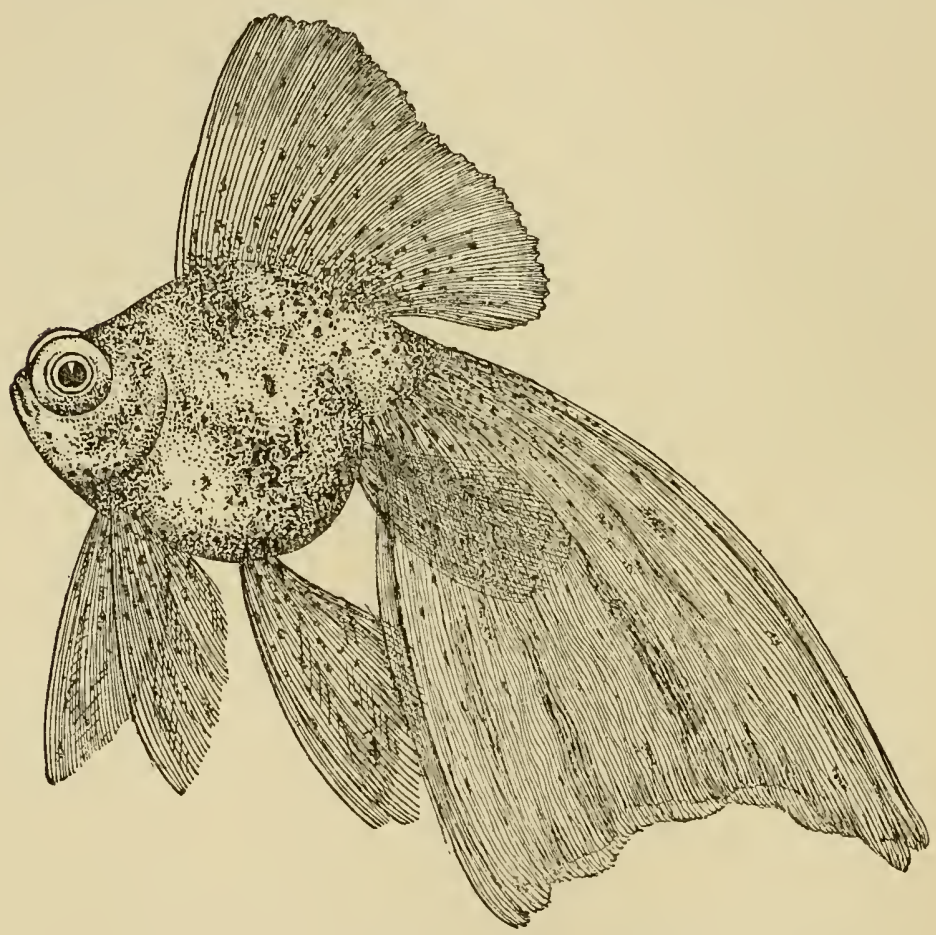

Fig. 157. Ideal Veiltail Calico Telescope

While it is true that some of the early Chinese scaleless importations had broad tails and medium length bodies, it is highly probable that none of them equaled in short bodies and long fins the present American standard type. We crossed Japanese Fringetails with Scaleless Chinese 
Telescopes, thereby producing two new varieties which have become permanent-Scaleless Japanese Fringetails and Scaleless Veiltail Telescopes. Both have been bred for broad-tail qualities (veiltail), and may be considered an American variation. The characteristic points of the Scaleless Veiltail Telescopes are the same as those for the body and fin formation of the Japanese Fringetail and the eyes and coloring of the Chinese Telescope. The coloring almost always tried for is calico, but if a fish fails in this and still retains the other characteristics of the breed, it is considered a good fish. If the fish turns out black, it comes under the following classification.

\section{THE CHINESE MOOR TELESCOPE GOLDFISH}

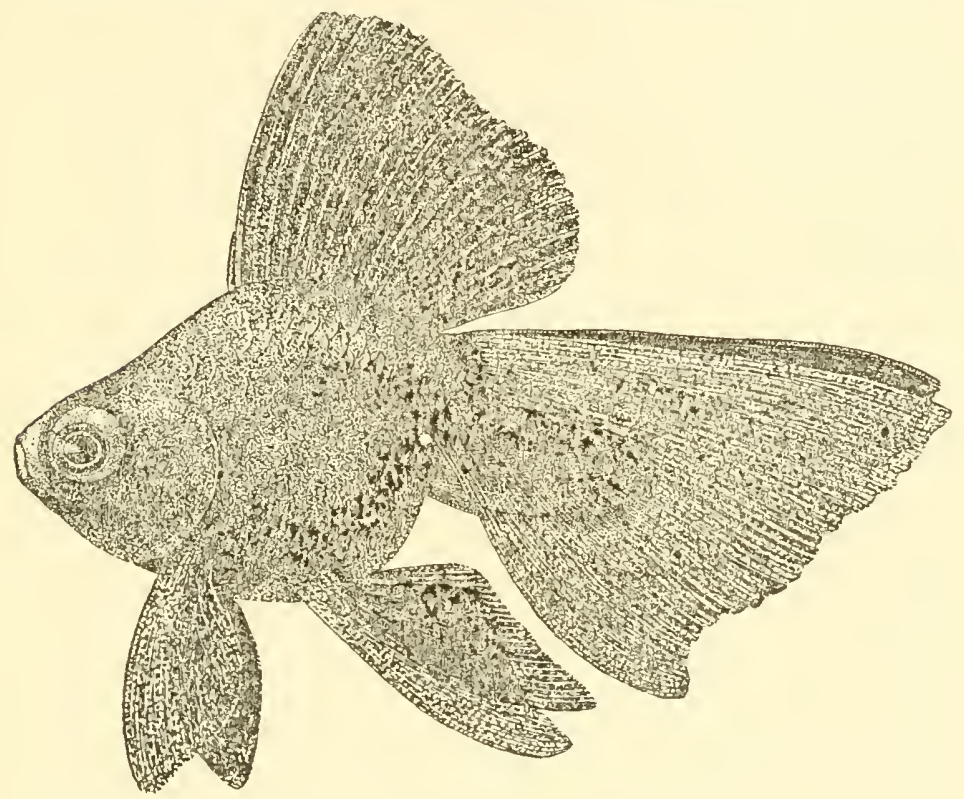

Fig. 158. The CHinese Moor

The Moor is a most striking breed of the goldfish, its intense, velvety black color forming a rich contrast for the more gaily colored specimens in the aquarium. The intense blackness extends to every part of the fish except the under side of the belly. This shades off to a blue-gray or a slight golden tint. In the latter case the fish is likely to eventually turn gold. This is not certain, nor is the blue-gray a guarantee against turning, although it is less likely to do so. Breeders have not found that the greatest percentage of blacks is produced by using two blacks, but by crossing a deep red scaled fish with a black. A good Moor, with the body 
and fin development of the Fringetail, is a very choice fish, and is always in demand. The accompanying illustration, made from a very fine yearling fish, does not give a full idea of the intense black color of the original. Some of this had to be sacrificed in order that the drawing might show all details of the fish. Our photographic illustration of a Veiltail Moor, on page 203, will give a better idea of the color.

If the foregoing references to Fringetails and Veiltails are found confusing to the reader, a more detailed explanation will be found under the following chapter, "Judging Goldfish Competitions."

\section{THE CHINESE CELESTIAL TELESCOPE GOLDFISH}

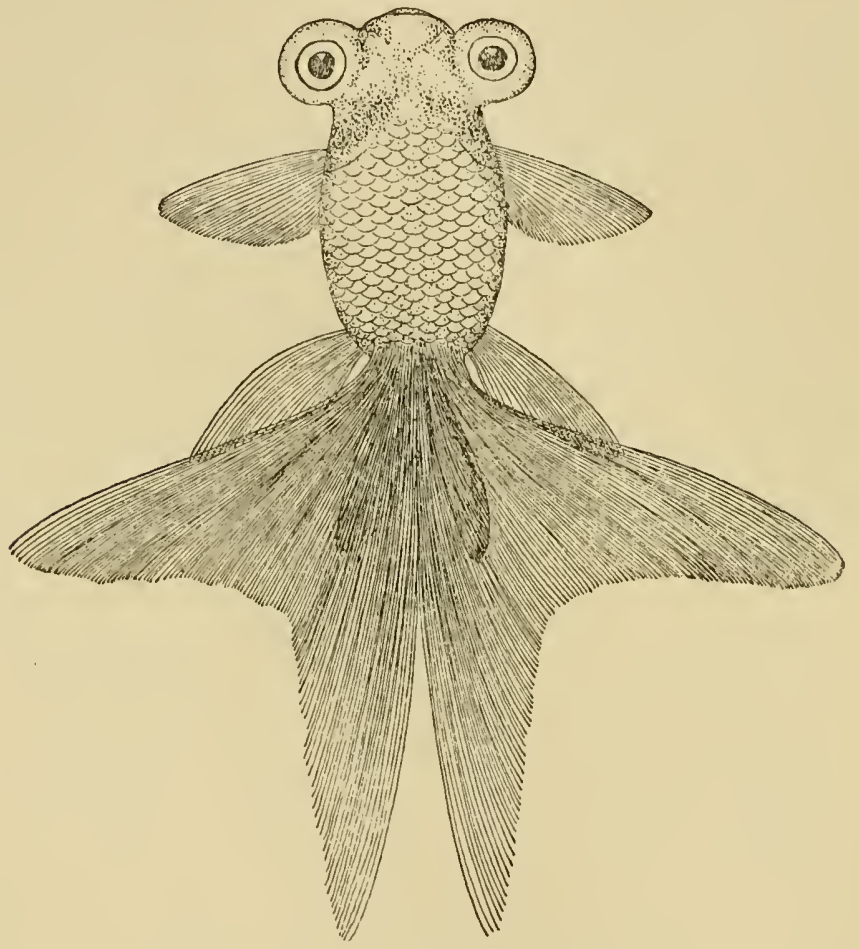

Fig. 159. The Celestial (Top viezw)

The Celestial is a telescopic fish without dorsal fin and with its pupils on the tops of the eyeballs. A most extraordinary creature indeed.

For a long time an erroneous belief existed that the peculiar eyes of the Celestial Goldfish are produced by placing the young in jars which were lighted only from a small slit in the top. Although this variety is 
difficult to breed, it has been done several times in the United States. No peculiar contrivances of any kind were used. At the usual period of about twelve weeks they developed ordinary telescope eyes in the regular way. Later the pupils gradually turned towards the top of the head, as shown in Figs. 159 and 182.

If any such peculiarity had been produced by mechanical means, it would not be reproduced in the offspring. By some Orientals the Celestial Goldfish is said to be considered sacred on account of its con. stant heavenward gaze, and is accorded a place in their temples.

The Celestial Telescope is the most difficult of the imported goldfishes to rear or to keep alive in the aquarium.

\section{THE LIONHEAD GOLDFISH}

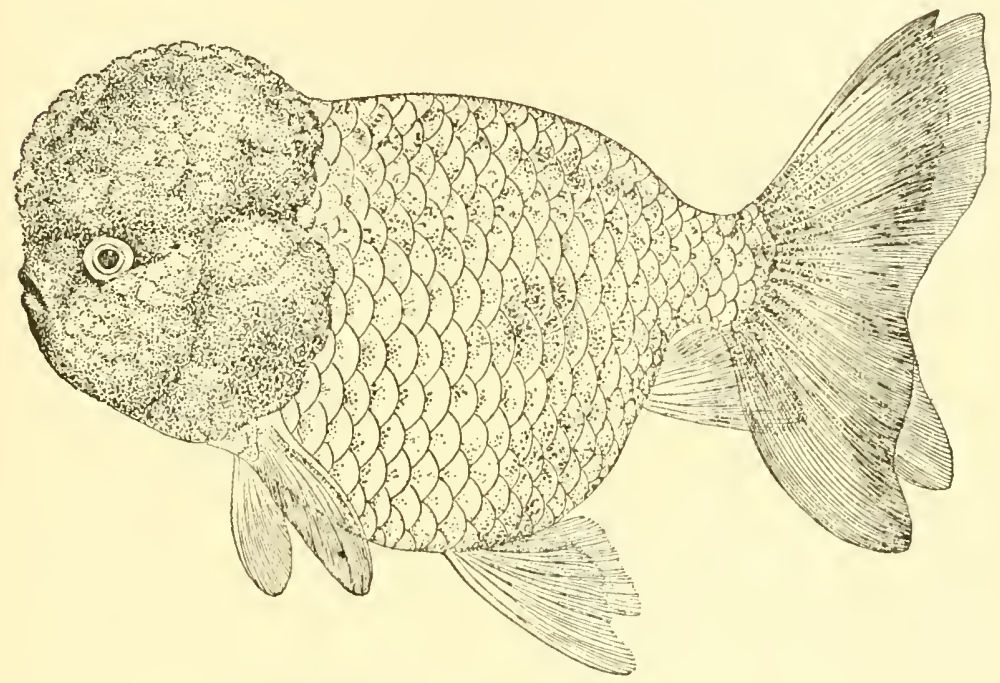

Fig. 160. The Lionhead, or Buffalonead

In point of grotesqueness and the amazing accomplishments of breeding fancy goldfishes probably nothing surpasses the so-called Lionhead. It is often remarked that the name is not particularly appropriate, but it seems to have become established. "Buffalo-head" would be a much more descriptive and appropriate name. There are three strong characteristics to this fish. The first is a thick growth over the gill plates and head somewhat resembling a large raspberry. The second is the entire absence of dorsal fin, and the third is the extremely thick, short body. The growth on the head seldom commences before the age of six months and sometimes never appears. It is frequently well developed in four 
years and increases in size as long as the fish lives. After the head growth has become quite thick it is advisable to keep the fish in running or other well oxygenated water. The mechanical difficulty of breathing, owing to the thickness of the gill plates, is considerable and unless there is plenty of oxygen the fish is liable to suddenly expire when in apparently good condition. The tails and anals should be double, but defects in these points are not considered serious if head and body are good. The colors are the usual white and red of the common goldfish. Pearl white bodies and pale yellow heads are not uncommon. A few transparently scaled specimens have been produced by crossing with transparently scaled fish of other breeds. One or two Lionheads in a mixed aquarium add considerably to the variety. It was believed by some that the absence of dorsal fin was the result of its being extracted by Japanese breeders while the fish was young. This has been proven a gross error for the same reasons stated in paragraph on Celestial Telescopes.

\section{THE ORANDA}

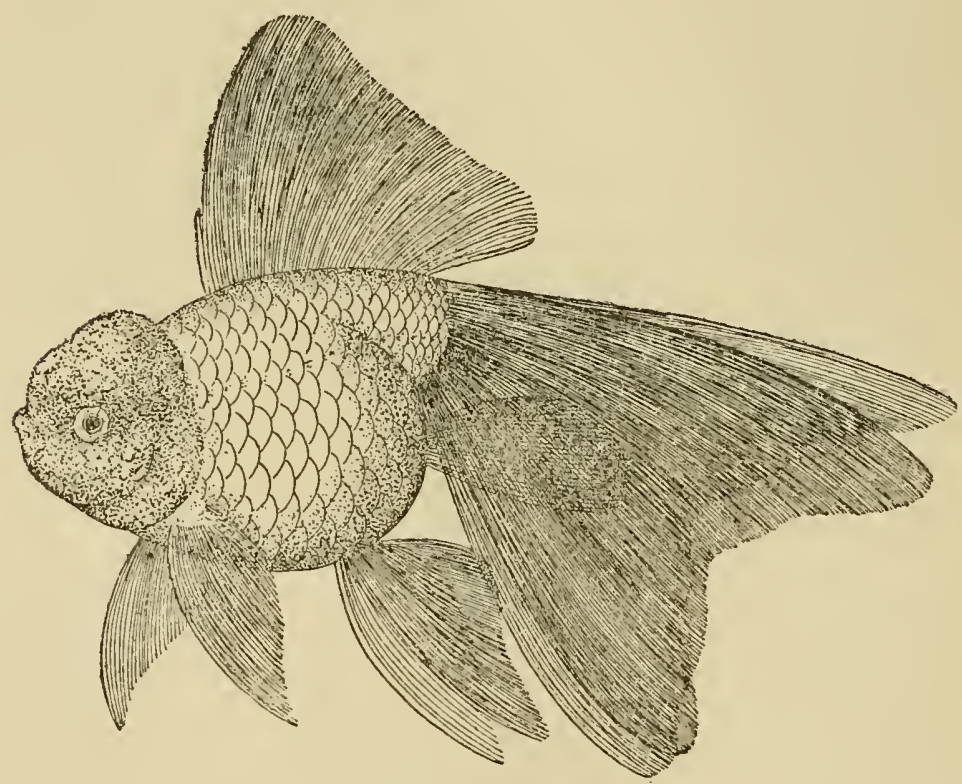

Fig. 161. THE ORANDA

In the opinion of the writer an Oranda was originally a Lionhead with a dorsal fin-in other words, a Lionhead which did not come true to form. However, it is recognized as a variety and is accorded a place in goldfish exhibitions. The fins and body are longer than in the Lionhead. 


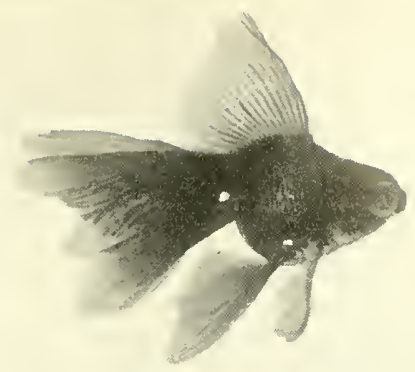

Fig, 162. Life Size Illustratjon of a

Precoriolsiy DeVeroped Yoltag Goldeish

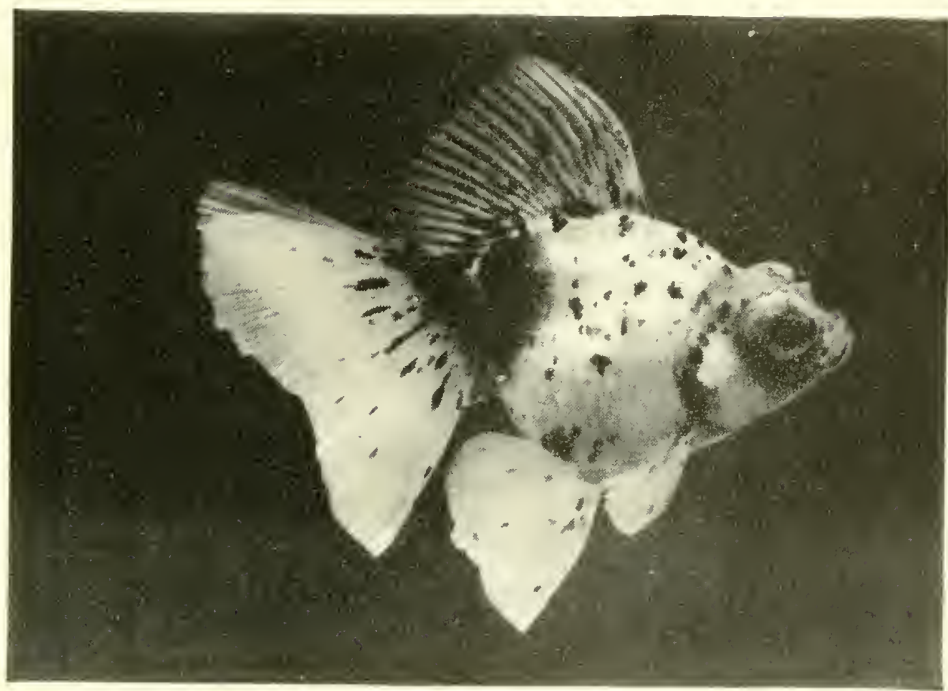

Fig. 163. Life Size Illustration of a Goldfish Same Age as Shown ABOVE

It scarcely seems credible that these two fishes are of the same age, but they are both between seven and eight months of age. Sometimes the difference in growth is even greater. The reason for this variation is unknown.

These illustrations also demonstrate the statement (page 2.3) that "runts" sometimes show extraordinary fin development. The upper fish will never increase much in size and will probably die within a year, whereas the lower fish has a good chance of living several years and developing into a beautiful aquarium specimen, because it has strength and the fins are of the right shape for future development.

This is about the right size for a fancy goldish in October which has been hatched in the Spring. 


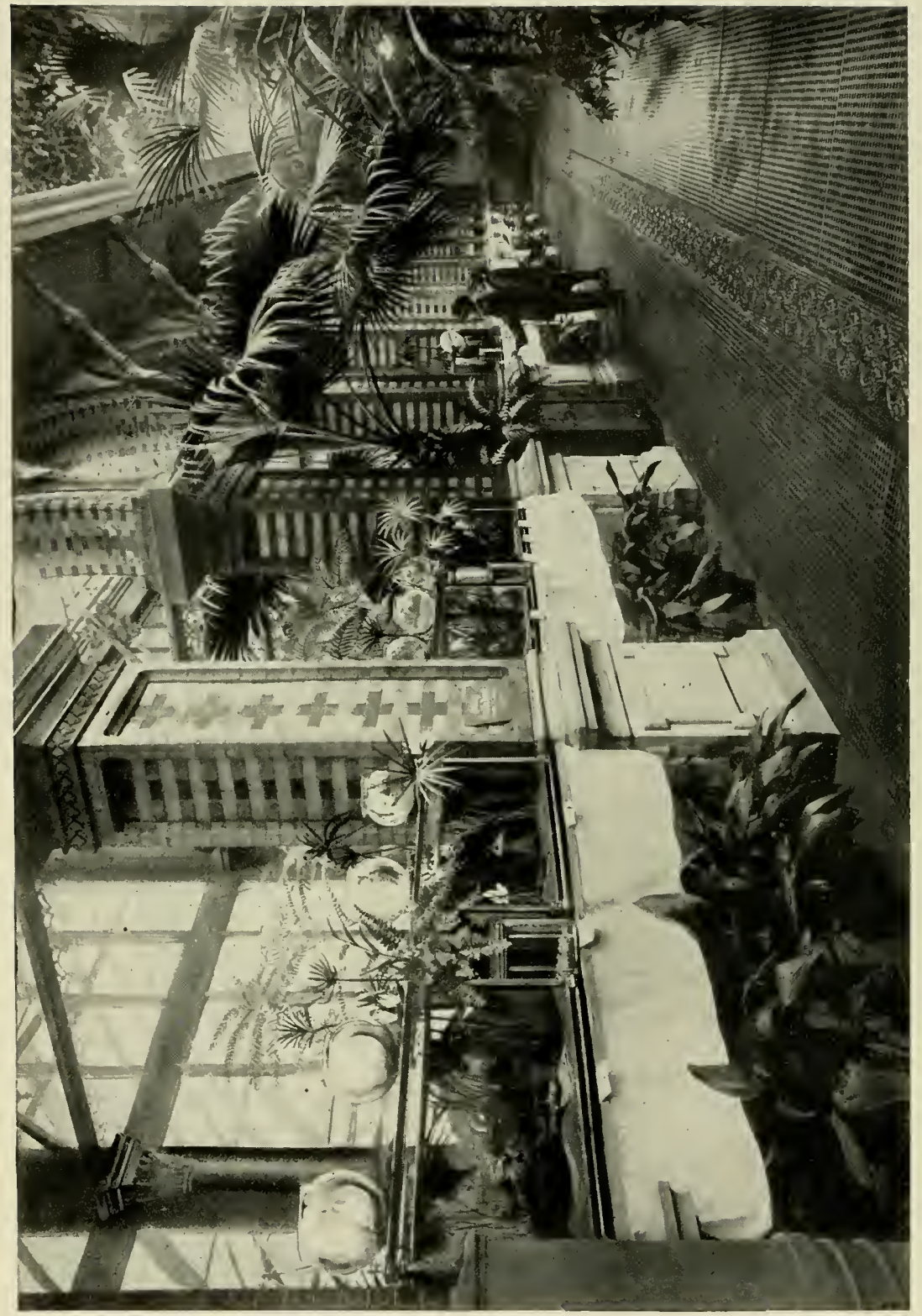

苞高苛

हิ.

$\stackrel{\Xi}{\approx}$

ต ำ ㅇำ

$\therefore$ ह

들

들.

है ज己

记

돌 ज़

름

近若艺

돈.

政

ఏ

돈 司出

U

응 되.

톯

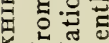

I

vo

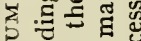

送比

a

安式记

. 章

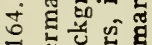

号

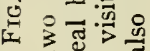

.

医冚

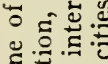

용

蛋

ㄷํํํㄹ

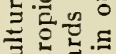

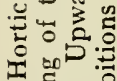

氙这 


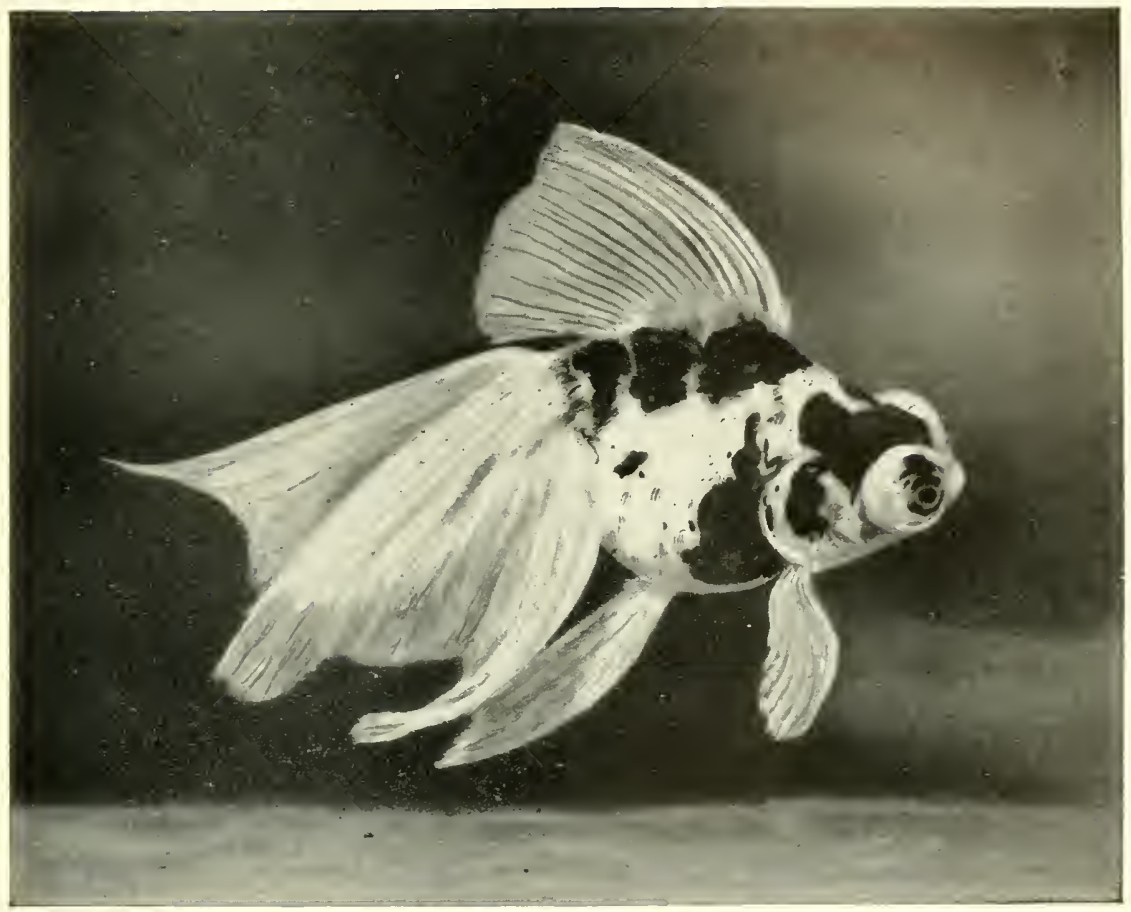

Fig. 165. Prize-Winnlvg Scaleless Telescope Goldfish 

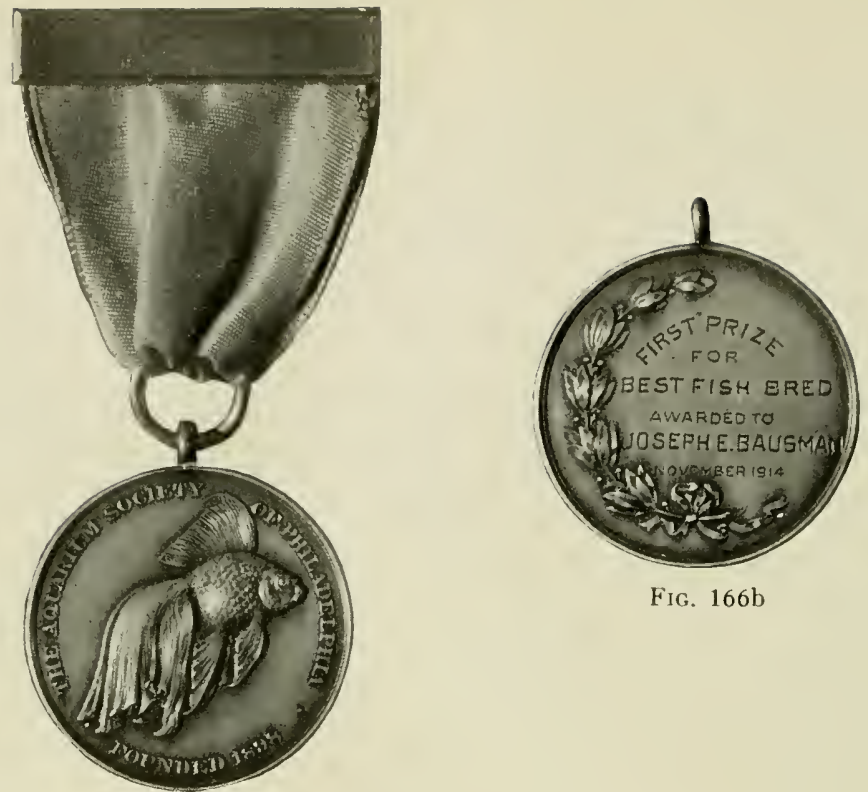

FIG. 166b

FIG. 166a

Mejal of the Aquarium Society of Philadelphia

(Exact size)

The first medal offered by an American Aquarium Society. It was awarded originally for the best fish owned and the best fish bred by a member; also for distinguished achievement or services in the advancement of aquarium study.

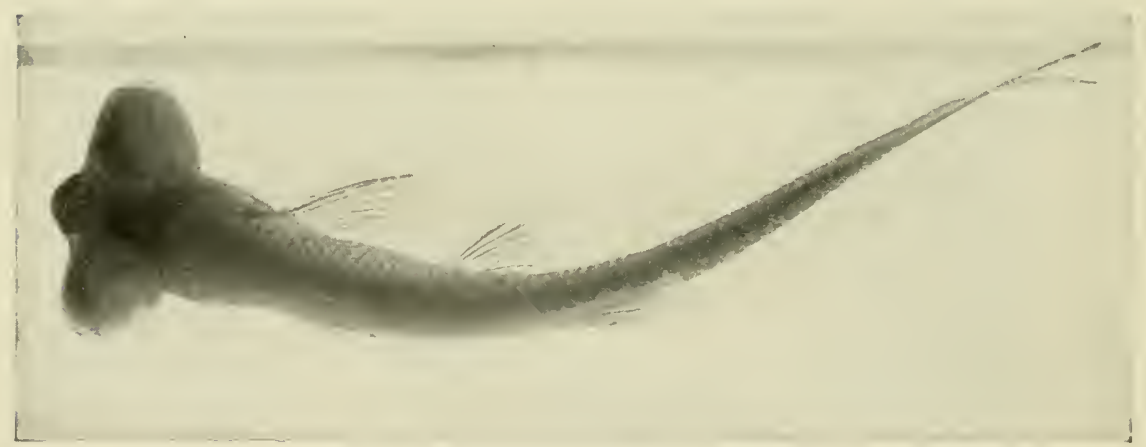

Fig. 167. Telescopic-Eyed Shiner

An extraordinarycase of natural development of the telescopic eye, giving us a hint that the early strain of Telescopic-Eyed Goldnishes was a freak of nature. (Referred to in text on Page 175). 


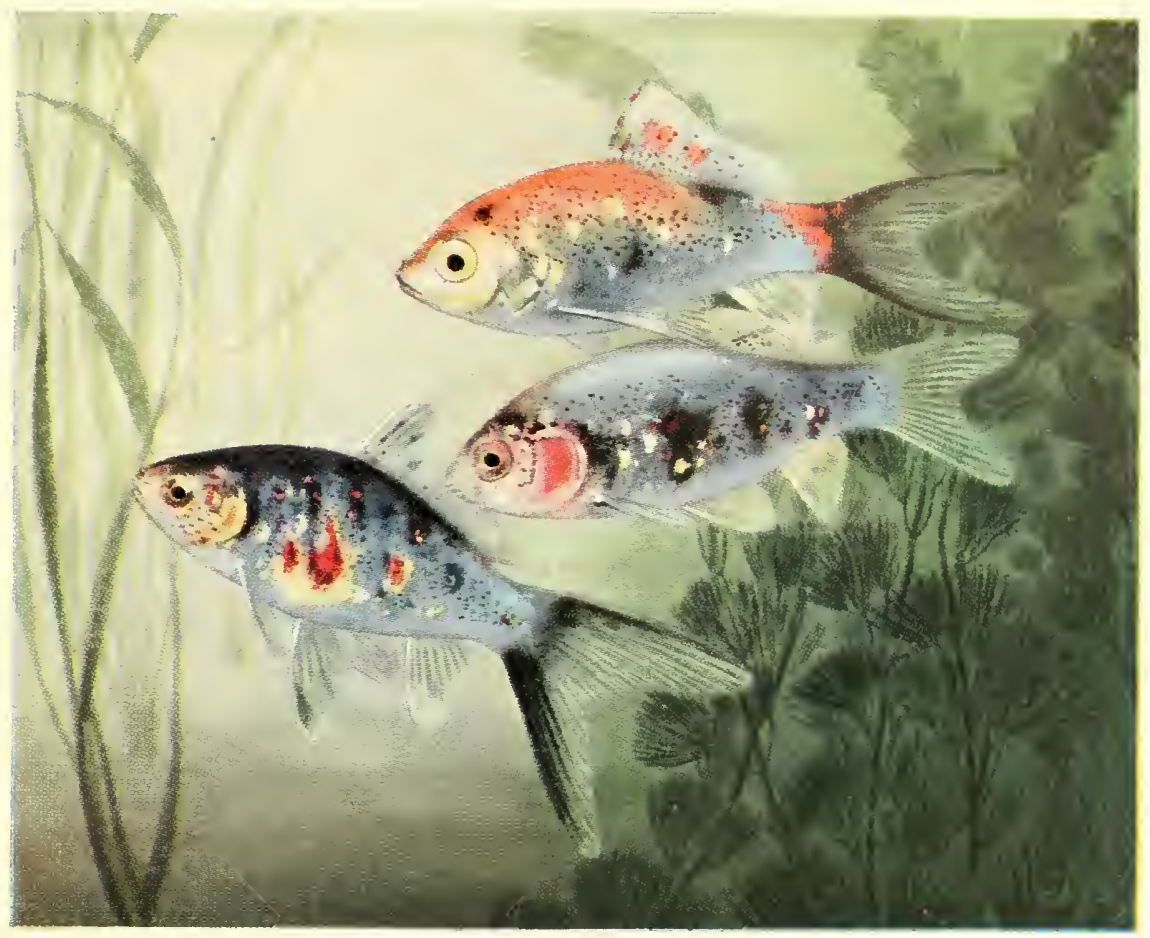

Fig, 10ia, Perfect Shubunkix:

(Photosraphed in netural colors) 



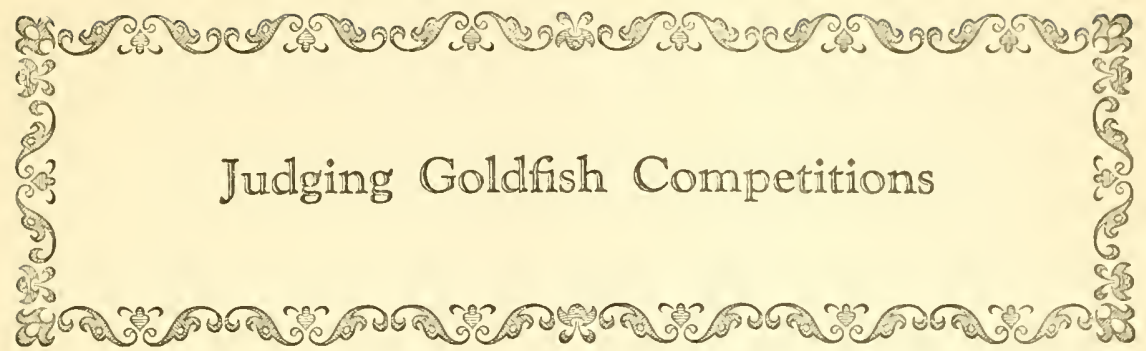

Among aquarium societies there is a certain demand for competitive exhibitions of goldfish varieties. The difficulties of making satisfactory awards are considerable, due in part to varying ideas as to what constitutes standards of perfection. To reduce this difficulty to a minimum the Aquarium Society of Philadelphia instituted a series of conferences of leading fanciers in order to establish a satisfactory and uniform scale of standards. The diagrams shown herewith represent a composite of the best ideas obtainable. The majority of leading societies have adopted them as a whole.

The "point system" of judging, as it is called, is too slow and laborious for use on an entire large exhibition. The two or three best fish, selected on general appearances, should be set aside from the others and judged independently by three judges, on points. The totals are then averaged and awards made.

In those classes requiring double anal fins the fish is penalized three points for having only one.

In the Fringetail classes the tails must be fully divided to receive consideration.

The Longtail or Fringetail group is divided into two classes, the Veiltail and the Ribbontail. These are also called "broad-tail" and "swallow-tail" or "cut-out-tail." In the Veiltail the centre of each tail is indented or forked less than one-third of its total length. The swallowtail is cut in to one-third or more. The diagram on page 196 will show this.

The making of these classes has caused some confusion. The author believes that fishes of these two types and those on the difficult dividing line should all take their chances together. The division was undoubtedly made as an expediency in order to make more awards and thereby please as many people as possible. So far as can be determined, no such divisions of fin shape have ever been recognized in China or Japan, and the same was true here until the period of 1910-12, when it became a conspicuous 
fact that nearly all winners of competitions were of the broad-tail type. While the Veiltail is the more difficult to handle and to breed, it is accepted as the standard to be striven for. The word "veiltail" was adopted by the author from the German Schleierschwanz, and is more truly descriptive than "fringetail," a word more apt to describe the split and ragged ends of the fins of a fish out of condition.

In competitions goldfish are divided into the scaled and "scaleless" classes, the latter being transparently scaled. The scaled fishes are colored gold (metallic red), silver (metallic drab or smoke), pearl (metallic white), and moors (blacks). The first should be of a deep shade of red. The second is a transitory color and varies but little. As a color value it ranks low. The pearl is a grade higher, but light colors in general are not favored. Moors should be of a deep blue-black, free from the appearance of a white scum. These blacks are never completely black under the belly. It is at this point that they usually begin to turn red, which is liable to happen to a Moor at any age.

"Sealeless" fishes are divided into red, white, mottled and calico. The preferred shade of red is of the deep oxblood color. White ranks lowest. Mottled is a combination of red and white, while the highest prized is the calico, a combination of all the colors in finely divided spots. In this class the all-important color is blue or lavender, the deeper the better, and also the more the better. The ideal Calico has a body background of blue, red and white, over which is a sprinkling of fine black dots. The black dots and some red ones are also freely distributed over all the fins, which are otherwise white in these and all "scaleless" fishes. The highest development of this color seldom occurs under the age of from two to three years.

There are special competitions for fishes under one year old. A recent ruling in this connection is that a fish to be judged must have a body as large as a half dollar. Also that the body of an adult must be as large as a dollar. This is because many "runt" fishes, if judged strictly on points, would carry off the awards, their development having gone all to fins.

With reference to Lionheads the main points are the hood and the shape of the body. The hood should be as large as possible. It should envelop the whole head and rise sharply at the point where the head joins the back. While color is not an important feature, the preference is for a brassy body and a deep red head. Pearl colored fishes with pale yellow heads are also prized. Anals should be double and the tails fully divided, but no credit is given for fin length. The body should be deep and broad, the back well arched, without flatness in the centre. Orandas require long fins, but not such chunky bodies. 
Charts Showing Ideal Figures of the Principal Goldfish Varieties, Together with Valuation Points

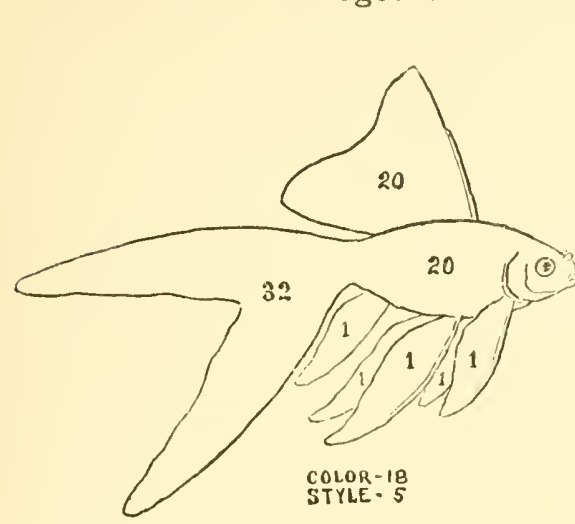

FIG. 168. COMET (Ribbontail)

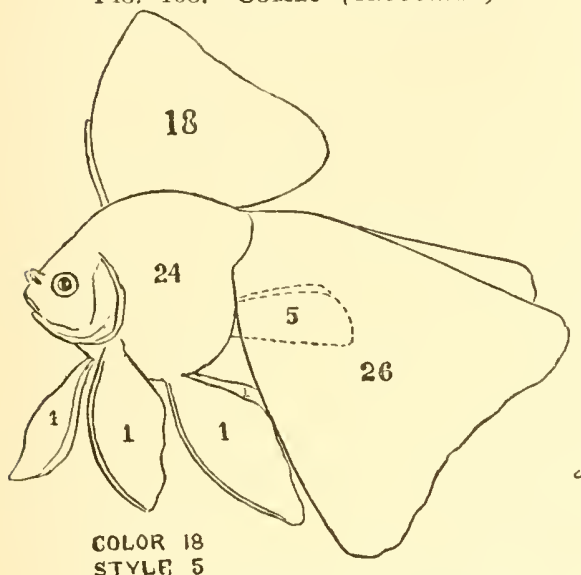

STYLE: 5
FIG. 170. FRINGETAIL (Veiltail)

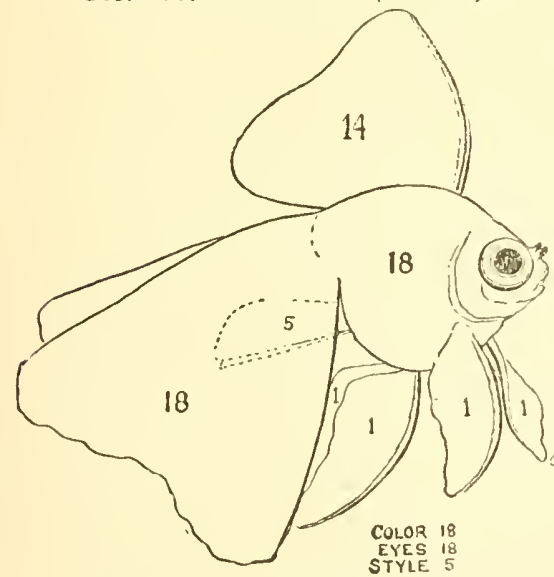

Fig. 172. Telescope (Veiltail)

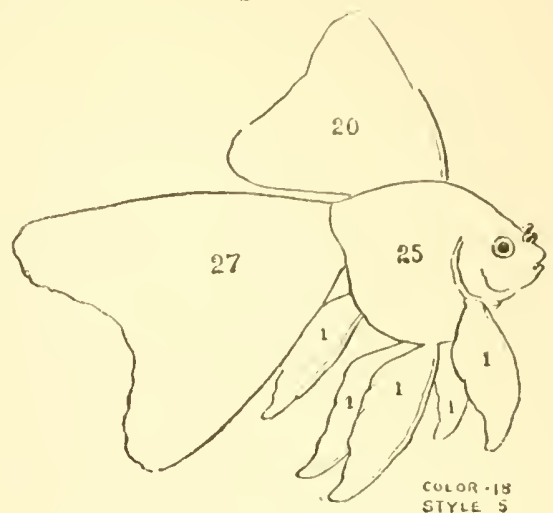

FIG. 169. NympI (Veiltail)

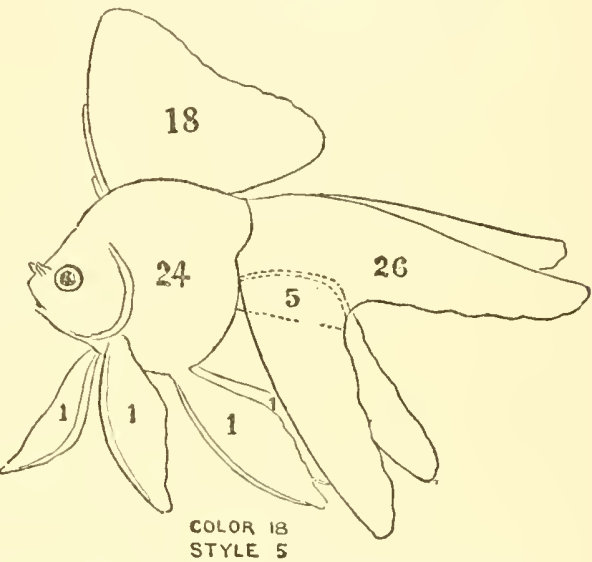

Fig. 171. FringetaIL (Ribbontail)

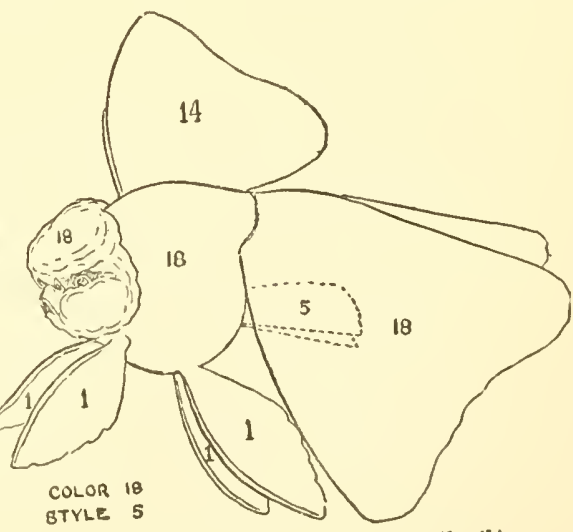

Fig. 173. Oranda (Veiltail) 


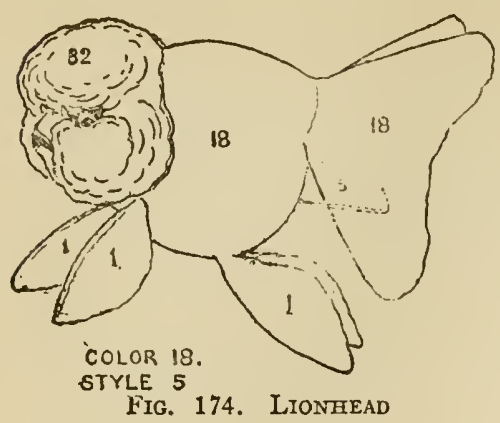

Fig. 174. LIONHEAD

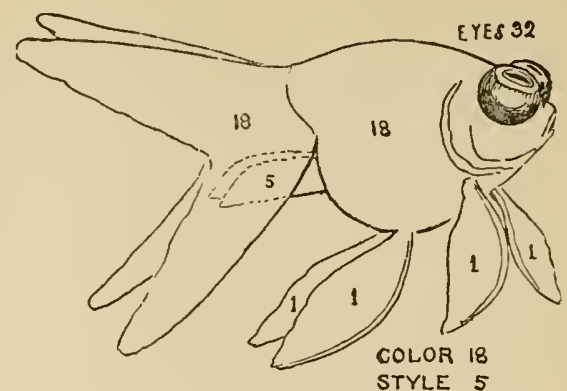

Fig. 175. Celestial

Body Tail Dorsal Fins Color Anals Style Eyes

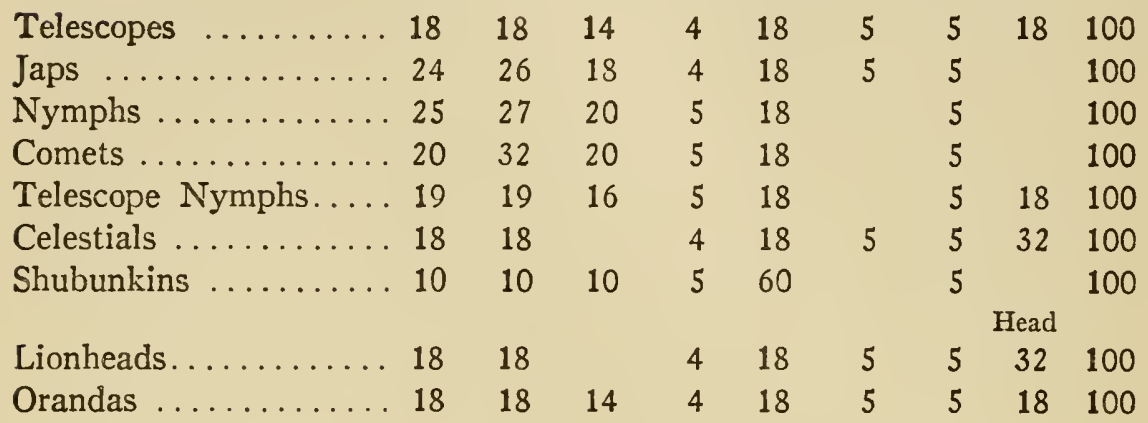

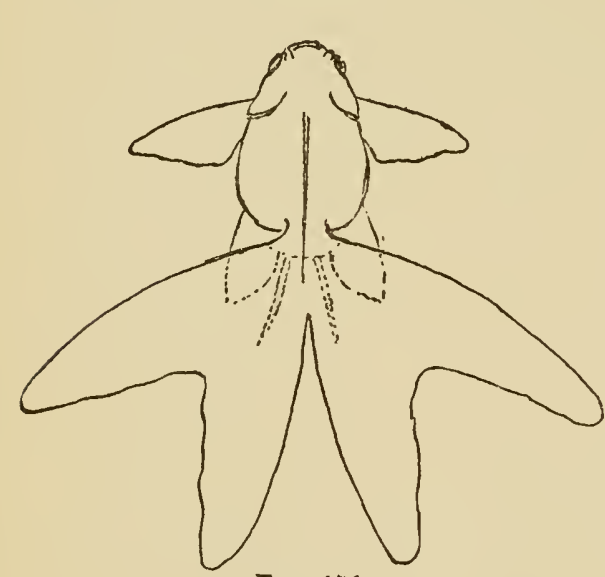

Fig. 176

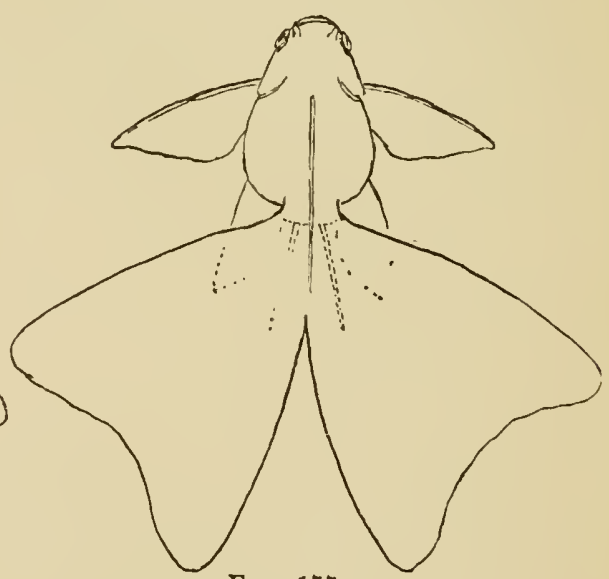

FIG. 177

The above two illustrations show the two types of tails. At the left the "Swallowtail", "Ribbontail" or "Cut-out-tail;" the right the "Veiltail" or "Broadtail." All varieties of the fancy goldfish may be subdivided into these two classes for purposes of competition, but it is a step of doubtful wisdom, for in many cases it is impossible for the judges to decide even to their own satisfaction in which class a fish belongs, much less to the satisfaction of the contestants. 
Prices of Goldfish. This is a difficult topic to cover in a satisfactory way, but as it is one which interests many readers, we will try. The commons up to two inches range from ten to twenty cents; up to four inches, about twenty-five to thirty cents. "Comets" are about twice the price of commons, and "Fantails" about three times These prices are for localities within easy shipping range of the wholesale supplies. In some places it would no doubt be necessary to charge more.

From commercial store fish to really fancy stock is quite a step, and it is here that the buying public needs a little enlightenment. On the one hand we often hear fanciful rumors of fish being worth hundreds and even thousands of dollars, and on the other hand the under-valuation of rare specimens is just as ridiculous. Many think that for two or three dollars they should be able to take home prize-winning beauties. As stated in the chapter on Breeding Goldfish, the percentage of truly fine fish in a hatching is small, and, as in other lines, those who want the best have to pay for it. Prices will change some from year to year owing to varying success in breeding, and at best these figures can only be approximate. Still, they are nearly enough correct to enable one to decide whether to go in for fancy goldfish stock, and if so on what basis.

\begin{tabular}{|c|c|c|c|c|}
\hline & $\begin{array}{c}\text { Young in } \\
\text { August }\end{array}$ & $\begin{array}{l}\text { Young in } \\
\text { October }\end{array}$ & Adults & $\begin{array}{l}\text { Extra } \\
\text { Fancy }\end{array}$ \\
\hline $\begin{array}{l}\text { Shubunkins } \\
\text { and Nymphs }\end{array}$ & $25 c$ & $50 c$ & $\$ 1.00$ & $\begin{array}{l}\$ 3.00 \text { to } \\
\$ 5.00\end{array}$ \\
\hline Jap. Veiltails & $\begin{array}{l}50 \mathrm{c} \text { to } \\
\$ 2.00\end{array}$ & $\begin{array}{l}\$ 1.50 \text { to } \\
\$ 4.00\end{array}$ & $\begin{array}{l}\$ 2.50 \text { to } \\
\$ 5.00\end{array}$ & $\begin{array}{l}\$ 5.00 \text { to } \\
\$ 15.00\end{array}$ \\
\hline $\begin{array}{l}\text { Telescopes } \\
\text { (scaled) }\end{array}$ & $\begin{array}{l}50 \mathrm{c} \text { to } \\
\$ 2.00\end{array}$ & $\begin{array}{l}\$ 1.50 \text { to } \\
\$ 4.00\end{array}$ & $\begin{array}{l}\$ 2.50 \text { to } \\
\$ 6.00\end{array}$ & $\begin{array}{l}\$ 8.00 \text { to } \\
\$ 16.00\end{array}$ \\
\hline $\begin{array}{l}\text { Telescopes } \\
\text { (blue Calicos } \\
\text { and Moors) }\end{array}$ & $\begin{array}{l}50 \mathrm{c} \text { to } \\
\$ 3.00\end{array}$ & $\begin{array}{l}\$ 2.00 \text { to } \\
\$ 6.00\end{array}$ & $\begin{array}{l}\$ 3.00 \text { to } \\
\$ 8.00\end{array}$ & $\begin{array}{l}\$ 10.00 \text { to } \\
\$ 30.00\end{array}$ \\
\hline Lionheads & $\begin{array}{l}50 \mathrm{c} \text { to } \\
\$ 3.00\end{array}$ & $\begin{array}{l}\$ 2.00 \text { to } \\
\$ 5.00\end{array}$ & $\begin{array}{l}\$ 4.00 \text { to } \\
\$ 12.00\end{array}$ & $\begin{array}{l}\$ 20.00 \text { to } \\
\$ 75.00\end{array}$ \\
\hline
\end{tabular}

Celestials are seldom on the market. When obtainable they are about the same price as good Orandas, $\$ 10.00$ to $\$ 25.00$ each.

The prices of fine Lionheads are high because it takes years to develop a large hood.

It might be added that it is no easy matter to procure the extra fancy grades, even at top prices. There are comparatively few of them and breeders naturally want to hold them for purposes of propagation.

As to sources of supply, note advertisements in the different aquarium magazines. 


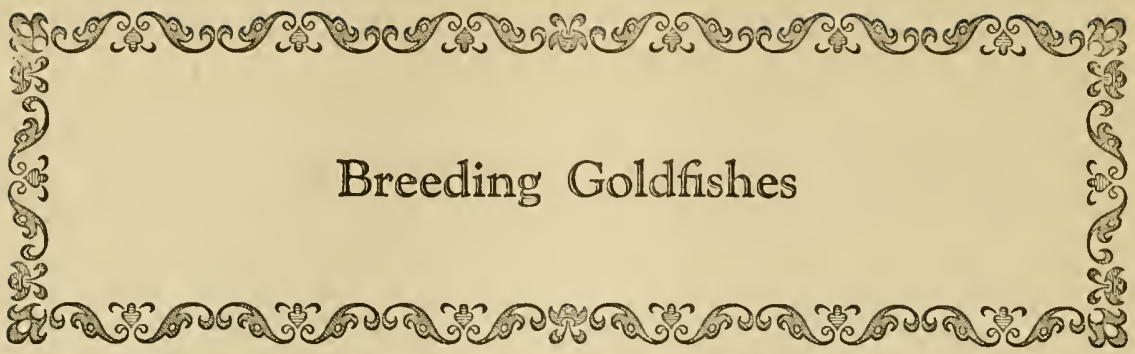

The breeding of fancy goldfishes is one of the most fascinating of diversions. Also it is one of the most instructive. It should be said that, on the whole, the breeding of the goldfish is not difficult, and may be undertaken by beginners with reasonable prospects of success. It is the production and maintenance of the finer and more exacting requirements of the fancy varieties which present the real difficulties. Goldfish, possibly more than any other creatures, draw their characteristics from far-removed ancestors. Or again they may become a counterpart of either parent. This makes a considerable element of uncertainty, since the characteristics of their preceding stock have for the most part contained a great deal of variety, due, no doubt, to experimental crosses. This produces a most interesting and sometimes annoying variation in a lot of young goldfish. As the fish gets beyond the small fry stage the breeder becomes intensely absorbed in daily observation of points of form, color and size as they appear.

The percentage of fancy fish coming true to type is usually small. Ten per cent. of fish to pass the critical inspection of the fanciers' eye is not considered bad. Besides these, about fifty per cent. of the hatch will come true, but will be qualified by slight defects. The balance may be anything at all, single-tail and web-tail fish from double-tail parents being the principal disappointment. These percentages are averaged from general breeding, but are liable to wide variation. Sometimes there is no fish in a hatching to approach the quality of either parent; sometimes a large percentage is better than both parents. If a strain is carefully watched for several generations and no fish varying from the desired type is allowed to breed, the percentage of young coming true can be kept very high.

Considering the other great variations of points in fancy goldfishes, it is remarkable how well-fixed we find the telescopic eyes. From welldeveloped telescopic stock there will probably be not over two per cent. of young which do not sooner or later show this peculiarity. 
The beginner should get his first experience in breeding the more hardy varieties - the comet, for instance-but this stage passed he should select none but the best breeding fish out of known good stock. As previously stated, the best time to purchase new stock is in September and October, preference being given to the larger fish about seven months old. At this period the dealer-fancier is usually willing to sell off some of his larger old breeders. These are more showy than the young, but should not be selected.

\section{SEX IN GOLDFISHES}

The chief indications of a male fish ("buck") in the breeding season -about January till August-are the small tubercles appearing on the gill plates, and sometimes on the first ray of the pectoral fins. These are quite a little smaller than pin-heads and the fish must be viewed at a certain angle in order to see them. (See illustrations, numbers 110, 153, and also 187). Females sometimes show these spots, but rarely.

The female fish ("roe") is usually shorter and fuller of body, particularly when carrying spawn. The spawn as a rule is larger on one side of the fish than the other, so that in looking directly down on the fish's back it may be found to be curved to one side. After spawning is over this deformity often remains. In a female which has spawned the vent is always a little protuberant. The eggs can often be seen through the abdominal skin of females of the scaleless type.

Early in the year the young males will begin swimming after the females, following close to the vent. Without observing any of the foregoing rules the sex may often be told in this way. If this is observed before March, the sexes should be separated, as early spawns are not to be desired, unless one has very special facilities for securing a supply of live food. If the spawning can be delayed until May, results will be more satisfactory. The reasons for this are that the harmful long cold spells are less likely to occur and that living food can be obtained with more certainty. Spawning may be somewhat delayed by separating the sexes and by keeping the fish in cool water. With this object in view the females should be placed where they cannot rub against plants, as it induces an excitement at this time liable to promote spawning, even without males being present.

\section{BREEDING METHODS}

As spawning time approaches the fishes should be well fed on nourishing food. Finely chopped earthworms are excellent. Live daphnia are as good. Scrambled egg, alternating every other day with regular fish-food, is a fair substitute for live food at this time. When the breed- 
ers have been selected they should be placed together by themselves. If possible there should be three males to one female. This insures a higher percentage of fertilized eggs than if only one male is used. If the definite results of a certain cross are wanted, then use only one male. A second female not spawning should never be present, as she will devour the eggs.

Papier maché tubs are very nice for spawning in, but seasoned wood tubs or tanks will do. The aquarium may be used, or the spawning net shown on page 124. Aquarium should be at least 10-gallon size.

Should there be no spawn after the fishes have been together several days, remove about a quarter of the water daily and replace by fresh, slightly cooler water. This is stimulating. Some intimation of an approaching spawning may be had by the fact that for several days before the spawning takes place the males occasionally "drive" the ripe female. This usually increases in intensity the evening before, and when spawning is in full swing it develops into a wild chase punctuated by short periods of rest. So vigorous is the swimming at this time that fish with large fin development generally have their fins torn and frayed. Males with shorter caudal fins (tails) are the more rapid swimmers and their fins become less torn. As these are also usually the young, vigorous males, they are to be preferred for breeding purposes. Spawning usually starts at daybreak and lasts till mid-afternoon. It may be repeated every few weeks until the first of August, but the first spawn of the season is the largest.

Goldfishes deposit their eggs preferably on floating aquatic plants, and these should be freely provided (first making sure they contain no snails or other enemies to fish eggs). The best are water hyacinths (with as large roots as possible) and bunches of myriophyllum. The female will swim over the plants and drop the eggs. As they fall the male passes over and fertilizes them by the ejection of spermatic fluid. The eggs are of a mucilaginous character and adhere where they touch. This egg adhesiveness is one of Nature's interesting little secrets. Man has never succeeded in making a substance that will "take hold" under water and yet not dissolve.

The eggs are about 1-16 of an inch in diameter and are at first of a pale amber hue, becoming still paler and more difficult to see on the second and third days. The infertile eggs turn white on the second day and soon become the centre of a ball of fungus. Their comparative prominence soon convinces the beginner that most of the eggs are bad. He is pleasantly surprised, as a rule, to see what a large number hatch after all. The fish drops from ten to twenty eggs at a time, and after short intermissions repeats the operation. A complete spawning of a mediumsized female runs from five hundred to one thousand eggs. Large fish not 


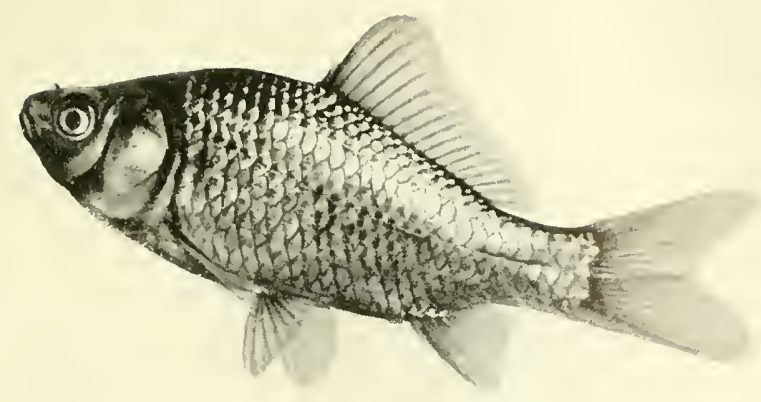

Fig. 178. THE CoMmoN Goldofish

This style fish is unquestionably the ancestor from which has been developed the extraordinary variations which we have today. It is probable the process has taken over a thousand years of patient effort by Oriental fish breeders.

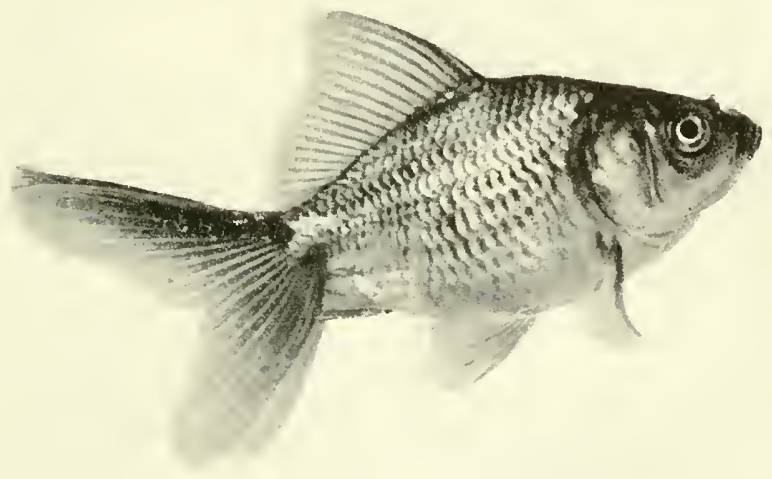

Fig. 179. The "Fantall" of Commerce

Representing the first stage in the development of fancy varieties. A hardy fish which ought to live at least five to ten years in good aquarium conditions.

Most commercial aquarium fishes are not over one year old when purchased.

Stock of this size when raised on fish farms is about one to two vears old. After being placed in aquarium the growth is much slower. 


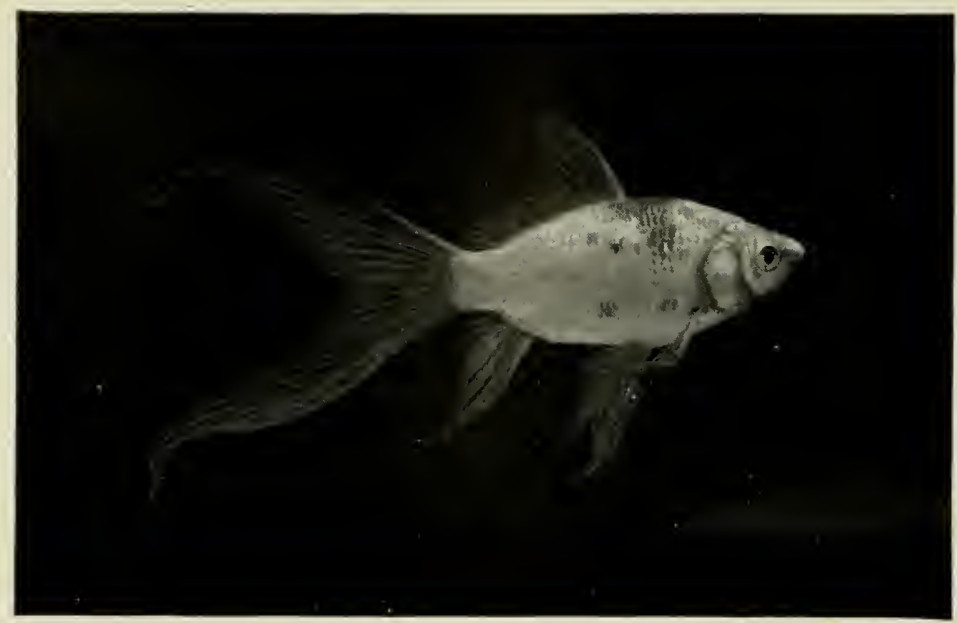

Fig. 180. ThE CoMet

This fish was bred for graceful lines and length of fins.

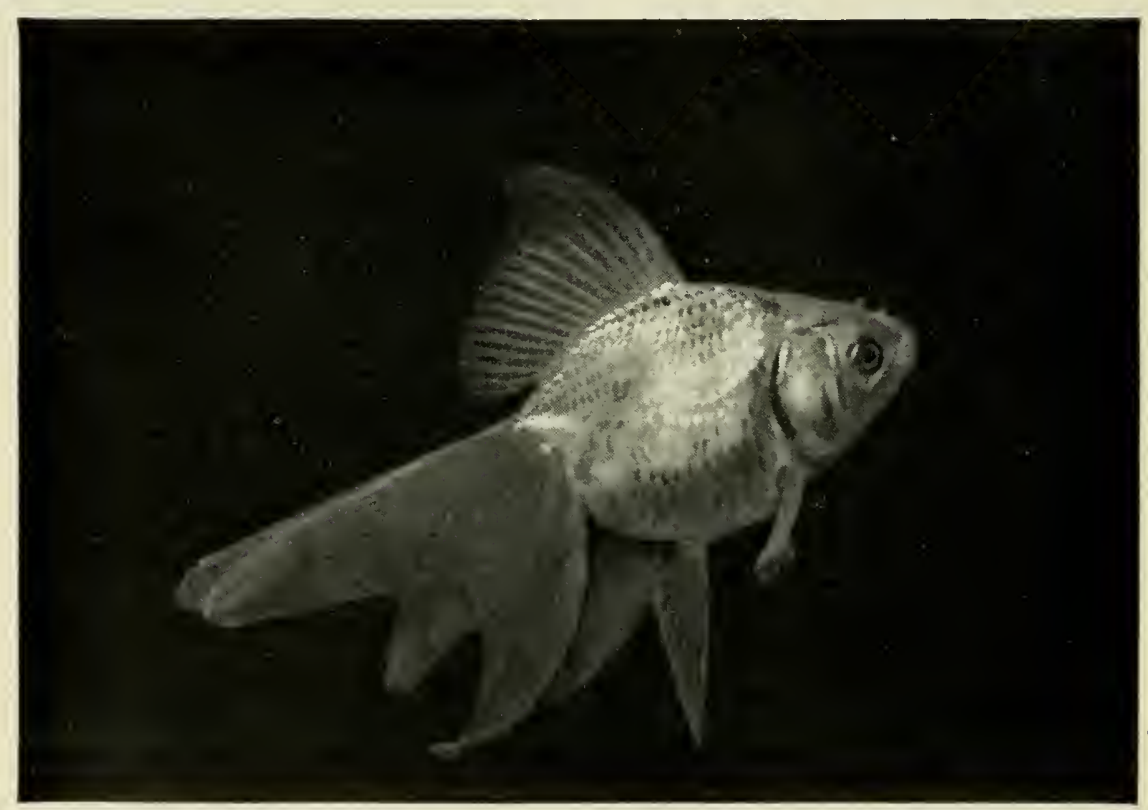

Fig. 181. High-Grade Fantail of Commerce

Here we have a connecting link between the Common Fantail and the highly developed Japanese Fringetail. The subject of this illustration is a brilliant, glistening, metallic white color, known in the trade as a "pearl" Goldfish, but which is more popularly known as a Silverfish. 


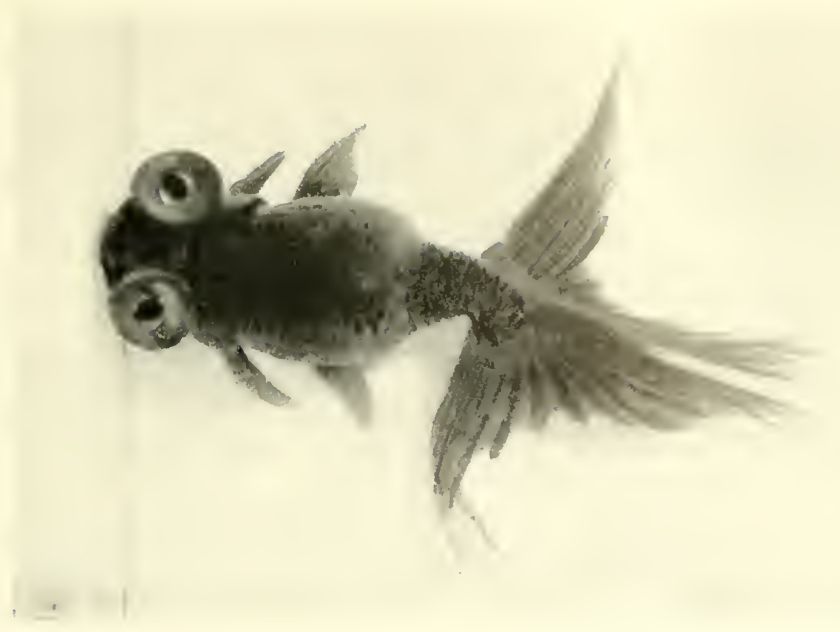

Fig. 182. Celestial Goldishe (Reduced one-hal f $^{\text {) }}$

One of the most extraordinary of all weird developments in domesticated fishes. The eyes, in addition to being telescopic, have the pupils in the top, gazing heavenward.

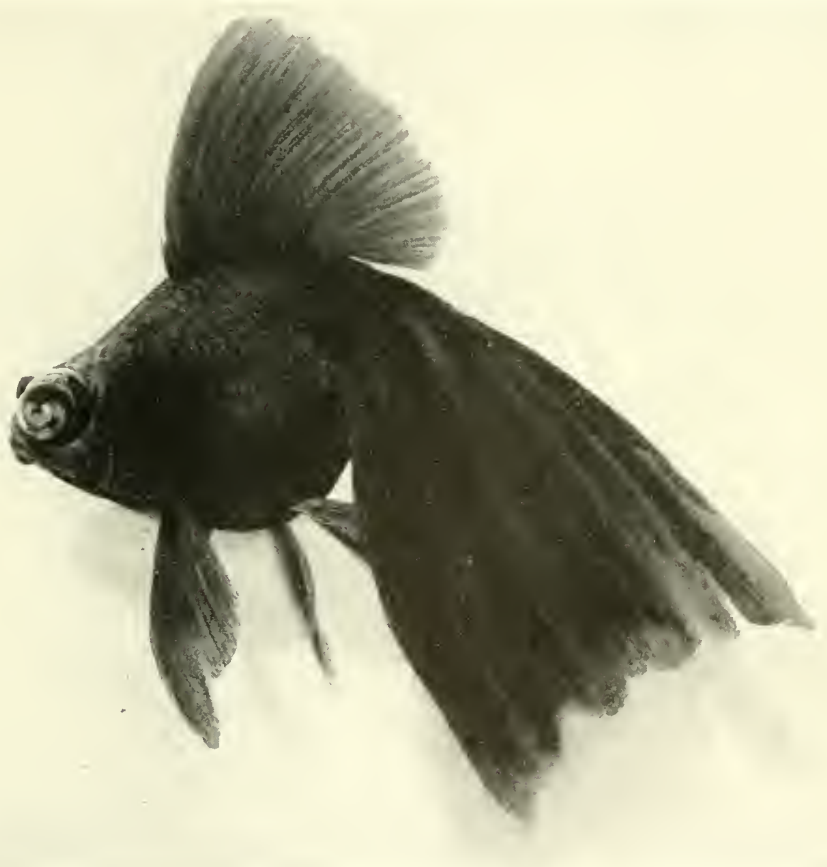

Fig. 183. A Perfect Veiltail Moor (Reduced one-third)

Considered one of the finest black goldishes ever bred. The short, deep body, the proud dorsal fin, the broad, luxuriant tails, the very prominent eyes, the velvety blueblack color, combinerl with splendid carriage, make this remarkable fish a pattern which we may hope to equal, but hardly to surpass. 


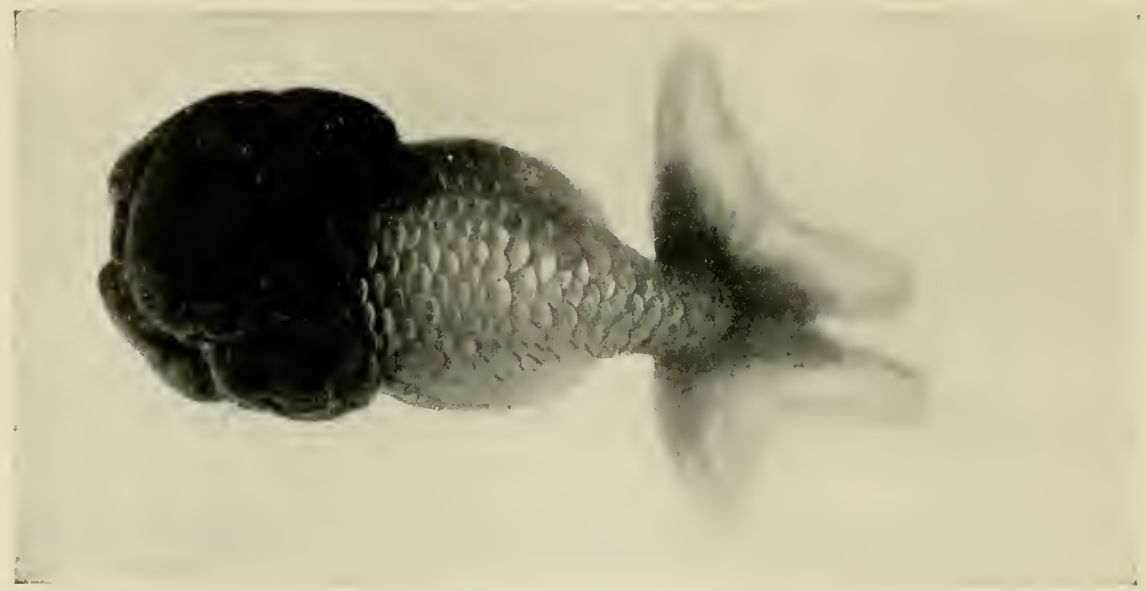

FIG. 184. TOP VIEW

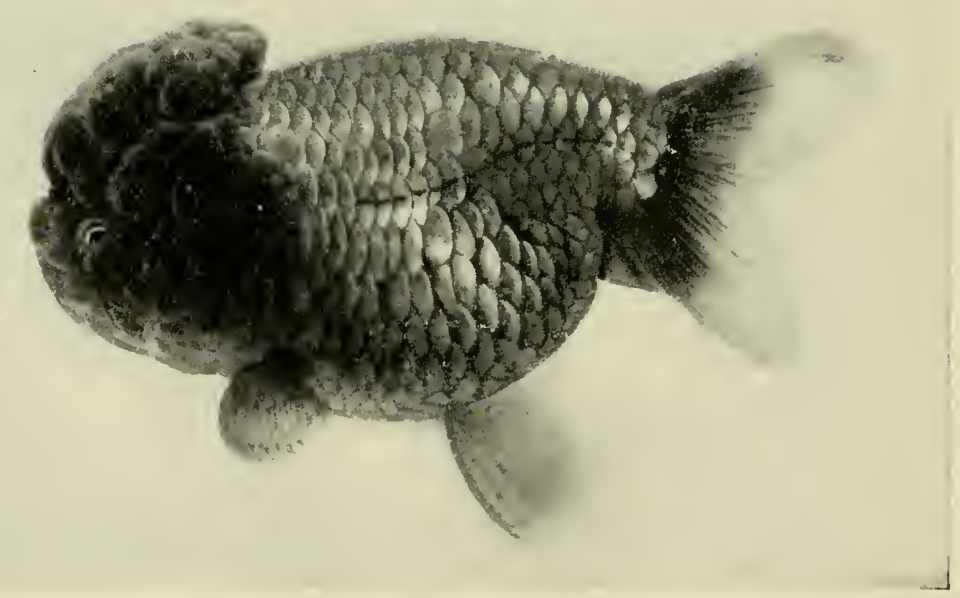

Fig. 185. A Champiox Lionilead Goldfish

While the Lionhead is a comparatively rare fish, there are several thousands of them imported annually from Japan and quite a few bred in this country. Of all specimens seen, this is probably the most highly developed. Experts consider this a wonderful specimen and not likely to be surpassed. In addition to the head, which looks like a huge raspberry, note the absence of dorsal fin. The preferred color for the body is a brassy yellow. The development of such a hood indicates an age of at least six years, and possibly much more. 
infrequently spawn over three thousand. This refers to the first breeding of the season. As previously remarked, subsequent spawnings are considerably smaller.

As the plants become covered with eggs they should be removed from time to time, allowing a few minutes for the last deposit to become fertilized. The eggs when dropped are slightly flattened. They have a tiny pore, and as the egg rounds itself like a rubber ball that has been squeezed, it sucks in water charged with the spermatic fluid, thus helping impregnate itself. The egg-covered plants should be removed to large enamel receptacles, containing clean water of the same temperature as breeding tank. Enamel is not absolutely necessary, but is desirable in the early stages, as it facilitates observation. If more convenient, the fish may be removed after spawning and allow the eggs to hatch where they have fallen. One of our leading breeders makes an egg-trap composed of a number of bunches of myriophyllum, secured together in a radiating circle, like the spokes of a wheel. About ten bunches are used. The tinfoil is removed from each and again tied with thread. The same thread is carried half an inch to the next bunch, and so on until they are all arranged on a string, which is then knotted together in the form of a circle. The fishes spawn in this with their heads to the centre, and as the eggs are discharged in the direction of the rays of plants, the chances of the eggs finding a lodging place in them are very good. Such a circle need not be removed until well filled with eggs. Some females eat their own spawn, so removal of eggs is safer if hyacinths or small bunches of myriophyllum are used. No snails should be present, as they eat the eggs. However, after eggs are hatched, snails should be used to eat the infertile ones.

Beginners frequently inquire whether it is possible to rear young along with the old fish. It is not. Upon completion of spawning the fishes begin eating the eggs. What few they miss may hatch, but the fry are sure to be eaten, except in a pool or pond having an abundance of protective vegetation in which they may hide for several weeks.

The development of the embryo under the microscope is plainly observable and is extremely interesting. The hatching time is from four to fourteen days, according to temperature. At a temperature ranging from 70 to 75 degrees Fahrenheit they should take from five to seven days. This is considered to produce stronger fish than a slow hatching. The hatching trays and young fish should be kept in a light place, and, if possible, where they may be protected from temperatures below 60 or over 80 degrees. If stood in hot sun for several hours in a shallow tray, the eggs are liable to be "cooked," and therefore spoiled.

When the alevin or newly-hatched embryo bursts from the egg it is a very weak creature. It appears a mere thread with a pair of eyes 
at one end and small lump in the centre. This lump is the yolk-sac and serves as subsistence for the first few days. At first the alevin can only swim by a few jerky motions, and has the power of sticking wherever it touches. At the age of one day they are to be found hanging on the plants and the sides of whatever receptacle they are in. In from two to three days they are swimming freely. When the yolk sac has been absorbed, which is in about three days, the babies will need some food which has been previously prepared. The first natural food is a large variety of microscopic animals known under the general heading of infusoria. These are present in all exposed water which has stood a few days, but in order to have sufficient for fish food it is necessary to have conditions favorable to their culture. This consists mainly of vegetable decay. Dried and powdered lettuce or duck-weed leaves or pea flour, sprinkled thickly on the water, produce good results in a few days, kept in a warm place and a subdued light. Also a quantity of hay over which boiling water is poured will soon produce the creatures. Decaying leaves of aquatic plants are very good for the purpose. A low-power microscope or cheap magnifying glass should be employed in this work. (See page 128.) After the culture is apparent and the fish are swimming freely, occasionally dips of culture water should be put in with the young fry. Sometimes the infusorians can be found freely in standing pools, particularly where the water is not very clean, and where there are no cyclops or other carnivorous crustaceans. A rotifer, Brachionus rubens, sometimes occurs so thickly that the surface of the water appears to be covered by a thin, rusty scum. When such a scum is observed in a stagnant pool some of it should be placed in a small bottle and observed with a low-power magnifying glass. If there is the appearance of dust-like particles moving continuously about, it is very likely they are rotifers. A thimbleful of this yellowish water which has been skimmed from the surface contains more rotifers than several gallons of ordinary stagnant water, and the breeder who can locate this kind of live food when his fish are from one to three weeks old is in good luck. Very small live food tends to keep the young fishes more nearly a uniform size. If daphnia are fed at first, it is only the more robust individuals that can eat them, and the result is a rapidly increasing disproportion in size that soon ends in cannibalism, unless the young giants are promptly placed by themselves. Small pools about a cattle yard are particularly favorable to infusoria and rotifera, but, of course, if the water is very dark it should be used sparingly. This sort of food should be used for about ten days to two weeks. Illustrations in figure 109 show types of this living food, but one does not need to be very particular as to the exact form. In general, anything alive that is too small to be well seen by the naked eye, but which is 
visible under an ordinary magnifying glass, will answer the purpose. Collection can be made with nets of fine bolting cloth. If green water can be had, some of it should be put in with the young fish. It contains vegetable matter of value to very small fry. After the fry have noticeably increased in size they should be fed young daphnia which have been screened through a fine wire tea strainer. As size increases, feed fullsize of daphnia. (See page 81.)

In instances where it is not possible to secure living food for raising young fishes they may be started on rice flour, yellow of egg forced through bolting cloth or fishfood reduced to a powder and sifted through chcese-cloth. As they increase in size an excellent diet is the paste from boiled oatmeal after straining it through muslin or cheesecloth. Powdered shrimp or codfish as described on page 70 can be added to the oatmeal to advantage. This oatmeal diet had best be fed in a miniature fish globe, bowl or deep saucer submerged in the tank. Scrambled egg with a little Cream of Wheat or Cream of Barley cooked in it makes one of the best substitutes for live food, to be used after the babies are six weeks old. Pancake flour (composed of different flours) is good either to sprinkle on the water or cook into a paste.

Whether fed on living or prepared food, young goldfish should be fed very liberally. They will eat more than their own bulk in a day. This is essential to securing large, strong stock of good constitution. They eat almost constantly. It is better to feed several times daily than to put in a whole day's supply at one time. With prepared food it is liable to foul the water with long standing. or too many daphnia introduced at one time exhaust the oxygen in the water. This lack of oxygen retards growth and may produce suffocation.

Forcing Growth. Contrary to previous theories, numbers of our leading breeders now use a drip of water in the tanks with young fish over one month old. In many cases this plan seems to produce remarkable growth. The use of an ordinary overflow in this connection is inadvisable, particularly if outdoors, as a heavy downpour of rain is liable to carry off the small fish. If the tank used has an overflow pipe, a large wire guard covered with cheesecloth will answer the purpose, but the cloth should be renewed occasionally, as the water rots the fabric. In a tub, a very good drain can be made by placing a two-inch collar of stiff felt around the top. Secure the felt in position by securely wrapping a cord around it as close to top of tub as possible, allowing the felt to stand about one inch above sides of tub. This will not only secure the young fish, but will prevent the loss of any daphnia by overflow.

Best results are had in raising fishes outdoors, but one invites catastrophe by placing them out in the first warm spell of spring unless it is 
possible to again bring them indoors promptly on the arrival of the cold spells sure to occur in most climates.

No matter how goldfishes are fed, there will be a tremendous difference in their growth, and it will be desirable to sort them into sizes several times in a season. The really practical thing to do is to pick out the "growers" which have good points (there will be few enough with this combination), and a few of the most promising of the second size. Dispose of all the rest by sale or gift. They will make someone happy.

This wholesale culling should not be done later than midsummer, so that the choice specimens will have the full benefit of the extra space and food. Even many expert fanciers fail to get the best results on account of trying to raise too many young in a given space.

A peculiar fact is that with otherwise identical conditions and food, goldfishes will attain a greater size in a large tank than in a small one. That is why fishes in small aquaria seldom grow after purchase.

Small fry should be dipped out and never poured. Rough handling kills them almost instantly.

Goldfishes at any age should be at least partially protected from the direct glare of the sun, so that they may at will go into the sun or shade. This is particularly true of young blue Calicos, whose delicate tints are apt to bleach in excessive direct sunlight. A few sticks to form a rough lattice over the tray or tub will do very well. In case of rain the sticks, unless already weather-beaten, should be removed, as water from new wood is injurious. If the fishes are in a position where they get only about two hours of sun, no protection from light need be considered.

Coloring Age. Most young will change in August from their baby color to approximately their final color.

Breeding Age. Strong goldfishes begin breeding at the age of about one year. For the spawn to amount to anything in quantity a female should have a body length of two inches or more.

Sterility. Excessive forcing of growth of deep-bodied fancy goldfishes often carries a penalty. In cases where the young in October have bodies of 3 inches or longer, and in general have the appearance of fishes at least two years old, they are likely to prove sterile and to have short lives. "Too much of a good thing" is a possibility here too.

In-breeding. A certain amount of in-breeding is necessary in order to preserve the best points of a strain of stock - say a cross as close as first cousins. Closer than this weakens the vitality of the stock. When we have two breeders of good ancestry, but of no blood relationship, we are likely to get strong fish, but with poor points.

Note: On pages 209 to 216 the principal points in the story of Goldfish Breeding are re-told in picture. 


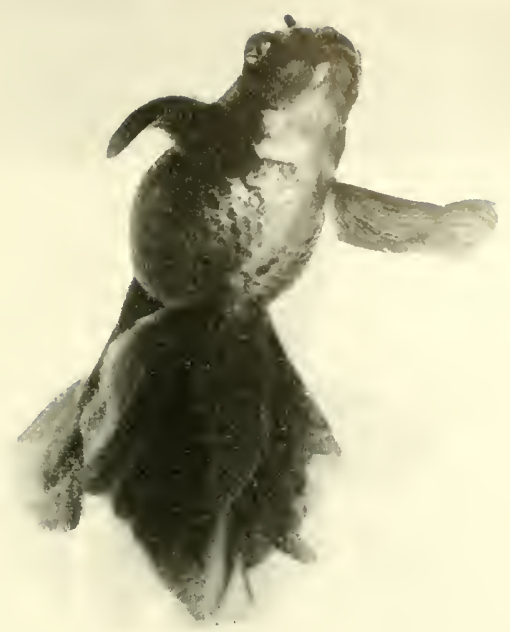

Fig. 186. A Ripe FeMtale

The body does not appear so full as this in all cases. One must be somiwhat familiar with the natural shape of the fish in question in order to jurlge its condition. If the scales stand out it is a case of dropsy.

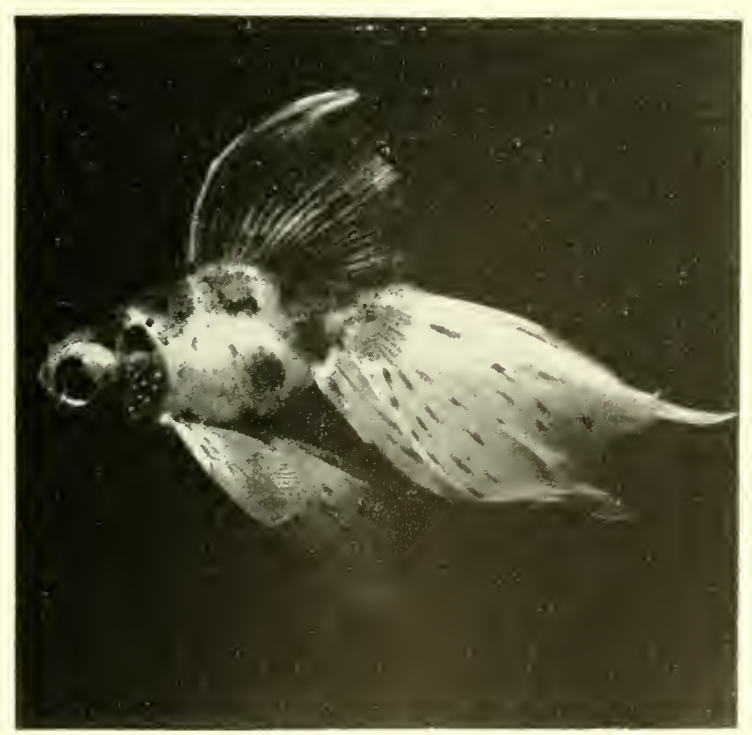

Fig. 187. A Ripe Male

Indicated by the small dots on the gill plate. 


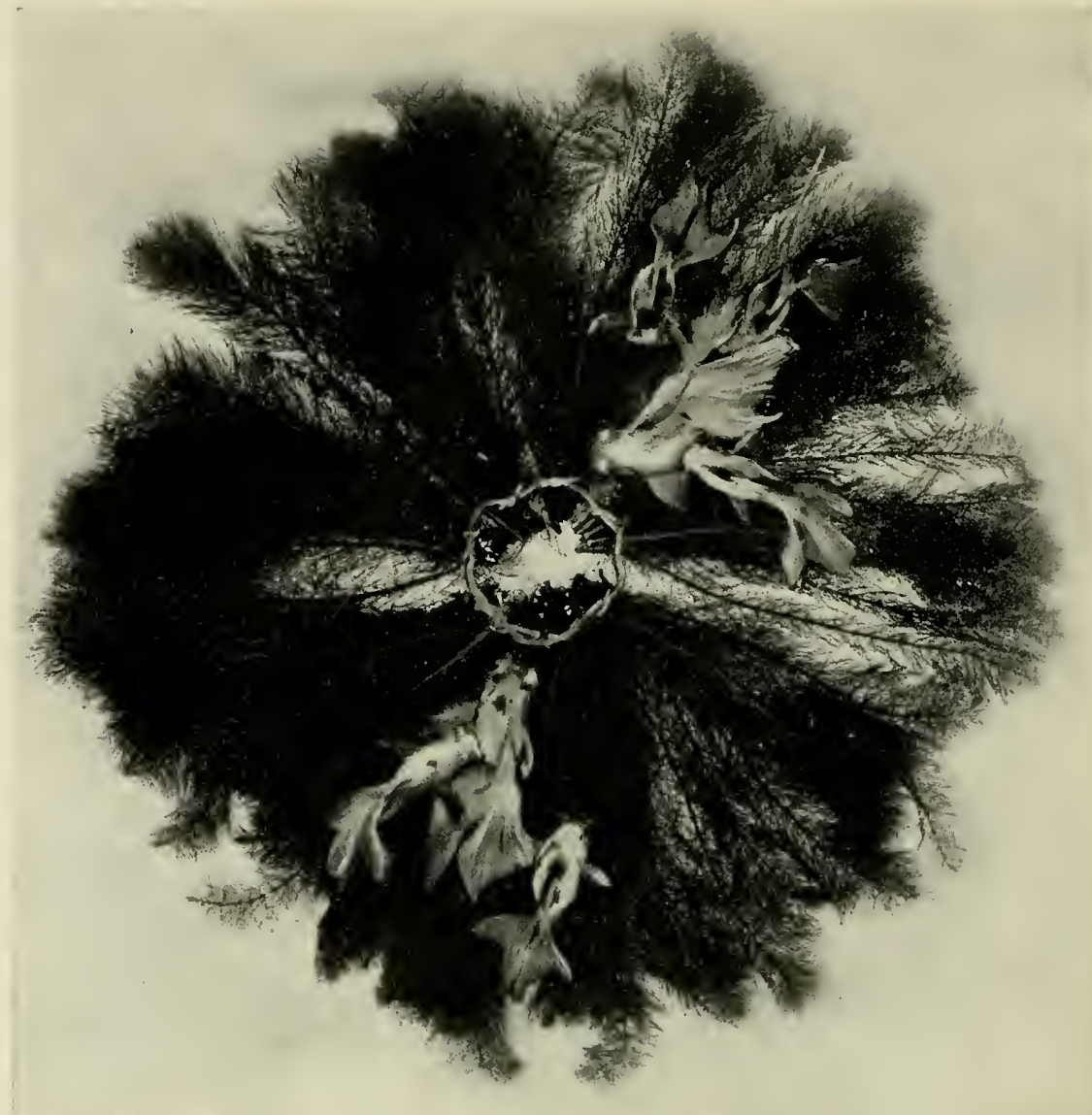

Fig. 18S. Telescope Goldfishes Spawning

This unusual photograph shows two females spawning on a ring of Myriophyllum. The smaller fishes are the males, in vigorous pursuit. Males do not average of smaller size than the females, but the younger ones are the more active and fertilize a higher percentage of eggs than when older.

On wholesale fish farms where it is not practicable to use or prepare a sufficient number of aquatic plants for spawning purposes, another method is in general use. A plain square frame is made of about $7 / 8$ inch lumber, 18 inches square and 3 inches deep. Poultry netting (about 1 inch) is attached to the bottom, making a general arrangement somewhat like a sieve. Egg-catching material is attached to the wire (on the inside). The frame is anchored and submerged one or two inches so that the fishes can swim over the edge, to spawn on top, but the spawning material itself should extend above the frame to lightly touch the surface, and should be dense enough to allow no eggs to fall through. Other fishes present cannot eat the eggs from the shallow position on top, while the frame prevents their nibbling from the sides. The spawning material used in Japan, and sometimes imported here, is willow roots. Sod of any strong grass with the earth washed away is more generally used in this country. In 1928 it was discovered that Florida Moss serves the purpose admirably. As it does not rot and is very cheap, it will probably come into general use. There is no reason why this scheme cannot be adapted to the needs of the small breeder, but one should remember to soak a new screened frame for several days before using it in a small body of water.

Florid, Moss is also very good as a refuge thicket for young tropicals. 


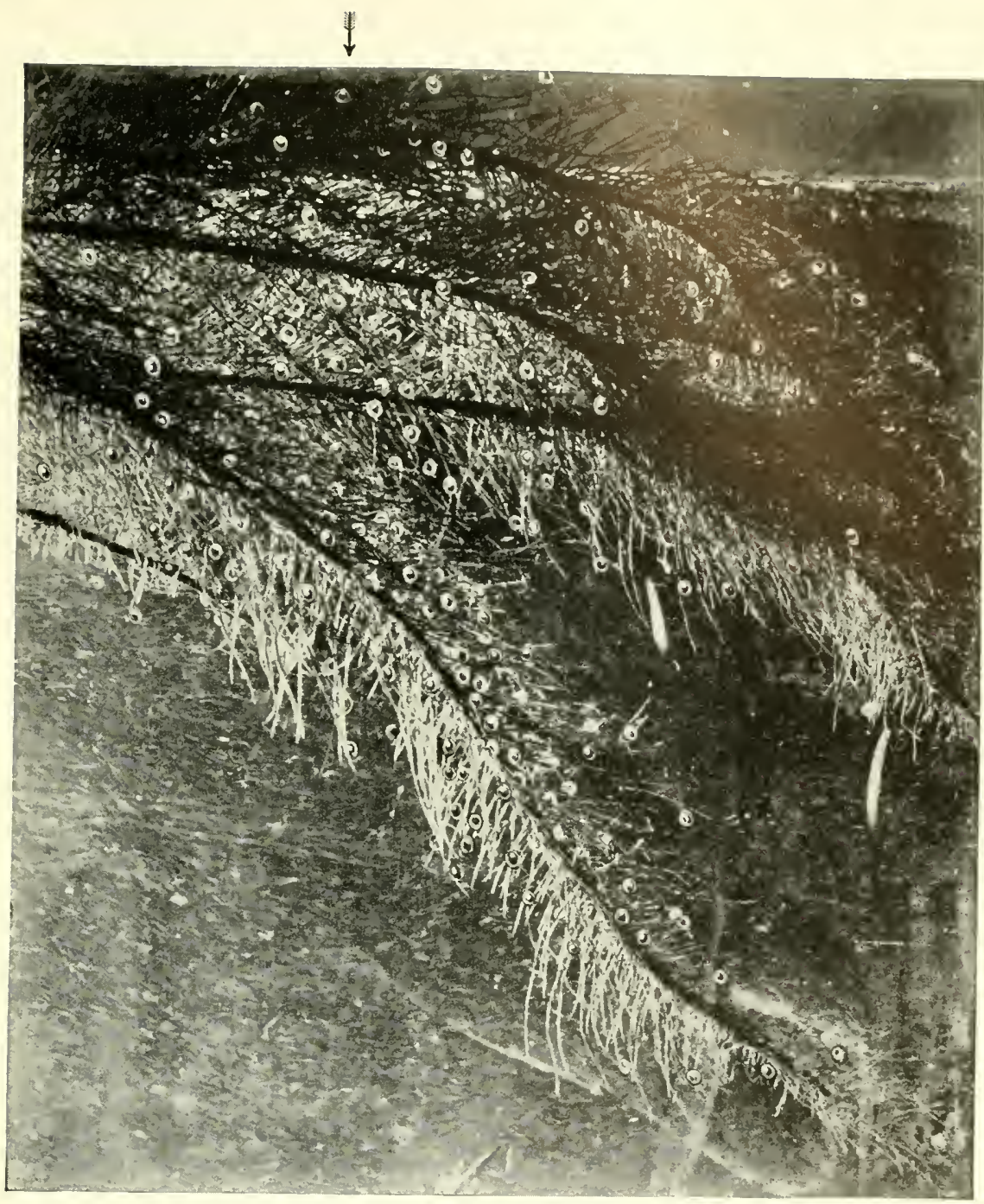

FIG. 189. Goldfish EgGs (Slightly magnified)

Being of a pale amber color, goldfish eggs are very difficult to photograph as they actually appear. The one beneath the arrow gives a more correct idea than any of the others, but the general distribution of the eggs on hyacinth roots is shown in a characteristic manner.

It is not uncommon for beginners to mistake the jelly-like masses of snail eggs for goldfish eggs, although they look nothing alike. 


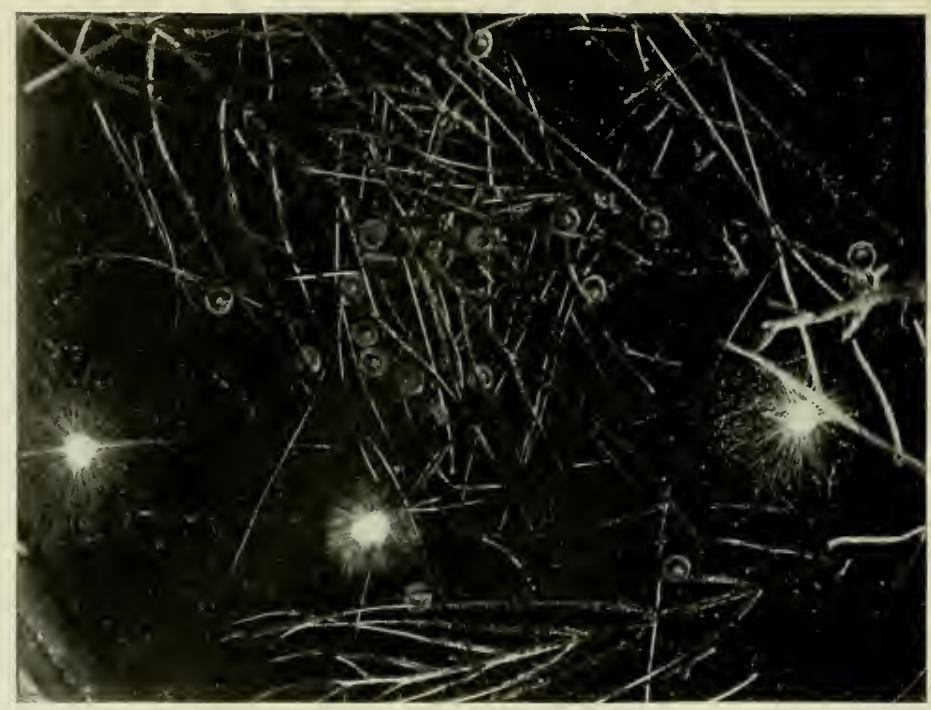

Fig. 190. Goldfish Eggs, Three Days Old (Magnified two diameters)

Three infertile ones have been attacked by fungus. The nineteen good ones are really more difficult to see at this stage than the illustration would indicate. The fungus does no harm to the fertile eggs.
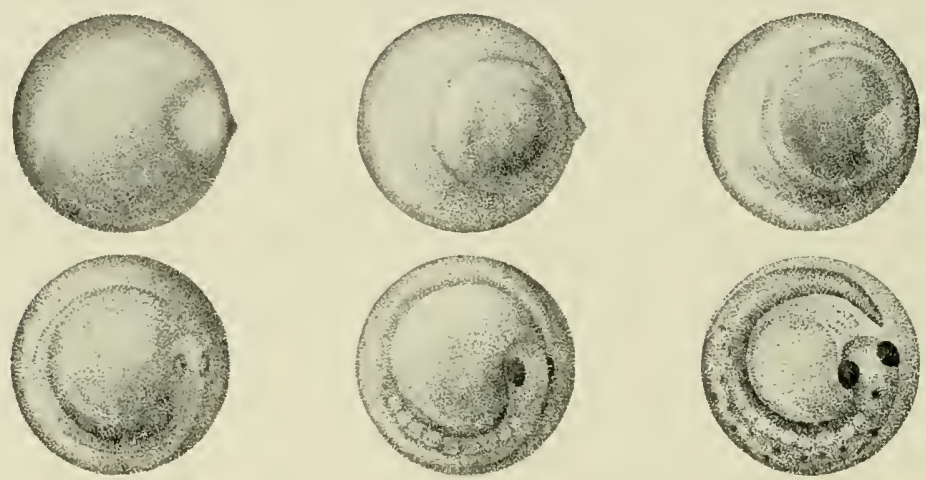

Figs. 191 to 196. Developuent of Goldfish Eggs

Greatly enlarged drawings made at intervals of thirty-six hours, in an average tem perature of sixty-five degrees. First figure made at age of one day.

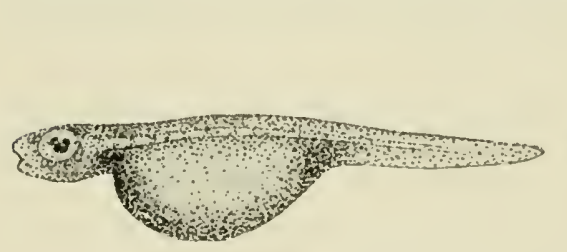

Fig. 197. Newly Hatched GOLDFISH FRY

(Same as shown in Fig. 199)

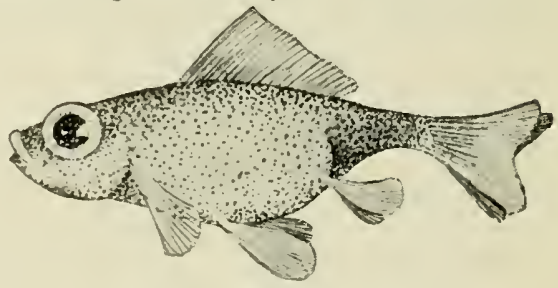

Fig. 198. Three Days Old, With Fins FORMED

(Same Enlargement as Eggs) 


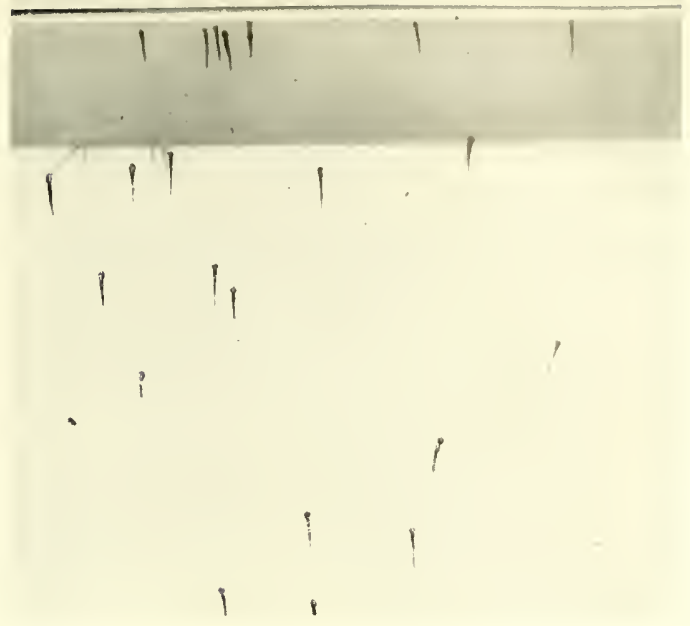

Fig. 199. Newly Hatched Goldfishes (Life size)

Clinging in characteristic fashion to the side of the aquarium. They move about frequently and swim with effort, the air bladder not having yet filled.

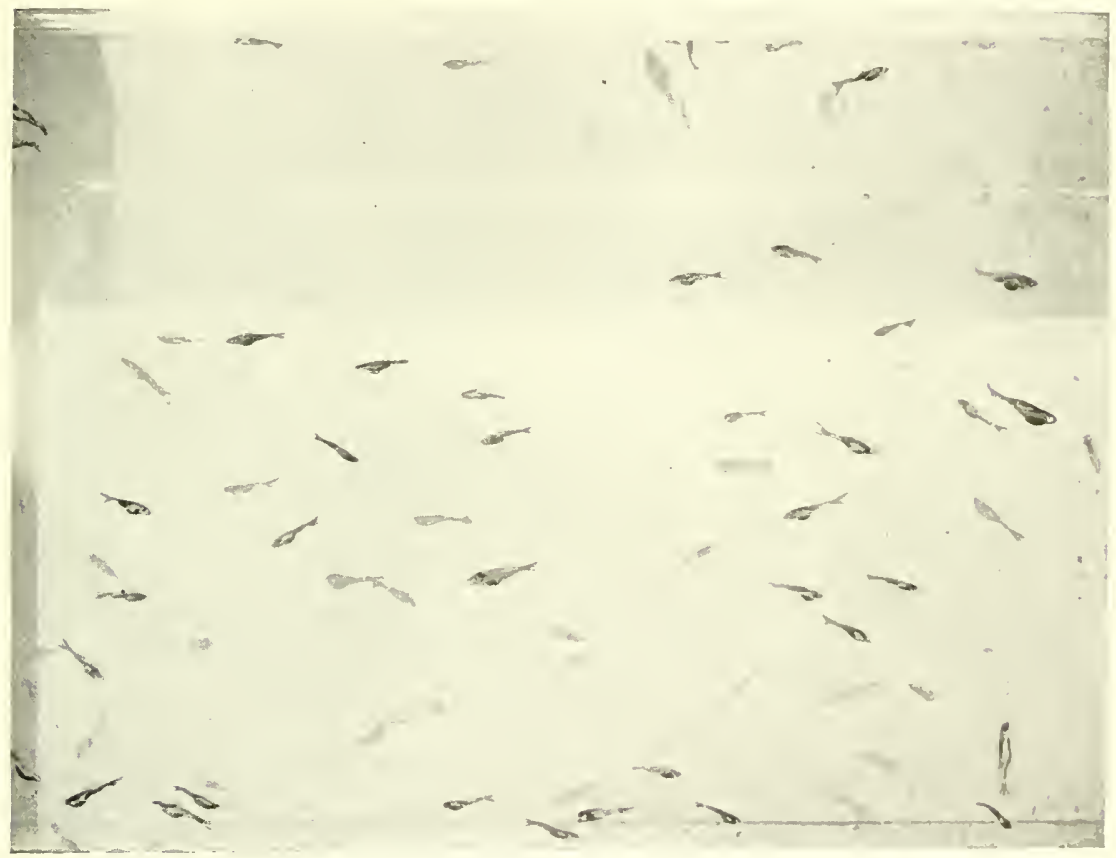

Fig. 200. Goldfishes at Eighteen Days (Reduced one-third)

The abdominal yolk-sacks have been absorbed, and the stumachs protrude in a way to show that plenty of food has been provided. 


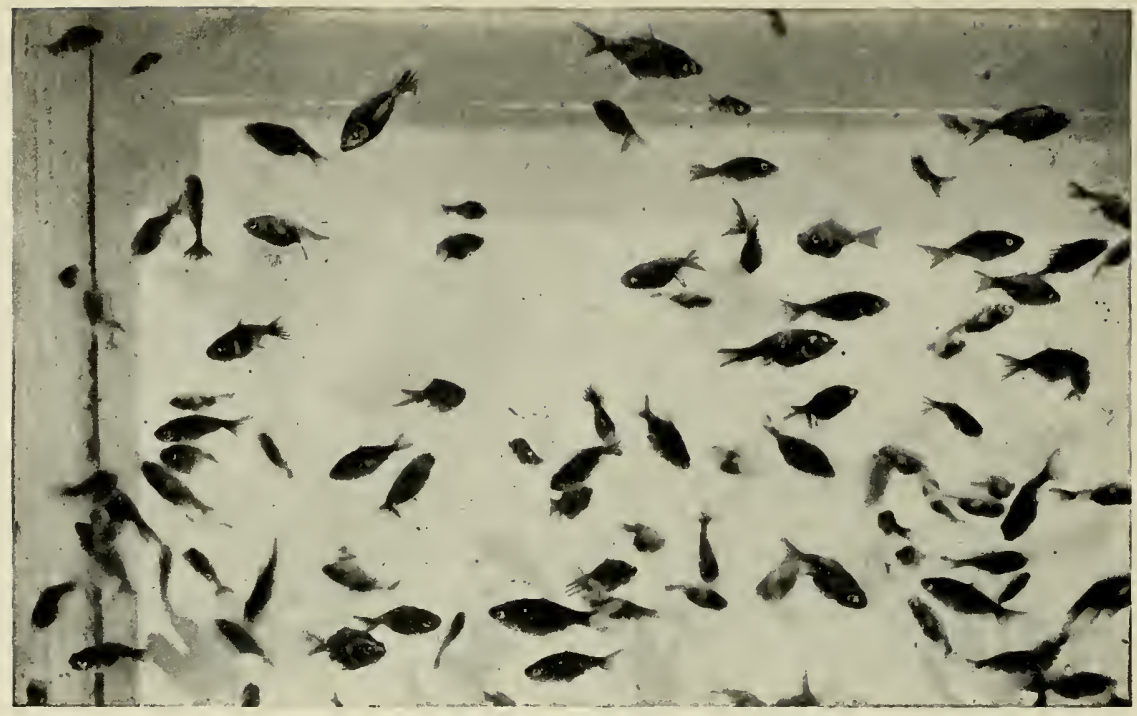

Fig. 201. Goldfishes at Six Weeks (Reduced one-third)

At this period they have come to look like fishes. From this point until late fall they eat the equivalent of at least their own bulk daily, and the bodies in fancy stock will continue to deepen and become more rounded.

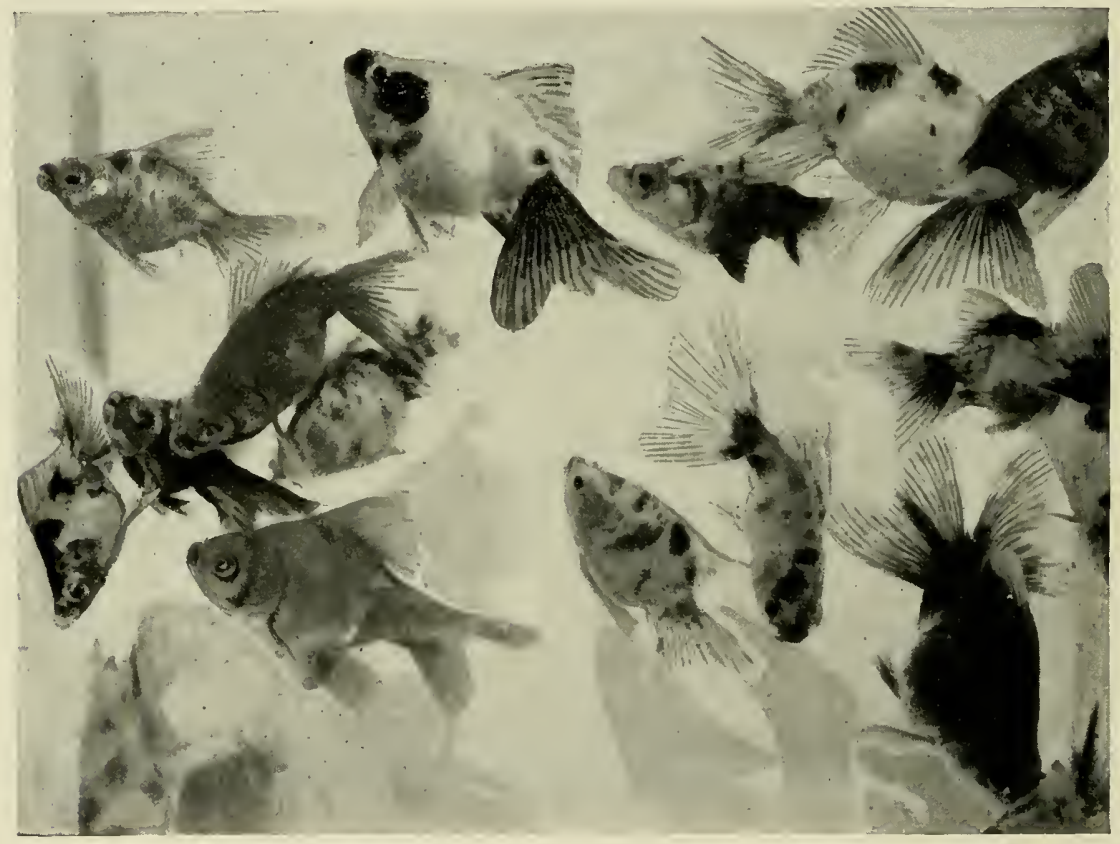

Fig. 202. Telescope Goldfishes at Tinelve Weeks (Reduced one-third)

They have now attained most of their body form and started to develop telescopic eyes. In the scaleless varieties the colors have largely appeared, but among scaled stock the young at this period remain "uncolored." At this time the best are selected as next year's breeders, and given ample room by themselves. 


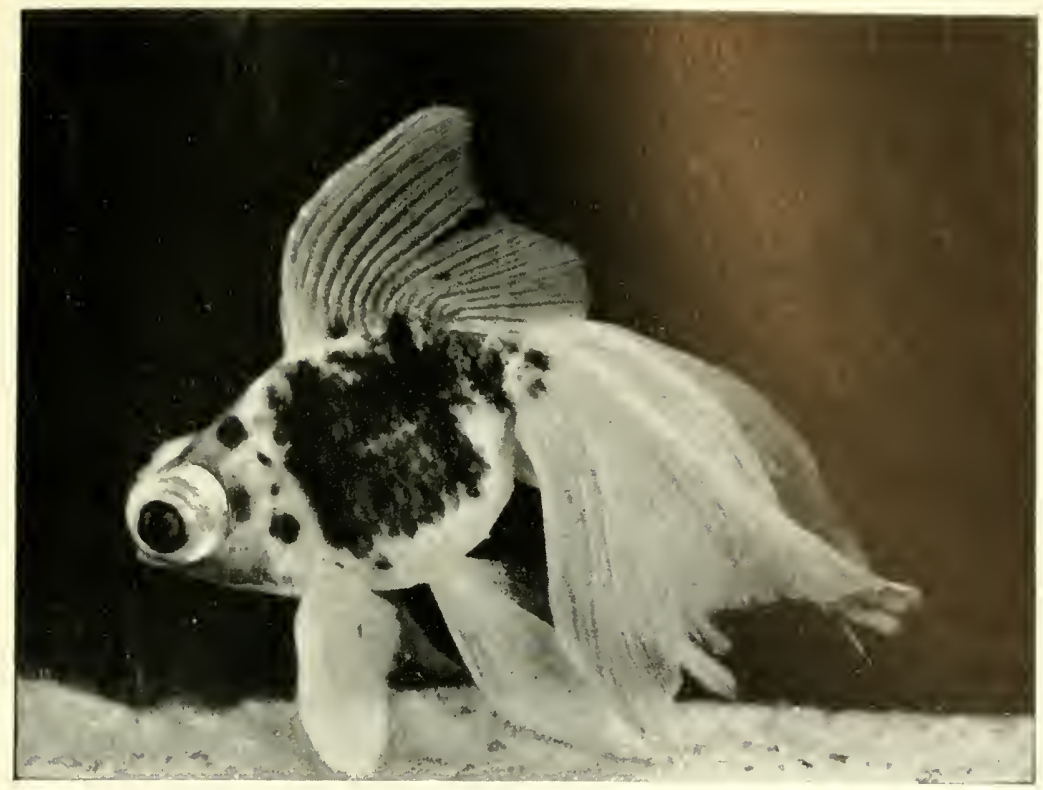

Fig. 203. Adult Japanese Telescope Goldfish

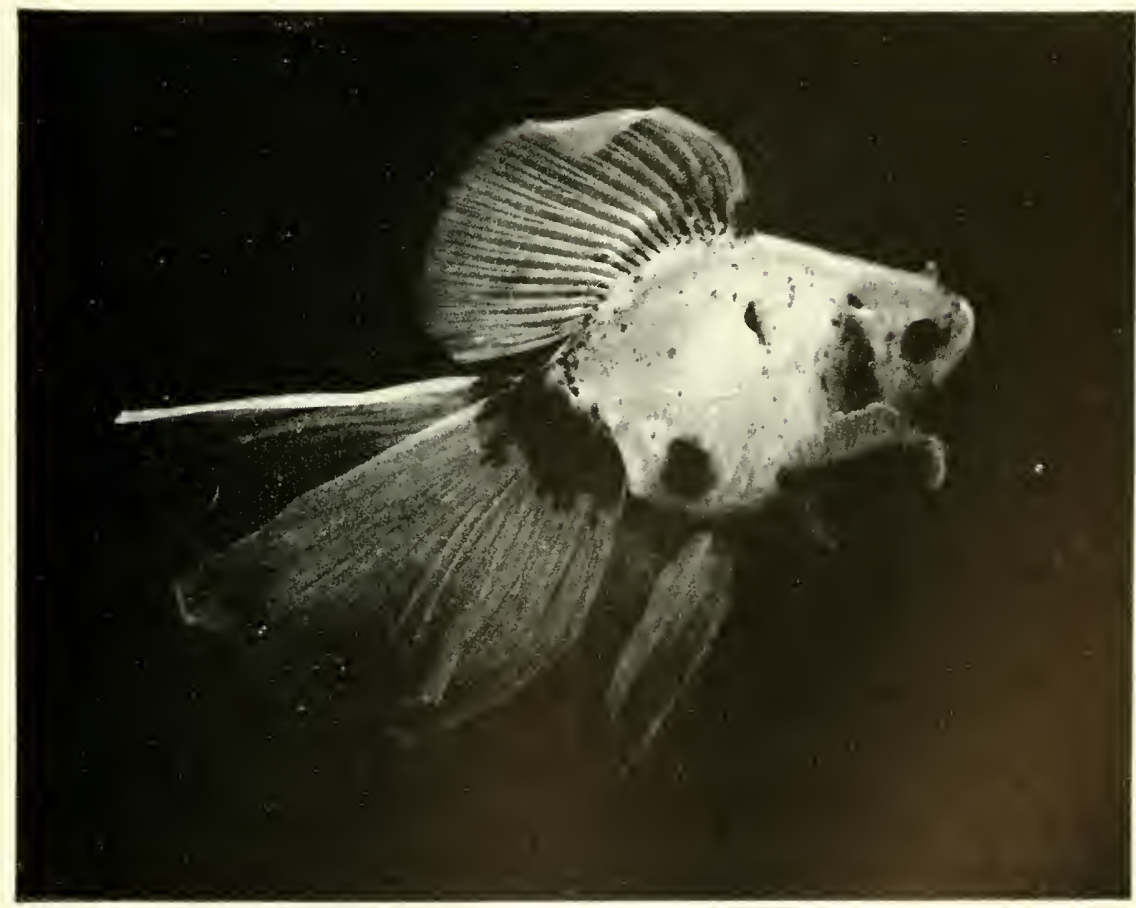

Fig. 204. Adult Japanese Fringetail Goldfist 


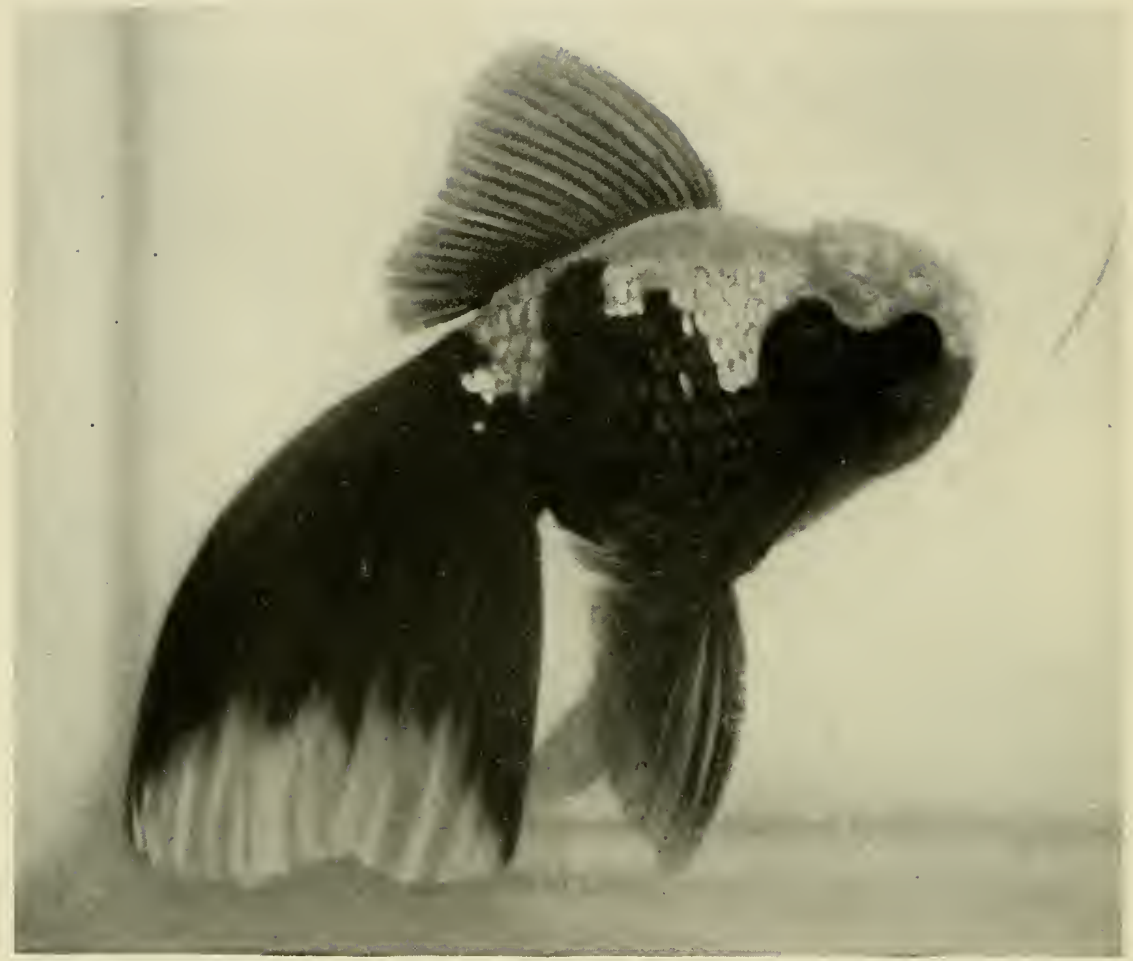

Fig. 205. Adult Oranda Goldfish

This represents the final stage in the development of one type of goldfish, the Oranda, because the hood on head as shown in this illustration only comes after several years of age, such hoods as these not being produced under four to five years. 


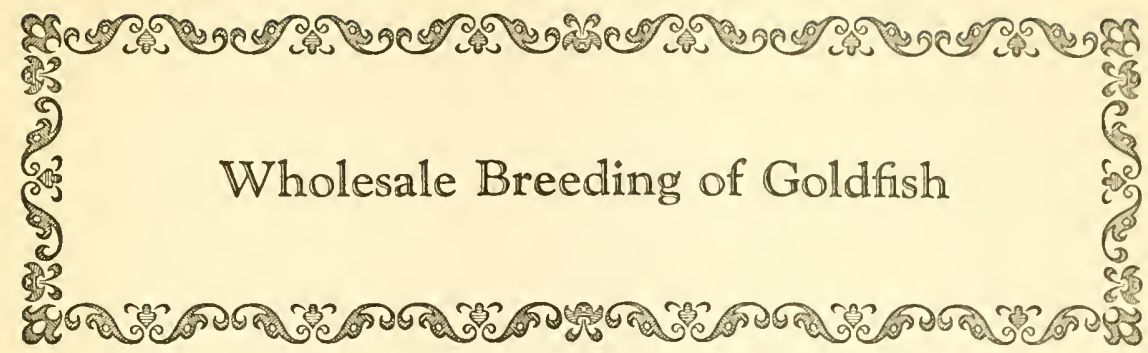

The principles of breeding and rearing goldfish are of course standard, but their application in producing huge quantities for the popular market is very different from the methods of the individual fancier who gives studious and loving care to each of his pets.

It is therefore with some hesitation that we advise inquirers to embark in goldfish farming, for, properly conducted, it is a real business requiring special training and the application of sound business principles. If one has these qualifications, a capacity for seasonal hard work, a wellselected site, and lastly a faculty for prompt and clear correspondence, there is no reason why a very fair living cannot be made in this industry. At the present time there are about 20 to 25 million goldfish being produced annually in the United States by about 400 fish farmers. About 18 of the millions are reared by perhaps half a dozen large, well-conducted farms. The balance are from dirt-farmers who merely stock a few ponds, let the fish grow if they will and usually sell their product to the larger producers because they themselves have no marketing facilities nor talents. Whether the demand will increase is anybody's guess. Many dyed-in-the-wool goldfish fanciers have been converted to tropicals and the general public is becoming aware of them. It seems unlikely that they will make any early inroads on the commercial goldfish, especially in the cheaper grades.

As we all take it for granted that we have good business judgment and executive capacity, let us pass those considerations and concern ourselves with the immediate, practical problems of those who are, or wish to be, goldfish farmers. The cardinal points are climate, soil, water supply, ground levels, shipping connections and room for expansion. We shall take them up in order.

Climate. Most of the large, successful farms are in a climatic region either near or equivalent to the "Mason and Dixon Line"-Maryland, Ohio, Indiana are the big producers, but distinct success is being had in other states-northern New Jersey-even New York State and 
Ontario, and again as far south as Florida. What is needed is a climate that is settled and balmy by May 15th and in which hard frost holds off until November 1. Also where the days are not excessively hot nor the nights cooler than say 60 degrees Fahrenheit in summer. It will therefore be seen that the actual climate of the spot is more to be considered than geographical location. There are many places where one side of a mountain range is satisfactory, yet on the other, only a few miles away, conditions are not at all favorable.

Goldfish need a long season and moderate warmth for size development. They also should have a winter rest period which is produced by moderate cold. The reaction from this winter lethargy stimulates them to strong breeding in the spring.

Soil. For economical construction and maintenance of large goldfish ponds there should be a soil capable of holding water with little loss by seepage. A clay bottom is almost essential.

Some regions are unsuited because the soil is either too acid or too alkaline. However, this point can best be considered under the next heading, for the state of the soil in this respect is pretty sure to be shared in by the quality of the

Water. For goldfish culture water should be nearly neutral or slightly impregnated with lime. Limestone water produces fish with good color and firm flesh that helps them withstand the hazards of shipping. In the testing sets now so generally in use the reading should be between 7. and 7.6. If not in possession of one of these sets, the test can be made either by a private chemist or the agricultural department of the state. In fact state and governmental departments are splendidly organized for helping the fish farmer in most of his problems. They are always keen and prompt to do everything possible. Correspondence with the Bureau of Fisheries at Washington, D. C., receives personal and careful attention, whether the farmer is working with goldfish or food-fish. So far as we know, the same can be said of the Departments of Agriculture in the different states. If the present chapter did no more than advise the reader where this help may be had, it would have served a good purpose.

Spring water is usually satisfactory and has two great advantages. It keeps warm enough over winter for the storage of surplus fish stock and eliminates the troubles caused by wild fish getting into the goldfish ponds where water is taken from streams. The difficulty about spring water usually is that there is not enough of it! A fish farm takes quite a quantity of water, and one of the most important considerations is that there be an unfailing, year-round supply. Water as it comes from the spring, especially in a limestone country, is likely to be suited to maintaining fish life, but too cool for putting growth on goldfish. There- 
fore in the rearing ponds it should be used simply for filling. In fact, actively running water is not used in any of the rearing ponds. It is let in by sluices, pumped in or flowed in from higher levels as needed.

From a practical standpoint the spring water section of a goldfish farm, if present at all, is a small proportion of the whole. Water from a good unpolluted stream must usually be depended upon for the main supply.

Ground Levels. It is better for the source of water to come from above, so as to flow into the various pools without the expense of pumping. But another important matter is to have a stream bed or other place of discharge below the entire pond system. This not only for emptying the ponds, but for taking care of surface drainage during protracted heavy rains or cloudbursts. In fact this matter of taking care of excess rain water is one of the most important to be worked out in planning the general lay-out. Each piece of ground presents its own problems, but usually ponds are maintained at a level about six inches below the overflow point, to take care of emergencies. The screened overflow itself usually discharges either into another pond or into a ditch or trench leading to the final discharge point of the farm. In general a fish farm should be located on a gentle slope with the water supply at the top, and preferably on a tract which is not the concentration point of a large water-shed above it.

Shipping. Good work on the fish farm can be undone in a few hours by improper shipping. Of course we all know that the fish must not be overcrowded in the cans. Ordinarily in a 15-gallon can there should be placed no more than 150 common fish of three-inch size for 24-hour travel. Fewer for hot weather and fewer for fancy breeds. But one of the main things is to get the cans moving as shortly after loading as possible, and to keep them moving until delivery. The vibration of travel (no doubt owing to splashing) oxygenates the water and so helps the fish. For this reason, especially in summer, it has been found that truck shipments are superior to rail transportation, because there is more vibration on trucks, but also in rail shipment it is almost unavoidable that the cans stand still for a fairly long time (in rail transfers and in stations prior to final delivery). These still periods are when the suffocation occurs.

Formerly it was thought necessary for a fish farm to be near an express office, but since the advent of the automobile it is more important to secure low-priced ground and corresponding taxes rather than be a short distance from the express company. And of express companies it is only fair to say that they are appreciative of the problems of the shipper of live fish and do all in their power to make good deliveries. 
They wish to avoid claims even more than the shipper cares to make them.

Fish are better prepared for shipping by being kept for about two weeks in cool water. Hard spring water is excellent for the purpose. As before noted this seems to toughen the fish considerably. Care must be taken in moving fish from warm rearing ponds to spring reservoirs not to make the temperature change too suddenly. Floating the warm containers in the cool water until temperature is nearly equalized before emptying the fish is a good method.

The Plant. Experience has abundantly proven that goldfish should be hatched and kept for the first few weeks in concrete tanks where they can be watched, well fed and protected from most enemies. It is equally certain that as soon as they are large enough to handle, say about half an inch, they should be transferred to mud-bottom ponds, where they grow much faster. This applies especially to commons. Fancy varieties are usually reared in cement pools, where they can be more carefully watched, and also removed with less risk of injury. Goldfish stir up the mud in the water and make the visibility bad, but on the whole this is an advantage, for it partially hides them from enemies and protects them from the full glare of all-day sun.

The size and style of concrete tanks varies with individual ideas. Personally we prefer them raised. It makes observation better and work easier. Six by twelve feet is a workable size for hatching-tanks and in the latter part of the season they are useful for storing graded fish as they are harvested from the mud-bottom ponds. Figure 207a shows such tanks, while figure 208c, from another farm, shows them at ground level and a size about twelve by twenty feet. Each is adapted to its own breeding methods, which will be described later.

Mud-bottom ponds also vary in size. A fair average would be about one-third acre. They are from two to three feet deep and are sloped to a point (usually in one corner) to which the fish will be drawn for catching when the water is removed. Where spring water is not available for winter' storage of fish, a few ponds are dug extra deep so that ice will not form to the bottom. Fancy brood stock, however, should be kept indoors over winter in liberal sized tanks, at a temperature of about 60 degrees.

The edges of mud-bottom ponds should be concrete reinforced with poultry netting. This retains the banks and keeps back vegetation. Plants harbor small but vicious fish enemies. This reminds us to state that it is not well to attempt to grow aquatic plants in goldfish ponds. They are difficult to hold in check, interfere with catching the fish, and 
while reeds and cattails protect fish from birds of prey, they also harbor their most active enemies-frogs, turtles and snakes.

Another method of holding back the vegetation is with boards held by stalses - as in figure 207. At this farm the boards are placed only on the breeding ponds, and for an entirely different reason from those already described. We will come to it in a moment.

Breeding Methods. At no point is the difference more marked between the small and the wholesale breeder than in methods of propagation. What is best for an individual would, when multiplied by the needs of the wholesaler, become a time-consuming burden. We refer principally to the preparation of the spawning bed. The standard method now in use by most establishments is pictured in figure 207a. It is a frame $24 \times 30$ inches, 5 inches deep, with a 12-inch strip of poultry: netting attached the long way in the centre of the lower edge. This allows a 6-inch opening on either side at the bottom. To this netting is attached with string either thick sod with the earth washed out, or, more recently, Spanish Moss which has had the outside covering removed, and which is used mainly for cheap furniture or mattress stuffing. Boards of trade in New Orleans, La., or Jacksonville, Fla., will give names of dealers to those interested. The material is quite cheap and is good for more than one season's use.

These frames are floated in the breeding ponds the evening before spawning is expected. The fish swim up through the lower openings and spawn on the material, which is from 2 to 3 inches thick. As the frames become well filled with eggs, they are removed to the hatching tanks. Single nail heads projecting from the centres of all four sides of the frames prevent the surfaces from bumping together and destroying fry which might be clinging there. After the fish are free-swimming, the frames are of course removed from the hatching tanks and, after exposure to the sun, used again or stored.

The object of the boarded edges in figure 207 is to keep the grass, as well as rootlets, out of the water, so that the fish will spawn only in the frames, and not on the grass, which would be their natural tendency. Obviously, concrete edges also will serve the same end. In ponds where fish are allowed to breed without supervision, grass edges are a help unless there are present plenty of aquatic plants with finely divided leaves.

In Japan and usually in Japanese hatcheries in America, willow roots are used to catch spawn. It is thrown into the breeding ponds in bunches and after being filled with eggs is placed in hatchery ponds (the large ones in figure 208c) and held down about a foot from the bottom by an arching piece of wire netting. Otherwise it is likely to 
float partially out of the water and dry some of the eggs. Willow roots can be gathered, but they are usually imported in a dry state from Japan.

Feeding. Goldfish can rear themselves on the natural food they will find in a pond and the insect life which falls into the water, but it is a poor policy leaving them to their own resources in this matter. They will grow much faster and be more valuable if fed liberally. The young should have daphnia. Pools for supplying this food ought to be prepared in the spring. Various methods are employed, most of them based on the decomposition of organic matter. A mixture of manure and leaves from a compost pile spread liberally on the bottom forms a good basis for a culture. A mixture of two-thirds sheep manure and one-third super phosphate (a fertilizer) has been found excellent. When the water has stood in the prepared pond for about two weeks, a culture of daphnia may be added. Multiplication will be very rapid. If the pond has previously contained daphnia probably no fresh culture will be needed, as the winter eggs withstand freezing and drying.

Finely divided yellow of hard boiled egg is a suitable first food when the fry is from 3 to 10 days old. Then up to an inch they ought to have as much daphnia as possible. After that they are fed heavily on mush composed at first of oatmeal and later of an equal mixture of oatmeal, cornmeal and "red dog," a low grade of wheat flour. In some hatcheries Epsom salts are cooked in with the mush about once a week. Fish meal and soy-bean meal are also ingredients occasionally added. In order to secure the best results the mush should be thoroughly cooked and stirred for approximately two hours. The most modern plants use pressure boilers and automatic agitators. This shortens both time and labor. Figure 208 shows such an equipment. We were fortunate to secure this picture just before it was to be enclosed by a building that would have made the photograph impossible. The mush is cooled 6 hours before use.

In large establishments the food has to be conveyed to the ponds on small automobile trucks, so in laying out a plant, space enough for a truck should be left in the main aisles between ponds.

Sorting: On account of the enormous difference in the rate of growth in goldfish, sorting is very important for a number of reasons. As stated elsewhere, the very large eat the very small. Grading for size prevents this. Then they are graded for color. In commons the principal standard is whether they have turned to gold. Sometimes they will not turn the first year and must be sold cheaply or carried over. In Fantails the sorting is more critical, and fins must be considered, as well as size and color. Another advantage of sorting is that the best fish can be given the best and most protected positions, and the best foed-occasional feedings of daphnia, for instance. 
Tables with oilcloth tops, ruled in inch squares, are a help in this work. Commons are deposited on the table, and with the aid of the squares it is possible for unskilled labor to grade for size. When fancy fins are to be considered the fish must be in the water. Besides, fancy fish are more likely to be injured by being dumped on a table. The Japanese gentlemen in figure 208c are sorting fancy fish in the usual way from pans. Sorting is not done once in a season, but several times.

Varieties to Breed. Experience seems to force the general conclusion that the common goldfish is the most paying breed for the beginner or for those who have not a good equipment. Fantails, Telescopes and Lionheads are easy victims to the enemies which abound everywhere, while their degeneracy from apparently good stock is very discouraging. Besides they are more difficult to transport. To say that fancy fish cannot be profitably raised on a wholesale scale would be contrary to the facts, but it is an undertaking only for those who are experienced and who are prepared to give close and constant supervision, and have ample and expensive equipments. Comets, while able to swim rapidly and look out for themselves, are apt to be slow in turning color.

Selecting Breeders. In commons the point of importance is early turning. Each season those which first turn red should be set aside, and from the strongest of these select the breeders for next year. Fantail brood fish should always have fully divided tails. Those with joined tails are already reverting to the original type. Also select deep colors. The tendency for colors, especially in the transparent specimens, is to turn lighter. These are less salable.

In this connection we draw attention to the Japanese screens in figure 208c. Calico fish are stored here in the fall after sorting and while waiting to be shipped. The muddy pond water protected their colors, but when in concrete tanks the delicate blue colors need protection from fierce sun rays. The screens accomplish this very well, and also keep out fishing birds.

Diseases, Parasites, etc. The goldfish farmer has to contend with more fish ailments than does the small breeder. Natural conditions favor more parasites and enemies, while life under the ice for several months leaves the fish weakened and susceptible, so that mortality in the early spring is very high at some farms.

The treatment of disease is another of the points which is outstandingly different on the farm from the conservatory. Quantity and speed nust be ever remembered on the farm.

Instead of the mild salt water treatment for fungus which we elsewhere recommend, and which we believe to be the best, goldfish farmers usually gather a net of fish and dip them for about half a minute in a 
fairly strong brine; about a pound of rock salt to 10 gallons of water. "Strong enough to float an egg" is the usual standard.

Fungus, while the most prevalent disease among parlor goldfish, is not the chief offender on the farm. Here the culprit is an animal parasite called

Gyrodactylus. We describe this elsewhere under the heading of "Flukes," which is due to a species which gets in the gills. The kind we now have in mind lives on the body and fins. The fish becomes emaciated and soon dies. The mortality from this parasite in the early spring is sometimes extremely heavy. Salt solution will not rid the fish of this enemy. A dip of 60 seconds into a solution made of 1 part of glacial acetic acid to 500 parts of water rids the fish of most of these parasites, but the treatment should be repeated a week later.

A pound of permanganate of potash to 30,000 gallons of water has been found effective in killing Gyrodactylus elegans, and other external flukes. Fish need not be removed from pond, but if there is no vegetation.it might be well to reduce the strength slightly. The formula worked out by Dr. Walter N. Hess for use in a tank without vegetation is a two-hour treatment in a solution of 1 part of permanganate to 270,000 parts of water. This is approximately 1 pound of the crystals to 33,000 gallons of water, and is very efficient.

Ichthyophthirius. Personally we have never found salt to be effective against this parasite, but we are reliably informed that 200 pounds of rock salt in a pond $30 \times 40 \times 1 \frac{1}{2}$ feet cures ichthyophthirius in a week. We have seen such wonderful results in aquaria with the use of mercurochrome, 4 drops of $2 \%$ solution to each gallon of water, that we feel strongly like recommending it. At this writing apparently no fish farmer has tried it on that basis. In bulk treatment this figures about 1 ounce of $2 \%$ mercurochrome to 1000 gallons of water. The fish may remain in this solution indefinitely.

Sunfish. This is not a disease, but an affiction, nevertheless. Accidentally admitted into the rearing ponds through defective screens or other source, they consume quantities of young goldfish, and what is worse, pick the eyes out of developed Telescope goldfish.

With regard to the many enterprising and efficient enemies of the goldfish, it seems to be the universal opinion among fish farmers that it is cheaper to accept the enormous losses they entail rather than use screened ponds, which would need to be smaller, require more labor and heavier cash outlay. The writer is not convinced that this conclusion would stand up under a careful test, especially in handling the fancy varieties, which are both more vulnerable and more valuable. 


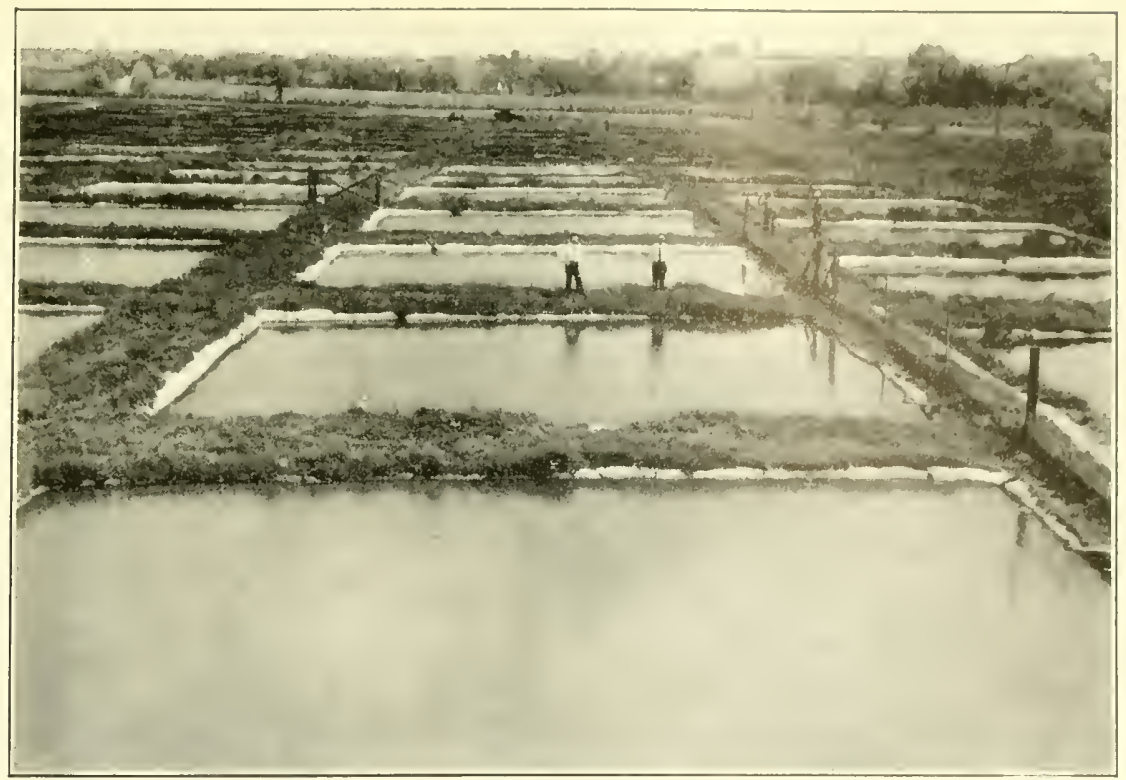

Fic, 206. Rearixg; Ponds for Faxcr Goldofish

Sloping sides and the bottom are covered with concrete 3 to 4 inches thick, which should be reinforced with heary poultry netting (for freezing climates).

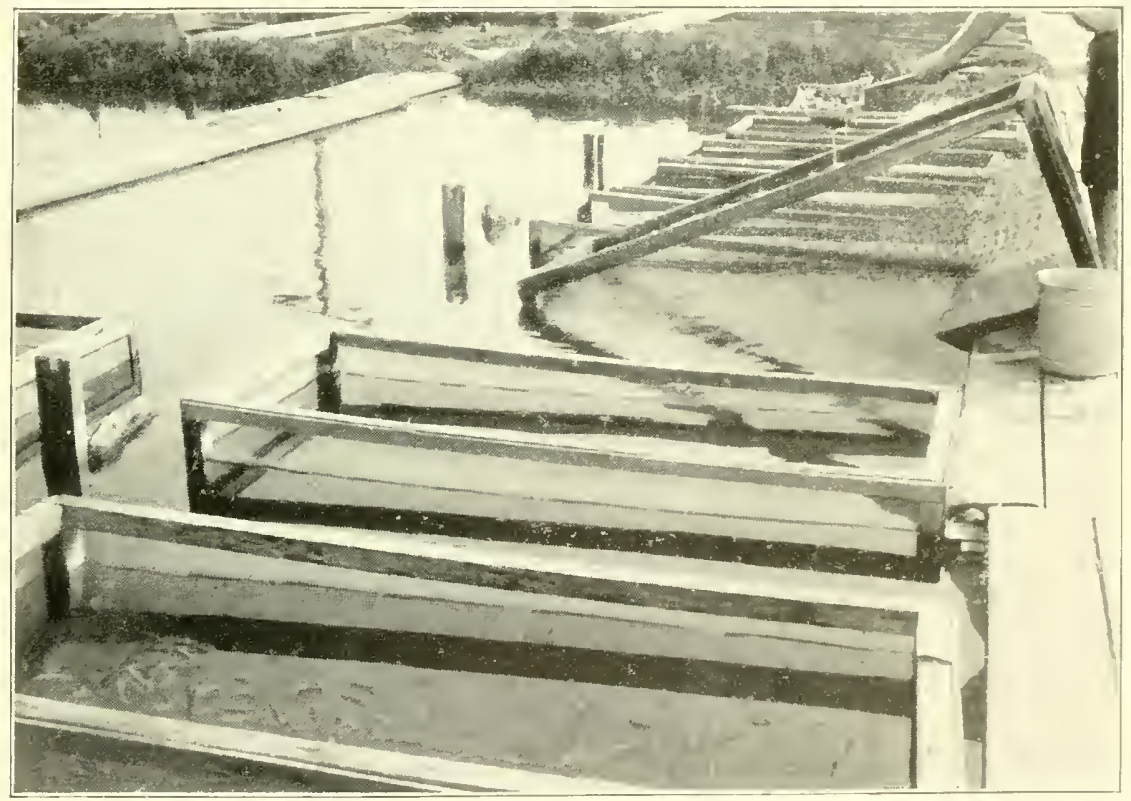

Fig. 206a. Live Boxes

These are for storage of common goldfish prior to shipping. Cool limestone water, it available, is best for the purpose. Attendant is dipping out a netful of fish. 


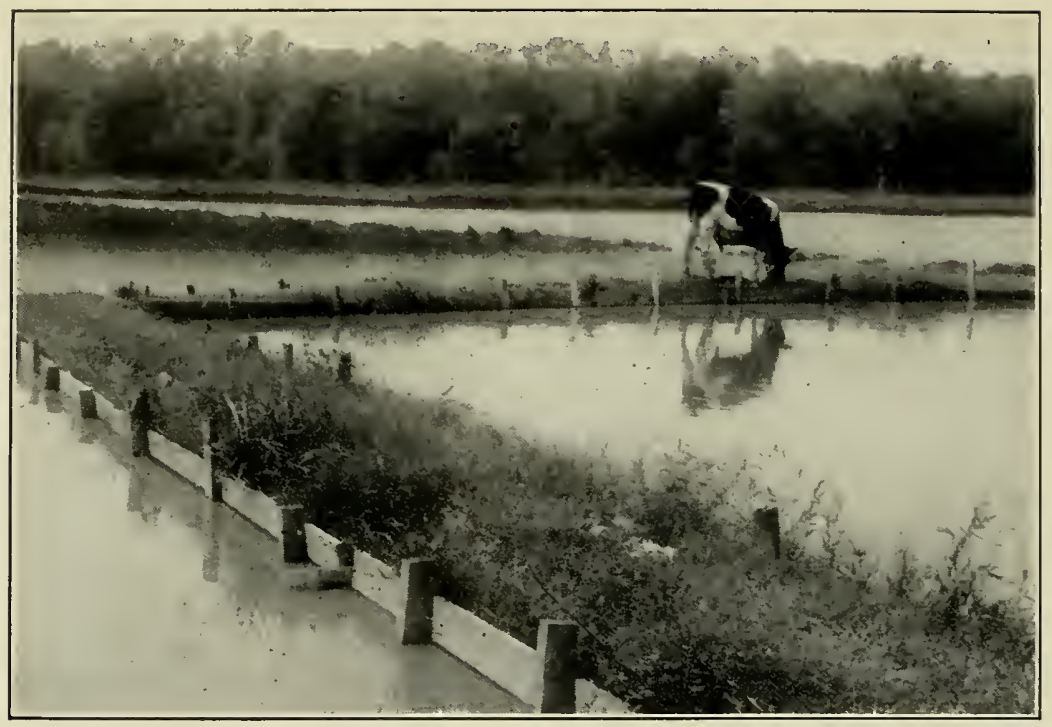

Fig. 207. Breeding Ponds With Boarded Edges

Also showing one of the world's best-known and cheapest grass cutters-a useful adjunct on a farm with acres of ponds. Some ish farms utilize sheep.

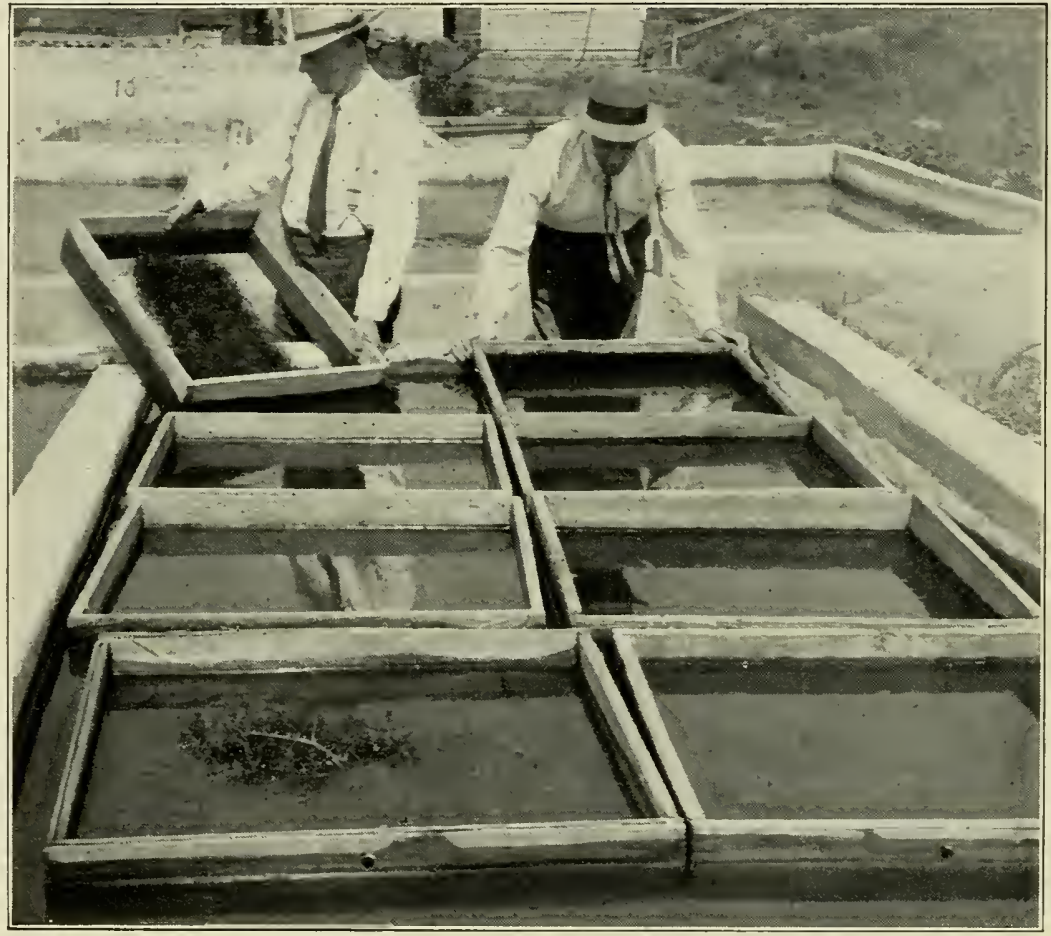

FIg. 207a. EgG Nests

They have just been removed from upper pond and are being placed in raised concrete hatchery tanks. Eggs are deposited on the grassy mat, which is supported by poultry netting. Fish enter through open side spaces in the bottom. 


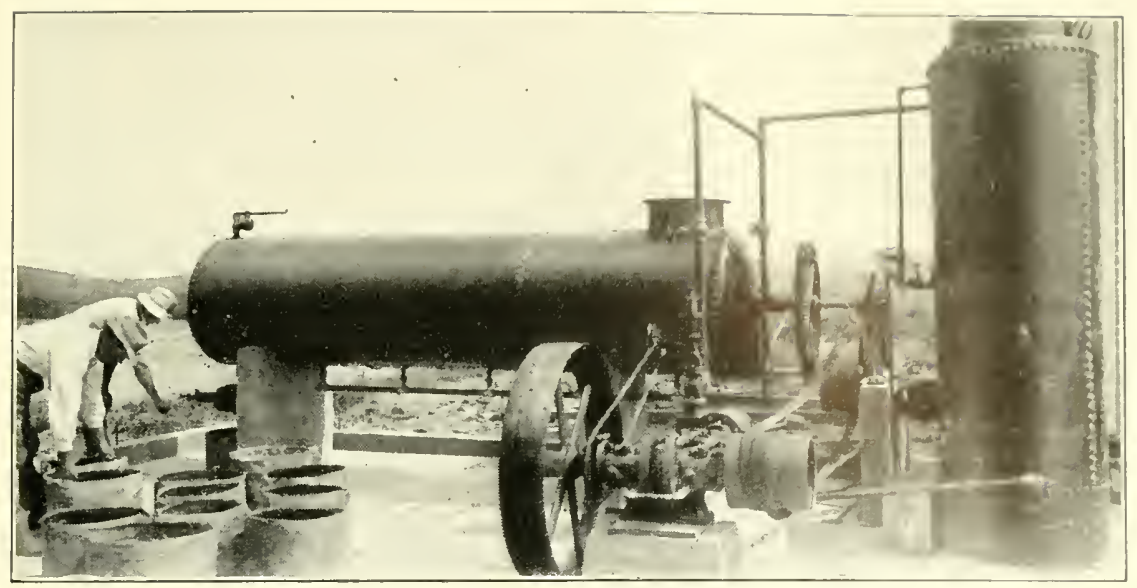

Fig. 208. Kitcinex ox a Monera Goldfisir Farm

Horizontal boiler cooks about 2000 pounds of mush per day, and, what is more remarkable, the trsh eat all of it! The mush is stirred by revolving spirals inside the boiler. They also serve to force the contents to the lower end, where the men are filling cans with the food. Vertical boiler runs engine and supplies live steam to coils in cooker.

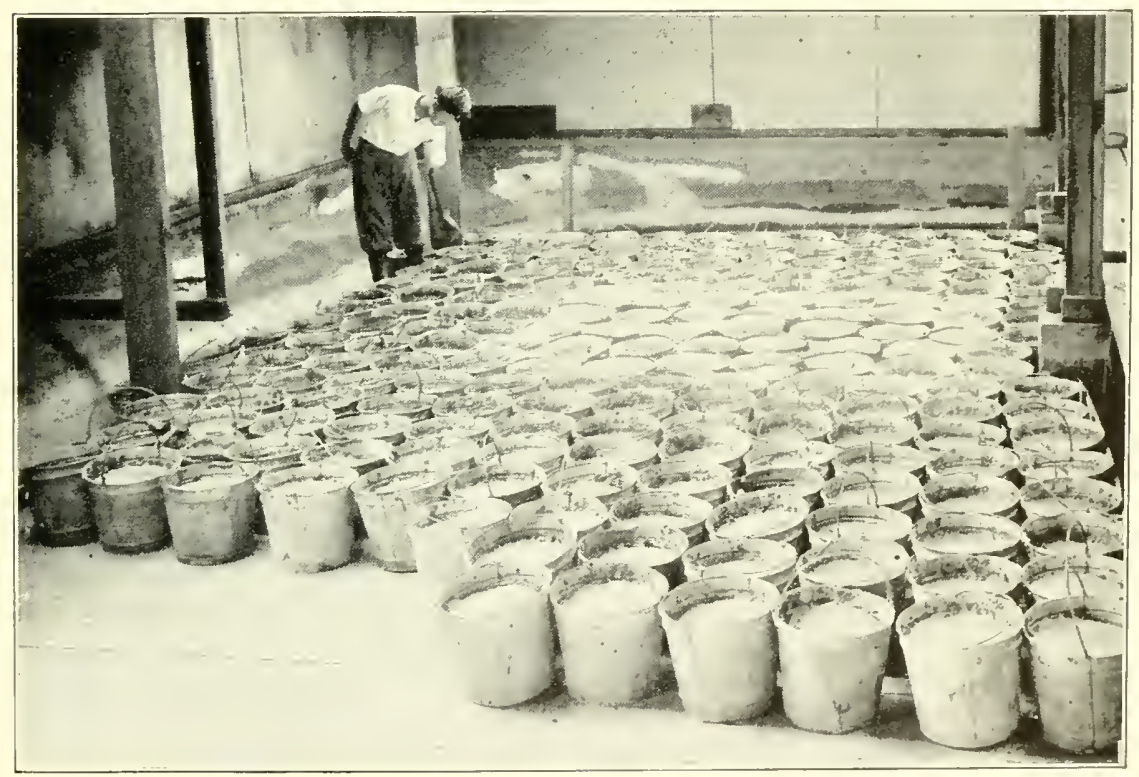

Fig. 208a. Pantri ox a Large Fancy Guldfisit Farai

Here the food is cooled about six hours before feeding. By an accident of photography the head of a gigantic fish seems to be begging honorable Japanese boy for dinner. 


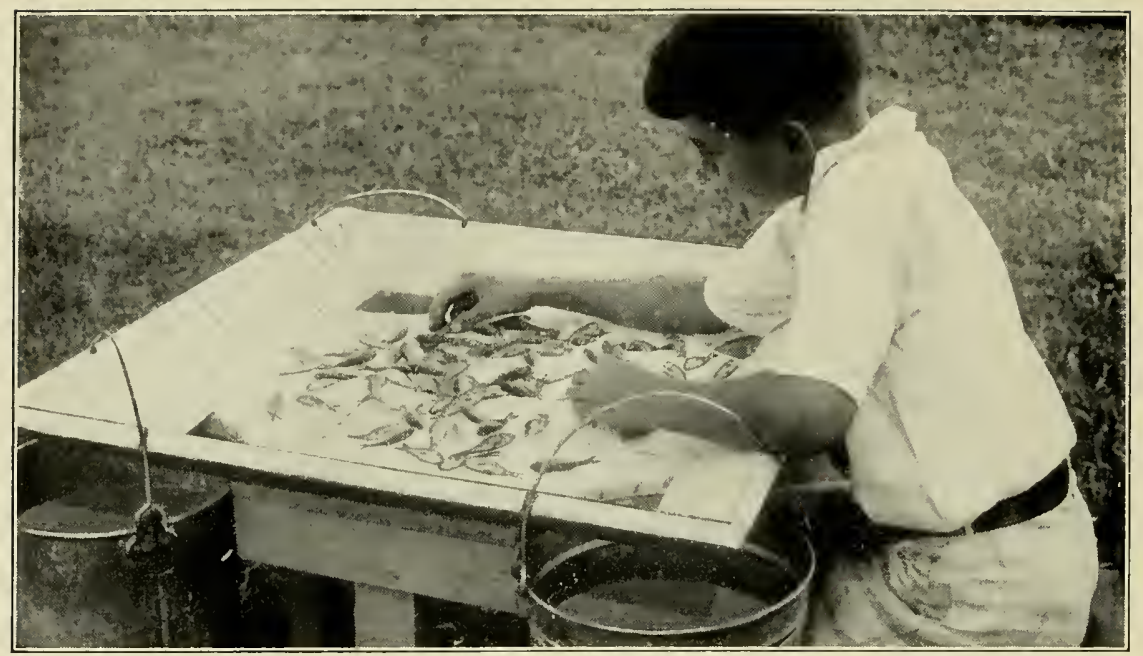

Fig. 208b. Sorting Comaion Goldfish

This is a specially designed table covered with oilcloth ruled in inch squares. The edges slope upward and at each corner is an opening somewhat like on a pocket billiard table, through which the fish of different sizes or colors are dropped into hanging buckets. The fish are not injured by a few minutes' exposure to air.

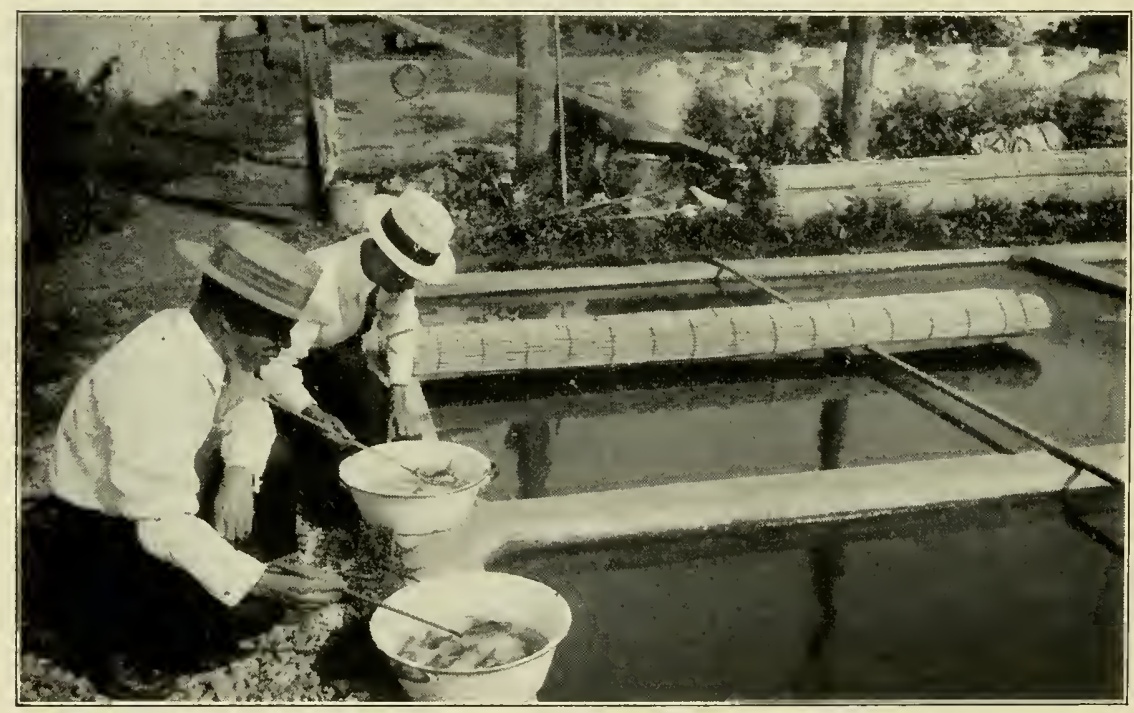

Fig. 208c. Japanese Griding Fancy Goldfisir

Fancy breeds are sorted in water partly because development can be better seen, and partly to avoid injury of delicate fins on a table top. These substantially built ground-level ponds are used in the spring for hatching and in the fall for storing after grading. The Japanese screen is sometimes rolled out to protect the fish from birds of prey, as well as from too much sun. Standard shipping cans in the distance. 
Included in the equipment of most goldfish farms are a few trusty shotguns to give a fitting welcome to the several birds that take fish without paying for them. These birds are named in the chapter on "Enemies."

In Conclusion. This chapter is more likely to be read by those contemplating a goldfish farm than those possessing one. To such we would say, start in a small way. All enterprises seem to be better built from a little start. But keep a weather eye open for expansion and select only a site possessing real possibilities. To those already established in a growing business of this sort we suggest an exchange of visits with fellow fish farmers. They are a good sort, willing to trade the benefits of experience. Most of them believe that "Co-operation, not competition, is the life of trade."

\section{COMMERCIAL BREEDING OF TROPICALS}

There is a rapidly growing demand for tropical fishes, and the purchasing public is always glad to learn of sources where a good selection of healthy stock may be had. From a business standpoint it would therefore seem that the rearing of tropical fishes offers favorable opportunities, especially to those who wish to start in a small way, and who are in a position to give close attention to the enterprise. The principal adverse possibility is one which overtakes many a new business-too many persons getting the same idea at the same time and causing overproduction. At the time this is written (nearly 1932) there has been a recent great increase in breeders, but as yet no one knows the potential purchasing power of the public. Interest in the subject is on the rise, and of the many who are starting with tropicals, few give them up.

Many are taking advantage of the climate of the Gulf States for rearing tropicals, where the use of buildings and artificial heat is reduced to a minimum. Northern breeders, however, enjoy closer touch with their markets.

A continuous warm temperature is imperative for some species and for these it is not worth while attempting to breed outdoors in a temperate climate.

In selecting a stock from which to breed for commercial purposes it is inadvisable to choose the kinds which have already become common, even though they are easy to breed. It is much better to pay more for something out of the ordinary if there seems to be a reasonable chance of breeding it. The "fashions" change so rapidly in tropical fishes that we could not attempt here to advise what to breed, as our suggestions might be antiquated in a few months. 


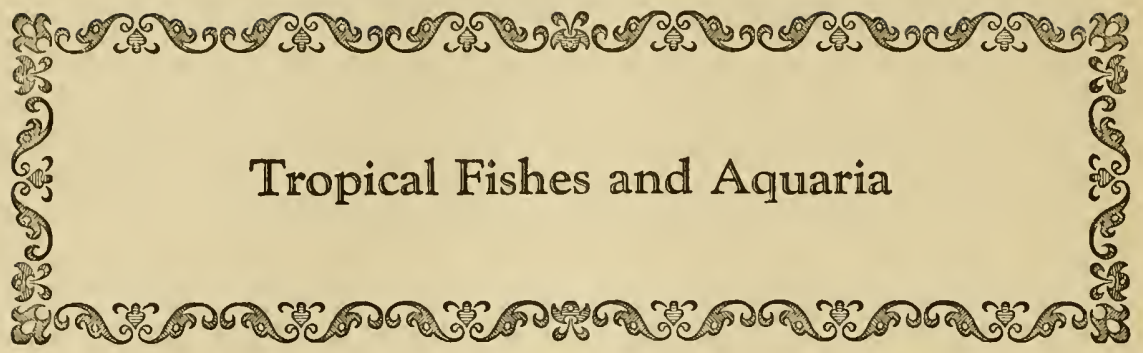

General Conditions. Where one has limited space and wishes for a variety of fishes, it will be found that many of the tropical varieties now available will do admirably. Most of them stand close quarters, thriving in aquaria which are not much more than quart jars. Some of the fishes are of such belligerent disposition that they must be kept alone, and in these cases it is well that they will live in cramped quarters. Larger aquaria with divisions for separating the different species are a convenience, especially if artificial heating has to be resorted to.

The question of space economy, however, is not the chief point in favor of tropical fishes. It is the endless variety of habit, structure and coloring, which gives us new avenues for personal study and observation. Some idea of the variation in breeding habits alone is continued on pages 237 to 243.

Water. Many tropical fishes are very sensitive to the bad effects of new water, even though it be of the proper temperature. It is well to keep some of the old water to mix with the new when the aquarium must be cleaned.

Feeding. The majority of tropical fishes are not heavy feeders like the goldfish, and there is not great danger of overfeeding. Care should, of course, be taken to leave no unconsumed food in the water. When they are warm and comfortable they may be fed twice daily, although this is not essential. Foods are described in Chapter Three.

Heating. The majority of tropical species thrive in temperatures ranging from 65 to 85 degrees $F$. Nearly all will do well at 72 degrees. For short periods they will stand temperatures below that at which they will thrive, and it is very probable that after a few generations in our climate they become accustomed to cooler water. When fishes are new and rare it is emphatically a mistake to experiment on seeing how low a temperature they will stand. That should be left for a later period after breeding has been accomplished and a stock secured. Tight-fitting glass 
covers should be provided for all tropical aquaria. This helps keep the temperature up and prevents the fish from leaping out, at which many of them are extremely expert. Failure to replace covers has caused the loss of many prized specimens. They will not suffocate if glass is down close.

If one is not blessed with a heated greenhouse or a room of warm, even temperature, artificial heating becomes necessary. There are several

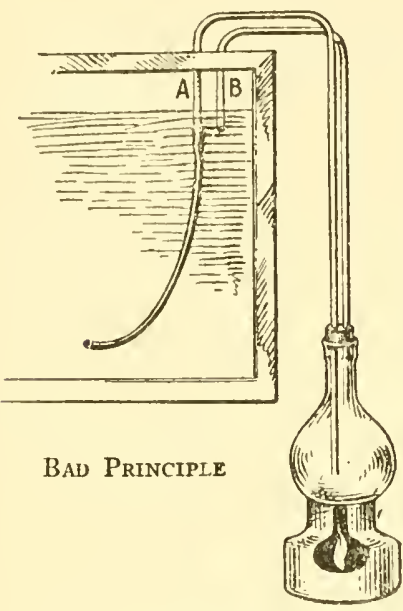

FrG. 209

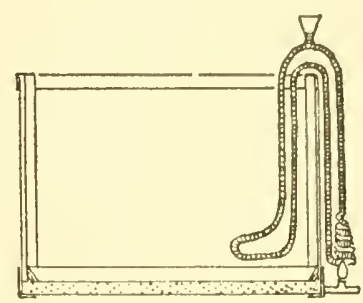

FIG. 210

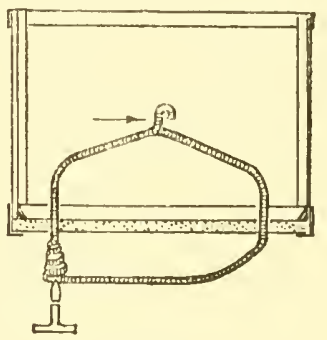

FIG. 211

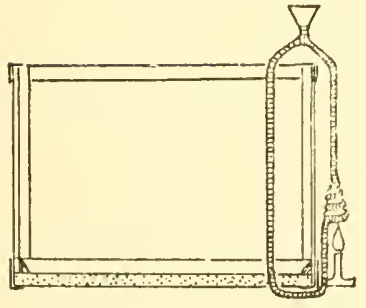

FIG. 212

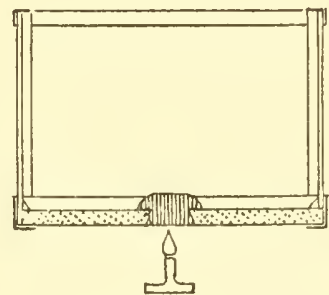

Fig. 213

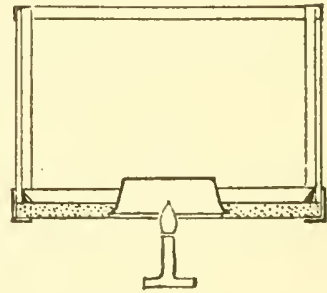

FIG. 214

Types of Heating Methods

devices which accomplish this purpose, but only a few are satisfactory. In general those are to be avoided which concentrate the heat on a small portion of the aquarium water. This action drives out oxygen and other 
life-giving qualities and also produces uneven temperature for the fish to pass through. Such an objectionable arrangement is shown in Fig. 209. Aquarium water is directly heated in the small outside reservoir and circulated back again. With this device the water intake may easily become clogged, which soon causes the water to boil. This heating method is used, but it is bad in theory and in practice. A better arrangement is shown in Figs. 210 and 212, which is a complete hot water system not using the aquarium water. The tubing is of copper, $1 / 4$-inch inside diameter, and of thin walls. Before bending any such work to shape it should be packed quite hard with dry sand and the ends corked up. This prevents buckling at the sharp curves. At the very top of the loop rising from the heating coil should be bored a $1 / 4$-inch hole and a small funnel soldered around this. All hot water systems create some vapor. If this were allowed to collect in the pipe there could be no circulation and boiling would soon take place. The two open ends need not be soldered together. They can be satisfactorily joined by rubber tubing, but this should be arranged to occur in the rising side of pipe in the water. In Fig. 210 the arrangement can be hooked over the edge of any aquarium and has the advantage that the aquarium does not have to be elevated to heat from underneath. The first filling of the system is not always easy. Water is poured in the funnel until it will take no more. Then the hand is placed over the funnel and the pipe turned upside down. Turn upright again and put in more water. Hold at different angles. When it will take no more water, try heat under the coil. If the water in funnel moves up and down, there is still air in the tube. Sometimes it can be removed by actively filling and discharging a fountain pen filler in the opening. When the water remains still in funnel when heated, it is all right to use. The funnel must always contain water, or boiling will soon occur. If a filled bottle with small neck is inverted, stood in funnel and secured in some manner, it will last a long time without refilling. The copper tubing should be nickeled after bending, as copper is fatal in the aquarium.

Fig. 211 shows a modification of the same idea with the pipe carried through aquarium base. The little hollow hook at top of the hot water system was devised by the writer to avoid the necessity of filling the funnel, and to have the heater more concealed. The tubes within the water are of glass, connected, by rubber, the end hook also being a separate piece. By removing hook the system is easily filled. When heat is on, vapor collects in top of curve, and when enough has collected to force a bubble out, a drop of water is automatically sucked back to take its place. The air space in hook also prevents any circulation between hot water system and aquarium water proper. This system also gives a higher percentage of heating efficiency than the outside form. 
For the highest efficiency and greatest all-round satisfaction, refer to Fig. 214. This is a 4-inch agate pan set in the cement base described on page 107. When making the aquarium it is little extra labor to set this in. For aquaria already constructed it is somewhat of an undertaking to cut a sufficiently large hole, but it can be done and the pan cemented on top. Fig. 213 shows a simple and fairly effective expedient. After hole is cut in slate, pour in lead or tin. When the metal is poured, use a form made of putty to make a circular dam so that the surface of metal will come as high as the sand. The object in using the inverted pan is to have the heating surface come just above the sand. Then the heat is the most efficient as well as fairly diffused and does not interfere with the roots of plants. The objections to this type are that the aquarium has to be raised and that there is an occasional drip of condensed water caused by combustion. The best flame to use is a small gas Bunsen burner. They may be had of some scientific apparatus concerns or dealers in German aquarium supplies. No more than the tip of flame should be allowed to touch the heating surface. Even this is not necessary in system shown in Fig. 214. Smells are caused by having the flame strike directly against a cool surface, which interferes with complete combustion.

Heat Control. In a room where there are wide changes of temperature, particularly when these dip to the cold side, it is desirable to have

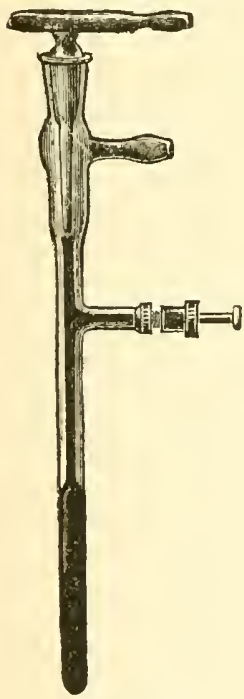

FIG. 215 some means of heat control. To start in the very simplest way first, an aquarium may be kept noticeably warmer over night by covering with a thick blanket, quilt or any warm fabric. If near a window the curtain should be pulled completely down. Another help for any aquarium near a window is to have a sheet of glass standing nearly vertical on the aquarium base and leaning against the top. This sheds much of the cold air which constantly falls from a window in cold weather and rapidly chills the water.

Tropical aquaria, if not too small, may be kept at a satisfactory temperature while standing on a board on the radiator of a hot-water system, the heating result not being so extreme as might be expected.

An occasionally used means of controlling temperature is to heat by gas and use a thermostat to regulate gas flow. See Fig. 215. This is placed either in the Gas Thermostat water or tightly against the outside of the aquarium, and insulated from the influence of surrounding air by plenty of wool or cotton batting. It contains a large body of mercury over which the gas passes through a small space. As the water rises in temperature, the mercury 
expands and so reduces this passageway, and vice versa. It is a very ingenious and effective device and may be obtained from makers of scientific glassware at small cost. Those selling them are glad to give complete instructions regarding regulation, etc.

The modern method of heating individual aquaria is by use of specially designed electrical units placed in the water and controlled by a thermostat. Several of these are advertised in the aquarium magazines. We suggest the avoidance of any design in this or other apparatus which brings aluminum into contact with water for lengthy periods. It is not very poisonous, but it disintegrates.

Electric light bulbs in the water are good heating units. Submarine sockets are made for immersing the whole light, or the ordinary socket may be used by immersing only about two-thirds of the bulb. The latter is one of the best ways of applying extra heat in an emergency, or for the heat treatment for certain fish diseases. The amount of heat can be regulated by the depth to which the bulb is submerged.

Shipping Tropical Fishes. It is doubtful policy taking risk of shipping tropical fishes when the weather is not settled and warm. They may keep warm during the train travel, only to receive a fatal chilling in delivery. To guard against this some shippers have designed special boxes equipped with an extra outside shell, the intervening space being filled with insulating substance, Celotex board being excellent for this purpose. A simple expedient consists of a tin can (with a tight lid) or glass jar set in a wooden box, then completely enclosed with ground cork, sawdust, papers or other substance, and the lid fastened down. The top of the box should be boldly marked, stating contents. A handle on the top will help keep the top side up. Some dealers guarantee safe delivery.

Large Thermos cans, properly protected, have been successfully used in shipping tropicals long distances.

The best method of transporting tropicals, where it does not interfere with interstate laws, is to get in touch with a Pullman porter and have him carry them through in jars, packed in a grip. Ventilation is unnecessary.

Aeration in Tropical Aquaria. Although plants have the same beneficial effect on the water of tropical aquaria as those containing goldfishes, many aquarists interested only in tropicals have little or no vegetation in their tanks. This is particularly the case with dealers, who must be able to catch fishes quickly and to keep close count of stock. Under such circumstances, and with the frequently added necessity for overcrowding, mechanical aeration, practically doubling the fish capacity of an aquarium, is a big advantage. Low-priced midget electric air pumps, combined with special liberators, deliver the air in small bubbles at the bottom of the water, both oxygenating it and setting up a beneficial circulation. 


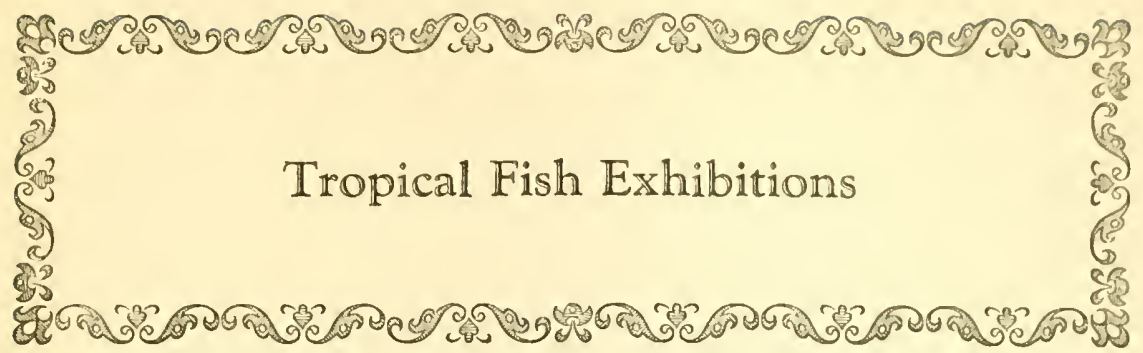

We believe that the remarkable growth of the tropical fish fancy is due in large measure to the enterprise of those who have organized and carried through public exhibitions of tropical aquaria. It is there many persons first learn that there are, besides the goldfish, literally hundreds of beautiful fishes which have been domesticated; that they will prosper in small aquaria, and that in form, coloring and habits they possess endless variety.

It is true that most tropicals, on account of fright and change of temperature, lose much of their color at exhibitions, and that owners are liable to lose some of their stock, due to chill. Happily there are always enthusiasts ready to take a risk in order to kindle a spark of interest in a study in which they themselves have found so much pleasure.

Exhibitions spread knowledge and ought to be encouraged, but to be of the most use they should be advertised. Newspapers are glad to give write-ups and even large "spreads," but it should be the duty of someone to give the reporters correct information about the fishes and try to hold in check their propensity for spectacular distortion. The first large exhibits of tropicals in this country were held through the joint co-operation of aquarium societies and large department stores. The shows were put up by the societies, but held in the stores and advertised by them. Attendance was always large, to the gratification of all concerned. While this plan is still in effect, it is largely superseded by exhibitions of a non-commercial character, held in halls, museums, large public buildings, amusement parks and public aquaria, most of the latter now having permanent exhibits of freshwater tropical fishes. We mention these things to encourage even small groups to "start something" and attract kindred spirits to themselves. There is benefit in numbers.

Competitive Exhibitions. Aquarium societies (along with the rest of the world) find that competition sharpens endeavor. At the regular meetings of societies, as well as at larger public shows, awards are usually made. For the benefit of those who would like to put such a program 
into effect, but who have no experience, we mention a few of the practices and rules which are successfully in operation.

Pairs receive consideration above a single fish, even though that fish is of superior quality.

Pairs should be matched in size according to their natural proportions towards each other. That is, for instance, if "Guppyis" were being shown, the female should be considerably larger than the male, and not the reverse.

Single fishes are eligible to compete against other singles if no pairs of the same variety are present.

The main points considered are condition, size and color.

Rarity is sometimes given separate consideration.

One competent judge is found to be more satisfactory than a committee of several.

It is the usual custom at society meetings to give separate evenings to exhibitions of different groups of fishes, such, for instance, as livebearers one night, and the following groups separately on other nights: Labyrinth or air-breathing fishes, Cypronoids, Characins, novelties and native aquarium fishes.

In addition to awards for the best and second-best in each class, it is usual to have a prize or award for the best pair in the show, any variety. In large public exhibits it is also usual to offer awards for the greatest number of varieties, for the rarest pair and for the best arranged exhibit.

Owners must declare the classification of fishes offered for exhibit.

One prominent society offers, at the end of the season, a prize to the member who has taken the greatest number of awards. 


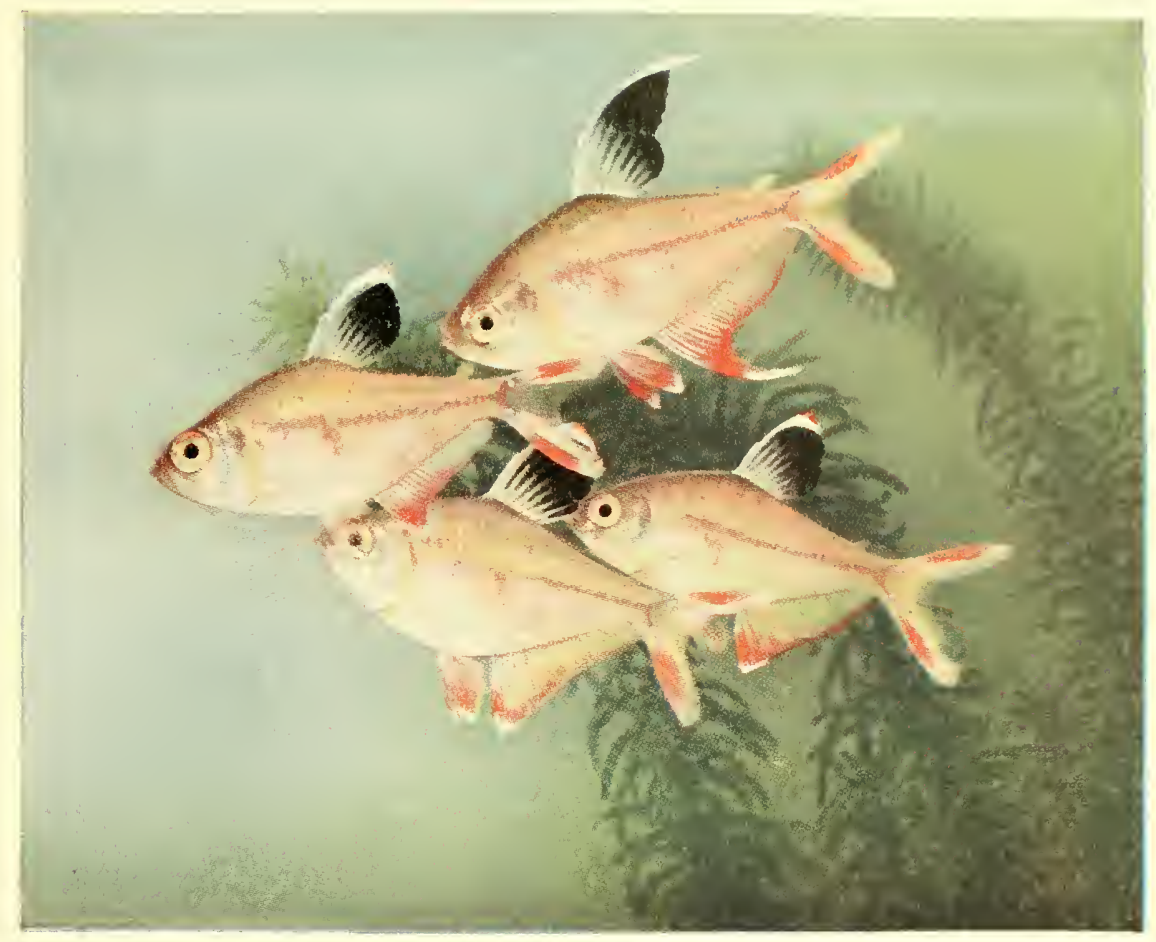

Fici. 215a. Hyphessobrycon rosacelus Durbin or Rosy. Tetra

Such a large spot of black in the dorsal fin is unique among aquarium fishes. Therefore this individual makes an interestine contrast with others in a tank of mixed species. or "happy family aquarium." as such a collection is usually called.

The Rosy Barb belongs to the Characin family, and, in common with its relativer. drops adhesive eggs. Although well adapted to aquarium life, and usually in the best of health, the species seldom spawn. Nearly all of our stock is dependent upon fresh importations from native waters in British Guiana and Brazil. 



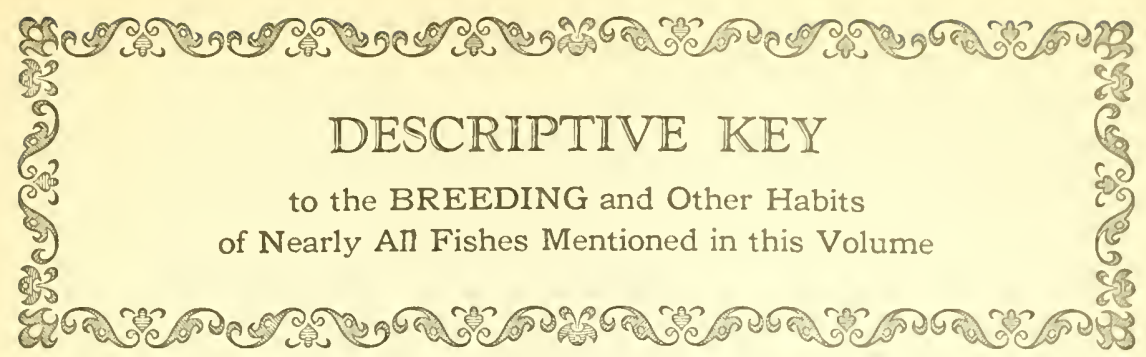

\section{AMBASSIDE-AMBASSIDS (No. 1)}

Ambassis ranga makes a nest and guards its young. The little ones swim around in a school. The fish is carnivorous. It is found in fresh and brackish waters in India.

\section{ANABANTIDÆ-GOURAMIES AND CLIMBING PERCHES} (No. 2)

The Labyrinth fishes are found in tropical Asia and Africa. All have a chamber above the gills in which they store atmospheric air for breathing.

Anabas is said to breed similarly to Channa of the Ophicephalidae. The African Ctenopoma has rarely, if ever, been bred in captivity. The Asiatic Gouramies all breed similarly. The male makes a floating nest of tiny mucous-covered air bubbles, preferably under the leaf of a floating plant. At spawning he places the eggs in the nest and chases away the female, who should be removed. He then assumes guard beneath his dome-nest of froth, driving away intruders and picking up falling eggs and young. The eggs require high temperature $\left(80^{\circ}\right.$ to $90^{\circ} \mathrm{F}$.) and hatch in from 20 to 48 hours. The young are kept in the nest a day or two by the male, until they are able to swim. Then he must be removed to prevent cannibalism. No success can be had without a good supply of Infusoria until the young are about a month old, as they are too tiny to take the smallest daphnia.

The young require a constant temperature of $80^{\circ}$ or above.

Labyrinth fishes are rather quarrelsome as a rule (except Dwarf Gouramies) and must be kept with their own species, preferably in numbers to prevent individual duels-to-the-death. Betta, the Siamese Fighting-fish, can be kept with other fishes as it fights only its own kind. All the family are carnivorous, but will take prepared fishfoods containing a good percentage of animal matter, which is true of most carnivorous fishes.

\section{CALLICHTHYIDE-ARMORED CATFISHES (No. 3)}

The Cascaduras or Armored Catfishes are all South American. Very little is known of the breeding. The species of Corydoras are especially valuable in the aquarium as scavengers. They are very quaint. 


\section{CENTRARCHIDE-SUNFISHES (No. 4)}

The Sunfishes are peculiar to North America. They are, as a rule, rather pugnacious, and cannot be kept with other fishes. Mesogonistius and Enneacanthus are exceptions to this. The species are, of course, not "tropicals" and this should be kept in mind when they are placed in aquaria.

Practically all the species excavate a shallow depression in the sand, where the eggs are deposited and guarded by the male.

Mesogonistius breeds among grasses, such as Vallisneria, depending more upon hiding its young than fighting for them.

\section{CHARACID E-CHARACINS (No. 5)}

The Characins are somewhat less peaceful than the carps, and nearly all of them have the jaws armed with sharp teeth. The smaller species, such as Hyphessobrycon and Hemigrammus, scarcely ever bother other fishes of their own size, but the larger ones (Astyanax, etc.) had best be kept to themselves.

Most of the species breed very similarly to the Barb group of the Carps and should be treated likewise. Some of the species of Copeina (arnoldi, callolepis), however, lay their eggs out of water, and the males guard them and splash water over them at intervals. Special arrangements should be made for this, such as smooth rockwork near the water, or ground glass sides or top to the aquarium.

Thoracocharax, Carnegiella, and Gasteropelecus, skim over the surface of the water of their haunts, similarly to Pantodon.

\section{CICHLIDZE-CICHLIDS (No. 6)}

The Mojarras or Cichlids are mostly savage fishes and cannot be kept with others, even their own mates, unless large numbers of the same size are present. Pterophyllum is an exception. Most Cichlids tear out and destroy rooted plants, although Equidens portalegrensis will not.

Some breeders first separate the proposed pair by a glass partition until they seem to display friendly intentions towards each other, then letting them together. If there is not an open combat they may presently interlock mouths in what seems to be either a tug-of-war or a protracted kiss. After the action is repeated several times it will end either in a happy marriage or murder, unless human interference steps in. It is preferable to try to mate fishes of the same size, otherwise the smaller is likely to lose heart and make a retreat. Males and females seem to be equally "temperamental," which is a polite way of describing a nasty disposition. In justice to them it should be said that in a large pool no such fatalities occur. The fishes deposit adhesive eggs 
on stones, or on the aquarium, on the convex side of a flowerpot laid on its side, or on porcelain. Eggs hatch in from 3 to 6 days, during which period the parents take turns in swimming over the eggs and fanning fresh water over them constantly. When the young hatch, the parents carry them in their mouths and deposit them in a depression previously made in the sand at the bottom, where they jealously guard them against all comers-terrestrial or aquatic-frequently removing dirt from the "nest" and transferring the baby fish to new nests. For several days after hatching the young eat nothing, but live in a swarm at the bottom, while they absorb the yolk-sac. At the end of this period they begin to "look like fish" and to swim around their parents in a "cloud." They then require first infusoria and later very fine daphnia. The parents may be removed any time after the young begin to swim. They require much room and clean pure water of a constant temperature of 78 or over. The dirt should be siphoned off the bottom occasionally and fresh water of the same temperature added.

Artificial incubation of the eggs of this group of fishes is secured by the use of compressed air liberated in the water in such position and volume as to produce a gentle circulation. Water must be clear. Parents and eggs are, of course, separated. This method is very successful and is used by wholesale breeders. Removal of eggs into clear water of same temperature has proven effective, even without circulation.

We have recently observed that fishes of this general type have a decided preference for spawning on a light-colored object, such as a piece of marble or other light stone. We have not tried white porcelain or crockery, but they should be successful, we believe.

\section{No. $6 \mathrm{~A}$}

Pterophyllum scalare varies from the foregoing in that at no period do the parents place the young in depressions in the sand. They have a pronounced preference for depositing eggs on broad, firm leaves, like giant Sagittaria. These fishes in captivity are very apt to eat their eggs, and the chances of successful propagation are greater if the parents or eggs are removed as soon as egg-eating is observed. Eggs should be in a clear, clean aquarium. Artificial circulation of water is desirable but not indispensable.

Haplochromis multicolor and Tilapia macrocephala are also Cichlids, but their breeding habits are quite different. They are mouthbreeders. After the eggs are dropped and fertilized, one of the parents places the eggs in the mouth and keeps them there until hatched, and for about two weeks more. With $H$. multicolor it is the female who assumes this arduous task, while with $T$. macrocephala it is the male. Further information on these species will be found under their illustrations. 


\section{COBITIDE-LOACHES (No. 7)}

The family of Loaches is a large one, and its members are found over Europe, Asia, the East Indies, and Northeast Africa. They are close to the Carp family, though their barbels make them externally similar to the Catfishes. The eggs of Misgurnus are deposited on the sides and plants of the aquarium, remaining there until hatched in a few days. The young swim in a school around the old fishes.

The Loaches are valuable as scavengers. They are entirely harmless to other fishes. (See figure 11.)

\section{CYPRINIDÆE-CARPS (No. 8)}

The Carps in general are of peaceful disposition. They seldom fight and when they do they cannot hurt each other, for they have no teeth in the jaws. The pharyngeal teeth in the throat are used for chewing their food, which consists in most cases, contrary to common belief, almost entirely of animal matter such as worms and insects. Certain species, such as the Carp itself, are to a large extent herbivorous. where.

Goldfishes belong to this family, but their habits are covered else-

Of the species considered, only the Brachydanios are known to have non-adhesive eggs. These are bred by placing the ripe adults together in a fair sized aquarium, the bottom of which is covered with large pebbles or small marbles. The eggs are dropped between the pebbles and are there safe from the appetite of the parents until the latter can be removed. (See also figure 104.) D. malabaricus has adhesive eggs.

The Barbs, and most Carps, drop adhesive eggs upon water plants. (See page 200.) The aquarium should be provided with a mat of Myriophyllum, Nitella or other bushy plant, over the bottom, weighted down with a few pebbles. The eggs are deposited on this mat and the parents must then be removed.

Rasbora heteramorpha places eggs on the under side of leaves such as Cryptocoryne, paying no further attention to them, nor to the young.

Many American brook minnows build "nests" of little stones but such species cannot, in general, be bred in aquaria.

Bitterlings by means of an ovipositor place their eggs within the shell of a live freshwater mussel. The young duly emerge from this protective refuge.

\section{GASTEROSTEIDE-STICKLEBACKS (No. 9)}

The Sticklebacks cannot be kept with other fishes. They are carnivorous and build an actual nest out of bits of plants. For more detailed description, see page 168 .

\section{GOBIIDÆ-GOBIES (No. 10)}

This large family is sparsely represented in our aquaria. The species are carnivorous and little is known of their breeding. 


\section{GYMNOTIDÆ-GYMNOTID EELS (No. II)}

Little is known of the habits of this South American group. They have never been bred in aquaria.

\section{HEMIRAMPHID E-HALFBEAKS (No. 12)}

Members of this family are common in most seas. A few tropical ones are fresh-water. Dermogenys is one of these. It is live-bearing and should be treated like the live-bearing Killifishes.

\section{LORICARIIDÆ-SPINY ARIMORED CATFISHES (No. 13)}

The family of Spiny Armored Catfishes is confined to South America. Practically nothing is known of the breeding.

\section{NANDIDÆ-NANDIDS (No. I4)}

A small Indian family. Nandus has never been bred in this country. Badis should be provided with a small flowerpot turned on its side near the middle of the aquarium. The eggs are placed on the upper inside of the flowerpot and are guarded by the male. The female should be carefully removed. As soon as the young are able to swim the male may be removed. The Nandids are carnivorous but not very savage.

\section{OPHICEPHALID $\mathbb{E}$-SNAKEHEADS (No. 15)}

This Asiatic and African family is largely carnivorous, feeding particularly on other fishes. They may be fed small chunks of meat in the aquarium. Channa asiatica and some Ophicephalus deposit their eggs loosely, floating on the surface. Some care is usually taken of the eggs but it is considered best to remove the adults. Certain species of Ophicephalus are said to build "nests," like the Sunfishes.

The Snakeheads are "Labyrinth Fishes" like Anabantidae, breathing atmospheric air, for which they must rise to the surface every few moments.

\section{PANTODONTIDE-BUTTERFLY FISH (No. 16)}

This peculiar family contains but a single species, from W. Africa. It is one of the few fresh-water flying fishes. Examples have been seen to dart quickly along the surface and, when sufficient momentum is gained, leave the water and skim over the surface, supported by the large pectoral fins. They, of course, cannot steer themselves in the air and drop back into the water when the momentum is spent.

The eggs are deposited loosely and float on the surface similarly to Channa and Ophicephalus.

\section{PERCIDE-PERCHES (No. 17)}

The Yellow Perch, Perca is too large a fish to be bred in small aquaria. The eggs are laid in bands on a sandy or pebbly bottom. The Darters, accustomed to swift, cold water (except Copelandellus and 
Boleichthys) are hard to induce to spawn in an aquarium. The eggs are deposited among the stones of the bottom. The parents should be removed. All the Perch family are carnivorous.

\section{POECILIIDE-KILLIFISHES (No. 18)}

This large family is almost cosmopolitan. The aquarist, for convenience, divides the family into two sections; one, in which the ova are hatched within the female's body and the young born alive, and the other in which the ova are deposited to hatch externally. The first or viviparous group (all of which species are marked with a $\mathrm{V}$. after the family name in the list) is separated into five sub-families: the Anablepinae, in which the anal fin of the male is modified into a long tubular copulatory organ; the Jenynsiinae, in which the male's anal fin is essentially the same; the Poeciliinae, in which the male's fin is troughshaped rather than tubular; the Characodontinae, in which the entire anal of the male is not modified into a long organ, but the first few rays are stiff and short and are separated from the rest of the fin by a notch, and the Phallostethinae, in which the male's ventral fins are modified into a singular process beneath the head. The egg-laying or oviparous division is comprised of three subfamilies: the Cyprinodontinae, which includes the Cyprinodons, etc., the Fundulinae which includes Fundulus, Oryzias, etc., and the Adrianicthyinae found only in Celebes.

The viviparous species are easily bred. The gravid female should be placed in a large jar with thick, bushy Nitella or Riccia on the light side. The young, when born, seek the light, and are protected by the plants from the cannibalistic parents. Excellent fish-traps are now made, obviating the necessity of the above treatment. (Some of these are shown on pages 122 and 123.)

In the egg-dropping group the breeding habits are more diverse. Of the species herein enumerated the breeding is as follows: For practical purposes $A$. sophiae, $J$. floridae, all the Funduli except $F$. caeruleum, the Panchaces, and Rivulus may be under one head. The pair should be kept separated for a week or two and fed on nourishing food. Then place them together in a warm, sunny tank with thick floating Utricularia or Riccia. Spawning should soon commence. Leave the pair together a day, separate, and repeat, removing the egg-filled plants to a hatching jar and replacing with new. Feed young on small daphnia.

In Oryzias, crystal-clear eggs are expelled and fertilized and hang in a tiny cluster from the female's vent. In moving about, the eggs are brushed off and adhere by a fine filament to the plants. The hatching and care are the same as for Panchax, etc.

Except Belenesox and Gambusia aff., the Killifishes are peaceable citizens. 
POLYCENTRIDE-POLYCENTRIDS (No. 19)

A small family of three species. Polycentrus breeds similarly to Badis (see under Nandidae). Polycentropsis is said to build a bubble nest similar to that of the Labyrinth fishes. It has been bred but few times.

SCATOPHAGIDE-ARGUS FISH (No. 20)

The Argus Fish is an inhabitant of brackish water in India. It has never been bred in this country.

\section{SILURIDE-CATFISHES (No. 21)}

This group is now split up into several families, but it is left intact here. Few of the species have been bred in aquaria. All are omnivorous, and good scavengers. They are mostly harmless, but should not be kept with long-finned goldfish.

\section{SOLEIDE-SOLES, FLATFISH (No. 22)}

The soles inhabit brackish and entirely fresh water. They are carnivorous and their breeding has seldom, if ever, been attempted in aquaria.

\section{TETRAODONTIDÆ-SWELL-FISHES (No. 23)}

These queer fishes are clowns in the aquarium. Two Indian species have been used in aquaria. They are carnivorous and the breeding is not known.

\section{GENERAL NOTES ON HABITS AND BREEDING}

The nature and breeding habits of the fishes listed are given in condensed form under the family headings, but a few remarks that are generally applicable are here presented.

In attempting to keep more than one kind of fish or even different individuals of the same species, it is always best to have all the fishes the same size. Even if of peaceable disposition, large fishes are apt to bully or eat little ones.

Young tropicals are in general treated much alike. The newly born live-bearers can eat fine Daphnia or powdered fishfood at once and they are very easy to raise. Even considerable variation in temperature is withstood. With the egg-laying fishes however, there must be a constant temperature, particularly in the Labyrinth fishes, Cichlids, etc. For Labyrinths it should be as high as $85^{\circ}$ or $90^{\circ}$ while for all tropicals it should be $5^{\circ}$ to $10^{\circ}$ higher than usual. This is needless in 
the hot summer months. The young must have a constant supply of infusoria, prepared beforehand by the methods described elsewhere in this book, until they are large enough to eat very finely screened Daphnia. Do not introduce the Daphnia while still feeding Infusoria. Daphnia do not, as has been supposed, devour Infusoria, but in large numbers they consume so much oxygen that the Infusoria die. Nearly all fishes will eat their own eggs and young, even the ones showing great parental care often forgetting and devouring their own offspring. Except when absolutely necessary, parent fish should be kept away from their young. Some fishes are like other animals in captivity, especially when closely confined. They destroy their young when in fear of having them fall into the hands of man. Liberal feeding tends to prevent cannibalism.

\section{TEMPERATURE FOR TROPICAL FISHES}

A good practical temperature for general use is 75 degrees Fahrenheit or 24 degrees Celsius. Ichthyophthirius and other diseases will seldom appear at this temperature. Most tropicals will do fairly well at 70 degrees, but here one is flirting with danger, because a drop of a few degrees from this point is likely to cause trouble.

If, through some unavoidable circumstance, the water has been chilled to the very dangerous point around 60 degrees, a special effort should be made to gradually raise the temperature to 75 to 80 degrees to anticipate and counteract any injurious effects.

Higher temperatures are required for breeding some of the fishes, as is noted on the pages just preceding this.

Temperature for goldfishes is covered in the early part of the book, and their requirements apply to most of our native aquarium fishes also.

\section{THE "HAPPY FAMILY” AQUARIUM}

In a small aquarium without many plants one must be careful to select only the most amiable of fishes for mixing together. Nearly all members of groups $3,7,8$ and 18 are perfectly safe, except in the few instances noted.

There is a world of difference in a large aquarium (25 gallons and upward) which is thickly planted and having rock, flowerpot, pipe or other refuges. Then we may also safely add members from groups 2,5 and 19. The individual fishes comprising groups will be found in the list on pages $286-297$.

One of the main things to keep in mind is not to have too great a difference in the sizes of members of the "happy family" aquarium.

A very attractive aquarium of mixed native temperate-water fishes can be made up, comprised of those we have described in Chapter Twelve, except for Sticklebacks and the more aggressive Sunfishes. 


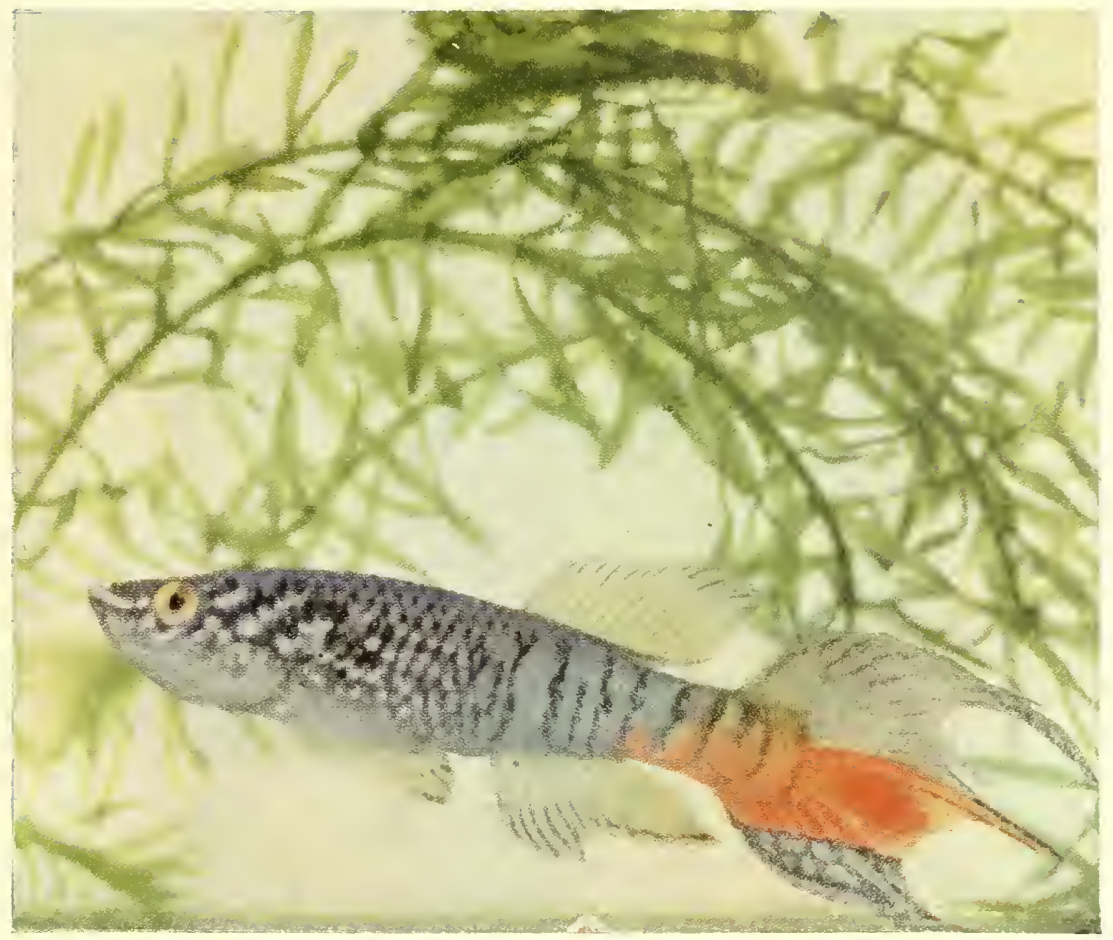

Fig. 210. BLuE Gulats Photographed direet m natwal colors) (Aphyosemion cacruleum)

We believe that, at least in America. this is the first Autochrome reproduction of an squarium fish. The colors are shown with wonderiul fidelity to life. Unfortunately th. process is not suited to many fishes because the plates require an exposure of at least three reconds, a length of time most of our ish iriends will not remain still. There is no known way of making the fish "look at the birdie." Breeding habits, page 242 (No, 18). 


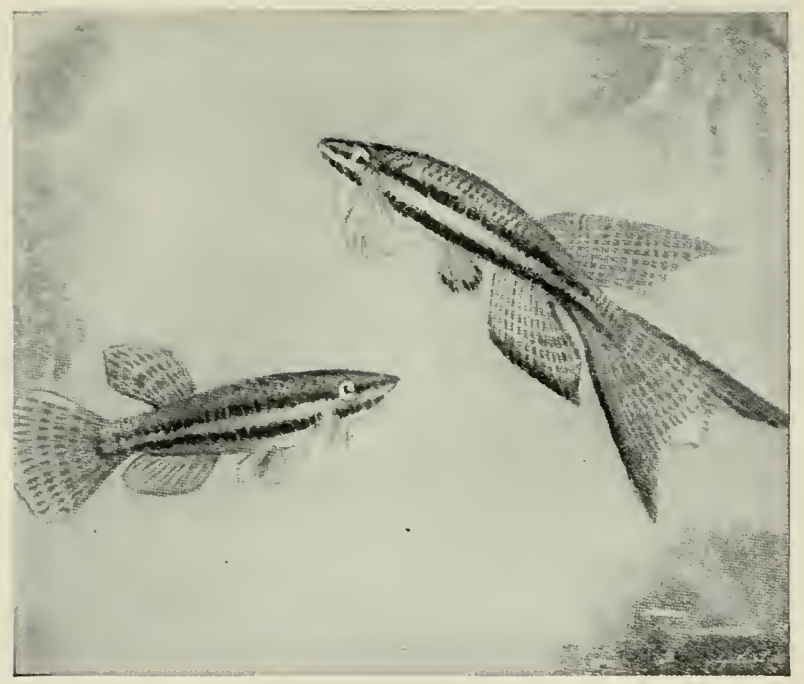

Fig. 217. Aplyyosemion bivittatum (Slightly Reduced)

One of the most graceful of the Killifishes, known as "top minnows." The general color of this variety is reddish brown, flaked and dotted on body and fins with carmine. As with many other fishes, the male has the higher coloring, and longer, more pointed fins. Breeding habits, page $2+2$ (No. 18).

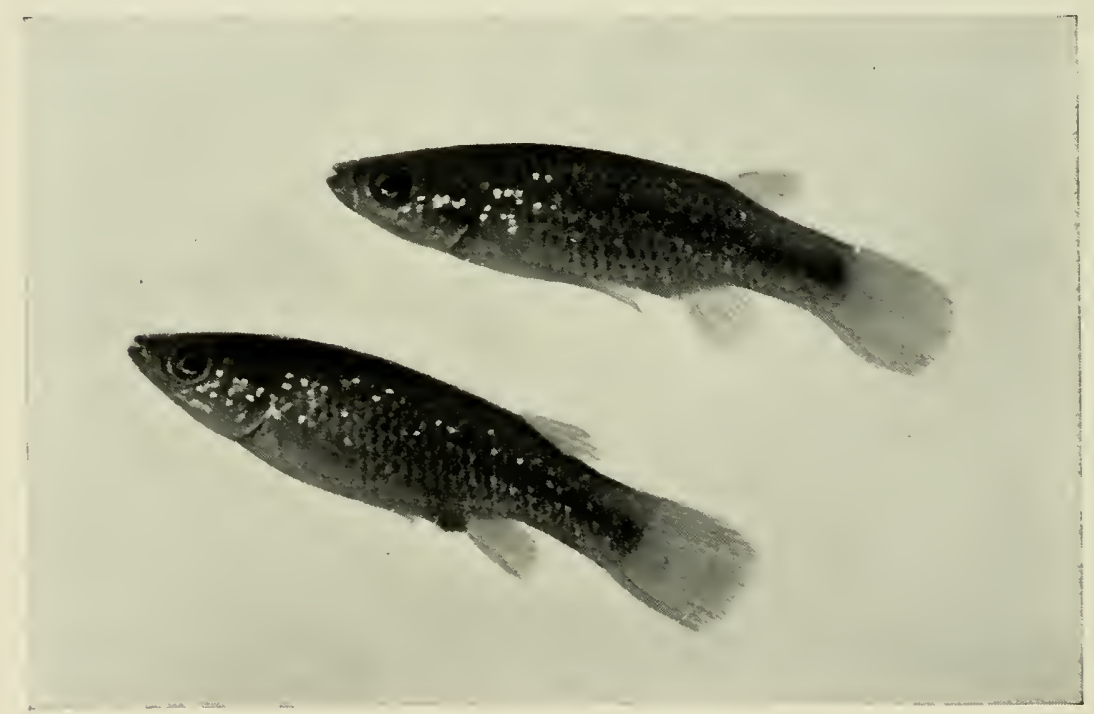

Fig. 218. Fundulus chrysotus

Although this is one of our own most attractive tropicals from Southern United States, we not infrequently import it from Europe. Breeding habits, page 242 (No. 18). 


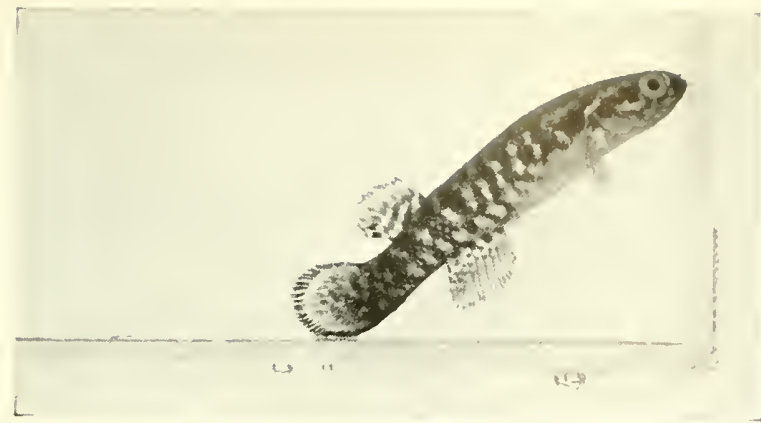

FIG. 219. Rivulus ocellatus (Hale) [Two-thirds size]

This is the best known and one of the most attractive of the genus. Breeding habits, page 242 (No. 18 ).

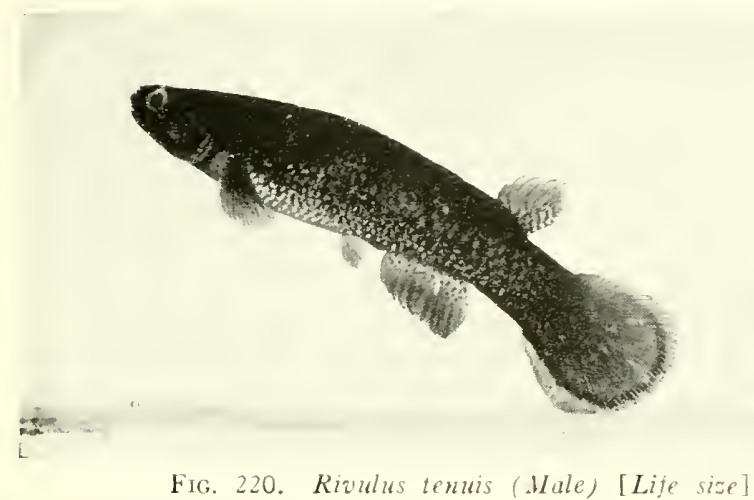

Rivulus of different species have much the same habits. They are rather inactive, but capable of leaping vigorously. Should not be kept with smaller fishes. From Central and South America. Breeding habits, page 242 (No. 18).

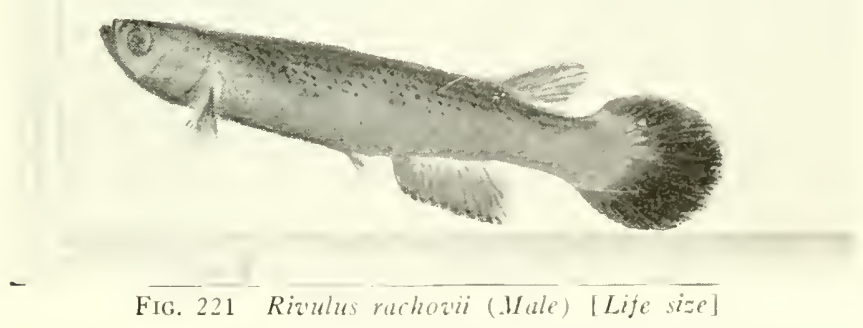

The tail fin is quite black, which gives an interesting characteristic. Female is lighter. Breeding habits, page 242 (No. is). 


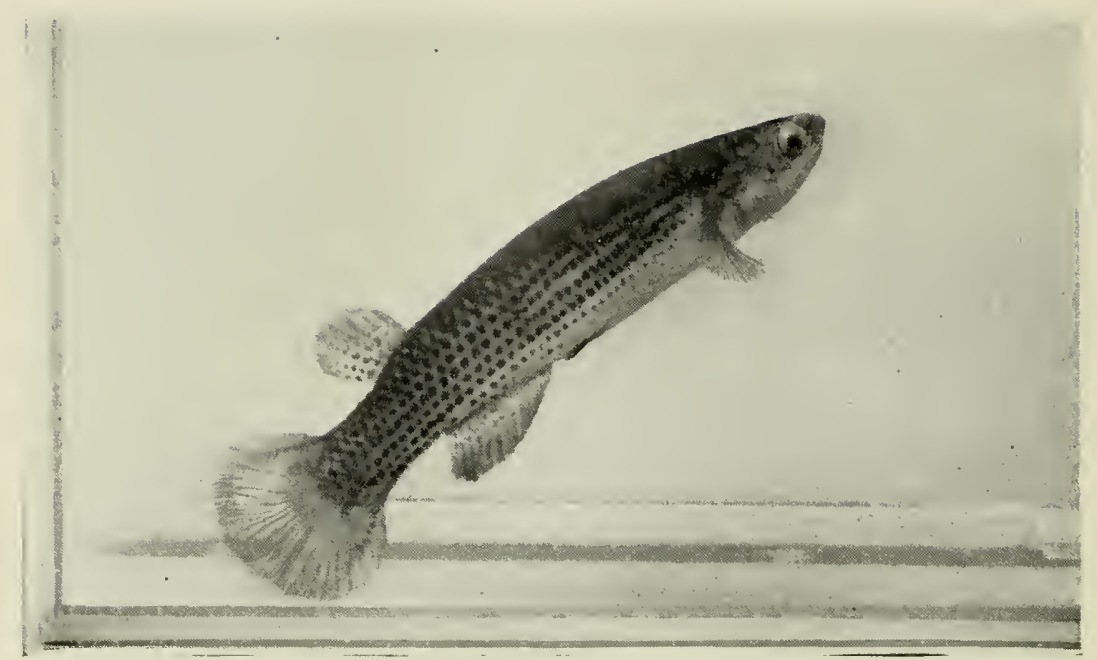

FIG. 222. Rivulus harti (Male) [Life size]

The lines of dots are deep red, giving the fish a handsome appearance. Breeding habits, page 242 (No. 18).

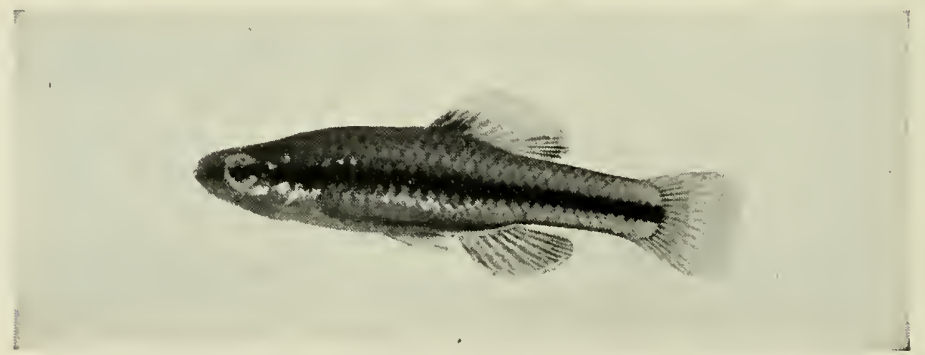

FIG. 223. Chriopeops goodei (Formerly known as Fundulus goodei)

This beautiful fish has been brought from Florida at a comparatively recent date The male is very beautiful in colors and is a desirable aquarium fish, but seems to do better either in a large indoor tank or in an outdoor pool in summer. Breeding habits, page 242 (No. 18). 


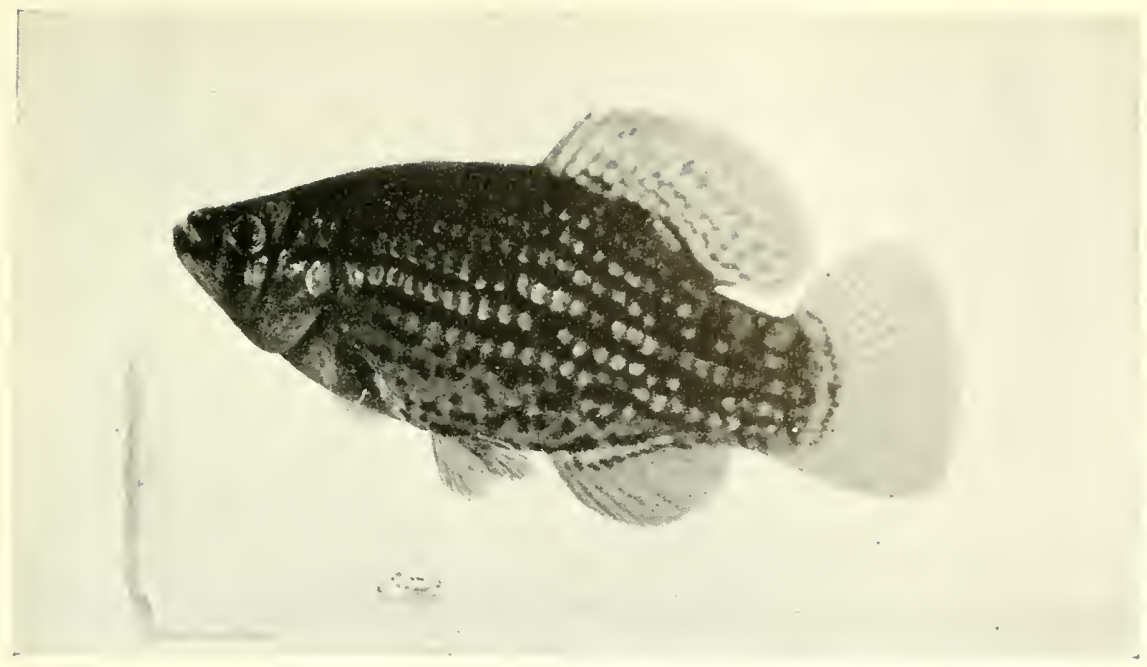

FIG. 224. Jordanella floridœ (Lije size)

One of our own particularly attractive native tropical fishes. The general color is a warm, reddish brown. Breeding habits, page 242 (No. 1S).

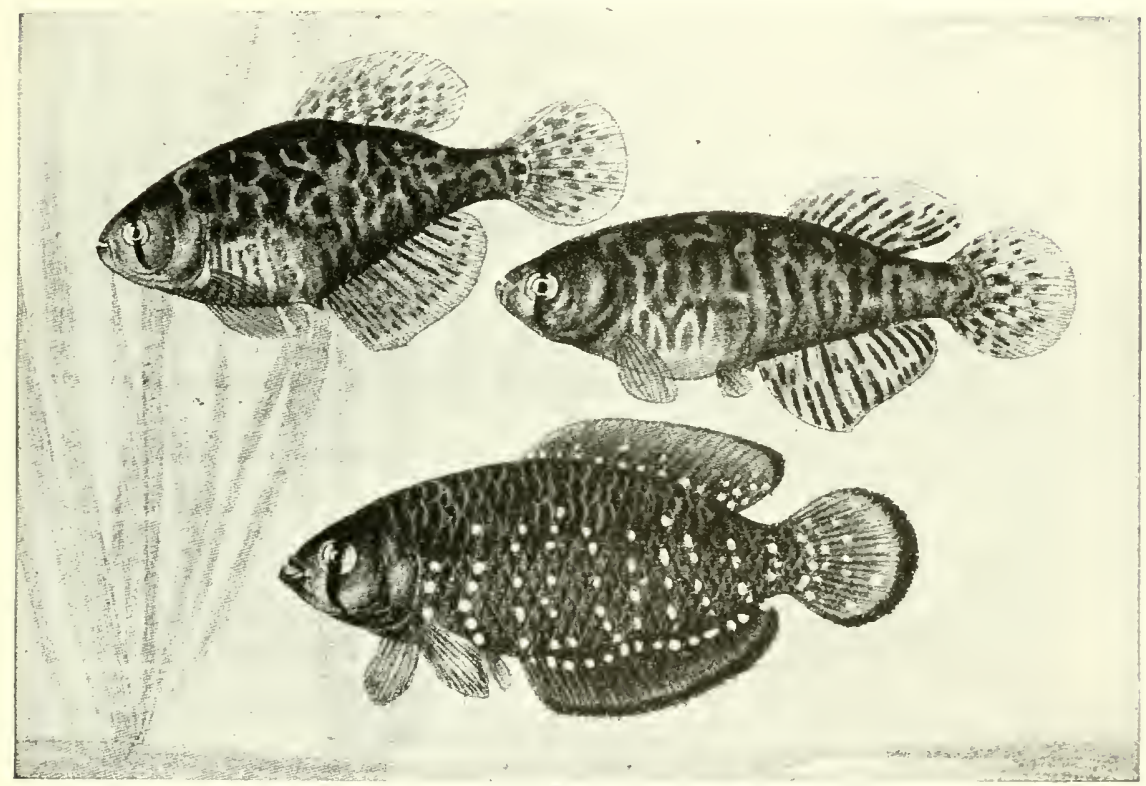

FIG. 225. Cynolebias belottii (Natural size)

The majority of imported aquarium nshes, especially the more handsome ones. come from tropical climates and naturally require fairly warm water. Cynolebias belottii is one of the exceptions, coming from Argentine. It prospers at a temperature of 68 degrees or lower, and is beautifully marked, especially the male, which is distinquished by clear white pearl-like dots. The prevailing color is blue. Breeding habits, same as egg-laying Killifishes, page 242 (No. 18). 

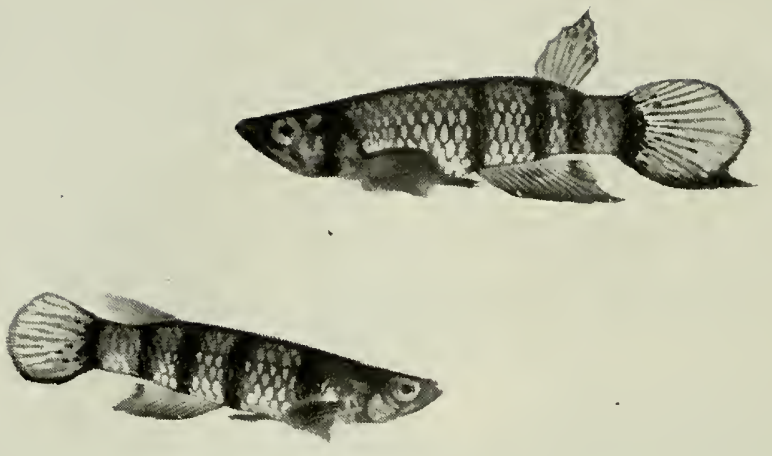

Fig. 226. Epiplatys chaperi (Slightly Reduced)

One of the best-known and easily bred of the tropical fishes. Not as large as some of the other Haplochilus division, it is also less likely to be cannibalistic, while in beauty it takes a high place. See page 242 (No. 18).

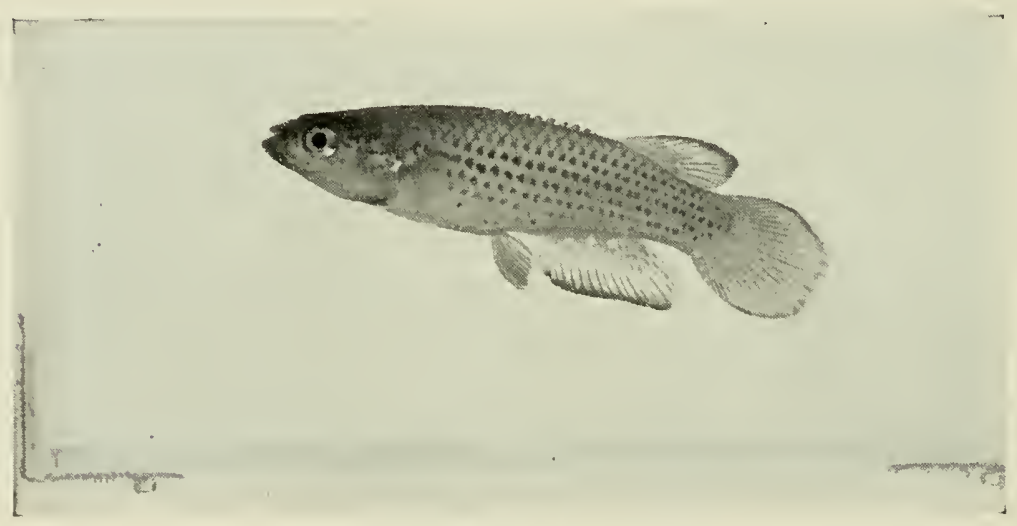

F1c. 227. Pachypanchax playfairii

Besides the attractive coloration of this fish (lines of deep red dots on shades of yellow) there is an interesting characteristic to the scales, which stand partly on end, giving the appearance of the fish disease known as "dropsy," but which is normal to the scales of the species. We have tried unsuccessfully to photograph the scales on a dropsical fish, but this illustration conveys the idea perfectly. However, there is nothing repellant about this fish. On the contrary, it is attractive. Being hardy and a good breeder it is likely to remain one of our permanent friends. Males have yellow fins edged black. Females have colorless fins and a black blotch at base of dorsal From Zanzibar. Breeding habits, page 242 (No. 18). 

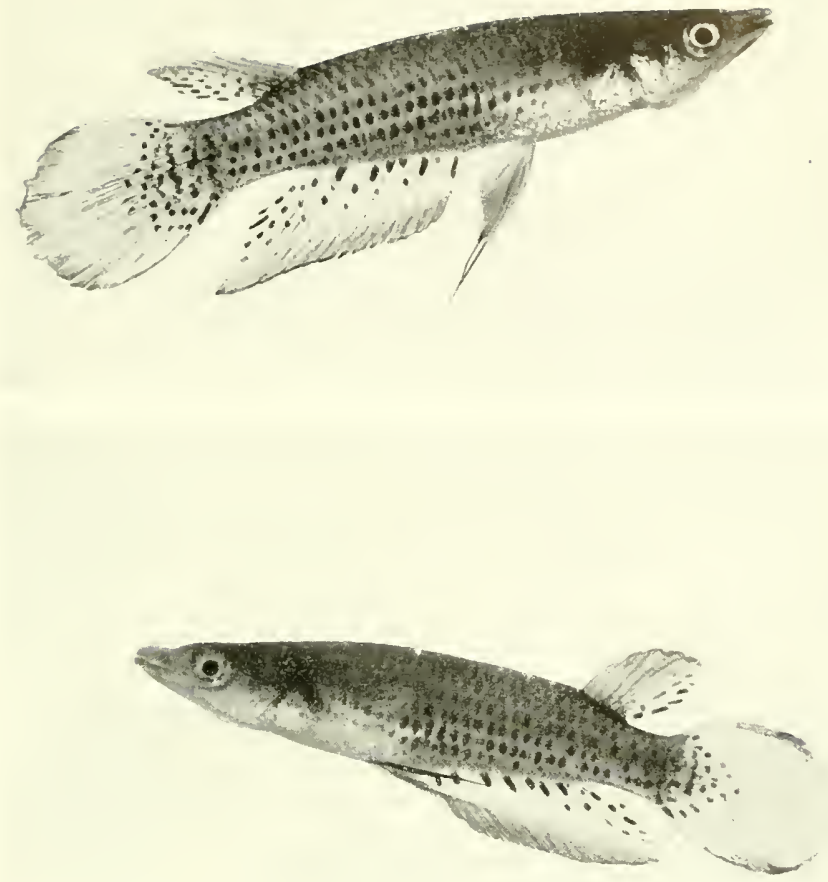

Fints. 228 AxD 229. Panchax lineatus

Upper, male; lower, female (Life size)

Larger members of the Panchax family. While not attacking other aquarium fishes for the pleasure of fighting, they are not to be trusted with smaller specimens, which might be swallowed. They are inveterate leapers. Considered to be among the handsomest of domesticated fishes. Breeding habits, page 242 (No. 18). 


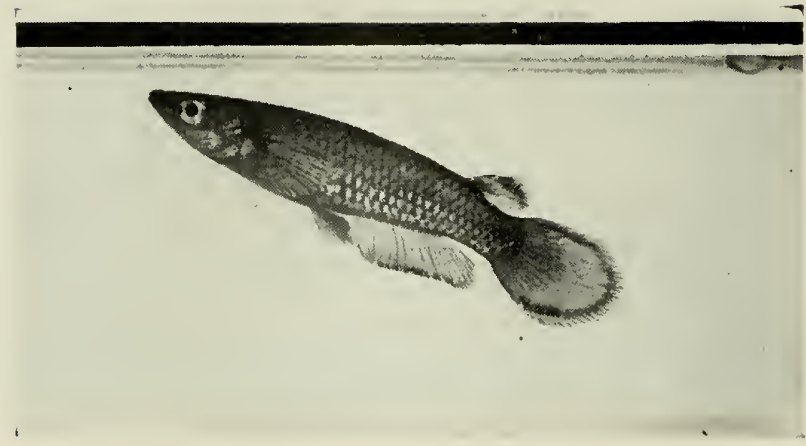

F1G. 230. Panchax panchax (Slightly Reduced

One of the regular aquarium favorites. The dark edging in the fins represents a bright orange-red, while the body is suffused with a glowing mixture of warm colors Males have dark outer edge on fins. Breeding habits, page 242 (No. 18).

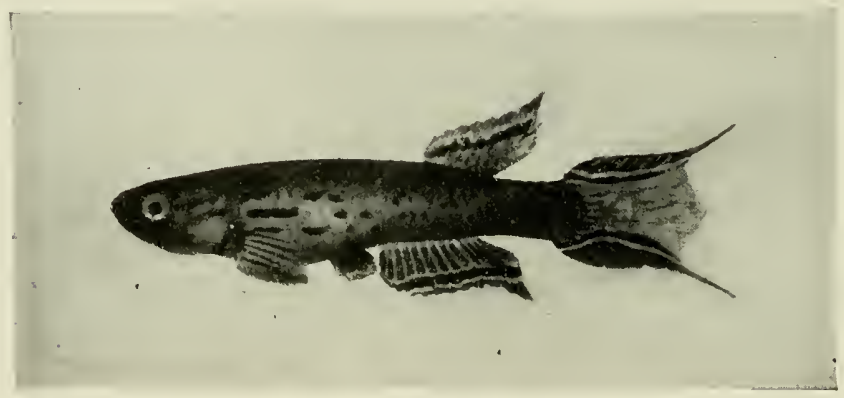

FIG. 231. Aphyosemion australe (formerly known as Haplochilus cameronensis)

In direct sunlight, coming from behind the observer and striking fully on the fish, he is indeed a sight to behold-a combination of harmonious blendings and striking contrasts. They die rather easily, especially if the water gets a little cool. The illustration is of a maximum size not usually reached. Females have rounded tails and are not at all brilliant. A callurium is so nearly similar that a photograph will not intelligibly record the difference. Breeding habits, page 242 (No. 18). 


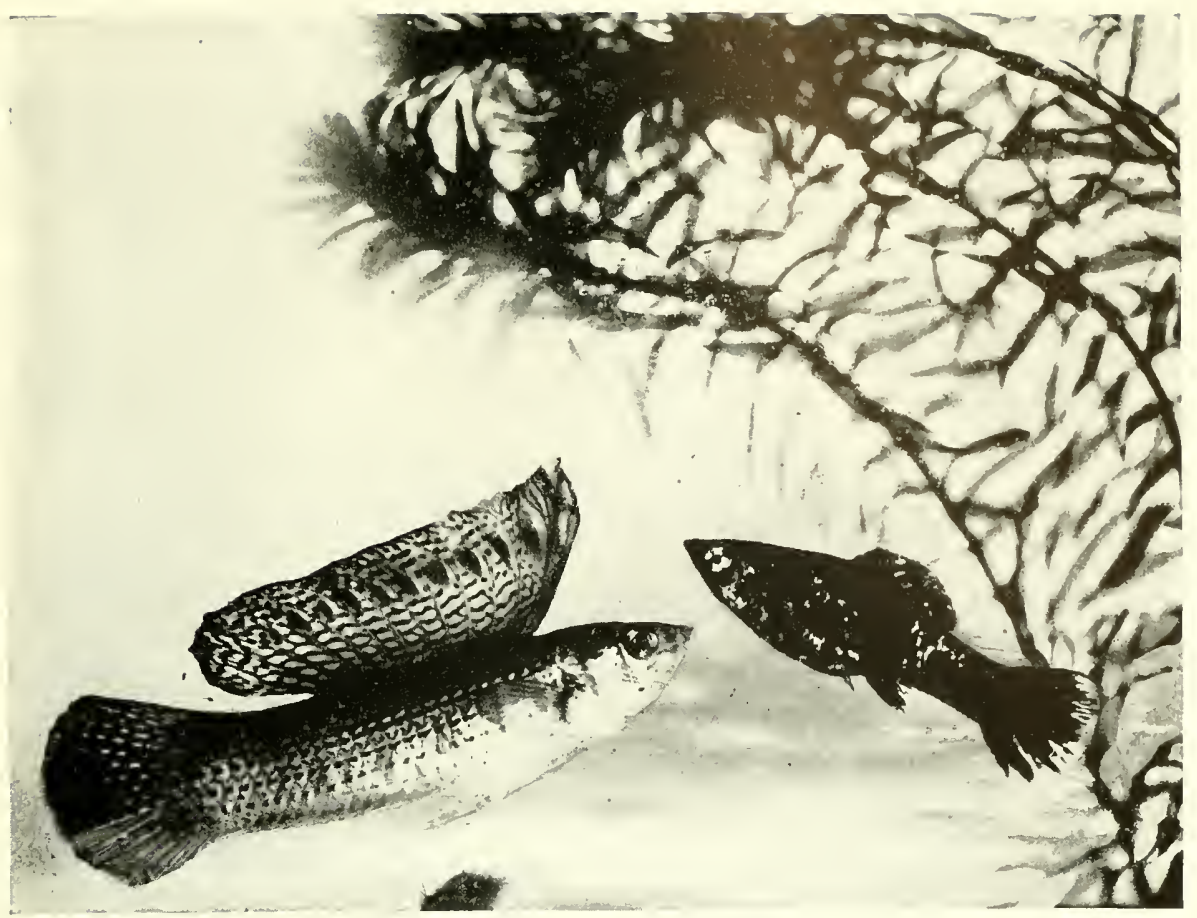

F1G. 232. Mollienisia latipinna

This is one of the most attractive of the fishes from Southeastern United States and Mexico. After many efforts we were fortunate enough to photograph the male in hi: courting regalia. The dorsal fin ordinarily is not so highly raised but appears as in $\mathrm{Fiz}$ 234. The female is of the same species but nearly black in color, a natural freak which occurs once in several million specimens. Breeders have mated black specimens together until now a fairly pure strain of blacks has been established. The young are born alive. Breeding habits, page 242 (No. 18).

These are principally marine fishes but live fairly well in fresh water. The author suspects they do best in a brackish water aquarium, and that if kept in fresh water they should, every few months, be given the progressive salt treatment described on page 83.

Most of the live-bearing speries mature early and breed before reaching full size, at ages from three to six months.

Although fertilization takes place in the same general manner as in warm-blooded animals, and the young are developed within the body of the female, still it is not a true process of gestation. There is no connection between the embryo and the circulatory system of the mother. The eggs merely develop and hatch within her body and are dropped when fully formed. The period of development is very variable, depending on the species to some extent, but more upon temperature. We believe the time varies from about six weeks to six months, the shorter time being more usual. It has been noticed that a change of water is liable to bring about a delivery when the young are about ready to appear, which can be judged by the development of a large dark spot near the vent of the female, as in figures 235,236 and 230.

Figures 232 to 241 are all viviparous or live-bearing species. 


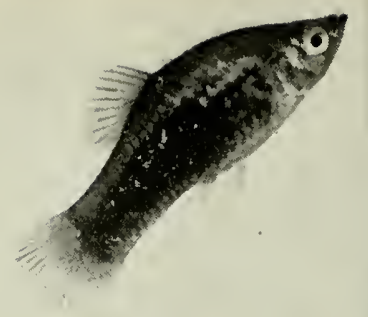

Fig. 233. Platypoecilus maculatus niger (Two-thirds size)

One of the popular variations of Platypoecilus maculatus, commonly known as "Black Platy." It is sometimes used as a progenitor in a number of hybridizing crosses. especially with Xiphophorus varieties.

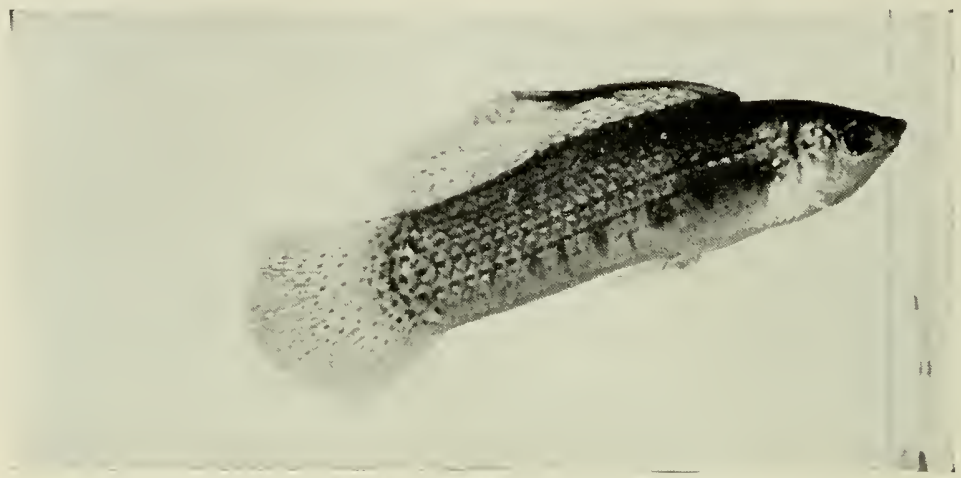

Fig. 234. Male Moluenisza latipinna

Here we see the male fish as he ordinarily appears when not "showing off." Mollienisias are exceedingly fond of nibbling at algæ, and this has an appreciable effect in keeping aquarium plants and glass somewhat cleaner. When the glass is scraped free of any green growth the fishes are unable to dislodge, they eat the scrapings. Finely chopped crisp lettuce leaves should be given them occasionally if algæ is not plentiful

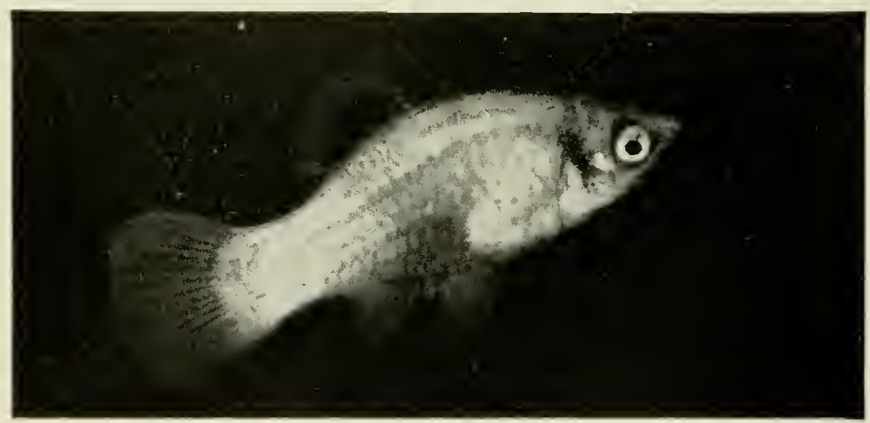

Fig. 235. Platypoecilus maculatus, FeMALE

These are popularly known as Moon Fish and this is the "golden" variety, being a light gold color. There is a beautiful red spot in the dorsal fin which can hardly be appreciated in an uncolored reproduction. Breeding habits, page 242 (No. 18). 


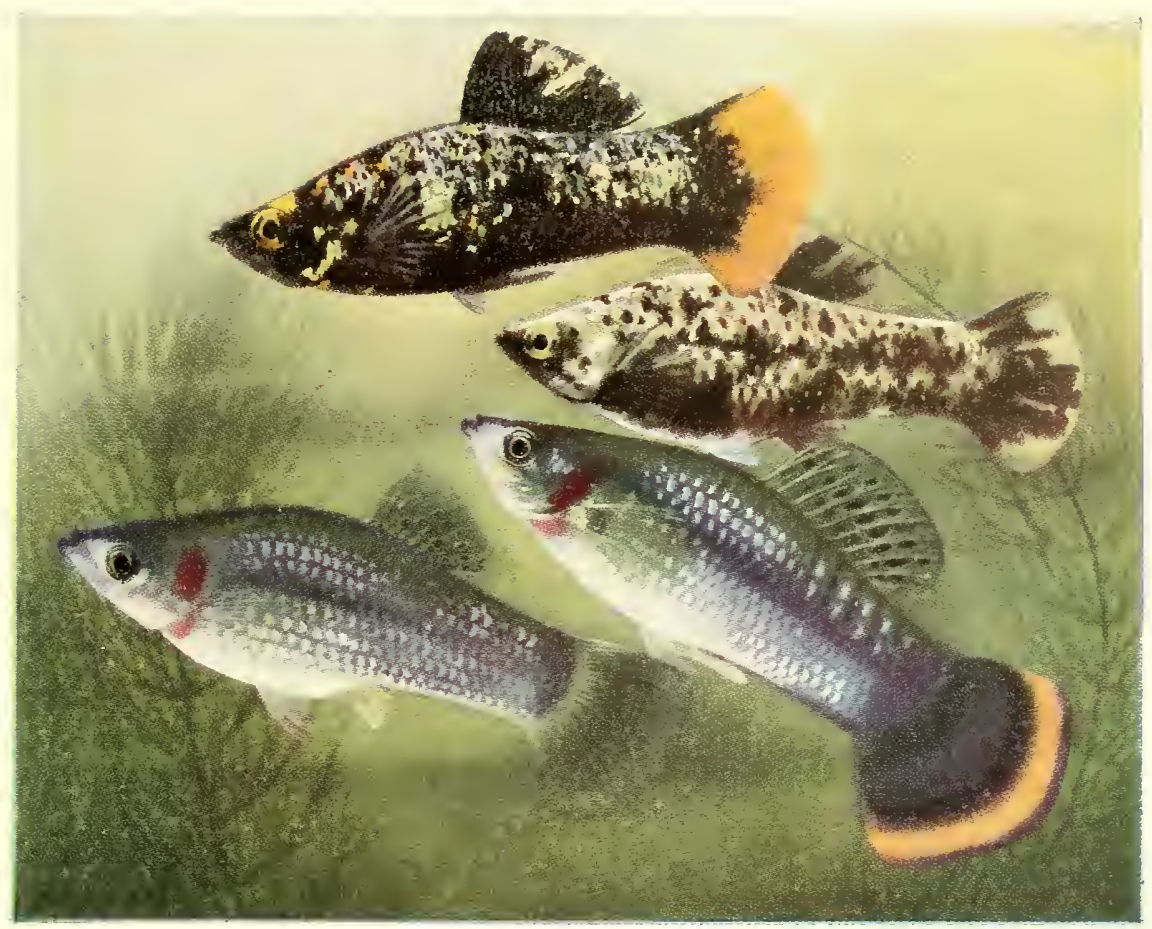

Fig. 273a. Mollieniviz sphenops (Curier and Valenciennes) Oranere-tail variet.es

Mollienisia sphenops, occurring on the Gulf Coast to Venezuela, and exhibiting a considerable variation in color and size, is always hardy. active, prolific and good-looking.

The dorsal fin has fewer rays than either $U$. ielitera or $1 \%$. latipinna. The easiest point of identification is the fact that the fin has its becinning at about the highest point on the back. The fin on the other two popular species besins well forward, close to the head.

All Mollienisias are live-bearers, and are benefitted by occasional feedings of bits of scalded spinach. 



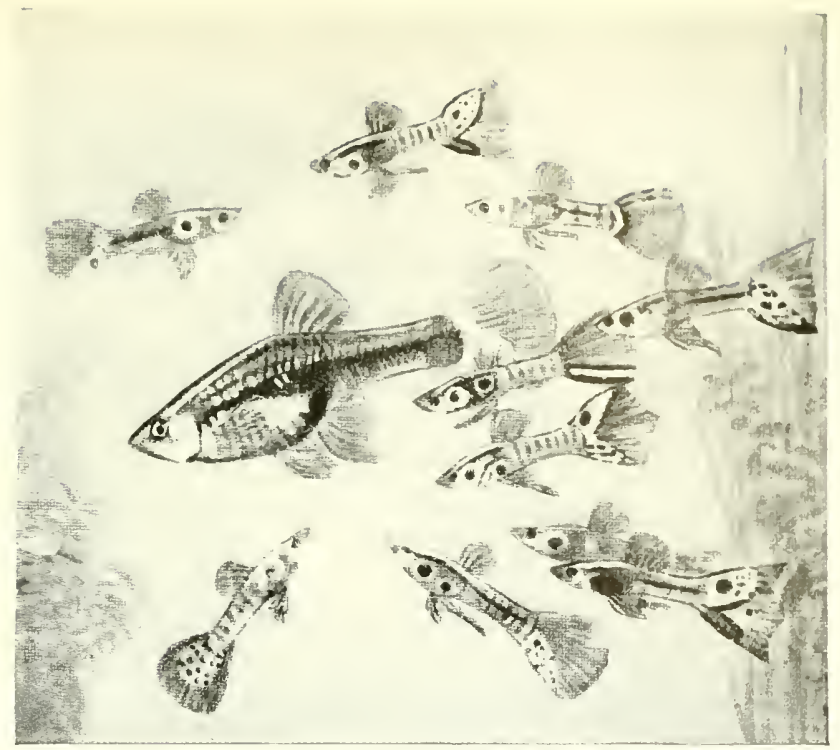

FIG. 236. Lebistes reticulatus (Incorrectly known as (iirardinus guppyz) [Life size]

The extraordinary variation in the coloring of the males makes this species a never. ending source of fascination. No matter how large the collection, it is practically impossible to find two just alike. They are appropriately called the "Rainbow Fish." The female is much larger than the male, and of a dull olive hue. See page $2+2$ (No. 18).
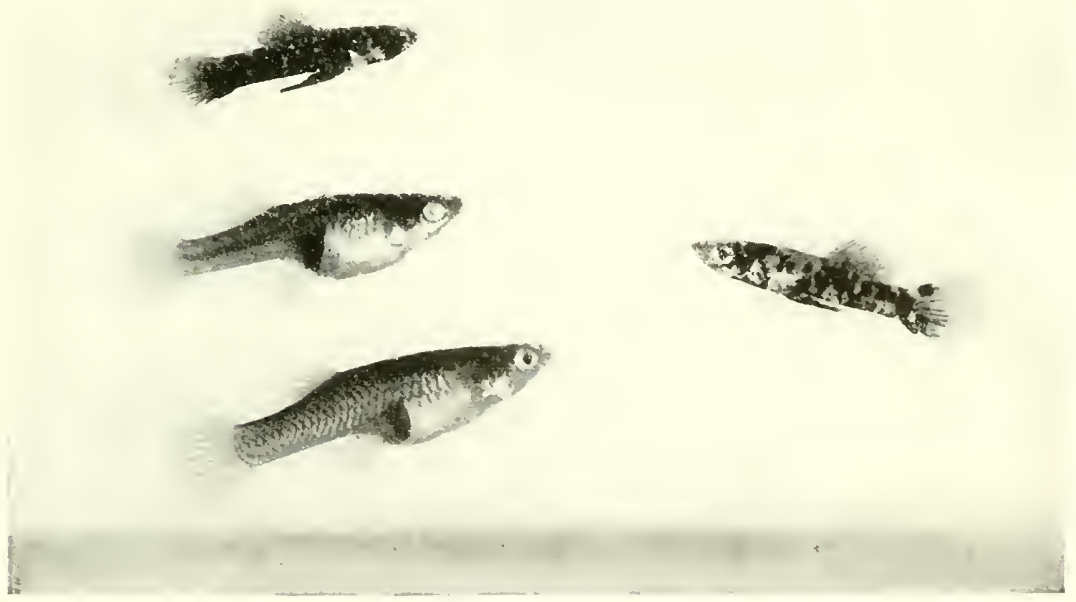

FIG. 237. Gambusia afinis (Average size)

Also known as holbrooki, these fishes were the first of the live-bearers to be genes ally introduced into the aquarium in America. They are native to the southeastern Atlantic States and occur as far north as Maryland. Gambusia affinis has been intro duced in many parts of the world on account of its efficiency in destroying mosquitn larvæ, thereby controlling malaria and yellow fever. Although hardier than most tropicals, this fish cannot withstand freezing temperature. They tear the fins of other fishes The darker specimens are the most sought after. Dark spots near vent of females are produced by unborn young. Breeding habits, page 242 (No. 1s). 


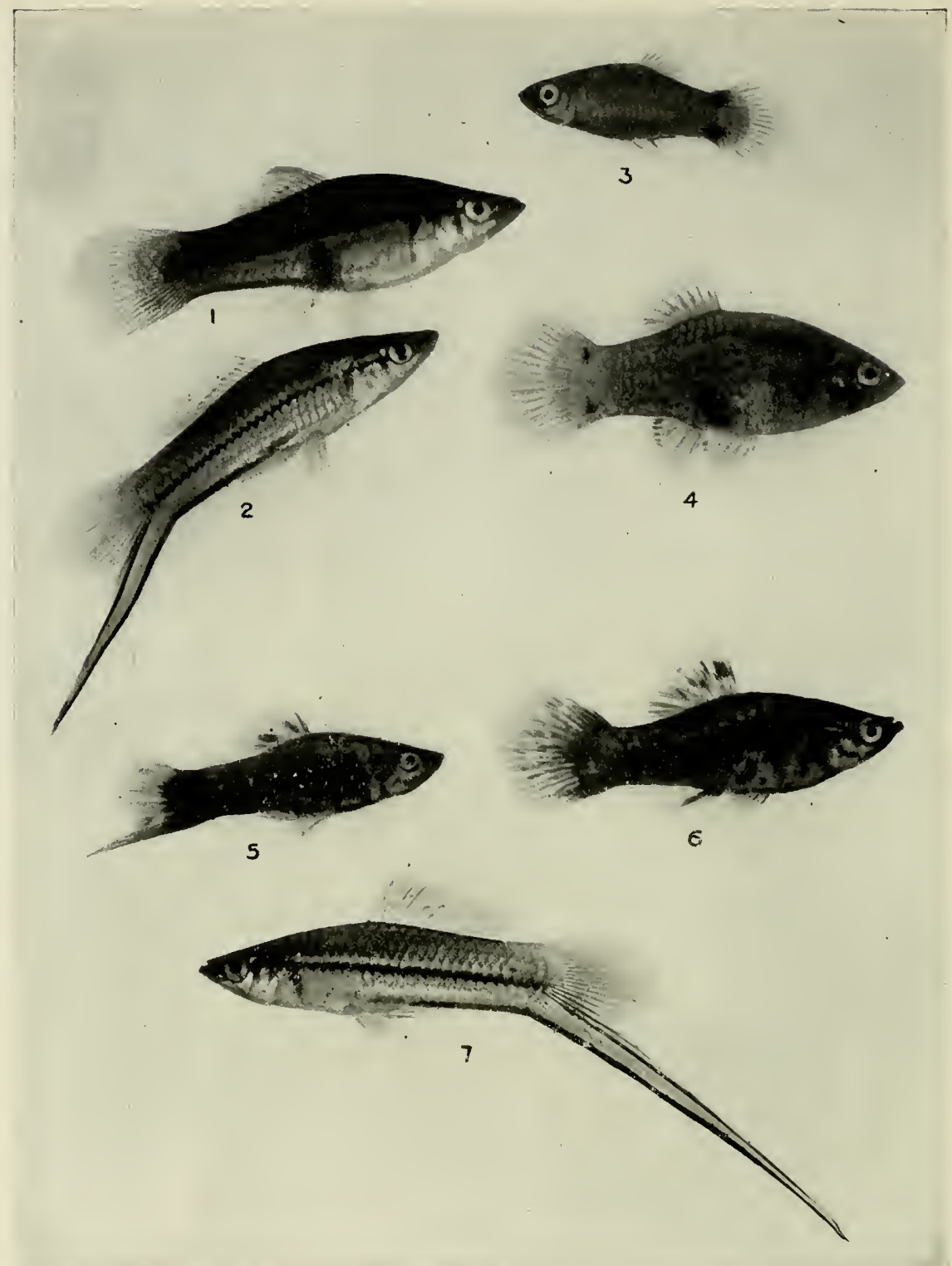

Fig. 238. Factors in Producing Hybrids Illustrated on Opposite Page

(Three-fourths size)

1, Xiphophorus helleri (green), female; 2, Xiphophorus helleri (green), male; 3, Platypoecilus maculatus (rubra), male; 4, Platypoecilus maculatus (rubra), female; 5, Hybrid male from crossing Nos. 3 and 1; 6, Hybrid female from crossing Nos. 3 and 1; 7, Xiphophorus helleri (orange), male.

Nos. 6 and 7 are the parents of hybrids shown in Fig. 239. All are live-bearing or viviparous fishes. 


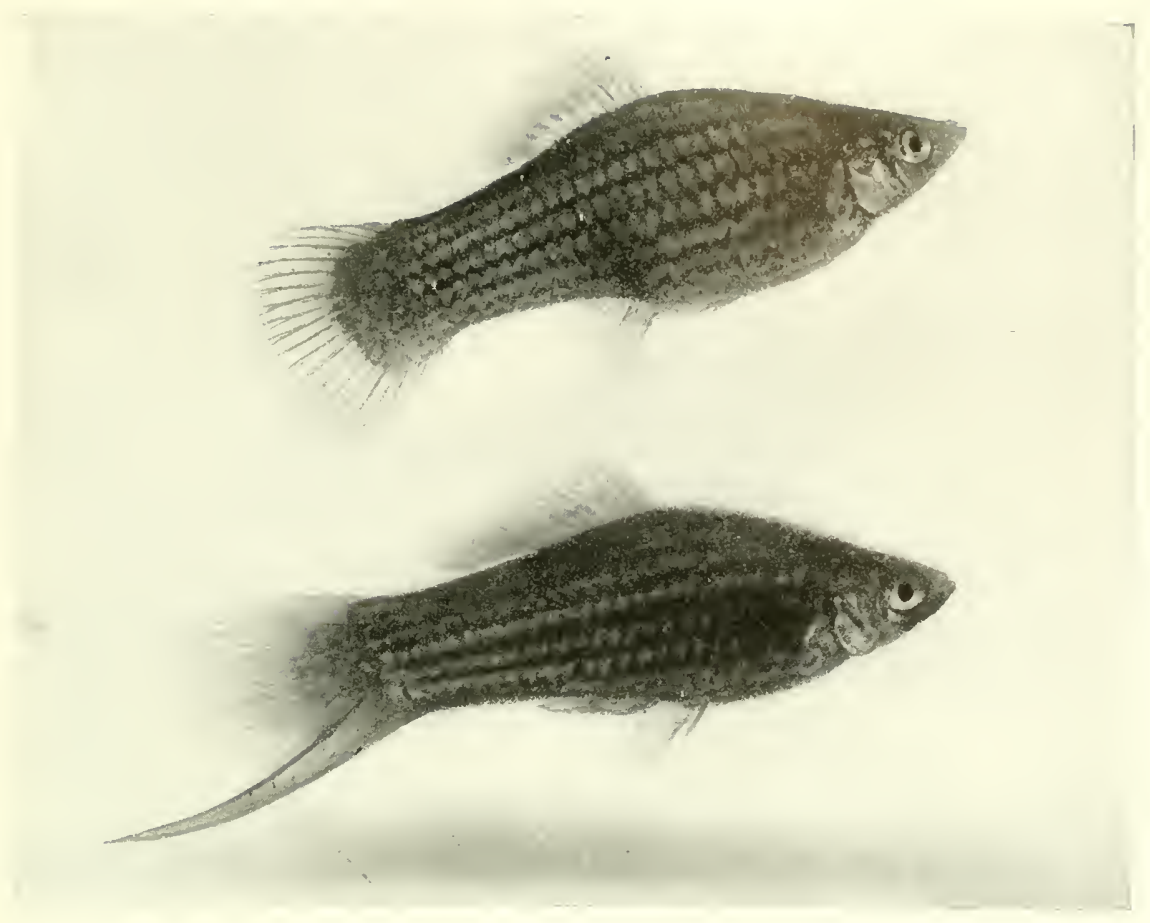

Fig. 239. Red Hybrids (Life size)

One of the most remarkable productions in hybridization. On opposite page, number 3 is a small, deep-red fish. Number 1 is greenish with some red markings. This cross produces some reddish hybrids, blotched black. When the reddest of these females is bred to number 7 , we get a magnificent, large red fish. It grows rapidly and becomes considerably larger than any of its progenitors. These hybrids bred together throw a surprisingly high percentage of reds-well over half. In a few generations of selective breeding we should have a very fine strain of these beautiful fishes. Hybrids in fishes seem to be moderately fertile.

The female (upper figure) was "ripe" when the photograph was made, shown by distended outline and by the dark spot near the vent, which is not so plain as in some of the more translucent fishes.

The possibilities of hybridization among live-bearing fishes are not fully known, but the subject is receiving careful study. To be sure of known crosses it is best to place the two fishes together before sexual characteristics have developed. If the sexes do not turn out right, one still has virgin fishes to cross with those from other experimental aquaria. A female once impregnated is fertile for four lots of young. Additional breeding habits page 242 (No. 1S). 


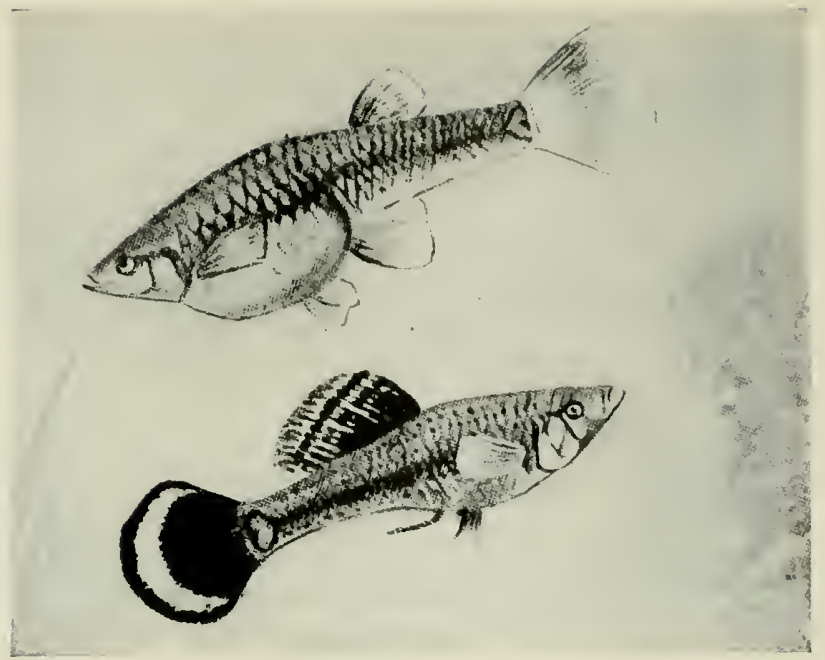

FIG. 240. Mollienisia species (Life size)

These fishes well illustrate the pronounced color differences shown between the sexes of some species. To the uninitiated the difference is sometimes so great that a pair would not be recognized as belonging to the same family. See page 242 (No. 18).

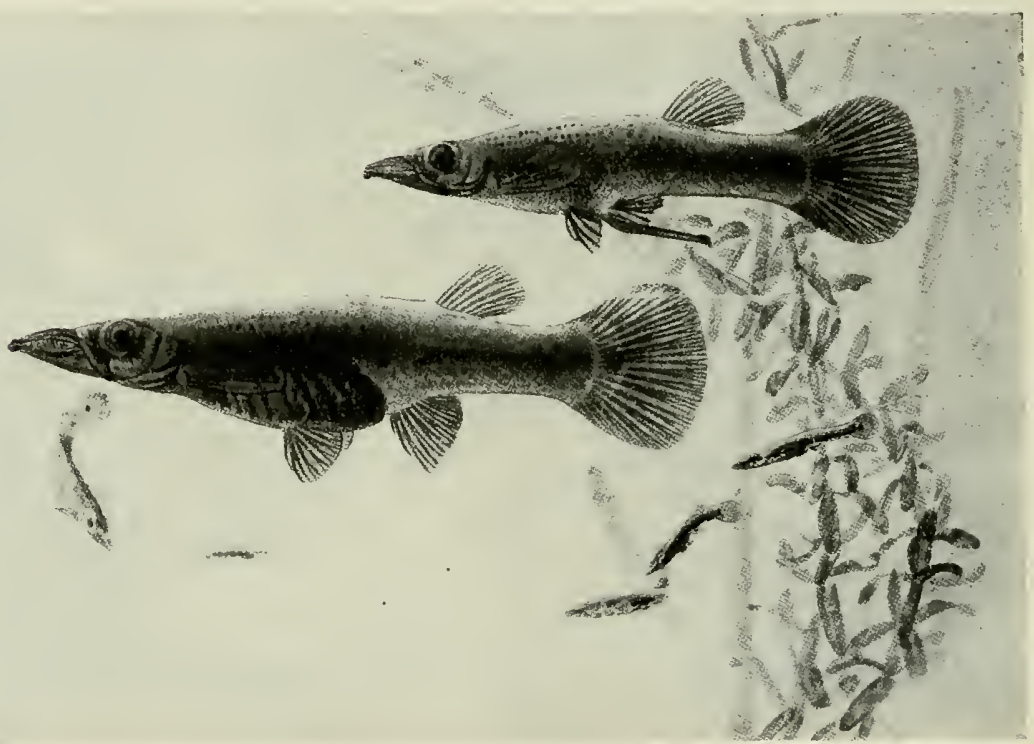

FIG. 241. Belonesox belizanus or Viviparous Killifish (Slightly reduced)

These little fishes are quite as bloodthirsty as their expression would appear to indicate. After they attain adult size they prefer being fed on small living fish, although worms are taken under protest. See page 242 (No. 18). 


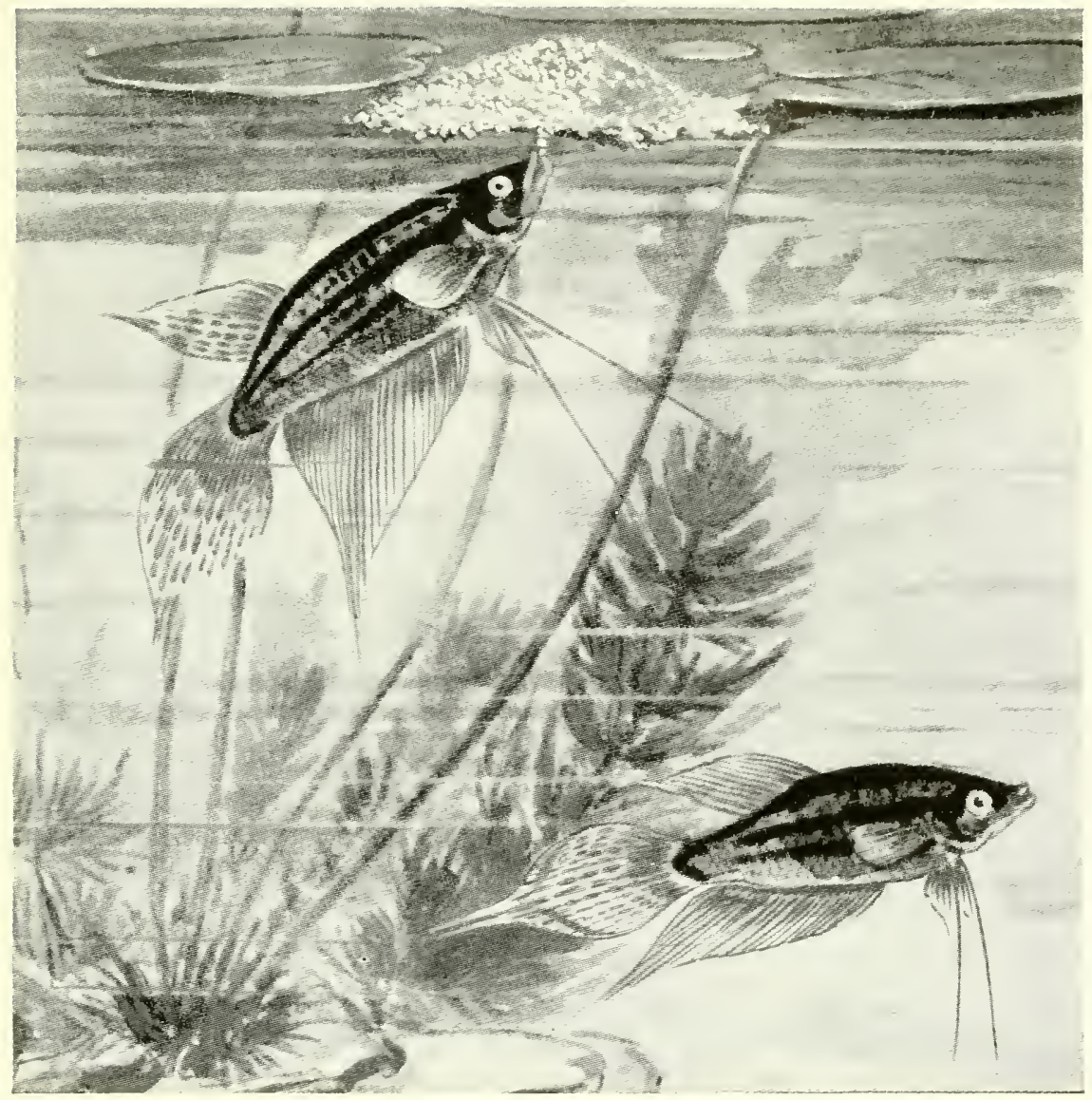

Fig. 242. Croaking Gourani (Ctenops vittatus)

The illustration shows one phase of the breeding habits of the bubble-nest builders, of which there are a number. The nest is built of bubbles from the mouth of the male, who takes entire charge of affairs. As the female drops a few eggs he at once fertilizes them, picks them up in his mouth, attaches a bubble, and floats them into the nest, where he guards them valiantly. If in a usual aquarium, the female must be removed after spawning is completed, otherwise he will kill her, so zealous is he in guarding the eggs and young from her possible cannibalism. In outdoor pool culture this does not always appear to be true. We have seen many pairs work together in common interest. Dwarf Gouramis like to interweave bits of vegetation into the nest, such as broken leaves of Myriophyllum. In this work the female helps with apparent enthusiasm. Illustra. tions 242 to 249 are all nest-builders. Additional breeding instructions on page 237 (No, 2). 


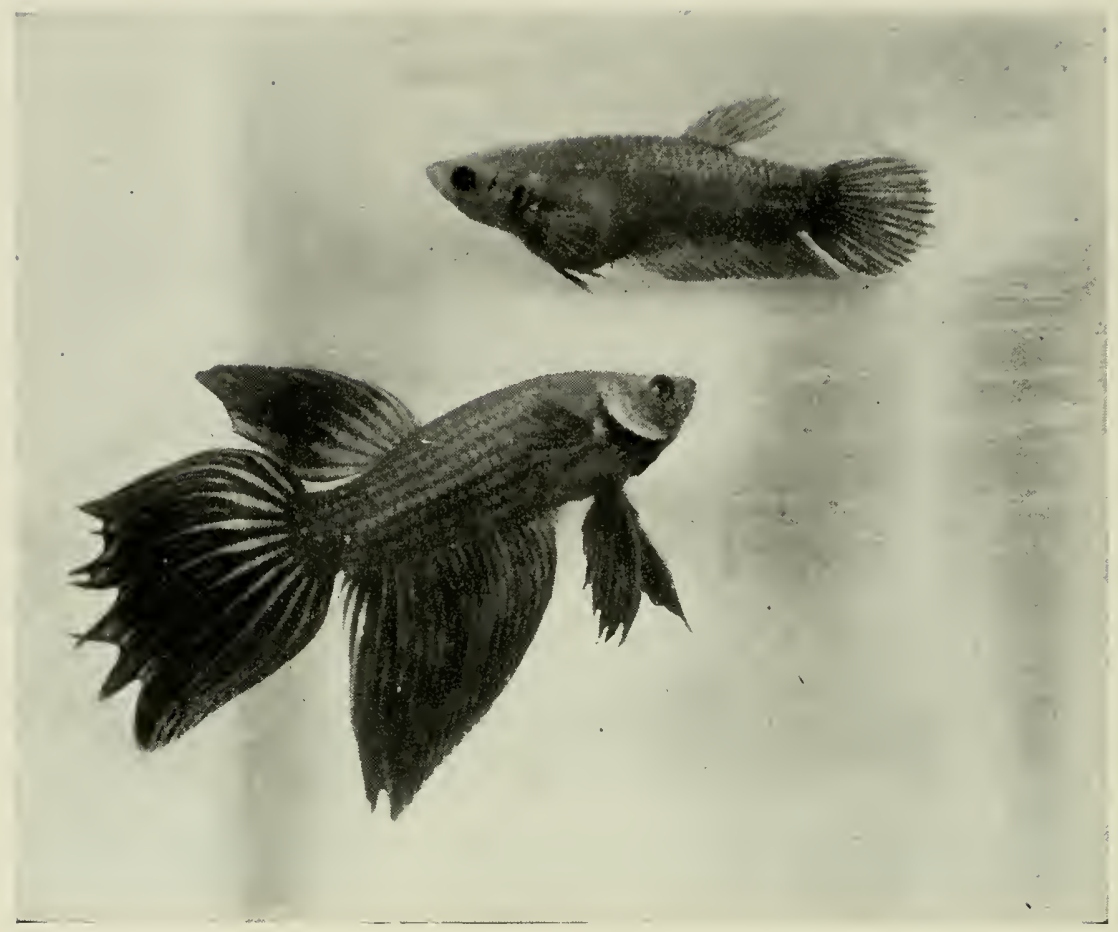

Fig. 243. Betta splendens, Cambodia variety, or Veiltail Siamese Albino Fighting Fish (Life size)

This fish and several other variations of the species suddenly appeared on the aquarium horizon in 1927. They seem to be "sports" from Betta splendens. This particular variation has flashing red fins which are usually very large in the second year, and gorgeous when spread. The fins are partly overcast with a metallic greenish blue, individuals varying considerably in this respect. The metallic hue extends somewhat on the body, which is a deep cream color. In some variations the body is darker and is nearly or completely covered with deep, metallic blue, comparable to that in a blue butterfly. Such color only develops fully in adults, and, when present, the fish is known as "Blue Betta."

Unfortunately males cannot be left together, as they tear each other's fins badly. This illustration shows the male with the usual ragged tail-fin. He is spreading himself, with gill-plates raised, in courtship before the demure lady above. Breeding habits, same as Fig. 242. 


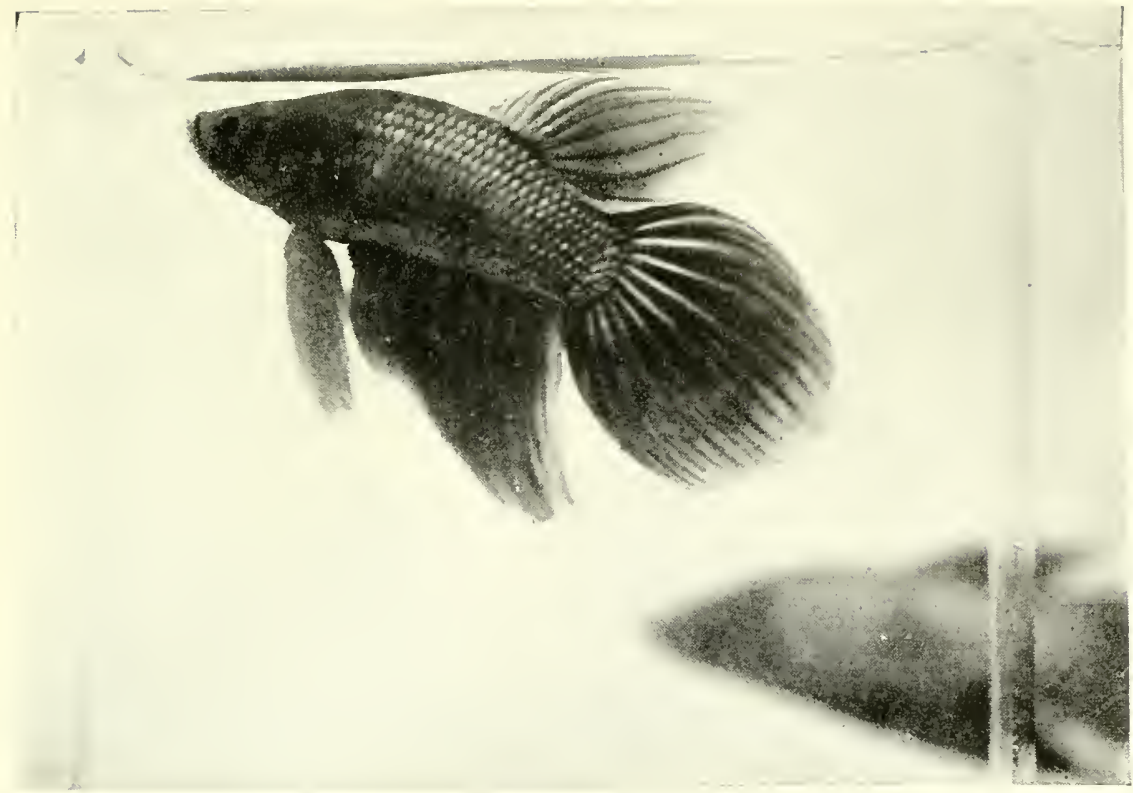

FIG. 244. Betta splendens, veiltail variety (Life size)

Text under preceding illustration for the most part applies here also. This specimen is more nearly similar in color to the regular dark red of Betta splendens. The fins of this individual have fortunately escaped injury.

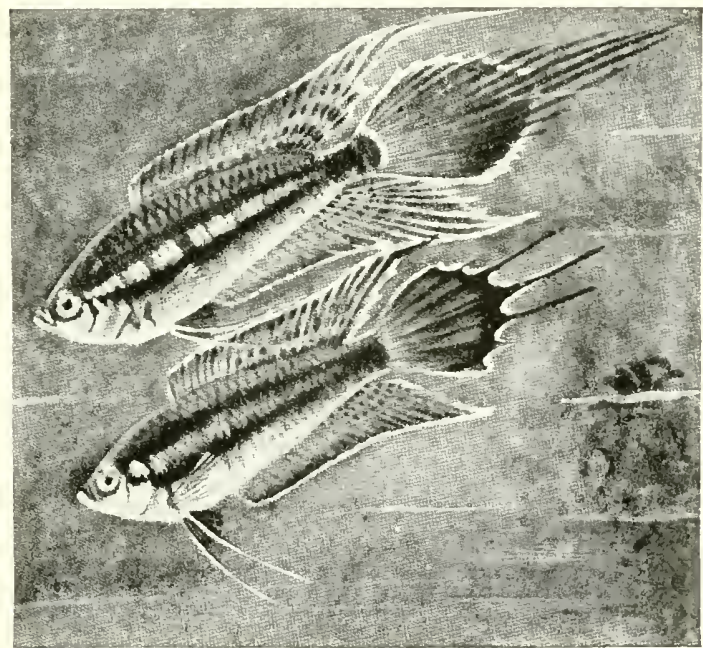

Fig. 245. Macropodus cupanus dayi

Habit description with Fig. 242 applies to both these illustrations. Note the more distinct coloring and longer fins of the upper fish. This is the male.

The scientific designations for male and female are: of male; of female. 


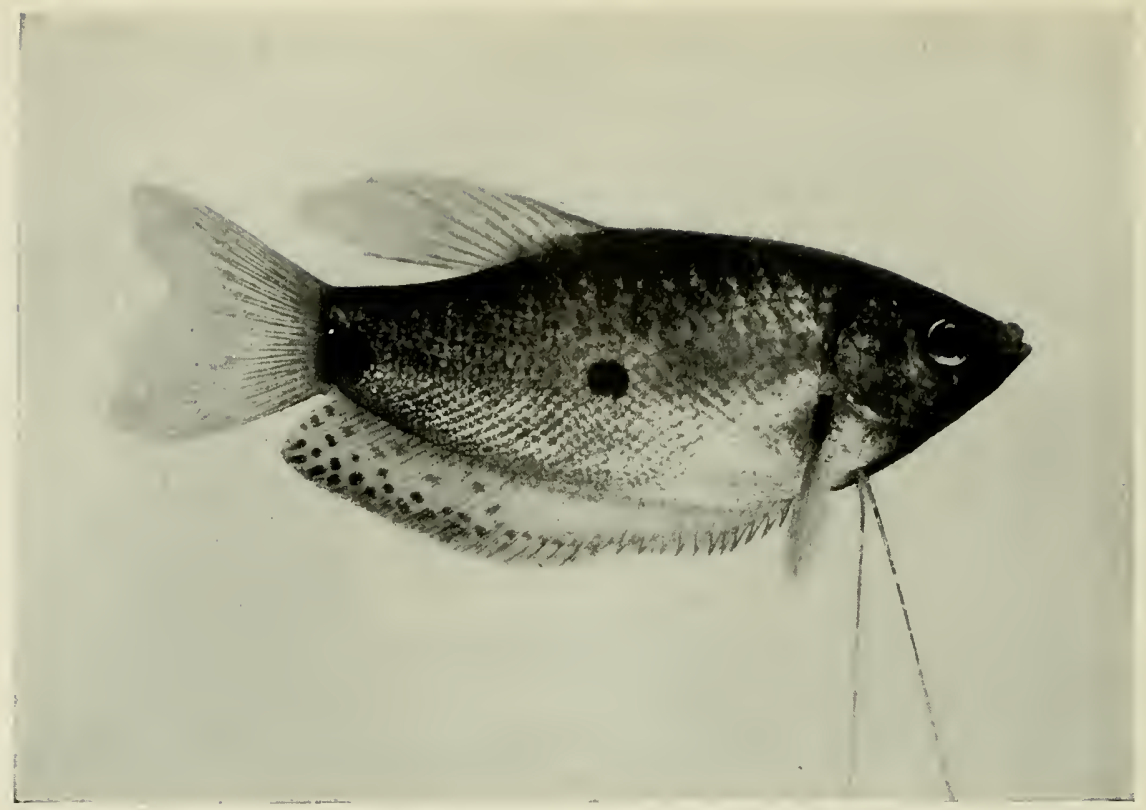

Fig. 246. Three-Spot Gourami (Trichogaster trichopterus) [Average size]

(Formerly known as Osphromenus trichopterus)

Breeding habits, same as Fig. 242

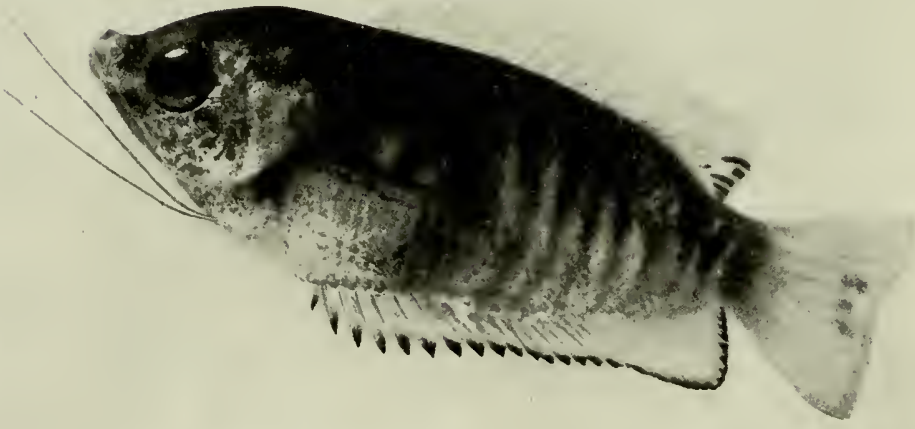

Fig. 247. Giant Gourami (Colisa fasciatus) [Average size]

Two of the larger bubble-nest builders, both very handsome. The Giant Gourami is particularly brilliant in breeding season. It is the eye which makes the third spot in the Three-spot variety. Breeding habits, same as Fig. 242. 


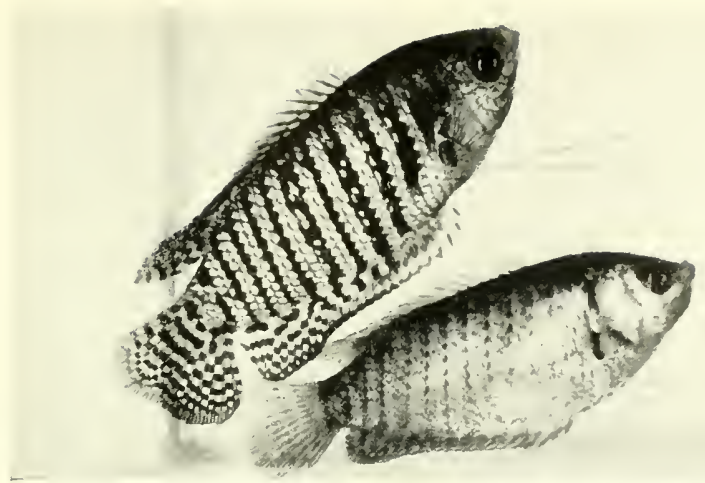

F1G. 248. Colisa lalia, or Dwari Gourami (Male [Top] and Female)

One of the most pleasing of aquarium fishes. The males are exceedingly brilliant when in a warm temperature.

The light bars are of a brilliant metallic blue, while the dark bars and fin markings are an intense deep orange. Same breeding habits as Fig. 242.

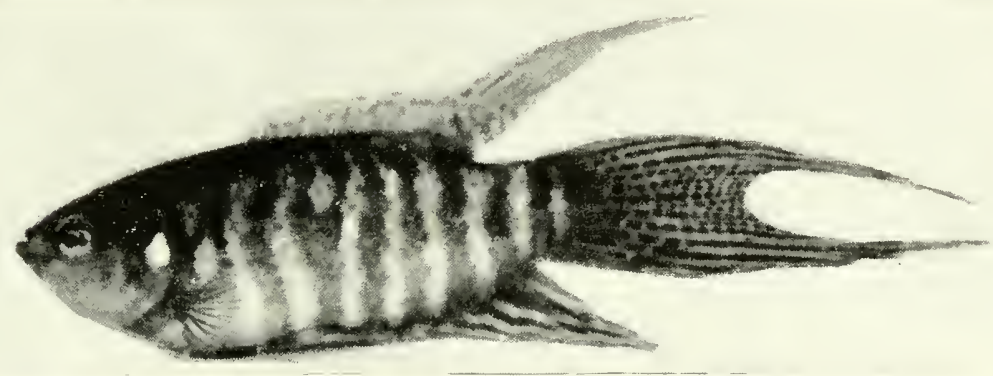

FIG. 249. Hacropodus opercularis, or Paradise Fish (Life size)

This is the first of the imported tropical fishes, and one of the best, although its popularity has waned somewhat owing to the fact that so many of them have been bred and newer species have taken its place in public interest. Habits, same as Fig. 242.

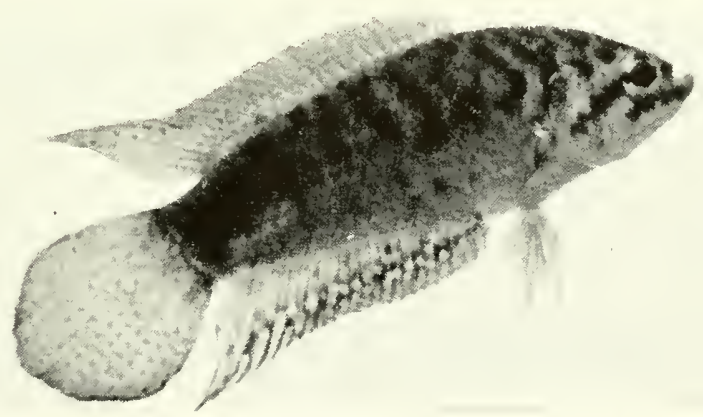

Fig. 250. Macropodus chinensis, or Roundtail Paradise Fish (Slightly enlarged)

This variety has very much the same habits of the old style Paradise Fish, but does not grow quite as large. Breeding habits, same as Fig. 242. 


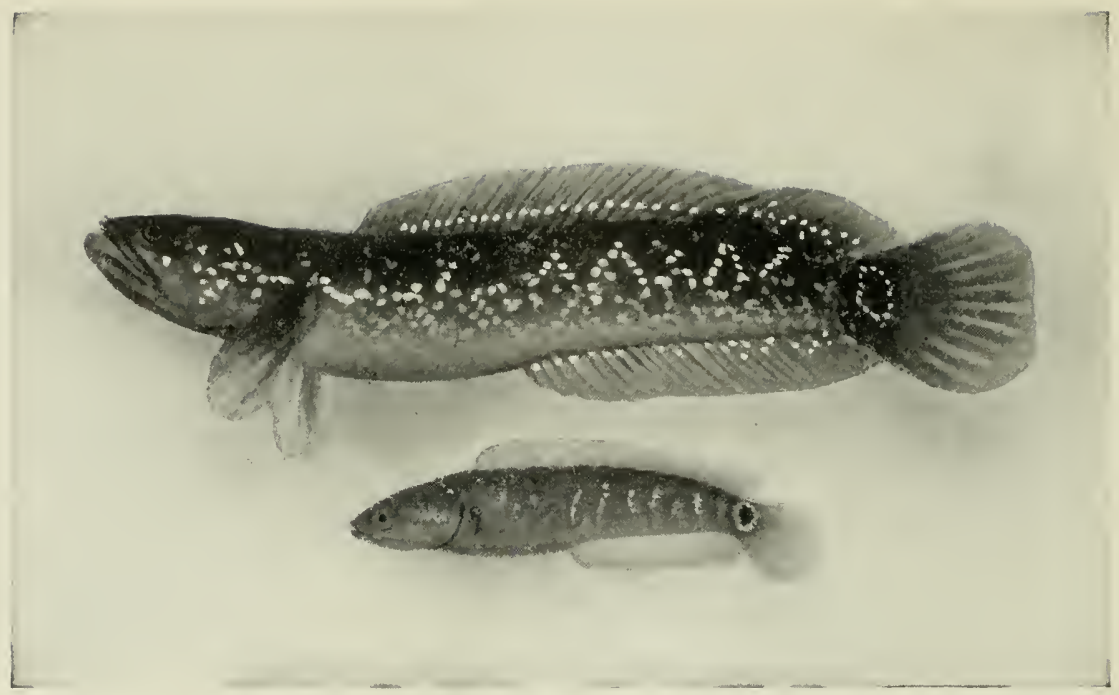

FIG. 251. Channa asiatica (Adult and Young)

One of the more newly introduced nshes, and may be classed as a handsome oddity. The dots are of a silvery whiteness. The zigzag lines divide a greenish color on top iruin a grayish color below. Gifted with tremendous swallowing capacity and appetites to match, they might prove dangerous associates to other fishes, although willing to eat prepared fishfoods containing a fair proportion of animal matter. They are air-breathing fishes and will survive very bad treatment, but cannot withstand cold. Breeding habits nage 241 (No. 15).

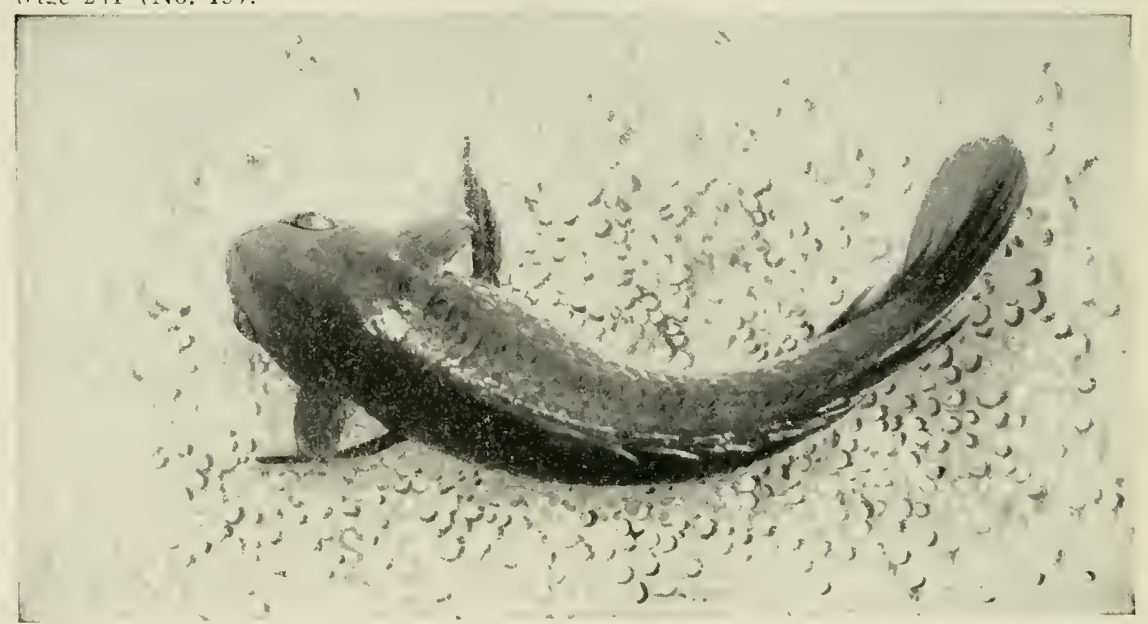

Fig. 252. Top View of Climbing Perch "Walking" on Land (Anabas testudineu, [Half size ]

Although this fish has no feet, "it gets there just the same." In its native habitat the ponds have a way of drying up at seasons. If the water becomes very low this fish leaves the pond at night. wriggles its way to a deeper one, and, if the dry spell continues, buries itself in mud until more favorable times return. The "walking" is done mainly by extending the spiny gill plates and working the body from side to side.

The fishes have air chambers in their gills and are known as "lung fishes." Breeding habits, page 237 (No. 2). 


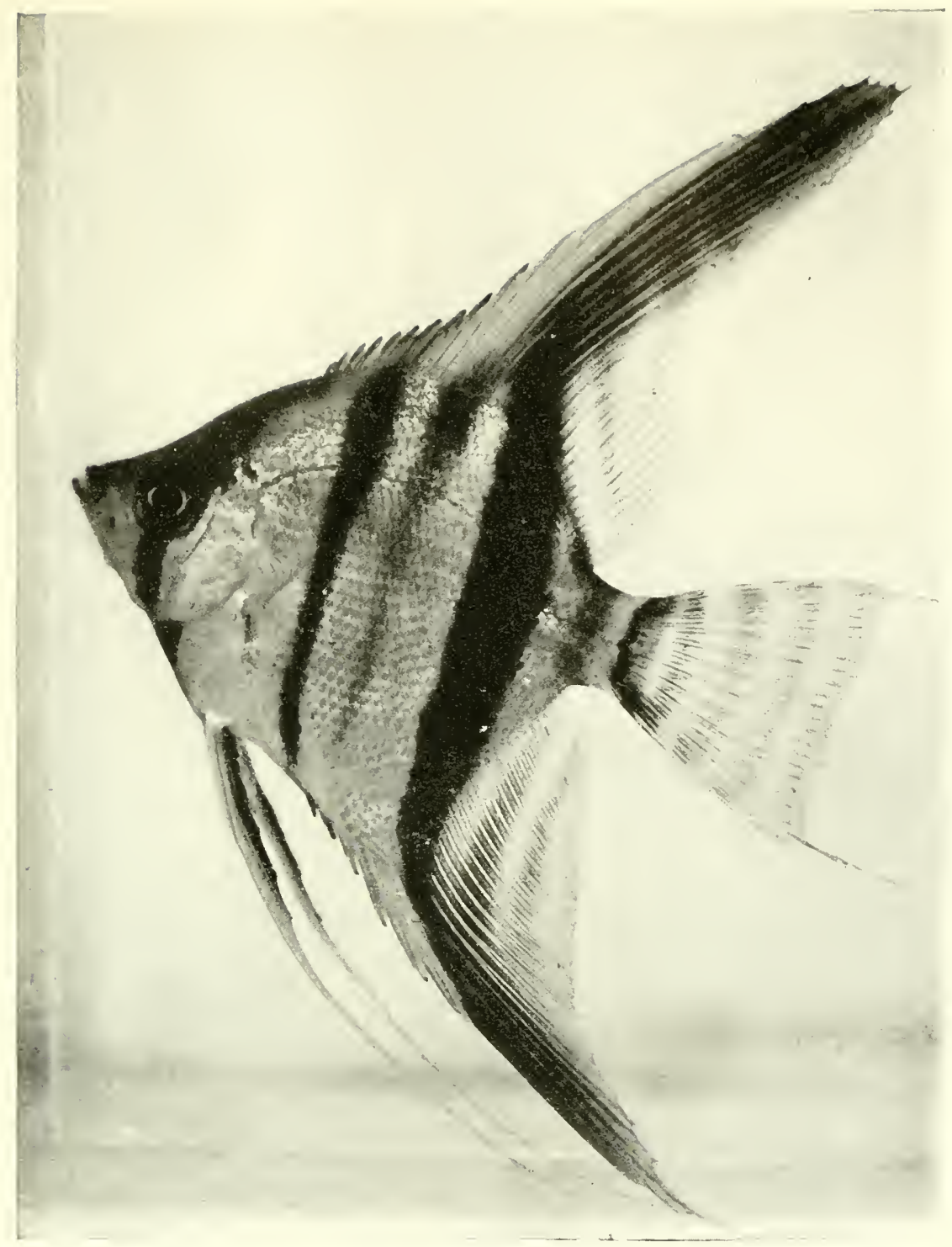

FIG. 253. Pterophyllum scalare (Life size)

An aristocrat of the aquarium, moving with the greatest of dignity, yet capable of dashing about at lightning speed.

For some years this was known as "the rich man's fish." but importations from European breeders have become so plentiful that young ones can now be had at fairly moderate prices. Figures 253 to 205 are nembers of the Cichlid family of nishes. $P$. scalare is not combative, but is fond of eating small fishes that may be swallowed whole.

Aquaria containing Scalares should be well stocked with large plants. They are very excitable at times and are liable to kill themselves by dashing head-on into the aquarium glass. Plants seem to give them a bearing as to location and prevent this suicidal tendency. Native to the Amazon River. Breeding habits, page 239. 


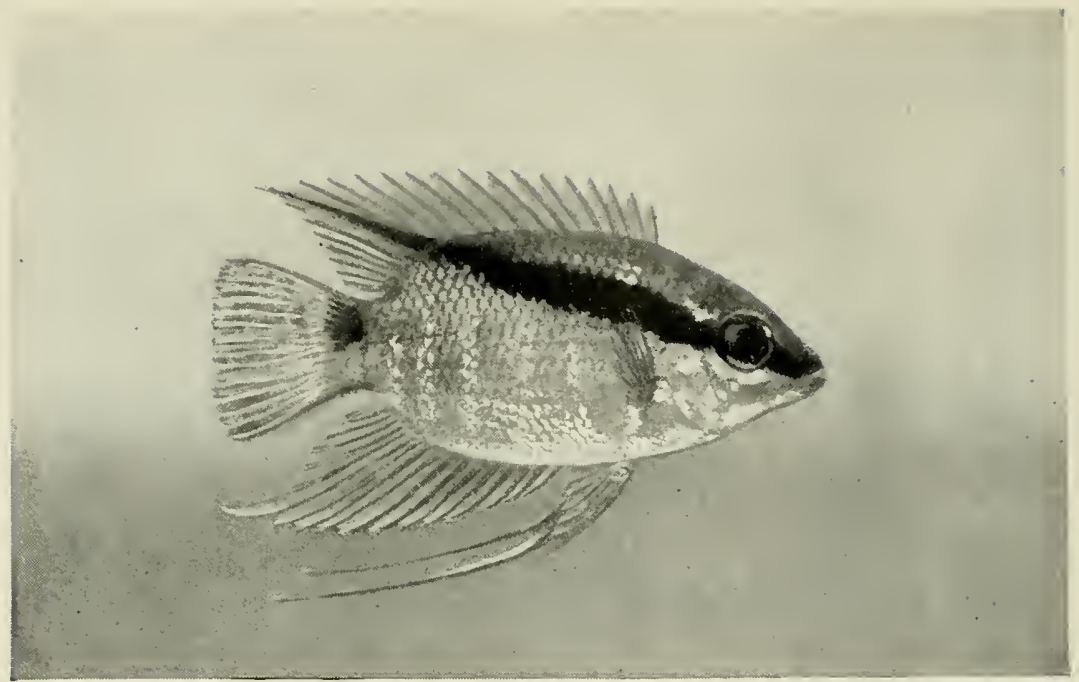

FIG. 254. Cichlasoma festivum (Slightly Reduced)

This beautiful fish from the Guianas is undoubtedly one of the most attractive of our many aquarium specimens. The background varies from brassy-yellow to silvery, sometimes crossed with faint vertical bars, but the strong, black, oblique characteristic bar is always present. Mesonauta festivum is rather delicate when young, but after reaching size shown in illustration it becomes more dependable. The "feelers," or extensions of the pectoral fins are not developed in the first year, but later become almost as pronounced as in Pterophyllum scalare. Although a cichlid, it is not war-like. Breeding habits, page 238 (No. 6).

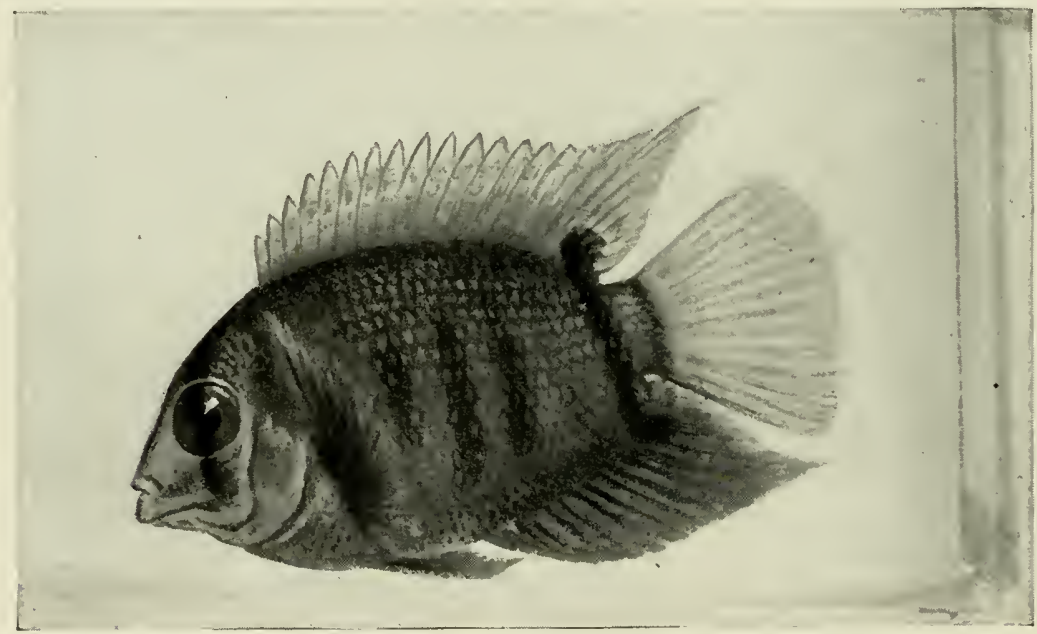

FIG. 255. Cichlasoma severum (Slightly reduced)

Generally known to aquarists as Heros spurius. One of the most beautiful and variable of the Cichlids. Color ranges from fleeting shades of yellow, orange, violet and green to dark green and black. When in one of its lighter dresses, the black bar from dorsal to ventral fins is extremely bold. Iris red, with trace of vertical black bar through it. Breeding habits, page 238 (No. 6). 


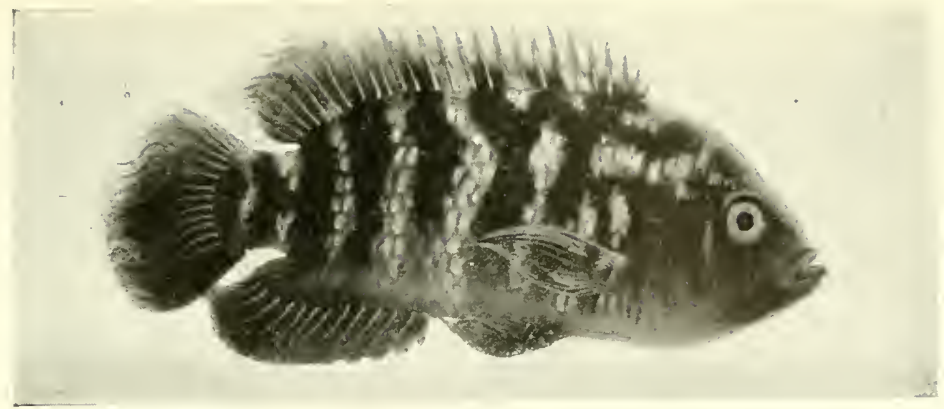

Fir, 250. Cichlasoma facetum or Chanchito (Hali size)

One of the most satisfactory of the Cichlid group of fishes. They will survive in moderately cool water and are not so savage as other members of the group. The breeding habits and family life of a mated pair are most interesting to watch. The upper figure shows the more rounded dorsal fin of the female. although it is not always so pronounced as shown here. Breeding habits, page 238 (No.6).

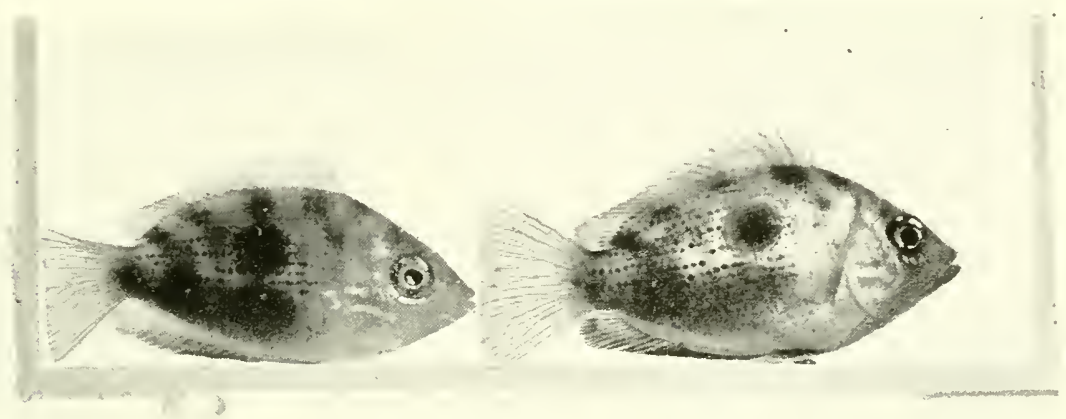

FIG. 257. Etroplus maculatus (Two-thirds size)

When we see the word maculutus in a scientitic name, it has reference to spots. Through the rapid color clianges of this species the large characteristic centre spot usually remains. Two others, one forward and one backward, sometimes appear. The fins are delicately dotted and edged with red and brown shades. This fish must be well cared for, especially as to continuous warmth. lut it is worth the effort. From India. Breeding habits, page 238 (No, 6).

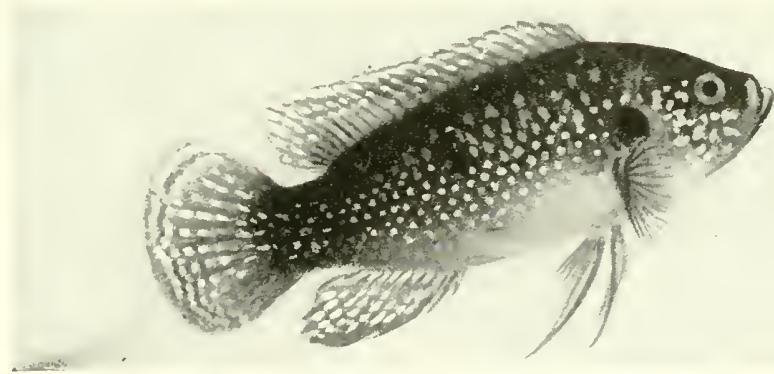

FIG. 258. Hemichromis bimaculatus or Jewel Fish (Three-fourths size)

Of the savage Cichlids, Hemichromis bimaculutus is the fiercest we know. Even small specimens cannot be safely kept together. If the fancier is fortunate enough to get a pair safely mated, he will be rewarded by seeing both fish develop the most gorgeous colors. Breeding habits, page 238 (No. 6). 


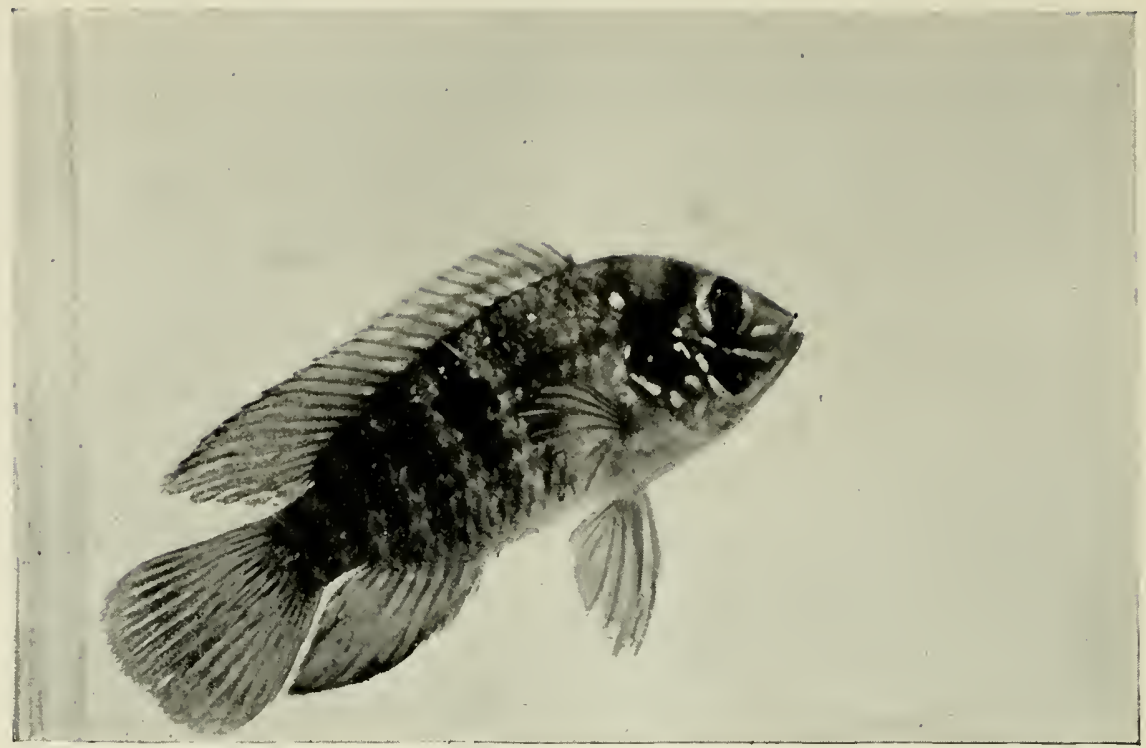

Fig. 259. Aquidens latifrons (Popularly known as Acara coeruleum punctata)

In general this fish has the characteristics of other members of the Cichlid group It is one of the later importations. Breeding habits, page 238 (No.6).

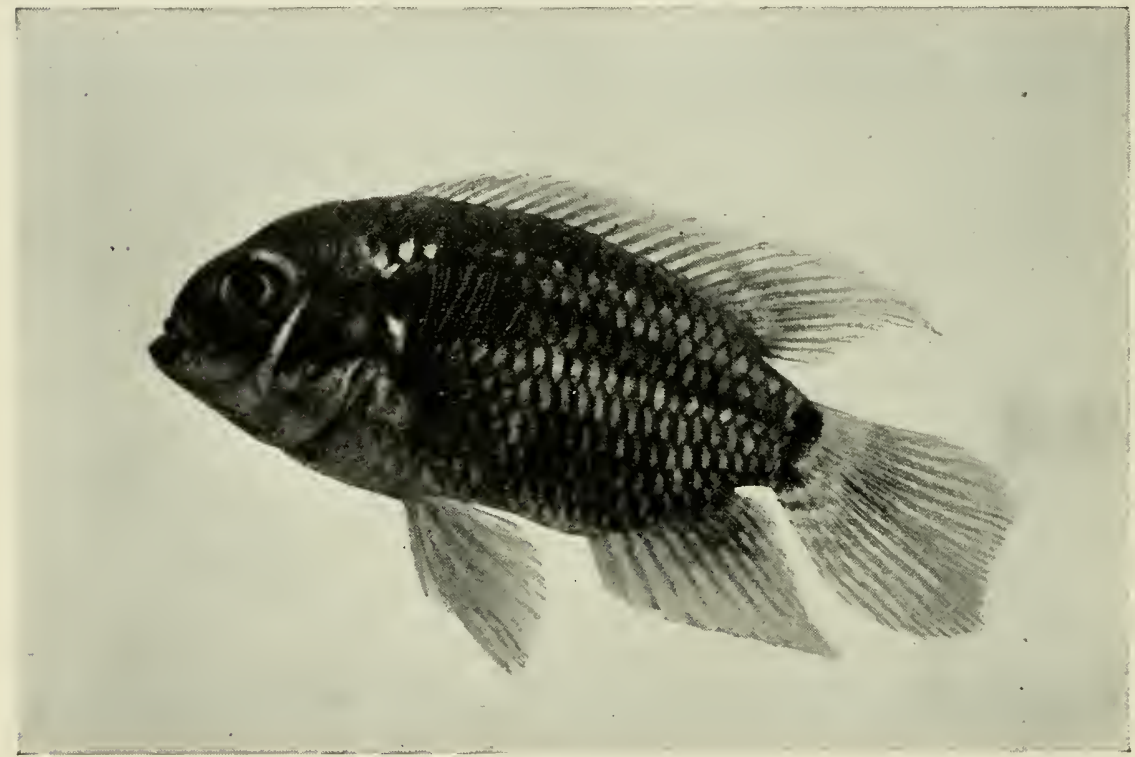

FIG. 260. Equidens portalegrensis

Although this fish is classed among the fighters, it is an exception to the rule and so far as has been observed it is a very peaceable citizen in the aquarium. Neither does it uproot plants, as do most of this strenuous family. Breeding habits, page 238 (No. 6). 


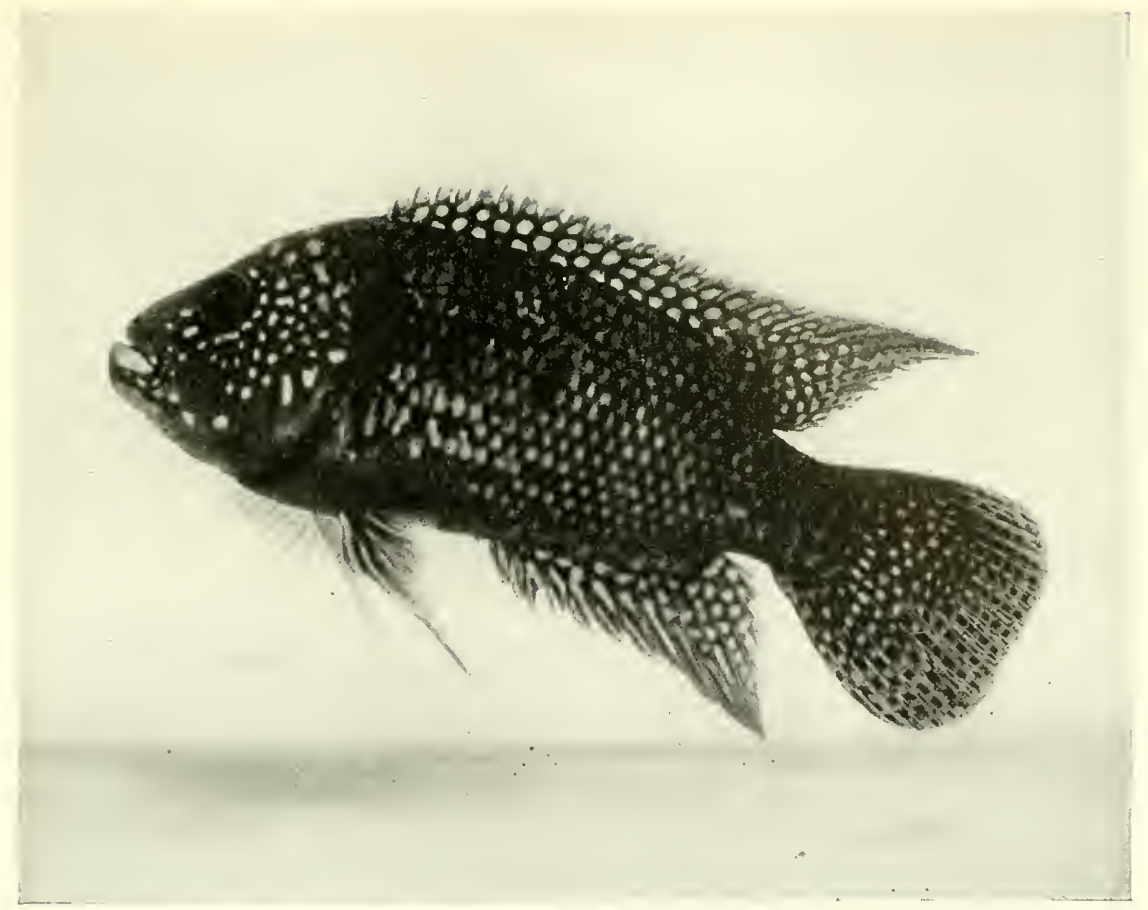

F1G. 261. Cichlasoma biocellat um or "Jack Dempsey"

A tish which varies greatly in color, according to temperature, excitement or state of health. At times the brilliant blue-green metallic spots disappear, the background color lightens and dark bars appear much the same as the normal markings of the Chanchito. When the fish is upwards of five years old the brilliant coloring becomes more permanent. This plate is made in slightly reduced size from a three-year-old specimen. Breeding habits, page 2.38 (No.6).

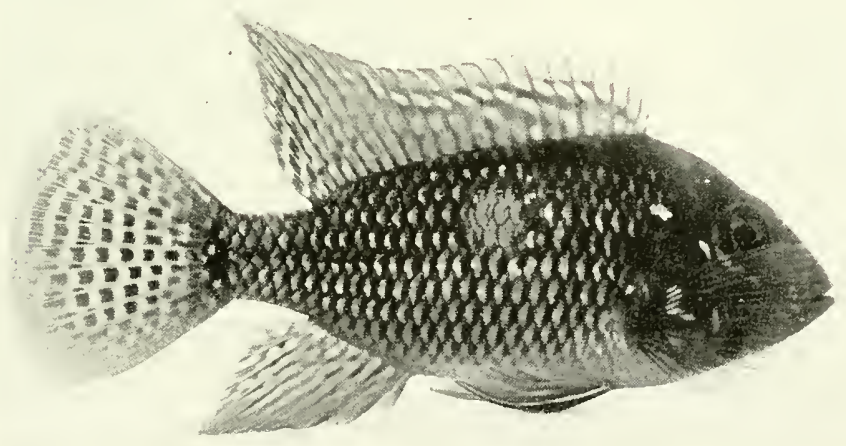

FIG. 262. Geophagus braziliensis

Not so well known as the foregoing, but somewhat different in coloring and at least as beautiful. Comments as to color changes and habits are the same. Breeding habits, page 238 (No. 6). 


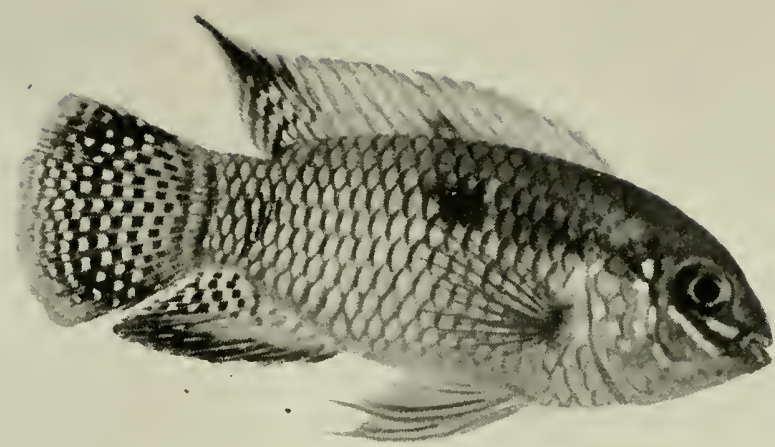

Fig. 263. Equidens curviceps (Incorrectly Acara thayeri)

This is one of the newer importations and bids fair to become popular. Breeding habits, page 238 (No.6).

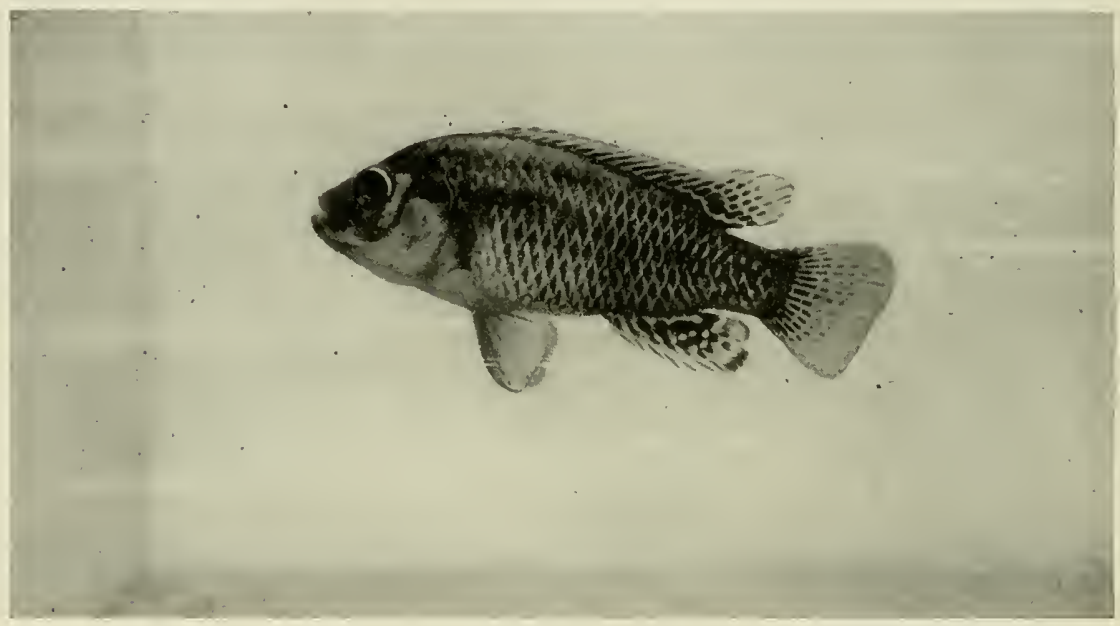

FIG. 264. Haplochromis multicolor, or Mouthbreeder (Life size)

There are many breeding methods among fishes which seem almost incredible to the novice, the Mouthbreeder being one of the most striking examples. After the eggs are fertilized the female fills her mouth with them, retains them until hatched, and carries the young about with her in the same way. During this period of several weeks she will touch no food herself, this being one of Nature's clever provisions so she will have no desire to swallow the eggs or young. Even if caught in a net, she tenaciously holds them. neither losing or swallowing any.

In addition to their interesting breeding habits, these fishes have attractive and very changeable markings. Further details of breeding on page 230 (No. 6a).

This fish and those shown in the eleven preceding illustrations are members of the Cichlid family, but the breeding habits are not the same. 


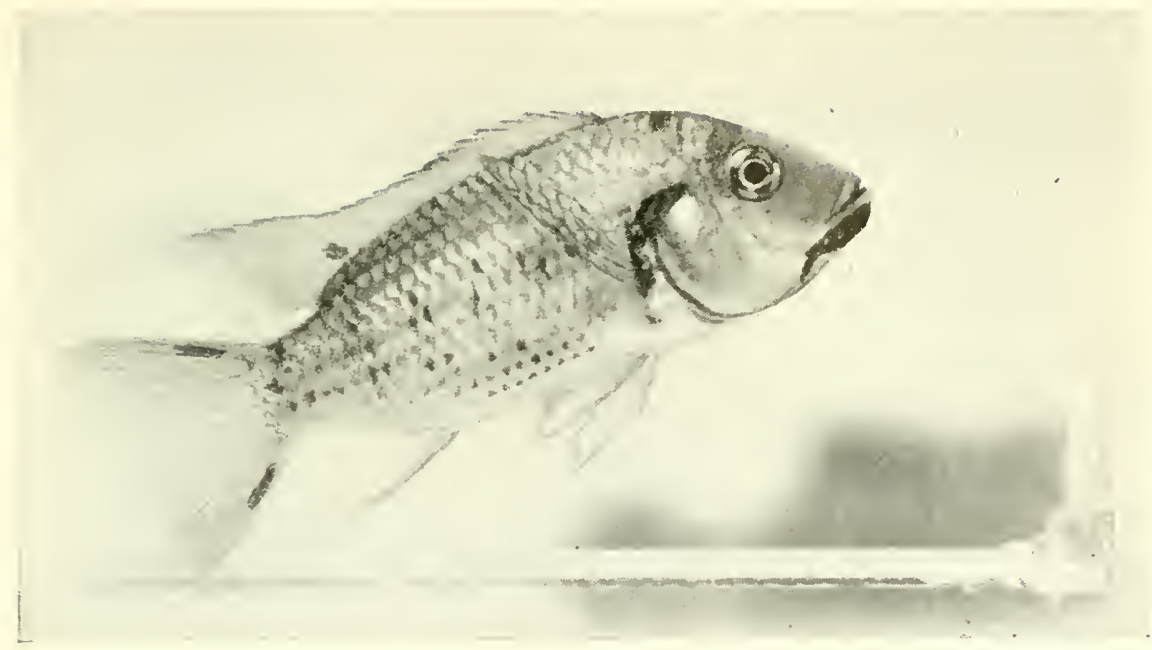

Fig. 205. Tilapia macrocephala

In this instance the male carries eggs and young in his mouth. If he is caught in a net, he is very likely to spit them all out. This does not mean they will not hatch. They may do so, but should be in clear, clean water. and be gently stirred several times daily. The eggs are very large, resembling mustard seed in size and color. Hatching takes about a wcek. The voung are mere threads attached to the egg, but in another two weeks they completely absorb the yolk-sac and become quite sizable fish. In adults the male has opaque gill plates. The female has a transparent pinkish area about where the hish light shows on the gill plate in the photograph.

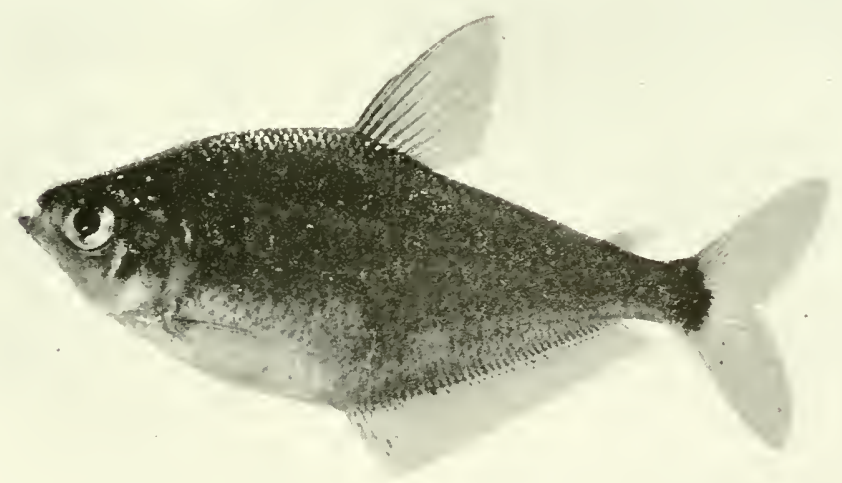

Fig. 260. Ctenobrycon spilurus

An attractive silvery fish which has taken a permanent place in the homes of tropical fish fanciers. Breeding habits same as Barbel group. pace 238 (No. 5). 


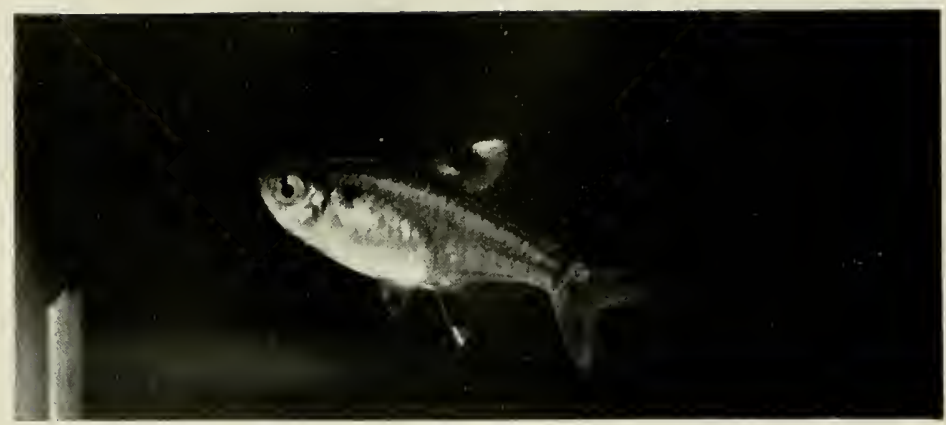

Fig. 267. Pristella riddlei (Slightly reduced)

Although not brightly colored, this little fish has many admirers. Milk-white spots on dorsal and anal fins, immediately adjoining intense black spots, make an outstanding effect, especially as the fish is very active. We do not often meet with opaque white in fins. Lower dot in dorsal is yellow; tail is reddish. From Venezuela and Guiana and the lower reaches of the Amazon. Breeding habits, page 238 (No. 5).

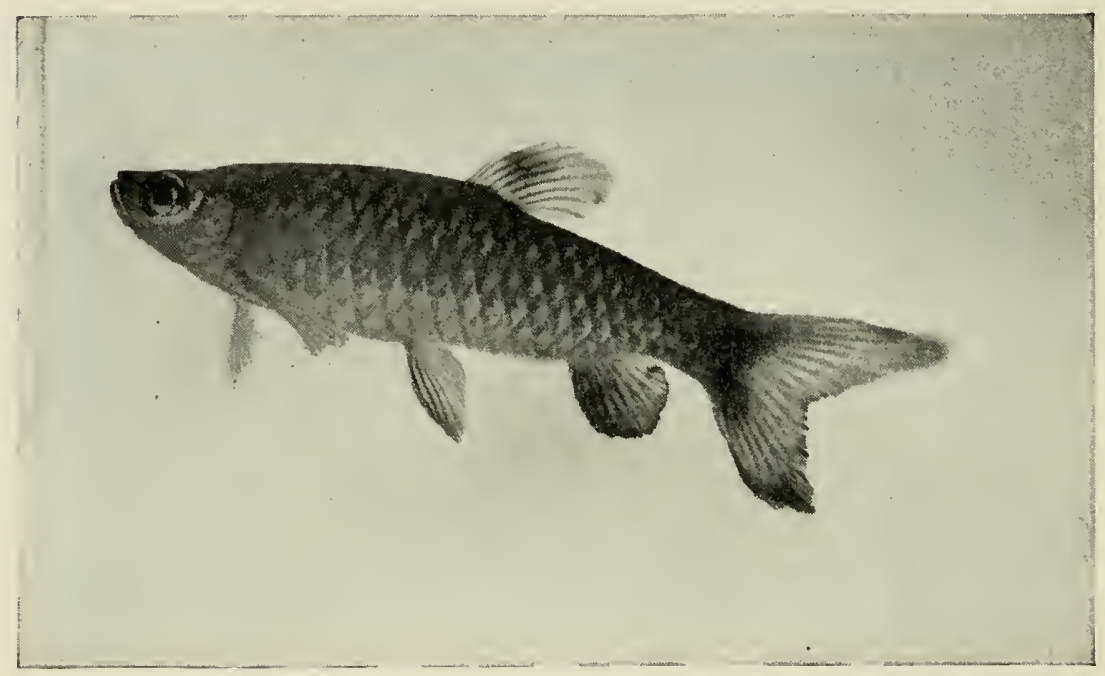

FIg. 268. Copeina guttata (Also known as Pyrrhulina guttata) [Life size]

An outstanding aquarium fish on account of its delicate lavender shade and some. what unusual fin formation. It is a suitable member for a "happy family" aquarium. Breeding habits, page 238 (No. 5). 


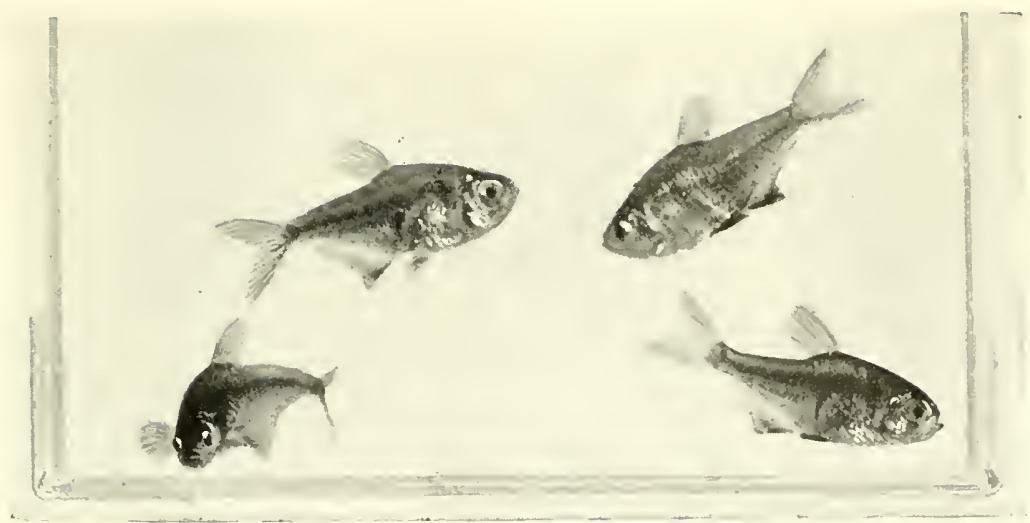

Fig. 209. Hyphessobrycon flammeus (Two-thirds size)

Our illustration falls far short of doing justice to this flaming little fellow. It should be shown in full color, which we hope to do later. The fore part of body is metallic green, shading off to red, while the fins are deep red. Known to some aquarists as Tetragonopterus from Rio, which is partially correct, for the fish comes from Rio de Janeiro. Breeding habits, page 238 (No. 5).

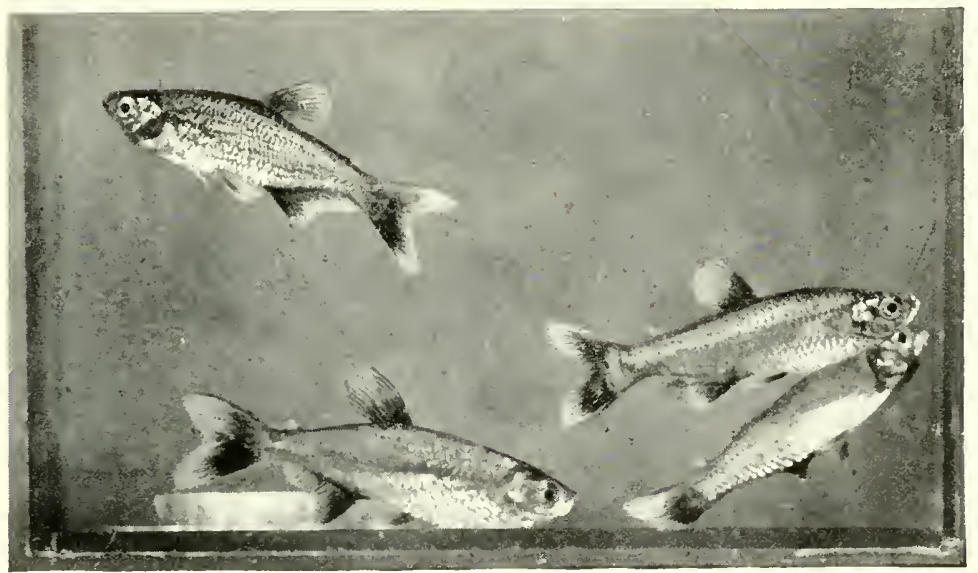

FIG. 270. Aphyocharax rubripinnis (Incorrectly Tetragonopterns rubropictus) [Slightly reduced]

The blood-red fins of this species attract instant attention. The body is greenish to silvery, making the contrast as strong as possible. Although this fish seems comfortable in the temperature of a tropical fish aquarium, it comes from a climate in Argentine comparable to that of our milder states, say like that of Virginia. At any rate it is capable of safely living in a temperature of about 60 degrees Fahrenheit, which is an advantage. A most charming aquarium fish. The sexes are distinguished somewhat peculiarly. The males have very small hooks on the anal fins. When the fish is lifted in a net of Brussels netting (the proper kind to use for all small fishes) the male fish sticks to the netting by these hooks and has to be shaken loose. Breeding habits, page 238 (No. 5). 


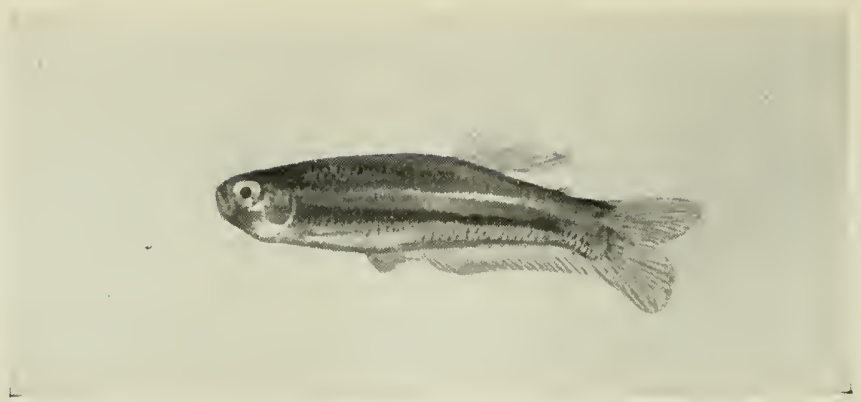

FIG. 271. Mimagoniates barberi (Slightly reduced)

One of the newer arrivals, and likely to be permanent, as it is quite attractive. The broal band down the body is deep blue. Fins orange to reddish. From Brazil and Paraguay. Breerling habits, page 238 (No. 5).

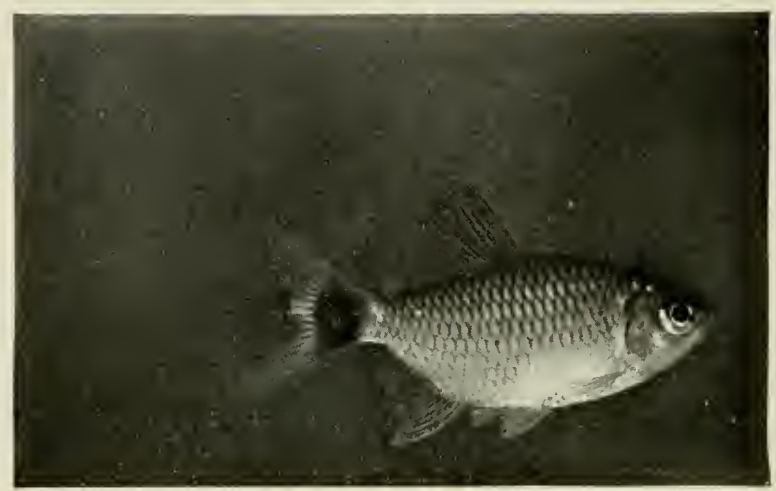

FIG. 272. Moenkhausia oligolepis (Half size)

One of the features of this fish is the fiery red of the upper half of the eye, contrasting with the subdued gray of the black-edged scales. It is a fish that stands out as being different. In the adult size it is fairly large, as tropical aquarium fishes go, and when fully grown the black spot in the caudal fin (tail) is less apparent. From Brazil. Fairly gentle disposition. Breeding habits, page 238 (No. 5).

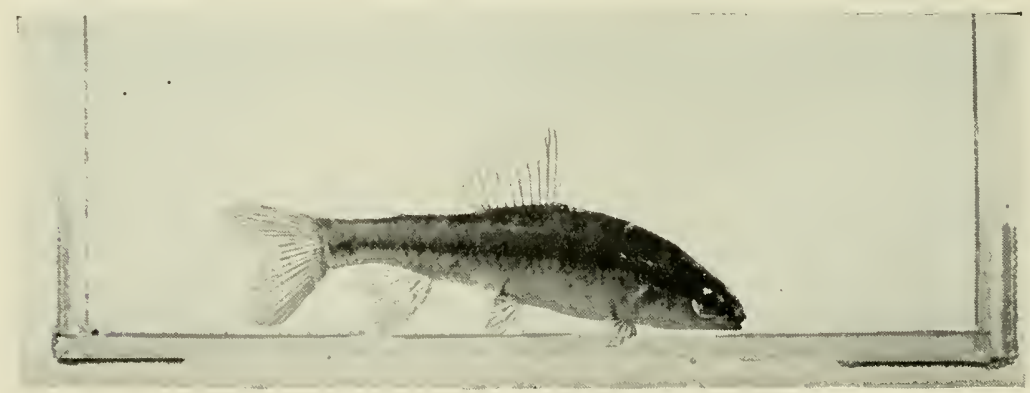

FIG. 273. Characidium rachovi (Slightly reduced)

An importation from southeastern Brazil. Anal and caudal yellowish. Otherwise fins are clear. Black line from mouth to tail, and is carried through the eye. Breeding habits, page 238 (No. 5). 


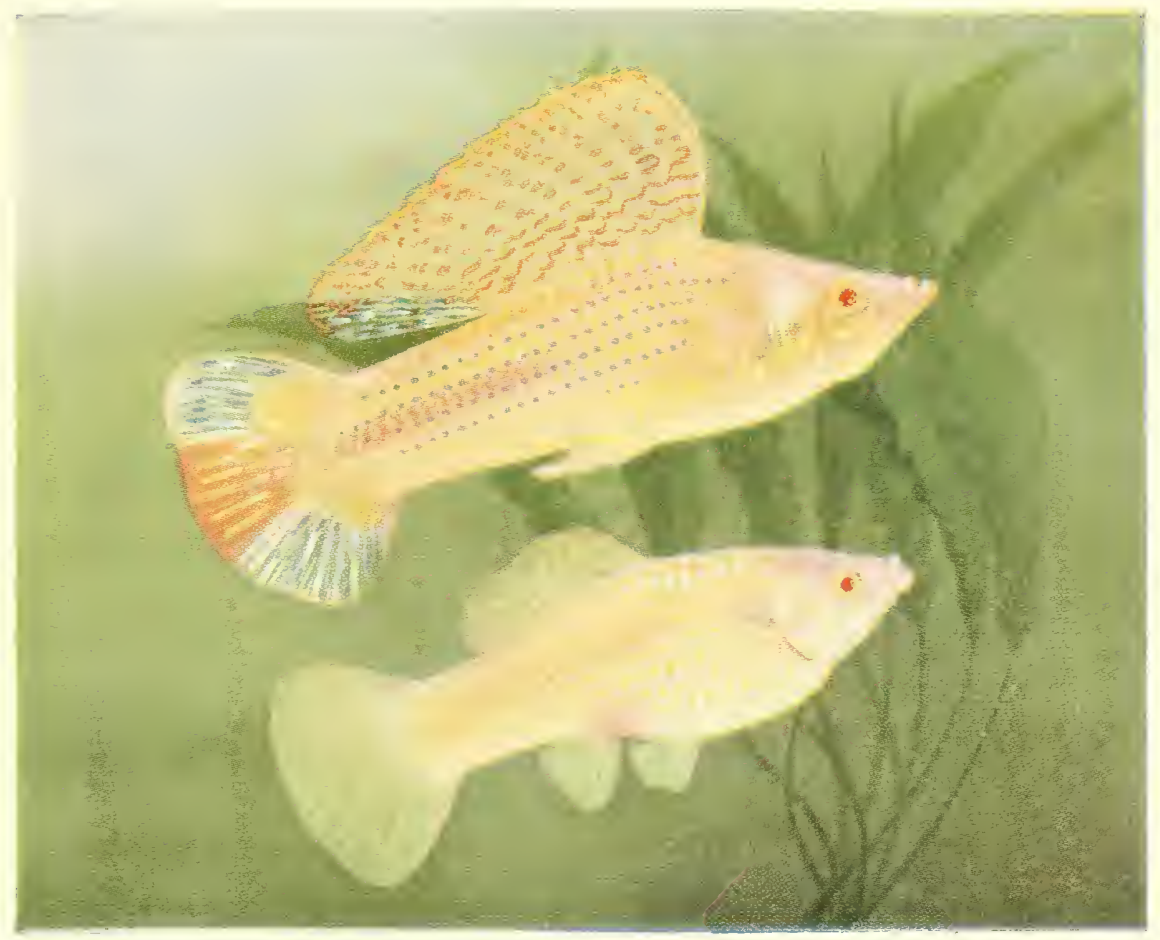

FIG, 235a. Hollienistu latipinna Golden Blond lariety

One of the comparatively new introductions into the aquarium, the Golden Blond Mollienisia soon established itself favorably among aquarists who are not constitutionally opposed to albinos of all sorts, for it must be said that this hish is a genuine pink-eyed variety. The breed was produced by selective breeding from a single albino specimen which was caught in the wild. The strain is now definitely established, and breeds true to color. 



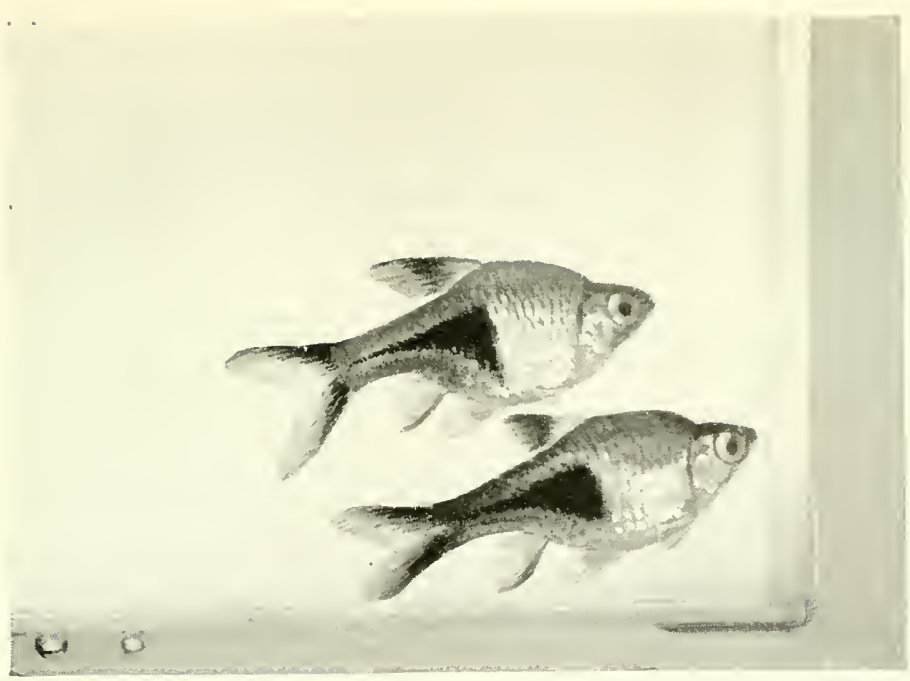

Fig. 274. Rasbora heteromorpha (Slightly enlarged)

Of a light reddish color, with a vivid triangle of blue-black on the side, this fish is most striking in appearance, particularly in a small aquarium. It lives for years if kept at a warm temperature, but it is difficult to breed, few in the United States having yet succeeded in propacrating them. Here is an opportunity for a clever aquarist to accomplish something well worth while. See page 240 (No. 8).

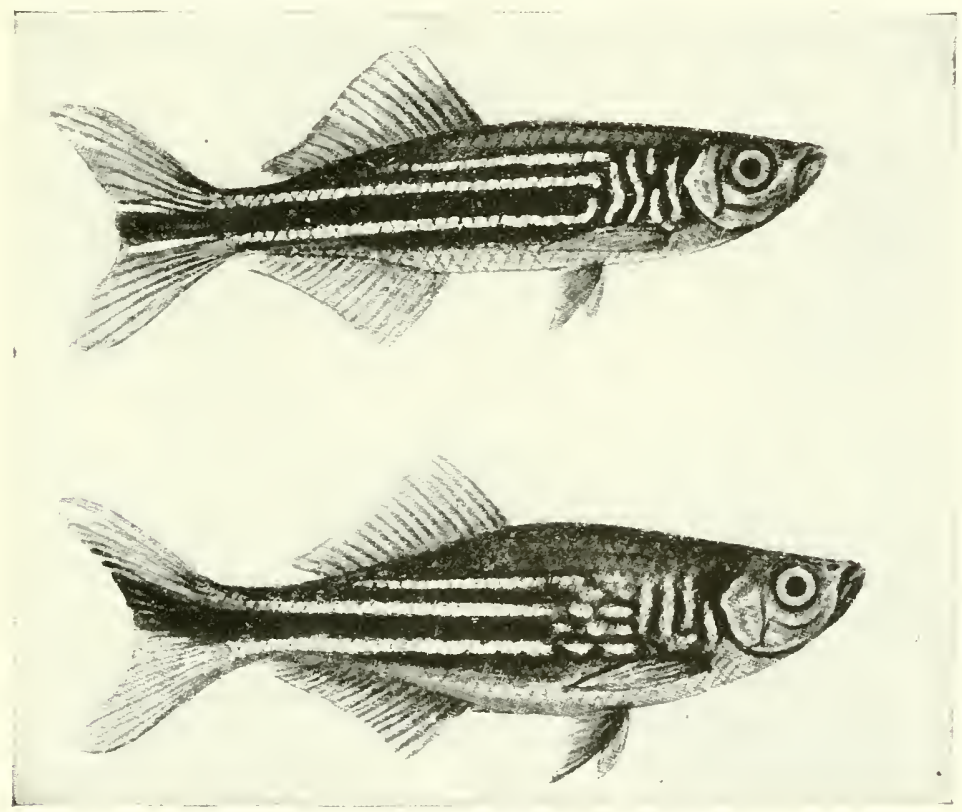

FIG. 275. Danio malabaricus (Life size)

In life the colors are not so strikingly marked as shown above. The darker parts are a delightful opalescent color verging towards blue, and must be seen by reflected light to be fully appreciated. The fins are shaded with reddish brown. The males are distinguished by the dark line running straight through the tail, while in the female it takes a sligh upward turn. Breeding habits, page 240 (No. S). 


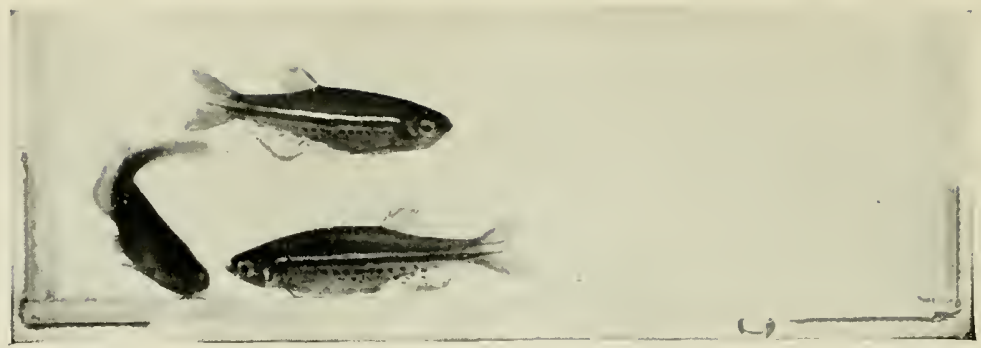

Fig. 270. Brachydanio nigrofasciatus

Slightly smaller than rerio and not quite so brilliant. Below the two lateral stripes is a line of dark dots. Although the life habits are the same as rerio, it is more difficult to propagate. They are found in Burma.

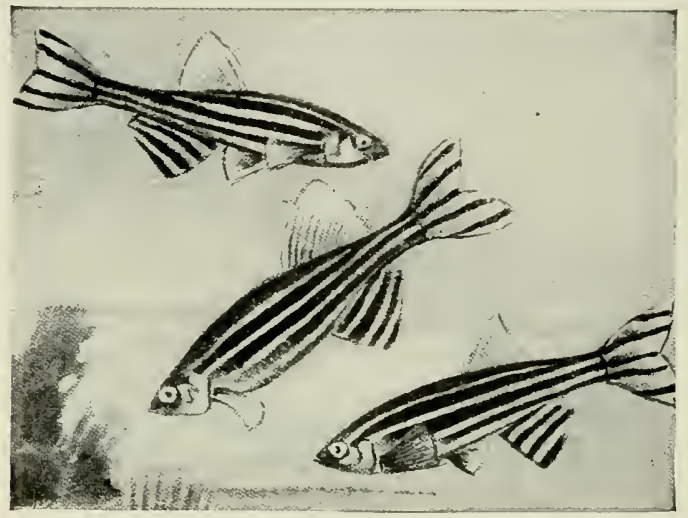

FIG. 277. Brachydanio rerio (Known as Danio rerio) [Life size]

A moderate-sized aquarium, containing a number of Brachydanio rerios in a good light, makes a beautiful picture. Their steel-blue stripes, alternating with white and carried through the fins, give a brilliant effect as the fish play through the water, never still a moment. The males have a slight yellowish cast in the lighter portion of the fins during the breeding season. Easily bred. See page 240 (No. 8).

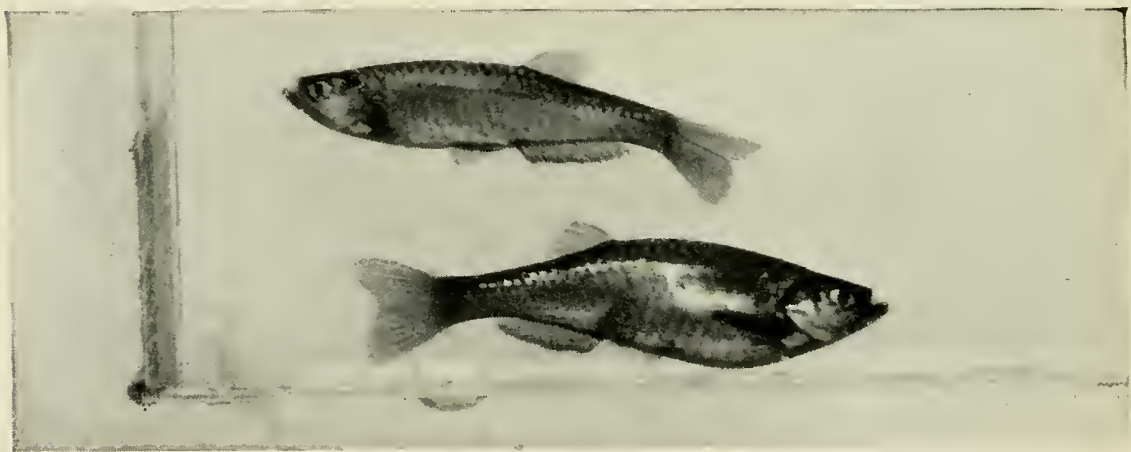

FIG. 278. Brachydanio albolineatus (Popularly known as Danio albolineatus)

This is a beautiful small fish of a pearly, warm iridescent nue. They have not been bred in this country in large numbers. Breeding habits, page 240 (No. 8). 


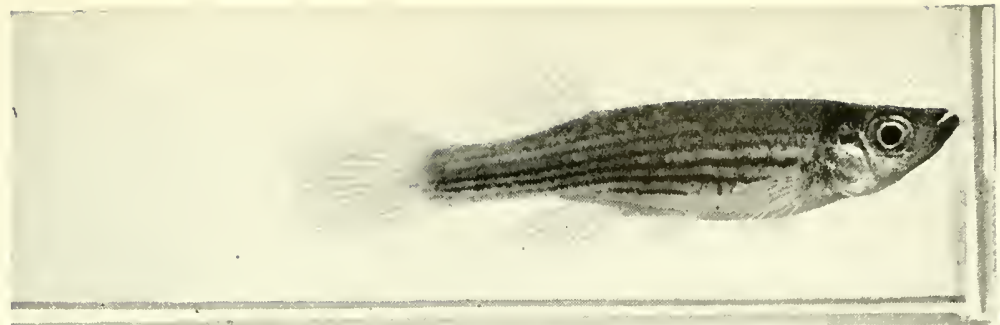

Fic. 279. Fundulus nottii (Male) [Life size]

As stated in the text, some of our desirable tropical fishes come from our own country. The subject of the illustration is a good example, the fish being native to the southeastern states. It is highly regarded by foreign aquarists as it well should be, for it is handsome, hardy and gentle. Breeding habits, page 240 (No. 8).

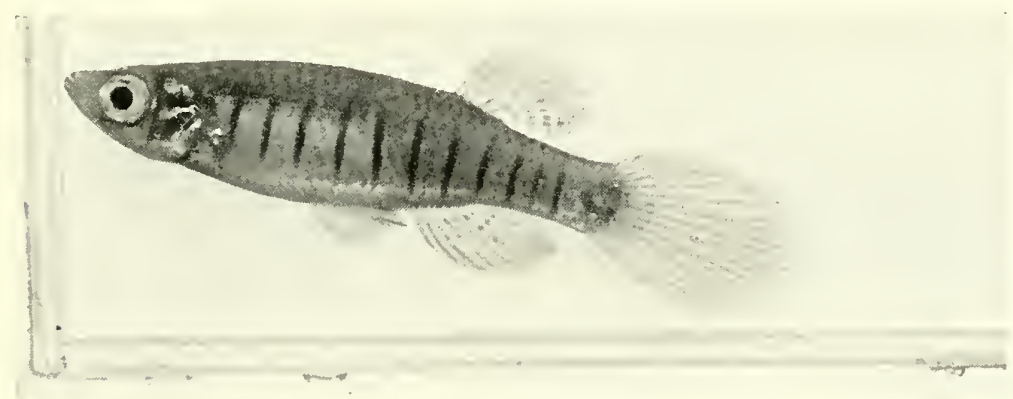

FIG. 280. Fundulus nottii (Female) [Lifp sizp]

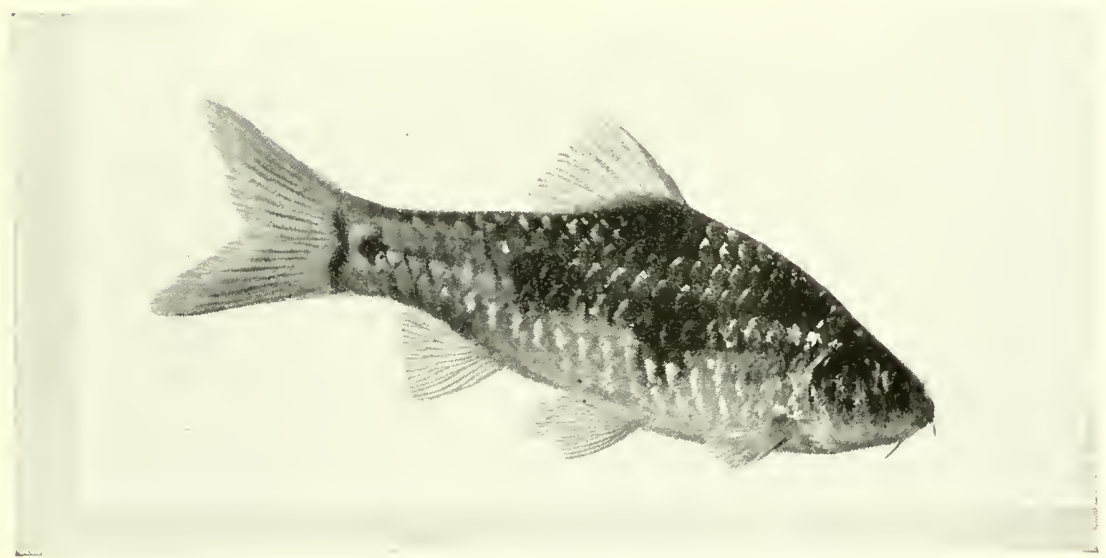

FIg 281 Barbus everetti (Slightly Reduced)

Owing to the large bluish spots on this fish, it might be described as one of the clowns of the aquarium, although its movements are rather sedate. As aquarium "barbs" go, this is quite large in size. Illustration shows the "whiskers" nearly always present in this extensive group of fishes. Lateristriga is none too hardy but is otherwise very desirable. From Sumatra, Java, Borneo and vicinity. Breeding habits, page 240 (No. 8). 


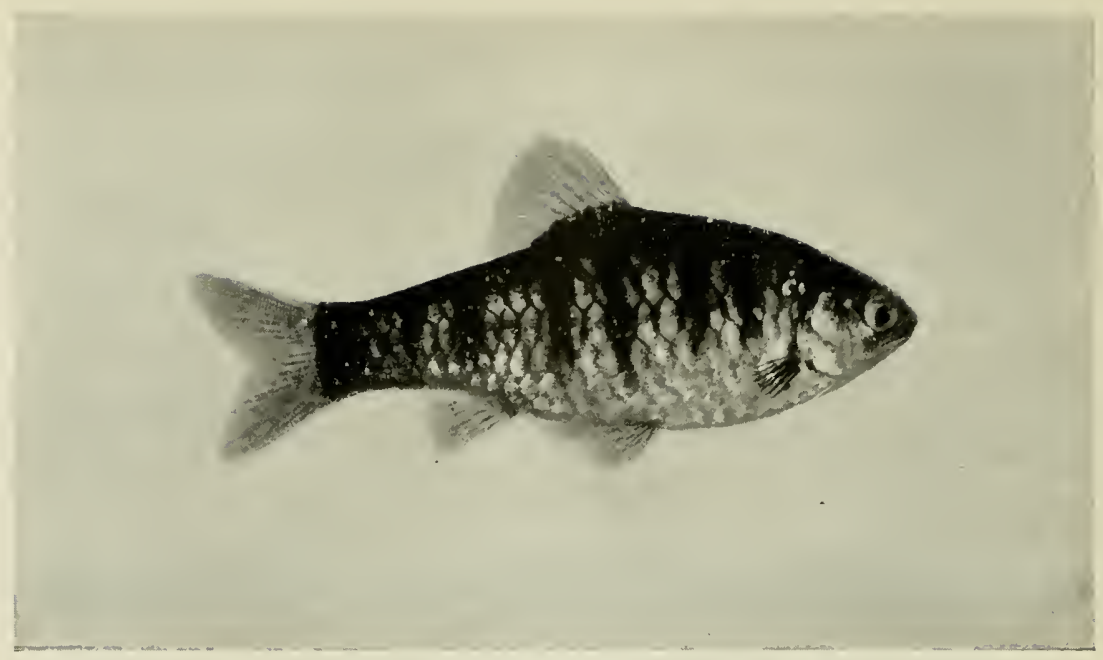

FIG. 282. Barbus semifasciolatus (Full size)

The small Barbs are excellent aquarium fishes. They are usually of a warm silver color, marked with black bars or dots. Yery gentle in disposition and thoroughly hardy in moderate temperatures. See page 240 (No. 8).

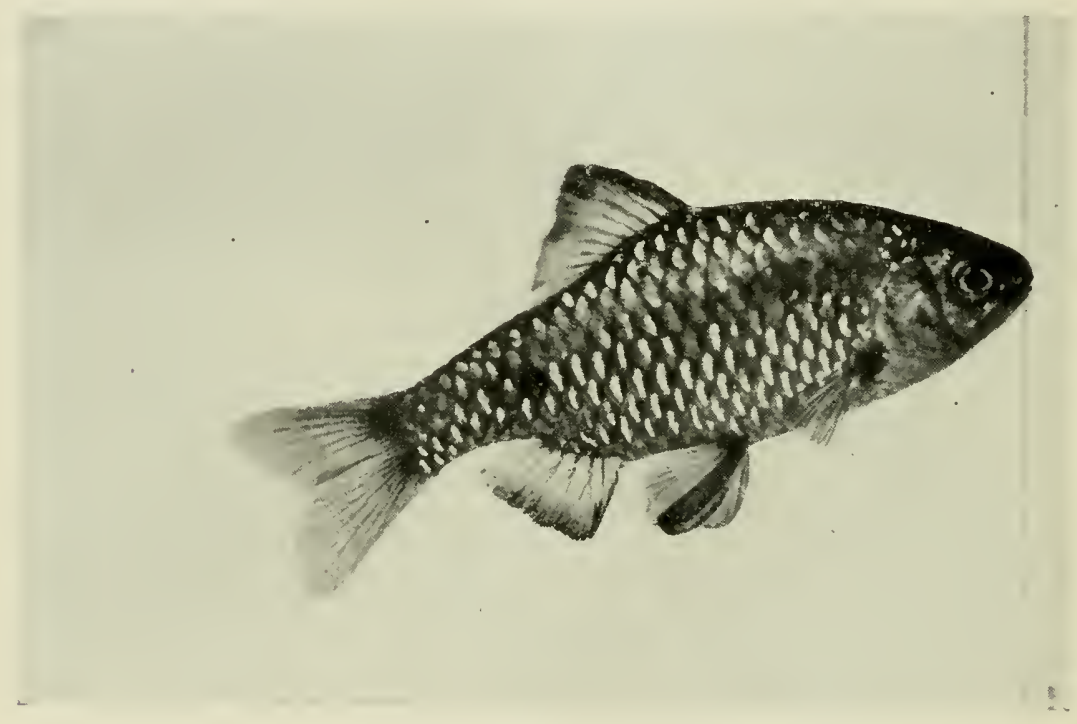

FIG. 283. Barbus conchonius

One of the most satisfactory of the Barbs. They are of a metallic, glistening appearance, very brilliant in the aquarium and in the breeding season the males are gorgeously suffused with a warm shade of pink. See page 240 (No. ช). 


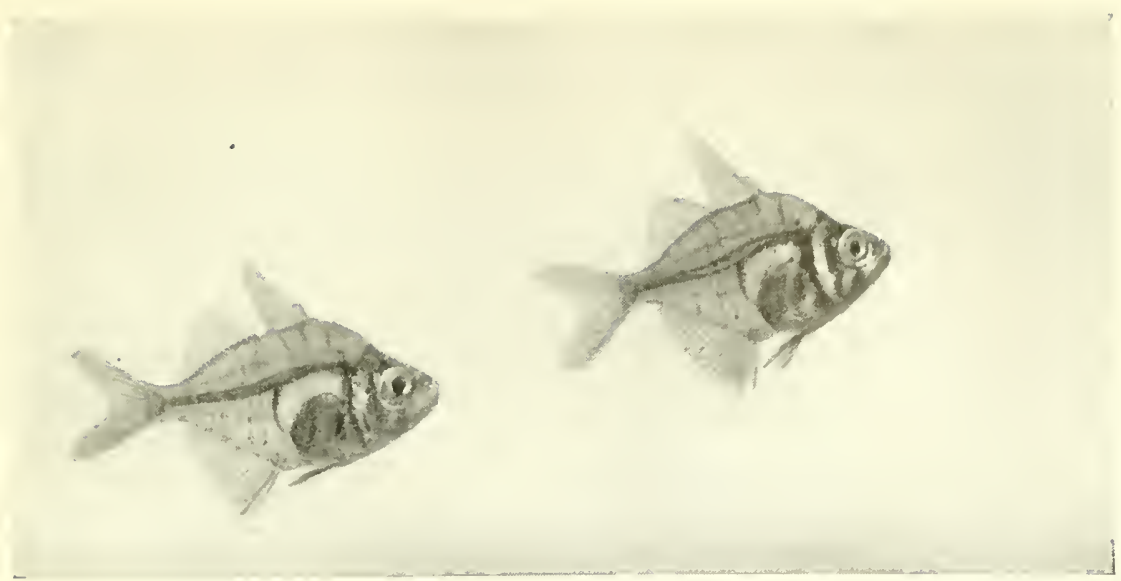

FIG. 2St. Ambassis liala or Glasshish (Slightly Reduced)

These interesting little fishes from India are so nearly transparent that most of the skeleton and "inner works" are plainly visible either by transmitted or direct light. The spinal column, air bladder and ribs are shown in the photograph. The fish is very flat. It is almost without color, except for a faint yellowish tinge, darker in the males than the females. Fins on males are delicately edged green. Although extremely delicate in appearance, this fish does fairly well in the aquarium, provided it is kept warm and fed on live daphnia or white worms. Certainly it is one of the most delightful aquarium novelties we have, and likely to remain in the select class for some time, as we have not mastered the breeding of this species. What little we know is on page 237 (No. 1).

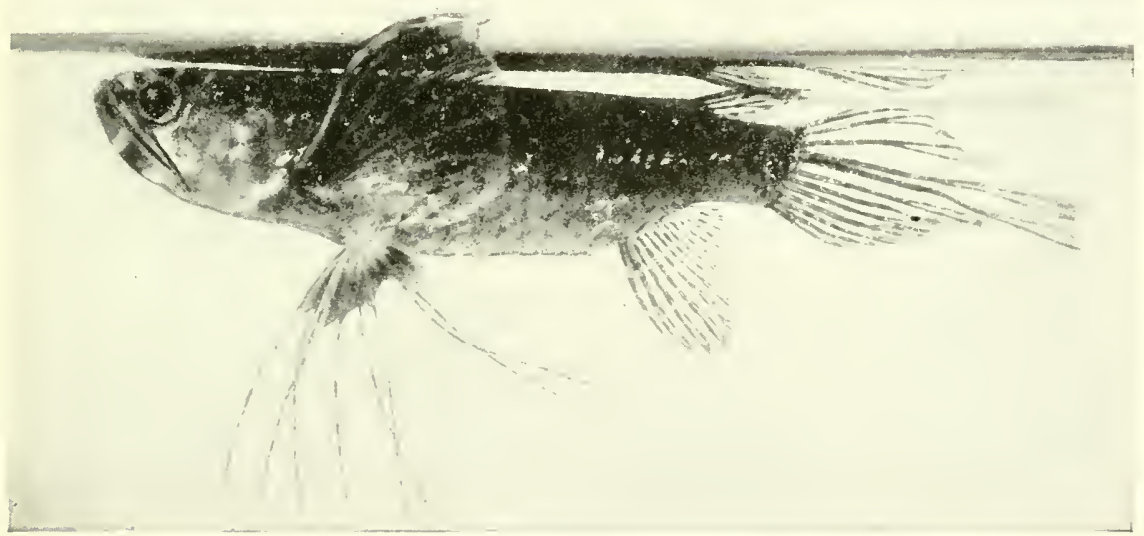

F1G. 285. Butterfly Fish (Pantodon buchholai) [Life size]

(Also Freshwater Flying Fish)

Although the Butterfly Fish has been with us quite some years, it has never beer. plentiful and we have heard of no records of its having been bred. It is the habit of these fishes to lie idly at the top of the water ready to pounce upon their prey, consisting of insects or anything that moves and which it is capable of swallowing. The mouth is enormous in proportion to the size of the fish. The fish's capacity for eating large victims is quite considerable. The most practical food for them in captivity is earth worms, which they soon learn to take from the fingers. From Congo and vicinity.

The fish is a great jumper and is said to be able to leap several feet. Aquaria containing Butterfy Fish should be tightly covered. Breeding habits, page $2+1$ (No, 16). 


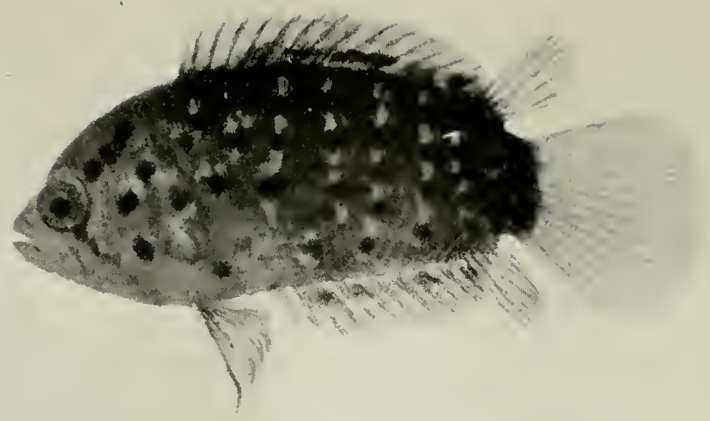

FIG. 286. Polycentrus schomburgki (Life size)

Although this interesting fish has been bred rather freely at times, it has so far remained in the select class and is only occasionally obtainable. Prefers live diet, but will eat the patent food, "Kennel Rations." Breeding habits, page 243 (No. 19).

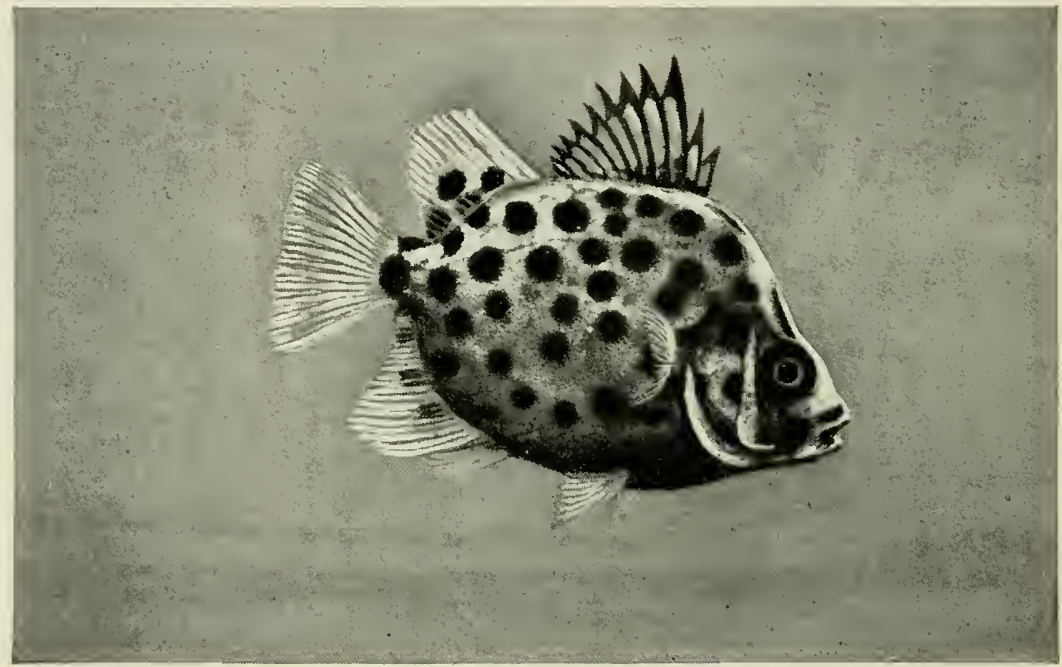

FIG. 287. Scatophagus argus (Aquarium size)

In a lithe fish with long fins we expect speed, and in a "dumpy" specimen with short fins we look for slowness of movement. It oftens works out in reverse. Uur present subject is a case in point. This odd-looking species is very active and quick of movement, especially in aggressively chasing those of its own kind.

The brilliant black or greenish dots are variable as to number, the background being a pale, metallic green. In others the dots are replaced by vertical or oblique bars of a brownish color. These are believed to be males. Little is known of their breeding habits. They are really marine fishes and not much can be expected of breeding them in the aquarium. They are not often obtainable, and are considered to be among the "first families" in the tropical aquarium.

Although they can live in fresh water, best results are had by keeping them in about one part of sea water and three parts fresh. As water evaporates, add only fresh. 


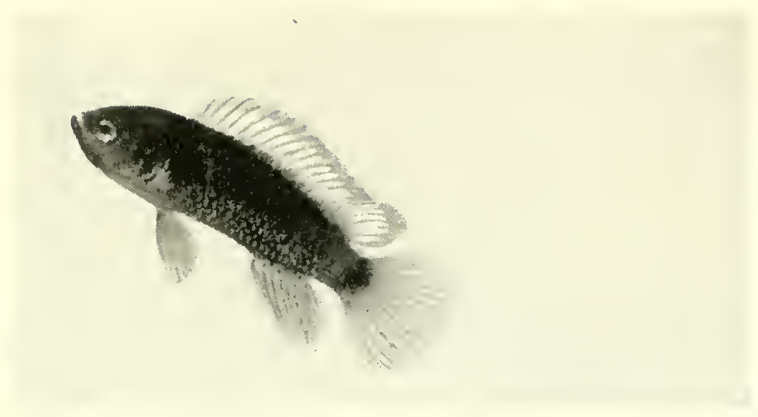

FIG. 288. Badis badis (Half size)

Although without striking coloration, Badis badis has long been a popular aquarium fish. Color purplish to bluish black with belly lighter. A carnivorous fish from India. Breeding habits, page $2+1$ (No. 14).

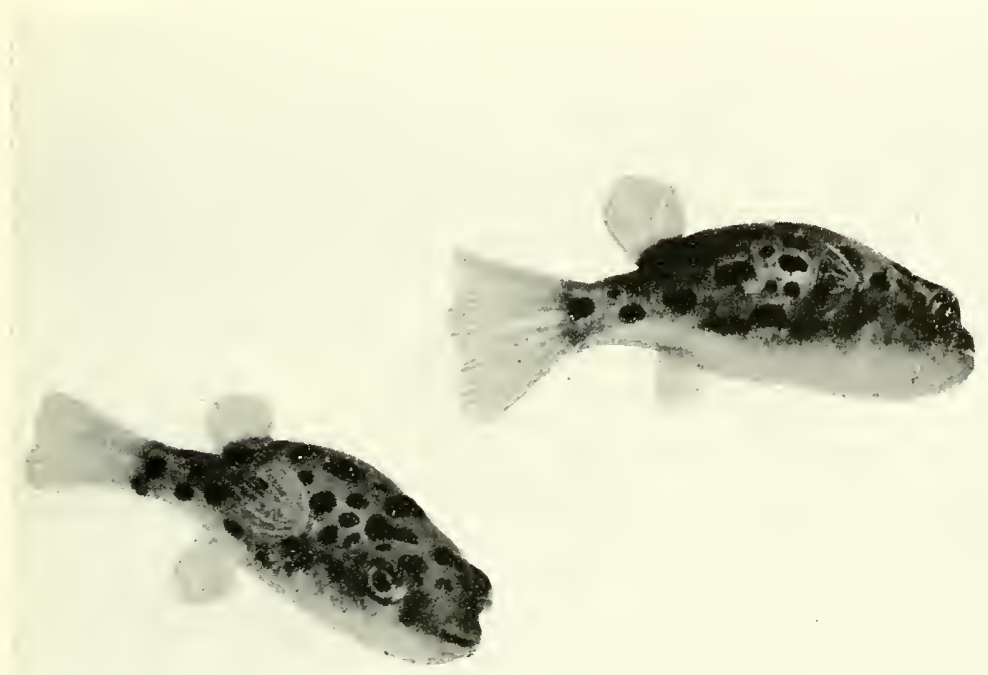

FIG. 289. Tetraodon fluviatilis (Life Size)

A strange little fish from India. It reminds one somewhat of the "Box Fish" which we see in the large city aquaria. They are very broad and although the body seems rigid, the fins and tails work with great vigor and the ish is never still an instant. The lower part of the body is white and the upper part is suffused with green, dotted over with large black spots. This fish is full of fight and not well suited to be in an aquarium with other fishes. Breeding habits, unknown. 


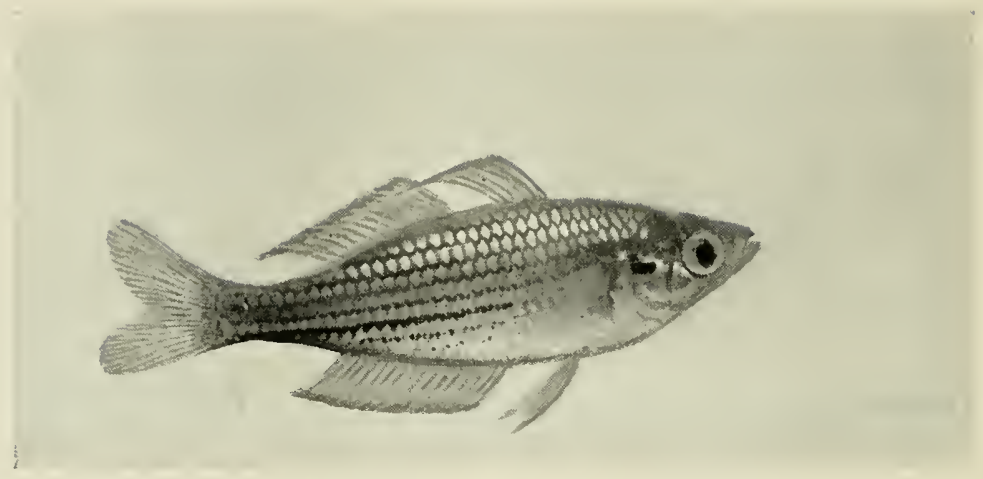

FIG. 290. Melanotaenia nigrans (Slightly reduced)

Recently imported from Australia and popularly known as the Australian Rainbou Fish. We predict a permanent place for this beautiful species. The general color is golden with stripes of brown, blue and red. Bright red spot on opercle (gill cover). Easily bred in large open warm pools or tanks. For a fish not coming from the tropics its period of incubation is short, being only about 54 hours at a temperature of 76 tegrees.

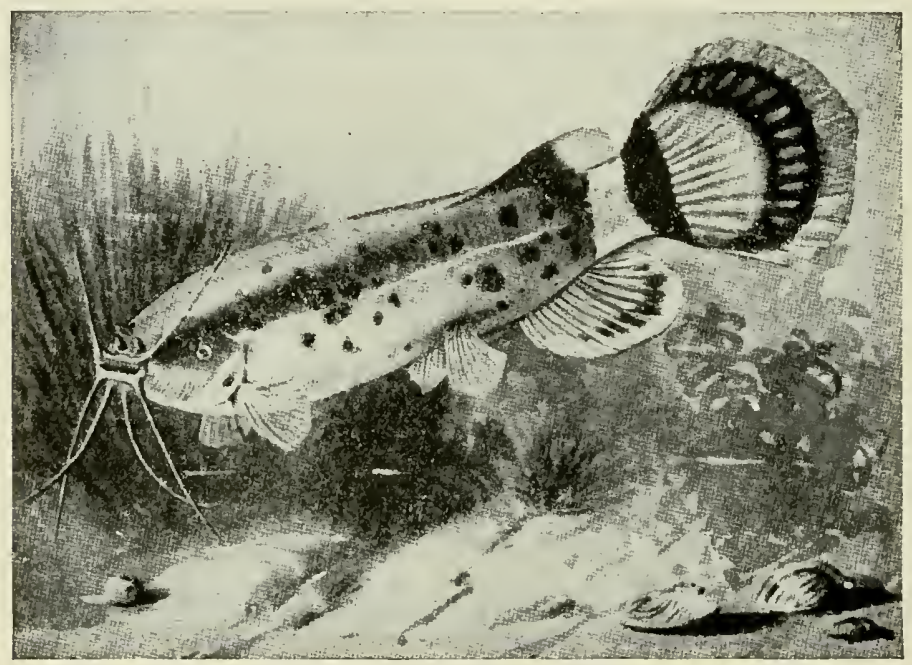

Fig. 291. Malapterurus electricus (Electric Catfish)

This most curious aquarium fish, when taken in hand, gives an electric shock whick may clearly be felt as high as the elbow. How this is accomplished is not clearly understood, as it is supposed to be necessary to touch two electric poles to receive a current. If the head and tail of the fish were the poles, the current would only pass from one part of the hand to the other, instead of up the arm. The fish is able to cause the shock either in or out of the water. This is doubtless a means of self-defense, as the current is scarcely strong enough to kill a victim intended for food. Breeding habits unknown. 


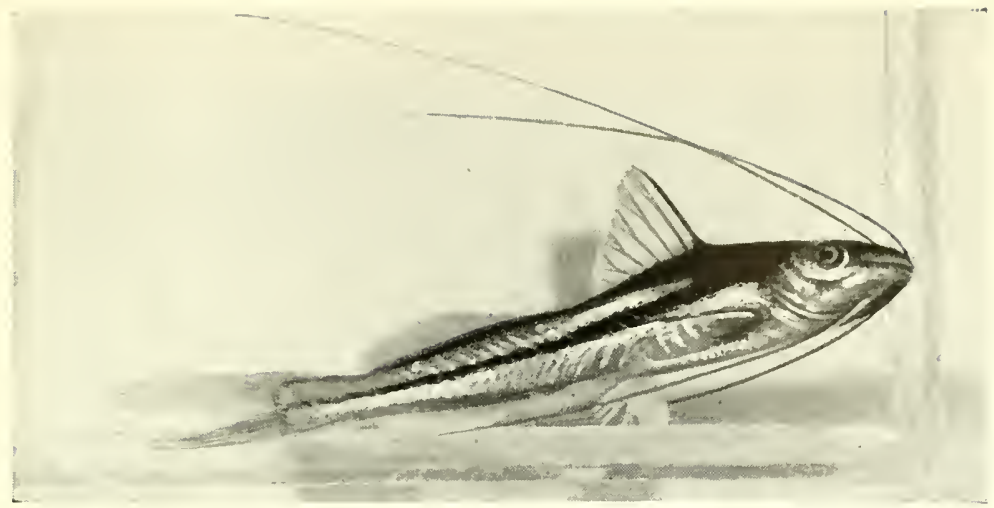

FIG. 292. Pimelodella gracilis (Slightly reduced)

One of the many small tropical catfishes from northern South America. There are three pairs of barbels, or "whiskers," two pairs of which are extremely long. The fish is an artive one, and, as it swims about the aquarium, the black line against silvery sides produces a striking and pleasing effect. Like other catfishes, it is easily fed. Breeding habits unknown.

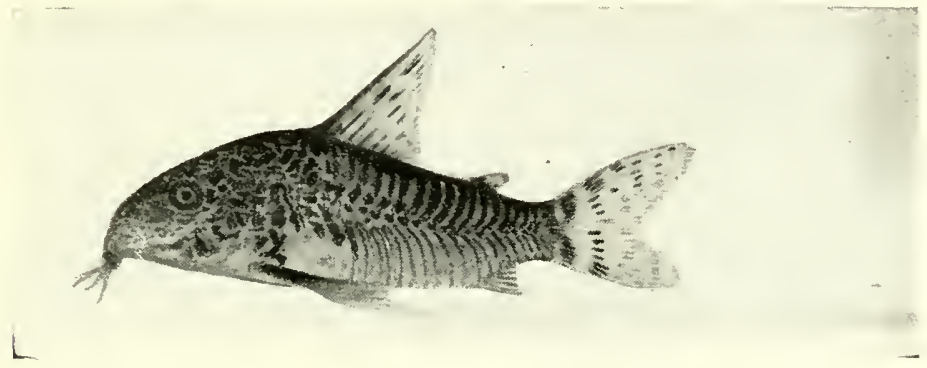

FIG. 293. Corydoras undulatus or Armored Catrish (Life size)

Sometimes known to aquarists as Callichthys. There are many species closely resembling this photograph, and they all come from northern South America.

Corydoras is a quaint little fish and very well adapted to life in the aquarium. Principally a ground-feeder, it is regarded as something of an aquarium scavenger Quite harmless. Breeding habits, page 237 (No. 3).

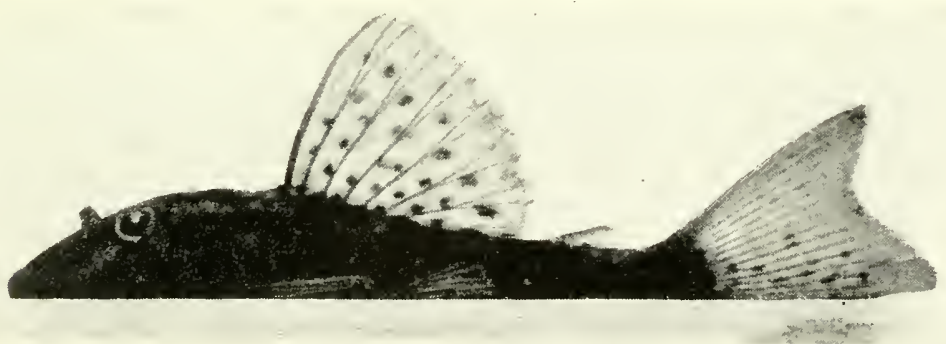

FIG. 294. Hy'postomus species

One of the oddities from South America, the fish tenaciously holding on to the bottom or sides of the aquarium by suction of the mouth and lower part of the body. Specimens so far imported have lived a long time but have not yet been bred. Catfish family. 


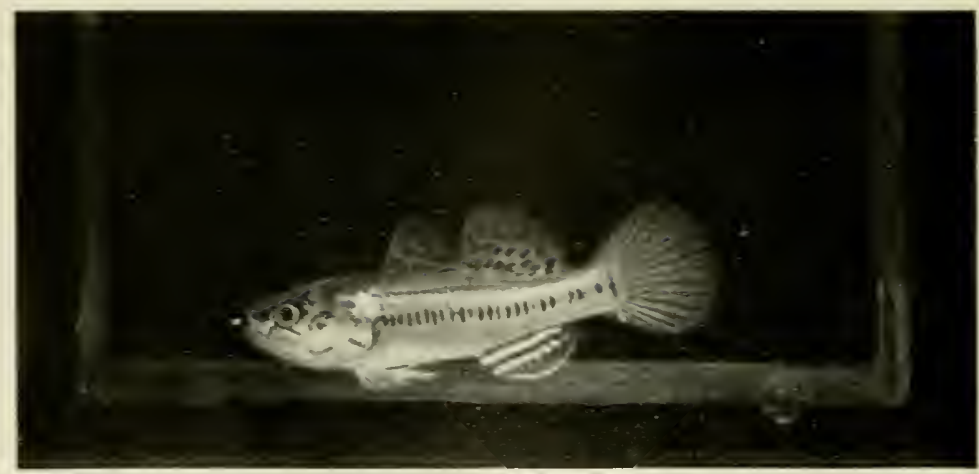

FIG. 295. Dormitator maculatus (Aquarium size)

In the West Indies, southeastern United States and northern South America whers this ish is found rather freely, it attains a size of ten inches. It is rather sluggish, spending much time on the bottom of the aquarium. I blue spot above the gill edye, white dots in fins and the line of dark vertical dots down the side are pleasing characteristics. It belongs to the Gobi family and little is known of the breeding habits.

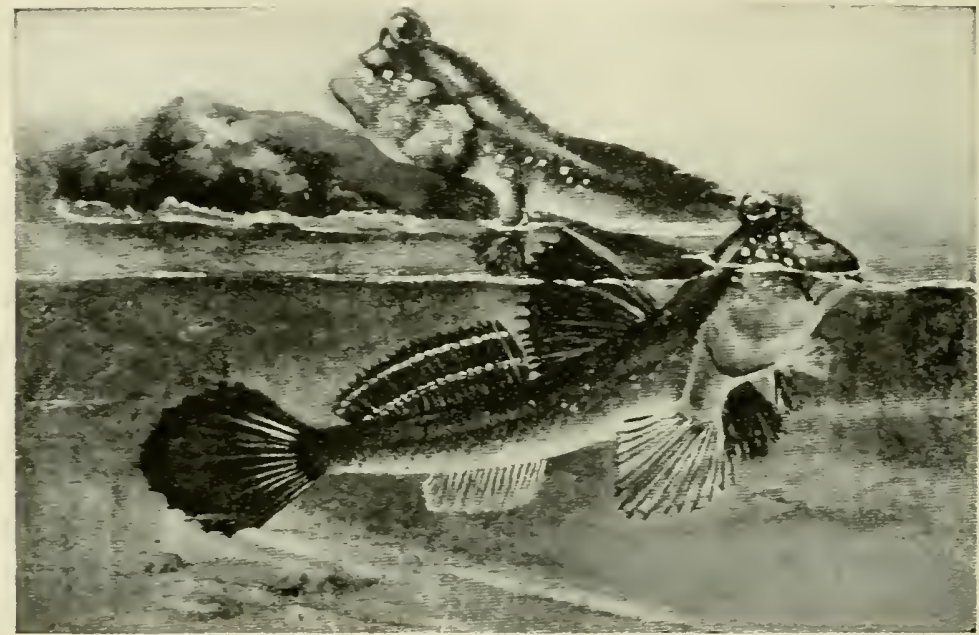

FIG. 200. Euchoristopus barbarus (Incorrectly listed in dealers" catalogs as

Periophthalmus koelreuteri (Popular names, "Mud Springer" and "Stone Skipper") ( $T$ wo-thirds life size)

This is one of the most remarkable of fishes and seems to form a connecting link between aquatic and amphibious animals. As the tide recedes, these little fellows make no effort to follow it, but instead come out on the mud flats. stones, and even climb sma!! bushes in search of insect prey, which they are adepts at catching "on the wing". The pectoral fins, nearly developed into legs, are used in vigorous leaping. See page 240 (.No. 10). 


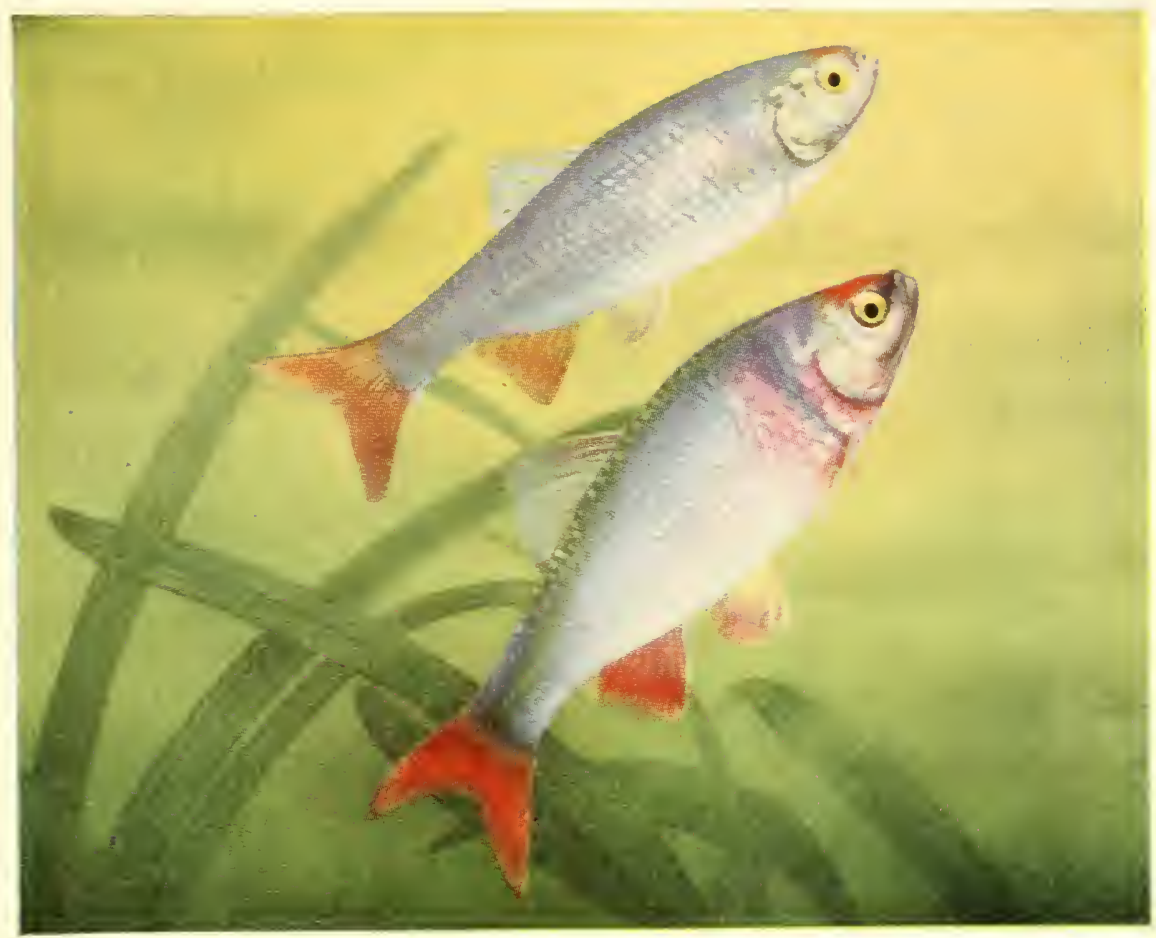

Fic. 2003 Yitepi, Lutrensis. Baird and Girard

As will be seen by the illustration. this is a most beautiul minnow. It is iound in the streams of the central and southern Mississippi Valley. In some places it is so) numerous that it is used as a bait insh.

Infortunately the bright, iridescent color shown here are at their best only in the spring months. during their breedin z season.

The species breeds like the Goldrish. scattering adhesive eccs and paying no attention to them. Ther are not reared commercially because it is easy enough to catch them in the wild. An aquarium of about :- - zallon capacity containin zerhaps a dozen of these nohes disporting themselves is indeed a beautiful sight. They readily take any kind of food, prepared or living. 



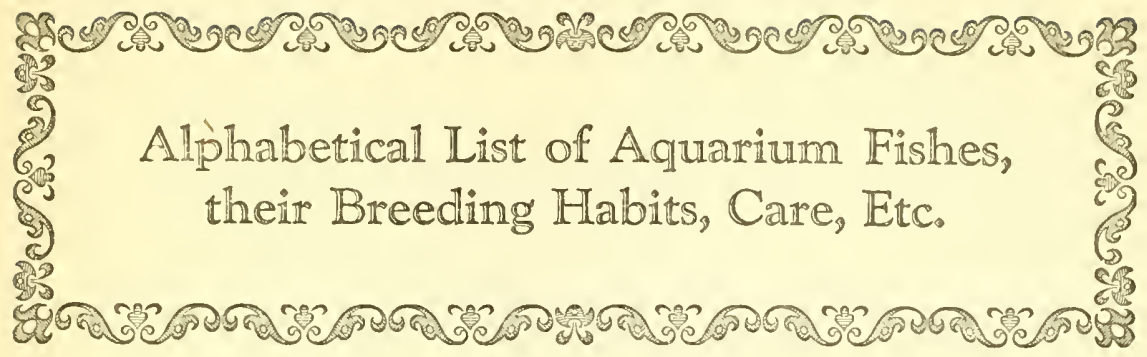

The compiling of a list of names of aquarium fishes presents severai difficulties which ought to be understood by the reader.

As new species are brought in by sailors and others they find their way into the hands of dealers who at best have only slight equipment for identifying specimens. Commercial necessity demands that some sort of name be given quickly. In many cases the aid of scientific friends and institutions is invoked for a hasty or general classification. The fact is that a quick and accurate identification is often impossible, and in many instances the careful work of an able scientist must be revised. This will easily be realized when it is remembered that science has so far listed upwards of 20,000 species of fishes.

The result has been that a considerable proportion of aquarium fishes have been mis-named as to species and not a few as to family also. As might be expected, many of the incorrect names have been popularly accepted and come into general usage among fanciers.

It will undoubtedly be helpful to many readers to have the fishes listed in different ways, so that no matter under what name the fish was first introduced to them, they will be able to readily locate it and secure the desired information regarding its requirements and habits. This has been done.

Those who care to correct names and bring them up to the latest scientific revisions will find the arrangement of the list makes it easy to do so.

Old or obsolete names which have been revised are in regular Roman type, such as is used here for these remarks. The accepted scientific names are in Italics, or sloping letter. In such lines comes first the fish name, then the name of the ichthyologist who first named the species. If the first name or genus has been changed to another genus since he named it, his name is placed in parenthesis. The common name, if any is known, follows. Then comes the habitat or natural geographical location of the fish, which is followed by the family to which it belongs. The 
family is an important matter. It furnishes the student with clues as to general appearance and habits. Length in inches follows. This represents maximum size so far as known, and in some instances is considerably larger than would be expected or desired in aquarium specimens. Lastly comes the reference or key number to general information regarding the fish, which is merely a convenient way of finding, on pages 237 to 244 , such data regarding the different fish families as will be needed by our fancier friends.

In a very few instances a family must be sub-divided into different methods of breeding, but this has been provided for in each case. The principal ones in this respect are the Killifishes (Poeciliidae), some being egg-droppers and others live-bearers or viviparous. The viviparous species are indicated by the letter (V.)

In just a few instances aquarists have known fishes by names of species which are not only incorrect, but which have never been imported. A star (*) is printed at the end of the line with these, together with the correct name of the aquarium specimen, sometimes abbreviated as Aq. sp.

Bearing in mind these few explanations the intelligent use of this list and the information key following is an extremely simple matter. In a few moments it is possible to secure practical data regarding almost any of the many established varieties of aquarium fishes.

In the preparation of the list in its present revised form the author has had the honor of the assistance of Mr. George S. Myers, of Smithsonian Institution. Mr. Myers did a vast amount of work in running down wrong nomenclature, in supplying needed information and in rewriting important parts of the chapter. The list follows:

KEY
NUMBER

Abramis chrysoleucas. See Notemigonus c.

Acara. See under Æquidens.

Achirus. See Trinectes.

Adiniops. See Nothobranchius.

Ėquidens cornleopunctatus (Kner \& Steindachner). Cichlidae. Co-

lombia. 6". Apparently not yet imported. The aquarists'

species probably $1 / 2$. latifrons..................... 6

Equidens curviceps (Ahl). Cichlidae. Amazon. 2" ......... 6

Equidens dorsigera. Not yet imp. Aquarium sp. $=$ E. curviceps.*

Equidens latifrons (Steindachner). Cichlidae. Colombia. 6".... 6

Equidens portalegrensis (Hensel). Cichlidae. Paraguay. 5".... 6

Equidens pulcher (Gill). Cichlidae. Trinidad, Venezuela. $6^{\prime \prime} \ldots 6$

Equidens tetramerus (Heckel). Cichlidae. Amazon, Guiana. 6". . 6

Equidens thayeri. Not yet imp. Aquarium sp. = Æ. curviceps.* 
Alfaro cultratum (Regan). Poeciliidae. Costa Rica. 21/2".

Allopoecilia caucana (Steindachner). Poeciliidae. Colombia. 11/2" 18 Ambassis lala (Hamilton Buchanan). Ambassidæ. India, in brack-

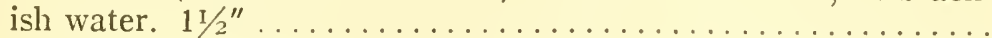

Ameiurus nebulosus Le Sueur. Common Catfish. Siluridae. East.

U. S. Up to $18^{\prime \prime}$.

Anabas argentoventer. See Ctenopoma a.

Anabas fasciolatus. See Ctenopoma f.

Anabas scandens. See Anabas testudineus.

Anabas testudineus (Bloch). Climbing Perch. Anabantidae. East Indies

Aoria vittata (Bloch). Siluridae. India. 7".

Apeltes quadracus (Mitchell). Four-spined Stickleback. Gasterosteidae. 2". .

Aphanius dispar (Ruppel). Poeciliidae. Brackish water, Red Sea, Persian Gulf, and Cutch. 3". .

Aphanius fasciatus (Valenciennes). Poeciliidae. Brackish water, shores of Mediterranean. 2"

Aphanius iberus (Cuvier \& Valenciennes). Poeciliidae. Spain and Algeria. 13/4"

Aphyocharax rubripinnis Pappenheim. Characidae. Argentina. 2" Aphyosemion australe (Rachow). Poeciliidae. Cape Lopez, W.

\section{Africa. 21/2"}

Aphyosemion caeruleum (Boulenger). "Blue Gularis." Poeciliidae.

Nigeria. 5"

Aphyosemion calliurum (Boulenger). Poeciliidae. Liberia. 21/2". . Aphyosemion gulare (Boulenger). "Yellow Gularis." Poeciliidae.

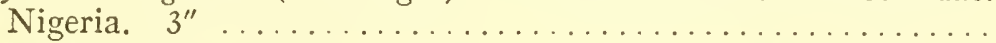
Aphyosemion sjoestedti (Loennberg). Poeciliidae. W. Africa. 3" Apistogramma corumbae (Eigenmann \& Ward). Cichlidae. Para-

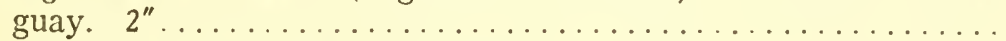
Aplocheilichthys spilauchen (Dumeril). Poeciliidae. W. Africa. 3" Aplocheilus latipes. Medaka. Japan. 2"................. Apomotis cyanellus (Rafinesque). Blue-green sunfish. Centrarchidae.

Mid-West U. S. $7^{\prime \prime} \ldots \ldots \ldots \ldots \ldots \ldots \ldots \ldots \ldots \ldots \ldots \ldots$ Arnoldichthys spilopterus (Boulenger). Characidae. W. Africa. 23/4" 5 Astyanax bimaculatus (Linnaeus). Characidae. S. America east of the Andes, north of B. Aires. $5 " \ldots \ldots \ldots \ldots \ldots \ldots \ldots$ Astyanax fasciatus (Cuvier). Characidae. Mexico to Buenos Aires.

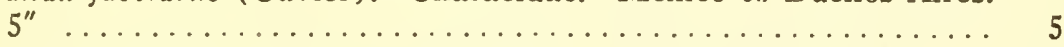

Astyanax taeniatus (Jenyns). Characidae. S. E. Brazil. $3{ }^{\mathrm{T}} / 2 " \ldots .$. Astyanax mexicanus (Filippi). Characidae. Mexico and S. Texas.

$33 / 4 " \ldots \ldots \ldots \ldots \ldots \ldots \ldots$
Badis badis (Hamilton Buchanan). Nandidae. India. $2^{\prime \prime} \ldots \ldots \ldots$ 
Barbus binotatus Cuvier \& Valenciennes. Cyprinidae. Malay Archipelago. $7^{\prime \prime} \ldots \ldots \ldots \ldots \ldots \ldots \ldots \ldots \ldots \ldots \ldots \ldots$

Barbus conchonius (Hamilton Buchanan). Cypinidae. India. 5". 8

Barbus lateristriga (Cuvier \& Valenciennes). Cyprinidae. Borneo. 8 Barbus maculatus. See B. binotatus.

Barbus oligolepis (Bleeker). Cyprinidae. Sumatra. $11 / 2 " \ldots . . .8$

Barbus phutunio (Hamilton Buchanan). Cyprinidae. India. 1".. 8

Barbus semifasciolatus Guenther. Cyprinidae. S. China. 31/2"... 8

Barbus terio (Hamilton Buchanan). Cyprinidae. India. 2" .... 8

Barbus vittatus (Day). Cyprinidae. India. 13/4" .......... 8

Belonesox belizanus Kner. Poeciliidae. (V.) S. Mexico, Brit. Hon-

duras, and Guatemala. $6^{\prime \prime} \ldots \ldots \ldots \ldots \ldots \ldots \ldots \ldots$

Betta rubra. Not yet imp. Aquarium species = B. splendens.*

Betta splendens Regan. Fighting Fish. Anabantidae. Siam. 2". .

Betta cambodia. Variety of above.

Boleichthys fusiformis (Girard). Percidae. East. U. S. 2" .......

Boleosoma nigrum (Rafinesque). "Johnny Darter." Percidae.

East. U. S. 2" ...............................

Brachydanio albolineatus (Blyth). Pearl Danio. Cyprinidae.

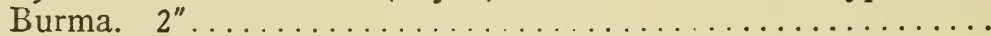

Brachydanio analipunctatus. See B. nigrofasciatus.

Brachydanio nigrofasciatus (Day). Spotted Danio. Cyprinidae.

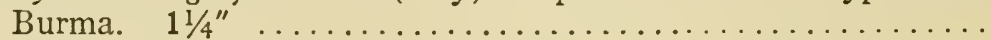

Brachydanio rerio (Hamilton Buchanan). Striped Danio. Cyprinidae. Coromandel to Bengal. $13 / 4^{\prime \prime} \ldots \ldots \ldots \ldots \ldots \ldots \ldots$

Brachyrhaphis episcopi (Steindachner). Poeciliidae. (V.) Panama. $11 / 2^{\prime \prime}$

Callichthys callichthys (Linnaeus). Callichthyidae. S. America. 6" Carassius auratus (Linnaeus). Goldfish. Cyprinidae. Asia. 12". .

Carnegiella strigata (Guenther). Characidae. Guiana and Peruvian Amazon. 11/2".

Centrarchus macropterus (Lacépède). "Flier." Centrarchidae. South Atl. coast region and Miss. Valley. 6" ............

Channa asiatica (Linnaeus). Snakehead, Walking-fish. Ophiceph-

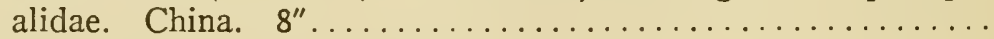

Channa fasciata. See C. asiatica.

Channa punctata (Bloch). Snakehead. Ophicephalidae. India. 12"

Cheirodon arnoldi. Not yet imp. Aq. sp. = Astyanax mexicanus.

Chriopeops goodei (Jordan). Poeciliidae. Peninsular Florida. 11/4"

Chrosomus erythrogaster Rafinesque. Cyprinidae. Mid. West. U. S.

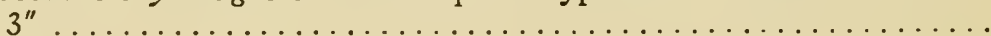

Chrosomus oreas. Painted Dace. Cope. Cyprinidae. Southeast

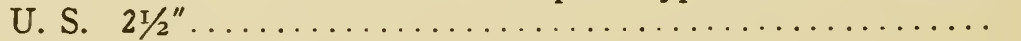
Cichlasoma biocellatum (Regan). Cichlidæ. Amazon. 8 or $9^{\prime \prime} \ldots$. 
Cichlasoma bimaculatım (Linnaeus). Cichlidae. Guiana and Brazil.

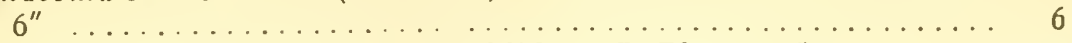

Cichlasoma facetum (Jenyns). Cichlidae. LaPlata. $8 " \ldots \ldots \ldots 66$

Cichlasoma festivum. See Mesonauta f.

Cichlasoma severum. Cichlidae. Brazil. $3^{\prime \prime}-6^{\prime \prime}, \ldots \ldots \ldots \ldots .66$

Clinostomus vandoisulus (Cuvier \& Valenciennes). Cyprinidae. East

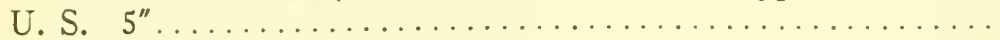

Cnesterodon decemmaculatus (Jenyns). Poeciliidae. (V.) La Plata.

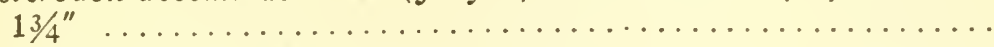

Cobitis fossilis. See Misgurnus $\mathrm{f}$.

Colisa fasciata (Bloch \& Schneider). Striped Gourami. Anabantidae.

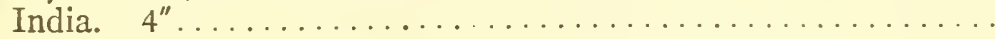

Colisa labiosa (Day). Thick-lipped Gourami. Anabantidae. Burma.

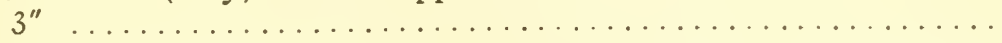

Colisa lalia (Hamilton Buchanan). Dwarf Gourami. Anabantidae.

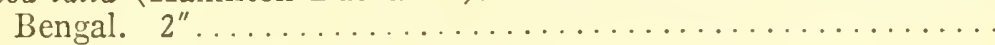
Colossoma nigripinnis. See Piaractus n.

Copeina arnoldi Regan. Characidae. Amazon. 2".......... 5

Copeina callolepis Regan. Characidae. Amazon. $3^{\prime \prime} \ldots \ldots \ldots \ldots .5$

Copeina guttata (Steindachner). Characidae. Amazon. 4" ...... 5

Corydoras nattereri (Steindachner). Callichthyidae. S. E. Brazil. 11/2" 3

Corydoras paleatus (Jenyns). Callichthyidae. Rio Grande do Sul. $2^{\prime \prime}$

Corynopoma riisci Gill. Characidae. Trinidad. $21 / 2^{\prime \prime} \ldots \ldots \ldots$.

Ctenobrycon hauxwellianus (Cope). Characidae. Amazon. 21/2". . Ctenobrycon spilurus (Cuvier \& Valenciennes). Characidae. Guiana.

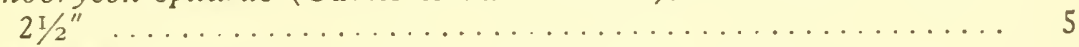

Ctenopoma argentoventer (Ahl). Anabantidae. Niger. 5"...... 2

Ctenopoma fasciolatum (Boulenger). Anabantidae. W. Africa. 3" 2

Cubanichthy's cubensis (Eigenmann). Poeciliidae. Cuba. 2"... 18

Cynolebias adloffi Ahl. Poeciliidae. S. E. Brazil. 11/2"......... 18

Cynolebias belottii Steindachner. Poeciliidae. LaPlata. $21 / 2 " \ldots .18$

Cynolebias wolterstorffii Ahl. Poeciliidae. S. E. Brazil. 4" ..... 18

Cyprinodon dispar. See Aphanius d.

Cyprinodon fasciatus. See Aphanius f.

Cyprinodon iberus. See Aphanius i.

Cyprinodon macularius (Baird \& Girard). Desert minnow.

Poeciliidae. Springs in deserts of S. Calif. $3^{\prime \prime} \ldots \ldots \ldots \ldots$.

Cyprinodon sophiae. See Aphanius s.

Cyprinodon variegatus Lacépède. Poeciliidae. Brackish water, E.

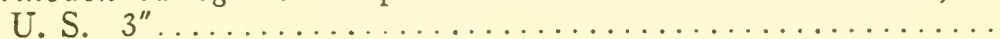

Cyprinus auratus. See Carassius a.

Cyprinus carpio Linnaeus. Carp. Cyprinidae. China. $3 \mathrm{ft} . . . . .$.

Danio albolineatus. See Brachydanio a.

Danio analipunctatus. See Brachydanio a. 
Danio malabaricus (Jordon). Malabar Danio. Cyprinidae. Mala-

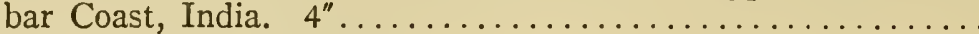

Danio rerio. See Brachydanio r.

Dermogenys pusillus van Hasselt. Live-bearing Halfbeak. Hemiramphidae. E. Indies, brackish water. $3^{\prime \prime} \ldots \ldots \ldots \ldots \ldots$

Diplesion blennioides. See Etheostoma b.

Dormitator maculatus (Bloch). Gobiidae. E. cost Cent. Amer. 6".

Elassoma evergladei Jordan. Pigmy Sunfish. Centrarchidae. South-

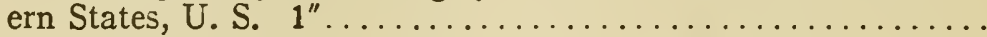

Elassoma zonatum Jordan. Pigmy Sunfish. Centrarchidae. South-

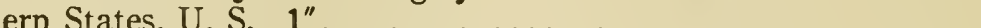

Enneacanthus gloriosus (Holbrook). Blue-spot Sunfish. Centrar-

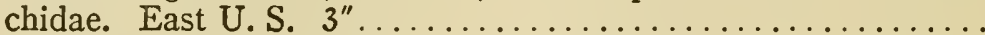

Enneacanthus obesus (Baird). Centrarchidae. East U. S. 3"... Epiplatys chaperi (Sauvage). Pœciliidæ. Liberia. 2"...

Epiplatys fasciolatus (Guenther). Pœciliidæ. Sierra Leone. 31/4".. Epiplatys grahami (Boulenger). Pœciliidæ. Nigeria. 2" ........ Epiplatys sexfasciatus (Gill). Pœciliidæ. IW. Africa. 4"........ Esomus danrica (Hamilton Buchanan). Flying Barb. Cyprinidae. India. $5^{\prime \prime}$

Esomus malabaricus Day. Cyprinidae. Malabar Coast, India. 21/4" Esomus malayensis Ahl. Cyprinidae. Habitat unknown. 11/2"... Etheostoma blennioides Rafinesque. Green-sided Darter. Percidae. Central U. S. 5". .

Etheostoma coeruleum. See Poecilichthys c.

Etroplus maculatus (Bloch). Cichlidae. India. 3"...........

Eucalia inconstans (Kirtland). Brook Stickleback. Gasterosteidae.

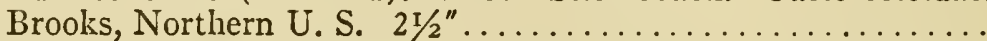

Eupomotis gibbosus (Linnaeus). Common sunfish, "Pumpkin seed."

Centrarchidae. E. U. S. $6 " \ldots \ldots \ldots \ldots \ldots \ldots \ldots \ldots \ldots$. . . . . . . .

Eupomotis gibbosus. See Lepomis g.

Eupomotis punctatus. See Lepomis p.

Fitzroyia lineata. See Jenynsia 1.

Fundulopanchax, all species. See under Aphyosemion.

Fundulus caeruleus. See Aphyosemion caeruleum.

Fundulus chrysotus Holbrook. Poeciliidae. South U. S. 21/2".....

Fundulus cingulatus Cuvier \& Valenciennes. Poeciliidae. S. E. U.S.

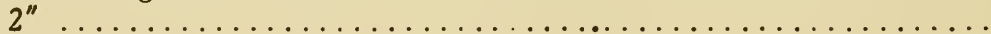

Fundulus confluentus Goode \& Bean. Poeciliidae. Maryland to

Texas, near coast. $3^{\prime \prime}$. . .

Fundulus cubensis. See Cubanichthys c.

Fundulus diaphanus (Le Sueur). Poeciliidae. N. E. U. S. 41/2"...

Fundulus dispar (Agassiz). Poeciliidae. Centr. U. S. $21 / 2 " \ldots \ldots$. Fundulus goodei. See Chriopeops g.

Fundulus guentheri. See Nothobranchius guentheri. 
Fundulus gularis blue. See Aphyosemion caeruleum.

Fundulus gularis yellow. See Aphyosemion gulare.

Fundulus notatus (Rafinesque). Poeciliidae. Central U. S. $3^{\prime \prime} \ldots$ 18

Fundulus nottii (Agassiz). Star-head Minnow. Poeciliidae. S. E. U. S. 3"

Fundulus ocellaris. See F. confluentus.

Fundulus sjoestedti. See Aphyosemion s.

Fundulus zebrinus. See Plancterus z.

Gambusia affinis (Baird \& Girard). Top Minnow. Poeciliidae.

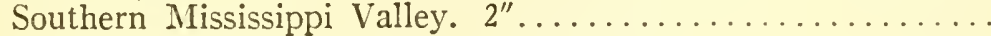

Gambusia bimaculata. See Pseudoxiphophorus b.

Gambusia episcopi. See Brachyrhaphis e.

Gambusia holbrookii (Agassiz). Poeciliidae. (V.) N. J. to Fla. 2"

Gambusia modesta Ahl. See G. patruelis.

Gambusia myersi Ahl. See G. patruelis.

Gambusia nicaraguensis Guenther. Poeciliidae. (V.) Centr. Amer. 2"

Gambusia nobilis (Baird \& Girard). Poeciliidae. (V.) Texas and

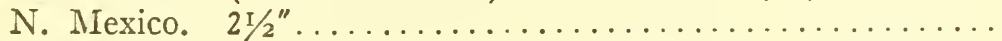

Gambusia patruelis (Baird \& Girard). Poeciliidae. (V.) Miss. Val-

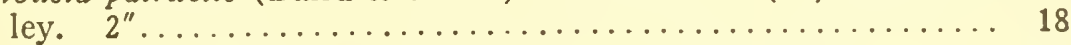

Gambusia punctata Poey. Poeciliidae. (V.) Cuba. $31 / 2^{\prime \prime} \ldots \ldots$. Gasteropelecus fasciatus. See Carnegiella.

Gasteropelecus securis. See Thoracocharax s.

Gasteropelecus stellatus. See Thoracocharax and Pterodiscus.

Geophagus brasiliensis (Quoy \& Gaimard). Cichlidae. Brazil. 5". Girardinus decemmaculatus. See Cnesterodon d.

Girardinus metallicus (Poey). Poeciliidae. Cuba. $21 / 2{ }^{\nu} \ldots \ldots$...

Girardinus reticulatus. See Phalloceros.

Gymnotus carapo Linnaeus. Gymnotidae. S. America. $16^{\prime \prime} . \ldots$. .

Haplochilus cameronensis. Not yet imp. Aquarium specimens $=$ Aphyosemion australe.*

Haplochilus calliurus. See Aphyosemion call.

Haplochilus chaperi. See Panchax chap.

Haplochilus fasciolatus. See Panchax fasc.

Haplochilus grahami. See Panchax gr.

Haplochilus latipes. See Aplocheilus lat.

Haplochilus lineatus. See Panchax lin.

Haplochilus from Madras. See Panchax parvus.

Haplochilus panchax. See Panchax pan.

Haplochilus playfairii. See Pachypanchax playf.

Haplochilus sexfasciatus. See Panchar sexf.

Haplochromis multicolor (Schoeller). Egyptian Mouthbreeder. Cich-

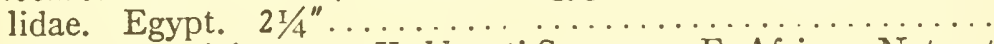

Haplochromis strigigena $=H$. bloyeti Sauvage. E. Africa. Not yet imp. Aquarium specimens $=\mathrm{H}$. multicolor. 
Helostoma temminckii Cuvier \& Valenciennes. Anabantidae. E.

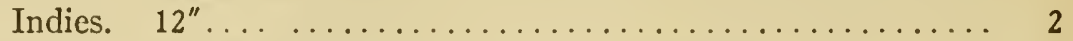

Hemibrycon guppyi (Regan). Characidae. Trinidad. $31 / 4$ ".... 5 Hemichromis auritus. See H. fasciatus.

Hemichromis bimaculatus Gill. Cichlidae. Trop. Africa. 6" .... 6 Hemichromis fasciatus Peters. Cichlidae. IV. Africa. 10" ..... 6 Hemigrammus caudovittatus Ahl. Characidae. Buenos Aires. 21/2" 5 Hemigrammus ocellifer (Steindachner). Characidae. E. Brazil. 21/2" 5 Hemigrammus rhodostomus Ahl. Characidae. Brazil. 2"...... 5 Hemigrammus rodwayi Durbin. Characidae. Guiana and Para. 2" 5 Homigrammus ulreyi (Boulenger). Characidae. Rio Paraguay. 11/2" 5 IIemigrammus unilineatus Gill. Characidae. Trinidad, Guiana. 13/4" 5 Hemiramphus fluviatilis. See Dermogenys.

Herichthys cyanoguttatus Baird \& Girard. Cichlidae. Texas and

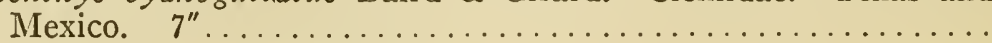

Heros facetus. See Cichlasoma f.

Heros spurius. See Cichlasoma severum.

IIeterandria formosa Agassiz. Poeciliidae. (V.) S. East. U. S. 11/4" Heterogramma corumbae. See Apistogramma c.

Heteropneustes fossilis (Bloch). Siluridae. India. $12^{\prime \prime} \ldots \ldots \ldots$ Hollandichthys multifasciatus (Eigenmann \& Norris). Characidae.

S. E. Brazil. 4" ...............................

Hyphessobrycon anisitsi. Not yet imp. Aquarium species $=$ Hemigrammus caudovittatus.*

Hyphessobrycon bifasciatus Ellis. "Yellow Tetra." Characidae.

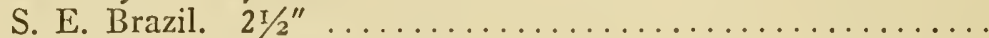

Hyphessobrycon fammeus Myers. "Red from Rio." Characidae.

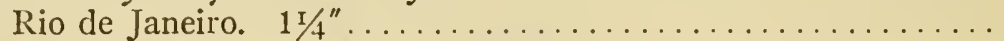

Hyphessobrycon innesi. Myers. Characidx. Upper Amazon. 11/4". . Hyphessobrycon heterorhabdus (Ulrey). Characidae. Amazon. 11/4" Hypopomus brevirostris (Steindachner). Gymnotidae. S. America.

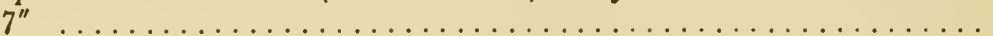
Idus idus (Linnaeus). Golden Ide. Cyprinidae. Europe and N.

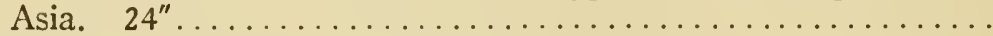
Iguanodectes rachovii. See I. tenuis.

Iguanodectes tenuis Cope. Characidae. Amazon. $3^{\prime \prime} \ldots \ldots \ldots \ldots$ Jordanella floridae Goode \& Bean. Poeciliidae. Florida. 2"...... Lebias. See Aphanius.

Lebistes reticulatus (Peters). "Guppy". Poeciliidae. (V.) North-

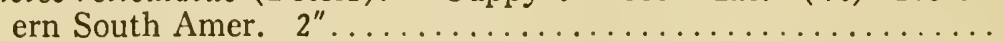
Lepomis auritus (Linnaeus). Long-eared Sunfish. Centrarchidae.

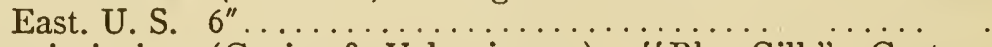

Lepomis incisor (Cuvier \& Valenciennes). "Blue-Gill." Centrarchidae. East. and Centr. U. S. $12^{\prime \prime} \ldots \ldots \ldots \ldots \ldots \ldots \ldots$ Lepomis megalotis (Rafinesque) . Western Long-eared Sunfish. Cen-

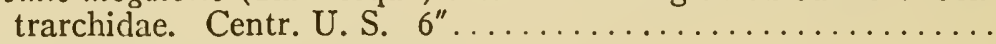
I epomis pallidus. See L. incisor. Leuciscus vandoisulus. See Clinostomus vand. 
Limia arnoldi ( - nigrofasciata). Aquarium species $=$ L. vittata.* Limia caudofasciata Regan. "Blue Poecilia." (V.) Jamaica. 2". . 18 Limia nigrofasciata Regan. Poeciliidae. (V.) Santo Domingo. 2" 18 Limia vittata (Guichenot). Poeciliidae. (V.) Cuba. 4"........ 18 Macrones vittatus. See Aoria vitt.

Macropodus chinensis (Bloch). Round-tail Paradise Fish. Anaban-

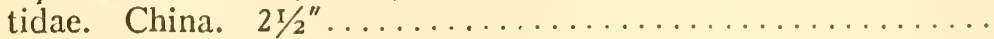
Macropodus cupanus (Cuvier \& Valenciennes). Anabantidae. India.

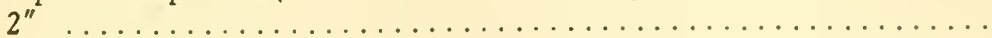

Macropodus opercularis (Linnaeus). Paradise Fish (Forked-tail). Anabantidae. S. China. 31/2"

Macropodus viridi-auratus. See M. opercularis.

Malapterurus electricus (Gmelin). Electric Goldfish. Siluridae.

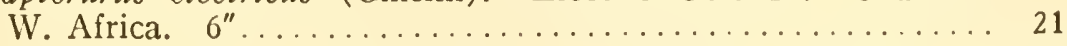

Melanotaenia nigrans. Rainbow Fish. Atherinidae. Australia. 4" Mesogonistius chatodon (Baird). Black-banded Sunfish. Centrarchidae. E. U.S. 2" ......................... 4

Mesonauta festivum (Heckel). Cichlidae. S. America. 4"..... 6 Mesonauta insignis. See M. festivum.

Mimagoniates barberi Regan. Characidae. S. E. Brazil. 2"...... Mimagoniates microlepis (Steindachner). Characidae. Southwestern Brazil. 2" .............................. 5

Misgurnus fossilis (Bloch). "Weather fish." Cobitidae. Europe. 6" 7 Mocnkhausia oligolepis (Guenther). Characidae. Amazon to Guiana. $7^{\prime \prime}$ 6

(1)

Mollienisia caucana. See Allopoecilia c.

Mollienisia latipinna LeSueur. Poeciliidae. (V.) Southern United

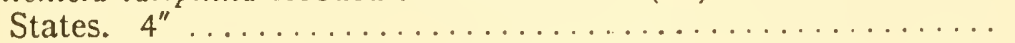
Mollienisia sphenops (Cuvier \& Valenciennes). Poeciliidae. (V.) Centr. America. $3^{\prime \prime} \ldots \ldots \ldots \ldots \ldots \ldots \ldots \ldots \ldots \ldots \ldots \ldots$ Mollienisia velifera Regan. Poeciliidae. (V.) Yucatan. 4ז²".... Monodactylus argenteus (Linnaeus). Monodactylidae. E. Indies,

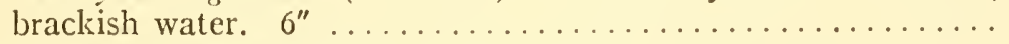
Mylossoma aurcum (Agassiz). Characidae. Amazon. 6" ...... Nandus marmoratus. See N. nandus.

Nandus nandus (Hamilton Buchanan). Nandidae. India. 7".... Neetroplus carpintis. See Herichthys.

Notemigonus chrysoleucas (Mitchell). Shiner; Roach. Cyprinidae.

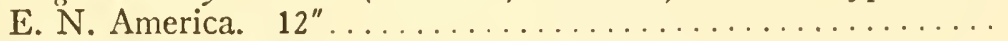
Nothobranchius guentheri (Pfeffer). Poeciliidae. E. Africa. $3^{\prime \prime} \ldots 18$

Nothobranchius orthonotus (Peters). Poeciliidae. E. Africa. 3".. 18 Notropis bifrenatus (Cope). Bridled Minnow. Cyprinidae. Maine

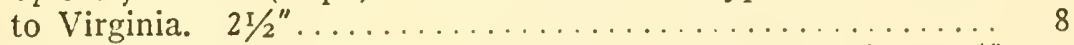
Notropis chrosomus (Jordan). Cyprinidae. Alabama Basin. 21/2" 8 Notropis hudsonius (DeWitt Clinton). "Spawn-eater." Cyprinidae.

Gt. Lakes and N. Y. South to S. Carolina. 4" ............. 
Notropis lutrensis (Baird \& Girard). Cyprinidae. Miss. Valley. 3"

Notropis maculatus (Hay). Cyprinidae. Mississippi to Southern

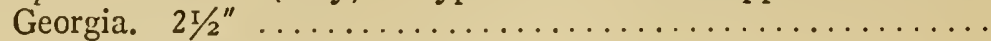

Notropis metallicus Jordan \& Meek. Cyprinidae. Ga. and N. Fla.

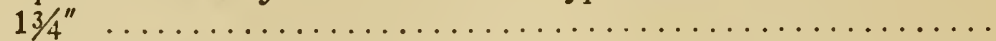

Notropis whipplii analostanus (Girard). "Silver-fin." Cyprinidae.

Atl. Coast States. 4" .........................

Nuria. See Esomus.

Ophicephalus. See Channa.

Oryzias latipes. Medaka. See Aplocheilus latipes.

Osphromenus striatus. See Ctenops.

Osphromenus malayanus. See Sphaerichthys.

Osphromenus trichopterus. See Trichogaster trich.

Otocinclus arnoldi Regan. Loricariidae. S. E. Brazil. 11/4" .....

Pachypanchax playfairii (Guenther). Poeciliidae. Seychelles Isl.

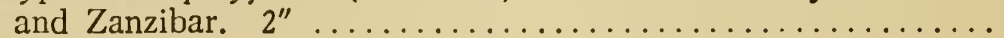

Panchax chaperi (Sauvage). Poeciliidae. Liberia. 2" .........

Panchax fasciolatus (Guenther). Poeciliidae. Sierra Leone. 31/4"

Panchax grahami (Boulenger). Poeciliidae. Nigeria. $2^{n} \ldots . .$.

Panchax lineatus Cuvier \& Valenciennes. Poeciliidae. Malabar,

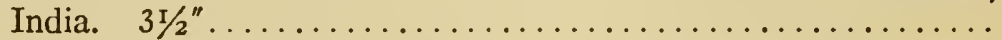

Panchax panchax (Hamilton Buchanan). Poeciliidae. India and the

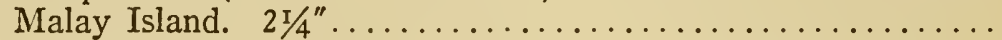

Panchax parvus Raj. "Haplochilus from Madras." Poeciliidae.

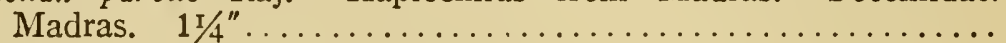

Panchax playfairii. See Pachypanchax.

Panchax sexfasciatus (Gill). Poeciliidae. W. Africa. 4"........

Pantodon buchholzi Peters. Pantodontidae. W. Africa. $5^{\prime \prime} \ldots$....

Paragoniates microlepis. See Mimagoniates m.

Paratilapia multicolor. See Haplochromis m.

Pelmatochromis arnoldi. See Hemichromis fasciatus.

Periophthalmus barbarus (Linnæus). Mud Skipper. Gobiidæ,

Brackish waters, shores of Indian and S. W. Pacific Ocean. 4". 10

Petersius spilopterus. See Arnoldichthys.

Phallichthys pittieri (Meek). Poeciliidae. (V.) Costa Rica. 2"..

Phalloceros caudimaculatus (Hensel). Poeciliidae. (V.) S. E. S.

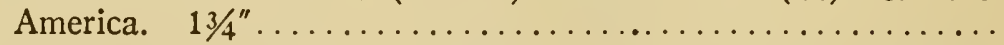

Phalloptychus januarius. Not yet imp. (This is a fish with vertical bars on the body.)

Phoxinopsis brocce (Myers). Characidae. Rio de Janeiro. 11/4". 5 Phoxinopsis typicus (Regan). Characidæ. Rio de Janeiro. 11/4”... 5 Phoxinus phoxinus (Linnaeus). Cyprinidae. Europe. 6"...... 8 Piaractus nigripinnis (Cope). Characidae. Amazon. $71 / 4^{\prime \prime} \ldots . .5$ Pimelodella gracilis. Nandidae. La Plata to Orinoco......... 3 Plancterus kansee (Garman). Poeciliidae. Kansas. $33 / 4^{n} \ldots \ldots .18$ 
Plancterus zebra (Jordan \& Gilbert). Poeciliidae. West. U. S. $4^{u} 18$ Platypocilus maculatus Guenther. Poeciliidae, (V.) Mexico. 21̌ㄹ". Various varieties have been named ruber, pulcher, niger, im-

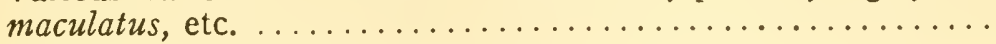

Pœcilia reticulata. See Lebistes.

Pœcilia sphenops. See Mollienisia sphen.

Pœcilia unimaculata. See P. vivipara.

Pocilia vivipara Bloch \& Schneider. Poeciliidae. (V.) S. America. $3^{\prime \prime}$. .....................................

Pocilichthys corneleus (Storer). Rainbow Darter. Percidae. Cen-

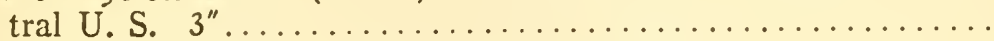

Pociliopsis isthmensis. See Phallichthys pittieri.

Pœciliopsis pittieri. See Phallichthys pitt.

Polyacanthus cupanus. See Macropodus c.

Polyacanthus dayi. See Macropodus cupanus.

Polycentropsis abbreviata Boulenger. Polycentridae. W. Africa. $3^{\prime \prime}$ Polycentrus schomburgkii (Mueller \& Troschel). Polycentridae.

Guiana \& Trinidad. $2^{\prime \prime} \ldots \ldots \ldots \ldots \ldots \ldots \ldots \ldots \ldots . . . \ldots \ldots$

Pristella aubynei Eigenmann. Characidae. Guiana. 2"...... 5

Pristella riddlei (Meek). Characidae. Venezuela and Guiana. 11/2" 5

Pseudocorynopoma doriae Perugia. Characidae. S. Eastern S. Amer-

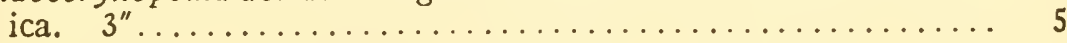

Pseudoxiphophorus bimaculatus (Heckel). Poecilidae. (V.)

Centr. America. $4 " \ldots \ldots \ldots \ldots \ldots \ldots \ldots \ldots \ldots \ldots . \ldots \ldots$

Pterodiscus levis Eigenmann. Flying Characin, "Gasteropelecus."

Characidae. Amazon. 2" .......................

Pterophyllum altum Pellegrin. Orinoco River. Not yet imp.

Pterophyllum eimekei Ahl. Cichlidae. Amazon. Diam. 21/2"....

Pterophyllum scalare (Cuvier \& Valenciennes). Cichlidae. Amazon.

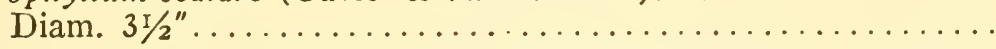

Pungitius pungitius (Linnaeus). Ten-spined Stickleback. Gasterosteidae. Europe, Asia, N. Amer. $3^{\prime \prime} \ldots \ldots \ldots \ldots \ldots \ldots \ldots \ldots$

Pygosteus. See Pungitius.

Puntius. See Barbus.

Pyrrhulina brevis Steindachner. Characidae. Amazon. $3 \mathrm{r} / 2 "$.....

Pyrrhulina filamentosa. Not yet imp. Aq. sp. = Copeina arnoldi.* Pyrrhulina guttata. See Copeina.

Pyrrhulina rachoviana Myers. Characidae. S. E. So. America... 5

Rasbora cephalotcnia (Bleeker). Cyprinidae. E. Indies. $5 " \ldots . .8$

Rasbora daniconius (Hamilton Buchanan). Cyprinidae. India. 4" 8

Rasbora heteromorpha Duncker. Cyprinidae. Malay Peninsula. 11/2" 8

Rasbora lateristriata elegans (Volz). Cyprinidae. E. Indıes. $4^{\prime \prime} \ldots 8$ 
Rasbora maculata Duncker. Cyprinidae. Malay Peninsula. 1"... 8 Rasbora taeniata Ahl. Cyprinidae. Sumatra. $3 / 4^{n} \ldots \ldots \ldots \ldots .8$ Rhamdia sebae. (Cuvier \& Valenciennes). Siluridae. S. America. 10" 21 Rhinichthys atronasus (Mitchell). Black-nosed Dace. Cyprinidae.

E. U. S. $3 " \ldots \ldots \ldots \ldots \ldots \ldots \ldots \ldots \ldots \ldots \ldots \ldots$

Rhodeus amarus (Bloch). "Bitterling." Cyprinidae. Europe. 2" 8

Rivulus cylindraceus Poey. Cuban Rivulus. Poeciliidae. Cuba... 18

Rivulus dorni Myers. Poeciliidae. Rio de Janeiro. 21/4"...... 18

Rivulus elegans. Not yet imp. Aq. sp. $=$ R. rachovii.

Rivulus flabellicanda ( $=$ isthmensis). Not yet imp. Aquarium species $=\mathrm{R}$. tenuis.*

Rivulus ocellatus Hensel. Poeciliidae. Rio de Janeiro. 2"....... 18

Rivulus harti Poeciliidae, Trinidad .................. 18

Rivulus poeyi. See R. urophthalmus.

Rivulus punctatus Boulenger. Not yet imp. Aquarium sp. $=\mathrm{R}$. dorni.

Rivulus rachovii Ahl. Poeciliidae. Pará. $21 / 2 " \ldots \ldots \ldots \ldots \ldots, 18$

Rivulus strigatus Regan. Poeciliidae. Amazon. 11/4" ......... 18

Rivulus tenuis (Meek). Poeciliidae. Mexico. 2" ........... 18

Rivulus urophthalmus Guenther. Poeciliidae. Amazon. 21/2"..... 18

Saccobranchus. See Heteropneustes.

Scardinius erythrophthalmus (Linnaeus). Rudd; Pearl Roach. Cyprinidae. Europe. 11".......................

Scatophagus argus (Gmelin). Scatophagidae. India, in brackish

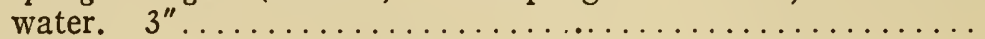

Semotilus atromaculatus (Mitchell). Fallfish. Cyprinidae. E. U.S. $5-10^{\prime \prime}$

(V.) Southern Mississippi Valley. $2^{\prime \prime} \ldots \ldots \ldots \ldots \ldots \ldots \ldots$

Sphcerichthys osphromenoides Canestrini. Anabantidæ. E. Ind. $2^{u} \ldots$ Spintherobolus. See Phoxinopsis.

Stethaprion innesi Myers. Characidae. Amazon. $3^{\prime \prime} \ldots \ldots \ldots$.

Stevardia albipinnis. See Corynopoma riisei.

Tetragonopterus argenteus Cuvier. Characidae. S. America. 5".. Tetragonopterus chalceus Agassiz. Characidae. Brazil and Guiana. $4^{\prime \prime}$........................................

Tetragonopterus fasciatus. See Astyanax fasc.

Tetragonopterus guppyi. See Hemibrycon g.

Tetragonopterus maculatus. See Astyanax bimaculatus.

Tetragonopterus ocellifer. See Hemigrammus ocell.

Tetragonopterus rubropictus. See Aphyocharax.

Tetragonopterus rutilus. See Astyanax fasciatus.

Tetragonopterus ulreyi. See Hemigrammus ul.

Tetragonopterus unilineatus. Hemigrammus uni.

Tetraodon fluviatilis Hamilton Buchanan. Swell-fish. Tetraodon-

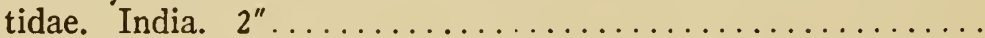

Thoracocharax securis (Filippi). Characidae. S. America. 2" ... 
Thoracocharax stellatus (Kner). Characidae. Amazons. 2"..... 5

Tilapia macrocephala.. Cichlidae. W. Africa. $7^{\prime \prime} \ldots \ldots \ldots$...... 6а

Tinca tinca (Linnaeus). Tench. Cyprinidae. Europe. 12".... 8 Trichogaster fasciatus. See Colisa fasc.

Trichogaster labiosus. See Colisa lab.

Trichogaster lalius. See Colisa lal.

Trichogaster trichopterus (Pallas). 3-Spot Gourami. Anabantidae. 4"

Trichopsis vittatus (Cuvier \& Valenciennes). Croaking Gourami.

Trinectes maculatus (Bloch \& Schneider). Common sole. Soleidae.

E. N. America, in brackish or fresh water. 6" ........ 22

Umbra limi (Kirtland). Mud-minnow. Umbridae. Centr. U. S. 4" 24

Umbra pygmæa (DeKay). Eastern Mud-minnow. Umbridae. E.

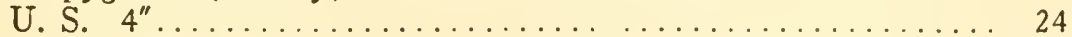

Valencia hispanica Valenciennes. Poeciliidae. Southern Spain 2" 18

Xiphophorus helleri Heckel. Swordtail. Poeciliidae. (V.) Centr. Amer. 6" (to tip of sword) ................... 18

Xiphophorus montezumee Jordan and Snyder. Not yet imp. Aq. sp. (red) is a hybrid betw. Platypoecilus and Xiphophorus.*

Xiphophorus rachovii Regan. Poeciliidae. (V.) Guatemala. 3" Perhaps a variety of helleri......................

SEE PAGES 237 TO 244 FOR DATA REGARDING KEY NUMBER REFERENCES 
CHAPTER TWENTY-ONE

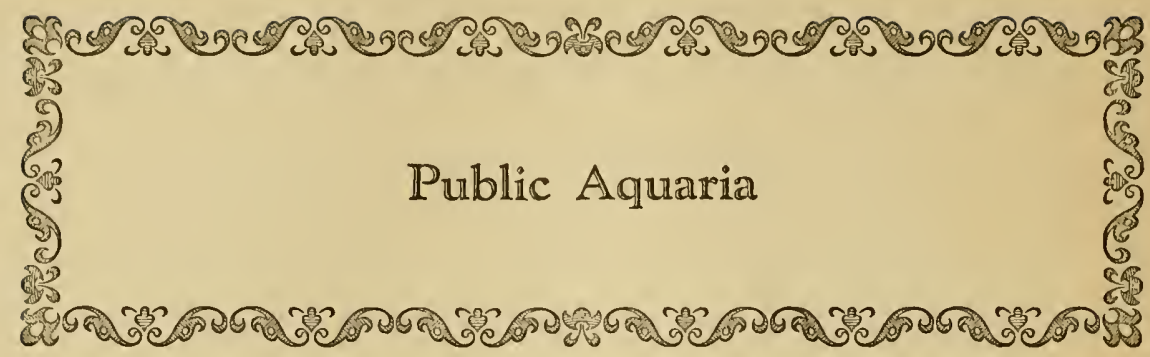

Millions of people get their first knowledge of the wonders of the water world in public aquaria. These institutions add immensely to popular education. Since most of them now have good collections of the smaller species available for the home (tropicals and goldfish) they cannot fail to introduce many a person to the pleasures of aquariumkeeping.

The magnetic attraction of water life is again proven (if need be) by the fact that the Aquarium at Battery Park in New York has, year after year, until recently, recorded the largest attendance of any institution or place of amusement in the world, the present approximate figures being about 7,000 visitors per day. This has only been exceeded by the Shedd Aquarium in Chicago, where the average attendance since its opening in June, 1930, has averaged more than 12,000 per day. Admission is charged on four days per week.

Chicago is the only city in our country which is successfully supporting two first-class public aquaria-the Lincoln Park and the Shedd, the latter being the most modern in the world today. It was erected at a cost of $\$ 3,000,000$ for the buildings and equipment alone. Sea water from Key West for a single filling costs about $\$ 39,000$. Needless to say, inland aquaria take precious care of their marine water by filtering, aeration and laboratory tests. The success they achieve in this respect is remarkable. Even coastwise aquaria must take care of their marine water, for they have to go out several miles to get an unpolluted supply.

In addition to various methods of purification it is necessary for most public aquaria to have plants for heating, refrigerating and storing water. Casual visitors have not the least idea of the "works" in back of the scene arranged for their pleasure and benefit, but those especially interested can see them on request.

The securing and transporting of specimens of fishes also entails difficulties, dangers and disappointments which can hardly be appreci- 


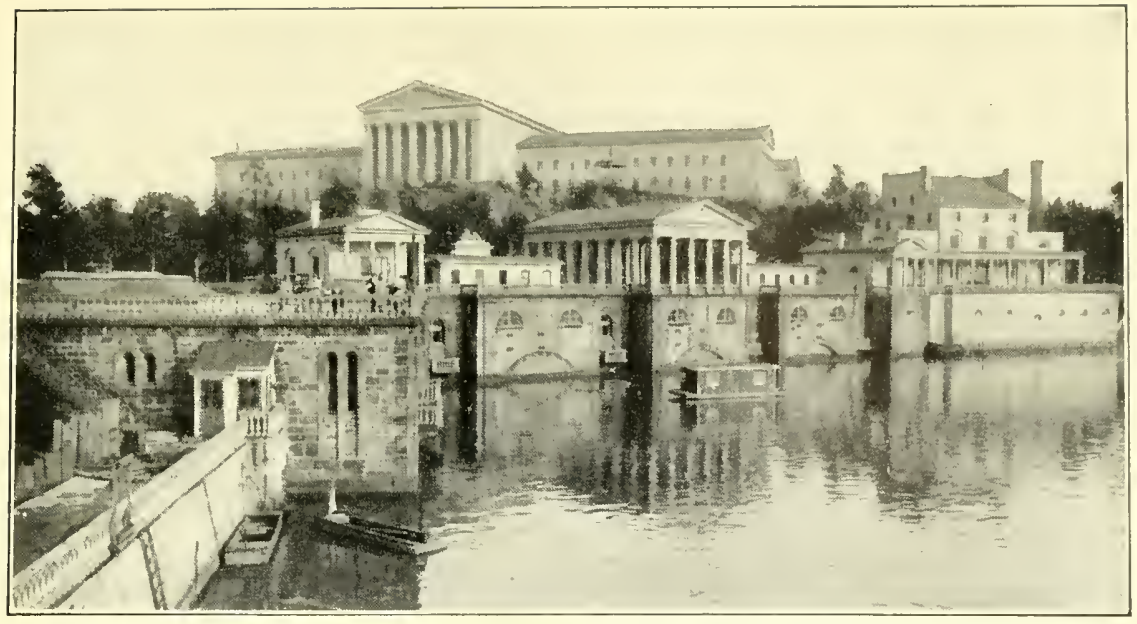

Fig. 29\%. Fairmount Park AQuartuar, Piflladelphia

Beautifully situated on the River Schuylkill and extending from extreme left to right of the photograph, this is the world's longest aquarium. The aquarium proper is within the granite walls rising from the river. Six buildings topping it are executive offices, pavilions and a research laboratory. The Art Muscum harmoniously dominates the background.

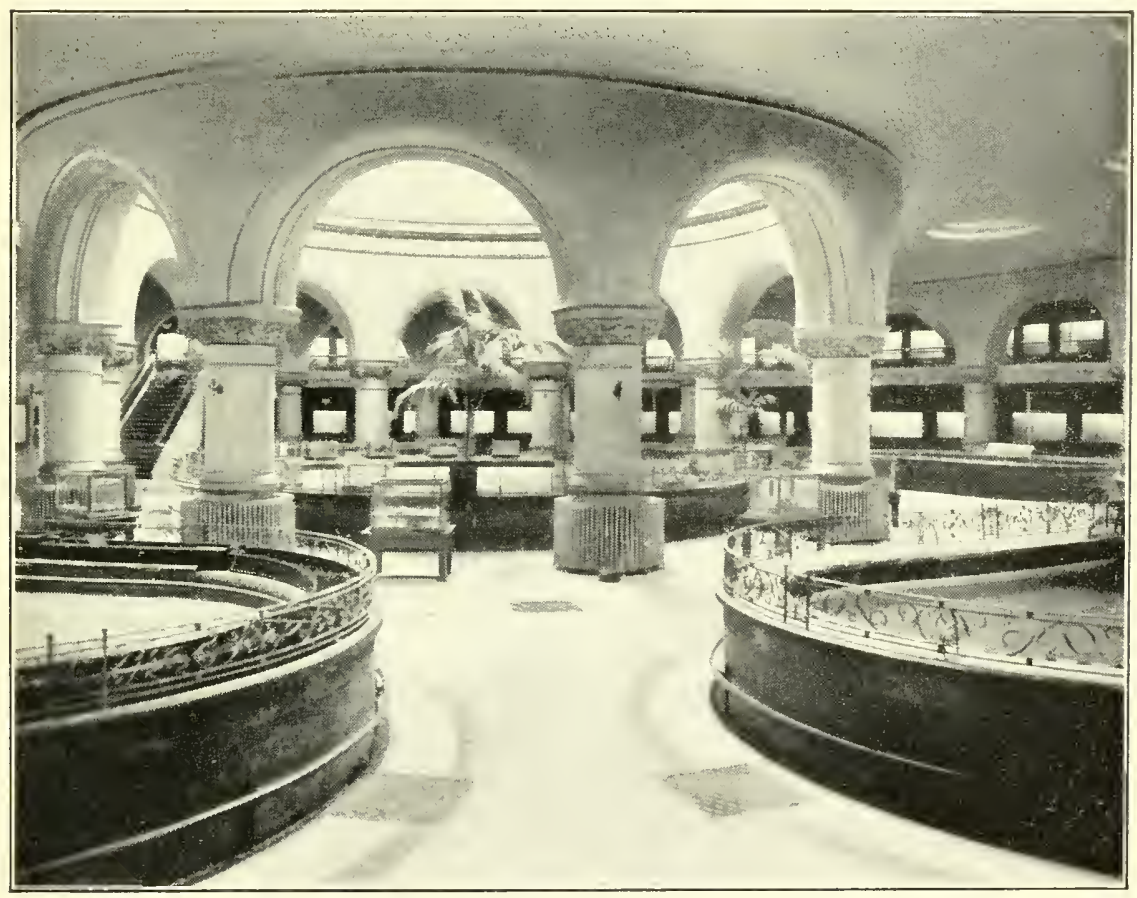

Fig. 208. Interfor, Battery Park Aquartul, New York

Originally built in 1807 as a fort, it was converted in 1896 to a public aquarium. for which it is splendidly qualified and located. It is our oldest and most famous aquarium. Completely circling it is a double tier of marine and fresh water tanks, while on the main floor numerous small aquaria, large pools and troughs contain household aquarium fishes, large aquatic and amphibian animals, a fish hatchery and other interesting natural history exhibits. 


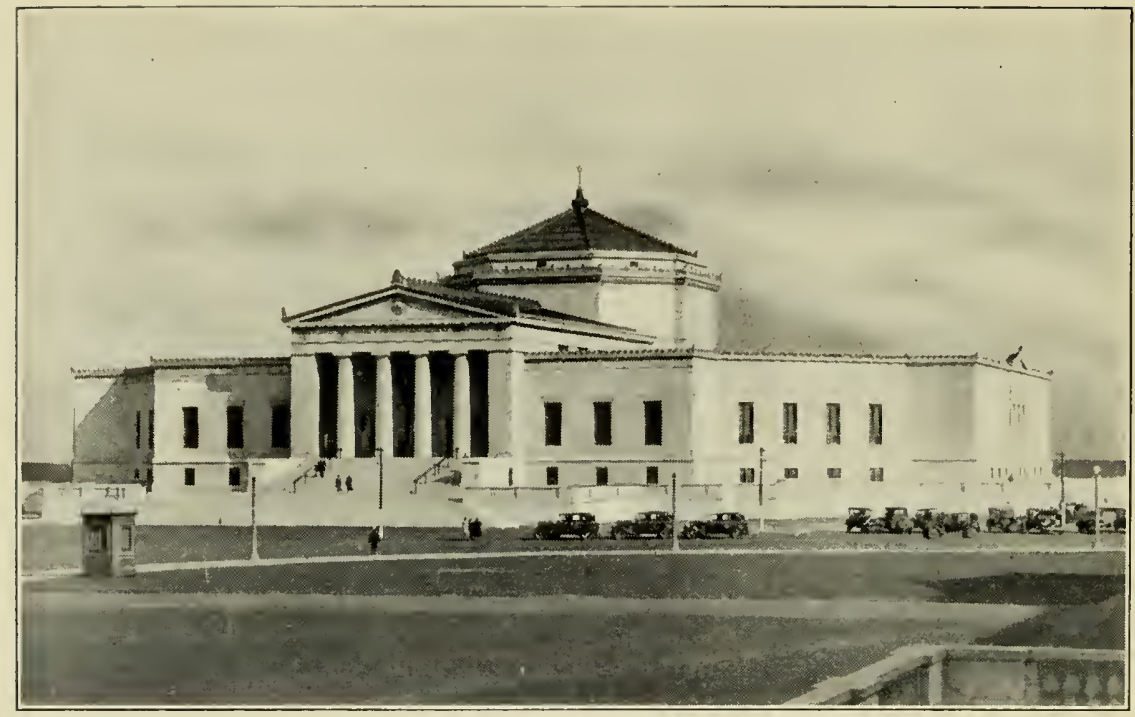

Fig. 299. Shedd Aquariudi, Chicago

This is the newest public aquarium in America. It is the gift of the late John (i Shedd. The building and equipment cost about $\$ 3.000 .000$. Annual maintenance, approximately $\$ 200,000$. It contains salt and fresh water fishes and has a fine collection of "tropicals." The size of the structure may be judged bv comparison with the automobiles in the photograph. Daily attendance averages over 12.000 .

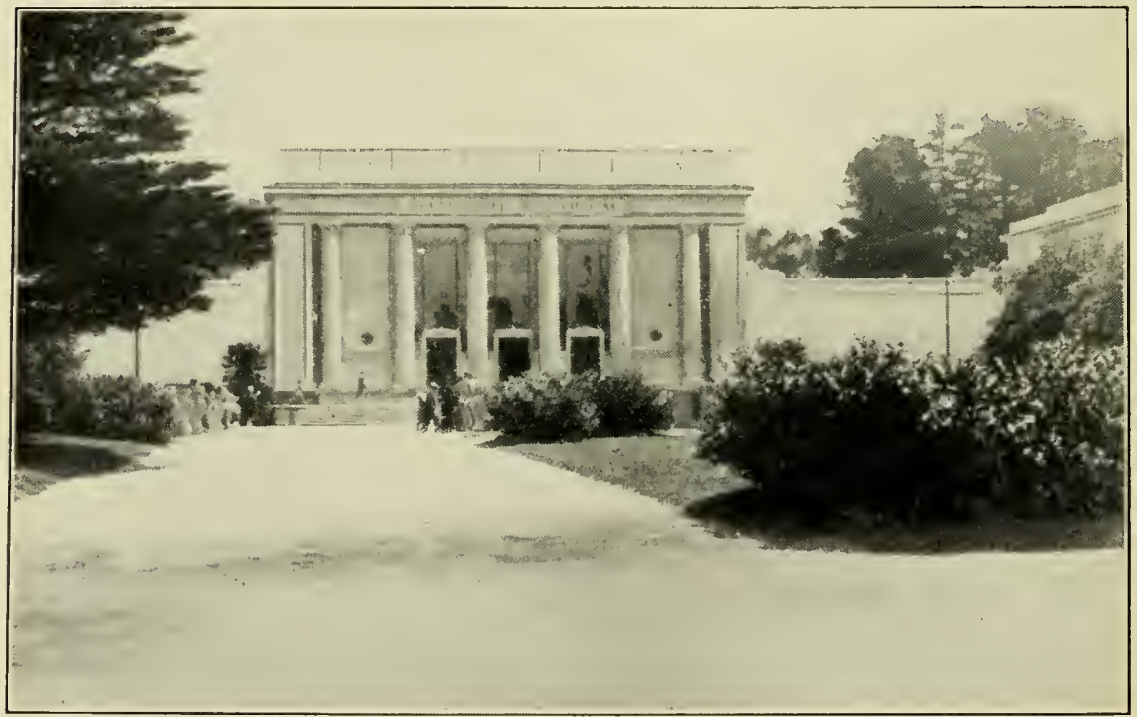

Fig. 300. Steinhart Aquirium, San Francisco

This aquarium has a striking collection of bizarre, gaudy and weird fishes mainly from Hawaiian waters. The photograph does not do justice to the size of the building, nor give any idea of the crowds which usually throng the institution. An artistically arranged swamp is in the vestibule room, populated with appropriate animals, large and small. 
ated. Fortunately politics plays little part in the appointment of personnel in these institutions. They are for the most part operated by men who have a passion for this particular work.

American cities having public aquaria are Boston, Chicago (2), Detroit, New Orleans, New York, Philadelphia, San Francisco and Washington. In other countries they are maintained at Amsterdam, Holland; Antwerp, Belgium; Berlin, Germany; Blackpool, England; Frankfurt, Germany ; Leipzig, Germany ; Honolulu, Hawaii ; Lisbon, Portugal ; London, England; Rio de Janciro, Brazil (2); Monaco; Sidney, Australia; Naples, Italy; Paris, France and Plymouth, England.

Of equal importance with the care of water in large aquaria (particularly marine) is the subject of feeding. Virtually all marine fishes are carnivorous, and while the flesh of warm-blooded animals may be used to some extent, it is not natural, so it becomes necessary to secure a liberal supply of clams, crabs, shrimp, small fish, worms, etc. While this involves a great deal of effort, there is no doubt that fishes respond very perceptibly to the benefits of natural food.

It will be recalled that when Benjamin Franklin was a young man he ate no meat, endeavoring to follow the commandment "Thou shalt not kill," but when he became acquainted with the universal cannibalism of the sea he decided it would be wise to follow nature's plan of "big fish eat little fish," and thenceforth gave up vegetarianism.

In most cities with public aquaria it is a regular practice with some schools to take classes of students to observe the marvels of fish life.

Indeed the public aquarium is a place in which we all can ponder. The impossible little Box Fish, unbelievably propelled by tiny transparent fins; fantastic Sea-ravens with beady eyes and enormous mouths ready to swallow victims as large as themselves; Angel Fish whose colors challenge our best analines; Gars perfectly poised to pounce on their little victims; fish with stony, sinister little blue eyes; Squirrel Fish with large, limpid eyes; fish with short, powerful jaws for crushing shells; File Fish, as flat as a pancake, a mere shrunken skeleton covered with skin; Flounders concealed in the sand (only their protruding eyes showing) awaiting some unsuspecting victim; droll little Sea-horses and fish that attach themselves to other fish for a free ride. These and hundreds of other wonder-provoking specimens freshly awaken us to the existence of lives so vastly different from our own, and we ponder on how they fit into the Pattern of Things, and possibly how we would appear to them, were the conditions reversed! 
CHAPTER TWENTY-TWO

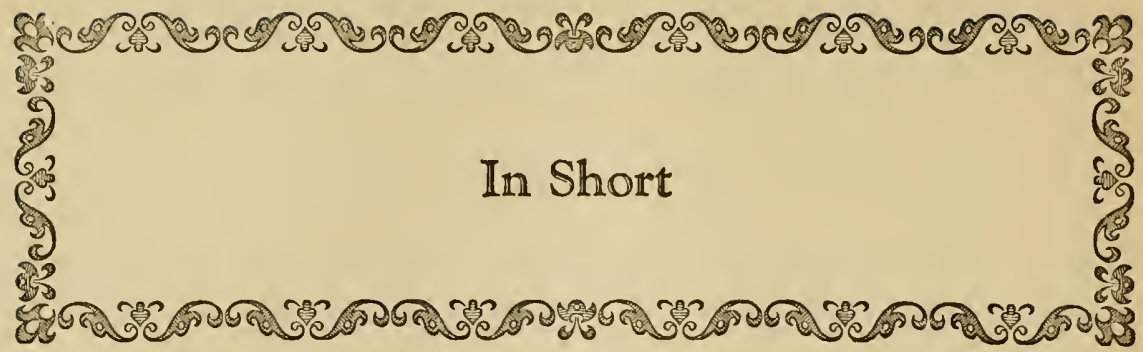

Feed sparingly.

Don't overcrowd.

Share your knowledge.

Treat sick fishes promptly.

Occasionally re-read chapter one.

Don't start with expensive fishes.

Remember coal gas poisons fishes.

Don't keep large and small fishes together.

Better not try to move large filled aquaria.

Be sure to replace covers on tropical aquaria.

Always sterilize net after lifting a diseased fish.

Don't leave fishes outdoors until frost threatens.

Don't use coarse nets. Brussels netting is better.

Fishes enjoy a change of food as much as you do.

If you sell your surplus stock get a fair price for it.

Thoroughly cleanse plants before introducing them.

Don't heat with oil stoves if anything else can be had.

Don't entrust the feeding to others if it can be avoided.

It is well to remember that some cats are good fishermen.

It is highly important to quickly remove unconsumed food.

Don't as a beginner, disregard the greater experience of others.

Don't assume that ordinary artificial light is of benefit to plants.

Muddy water will probably stop an aquarium leak in a few days.

Goldfishes cannot be expected to grow much in a small aquarium.

Don't slide all-glass aquaria. Scratches may cause them to crack.

Be careful of the plants in catching a fish. A little patience will repay.

Don't overwork the aquarium hobby. It will last longer in moderation.

Temperature changes of water, either higher or lower, must never be sudden.

Be sure to disinfect an aquarium where there has been a contagious disease. 
Don't forget to allow freshly-drawn water to stand before use, especially in winter.

Don't depend upon running water, but balance your aquarium with proper conditions.

Safety requires a week's quarantine before placing new fishes in with your stock.

Take occasion, once in a while, to give your fishes a meal of chopped earthworms.

First look through a catch of daphnia for enemies before feeding them to the fishes.

Don't treat diseased fishes with salt water in an aquarium containing plants or snails.

Don't be stingy, but give away a few interesting fishes to those who might become fanciers.

Don't use aquatic plants at all unless the aquarium is near a window with plenty of light.

Don't suppose that a few plants can do much water-purifying. A liberal number of them is needed.

Don't, as a beginner, purchase a igoldfish with very long fin development. It is apt to be past its prime.

Don't attempt to keep aquatic plants in a very subdued light. They cannot prosper and only do harm.

Even though goldfishes and certain tropicals get along together, it is better taste to keep them in separate aquaria.

If your home must be shut for several days, don't worry about the fish starving. They will be all right if the temperature is correct.

Don't resort at once to chemical treatment of a fish a little out of condition. A change of food or of aquarium may be all that is needed.

Don't overlook the great possibilities of the native fish aquarium, both freshwater and marine. The terrarium, too, is well worthy of attention.

Don't keep fishes in galvanized iron or zinc receptacles, nor have copper or brass in contact with aquarium water. Unseasoned wood is bad; unseasoned concrete, fatal.

If goldfish are to be brought indoors for the winter, wait for cool, but not cold, weather. A great change in temperature, even when graduated over several days, is injurious. If possible, fill the aquarium with the same water they had outdoors. 


\section{ILLUSTRATIONS AND THEIR SOURCES}

Frontispiece. Veiltail Goldfish. Bred by Thomas Ayling and owned successively by Franklin Barrett and Otis T. Gregg. Photograph from Life by the Author.

End Papers. Original Drawing by Franklin Barrett.

\section{FigURE}

1. Deep Aquarium. Drawn by Wm. L. Bockius

2. Shallow Aquarium. Drawn by $W m$. L. Bockius................

3. Ordinary Type Fish-Globe. Drawn by Wm. L. Bockius $\ldots \ldots \ldots \ldots \ldots \ldots \ldots$. 9

4. Flattened Globe. Drawn by Wm. L. Bockius................... 9

5. Dish-shape Globe. Drawn by Wm. L. Bockjus................. 9

6. Keystone Globe. Drawn by Wm. L. Bockius................. 11

7. African Snail. Drawn from Life by John A. Bauer................. 18

8. Ramshorn Snail. Drawn from Life by John A. Bauer.............. 18

9. Japanese Snail. Drawn from Life by John A. Bauer................. 18

10. Freshwater Mussel. Drawn from Life by Evelyn B. Innes........... 20

11. Weatherfish. Drawn from Life by Henry W. Fowler............. 20

12. Plant Roots. Drawn by the Author....................... 25

13. Sagittaria natans. Drawn by Franklin Barrett................... 29

14. Giant Sagittaria. Drawn by Franklin Barrett.................. 30

15. Ludwigia. Drawn by Franklin Barrett...................... 31

16. Sagittaria subulata. Drawn by Franklin Barrett................... 31

17. Vallisneria spiralis. Drawn by Franklin Barrett................. 33

18. Giant Vallisneria. Drawn by Franklin Barrett.................... 35

19. Cabomba. Traced from Photograph by the Author............... 37

20. Giant Anacharis. Drawn by Helen Winchester................. 37

21. Wild Anacharis. Drawn by Helen Winchester ................. 38

22. Myriophyllum. Drawn by Helen Winchester.................. 40

23. Bladderwort. Drawn by Helen Winchester................... 40

24. Hair Grass. Drawn by Franklin Barrett........................ 41

25. Potainogeton densus. Drawn by Henry P. Schwing............... 42

26. Nitella gracilis. Drawn by Helen Winchester..................... 42

27. Cultivated Ludwigia. Drawn by Franklin Barrett................. 44

28. Southern Spatterdock. Drawn by Henry P. Schwing.............. 45

29. Japanese Spatterdock. Drawn by Henry P. Schwing................ 46

30. Quillwort. Drawn by W. A. Poyser...................... 47

31. Fontinalis gracilis. Drawn by Mary Weber........................ 48

32. Fontinalis antipyretica. Drawn from Life by Mary Weber............ 48

33. Herpestis. Drawn by Franklin Barrett....................... 50

34. Spring Starwort. Drawn by Helen Winchester.................... 50

35. Madagascar Lace Plant. Drawn by Franklin Barrett............... 51

36. Mare's Tail. Drawn by Franklin Barrett.................... 52

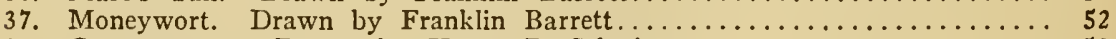

38. Cryptocoryne. Drawn by Henry P. Schwing................. 53

39. Heteranthera. Drawn by Franklin Barrett..................... 54

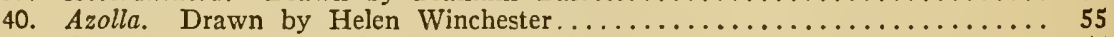

41. Crystalwort. Drawn by Helen Winchester.................... 55

42. Duckweed. Drawn by Helen Winchester...................... 55

43. Water Poppy. Drawn by Henry P. Schwing................... 55

44. Salvinia. Drawn by Henry P. Schwing................... 56

45. Trianea. Drawn by Henry $\mathrm{P}$. Schwing ......................... 56 
46. Frogbit. Drawn by Henry P. Schwing.................. 57

47. Water Lettuce. Drawn by Henry P. Schwing................... 58

48. Water Fern. Drawn by Henry P. Schwing ................... 59

49. Water Chestnut. Drawn by Henry P. Schwing................. 59

50. Water Hyacinth. Photograph by the Author..................... 61

51. Water Snowflake. Photograph by the Author.................. 62

52. Water Lily. Courtesy of Henry A. Dreer Company................. 63

53. Lotus. Courtesy of Henry A. Dreer Company.................... 64

54. Aquatic Cutworm. Drawn from Life by Henry P. Scbwing........... 66

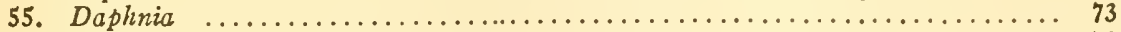

56. Mosquito Larva. After Howard ........................ 73

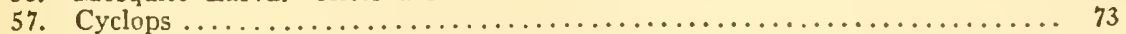

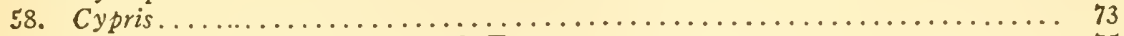

59. Carrying Case and Live-Food Trays......................... 75

60. Bloodworm. Drawn from Life by Helen Winchester.............. 78

61. Tubifex Worms. Drawn from Life by Helen Winchester............ 78

62-64. Rotifers. Drawn from Life by Dr. F. J. Myers................. 79

65. Freshwater Shrimp. Drawn from Life by Helen Winchester............. 79

66. White Worm Feeder. Drawn by Wm. L. Bockius................. 80

67. Daphnia. Photo-micrograph by Chauncey Juday.................. 81

68. Breeding Establishment. Photograph by George Seip ............ 82

69. Fish With Fungus. Drawn from Life by Franklin Barrett............ 86

70. Fish Louse. Drawn from Life by Helen Winchester............... 92

71. Water Tiger. Drawn from Life by Helen Winchester................ 96

72. Spearmouth. Drawn from Life by Helen Winchester............... 97

73. Dragon Fly. Drawn from Life by Helen Winchester............... 97

74. Dragon Fly Larva. Drawn from Life by Helen Winchester............ 97

75. Diving Beetle. Drawn from Life by Helen Winchester............... 98

76. Water Scavenger Beetle. Drawn from Life by Helen Winchester.......... 98

77. Water Strider. Drawn from Life by Helen Winchester.............. 99

78 and 79. Giant Water Bugs. Drawn from Life by Helen Winchester........ 99

80. Water Scorpion. Drawn from Life by Helen Winchester............. 100

81 and 82. Whirligig Beetle. Drawn from Life by Helen Winchester......... 100

83. Water Boatman. Drawn from Life by Helen Winchester.............. 100

84. Water Mite. Drawn from Life by Helen Winchester................ 101

85. Hydra. Drawn from Life by Evelyn B. Innes................... 101

86. Cut in Angle Brass. Drawn by John A. Bauer................. 105

87. Aquarium Frame and Wooden Form. Drawn by John A. Bauer......... 105

88. Wooden Tank. Drawn by John A. Bauer................... 110

89. Concrete Aquarium (In Colors). Photograph by the Author........... 111

90. Seining for Black-Banded Sunfishes. Photograph by the Author.......... 112

91. Simple Concrete Pool, Drawn by Lewis M. Dorsey, Jr............. 114

92. Strong Concrete Pool, Drawn by Lewis M. Dorsey, Jr.............. 115

93. Straight-side Raised Concrete Pool. Photograph by the Autbor......... 117

94. Straight-side Raised Concrete Pool in Use. Photograph by the Author..... 117

95. Concrete Pool and Bog. Photograph by the Author................ 118

96. Fish Nets. Drawn by Andrew Koler ....................... 119

97. Razor-Blade Scraper. Drawn by Andrew Koler.................. 120

98. Aquarium Forceps. Drawn by John A. Bauer................ 120

99. Planting Stick. Drawn by John A. Bauer.................. 121

100. Aquarium Scissors. Drawn by John A. Bauer................ 121

101. Funnel Trap for Live-Bearers. Drawn by John A. Bauer............ 122

102. Aquarium Trap for Live Bearers. Drawn by John A. Bauer.......... 122

103. Glass Breeding-Cage. Drawn by Wm. L. Bockius............... 123

104. Mat of Glass Bars. Drawn by Wm. L. Bockius................. 124

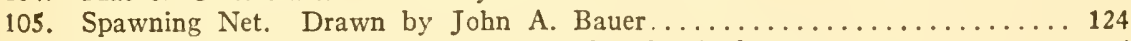

106. Water Circulation Apparatus. Drawn by the Author............. 125

107. Fish Carrying Case. Drawn by John A. Bauer................... 127

108. Glass Feeding Ring. Drawn by Jobn A. Bauer................ 127

109. Fourteen Figures of Microscopic Life in Water. Drawn by Dr. F. J. Myers. 129 
Figure

110. Young Calico Telescope Goldfish (In Colors). Fish Owned by C. C. Vowinkel.

Photograph from Life by the Author................... 131

111. Photographing Aquarium. Photograph by the Author.............. 132

112. Photographing Apparatus. Drawn by John A. Bauer.............. 134

113. Sea Horse. Drawn from Life by Henry W. Fowler................ 140

114. Swamp Aquarium. After German Print..................... 143

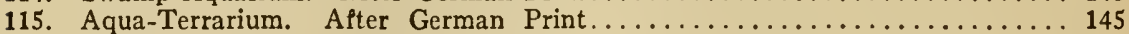

115a. Pine-tree Lizard. Photograph from Life by the Author.............. 146

116. Skink. Photograph from Life by the Author................... 146

117. Geographic Turtles. Photograph from Life by the Author............. 147

118. Soft-Shelled Turtle. Photograph from Life by the Author............ 147

119. American Chameleon (In Colors). Photograph from Life by the Author.... 143

120. Section of Hand Net. Drawn by John A. Bauer................. 152

121. Southern Minnow. Photograph from Life by the Author............. 157

122. Rainbow Darter. Owned and Photographed from Life by the Author..... 157

123. Orange-Spotted Sunfish. Owned and Photographed from Life by the Author.. 158

124. Blue Spot Sunfish. Owned and Photographed from Life by the Author..... 158

125 and 126. Silverfin. Owned and Photographed from Life by the Author...... 159

127. Killifish. Owned and Photographed from Life by the Author.......... 160

128. Black-Banded Sunfish. Owned and Photographed from Life by the Author. 160

129. Golden Ide. Owned and Photographed from Life by the Author......... 161

130. Redfin. Owned and Photographed from Life by the Author............ 161

131. Chub Sucker. Owned and Photographed from Life by the Author....... 162

132. Shiner. Owned and Photographed from Life by the Author........... 162

133. Colored Carp. Owned and Photographed from Life by the Author....... 163

134. Mud Trout. Owned and Photographed from Life by the Author........ 163

135. Black-Headed Minnow. Owned and Photographed from Life by the Author.. 164

136. Pearl Roach. Owned and Photographed from Life by the Author........ 164

137. Red-Bellied Dace. Drawn from Life by Henry W. Fowler........... 166

138. Rosy-Sided Dace. Drawn from Life by Henry W. Fowler............. 166

139. Black-Nosed Dace. Drawn from Life by Henry W. Fowler............ 167

140. Sticklebacks. Drawn from Life by Franklin Barrett................ 163

141. Catfish. After Jordan and Evermann....................... 169

142. Golden Orfe. Drawn from Life by Henry W. Fowler................ 169

143. Golden Tench. Drawn from Life by Henry W. Fowler.............. 170

144. Sole. Drawn from Life by Henry W. Fowler................. 171

145. Single-Tail Goldfish. Drawn by Franklin Barrett.............. 175

146. Tripod-Tail Goldfish. Drawn by Franklin Barrett................ 175

147. Web-Tail Goldfish. Drawn by Franklin Barrett.................. 175

148. Double-Tail Goldfish. Drawn by Franklin Barrett............... 175

149. Common Goldfish. Drawn from Life by Henry W. Fowler. . . . . . . . . . 177

150. Comet Goldfish. Drawn from Life by Henry W. Fowler............ 178

151. Shubunkin Goldfish. Drawn from Life by Henry W. Fowler.......... 178

152. Fantail Goldfish. Drawn from Life by Henry W. Fowler.............. 179

153. Japanese Fringetail Goldfish. After Life Sketch by Franklin Barrett....... 180

154. Nymph Goldfish. Drawn from Life by Henry W. Fowler............ 181

155. Chinese Telescope Goldfish. Drawn from Life by Henry W. Fowler....... 182

156. Chinese Scaleless Telescope Goldfish. Drawn by Henry P. Schwing........ 183

157. Ideal Veiltail Calico Telescope Goldfish. Drawn by Henry W. Fowler....... 184

158. Chinese Moor Goldfish. Drawn by Henry W. Fowler................ 185

159. Celestial Goldfish (Dorsal View). Drawn by Henry W. Fowler.......... 186

159. Celestial Goldfish (Dorsal View). Drawn by Henry W. Fowler........ 186

161. Oranda Goldfish. Drawn from Life by Henry W. Fowler............. 188

162. Precociously Developed Goldfish. Photograph from Life by the Author.... 189

163. Strong Young Goldfish. Photograph from Life by the Author.......... 189

164. Aquarium Exhibition, Philadelphia. Photograph by the Author......... 190

165. Prize-winning Scaleless Telescope Goldfish. Photograph from Life by Author.. 191

166a and 166b. Medal, Aquarium Society of Philadelphia. Photograph by Author.. 192

167. Telescopic-eyed Shiner. Photograph from Life by the Author........... 192

167a. Perfect Shubunkins. Photographed in Natural Colors................... 192a

168. Comet Goldfish (Diagram). Drawn by Franklin Barrett............. 195

169. Nymph Goldfish (Diagram). Drawn by Franklin Barrett............. 195 
170. Veiltail Goldfish (Diagram). Drawn by Franklin Barrett............. 195

171. Ribbontail Goldfish (Diagram). Drawn by Franklin Barrett............. 195

172. Veiltail Telescope Goldfish (Diagram). Drawn by Franklin Barrett....... 195

173. Oranda Veiltail Goldfish (Diagram). Drawn by Franklin Barrett........ 195

174. Lionhead Goldfish (Diagram). Drawn by Franklin Barrett........... 196

175. Celestial Goldfish (Diagram). Drawn by Franklin Barrett........... 196

176. Cut.out Tail Goldfish (Diagram). Drawn by Franklin Barrett ......... 196

177. Veiltail Goldfish (Diagram). Drawn by Franklin Barrett............... 196

178. Common Goldfish. Photograph from Life by the Author............. 201

179. Fantail Goldfish. Photograph from Life by the Author............. 201

180. Scaleless Comet Goldfish. Photograph from Life by the Author......... 202

181. High-grade Commercial Fantail Goldfish. Photograph from Life by Author. . 202

182. Celestial Goldfish. Photograph from Life by the Author............. 203

183. Veiltail Moor Goldfish. Photograph from Life by the Author......... 203

184 and 185. Lionhead Goldfish. Photograph from Life by the Author........ 201

186. Breeding Female Goldfish. Photograph from Life by the Author........ 209

187. Breeding Male Goldfish. Photograph from Life by the Author......... 209

188. Goldfishes Spawning. Photograph from Life by the Author.......... 210

189. Goldfish Eggs on Plants. Photograph from Life by the Author......... 211

190. Goldfish Eggs, Three Days Old. Photograph from Life by the Author..... 212 191-196. Development of Goldfish Eggs. Drawn under Microscopical Observations

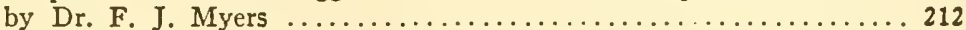

197 and 198. Goldfish Fry. Drawn from Life under Microscopical Observations

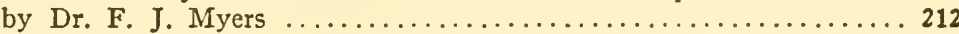

199. Newly Hatched Goldfishes. Photograph from Life by the Author....... 213

200. Goldfishes at Eighteen Days. Photograph from Life by the Author...... 213

201. Goldfishes at Six Weeks. Photograph from Life by the Author........ 214

202. Goldfishes at Twelve Weeks. Photograph from Life by the Author....... 214

203. Adult Telescope Goldfish. Photograph from Life by the Author........ 215

204. Adult Scaleless Veiltail Goldfish. Photograph from Life by the Author.... 215

205. Adult Oranda Goldfish. Photograph from Life by the Author......... 216

206. Rearing Ponds for Fancy Goldfish. Photograph by Alfred C. Bliss....... 225

206a. Live Boxes. Photograph by the Author .................... 225

207. Breeding Ponds With Boarded Edges. Photograph by the Author....... 226

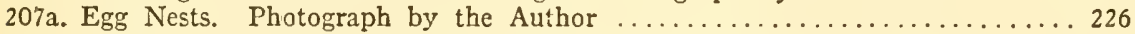

208. Kitchen on a Modern Goldfish Farm. Photograph by the Author....... 227

208a. Pantry on a Large, Fancy Goldfish Farm. Photograph by the Author..... 227

208b. Sorting Common Goldfish. Photograph by the Author................ 228

208c. Japanese Grading Fancy Goldfish. Photograph by the Author.......... 228

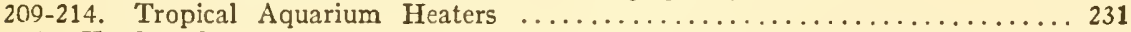

215a. Hyphessobrycon rosaceus. Natural color photograph by the Author.........236a

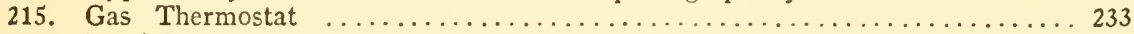

216. Fundulopanchax caeruleus (Blue Gularis). Photograph from Life in natural colors by the Author. Fish owned by Joseph E. Bausman......... 245

217. Fundulopanchax bivittatum. After German Illustration................ 246

218. Fundulus chrysotus. Owned by J. L. Troemner. Photograph from Life by

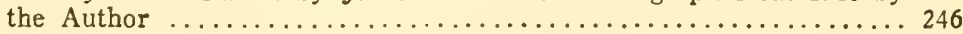

219. Rivulus ocellatus. Photograph by the Author................... 247

220. Rivulus tenuis. Photograph by the Author.................... 247

221. Rivulus rachovi. Photograph by the Author...................... 247

222. Rivulus harti. Photograph by the Author...................... 248

223. Chriopeops goodei. Owned and Photographed from Life by the Author.... 248

224. Jordanella floridae. Owned by J. L. Troemner. Photograph from Life by

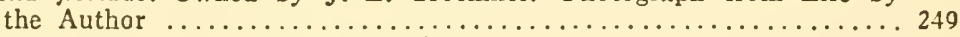

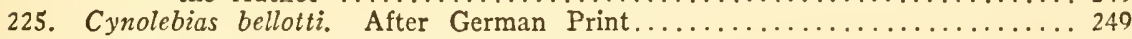

226. Epiplatys chaperi. Photograph by the Author.................... 250

227. Pachypanchax playfairii. Photograph by the Author.................. 250 228 and 229. Panchax lineatus. Owned and Photographed from Life by the Author 251 230. Panchax panchax. Photograph by the Author.................... 252

231. Aphyosemion australe. Fish Owned and Photographed from Life by Author.. 252

232. Mollienisia latipinna (male and female). Owned and Photographed from Life

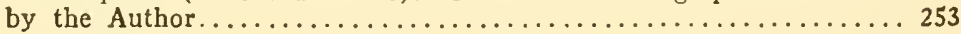




\section{FigURE}

233. Platypoecilus maculatus niger. Photograph by the Author............. 254

234. Mollienisia latipinna. Owned and Photographed by the Author........... 254

235. Platypoecilius maculatus. Photograph from Life by the Author........... 254

235a. Mollienisia latipinna (golden). Natural color photograph by the Author.....254a

236. Lebistes reticulatus. After German Illustration.................. 255

237. Gambusia afinis. Fishes Owned and Photographed from Life by the Author 255

238. Parents of Hybrids (Seven Figures). Fishes Owned by the Author and Photo-

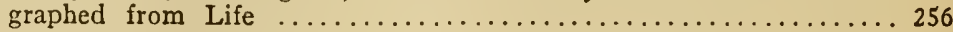

239. Red Hybrids (male and female). Owned and Photographed from Life by

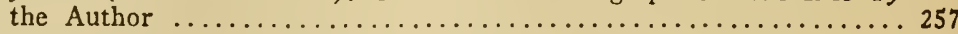

240. Mollienisia specics. After German Illustration............................ 258

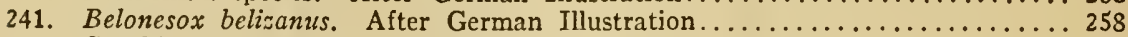

242. Croaking Gourami. After German Illustration.................. 259

243. Betta splendens (Cambodia). Photograph by the Author............... 260

244. Betta splendens (Veiltail). Photograph by the Author................ 261

245. Macropodus cupanus dayi. After German Illustration................. 261

246. Three-Spot Gourami. Photograph from Life by the Author............. 262

247. Giant Gourami. Owned by Joseph E. Bausman. Photograph from Life by

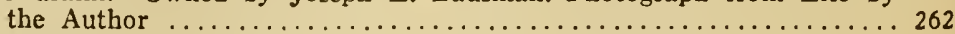

248. Dwarf Gourami. Owned by Joseph E. Bausman. Photograph from Life by

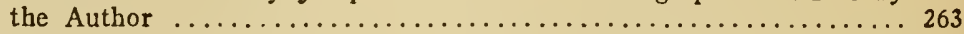

249. Paradise Fish. Owned by Franklin Barrett. Photograph from Life by Author 263

250. Roundtail Paradise Fish. Owned and Photographed from Life by the Author 263

251. Channa asiatica. Owned and Photographed from Life by Author......... 264

252. Climbing Perch. Owned by Louis Burk. Photograph from Life by Author.. 264

253. Pterophyllum scalare. Owned by Louis Burk. Photograph from Life by Author 265

254. Cichlasoma festivum. Photograph by the Author................... 266

255. Cichlasoma severum. Photograph by the Author.................. 266

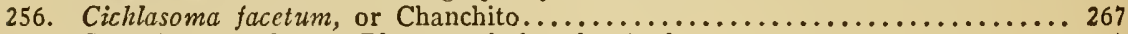

257. Etroplus maculatus. Photograph by the Author................. 267

258. Hemichromis bimaculatus, or Jewel Fish ................... 267

259. AEquidens latifrons. Owned by Franklin Barrett. Photograph from Life by

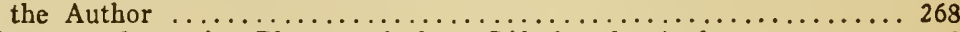

260. AEquidens portalegrensis. Photograph from Life by the Author.......... 268

261. Cichlasoma biocellatum, or Jack Dempsey. Photograph from Life from Fish

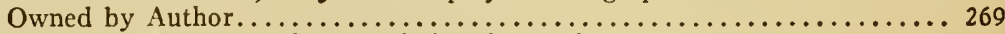

262. Geophagus braziliensis. Photograph by the Author..................... 269

263. AEquidens curviceps. Owned by Franklin Barrett. Photograph from Life by

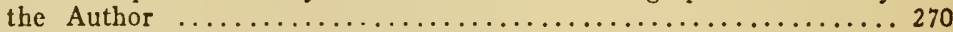

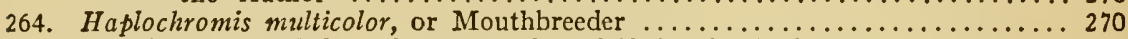

265. Tilapia macrocephala. Photograph from Life by the Author....................... 271

266. Ctenobrycon spilurus. Owned by J. L. Troemner. Photograph from Life by the Author

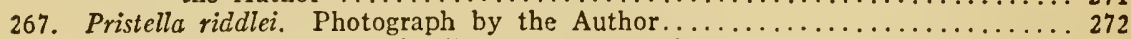

268. Copeina guttata. Owned by J. L. Troemner. Photograph from Life by Author 272

269. Hyphessobrycon flammeus. Photograph by the Author.............. 273

270. A phyocharax rubripinnis. Photograph by the Author............... 273

271. Mimagoniates barberi. Photograph by the Author................ 274

272. Moenkhausia oligolepis. Photograph by the Author................ 274

273a. Mollienisia sphenops. Natural color photograph by the Author............274a

273. Charicidium rachovi. Photograph by the Author................. 274

274. Rasbora heteramorpha. Photograph by Author................... 275

275. Danio malabaricus. After German Illustration................... 275

276. Brachydanio nigrofasciatus. Photograph by the Author................ 276

277. Brachydanio rerio. After German Illustration ................... 276

278. Brachydanio albolineatus. Owned and Photographed by the Author...... 276

279 and 280. Fundulus notti. Photograph by the Author.............. 277

281. Barbus everetti. Photograph by the Author........................ 277

282. Barbus semifasciolatus. Owned and Photographed from Life by the Author.. 278

283. Barbus conchonius. Owned and Photographed from Life by the Author.... 278

284. Ambassis ranga. Photograph by the Author................... 279

285. Butterfly Fish. Owned by J. L. Troemner. Photograph from Life by Author 279 
286. Polycentrus schomburgki. Photograph by the Author............... 280

287. Scatophagus argus. Photograph by the Author................... 280

288. Badis badis. Photograph by the Author...................... 281

289. Tetraodon fluviatilis. Owned by Franklin Barrett. Photograph from Life by

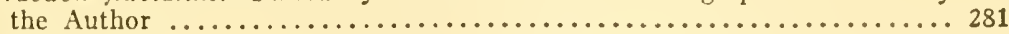

290. Melanotaenia nigrans. Photograph by the Author................... 282

291. Malapterurus electricus. After German Print .................. 282

292. Pimelodella gracilis. Photograph by the Author.................... 283

293. Corydoras undulatus. Photograph by the Author................... 283

294. Hypostomus species. Owned by J. L. Troemner. Photograph from Life by

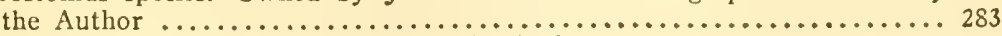

295. Dormitator maculatus. Photograph by the Author................... 284

296. Euchoristopus barbarus. After German Print................... 284

296a. Notropis lutrensis. Natural color photograph by the Author..............284a

297. Fairmount Park Aquarium, Philadelphia. Photograph by the Author....... 299

298. Interior, Battery Park Aquarium, New York. Photograph by Elwin R.

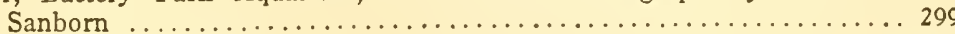

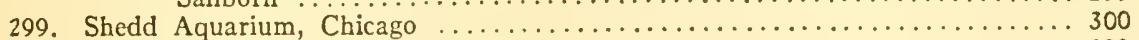

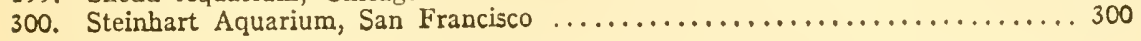




\section{BIBLIOGRAPHY}

A Bibliography usually undertakes to present a general outline of the literature on a subject, and to especially include the sources from which the author has drawn. No such attempt is made here. Except for a few of the early outstanding classics on aquarium study we mention only works, which, in our opinion, are likely to be of interest to our readers, and which there is a reasonable chance of procuring.

European interest in the aquarium had a sudden awakening in about 1850 , and for some years a flood of books followed. These were much alike and naturally were written out of a considerable inexperience. One of those authors (Arthur M. Edwards in "Life Beneath the Waters," New York, 1858) in setting forth his standing as a competent authority submits the fact that he has kept an aquarium for two years! Pages 91 and 92 contain statements too interesting to pass by unquoted:

"Sixty degrees of Fahrenheit's scale is about as high as we should allow the aquarium temperature to rise." If in danger of passing this point it is recommended to "wrap the aquarium in coarse cloth, kept saturated with water." As to white fungus disease, which seems to have been known as "the slime," the author directs that the fish be placed in "a pail full of fresh water and throw over it a handfull of silver sand, so that it may fall on the skin of the fish. It will cause it to rub itself and entirely eradicate the slime without injurying the fish," followed by the fatal admission "I have lost many gold-fish from this disease." Again we are told "Sometimes the tail becomes coated with a fungoid growth. The tail should be removed at once with a pair of fine scissors."

On the other hand Robert Warrington, an Englishman, as far back as 1850 set forth, in papers before The Chemistry Society and in the "Annals and Magazine of Natural History," the correct principles of the "balanced aquarium."

Aquarium keeping at that period seems to have been more of a fad than a hobby, and, with its passing, the tide of books subsided considerably. The subject of course continued to develop among scientific investigators, but the literature experienced no great advance until towards the close of the century, coincident with the importation of tropical fishes and highly developed gold-fishes. Innumerable aquarium societies sprung up in Europe, especially in Germany, and it is to their support and influence that we owe much of our modern literature on the subject. 
Any readers desiring to consult a more elaborate bibliography are referred to that most remarkable work, "A Bibliography of Fishes," by Bashford Dean, published in three volumes by The American Museum of Natural History in New York. For the convenience of our readers we have arranged to sell any of the listed books showing prices.

Arderon, F.R.S., William On Keeping of Small Fish in Glass Jars; and of an easy method of catching fish.

Philosophical Transactions, No. 44, p. 23-27. London 1747. (First article on the aquarium).

Arnold, Augusta F.

Bade, Dr. E.

Bade, Dr. E.

Bade, Dr. E.

Bade, Dr. E.

Bade, Dr. E.

Bade, Dr. E.

Bade, Dr. E.

Bateman, Rev. Gregory C.

Bateman, Rev. Gregory

Beebe, William

Cassino, Samuel

Comstock, A. B.

Eggeling, Otto and

Ehrenberg, Frederick

Embody, Geo. C.

Fearnow, E. C.

Gluck

Gosse, P. H.

Harring and Myers

Holder, Chas. Frederick

Innes, Wm. T.

Innes, Wm. T.
The Sea Beach at Ebb Tide. The Century Co., New York, 1901.

Das Seewasser Aquarium. \$1.50.

Das Susswasser Aquarium. Bound, $\$ 8.15$; not bound, $\$ 7.00$.

Der Schleierschwanz und der Teleskopschleierschwanz.

Die auslandischen Aquarienfische. $\$ 1.50$.

Die kunstliche Fischzucht. 80 cents.

Praxis der Aquarienkunde. $\$ 1.50$.

Praxis der Terrarienkunde. $\$ 1.50$.

C. Freshwater Aquaria, Their Construction, Arrangement, Etc.

London "The Bazaar, Exchange \& Mart Office." 1925.

C. The Vivarium. Gill, London, 1897.

The Arcturus Adventure: An Account of the New York Zoological Society's First Oceanographic Expedition.

Putnam, New York, 1926.

Edinburgh. McFarlane \& Erskine. 1885.

Naturalists' Directory. Salem, Mass. A comprehensive list of about 4,500 names of scientists, collectors, etc. Tells their specialties and whether they exchange, sell or buy specimens. (A good idea).

Handbook of Nature Study. $\$ 4.00$.

(A textbook for the beginner in the study of fishes, insects, birds, plants, etc.)

The Fresh-Water Aquarium and Its Inhabitants.

Henry Holt \& Co., New York, 1908.

The Fish Notebook (Nature Notebook Series).

Comstock Pub. Co., Ithaca, N. Y.

Goldfish; Their Care in Small Aquaria.

Washington, Government Printing Office. 1923.

Biologische und morphologische Untersuchungen uber Wasser und Sumpfgewachse. (Four parts).

Gustav Fischer. Jena, 1924. (The standard work on aquatic plants, but has not been translated).

The Aquarium: An Unveiling of the Wonders of the Deep Sea London, 1856.

The Rotifera of Wisconsin. University of Wisconsin, 1924-26.

(Describes most of the known Rotifera of the world).

Method of Studying the Life History of Fishes; Also Plan for an Educational Exhibit of Fishes.

Government Printing Office, Washington, 1910.

The Modern Aquarium. \$1.00.

Innes Publishing Co., Philadelphia

Exotic Aquarium Fishes, 1935, $\$ 5.00$

Innes Publishing Co., Philadelphia

The Aquarium, a monthly magazine, $\$ 2.00$ yearly

Innes Publishing Co., Philadelphia

Jonstonus, M.D., JohannesDe Piscibus. Amsterdam, 1657. (First natural history on fishes). 
Jordan and Evermann Kendall, William C.

Krefft, P.

La Gorce, John Oliver

Leonhardt, E. E.

Mather, Frederick

Matsubara, S.

Mellen, Ida M.

Mellen \& Lanier

Morgan, Alfred

Morgan, Ann Haven

Mulertt, Hugo

Myers, George S.

Needham and Lloyd

Norman, J. R.

Osburn, Raymond C.

Peters, C. H.

Ramsey, L. W. and

Lawrence, Chas. H. Reuter, Dr. Fritz

Rossmassler, E. A. Ryder, John A.

Samuel, Mark

Sauvigny

Seal, William $\mathbf{P}$.

Smith, Eugene

Smith, Hugh M.

Stead, David G.

Stoye, F. H.

Stranahan, J. J.

Townsend, Chas.

Ward, Lester F.

Ward and Whipple
The Fishes of North and Middle America. 1896.

Fresh-Water Crustacea as Food for Young Fishes.

U S. Bureau of Fisheries, Washington, 1921.

Das Terrarium. Fritz ${ }^{\circ}$ fennigstorff, Berlin, 1907.

Book of Fishes.

National Geographic Society, Washington, 1924.

Das Susswasser-Aquarium. Strecker \& Scroeder, Stuttgart, 1923.

Fishes Which Can Live in Both Salt and Fresh-Water. Transactions of American Fish Cultural Ass'n, N. Y., 1881.

Goldfish and Their Culture in Japan.

Proceedings of the Fourth International Fishery Congress, Washington (1908). 1909.

Fishes in the Home. $\$ 2.00$.

1000 Questions Answered About Your Aquarium, \$3.00

Dodd, Mead \& Co., or through Innes Publishing Co., Phila.

An Aquarium Book for Boys and Girls, $\$ 2.50$

Charles Scribncr's Sons, or through

Innes Publishing Co., Philadelphia

Field Book of Ponds and Streams. Putnams, N. Y., 1930. $\$ 3.50$.

(An excellent guide to the general study of aquatic life.)

The Goldfish and Its Systematic Culture.

Clarke, Cincinnati, 1883.

The Aquarium and Its Denizens.

A. M. Roth, World Bldg., Baltimore, Md.

Life in Inland Waters.

A History of Fishes, $\$ 7.00$

Ernest Benn, Ltd., London

The Care of Home Aquaria.

New York, New York Zoological Society, 1914.

Life and Love in the Aquarium, $\$ 3.00$

Through Innes Publishing Co., Philadelphia

Garden Pools. 1930. $\$ 2.50$.

(One of the best books on water gardening.)

Through Innes Publishing Co., Philadelphia

Die fremdlandischen Zierfische.

J. E. G. Wegner, Stuttgart, Germany, 1913.

Het Zoetwater-Aquarium. Leyden, 1872.

The Inheritance of Modifications due to Disturbances of the Early Stages of Development, especially in the Japanese Domesticated Races of Gold-Carp.

Proceedings of the Academy of Natural Sciences, Phila., 1893. The Amateur Aquarist. The Baker \& Taylor Co., N. Y., 1894.

Histoire Naturelle des Dorades de la Chine. 1780.

The Aquarium: A Brief Exposition of Its Principles and Management.

Bulletin of the Bureau of Fisheries. Vol. y., Washington, 1889

The Home Aquarium and How to Care For it.

New York, Dutton \& Co., 1902.

Japanese Goldfish, Their Varieties and Cultivation.

Washington, W. F. Roberts Co., 1909.

The Aquarium in Australia.

Aquarium Society of New South Wales, Sydney, 1011.

Tropical Fish for the Home, Their Care and Propagation, $\$ 4.00$

Through Innes Publishing Co., Philadelphia

Fish Culture on the Farm.

Transactions of the American Fisheries Society, N. Y., 1903.

The Cultivation of Fishes in Natural and Artificial Ponds.

Report of the New York Zoological Society. New York, 1906

Marsh and Aquatic Plants of Northern United States.

Bulletin of Bureau of Fisheries, Vol. 3, Washington, 1883.

Freshwater Biology. John Wiley \& Sons, New York, 1918. \$7. 


\section{CROSS INDEX}

\begin{tabular}{|c|c|}
\hline $\begin{array}{r}\text { Page } \\
\end{array}$ & PAGE \\
\hline Abramis crysoleucas . . . . . . 154, $* 162$ & Bog Plants. \\
\hline Acara thayeri .... & Boiled Water .. \\
\hline Acid-Alkali Tests & Brachydanio albolineatus \\
\hline Equidens curviceps & Brachydanio nigrofascialus ........ \\
\hline Equidens latifrons .... & Brachydanio rerio ............... \\
\hline Eqquidens porlalegrensis & $15,105,123$ \\
\hline$\ldots \ldots 22,135,234$ & Breeding Age...... \\
\hline Alphabetical List of Fishes .......285 & Breeding Establishment .... \\
\hline Alga $\ldots \ldots \ldots \ldots \ldots \ldots . . . . . .$. & Breeding Female (Goldfish) \\
\hline Aluminum.. & Breeding Goldfishes ............198, 223 \\
\hline Ambassis lala ................. & Breeding Habits, Tropical Fishes.... 237 \\
\hline Ammonia Treatment .......... & Breeding Male (Goldfish) ........ \\
\hline Anyda spinifera ... & Brceding Methods ........ \\
\hline Anabas testudincus $\ldots . . . \ldots \ldots \ldots$. & Breeding Ponds $\ldots \ldots \ldots \ldots \ldots \ldots$ \\
\hline nacharis $\ldots \ldots \ldots \ldots \ldots 36, * 37, * 38$ & Breeding Tropicals Commercially. \\
\hline$\ldots \ldots \ldots \ldots \ldots$ & Butterfly Fish $\ldots \ldots \ldots \ldots \ldots \ldots$ \\
\hline imal Parasites & Cabomba .... \\
\hline carolinensis & Calico Goldfish \\
\hline$r \ldots \ldots \ldots \ldots \ldots \ldots$, & Care Fish Nets ...... \\
\hline Aphyocharax rubripinnis ........ & $\ldots \ldots 155, * 163$ \\
\hline Aphyosemion australe...$\ldots \ldots$. & \\
\hline Aphyosemion callurium ......... 252 & $\ldots \ldots * 186, * 203$ \\
\hline Appliances $\ldots \ldots \ldots \ldots \ldots \ldots$. & $\ldots \ldots \ldots \ldots 117, * 118$ \\
\hline Aquarium Cements...$\ldots \ldots$. & Cements (for aquaria) $\ldots \ldots \ldots \ldots$ \\
\hline Aquarium Construction...$\ldots \ldots$ & Ceratophyllum $\ldots \ldots \ldots \ldots \ldots$ \\
\hline quarium Covers..$\ldots \ldots \ldots \ldots$ & $\ldots \ldots \ldots \ldots \ldots 156, * 160$ \\
\hline Aquarium Exhibition $\ldots \ldots \ldots$. & \\
\hline Aquarium Filter $\ldots \ldots \ldots \ldots \ldots$ & *267 \\
\hline quarium Leaks ........ & Changing Water \\
\hline fuarium Management ........ & a a siatica. \\
\hline erraria ............. & idium rachovi ..... \\
\hline$* 145$ & Chemical Changes in Water ... \\
\hline *66 & ps goodei ............. \\
\hline tic Plants. & $\ldots \ldots \ldots \ldots \ldots \ldots$ \\
\hline olla ................... & Eall ... \\
\hline ack Swimmer ............... 100 & 62,165 \\
\hline dis badis $\ldots \ldots \ldots \ldots \ldots \ldots$ & a biocellatum .. \\
\hline aced Aquarium $\ldots \ldots \ldots \ldots$ & facetum ...... \\
\hline honius & ta festivum ..............*266 \\
\hline Barbus everetti... & na severum ............*266 \\
\hline bus sem & Cleaning Glass . \\
\hline Battery Park Aquarium .......... & te $\ldots . .$. \\
\hline sox belizanus $\ldots \ldots \ldots \ldots$ & Climbing Perch \\
\hline ta splendens (Cambodia)... & $1 \mathrm{Gas} \ldots \ldots \ldots \ldots \ldots \ldots$ \\
\hline splendens (Veiltail) ........ & Ifish (Powdered) $\ldots \ldots \ldots$. \\
\hline 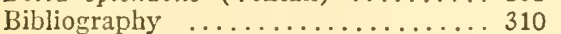 & a fasciatus ... \\
\hline Black-banded Sunfish & $* 263$ \\
\hline & cting IVild Fishes .. \\
\hline headed Minnow & Age $\ldots \ldots \ldots \ldots \ldots \ldots$ \\
\hline Black-nosed Dace . & $\mathrm{s}$ in Goldfish $\ldots \ldots \ldots \ldots \ldots$ \\
\hline Bladderwort ....... & $\ldots * 178, * 202$ \\
\hline od Worms .. & $\ldots * 177, * 201$ \\
\hline Alge ... & $\ldots \ldots \ldots \ldots \ldots * 111$ \\
\hline$* 245$ & $\ldots \ldots * 114, * 117, * 118$ \\
\hline$t$ Sunfish ..... & Constipation . \\
\hline & Construction (Aquaria). \\
\hline
\end{tabular}

*Star indicates that subject is accompanied by illustration. 
PAGE

Construction (concrete aquaria) .... 109

Construction (Pools) ............ 113

Construction (Wooden Tanks) .... 109

Consumption ............... 89

Copeina guttata .................. $* 272$

Copper $\ldots \ldots \ldots \ldots \ldots \ldots \ldots \ldots 15,302$

Corydoras undulatus ...........*283

Croaking Gourami .............259

Cryptocoryne ............... *53

Crystalwort ................55, *56

Ctenobrycon spilurus ...............271

Ctenops vittatus .................*259

Cyclops .................73, 76

Cynolebias belloti ....................*249

Cyprinus carpio ................163

Cypris .................... *73

Danio albolineatus ..............*276

Danio malabaricus ...............275

Danio rerio ...................*276

Daphnia .................*73,*81

Darters ................. 153

Descriptive Key Breeding Habits.... 237

Development Fancy Breeds (Goldfishes)

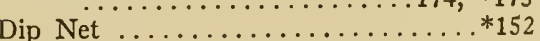

Dip Tube .................... 119

Diseases ................83, 223

Diseases (Tropical Fishes) ....... 94

Disinfecting .................. 102

Dormitator maculatus ...........284

Dragon-Fly Larvæ .............*97

Dropsy .................. 89

Duckweed .................. *55

Dwarf Gourami .................*263

Dytiscus ................... *96

Earthworms .............. 72

Eel ....................... 169

Egg Nests ...................226

Eggs (Goldfish) ............ 200

Electric Light Bug ............* *99

Electric Catfish ................*282

Eleocharis acicularis ............**41

Elodea ....................... *36

Epiplatys chaperi ................250

Enchytrce................. 79

Enemies of Aquatic Plants ....... 66

Enemies of Fishes ............ 96

Enneacanthus gloriosus .........*158

Erimyzon sucetta ...............*162

Etroplus maculatus ............... 267

Euchoristopus barbarus .........*284

Exhibition ..................190

Eye Inflammation ............ 91

Fairmount Park Aquarium ........*299

Fantail Goldfish .......*179, 201, 202

Feeding $\ldots \ldots \ldots \ldots \ldots \ldots \ldots \ldots \ldots \ldots \ldots \ldots \ldots \ldots \ldots, 222$

Feeding Ring ...............127

Feeding (Tropicals) ............ 230

Fin Congestion .............. 85

Fish Capacity Rule ...........8, 234

Fish-carrying Case ...........*127

Fish Diseases ................. 83

Fish Enemies ............ 96
Page

Fishfoods (Living) .......... 72

Fishfoods (Prepared) ......... 67

Fish Lice $\ldots \ldots \ldots \ldots \ldots \ldots \ldots * \ldots 2$

Flies ................... 76

Florida Moss .................2 210

Flukes .................. 92

Fontinalis ............... *48

Food for Baby Fishes $68,71,73, * 78, * 128$

Forceps ................120

Forcing Growth (Goldfishes) ..... 207

Foul Sand ............... 22

Fringetail Goldfish ........179, *180

Frogbit ................ *57

Frogs .................. 102

Fundulopanchax bivittatum ........*246

Fundulopanchax caeruleus ........*245

Fundulus chrysotus ............*246

Fundulus heteroclitus .........*160

Fundulus goodei ..............*248

Fundulus gularus ...............245

Fundullus notti ...............277

Funnel Trap ..................122

Gallon Capacity ............. 10

Galvanized Iron ..............15, 302

Gambusia affinis ................255

Gambusia holbrooki .............255

Gammarus ....................79

Geographic Turtles ............*147

Geophagus braziliensis ............*269

Giant Gourami ...............*262

Giant Water Bug ............. *99

Gill Congestion ................. 90

Girardinus guppyi .................255

Glass Cutting ............. 108

Glass Cleaners ................. 120

Globes ..................... $* 9,10, * 11$

Golden Ide ............161,*169

Golden Moon Fish .............254

Goldfish $172, * 189, * 191, * 201, * 202$, $* 203, * 204, * 209, * 210, * 212, * 213$, $* 214, * 215, * 216$

Goldfish Competitions ........... 193

Goldfish Eggs .............*211, *212

Goldfish Fry ............*212,*213

Goldfish Young ...............214

Grading Goldfish ..............228

Green Water ............... 15

Green Water (Marine) ........ 137

Ground Levels ............... 219

Gum Shellac ............... 126

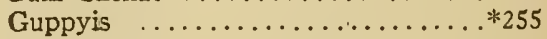

Gyrodactylus .............92, 224

Hair Grass ...............*41

Haplochilus cameronensis ........*252

Haplochilus chaperi ............248

Haplochilus lineatus ............*251

Haplochromis multicolor .........*270

Happy Family Aquarium ......... 244

Hard-Shell Daphnia ............*73

Hatching Time (Goldfishes) ..... 205

Heating (Tropicals) ........... 230 
Page

Heros facetus ................267

Herpestis ................49,*50

Heteranthera ................**54

Hints to Beginners ............ 23

Houseflies .................. 76

Hybrids ................ 256

Hydra ..................101

Hyphessobrycon flammeus ........*273

Hyphessobrycon rosaceus .......*236a

Hypostomus species .............*283

Ichthyophthirius ..........92, 224

Ide ........................161

Idus idus ..................161

Illustrations and their Sources..... 304

In-breeding . . . . . . . . . . . 208

In Short ................... 302

Infusoria ... ..........78, *129, 206

Isnardia ..................*44

Itch $\ldots \ldots \ldots \ldots \ldots \ldots \ldots \ldots . \ldots \ldots$

Judging Scale (Goldfishes) ......... 196

Jordanella florido ..............*249

Killifish ...............154,*160

Kitchen on Goldfish Farm........227

Lace Plant .................*51

Last Resorts .................. 95

Leaks ..................... 108

Lebistes reticulatus .............255

Leeches ................... 91

Length of Life (Goldfishes) ....... 174

Lepomis humilus ..............158

Light . . .............. 13

Lighting (Marine Aquaria) ........ 136

Lily Pool .................*117

Limnanthenum indicum ......... *62

Limpets ................. 19

Lionhead ................204

Lionhead Goldfish ........... . 187

Live-bearers ................. 253

Live-bearing Traps. 121, *122, *123, *124

Live Boxes .................225

Live Food (Carrying) .......... 75

Lotus ..................64 65

Ludwigia . . . . . . . . . . . *31, *44

Macropodus chinensis ...........263

Macropodus cupanus dayi..........*261

Macropodus opercularis .........*263

Macropodus veridi-auratus .......*263

Malopterurus electricus ...........252

Mare's Tail ..............51, *52

Marine Aquaria .............. 135

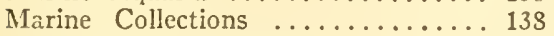

Marine Water .............. 137

Marine Water (Shipping) ........ 137

Marine Water (Temperature) ..... 138

Mealworms .............. 80

Medal (Aquarium Society) .......*192

Melanotaenia nigrans ..........*282

Mesonauta festivum ............266

Mesogonistius chotodon .........*160

Microscope ................ 128

Mimagoniates barbcri .........*274

Mites .................*101

PAGE

Hemichromis bimaculata ........*267

Moenkhausia oligolcpis ..........*274

Mollienisia latipinna.....*249,*254,*254a

Mollienisia species ..............258

Mollienisia sphenops ............. 274a

Monel Metal ................. 136

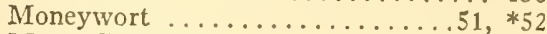

Moor Goldfish ...........*185,*203

Mosquito Larva .............73, 76

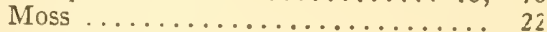

Mouthbreeder ................270

Mud Trout ...................

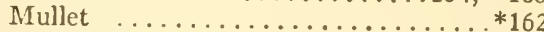

Mussel ....................20

Myers, George S................ 286

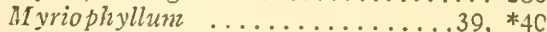

Native Aquarium Fishes............ 151

Nelumbium ..............64, 65

Nets ................... 119

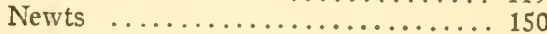

New Wood ................... 15

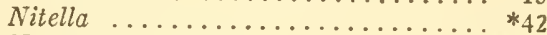

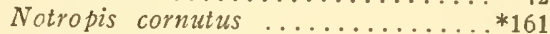

Notropis lutrensis ............... 284a

Notropis whippelei analostanus ....*159

Nymph Goldfish ..............*181

Oranda Goldfish . . . . . . . . .**188, *216

Orange-spotted Sunfish .........*158

Oriental Origin ............ 176

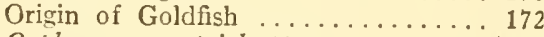

Osphromenus trichopterus ........*262

Panchax lineatus ...............251

Panchax panchax ................252

Pachypanchax playfairii ...........*250

Pantodon buchholi ................279

Pantry on Goldfish Farm .........*227

Paradise Fish ...............

Paraffining ................ 107

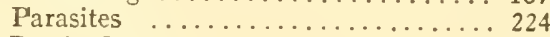

Pearl Organs ............... 181

Pearl Roach ............*155, 164

Permanganate of Potash ......16, 85, 224

Pet Store Man .............. 24

Photographing Aquarium .........*132

Photographing Fishes ........... 133

Pimelodella gracilis ............*283

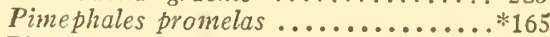

Pine-tree Lizard ...............*146

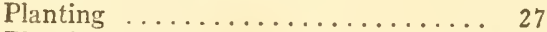

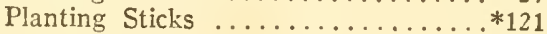

Plant Lice ................ 66

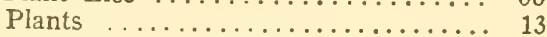

Plants (for Terrarium) ............ 149

Plants in Tropical Aquaria ......... 234

Plants (Necessary Quantity) ..... 26

Plaster-of-Paris ............. 17

Platypoecilus maculatus .............254

Platypoecilus maculatus niger ........*254

Poecilichthys coerulus ..........*15?

Point System (Judging) . . . . . . . . . 193

Polycentrus schomburgki ........*280

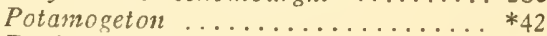

Predaceous Beetle ..............*98 
PAGE

Prices (Goldfishes) ............. 197

Pristella riddlei ...............*272

Pterophyllum scalare ...........*265

Public Aquaria .............. 298

Publisher's Preface ........... 3

Puntius conchonius ............*278

Puntius semifasciolatus .........*278

Pyrrhulina guttata ..............*272

Quillwort .................*47

Rainbow Darter ..............157

Rasbora heteramorpha ..........*275

Rats ..................... 102

Raw Water ............... 12

Rearing Ponds ................*225

Red-bellied Dace ............165,*166

Redfin .................155,*161

Red Hybrids .................. $* 257$

Removing Dust ............. 22

Reversion to Original Type ...... 175

Rivulus harti .................*248

Rivulus ocellatus ..............247

Rivulus rachovi ...............*247

Rivulus tenuis ..............*247

Rosy-sided Dace ..............166

Rotifera ..................**79

Roundtail Paradise Fish .........*263

Sagittaria .......26, 28, *29,*30,*31

Salamanders ................. 150

Salt Treatment ............ 83

Salvinia .................... *56

Sand or Pebbles .............. 26

Scaleless Telescope Goldfish ...*184, *191

Scales Knocked Off .............. 94

Scardinitus erythropthalmus ......**164

Scatophagus argus ..............*280

Scavengers ................. *1s

Sceloporus undulatus ...........*146

Scissors (Aquarium) ..........*121

Scrapers (Aquarium) ............120

Sea Horses ................. * 140

Seasoning Tanks (Cement) ....... 113

Seine Net-How to Work......... 151

Seining $\ldots \ldots \ldots \ldots \ldots \ldots \ldots \ldots \ldots \ldots \ldots \ldots \ldots \ldots 112$

Sex in Goldfishes ............. 199

Shedd Aquarium ..................

Shiner ..................... 154, *162

Shipping Goldfishes ............. 219

Shipping Tropical Fishes ......... 234

Shrimp (Freshwater) ...........*79

Shrimp (Powdered) .......... 70

Shubunkin Goldfish .............178

Sick Fishes .................. 17

Silverfin ...............*153,*159

Siphon ...................... 120

Skink ........................ * 146

Snail Breeding .............. 21

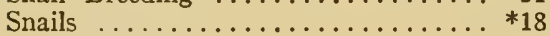

African

Australian

Japanese

Pond

Ramshorn
Soft-shelled Turtle ...........*147

Soil .................... 218

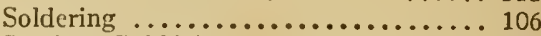

Sorting Goldfish ...........222,*228

Spatterdock .............*45, *46

Spawning Net ..............*124

Spawning Ring ..................*210

Spearmouth ................. 97

Sprinkling Pot .............. 12

Starwort ................... $*_{50}$

Steel Trap .................. 102

Steinhart Aquarium ............*300

Sterility ..................208

Stickleback $\ldots \ldots \ldots \ldots \ldots \ldots \ldots \ldots \ldots \ldots$

Stocking Aquarium (Marine) ..... 139

Strangulation ................. 95

Strong Concrete Pool ...........*115

Sunfishes ............156, *158, 224

Surface Measure (Circle) ....... 8

Surface Measure (Square) ........ 7

Swamp Aquarium ............. 143

Swimming Bladder Trouble ........ 90

Tadpoles ................. 19

Tail-rot ............... 89

Telescope Goldfish .....*182, *183,*191

Telescopic-eyed Minnow ..........*192

Temperature Changes ........... 12

Temperature (goldfish) ......... 15

Temperature (tropicals) ......... 244

Tench ........................ 170

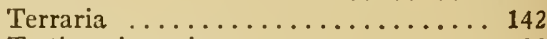

Testing Aquaria .............. 22

Tetraodon fluviatilis ..............281

Tetragonopterus rubropictus ...... 273

Thermos Bottles .............. 234

Thermostat ..............233, 234

Three-spot Gourami .............*262

Tilapia macrocephala ............*271

Transparently Scaled Goldfish...183, *184

Transparent Scales ........... 173

Trianea ................ $56, \quad 57$

Trichogaster fasciatus ...............*262

Trichogaster trichopterus .........*262

Trinectes maculatus ..............**171

Tripod Tails ................175

Tropical Fishes .............. 230

Tropical Fish Exhibitions ........ 235

Tubifex Worms ..............78

Turtles .................*147, 150

Umbra pygmaea ..............163

Utricularia ................*40

Vallisneria ..................... *33, *35

Veiltail Goldfish ............Frontispiece

Veiltail Telescope Goldfish ........*184

Wandering Jew .............. $51, * 52$

Water ........................... 218

Water Boatmen ...............100

Water Chestnut .............59, 60

Water Fern ................... *59

Water for Tropicals ............. 230

Water Hyacintb ...........60, *61 


\begin{tabular}{|c|c|c|}
\hline & Page & PAGE \\
\hline IVater & Lettuce & Web Tails .... \\
\hline Wate & Lilies. & Weight of Water \\
\hline Water & Lily...$\ldots \ldots \ldots \ldots \ldots \ldots *^{6}$ & Whirligig Beetle \\
\hline ater & Poppy $\ldots \ldots \ldots \ldots \ldots \ldots \ldots$ & White Fungus .. \\
\hline Water & Scavenger Bectle .........*08 & White Worm Feeder ...... \\
\hline Tater & Scorpion...$\ldots \ldots \ldots \ldots \ldots \ldots \ldots$ & White Worms ............. \\
\hline ater & Snowflake $\ldots \ldots \ldots \ldots 60, * 62$ & Wholesale Breeding (goldfishes) \\
\hline Water & $\begin{array}{l}\text { Strider } \ldots \ldots \ldots \ldots \ldots \ldots \ldots \\
6\end{array}$ & 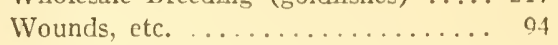 \\
\hline & 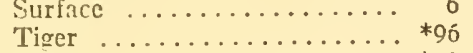 & Young Goldfishes (Comparative sizes) 1 \\
\hline & erfish $\ldots \ldots \ldots \ldots \ldots \ldots \ldots * 20$ & Zinc $\ldots \ldots \ldots \ldots \ldots \ldots \ldots \ldots$ \\
\hline
\end{tabular}

* Star indicates that subject is accompanied by illustration. 




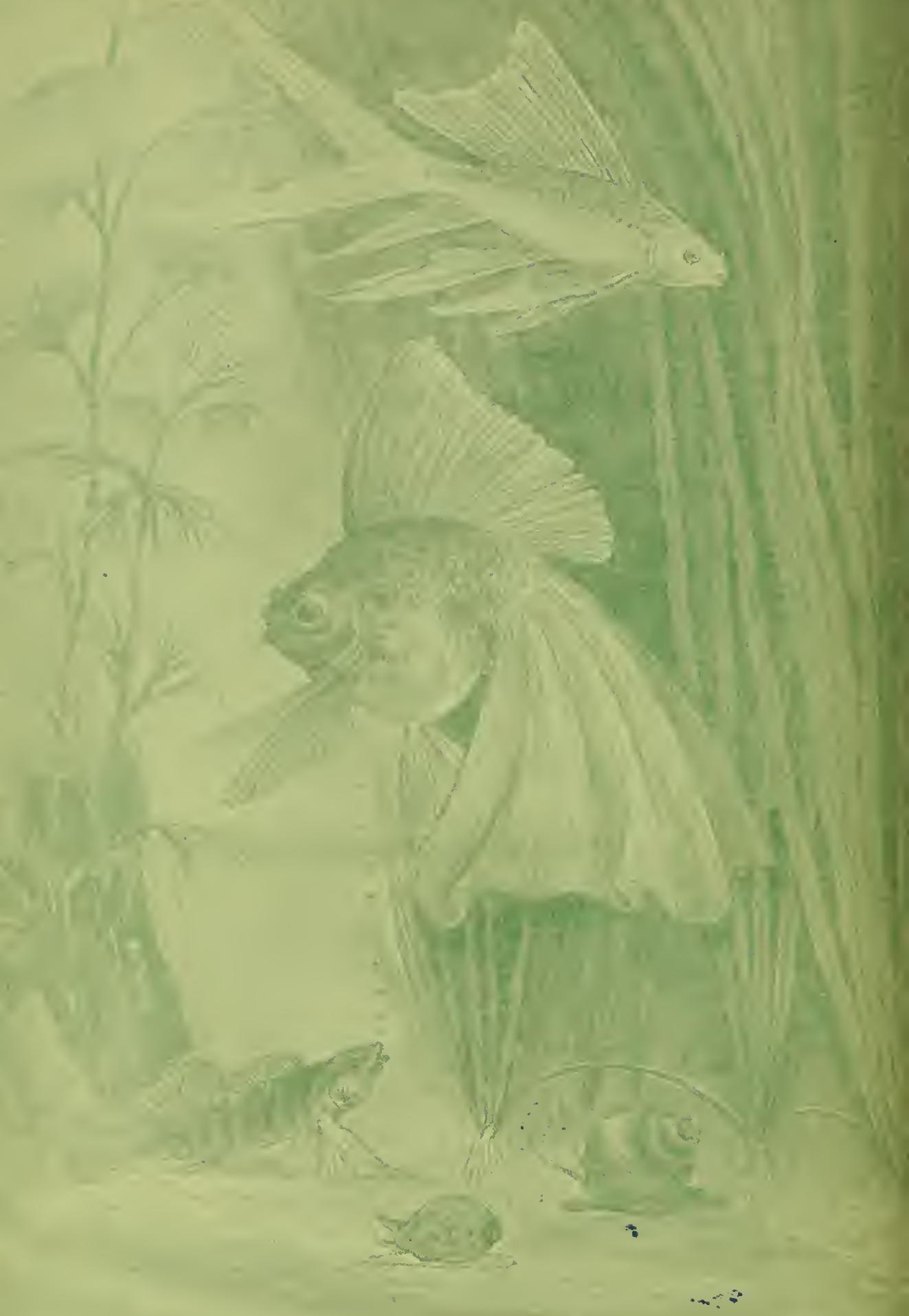




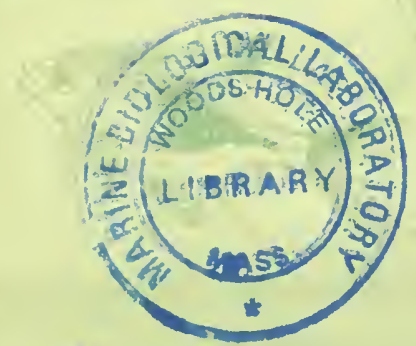

Hat

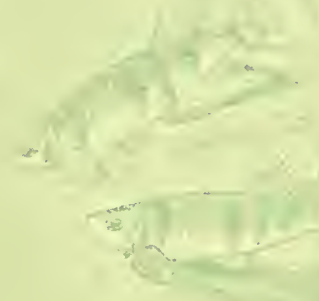


